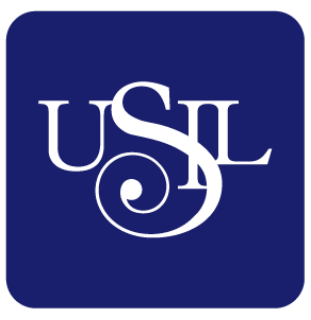

UNIVERSIDAD

SAN IGNACIO

DE LOYOLA

ESCUELA DE POSTGRADO

\title{
PLANEAMIENTO ESTRATÉGICO DE LA EMPRESA SF HERMANOS S.R.L. 2019 - 2021
}

Trabajo de Investigación para optar el grado de:

MARLÉN CÁRDENAS WAIDHOFER

Maestro en Ciencias Empresariales con Mención en Gestión Comercial

ANDY RONALD CARRANZA QUIROZ

Maestro en Ciencias Empresariales con Mención en Gestión de Proyectos

EMILIO ENRIQUE LAMA VRECA

Maestro en Ciencias Empresariales con Mención en Gestión Comercial

PATRICIA MARINA TAGLE ACURIO

Maestro en Ciencias Empresariales con Mención en Gestión de Proyectos

Asesor:

Dr. Edmundo Rafael Casavilca Maldonado

Lima - Perú

2019 


\section{DEDICATORIA}

A Dios, por brindarnos salud y fortaleza para lograr cumplir con nuestros objetivos.

A nuestros padres: Héctor Tagle, Lourdes Acurio, Bertha Vreca, Diómedes Carranza,

Luz Quiroz, Fortunato Cárdenas y Heddy Waidhofer por inculcarnos a estudiar y seguir adelante para lograr cumplir nuestros sueños, a ellos se los dedicamos con mucho amor.

A nuestro sobrino Benjamín, por alegrarnos con una sonrisa y entusiasmo, en cada reunión que teníamos al momento de elaborar nuestro trabajo.

A nuestra casa de estudios, Universidad San Ignacio de Loyola por permitirnos ser parte de los profesionales que hacemos patria. 


\section{AGRADECIMIENTOS}

A nuestros profesores, quienes impartieron su conocimiento y compartieron sus experiencias, sus enseñanzas han sido de gran apoyo para nuestro desarrollo profesional.

A nuestros compañeros de clase, pues fue un gusto compartir este tiempo juntos dentro y fuera de las aulas.

A todos los que colaboraron en la elaboración de este trabajo.

Agradecimiento especial a nuestro asesor, el Dr Edmundo Rafael Casavilca Maldonado por su orientación metodológica y apoyo en la realización de esta tesis. 


\section{RESUMEN EJECUTIVO}

El presente plan estratégico ha sido desarrollado para la empresa SF Hermanos S.R.L., la cual cuenta con casi 30 años de experiencia en la fabricación de muebles de madera, acero inoxidable y melamine, en el horizonte de tres años comprendidos entre los años 2019 y 2021, tomando el enfoque en el sector construcción con la finalidad de que este plan alcance y mantenga en el futuro, su ventaja competitiva. SF Hermanos S.R.L. se encuentra ubicado en el departamento de Lima, provincia de Lima, distrito de Ate Vitarte, Av. Los Angeles Mz K Lt 2 Parque Industrial.

Se analizó a la competencia, al sector y su potencial. Se identificaron a los grupos de interés que rodean al negocio y la propuesta a ejecutarse. De esta manera la misión propuesta ayudará a SF Hermanos a desarrollar estrategias que busquen satisfacer a los grupos de interés identificados.

Los principales aspectos que generan oportunidad son: el crecimiento del sector construcción y la disponibilidad de recursos de las familias para poder financiar remodelaciones de sus casas o departamentos.

Los objetivos propuestos, tanto los estratégicos como los operativos, buscan alcanzar la ventaja competitiva. Para lograr esto, fue necesario identificar las fuentes de creación de valor de las actividades del negocio.

Con el fin de elaborar estrategias necesarias para lograr los objetivos propuestos, se desarrolló el análisis del entorno para identificar los temas estratégicos que afectan a la empresa y en consecuencia a su margen neto, así como las oportunidades y amenazas. 
Por otro lado, se han identificado los factores críticos de éxito para la industria, los cuales han permitido identificar las fortalezas y debilidades que posee la empresa actualmente, así como las de su competencia.

En la elaboración del plan se han propuesto varias alternativas de las cuales la estrategia a desarrollar es la de penetración de mercados específicamente enfocándose en el segmento de hogares del NSE A y B.

El proyecto va a ser financiado a través del capital propio de los accionistas por un monto de S/ 120,566 el cual representa para la empresa el $28.88 \%$ de la inversión total y será asignado para los activos intangibles y el capital de trabajo. La diferencia de la inversión (71.12\%) será financiada a través de un préstamo por S/ 296,967 para la adquisición de activos fijos con una tasa de interés efectiva del 14\%.

Por lo mencionado, el proyecto es rentable debido a que va a obtenerse un VANE de S/ 569,777 y un TIRE de 58.30\%, valor que supera al valor del WACC de $12.30 \%$. Además de observarse que el proyecto presenta flujos positivos desde su primer año.

Por el lado financiero se observa que el proyecto también es rentable en este sentido debido a que se obtiene un VANF de S/ 480,239 y un TIRF de $115.38 \%$, valor que supera al COK de $19.51 \%$ con flujos positivos para todo el horizonte de evaluación.

Finalmente, con todo lo evaluado anteriormente, se cumple con el objetivo estratégico de superar los 1.8 millones de soles al quinto año de implementar la estrategia. 


\section{INDICE GENERAL}

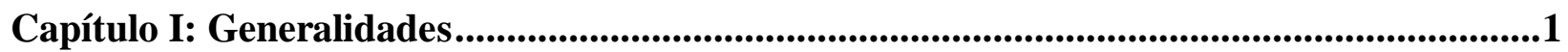

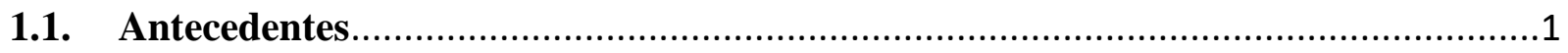

1.2. Determinación del problema u oportunidad .......................................................11

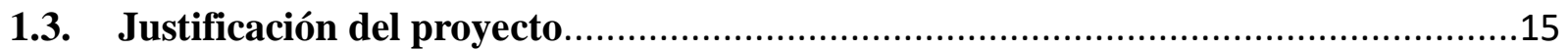

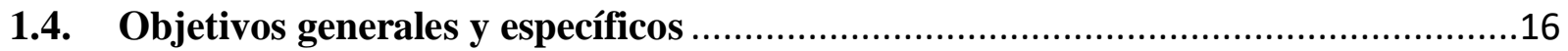

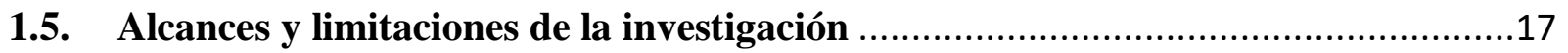

Capítulo II: La Empresa .....................................................................................................................18

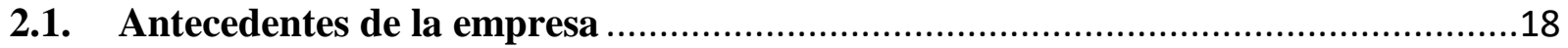

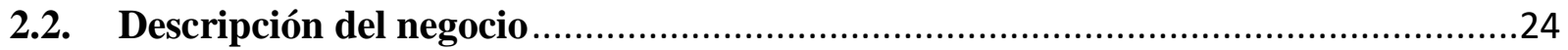

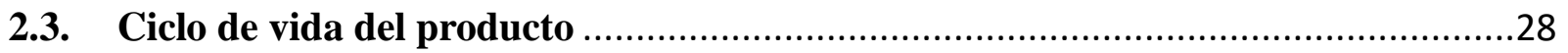

2.4. Estructura organizacional actual de la empresa .................................................

2.5. Situación del mercado y financiera actual de la industria ...................................46

Capítulo III: Formulación de la visión, misión y valores de la empresa ..................................49

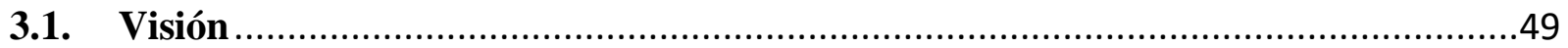

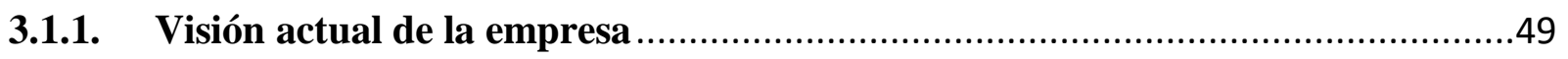

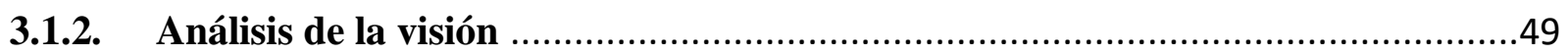

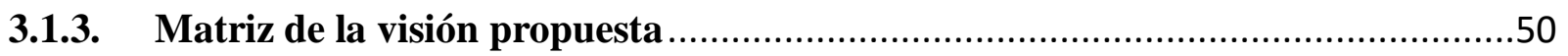

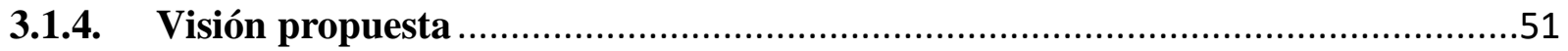

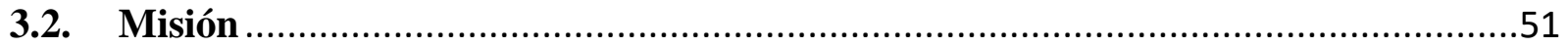

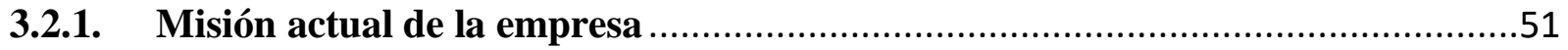

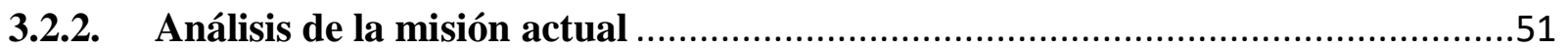

3.2.3. Elementos de la misión propuesta para la empresa …………………..............54

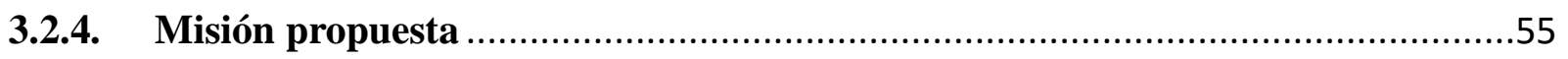

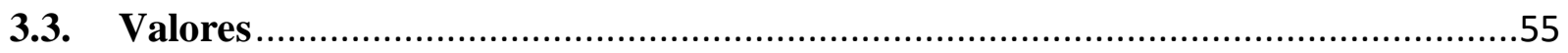

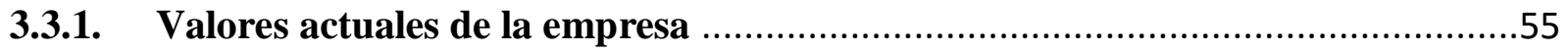

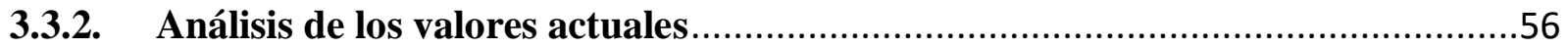

3.3.3. Elementos de los valores propuestos para la empresa …................................57

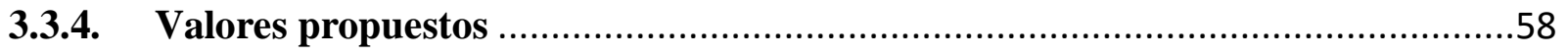

Capítulo IV: Análisis Externo ...........................................................................................................661

4.1. Tendencias de las variables del entorno ........................................................................661

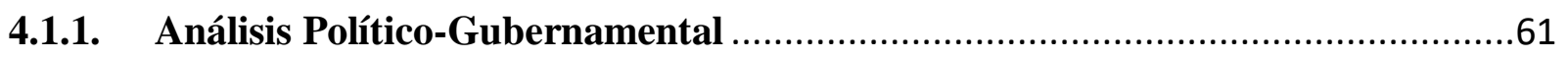

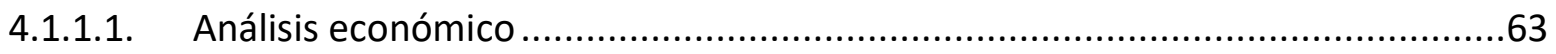

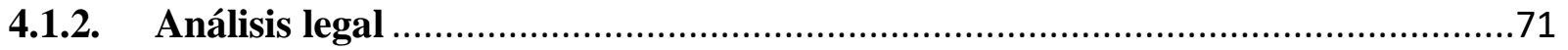




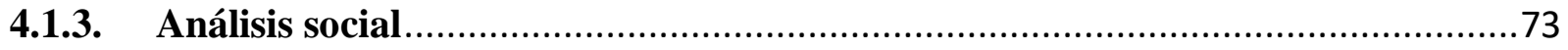

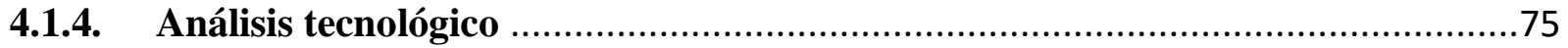

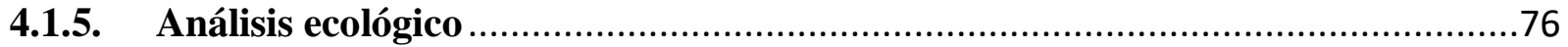

4.2. Efecto en la empresa de cada una de las variables del entorno ......................................76

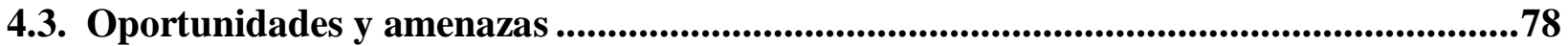

4.4. Matriz de evaluación de los factores externos (EFE) ...................................................80

Capítulo V: Análisis de la industria ........................................................................................82

5.1. Descripción del mercado (demanda) e industria (oferta) .....................................82

5.2. Descripción de las cinco fuerzas competitivas de la industria ...............................85

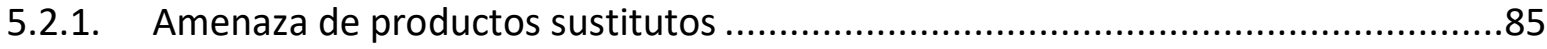

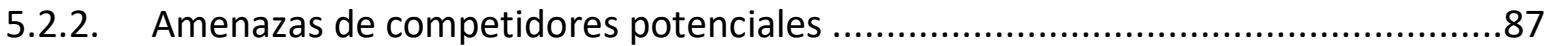

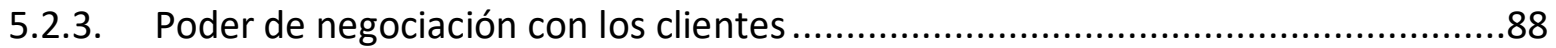

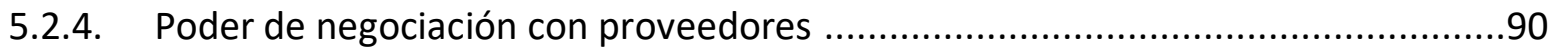

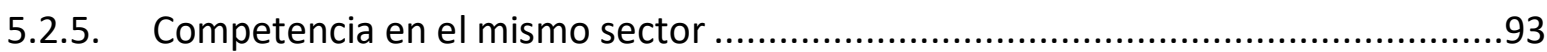

5.3. Matriz de atractividad de cada una de las cinco fuerzas: .......................................97

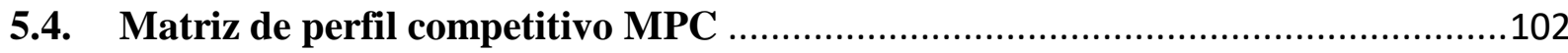

Capítulo VI: Análisis Interno .....................................................................................................106

6.1. Descripción de las actividades de la cadena de valor de la empresa ....................106

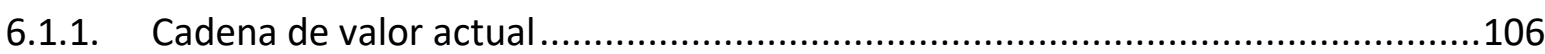

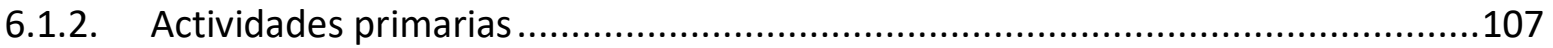

6.2. Indicadores de cada una de las actividades de la cadena de valor .........................122

6.3. Benchmarking y comparación con los líderes de la industria de cada una de las

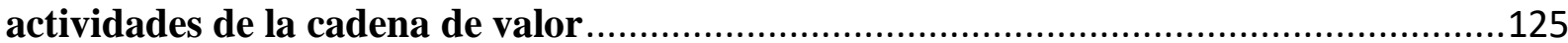

6.4. Determinar las competencias de la empresa ….............................................128

6.5. Identificación y determinación de las ventajas competitivas de la empresa ..........133

6.6. Matriz de Evaluación de los Factores Internos EFI …........................................137

Capítulo VII: Formulación de los objetivos y diseño de las estrategias ..................................138

7.1. Alcance y planteamiento de los objetivos estratégicos .........................................138

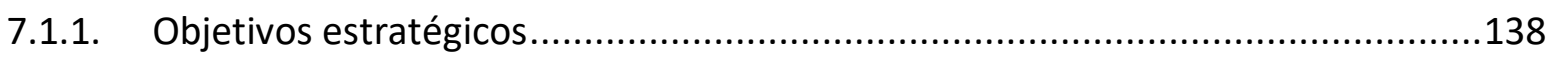

7.1.2. Análisis de los objetivos estratégicos ..........................................................141

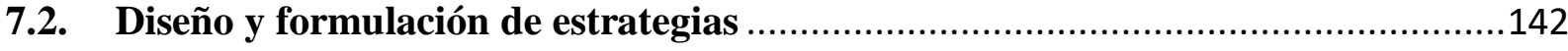

7.2.1. Modelo de Océano Azul ...................................................................................142

7.2.2. Lienzo de la estrategia actual de la empresa ....................................................143

7.2.3. Lienzo de la estrategia actual de la industria ..................................................146 
7.2.4. Matriz (Eliminar, reducir, incrementar, crear) .......................................... 148

7.2.5. Matrices de formulación de estrategias ....................................................150

7.3. Resumen de estrategias formuladas ...................................................... 162

Capítulo VIII: Selección de la estrategia ............................................................................163

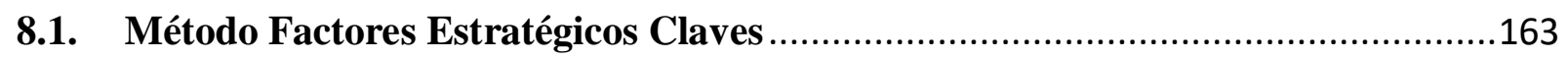

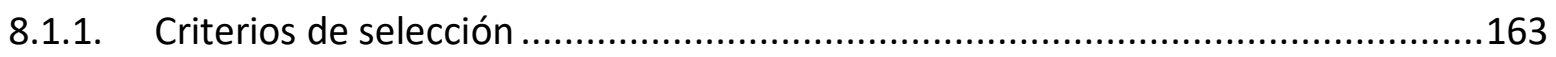

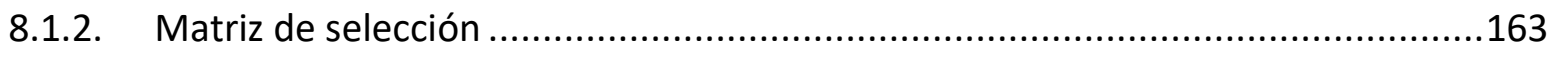

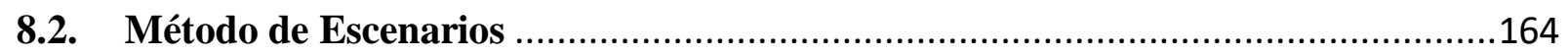

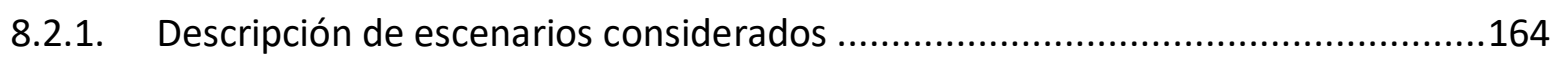

8.2.2. Comparación de Estrategias con escenarios ...................................................166

8.2.3. Matriz de Planeación Estratégica Cuantitativa MPEC ......................................168

8.2.4. Descripción de estrategia seleccionada ....................................................170

8.2.5. Descripción de estrategia contingente ................................................171

Capítulo IX: Implantación mediante el Balanced Scorecard ............................................172

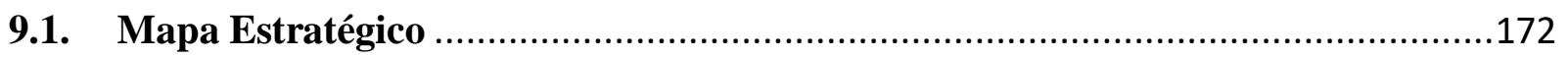

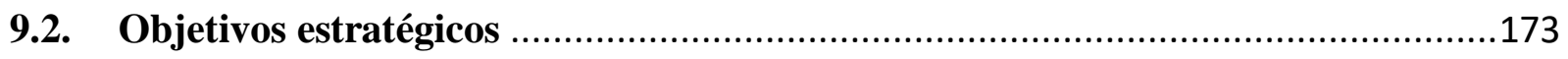

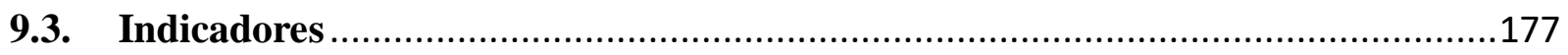

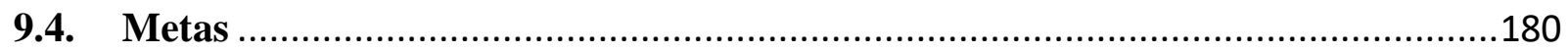

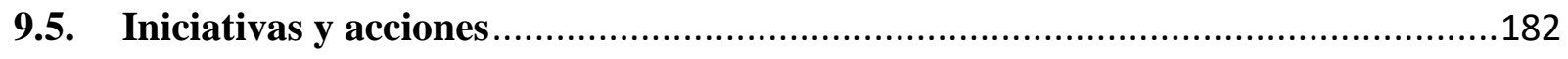

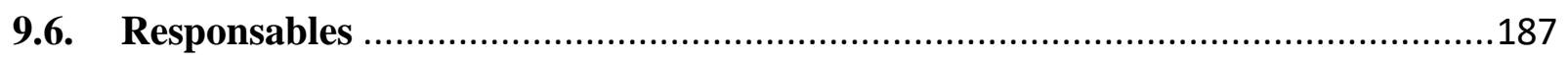

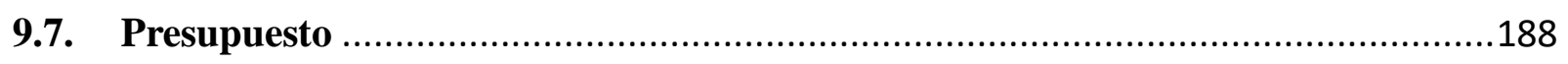

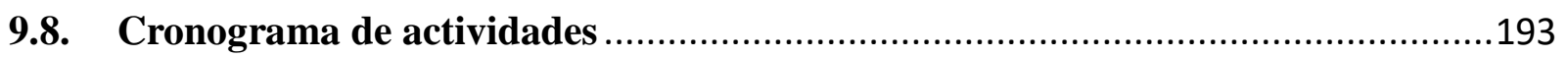

Capítulo X: Evaluación Financiera ..............................................................................195

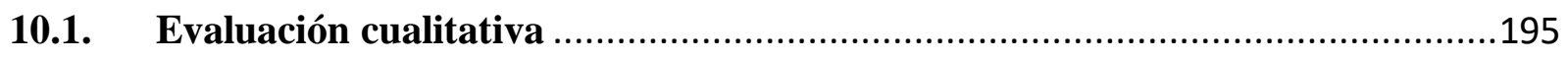

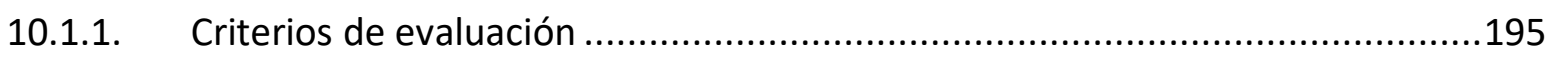

10.1.2. Comparación de la estrategia con los criterios...........................................196

10.2. Evaluación financiera de la nueva estrategia .............................................202

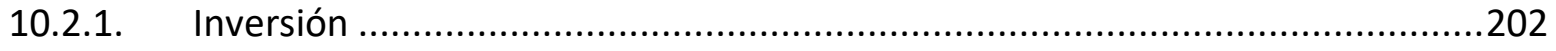

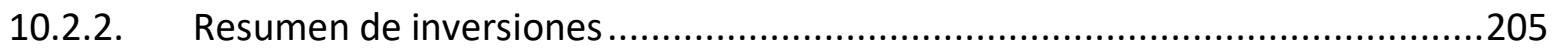

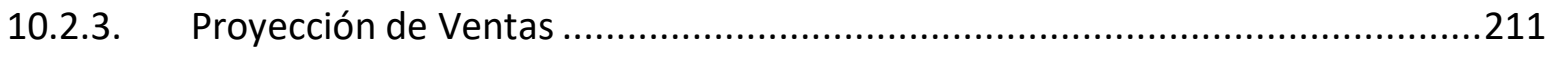

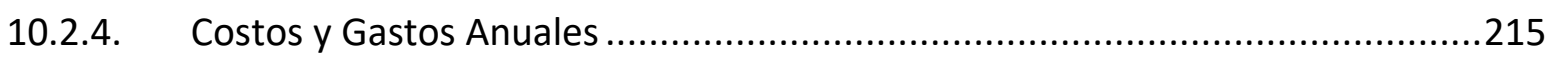

10.2.5. Estado de Resultados (proyectado y con la nueva estrategia)........................223

10.2.6. Balance General (con la nueva estrategia) ............................................227 


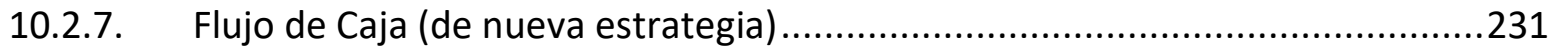

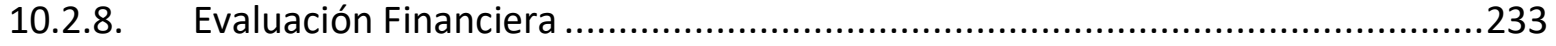

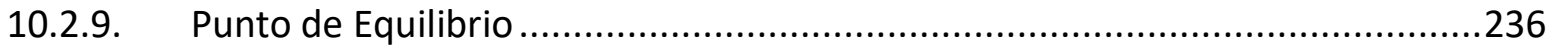

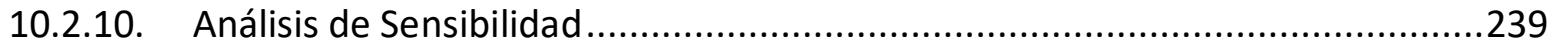

Capítulo XI. Conclusiones y Recomendaciones ...........................................................246

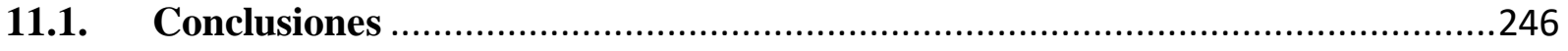

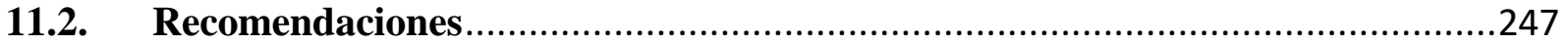




\section{INDICE DE TABLAS}

Tabla $N^{\circ}$ 1: Producto Bruto Interno - años 2014, 2015 y 2016

Tabla $\mathrm{N}^{\circ}$ 2: Lima: Número de establecimientos censados, según actividad económica 11

Tabla $\mathrm{N}^{\circ}$ 3: Ventas por línea de negocio de SF Hermanos 23

Tabla $\mathrm{N}^{\circ}$ 4: Utilidades por línea de negocio de SF Hermanos 23

Tabla $\mathrm{N}^{\circ}$ 5: Criterios para ubicar en qué etapa se encuentra el producto 29

Tabla $\mathrm{N}^{\circ}$ 6: Ventas vs Utilidades de la línea de muebles de hogar 30

Tabla $N^{\circ}$ 7: Ventas vs Utilidades de la línea de muebles de oficina 31

Tabla $\mathrm{N}^{\circ}$ 8: Ventas vs Utilidades de la línea de muebles comerciales 32

Tabla $N^{\circ}$ 9: Ventas vs Utilidades de la línea de carpintería en obra 34

Tabla $N^{\circ}$ 10: Carpintería en Obra: Ventas vs Tiempo vs Utilidades 35

Tabla $\mathrm{N}^{\circ}$ 11: Ventas vs Utilidades del producto parrilla de acero inoxidable 36

Tabla $\mathrm{N}^{\circ}$ 12: Análisis de la Visión $\quad 50$

Tabla $\mathrm{N}^{\circ}$ 13: Análisis de la Visión propuesta $\quad 50$

Tabla $N^{\circ}$ 14: Análisis de la Misión $\quad 52$

Tabla $\mathrm{N}^{\circ}$ 15: Antecedentes para la misión $\quad 52$

Tabla $\mathrm{N}^{\circ}$ 16: Prioridad 53

Tabla $N^{\circ}$ 17: Alineamiento estratégico de la visión, misión y valores de la empresa SF 60

Hermanos S.R.L.

Tabla $\mathrm{N}^{\circ}$ 18: Variación porcentual del PBI por sectores económicos 65

Tabla N 19: Tabla oficial del dólar en el 2018

Tabla N²0: Análisis Político Gubernamental 77

Tabla N²1: Análisis Económico $\quad 77$

Tabla $N^{\circ} 22:$ Análisis Tecnológico $\quad 78$

$\begin{array}{ll}\text { Tabla } N^{\circ} 23: \text { Análisis Legal } & 78\end{array}$

$\begin{array}{ll}\text { Tabla N²4: Análisis Social } & 78\end{array}$

Tabla $N^{\circ} 25:$ Análisis Ecológico $\quad 78$

Tabla $N^{\circ}$ 26: Matriz de Factores Externos - EFE $\quad 80$

Tabla $N^{\circ}$ 27: Ventas según tipo de clientes $\quad 89$

Tabla N 28: Porcentaje de ventas por cliente - Año 2018 
Tabla $\mathrm{N}^{\circ}$ 29: Matriz de Atractividad: Amenaza de productos sustitutos 97

Tabla $N^{\circ}$ 30: Matriz de Atractividad: Amenaza de competidores potenciales 98

Tabla N $\mathrm{N}^{\circ}$ 31: Matriz de Atractividad: Poder de negociación con los clientes 99

Tabla $N^{\circ}$ 32: Matriz de Atractividad: Poder de negociación de los proveedores $\quad 100$

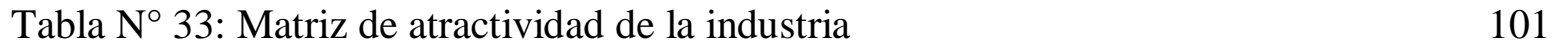

Tabla No 34: Matriz Perfil Competitivo - MPC 105

Tabla $N^{\circ}$ 35: Indicadores de cada una de las actividades de la cadena de valor $\quad 124$

Tabla $N^{\circ}$ 36: Indicadores para logística de entrada y salida 125

Tabla $N^{\circ}$ 37: Indicadores para operaciones y recursos humanos 126

Tabla N $\mathrm{N}^{\circ}$ 38: Indicadores para logística de marketing y post venta 127

$\begin{array}{ll}\text { Tabla } N^{\circ} \text { 39: Criterios } & 128\end{array}$

Tabla $N^{\circ}$ 40: Leyenda de cada recurso VRIO 129

Tabla N 41: Competencia de la empresa SF hermanos: "Recursos Tangibles" 130

Tabla N ${ }^{\circ}$ 42: Competencia de la empresa SF hermanos: "Recursos Intangibles" 131

Tabla N ${ }^{\circ}$ 43: Competencia de la empresa SF hermanos: "Capacidades" 132

Tabla $N^{\circ}$ 44: Leyenda de clasificación de ventaja competitiva 133

Tabla N 45: Identificación de ventaja competitiva: "Recursos Tangibles" 134

Tabla N 46: Identificación de ventaja competitiva: "Recursos Intangibles” 135

Tabla N $N^{\circ}$ : Identificación de ventaja competitiva: "Capacidades" 136

Tabla N $\mathrm{N}^{\circ}$ 48: Matriz de Factores Internos 137

Tabla N 49: Análisis situacional de la empresa 142

Tabla N $N^{\circ}$ : Criterios 143

Tabla $\mathrm{N}^{\circ}$ 51: Variables $\quad 145$

Tabla N 52: Definición de variables 145

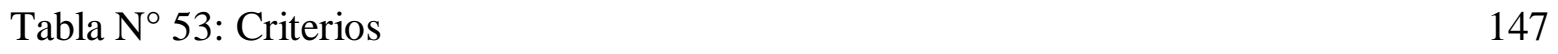

Tabla N $\mathrm{N}^{\circ}$ 54: Matriz FODA 152

Tabla N 55: Cuadro de calificaciones - Matriz PEYEA 157

Tabla $N^{\circ}$ 56: Cuadro de resumen de las estrategias 162

Tabla N $N^{\circ}$ 7: Matriz de Factores Externos 163

Tabla $\mathrm{N}^{\circ}$ 58: Matriz de Factores Internos 164

Tabla $N^{\circ}$ 59: Escenarios de las estrategias planteadas 167 
Tabla $N^{\circ}$ 60: Matriz de Planeación Estratégica Cuantitativa

Tabla N 61: Objetivos del Mapa Estratégico de SF Hermanos S.R.L. 176

Tabla $N^{\circ}$ 62: Indicadores de SF Hermanos S.R.L. 180

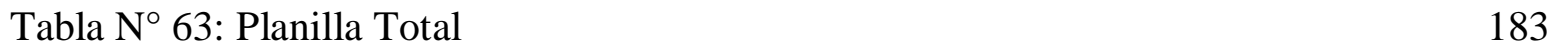

Tabla $N^{\circ}$ 64: Descripción de la estrategia 185

Tabla N ${ }^{\circ}$ 65: Responsabilidades de actividades $\quad 188$

Tabla $N^{\circ}$ 66: Inversión Tangible 189

Tabla $\mathrm{N}^{\circ}$ 67: Inversión Intangible $\quad 189$

Tabla N 68: Marketing de Lanzamiento 190

Tabla N ${ }^{\circ}$ 69: Capital de Trabajo Incremental 190

Tabla N $N^{\circ}$ 70: Planilla del proyecto por centro de costos 191

Tabla N $N^{\circ}$ 71: Gasto total por planilla $\quad 191$

Tabla N $N^{\circ}$ : Gastos de administración del proyecto 192

Tabla N $N^{\circ}$ 73: Gastos de ventas del proyecto 193

Tabla N $\mathrm{N}^{\circ}$ 74: Cronograma de actividades 194

Tabla N $\mathrm{N}^{\circ}$ 75: Mercado total 196

Tabla N $N^{\circ}$ 76: NSE en Lima Moderna 197

Tabla N 77: NSE en Lima Moderna 197

$\begin{array}{ll}\text { Tabla N } N^{\circ} \text { 78: Mercado Potencial } & 198\end{array}$

Tabla N $N^{\circ}$ 79: Nivel porcentual de personas que desean remodelar 198

Tabla $N^{\circ}$ 80: Nivel porcentual de personas que desean contratar una empresa para la remodelación 199

Tabla No 81: Mercado disponible 199

Tabla N 82: Hogares dispuestos a solicitar el servicio "Renuévate" 200

Tabla $N^{\circ}$ 83: Porcentaje de mercado objetivo 200

Tabla No 84: Mercado Objetivo 200

Tabla N $N^{\circ}$ 85: Inversión Tangible 202

Tabla N N6: Inversión Intangible $^{203}$

Tabla N ${ }^{\circ}$ 87: Capital de Trabajo Incremental 203

$\begin{array}{ll}\text { Tabla No 88: Estructura de inversiones } & 204\end{array}$

Tabla $N^{\circ}$ 89: Estructura de financiamiento 205 
Tabla N ${ }^{\circ}$ 90: Tarifario de TEA - Convenio activo fijo Caja Arequipa 207

Tabla N ${ }^{\circ}$ 91: Tarifario de Tasa Crédito Leasign - Banco de Crédito 208

Tabla N 92: Condiciones del préstamo 209

Tabla $\mathrm{N}^{\circ}$ 93: Cronograma de pagos anual 209

Tabla N 94: Determinación de costos variables para servicios Casa 210

Tabla N ${ }^{\circ}$ 95: Determinación de precio de venta para servicios Casa 211

Tabla N ${ }^{\circ}$ 96: Determinación de costos variables para servicios Departamento 211

Tabla N ${ }^{\circ}$ 97: Determinación de precio de venta para servicios Departamento 211

Tabla N 98: Programa de ventas anual 212

Tabla N 99: Proyección de ventas anual 213

Tabla $\mathrm{N}^{\circ}$ 100: Costo promedio por servicio 214

Tabla N $\mathrm{N}^{\circ}$ 101: Presupuesto anual de insumos 215

Tabla $N^{\circ}$ 102: Presupuesto de mano de obra 216

Tabla $N^{\circ}$ 103: Distribución de las áreas del local por función en m2 216

Tabla N 104: Distribución de costos comunes 218

Tabla $N^{\circ}$ 105: Consumo anual de combustible $\quad 219$

Tabla N $N^{\circ}$ 106: Costos Indirectos de Fabricación 219

Tabla $\mathrm{N}^{\circ}$ 107: Gastos de administración 220

Tabla N 108: Gastos de ventas 221

Tabla $N^{\circ}$ 109: Gastos de promoción y publicidad 222

Tabla N $N^{\circ} 110$ : Estado de Resultado de la Estrategia (soles) 223

Tabla N ${ }^{\circ}$ 111: Estado de Resultados Histórico (soles) 224

Tabla N $N^{\circ} 112$ : Drivers $\quad 225$

Tabla N ${ }^{\circ}$ 113: Estado de Resultados Proyectado (soles) 225

Tabla N ${ }^{\circ}$ 114: Estados de Resultados Proyectado más Estrategia (soles) 226

Tabla N $N^{\circ} 115$ : Balance General Histórico 227

Tabla $N^{\circ}$ 116: Reparto de Dividendos 228

Tabla N ${ }^{\circ}$ 117: Balance General con Estrategia 229

Tabla N $N^{\circ} 118$ : Flujo de Caja Operativo (estrategia) 230

Tabla $\mathrm{N}^{\circ}$ 119: Flujo de Inversiones 231

Tabla N 120: Flujo de Caja Económico (FCE) 231 
Tabla N 121: Flujo de la Deuda Neto 232

Tabla N $N^{\circ}$ 122: Flujo de Caja Financiero (FCF) 232

Tabla N ${ }^{\circ}$ 123: Indicadores de Rentabilidad - Evaluación Económica 233

Tabla $N^{\circ}$ 124: Indicadores de Rentabilidad - Evaluación Financiera 233

Tabla $\mathrm{N}^{\circ}$ 125: Cálculo de tasa de descuento 234

Tabla N ${ }^{\circ}$ 126: Cálculo del Koa 234

Tabla N $N^{\circ}$ 127: Costo de oportunidad del accionista 234

Tabla $\mathrm{N}^{\circ}$ 128: Costo de capital promedio ponderado 235

Tabla N ${ }^{\circ}$ 129: Margen de Contribución 236

Tabla N $N^{\circ}$ 130: Costos Fijos $\quad 237$

Tabla $N^{\circ}$ 131: Punto de equilibrio (servicios) 237

Tabla $N^{\circ}$ 132: Punto de equilibrio (soles) 238

Tabla $N^{\circ}$ 133: Participación del punto de equilibro en las ventas 239

Tabla $\mathrm{N}^{\circ}$ 134: Sensibilidad de Ventas $\quad 240$

Tabla $\mathrm{N}^{\circ}$ 135: Sensibilidad de Costo de Ventas 241

Tabla N $N^{\circ}$ 136: Sensibilidad de Gastos de Ventas y Administración 242

Tabla N $N^{\circ}$ 137: Sensibilidad del VANE según Ventas y Costo de Ventas 242

Tabla $N^{\circ}$ 138: Sensibilidad del TIRE según Ventas y Costo de Ventas 242

Tabla N ${ }^{\circ}$ 139: Sensibilidad del VANE según Costo de Ventas y Gastos de Ventas y Administración 243

Tabla $\mathrm{N}^{\circ}$ 140: Sensibilidad del TIRE según Costo de Ventas y Gastos de Ventas y Administración 


\section{INDICE DE FIGURAS}

Figura $\mathrm{N}^{\circ}$ 1: Evolución del PBI del sector construcción 2

Figura $\mathrm{N}^{\circ}$ 2: Cantidad de créditos otorgados por el programa MIVIVIENDA 5

Figura $N^{\circ}$ 3: Venta de Viviendas en Lima Metropolitana $\quad 8$

Figura N 4: Página web de la empresa SF Hermanos S.R.L. 15

Figura $\mathrm{N}^{\circ}$ 5: Muebles para el hogar $\quad 25$

Figura $\mathrm{N}^{\circ}$ 6: Muebles para oficina $\quad 26$

Figura $\mathrm{N}^{\circ}$ 7: Muebles comerciales $\quad 26$

$\begin{array}{ll}\text { Figura } \mathrm{N}^{\circ} 8 \text { : Acabado de escalera } & 27\end{array}$

Figura $N^{\circ}$ 9: Muebles de hogar: Ventas vs Tiempo vs Utilidades 30

Figura $\mathrm{N}^{\circ}$ 10: Muebles de oficina: Ventas vs Tiempo vs Utilidades 31

Figura $\mathrm{N}^{\circ}$ 11: Muebles comerciales: Ventas vs Tiempo vs Utilidades 33

Figura $N^{\circ}$ 12: Carpintería en Obra: Ventas vs Tiempo vs Utilidades 34

Figura $\mathrm{N}^{\circ}$ 13: Servicios de mantenimiento: Ventas vs Utilidades 35

Figura $\mathrm{N}^{\circ}$ 14: Tienda de acero inoxidable: Ventas vs Tiempo vs Utilidades 37

Figura $\mathrm{N}^{\circ}$ 15: Ciclo de vida del producto 38

Figura $\mathrm{N}^{\circ}$ 16: Estructura Organizacional de SF Hermanos S.R.L. 39

Figura N ${ }^{\circ}$ 17: Perspectivas de crecimiento en América Latina y Caribe: 2016 y $2017 \quad 64$

Figura N $\mathrm{N}^{\circ}$ 18: Proyección de la inflación 2010 - 2017

Figura $N^{\circ}$ 19: Balanza Comercial (Millones de US\$) 68

Figura $N^{\circ}$ 20: Distribución de hogares según NSE - Lima metropolitana 74

Figura $N^{\circ} 21$ : Evolución de gastos del NSE B - Lima metropolitana. (S/.) 75

Figura $\mathrm{N}^{\circ}$ 22: Ofertas de vivienda $\quad 82$

Figura $\mathrm{N}^{\circ}$ 23: Demanda de viviendas por sectores urbanos (miles de hogares) al $2016 \quad 83$

Figura $N^{\circ} 24$ : Tipos de viviendas que ocupan los hogares al 2016

Figura $N^{\circ} 25$ : Ingreso promedio mensual Lima Metropolitana 2007-2016 85

Figura $\mathrm{N}^{\circ}$ 26: Muebles de lata o cromado 86

Figura $N^{\circ}$ 27: Proveedor - Novopan del Perú S.A. $\quad 91$

Figura $N^{\circ}$ 28: Proveedor - Tableros Peruanos S.A. $\quad 91$

Figura $N^{\circ}$ 29: Proveedor - Interforest SAC 91 
Figura No 30: Proveedor - Masisa S.A. $\quad 92$

Figura $N^{\circ}$ 31: Proveedor - Miyasato S.A.C 92

Figura N $\mathrm{N}^{\circ}$ 32: Proveedor - Dilfas S.A.C 92

Figura $N^{\circ}$ 33: Proveedor - Representaciones Martin S.A.C. 93

Figura N 34: Cadena de valor actual - SF Hermanos 107

Figura $\mathrm{N}^{\circ}$ 35: DOP del mueble (Melamine) 111

Figura $\mathrm{N}^{\circ}$ 36: DOP del mueble $\quad 117$

$\begin{array}{ll}\text { Figura } \mathrm{N}^{\circ} \text { 37: DOP del mueble - producto final } & 118\end{array}$

Figura $\mathrm{N}^{\circ}$ 38: Identificación de necesidades del cliente 122

Figura $\mathrm{N}^{\circ}$ 39: Estrategia actual para la empresa SF Hermanos S.R.L. 144

$\begin{array}{ll}\text { Figura } \mathrm{N}^{\circ} \text { 40: Estrategia actual de la industria } & 147\end{array}$

$\begin{array}{ll}\text { Figura } \mathrm{N}^{\circ} \text { 41: Matriz ERIC } & 148\end{array}$

Figura $\mathrm{N}^{\circ}$ 42: Matriz PEYEA 158

Figura $\mathrm{N}^{\circ}$ 43: Matriz interna externa $\quad 160$

Figura $N^{\circ} 44$ : Gran estrategia 161

Figura $\mathrm{N}^{\circ}$ 45: Mapa Estratégico $\quad 172$

Figura $\mathrm{N}^{\circ}$ 46: Diseño potencial de página Web 186

Figura $\mathrm{N}^{\circ}$ 47: Modelo de camión a comprar $\quad 186$ 


\section{INDICE DE ANEXOS}

Anexo $N^{\circ}$ 1: Entrevista de Profundidad 250

Anexo $\mathrm{N}^{\circ}$ 2: Cuestionario aplicado a clientes 264

Anexo $\mathrm{N}^{\circ} 3$ : Competidores 265

Anexo $\mathrm{N}^{\circ}$ 4: Proveedores $\quad 268$

Anexo $\mathrm{N}^{\circ}$ 5: Pagos mensuales del préstamo 275

Anexo $\mathrm{N}^{\circ}$ 6: Programa de ventas mensual 276

Anexo $\mathrm{N}^{\circ}$ 7: Proyección de ingresos mensual 279

Anexo $\mathrm{N}^{\circ}$ 8: Requerimiento de componentes por servicio 282

Anexo $\mathrm{N}^{\circ}$ 9: Presupuesto de compras mensual 298

Anexo $\mathrm{N}^{\circ}$ 10: Liquidación del IGV 301

Anexo $\mathrm{N}^{\circ}$ 11: Perpetuidad de las Inversiones $\quad 302$

Anexo $\mathrm{N}^{\circ}$ 12: Imágenes de línea de productos 303

Anexo No 13: Encuestas de Campo 322

Anexo $\mathrm{N}^{\circ}$ 14: Resultados de Cuestionario 325

Anexo $\mathrm{N}^{\circ}$ 15: Determinación del Margen de Contribución 355

Anexo $\mathrm{N}^{\circ}$ 16: Cálculo del análisis de sensibilidad 361

Anexo $\mathrm{N}^{\circ}$ 17: Efecto por variación en el tipo de cambio 363

Anexo $\mathrm{N}^{\circ}$ 18: Proyección de ingresos de productos comercializados actualmente por SF Hermanos E.I.R.L. 


\section{Capítulo I: Generalidades}

\subsection{Antecedentes}

\section{Situación General del Sector Construcción en el Perú}

La construcción es una actividad que describe la situación actual de la economía, y con mayor razón la demanda interna. Es por este motivo, que las personas ostentan mayores ingresos, probablemente demanden casas, departamentos y centros comerciales. Asimismo, la construcción de mejores viviendas, más cantidad de carreteras y redes viales es un claro reflejo de un progreso en infraestructura, área de vital importancia para el desarrollo de un país.

Desde hace varios años el Perú viene experimentando un crecimiento económico sostenido, a pesar de las situaciones adversas que se han presentado, como son la crisis financiera del 2008 o una posterior desaceleración de la economía china. Este crecimiento tiene una explicación, y es debido a la evolución del sector construcción en el Perú, el cual registra una tasa de promedio de crecimiento anual del 12.5\% en el periodo 2006-2012. El mayor dinamismo de la construcción también se refleja en el aumento que han tenido los precios de las materias primas desde mediados de la década pasada, como sucedió con el cemento (+5\%), los fierros de construcción (+6\%), los ladrillos King Kong (+93\%) y los ladrillos para techo $(+109 \%)$. Lo mismo ocurrió con los préstamos del programa Mi Vivienda que creció en un 127 \% si se compara el año 2006 con el 2012. 


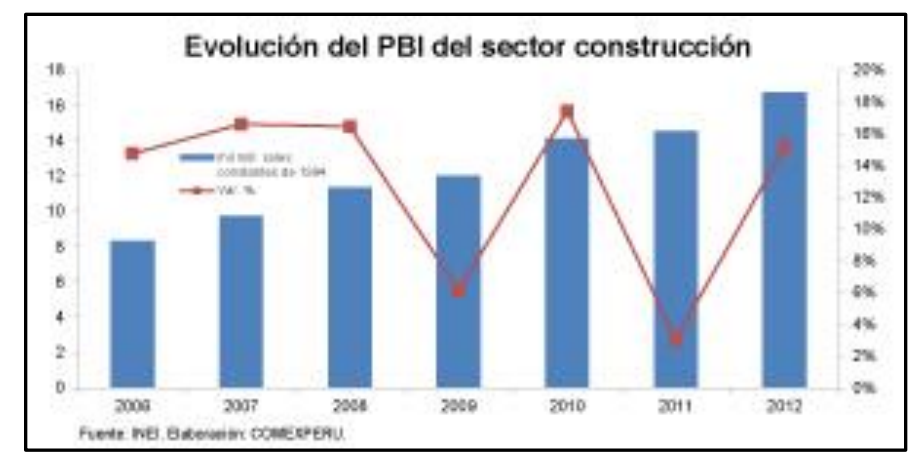

Figura $N^{\circ}$ 1. Evolución del PBI del sector construcción Nota: Tomado de Semanario Comex Perú, Recuperado de https://semanariocomexperu.wordpress.com/construyendo-el-futuro-situacionactual-y-perspectivas-del-sector/

El crecimiento de la construcción en 15\% durante el año 2012 mostró recuperación del dinamismo del sector, luego de reportar un crecimiento de solo el 3.4\% en el año 2011. Así también, fue uno de los principales motores del crecimiento del 6.3\% del PBI - según lo mencionado en cifras por el Instituto Nacional de Estadística e Informática (INEI) además de representar más del 7\% de la producción total del país. Se estima que en el año 2012 el sector producción empleó un buen porcentaje de la PEA Urbana, por lo que habría superado el $6.7 \%$ registrado en el año 2011. Todo esto, pese al complicadísimo y distorsionado régimen laboral de construcción civil que posee el Perú. Las razones del incremento en los niveles de valor agregado de la rama de construcción fueron los siguientes:

- Mayores ingresos de la población, se estima que el PBI per cápita ha aumentado en un $5 \%$ el año pasado. Sumando a esto que el crecimiento poblacional aproximado en el Perú es del 1.1\%, no sorprende que la demanda por construcciones (viviendas, hospitales, centros comerciales, reasentamiento de 
ciudades en el interior del país, entre otros) haya aumentado también, tomando en cuenta que el $80 \%$ de los peruanos viven en zonas urbanas.

- Aumento de la inversión, tanto la inversión bruta fija privada (+13.6) como la inversión bruta fija pública $(+21 \%)$ presentaron tasas de crecimiento resaltantes en el último año. Este aumento general repercutió en el avance físico de obras $(+5.8 \%)$, debido a la mayor inversión en obras de rehabilitación, mejoramiento y construcción de carreteras de la red vial nacional.

- Reducción de trabas burocráticas, el Perú pasó del puesto 101 al 86 en la facilidad de la obtención de permisos de construcción, según el ranking Doing Business 2013. Asimismo, el número de procesos involucrados, los días invertidos en los trámites y el costo de los mismos se redujeron de manera importante. Esto es debido a que se realizaron reformas que permitieron eliminar requerimientos innecesarios, como los del Ministerio de Salud, y la reducción de los costos de los estudios geotécnicos correspondientes.

Los especialistas comentan que el alza de precios de las viviendas, a un ritmo anual del $8 \%$ desde el 2006, es el reflejo de una posible burbuja inmobiliaria. Sin embargo, diversos especialistas descartan está hipótesis y aseguran que está alza responde a una demanda por viviendas de 25 veces mayor que la oferta. Todo esto sumado al déficit habitacional de dos millones de viviendas en el Perú, se descartaría la existencia de una burbuja, y con mayor razón, su posible explosión para el año 2013. 
Por otro lado, la estrategia empleada por el Ministerio de Vivienda será la de priorizar la diversificación de viviendas en Lima, mientras que en provincias se trabajará mediante programas de extensión. En temas de financiamiento, se prevé que el presupuesto del Ministerio para el 2013 pasará de S/. 2,800 millones a cerca de S/. 4,000 millones con lo que se intentará superar las 80,000 viviendas construidas el año pasado.

A pesar de estas medidas, sumadas al crecimiento de la actividad económica local $(+6 \%)$, se proyecta una desaceleración del sector construcción para este año. El Banco Central de Reserva, estima que este sector crecerá en un 9.6\%, mientras que algunas entidades financieras prevén el aumento del 8.3\%. El Ministerio de Vivienda, por su parte, en menos preciso en sus estimaciones y asegura que el crecimiento del sector será menor al $16 \%$ pero mayor al del PBI $(6 \%)$.

En conclusión, tener un Sector Construcción sólido y competitivo es sinónimo de crecimiento y desarrollo. Mientras más se reduzca el déficit habitacional, mayor calidad de vida tendrán las personas. Además, una mejora en infraestructura, incluyendo puentes, carreteras, redes viales, hospitales o colegios, se traduce en mayores niveles de bienestar social y oportunidades de desarrollo. Se espera que el futuro de este Sector, con una correcta dirección del Ministerio de Vivienda e impulsado por la empresa privada, sea auspicioso y continúe fortaleciendo como hasta hoy la economía y sociedad peruana. 


\section{Cantidad de créditos otorgados por el programa} MIVIVIENDA

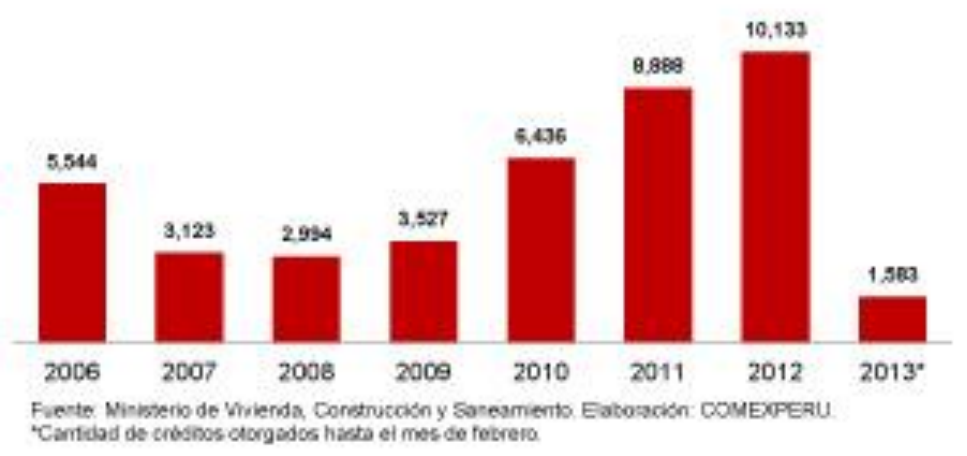

Figura $N^{\circ}$ 2. Cantidad de créditos otorgados por el programa MIVIVIENDA Nota: Ministerio de Vivienda, Construcción y Saneamiento, Recuperado de https://semanariocomexperu.wordpress.com/construyendo-el-futuro-situacionactual-y-perspectivas-del-sector/

Según indica Capeco en su informe de mayo 2019, La reducción de las expectativas está alineada con el BCR e influenciadas por la baja ejecución de la inversión pública, destacó el gremio. Los agentes del sector construcción volvieron a reducir sus expectativas de crecimiento para este año, de acuerdo a la última Encuesta de Expectativas del IEC de Capeco realizada en junio. Así, esperan que el PBI del sector crezca 5.55\%, por debajo del $6.22 \%$ estimado en mayo (cuando lo elevaron desde el $4.75 \%$ estimado en febrero).

Solo el sector infraestructura redujo su estimado de crecimiento de $7.98 \%$ a $4.8 \%$. Los proveedores aumentaron su tasa de $3.91 \%$ a $5.07 \%$; mientras que los inmobiliarios lo hicieron de $6.59 \%$ a $6.66 \%$. Cabe destacar que estas menores expectativas coinciden con el recorte que hizo el Banco Central de Reserva (BCR), que pasó de 6.5\% en marzo a 5.4\% en junio para este año; y de $7.5 \%$ a $3.8 \%$ para el 2020. 
Hasta mayo, el crecimiento sectorial fue de $2.81 \%$. Con ello, entre junio y diciembre de este año, el sector construcción tendría que crecer a un ritmo de $7.5 \%$ para alcanzar el estimado de Capeco. "Ha influido el resultado de PBI sectorial de mayo (-0.3\%) y la abrupta caída del avance de la obra pública en ese mes (-17\%)", indicó Capeco.

\section{Inversión Pública}

Guido Valdivia, director ejecutivo de Capeco, indicó que los bajos niveles de inversión pública se deben a la eficiencia del actual modelo de descentralización, que ha concentrado el $65 \%$ de los recursos estatales de inversión en los últimos cinco años.

"Cada vez queda más claro que la baja ejecución de la obra pública se debe a que el modelo de gestión estatal de infraestructura no es capaz de ejecutar eficientemente los recursos presupuestales, los que se han ido incrementando paulatinamente", destacó.

Según Capeco, en el Perú existen 26 regiones (antes había 24 departamentos), con 196 provincias, de los cuales el 43\% tiene una población promedio de 25 mil pobladores. Asimismo, existen 1.874 distritos, del cual $75 \%$ cuenta con un promedio de 3 mil pobladores.

En ese sentido, explicó que no existe diferencia significativa en las competencias de los gobiernos subnacionales en función de su mayor población o actividad económica. (Diario El Comercio, Sección Economía, 2018). 
Tabla $\mathrm{N}^{\circ} 1$

Producto Bruto Interno - años 2014, 2015 y 2016

\begin{tabular}{lccc}
\hline Sectores Económicos & $\mathbf{2 0 1 4}$ & $\mathbf{2 0 1 5}$ & $\mathbf{2 0 1 6}$ \\
\hline Agropecuario & 1.9 & 3.2 & 1.8 \\
Pesca & -27.9 & 15.9 & -10.1 \\
Minería e & -0.9 & 9.5 & 16.3 \\
Hidrocarburos & -3.6 & -1.5 & -1.6 \\
Manufactura & 4.9 & 5.9 & 7.3 \\
Electricidad y agua & 1.9 & -5.8 & -3.1 \\
Construcción & 4.4 & 3.9 & 1.8 \\
Comercio & 5 & 4.2 & 3.9 \\
Servicio & $\mathbf{2 . 4}$ & $\mathbf{3 . 3}$ & $\mathbf{3 . 9}$ \\
PBI GLOBAL &
\end{tabular}

Nota: Tomado de Banco Central de Reserva del Perú BCR 2016, Recuperado de http://www.bcrp.gob.pe/estadisticas/cuadros-de-la-nota-semanal.html

El sector construcción registró un cambio de $-5.8 \%$ a $-3.1 \%$ en el 2016, los indicadores que se encuentran relacionados al proceso de crecimiento y productividad tienen una relación positiva y directa con el incremento del Producto Bruto Interno (PBI) per cápita que en el año 2015 alcanzó un monto 6, 027 dólares anuales con una desaceleración de $8 \%$ con respecto al año anterior a causa de una contracción de la economía. No obstante, del 2011 al 2013 se registró un incremento de 14\% del PBI per cápita fluctuando de 5, 770 dólares a 6,581 dólares anuales; en consecuencia este poder adquisitivo de la población se vinculó a las primeras necesidades, como la obtención de viviendas y departamentos cuyo comportamiento tuvo un crecimiento en los últimos siete años, pasando del 2008 de un total de 303 viviendas vendidas a 444 viviendas vendidas en el 2014, crecimiento del $45 \%$ en dicho periodo, según lo muestra CAPECO en un estudio inmobiliario, tal como se aprecia en la figura 3, una mayor adquisición de viviendas y 
departamentos que van a requerir que las personas acondicionen estos espacios, entre los cuales encontramos a los muebles de madera (Scotiabank, 2015).

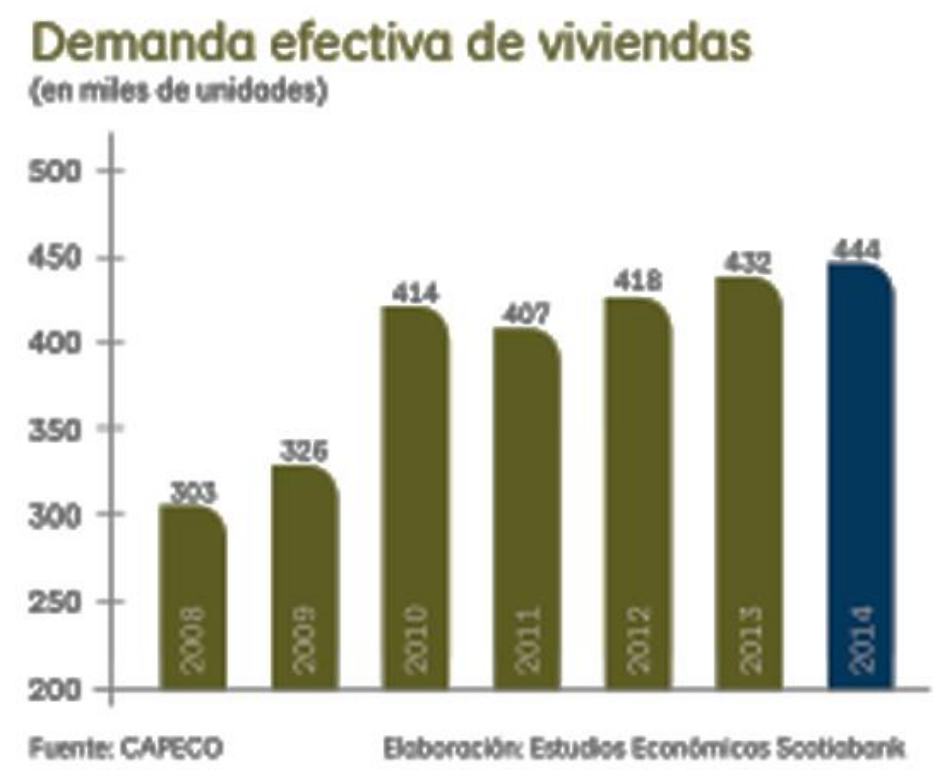

Figura $N^{\circ}$ 3. Venta de Viviendas en Lima Metropolitana

Tomado de "El Mercado Inmobiliario en perspectiva”, por Scotiabank 2015, p 16. Recuperado de https://scotiabankfiles.azureedge.net/scotiabankperu/PDFs/personas/prestamos/InformeInmobiliario_ESPANOL.pdf

Se analizó al mercado del sector de vivienda, el cual para el año 2017, creció en $4 \%$, impulsado por un mejor desempeño del consumo privado. Por otro lado, en ese mismo año se colocaron 78,000 viviendas, y se busca alcanzar un ritmo anual de 140,000 viviendas por año. Para el presente año (2018) se estima llegar a 100,000 viviendas colocadas, de esta manera se estaría acercando a la meta anual que deberá lograrse hasta el año 2021. (Diario Gestión, Sección Inmobiliarias, 2018). 
Los cambios en la administración pública se suscitaron variándose las normas, las cuales lograron agilizar los procesos de compras de vivienda para los consumidores. La contraparte de todo este crecimiento se aprecia en el déficit de viviendas en el país, lo que trae como consecuencia la necesidad de edificar más viviendas habitacionales considerando que al año se forman 120,000 hogares, incluso en el año de mayor demanda como fue el 2011, cubriendo dicha brecha con la invasión a los terrenos, la informalidad del sector, las ampliaciones, entre otros temas. En cuanto a los factores que dinamizan las transacciones en el Perú se encuentran la compra de nuevas viviendas, las cuales van a necesitar muebles con medidas que se adecuen a sus dimensiones; otro factor que influye es el mayor poder adquisitivo de las personas, las cuales poseen diferentes necesidades y estas cada vez van cambiando por muchos factores como: antigüedad, moda, diseño, etc. (Diario El Comercio, 2016).

Según lo mencionado en la revista Caser Maximixe, en la sección de riesgos sectoriales se tiene lo siguiente:

Se aprecia una dinámica de precios, basado en el incremento del IPMC (Índice de precios de materiales de construcción) de los últimos 12 meses (Ene 2017 - Ene 2018) el cual alcanzó $1.73 \%$ debido a que los mayores precios en los productos metálicos (varillas de construcción y planchas laminadas). Asimismo, los aglomerantes, suministros eléctricos, maderas, tubos y accesorios de plásticos, mientras se observó la reducción de precios de vidrios, mayólicas, mosaicos, ladrillos, agregados y estructuras de concreto. 
En cuanto a la dinámica sectorial, el empleo del sector construcción volvió a caer durante los meses de noviembre-diciembre-enero donde la PEA ocupada en Lima Metropolitana se incrementó en $0.40 \%$ (21.5 miles de empleos adicionales) alcanzando los 4,853 miles de personas. En el caso del sector Construcción, que concentró el $6.80 \%$ del total de la PEA ocupada. El ingreso promedio mensual en el sector aumentó en $8.50 \%$ interanual, equivalente a S/ 155 más, alcanzando así S/ 1,987.70.

Los créditos hipotecarios aumentaron en 7.2\%, la cifra más alta de los últimos 15 meses, donde los créditos hipotecarios ascendieron a S/ 41,285 millones, mayor en 7.2\% interanual, favorecido por menores tasas de las hipotecas. Según el tipo de moneda, los préstamos hipotecarios en soles aumentaron en $11.7 \%$, mientras que en moneda extranjera se contrajeron en $7.8 \%$.

A febrero del 2018, el Sector Construcción creció en 6.6\%, registrando un incremento por séptimo mes consecutivo, explicado por el consumo interno de cemento (6.7\%). Además de la actividad inmobiliaria desarrolló obras de construcción de viviendas multifamiliares.

En lo referido al diseño, forma, material entre otros factores de decisión, se observa que la renovación de muebles no es como hace más de 15 años, donde las personas solían conservar sus muebles por mucho tiempo, ahora la tendencia está dirigida a la moda, lo cual ha reducido esta brecha a cada cinco años, período en el cual las personas buscan renovar sus muebles con nuevas tendencias. (Diario El Comercio, 2016). 
En relación al material preferido por los peruanos en los últimos tiempos se observa que es la melamine, debido a que posee gran practicidad y simpleza para limpiar tanto al momento de realizar la instalación, así como al usarla en los muebles. (Barreto, Gamero \& Sánchez, 2011).

Tabla $N^{\circ} 2$

Lima: Número de establecimientos censados, según actividad económica.

\begin{tabular}{|c|c|c|}
\hline Código CIU & Actividad Económica & Nro Establecimientos \\
\hline 01 & $\begin{array}{c}\text { Fábrica de colchones con } \\
\text { Muelles }\end{array}$ & 57 \\
\hline 02 & $\begin{array}{c}\text { Fábrica de colchones con } \\
\text { caucho celular }\end{array}$ & 9 \\
\hline 03 & $\begin{array}{l}\text { Fábrica de colchones con } \\
\text { plásticos sin forro }\end{array}$ & 17 \\
\hline 04 & $\begin{array}{l}\text { Fábrica de colchones de } \\
\text { muebles para artefactos }\end{array}$ & 13 \\
\hline 05 & Fábrica de muebles para cocina & 12 \\
\hline 06 & Fábrica de muebles para hoteles & 6 \\
\hline 07 & $\begin{array}{c}\text { Fábrica de muebles para } \\
\text { oficinas }\end{array}$ & 62 \\
\hline 08 & $\begin{array}{l}\text { Fábrica de muebles para } \\
\text { vivienda y carpinterías }\end{array}$ & 1738 \\
\hline 09 & Fábrica de somieres & 4 \\
\hline 10 & Acabado de muebles & 18 \\
\hline
\end{tabular}

Recuperado de http://censos.inei.gob.pe/bcoCuadros/cuadros.asp? bco=02\&dep=00\& pro $=00 \&$ dis $=00 \&$ cua $=00003042$

\subsection{Determinación del problema u oportunidad}

\section{Situación actual}

La empresa SF HERMANOS S.R.L. inició operaciones en la fabricación de muebles en el año 1990, actualmente cuenta con 30 años de experiencia trabajando con 
importantes empresas del medio, siendo su principal objetivo la calidad de cada uno de sus productos, con el transcurso de los años SF Hermanos S.R.L. se consolidó como una empresa fabricante de muebles de forma especializada en carpintería fina, acero inoxidable y melamine, productos que siguen controles de calidad a detalle para cada uno de sus procesos, logrando con todo esto la satisfacción de principales clientes.

Actualmente la empresa no cuenta con un plan estratégico definido, la toma de decisiones se encuentra a cargo de los directivos de la empresa, en su mayoría familiares, quienes toman las mismas basadas en sus años de experiencia en el rubro.

En cuanto a los problemas encontrados en la empresa se observa rivalidad entre áreas por sobresalir una sobre otra, causa común presentada en empresas de conformación familiar, las cuales solo observan el beneficio propio y no el de la organización, dejando de lado los objetivos de la compañía, además de no contar con un plan de marketing para afrontar sus ventas, los directivos indican que las ventas se basan en recomendaciones directas, no llegando a una mayor cantidad de clientes, posee una estructura organizacional mal definida, la cual no permite adecuarse a la situación actual de la empresa en el mercado y por último una competencia agresiva por parte del mercado informal, basado netamente en microempresas que ofrecen productos de menor calidad y a un menor precio.

A continuación, se listan los problemas identificados de las áreas principales de SF Hermanos S.R.L.: 
Área de Ventas:

- No existe un análisis especifico de los clientes a quien van dirigidos los productos por lo cual no se aprecia la fidelización de los mismos.

- No se lleva un control de las ventas realizadas, el servicio de post venta no se encuentra implementado.

- SF Hermanos no realiza estrategias de ventas mensuales o anuales.

- Se aprecia poco manejo de la atractividad a los clientes frente a los productos que ofrece la empresa.

- SF Hermanos no cuenta con un análisis de los principales competidores.

- Si un cliente coloca una queja, está es resuelta después de un mes de realizada la compra.

Área de Producción:

- No existe una producción planificada.

- En el proceso productivo existe una mala distribución del trabajo.

- La empresa no cuenta con innovación tecnológica.

- No existencia de una estructura de costos para el proceso productivo.

- La especialización del trabajo es centrada en solo una persona.

- Existencia de alto índice de rotación y ausencia del personal.

- Se aprecia un alto tiempo ocio por parte del personal de producción.

Área de Logística:

- Falta de planificación de compras. 
- No existe un control de stock.

- El transporte no es tomado con la importancia debida.

- La trazabilidad externa e interna de los productos no es realizada.

- Falta de capacitación al personal.

- No existen indicadores de calidad.

- Gestión de la información e integración de sistemas no desarrollada.

Área de Administración:

- La empresa contrata personal no capacitado.

- No existencia de una descripción detallada de las funciones y procesos de la empresa.

- Incapacidad o falta de interés gerencial en los mandos medios para poder dirigir a toda la cadena a su cargo.

- Improvisación en el trabajo además de la inexistencia de planes y programas administrativos.

- Falta de comunicación y coordinación entre el personal a todo nivel.

- Falta de información oportuna para la toma de decisiones adecuada.

- Obsolescencia de procedimientos, métodos y técnicas de trabajo.

- Duplicidad de funciones.

- Exceso de mandos.

En cuanto a la oportunidad en este mercado se observa que SF Hermanos S.R.L. debe poner énfasis en viviendas y departamentos construidos con el objetivo de remodelar 
los espacios, esto queda demostrado en el ciclo de vida del producto (Ver figura 15) debido a que los gustos de los consumidores son cada vez más cambiantes, en lo referido a diseño, forma, nuevas tendencias entre otros aspectos pero sin dejar de lado a los nuevos proyectos del sector construcción, los cuales en la actualidad encuentran menores trabas debido a la instalación del nuevo gobierno y las instituciones gubernamentales que hacen que el proceso de compra de viviendas sea menos engorroso.

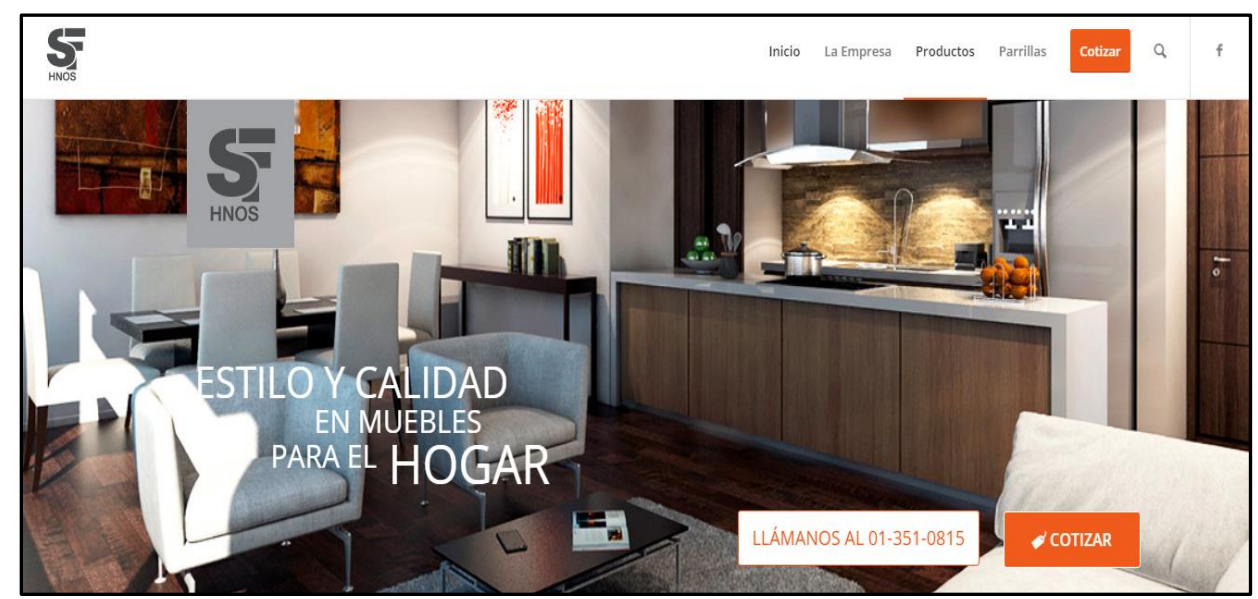

Figura $N^{\circ}$ 4. Página web de la empresa SF Hermanos S.R.L. Recuperado de http://www.sfhnos.com

\subsection{Justificación del proyecto}

\section{Justificación económica}

La presente investigación se justifica por la necesidad de la empresa S.F. Hermanos S.R.L. de contar con un plan estratégico, el cual será implementado y transmitido a todos los colaboradores e involucrados en la empresa, para que se enfoquen en una visión en común que permita mantenerse competitivos y vigentes en el mercado. 


\section{Justificación académica}

El presente documento busca poner en práctica los conocimientos adquiridos en el desarrollo de la maestría realizada. Asimismo, busca servir de ejemplo para que futuros investigadores y tesistas puedan aplicar y desarrollar planes estratégicos de desarrollo en empresas nacionales de Lima o el interior del país, de los diferentes sectores económicos.

\subsection{Objetivos generales y específicos}

\section{Objetivo general}

Desarrollar un plan estratégico para la empresa S.F. Hermanos S.R.L. para el periodo 2019 - 2021, el cual se realizará con la finalidad de alinear los esfuerzos de las diferentes áreas de la empresa.

\section{Objetivos específicos}

- Analizar y definir la visión, misión y valores de la empresa.

- Realizar el análisis interno y externo de la empresa.

- Formular los objetivos estratégicos y operativos de la empresa.

- Seleccionar la estrategia a seguir por la empresa.

- Desarrollar un plan de trabajo detallado.

- Evaluar económicamente la estrategia elegida. 


\subsection{Alcances y limitaciones de la investigación}

\section{Alcances}

El presente plan estratégico se va a desarrollar para la empresa SF HERMANOS

S.R.L, en el período 2019 - 2021, dentro del mercado de Lima - Metropolitana.

\section{Limitaciones}

El presente plan tiene las siguientes limitaciones:

- Carencia de información respecto a la competencia.

- Limitada información actualizada del sector. 


\section{Capítulo II: La Empresa}

\subsection{Antecedentes de la empresa}

El 30 de mayo de 1990 se constituyó la empresa SF Hermanos S.R.L. siendo los accionistas: Fortunato Cárdenas Alvarado, Víctor Cárdenas Alvarado y Matías Cárdenas Alvarado, emprendedores innatos, los cuales, con solo estudios de nivel básico, formaron SF Hermanos S.R.L. con el objetivo de dejar una empresa rentable a sus generaciones.

Fortunato Cárdenas Alvarado asumió la gerencia general de la empresa y bajo su dirección inició operaciones realizando puertas de fierro y seguridad para oficinas y hogar, además de muebles de madera en general, con cinco personas en tareas operativas incluyendo a los mismos accionistas, quienes laboraban como sus propios operarios, sus clientes eran referidos de amigos y conocidos, por lo cual empezaron a ser conocidos por la calidad y eficiencia de sus trabajos.

El 14 de octubre de 1993, la empresa SF Hermanos S.R.L. decide incrementar su capital mediante la capitalización de utilidades, por lo cual su capital social asciende a 50,000 soles. Más adelante la empresa cambia el rubro de seguridad en puertas de fierro por el de carpintería metálica, donde se especializaron en muebles en acero inoxidable, madera y melamine después de tres años de haber constituido la empresa.

En el año 2003, la empresa gana el primer contrato de servicios de mantenimiento de todo tipo de mobiliario en Lima y Callao con la institución pública SUNAT, adicionando como rubro los servicios para instituciones del Estado Peruano. En el campo 
organizacional de la empresa, don Fortunato Cárdenas, gerente general de la empresa renunció a su puesto, asumiendo la gerencia doña Elba Cerrón Cárdenas, además del incremento del capital a 134,800 soles, el 24 de octubre del 2008 (SUNARP, 2016).

Luego de ocho años la empresa SF Hermanos S.R.L., se hace acreedor de un terreno en la zona ecológica Fundos de Pariachi, local donde se realiza todo tipo de servicios para los contratos contraídos con el estado.

En el año 2014, la empresa obtiene la homologación como proveedor con la empresa Alicorp cumpliendo con todas las normas de calidad requeridas por el cliente.

A comienzos del año 2016 la empresa SF Hermanos S.R.L, decide implementar una tienda de acero inoxidable y todo tipo de servicios para este producto lo que generó su participación por primera vez en la feria Expo Drinks \& Food, la cual fue organizada por la Cámara de Comercio de Lima, donde se presentó uno de sus productos bandera llamado Parrilleros en acero inoxidable.

Actualmente la empresa sigue siendo familiar, por lo cual los principales puestos y jefaturas están a cargo de integrantes de la familia debido al grado de confianza que tiene cada uno para tomar las decisiones correctas según la junta de accionistas. Cuentan con 30 personas laborando para la empresa siendo la distribución de los mismos la siguiente: tres son directivos, dos en jefaturas, seis administrativos y 19 operarios. 
SF Hermanos S.R.L, busca cumplir las necesidades de sus clientes en todos los diseños que se realizan para el sector construcción en el área de mobiliario, con la experiencia obtenida en el transcurso de los años realizando diferentes tipos de proyectos de gran importancia.

En cuanto al segmento de los clientes SF Hermanos S.R.L. los clasifica de la siguiente manera:

Principales Clientes: Conformados por Arquitectos, Ingenieros y Constructoras.

Clientes Secundarios: Conformados por las Instituciones Públicas a las cuales les brinda el servicio de mantenimiento.

Clientes Complementarios: Conformados por empresas privadas y personas naturales que llegan hasta la compañía en busca de realizar sus proyectos.

\section{La relación con sus clientes}

Es de vital importancia, por este motivo SF Hermanos S.R.L. cumple con todos los detalles y estándares solicitados por cada cliente. Es por eso que la comunicación debe de ser fluida e inmediata, además de que todos los acuerdos son realizados en la propia área de trabajo siendo una negociación face to face. 


\section{Canales de distribución}

SF Hermanos S.R.L. para la distribución de sus productos desarrolla dos canales de distribución:

Canal directo: Utilizado debido a que la empresa realiza venta directa de sus productos y/o servicios con el cliente final, dando una atención rápida y eficaz.

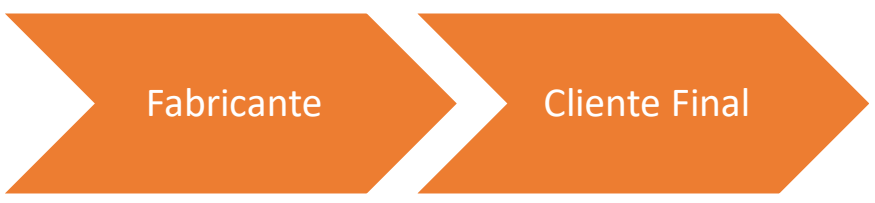

Canal agente/intermediario: Este canal es usado por la empresa debido a que los proyectos que se obtienen por medio de Arquitectos, Ingenieros y constructoras, proceso en el cual se coordina con el cliente final para realizar el diseño de su proyecto o producto.

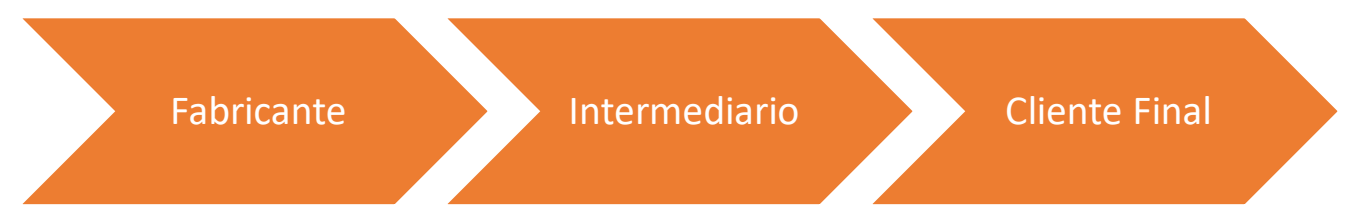

\section{Red de socios}

SF Hermanos S.R.L. tiene una alianza estratégica para el desarrollo de mobiliario de material de melamine con la empresa EJM CARDENAS, por lo cual pueden realizar la verificación directa y obtención inmediata del producto solicitado.

Además, posee como socios estratégicos a las empresas Polimetales, Discovery Inox, y JN Aceros las cuales proveen los insumos para el mobiliario de acero inoxidable. Y para realizar los mobiliarios de madera realizan las compras directamente con pymes que 
se encuentran ubicadas en el parque industrial de Villa El Salvador y madereras aledañas a las instalaciones de la empresa.

\section{Recursos claves}

Capital, SF HERMANOS trabaja con capital propio.

Capital humano, la capacitación constante del personal es importante además de la retención de cada uno de ellos.

Operaciones (almacén y distribución), claves para asegurar el flujo de compras y ventas en los términos y calidad requeridos.

Gestión comercial, indispensable para mantener las relaciones comerciales actuales, así como para expandir y explorar nuevos mercados y segmentos.

\section{Actividades claves}

Las actividades claves que se realizan son:

- Logística (compras, almacén y distribución).

- Ventas y gestión comercial.

- Administración y finanzas.

Por otro lado, la preocupación de la empresa es la dependencia de los contratos con las instituciones del Estado, debido a que reflejan el 30\% y en algunos casos el $50 \%$ de las ventas de la empresa, estos contratos son temporales por lo cual siempre deben participar por adjudicaciones o licitaciones que se publican en el Organismo Supervisor de las 
Contrataciones del Estado (OSCE) donde el mejor postor es quien consigue el siguiente contrato (Estados financieros de SF Hermanos S.R.L., 2015).

A continuación, se muestra el detalle de las ventas y utilidades por líneas de productos para SF Hermanos de los últimos 4 años:

Tabla $\mathrm{N}^{\circ} 3$

Ventas por línea de negocio de SF Hermanos

\begin{tabular}{lcccc}
\hline Línea de negocio & 2014 & 2015 & 2016 & 2017 \\
\hline Muebles para el hogar & 455,000 & 476,000 & 580,000 & 650,000 \\
Muebles de oficina & 96,000 & 109,000 & 89,000 & 78,000 \\
Muebles comerciales & 105,000 & 112,000 & 110,000 & 88,000 \\
$\begin{array}{l}\text { Carpintería en obra } \\
\text { Servicios de }\end{array}$ & 245,000 & 265,000 & 271,000 & 287,000 \\
mantenimiento & 829,894 & 846,999 & 857,636 & 869,390 \\
$\begin{array}{l}\text { Tienda de acero } \\
\text { inoxidable }\end{array}$ & 166,735 & 196,235 & 255,990 & 292,682 \\
\hline
\end{tabular}

Nota: Elaboración propia

Tabla $N^{\circ} 4$

Utilidades por línea de negocio de SF Hermanos

\begin{tabular}{lcccc}
\hline Línea de negocio & 2014 & 2015 & 2016 & 2017 \\
\hline Muebles para el hogar & 104,650 & 99,960 & 104,400 & 130,000 \\
Muebles de oficina & 17,280 & 20,710 & 20,470 & 17,160 \\
Muebles comerciales & 16,800 & 17,920 & 17,600 & 11,440 \\
$\begin{array}{l}\text { Carpintería en obra } \\
\text { Servicios de }\end{array}$ & 122,500 & 124,550 & 111,110 & 140,630 \\
mantenimiento & 240,669 & 186,339 & 231,561 & 208,653 \\
$\begin{array}{l}\text { Tienda de acero } \\
\text { inoxidable }\end{array}$ & 66,694 & 78,494 & 102,396 & 117,073 \\
\hline
\end{tabular}

Nota: Elaboración propia 


\subsection{Descripción del negocio}

La empresa SF Hermanos S.R.L. se dedica a la fabricación y comercialización de muebles en madera, melamine y acero inoxidable.

El CIIU es la clasificación industrial uniforme emitida por la oficina de estadísticas de la Organizaciones de las Naciones Unidas (ONU), el cual permite a cada país obtener datos económicos clasificados en categorías y subcategorías de cada actividad económica que realice el país (Sistema de clasificación DIGESTYC, 2016).

A continuación, se determina el CIIU en la que se encuentra la empresa SF Hermanos S.R.L.:

\section{Clasificación CIIU:}

Categoría de tabulación: D - Industrias manufactureras

División: 36 - Fabricación de muebles; industrias manufactureras n.c.p.

Grupo: 361 - Fabricación de muebles

Clase: 3610 - Fabricación de muebles

Categoría de tabulación: S - Otras actividades de servicios

División: 95 - Reparación de ordenadores y de efectos personales y enseres domésticos.

Grupo: 952 Mantenimiento y reparación de efectos personales y enseres domésticos.

Clase: 9524 - Reparación de muebles y accesorios domésticos

SF Hermanos S.R.L. es una empresa familiar que se dirige al público objetivo perteneciente al sector A y B en empresas y público en general contando con 30 de años de 
experiencia en el mercado. Por lo cual es un sector exclusivo donde los muebles que se realizan siempre son a diseño del cliente y personalizados según el ingeniero o arquitecto a cargo. Poseen cuatro líneas de productos las cuales son las siguientes:

a) Muebles para el hogar: Muebles diseñados con las últimas tendencias en colores, texturas y acabados especialmente elaborados para clientes exclusivos que trabajan solo con diseñadores de interiores, arquitectos e ingenieros. Estos muebles son trabajados con diferentes materiales como madera de alta calidad, melamine, MDF, aglomerado y acero inoxidable acompañados de acabados especiales que son en poliuretano, DD, barniz y otros. Por lo general estos muebles tienen medidas especiales, y diseños de complejidad designados por los clientes.

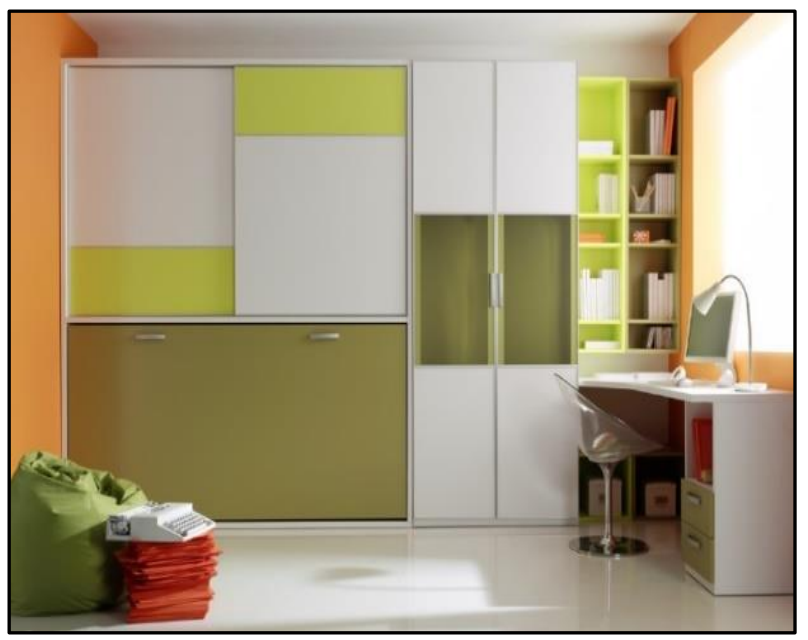

Figura $N^{\circ}$ 5. Muebles para el hogar. Recuperado de http://www.sfhnos.com

b) Muebles para oficina: Los diseños son realizados para mobiliario de Centros Comerciales, su elaboración es en base del material MDF y aglomerado con 
acabados de poliuretano. Estos muebles son góndolas, repisas, muebles para organización de diseños especiales, etc.

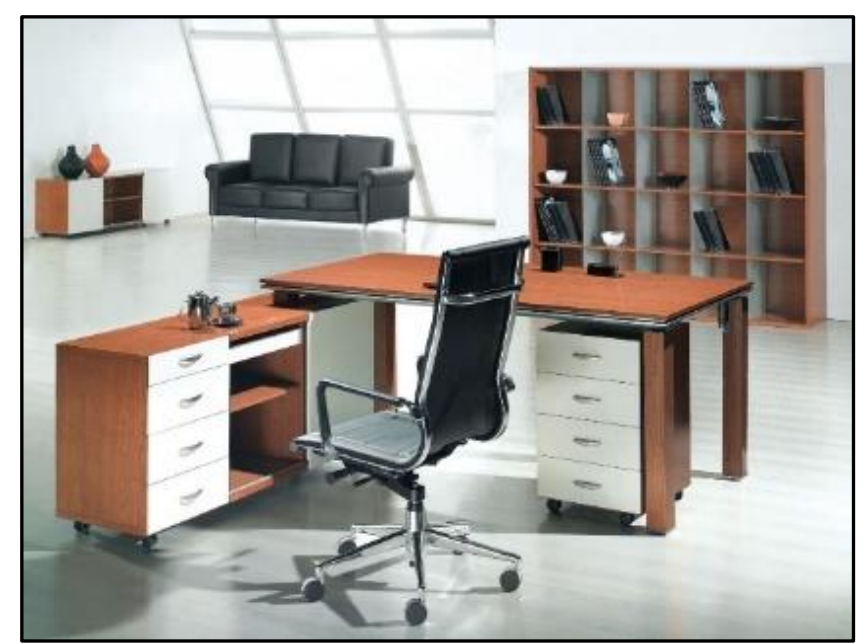

Figura $N^{\circ}$ 6. Muebles para oficina. Recuperado de http://www.sfhnos.com

c) Muebles comerciales: Muebles diseñados para cubrir espacios especiales para el comercio, como góndolas, counters, módulos, amueblamientos de tiendas comerciales.

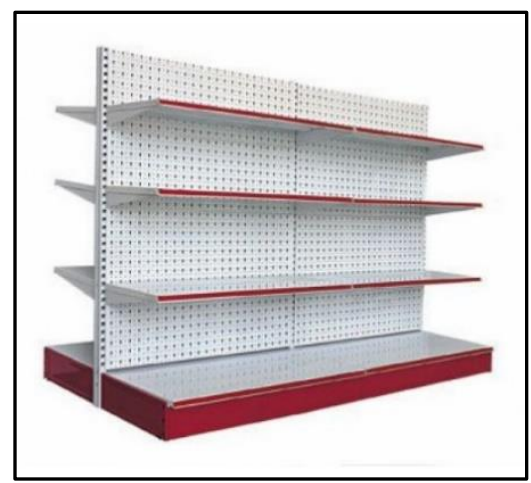

Figura $N^{\circ}$ 7. Muebles comerciales. Recuperado de http://www.sfhnos.com 
d) Carpintería en obra: Estos diseños por lo general son estructuras que se realizan en los exteriores de oficinas, hogares, condominios, y más.

Por lo general son trabajos como barandas de acero inoxidable, estructuras de acero inoxidable o fierro, techo sol y sombra, enchapados de paredes exteriores, diseños de muebles especiales para un diseño de fachadas.

Además, la empresa realiza servicios de mantenimiento de mobiliario para las instituciones del Gobierno en Perú, por lo cual se ha realizado trabajos en Lima, en provincias y la implementación de una tienda de acero inoxidable.

Cuentan con una cartera de clientes conformada por personas jurídicas y personas naturales por lo cual tienen diversos productos que ofrecer en cada línea.

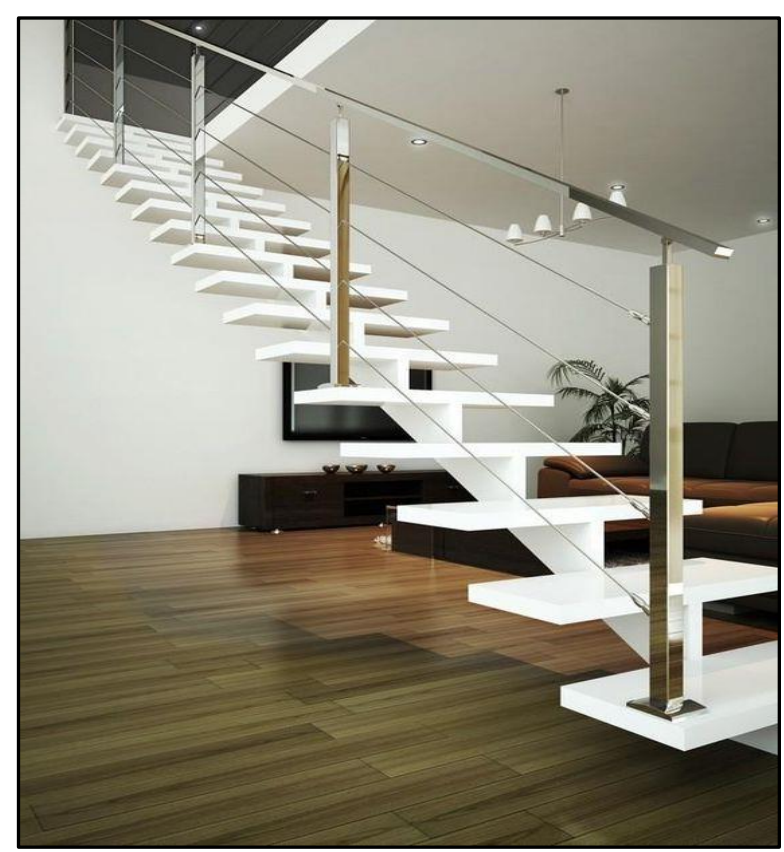

Figura $N^{\circ}$ 8. Acabo de escalera. Recuperado de http://www.sfhnos.com. 


\subsection{Ciclo de vida del producto}

El ciclo del producto es una herramienta que ayuda a reconocer la situación en la que se encuentra cada producto según las ventas y utilidades que presenta la empresa para cada línea de productos. (Kotler\& Armstrong, 2013).

Por lo tanto, este ciclo contiene cuatro fases, las cuales se describen a continuación:

1. Introducción: En esta fase se presenta un período bajo en ventas tras el lanzamiento del producto al mercado. Los beneficios en esta fase son nulos dados los altos gastos desembolsados por la empresa para la creación del nuevo producto.

2. Crecimiento: Se logra la aceptación del nuevo producto en el mercado; después de esta fase se comienza a vislumbrar un aumento en los beneficios para la empresa.

3. Madurez: Aquí el producto no experimenta un incremento exponencial en ventas en el mercado, sino que para su crecimiento por un período. Esto se debe a la aceptación del producto por la mayor parte de los compradores potenciales. Es aquí donde los beneficios comienzan a estabilizarse, sólo si la empresa pone esfuerzos para seguir promocionando e innovando su producto en el mercado.

4. Declive: Como su nombre lo dice, es cuando el producto cae debido a la disminución de las ventas y beneficios que genera tanto para el cliente como para la empresa. 
Cada producto por lo general pasa por cada fase del ciclo de vida, no obstante, hay casos donde observamos que después de la introducción del producto este cae por la poca promoción o que no llega a satisfacer las necesidades que demanda el mercado, u otros pueden permanecer en la etapa de madurez por muchos años.

Entonces se observan los criterios a tomar para ubicar a cada línea o producto en qué fase del ciclo de vida pertenece como se visualiza en la tabla.

Tabla $\mathrm{N}^{\circ} 5$

Criterios para ubicar en qué etapa se encuentra el producto

\begin{tabular}{ccc}
\hline Etapa & Ventas & Utilidades \\
\hline Introducción & Bajas & Son muy bajas o negativas \\
Crecimiento & Suben con rapidez & Aumentan \\
Madurez & $\begin{array}{c}\text { Siguen aumentando, pero a } \\
\text { ritmo decreciente, hasta } \\
\text { que llega el momento en } \\
\text { que se detiene. }\end{array}$ & $\begin{array}{c}\text { Las utilidades se mantienen } \\
\text { Declinación }\end{array}$ \\
& Declive & $\begin{array}{c}\text { Existe una baja hasta que éstos } \\
\text { son nulos, e incluso, se } \\
\text { convierten en negativos. }\end{array}$ \\
\hline
\end{tabular}

Nota: Adaptado de "Fundamentos de Marketing, Sexta Edición", por Kotler Philip y Armstrong Gary, Prentice Hall, 2013, Pág. 337.

\section{Muebles para el hogar}

Se muestra el detalle del ciclo del producto para la línea muebles de oficina en la siguiente tabla: 
Tabla $\mathrm{N}^{\circ} 6$

Ventas vs Utilidades de la línea de muebles de hogar

\begin{tabular}{ccc}
\hline Período & Ventas & Utilidades \\
\hline 2013 & S/. 430,000 & S/. 103,200 \\
2014 & S/. 455,000 & S/. 104,650 \\
2015 & S/. 476,000 & S/. 99,960 \\
2016 & S/. 580,000 & S/. 104,400 \\
2017 & S/. 650,000 & S/. 130,000 \\
\hline
\end{tabular}

Nota: Elaboración propia

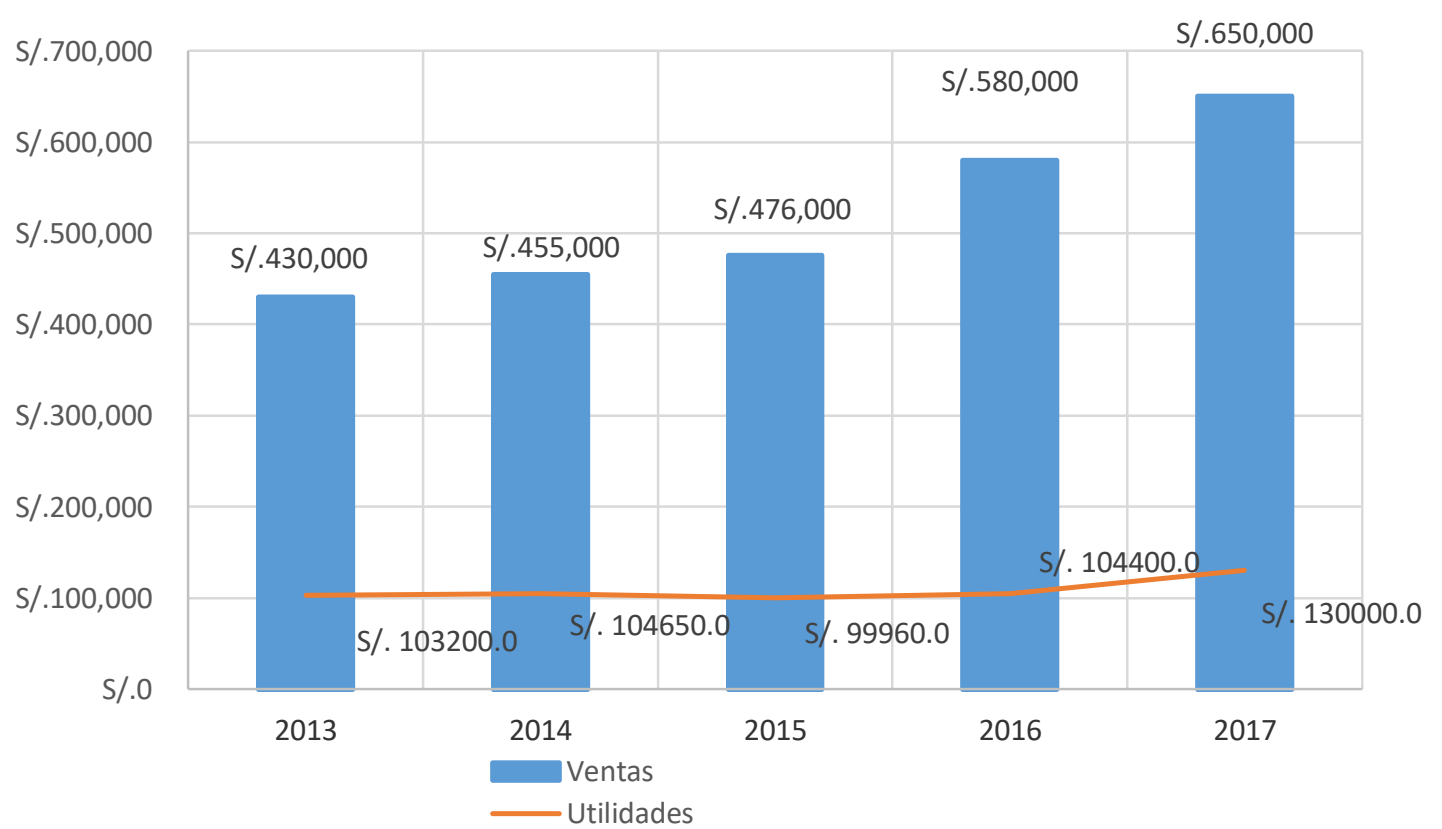

Figura $N^{\circ}$ 9. Muebles de hogar: Ventas vs Tiempo vs Utilidades. Nota: Elaboración propia

Para la línea de muebles de hogar se observa que esta se encuentra en la etapa de madurez, debido a que durante los últimos años se ha mantenido en sus ventas obteniendo como beneficio utilidades constantes en conclusión se observa que la empresa está promocionando e innovando en esta línea. 


\section{Muebles de oficina}

Se muestra el detalle del ciclo del producto para la línea muebles de oficina en la siguiente tabla:

Tabla $\mathrm{N}^{\circ} 7$

Ventas vs Utilidades de la línea de muebles de oficina

\begin{tabular}{ccc}
\hline Año & Ventas & Utilidades \\
\hline 2013 & S/. 89,000 & S/. 13,350 \\
2014 & S/. 96,000 & S/. 17,280 \\
2015 & S/. 109,000 & S/. 20,710 \\
2016 & S/. 89,000 & S/. 20,470 \\
2017 & S/. 78,000 & S/. 17,160 \\
\hline
\end{tabular}

Nota: Elaboración propia

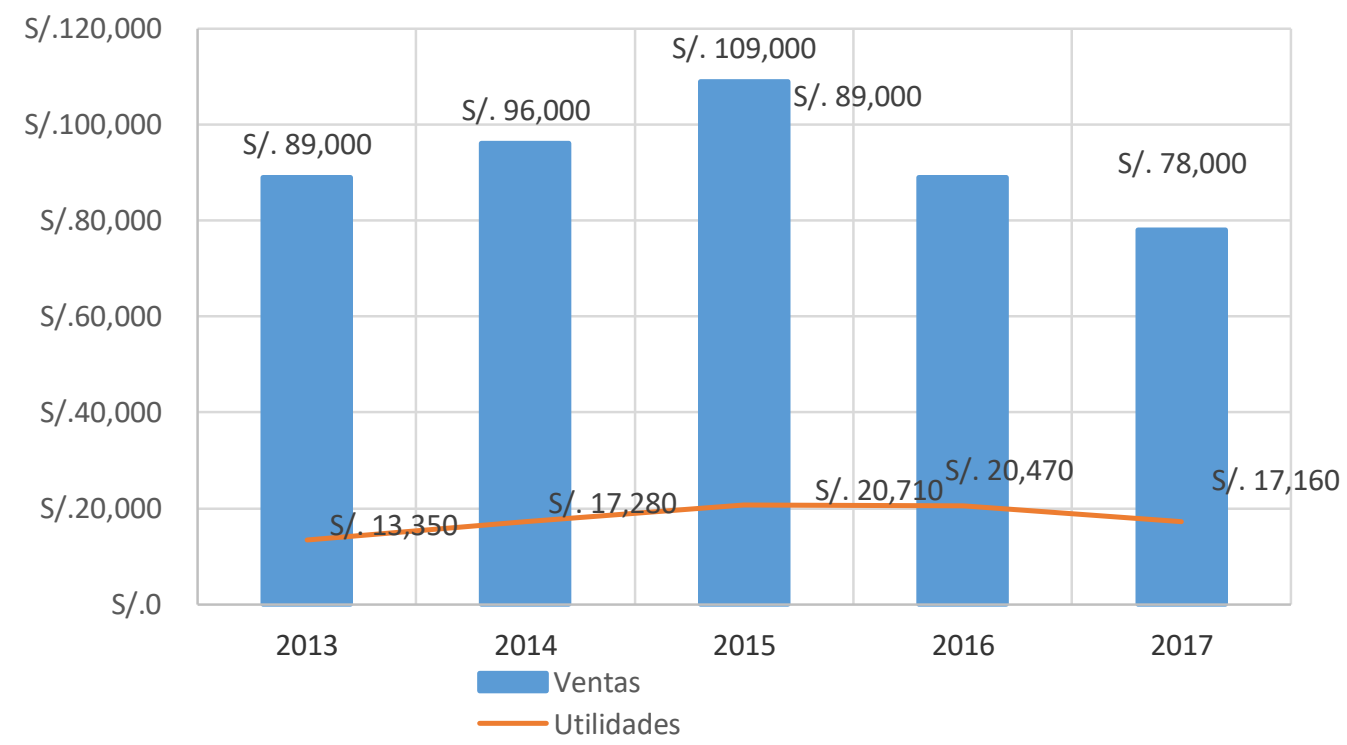

Figura $N^{\circ}$ 10. Muebles de oficina: Ventas vs Tiempo vs Utilidades. Nota: Elaboración propia 
La línea de muebles de oficina se encuentra en la fase de declive, debido a que desde el año 2015 hasta el año 2017 se presenta una disminución en las ventas de los productos, además de la reducción de las utilidades en paralelo, por lo cual SF Hermanos considera optar por retirar este producto de la línea, además de realizar algún cambio en el producto para más adelante relanzarlo con el fin de que pueda representar utilidades en la empresa en un plazo determinado.

\section{Muebles comerciales}

Se muestra el detalle del ciclo de producto para la línea muebles comerciales como se muestra en la siguiente tabla:

\section{Tabla $\mathrm{N}^{\circ} 8$}

Ventas vs Utilidades de la línea de muebles comerciales

\begin{tabular}{ccc}
\hline Año & Ventas & Utilidades \\
\hline 2013 & S/. 90,000 & S/. 14,400 \\
2014 & S/. 105,000 & S/. 16,800 \\
2015 & S/. 112,000 & S/. 17,920 \\
2016 & S/. 110,000 & S/. 17,600 \\
2017 & S/. 88,000 & S/. 11,440 \\
\hline
\end{tabular}

Nota: Elaboración propia 


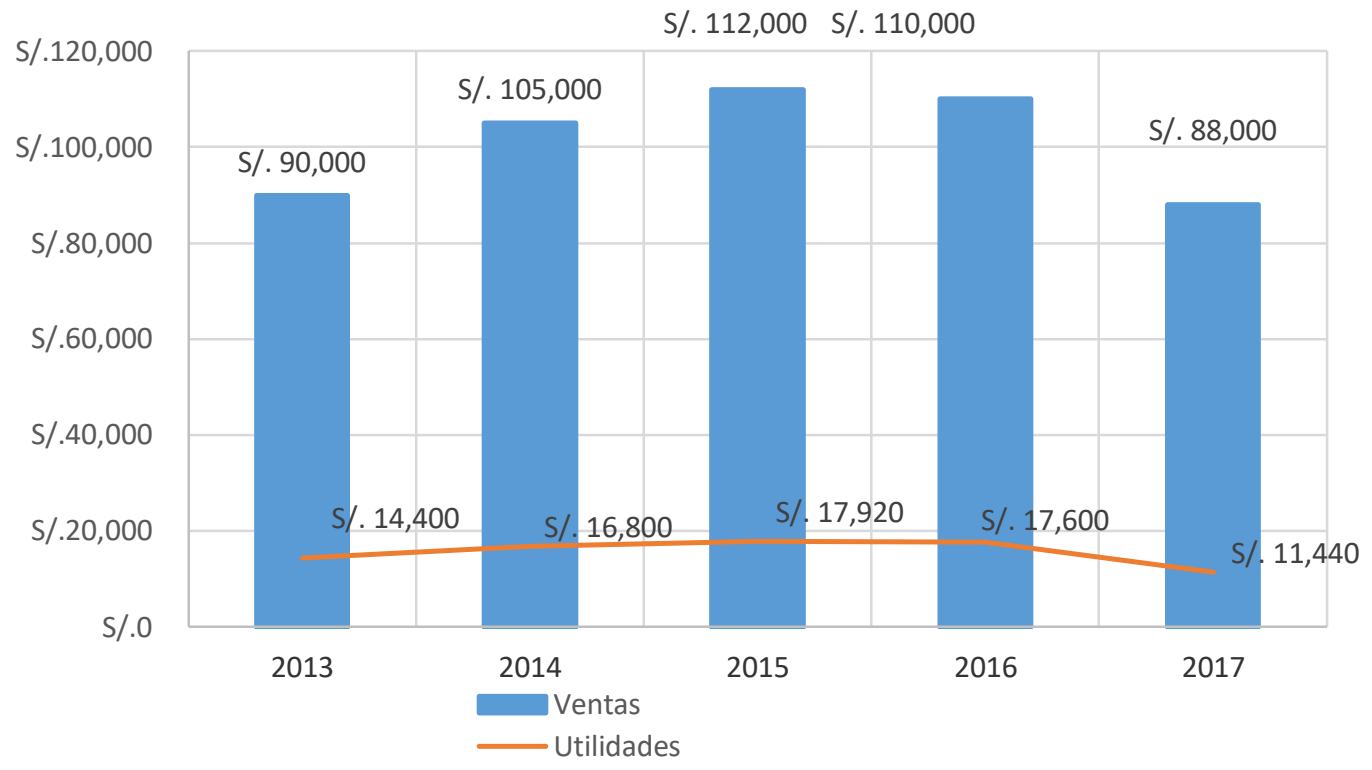

Figura $N^{\circ} 11$. Muebles comerciales: Ventas vs Tiempo vs Utilidades. Nota: Elaboración propia

La línea de muebles comerciales se encuentra en la fase de declive, por las bajas ventas presentadas entre el año 2015 - 2017 lo cual generó una disminución de las utilidades para la empresa, debido a que el costo de mantener la línea es superior al ingreso por ganancias, todo esto ocasionado por el ingreso de productos sustitutos importados provenientes de China.

\section{Carpintería en obra}

Se muestra el detalle del ciclo de producto para la línea carpintería como se muestra en la siguiente tabla: 
Tabla $\mathrm{N}^{\circ} 9$

Ventas vs Utilidades de la línea de carpintería en obra

\begin{tabular}{ccc}
\hline Año & Ventas & Utilidades \\
\hline 2013 & S/. 220,001 & S/. 99,000 \\
2014 & S/. 245,000 & S/. 122,500 \\
2015 & S/. 265,000 & S/. 124,550 \\
2016 & S/. 271,000 & S/. 111,110 \\
2017 & S/. 287,000 & S/. 140,630 \\
\hline
\end{tabular}

Nota: Elaboración propia

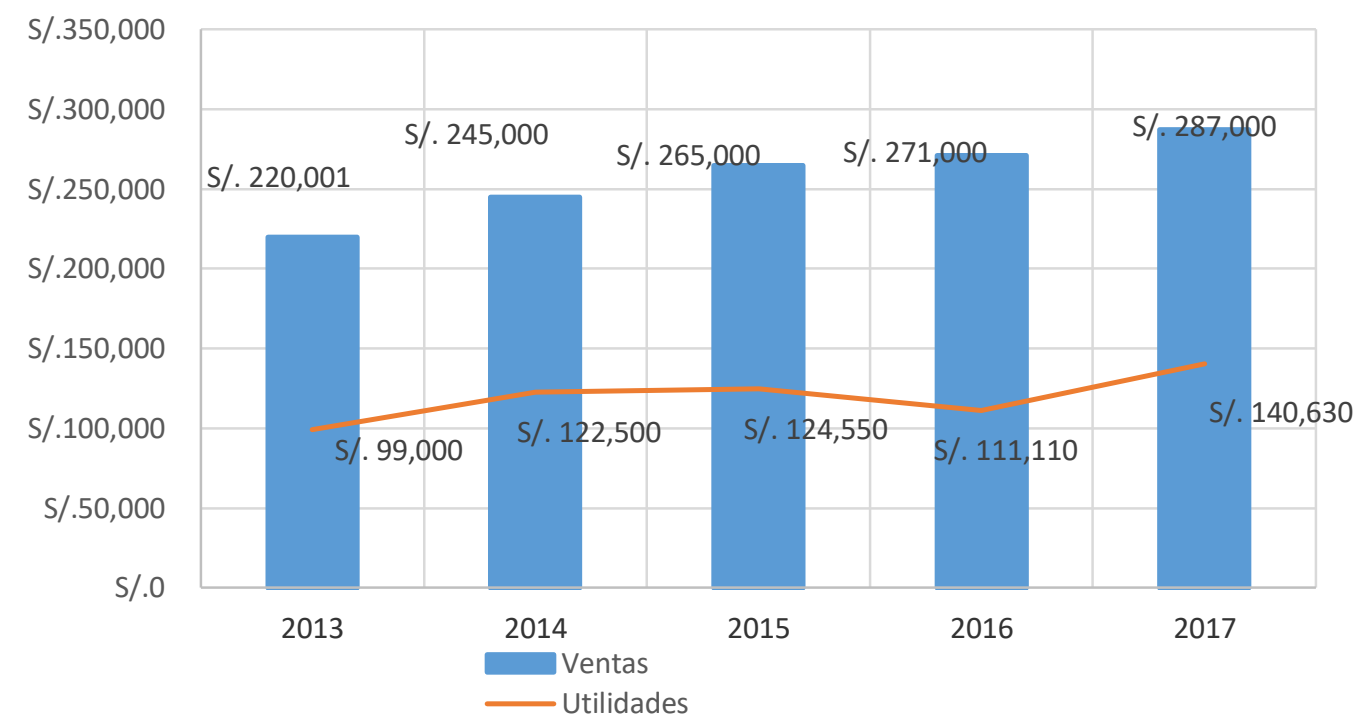

Figura $N^{\circ}$ 12. Carpintería en Obra: Ventas vs Tiempo vs Utilidades. Nota: Elaboración propia

Las ventas durante los periodos de los años 2014 al 2017 se han incrementado pero de forma muy leve, lo cual determina que esta línea está en fase de madurez, por lo cual estos productos se pueden ir manteniendo en el mercado pero la empresa deberá optar por presentar ideas innovadoras, tendencias o manejar promociones para que esta línea no se coloque en la fase final del ciclo del producto, la cual es una fase en donde la mayoría de 
veces la empresa decide retirar el producto debido a que al realizar una reestructuración resulta más cara que el retiro de este mismo.

\section{Servicios de mantenimiento}

Se muestra el detalle del ciclo de producto para la línea servicios de mantenimiento como se muestra en la siguiente tabla:

Tabla $\mathrm{N}^{\circ} 10$

Carpintería en Obra: Ventas vs Tiempo vs Utilidades

\begin{tabular}{ccc}
\hline Año & Ventas & Utilidades \\
\hline 2013 & S/. 818,492.00 & S/. 204,623.00 \\
2014 & S/. 829,894.00 & S/. 240,669.26 \\
2015 & S/. 846,999.73 & S/. 186,339.94 \\
2016 & S/. 857,636.31 & S/. 231,561.80 \\
2017 & S/. 869,390.17 & S/. 208,653.64 \\
\hline
\end{tabular}

Nota: Elaboración propia

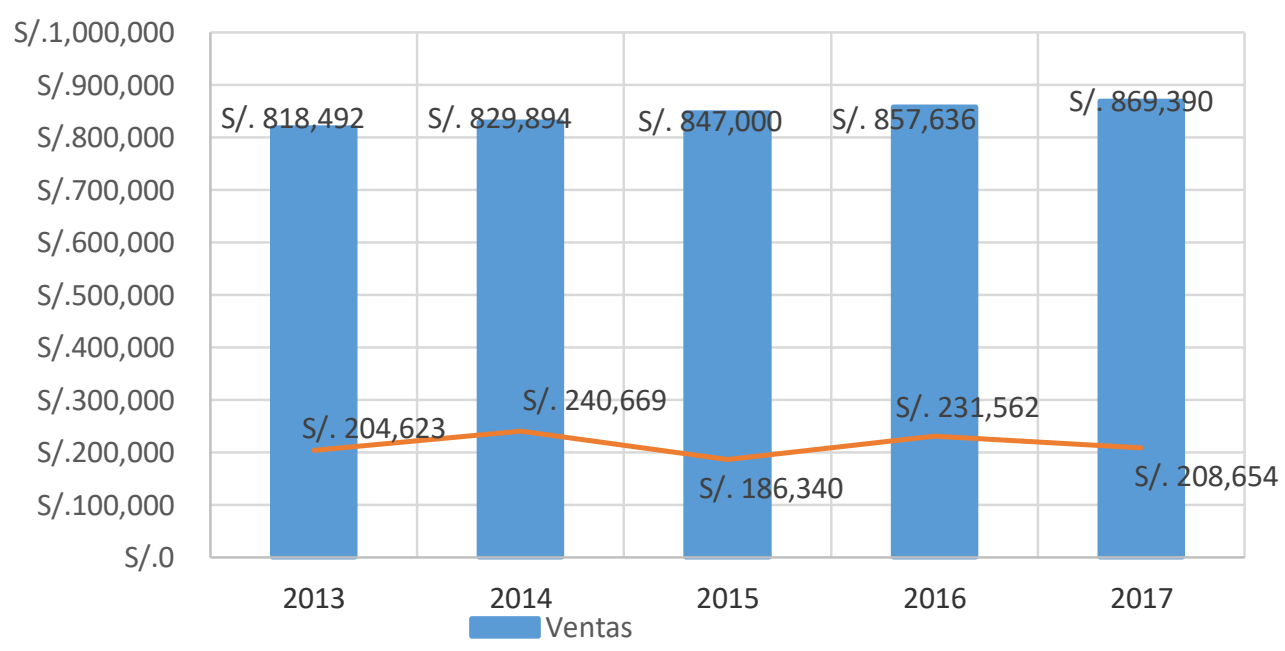

Figura $N^{\circ}$ 13. Servicios de mantenimiento: Ventas vs Utilidades. Nota: Elaboración propia 
Los servicios de mantenimiento se pueden analizar como aquellos contratos que ya se encuentran definidos con el estado, se mantiene las ventas constantes, obteniendo el beneficio de optar por utilidades que se mantienen en los años de contrato. Por lo tanto, esta línea no depende mucho de la promoción o innovación sino del tiempo de contrato a realizar.

En este tipo de servicio SF Hermanos S.R.L. siempre está a la expectativa de la renovación del contrato, el cual es realizado en su mayoría cada 5 años, por lo que siempre se trata de cumplir con todo lo que pide el cliente para que la línea siga manteniéndose en el tiempo y no ingrese a una fase de declive.

\section{Tienda de acero inoxidable}

Se muestra el detalle del ciclo de producto para la línea tienda de acero inoxidable como se muestra en la siguiente tabla:

Tabla $\mathrm{N}^{\circ} 11$

Ventas vs Utilidades de la tienda de acero inoxidable

\begin{tabular}{ccc}
\hline Año & Ventas & Utilidades \\
\hline 2013 & S/. 129,853 & S/. 51,941 \\
2014 & S/. 166,735 & S/. 66,694 \\
2015 & S/. 196,235 & S/. 78,494 \\
2016 & S/. 255,990 & S/. 102,396 \\
2017 & S/. 292,682 & S/. 117,073 \\
\hline
\end{tabular}

Nota: Elaboración propia 


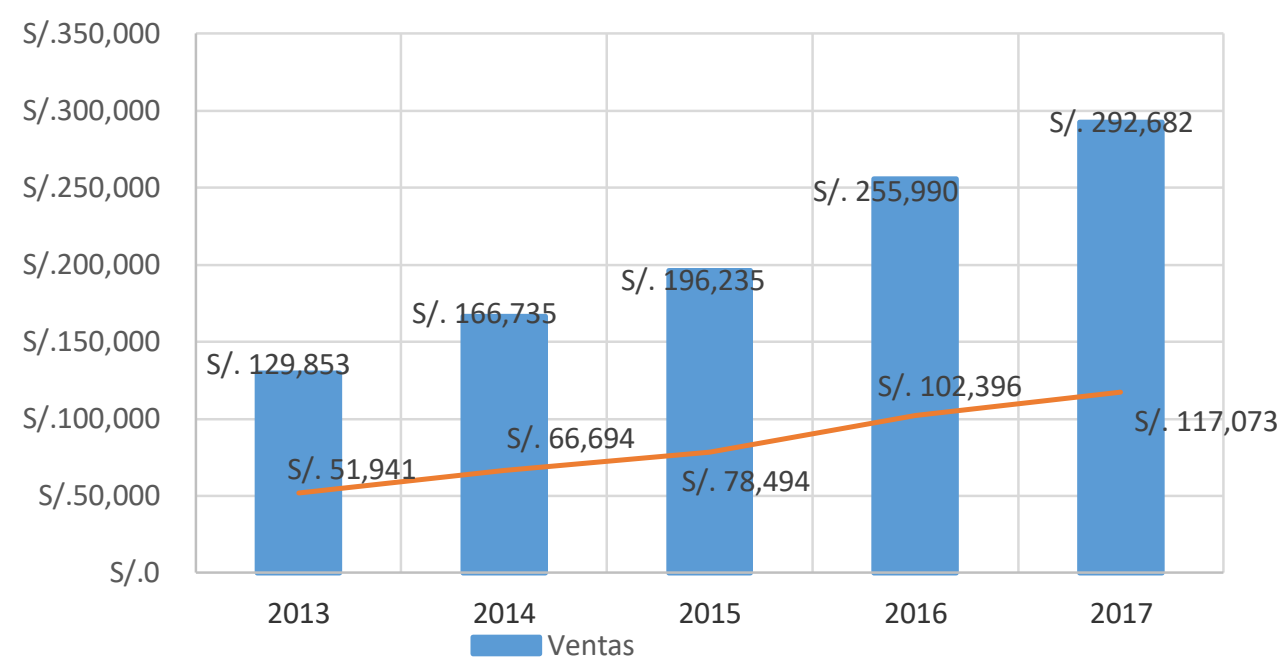

Figura $N^{\circ}$ 14. Tienda de acero inoxidable: Ventas vs Tiempo vs Utilidades. Nota: Elaboración propia

La tienda de acero inoxidable se encuentra en la fase de crecimiento según los criterios mencionados anteriormente por lo que se observa que las ventas y utilidades han ido creciendo en los últimos años, debido a que los insumos de la tienda de acero se están impulsando como productos potenciales para la empresa, presentando varios modelos según tendencia y necesidad del cliente.

La implementación de la tienda de acero ha permitido abaratar los costos de producción, debido a que dicho producto se importa en mayores cantidades y el proveedor disminuye el precio.

Asimismo, se reducen los costos fijos y variables, debido a que se reutilizan los saldos, producto de la venta de las planchas de acero en las cuales los clientes solicitan 
cortes específicos dejando retazos, que son evaluados por el área de control de calidad antes de mandar al área de producción de muebles.

Por el lado de los costos fijos, para los cortes de acero en la tienda, se designa las tareas a los colaboradores del área de producción, los cuales están capacitados para poder satisfacer a los clientes de tienda y asimismo cuidar el producto para dejar los retazos en optimadas condiciones y ser reutilizados en la producción de muebles.

Habiendo analizado en qué fase se encuentra cada línea de productos y el producto potencial de SF Hermanos, se muestra con el resumen de las líneas en la siguiente figura:

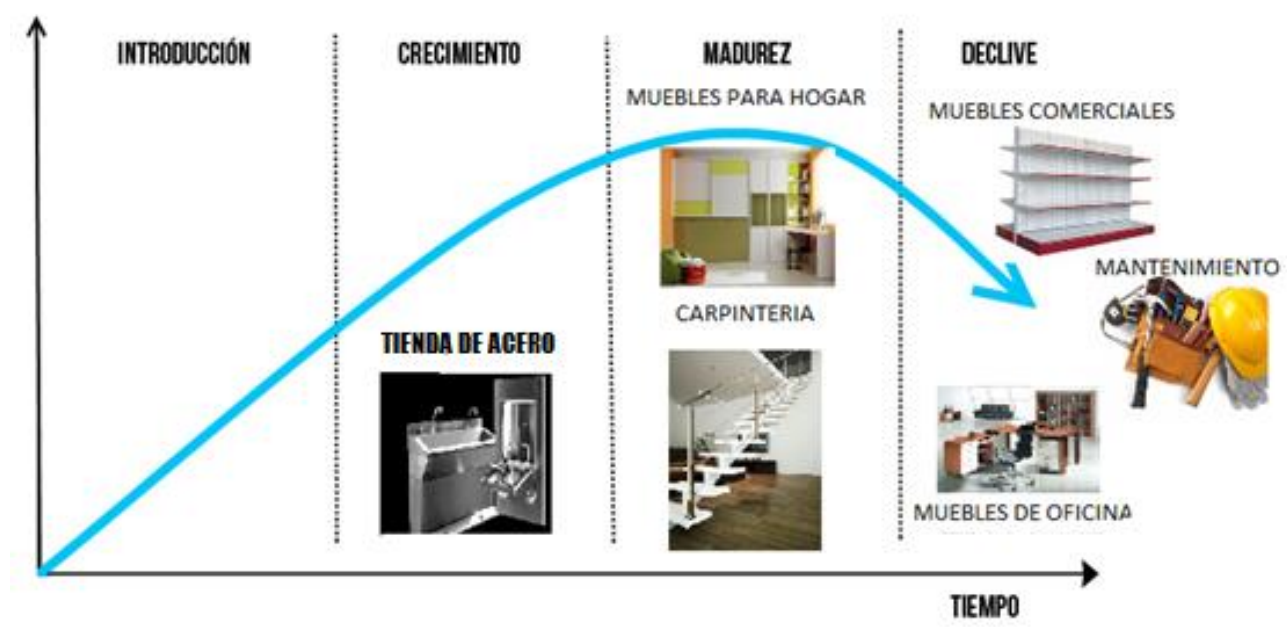

Figura $N^{\circ}$ 15. Ciclo de vida del producto. Nota: Adaptado de Theodore Levitt, 1965.

En conclusión, la empresa mantiene líneas y productos en diferentes fases del “ciclo del producto". Donde se encuentran dos productos en la fase de declive, lo que trae como consecuencia que se está afectando a la empresa debido a sus resultados negativos, 
reflejándose todo esto en las utilidades de la empresa, la pérdida de tiempo y dinero en el intento de levantar las ventas de estos productos o líneas.

\subsection{Estructura organizacional actual de la empresa}

El organigrama es la composición de las unidades administrativas, las cuales se integran por sus relaciones, funcionales, supervisión, asesoría, canales de comunicación los cuales son representadas mediante un gráfico (Franklin, 2009).

A continuación, se muestra el organigrama actual de la empresa SF Hermanos S.R.L.

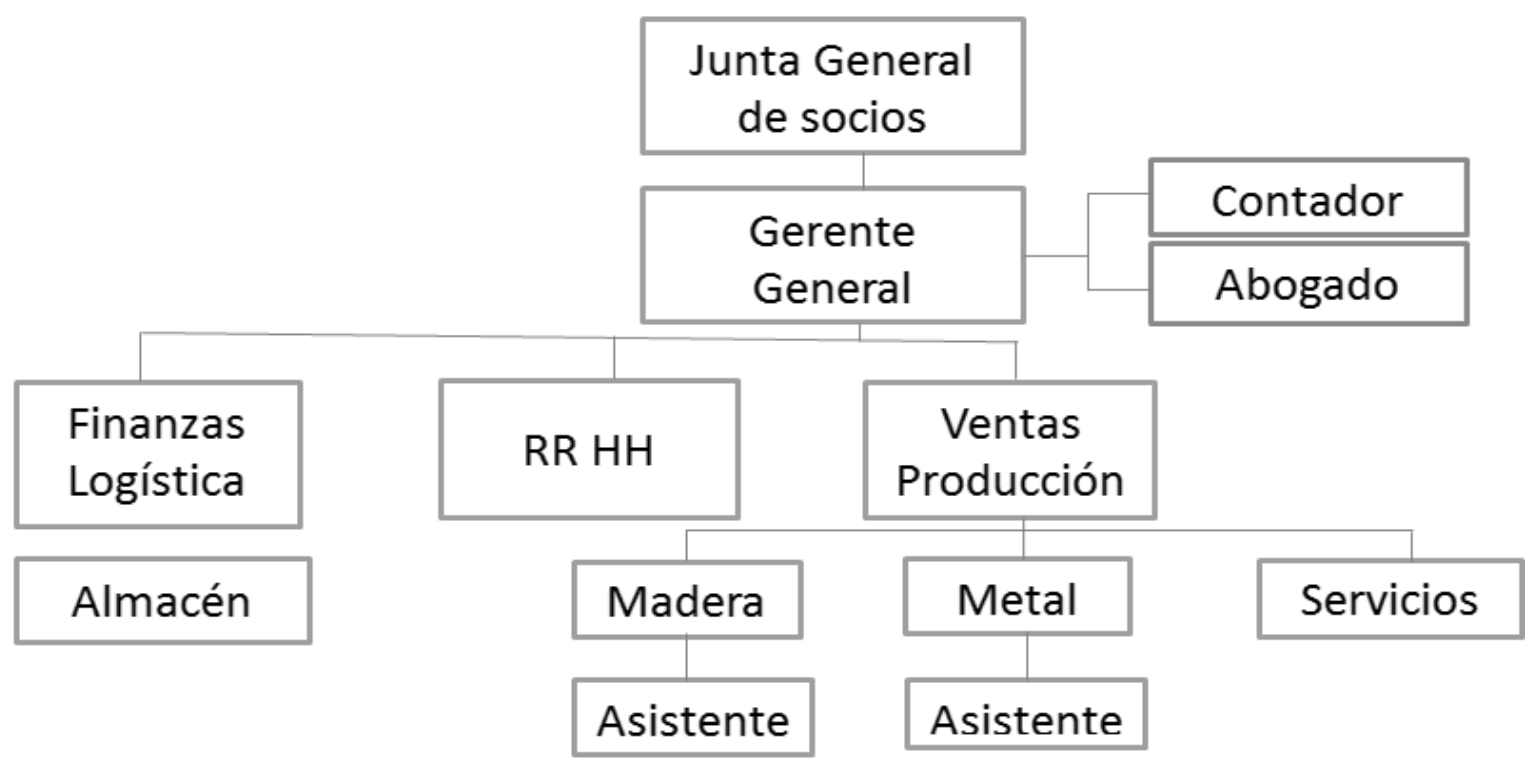

Figura $N^{\circ}$ 16. Estructura organizacional de SF Hermanos S.R.L. Nota: SF Hermanos

A continuación, se describen cada uno de los niveles:

a) Junta general de socios: Tiene como funciones las siguientes: 
- Aprobar o desaprobar la gestión y los resultados económicos del ejercicio anterior.

- Disponer la aplicación de las utilidades que hubiese.

- Modificar el Estatuto.

- Aumentar o reducir el capital y modificar el Estatuto.

- Acordar la transformación, fusión, escisión, reorganización, disolución y liquidación de la Sociedad.

- Resolver en los demás casos en los que la ley o el Estatuto dispongan su intervención y en cualquier otro asunto que requiera el interés social, inclusive respecto de aquellos asuntos sobre los que puede resolver el gerente general.

- Solicitar reportes de la situación económica de la empresa en el momento que crea conveniente.

b) Gerente general:

- Reporta a: Junta general de Participantes

Funciones:

- Dirigir las operaciones comerciales y administrativas.

- Representar a la sociedad ante toda clase de autoridades, sean políticas, administrativas, municipales, o judiciales, gozando para estas últimas de las facultades señaladas en los artículos 74,75,77 y 436 del código procesal civil; así como con las facultades de representación prevista en el artículo 10 de la ley 26636 y demás normas conexas y 
complementarias; teniendo en todos los casos facultad de delegación o sustitución.

- Intervenir en licitaciones y/o concursos de precios; organizar el régimen interno de la sociedad pudiendo nombrar a los empleados y obreros.

- Celebrar contratos de créditos en general, créditos en cuentas corrientes, créditos documentarios, préstamos o mutuos advance account, arrendamientos financiero, solicitar y contratar fianzas; abrir y cerrar cartas de crédito; abrir y cerrar cuentas corrientes; abrir, retirar y cerrar cuentas a plazo, cuentas de ahorros; depositar y retirar valores en custodia; alquilar y operar cajas de seguridad; afectar cuentas o depósitos en garantía; otorgar fianzas a favor de sí mismo o de terceros; endosar warrants, conocimiento de embarque, certificado de depósito, pólizas de seguro; cobrar y otorgar recibo de cancelaciones; ceder créditos; comprar, vender valores.

- Implementar y ejecutar procesos administrativos y/o operativos de la empresa.

- Realizar los trámites pertinentes referidos a las importaciones que ejecuta la empresa.

- Realizar los pagos de las letras a vencer de acuerdo al flujo de caja proyectado.

- Elaborar el flujo de caja proyectado y realizar el seguimiento respectivo.

- Capacitar al personal administrativo y/o operativo sobre el correcto manejo del sistema Ventor. 
- Elaborar y hacer seguimiento de la estructura de costos de la empresa por área.

- Designar el porcentaje y/o proporción de los gastos a cada área.

- Seguir y mejorar los procesos administrativos y/o operativos.

- Elaborar presentación de los avances económicos, operativo y/o administrativo mensual. (cada 8 del mes siguiente)

- Implementar normas y políticas para cada área de la empresa

- Tramitar SCTR mensuales y enviar a cada área por medio de correo electrónico.

Reportes a presentar:

- Flujo de caja proyectado vs flujo de caja real.

- Estado de resultados y Balance económico mensual.

- Estrategias mensuales de la empresa ámbito económico y operativo.

c) Finanzas y Logística:

- Reporta: A Gerente General.

- Se encarga de registrar las operaciones contables y datos financieros.

- Planificar, analizar y evaluar la información registrada, buscar opciones de inversión para el negocio.

- Controlar las operaciones ejecutadas, y del abastecimiento de recursos materiales para el desarrollo de la empresa en el proceso productivo. 
- El control de inventarios es el encargado de supervisar al asistente de compras y almacén, en cuanto a la toma de decisiones todas estas tienen que ser reportadas al gerente general para su aprobación y ejecución.

d) Recursos Humanos:

- Reporta: A Gerente General.

- Área encargada de administrar a los recursos y procesos involucrados a la disponibilidad de personal, beneficios para los trabajadores, control y evaluación del desempeño.

- Alinear las políticas de RRHH, seleccionar y evaluar al personal.

- Encargado de Inducciones, capacitaciones.

- Llevar el control de las remuneraciones, elaborar propuestas para el personal y las ejecuta únicamente con la aprobación de la gerencia general.

e) Ventas:

- Reporta: A Gerente General.

- Realizar presentación de los cuadros estadísticos de la TIENDA.

- Planificar estrategia de ventas.

- Plantear e implementar mejoras.

- Colocar anuncios en Facebook cada quincena (dos anuncios de uso y uno de producto semanalmente). 
- Realizar presentación de los cuadros estadísticos de ventas METAL (parrillas, cajas chinas y/u otros).

- Planificar estrategias de ventas mensuales.

Reportes a presentar:

- Reporte de Ventas por cada área TIENDA, METAL y MADERA.

- Reporte de los gastos de publicidad frente a las ventas.

f) Producción:

- Reporta: A Gerente General

- Se encarga de hacer funcionar el área de carpintería de madera.

- Realizar el registro de la producción, hacer el requerimiento de los insumos para ejecutar las órdenes de producción.

- Elaborar la planificación de la producción, seguimiento de procesos de producción y cumplimiento de fechas de entrega.

- Se encarga de supervisar al asistente de producción y personal operativo de la carpintería de madera en todo el proceso productivo.

- Realizar el seguimiento del desarrollo de producción en TIENDA.

- Realizar el inventario cada fin de mes TIENDA INOX.

- Coordinar los trabajos a desarrollar del MEF y SUNAT

- Realizar el Seguimiento del desarrollo de producción en TIENDA.

Reportes a presentar:

- Seguimiento de los controles de calidad fijado por el Jefe de Calidad. 
- Presentación de los reportes de producción mercadería utilizada y suministros.

- Reporte de la cantidad de productos terminados producido por semana y mensual.

g) Contabilidad (personal externo):

- Reporta: A Gerente General

- Está área es la encargada del registro de compras, gastos y ventas bajo supervisión de personal de SF Hermanos.

- Elaborar las declaraciones de impuestos, planillas electrónicas, declaraciones juradas ante SUNAT, Ministerios de Trabajo e INEI.

- La representación de la empresa ante las entidades públicas y privadas cuando sea necesario, al ser un personal externo la toma de decisiones es nula siempre debe de reportarse a su jefe inmediato superior.

h) Abogado:

- Se encarga de representar legalmente a la empresa.

- Controlar las normativas generales.

- Resolver problemas internos y aplicar sanciones administrativas correspondientes por faltas al interior de la empresa.

- Brindar apoyo al área laboral, aspectos comerciales, revisión de elaboración y revisión de contratos. 


\subsection{Situación del mercado y financiera actual de la industria}

Para el año 2019, el sector construcción mostrará un mayor ritmo de crecimiento que el resto de las actividades productivas, alcanzando una variación positiva de 6,7\%, revelando así un avance por tercer año consecutivo, indicó el Instituto de Economía y Desarrollo Empresarial (IEDEP) de la Cámara de Comercio de Lima (CCL).

Cabe señalar que en el 2018 el sector construcción creció en 4,6\%, porcentaje mayor que el 2,4\% registrado en el 2017.

“Ello se explica esencialmente por la puesta en ejecución de obras de infraestructura pública y un impulso positivo proveniente de la actividad minera en la demanda de cemento y estructuras metálicas, además de la recuperación de la inversión privada en proyectos del sector", dijo el director ejecutivo del IEDEP de la CCL, César Peñaranda.

Precisamente para el primer semestre de este año se espera que concluyan las sedes de los Juegos Panamericanos, cuyo presupuesto asciende a US\$900 millones.

A ello se suman las obras programadas para el Plan de Reconstrucción de US\$7.400 millones para el periodo 2017-2020, y la Línea 2 del Metro de Lima que cuenta con un presupuesto de US\$5.700 millones. 
El sector servicios mantendrá un crecimiento de $4.1 \%$ en donde destacaría el dinamismo de telecomunicaciones, transporte y otros servicios, rubros que se complementan con el sector construcción.

“También hay que tomar en cuenta que hay otros proyectos que impulsarán al sector como la ampliación del aeropuerto internacional Jorge Chávez y el inicio de la construcción del aeropuerto Chinchero en Cusco”, precisó Peñaranda.

En los últimos años la construcción se ha posicionado como un sector dinamizador del crecimiento económico del país, es así que el Perú lidera el crecimiento del sector construcción en América Latina. De acuerdo a las proyecciones del MEF, la Construcción será el sector con mayor dinamismo y experimentará un crecimiento superior al 10\% durante los próximos tres años, lo cual va en línea con la expansión de la inversión pública y de los proyectos de construcción privados (centros comerciales, tiendas por departamentos, viviendas, centrales hidroeléctricas y termoeléctricas, proyectos de irrigación, ampliación y modernización de plantas industriales y centros mineros, construcción de carreteras y aeropuertos, entre otros).

El crecimiento de la población y de sus ingresos, así como la expansión del crédito para vivienda ha aumentado la demanda de las familias para la construcción de viviendas. Por otro lado, la mejora en los ingresos fiscales ha hecho que el Estado sea un dinamizador importante del sector, demandando la construcción de carreteras, centrales hidroeléctricas, 
espacios públicos, entre otros. Sin embargo, el déficit de infraestructura y habitacional aún es persistente, quedando pendiente el acortamiento de estas brechas de mercado.

\section{Trabajo en el Sector}

En el 2014, el sector construcción absorbió a 916 mil trabajadores. En el Perú, la construcción es uno de sectores con mayores niveles de productividad para el trabajo (después de minería y manufactura). Sin embargo, existe precariedad en las relaciones laborales y limitada participación de los trabajadores en sistemas de protección social, teniendo en cuenta los riesgos para la salud a los que se encuentran expuestos los trabajadores del sector.

Por otro lado, el $95.8 \%$ de trabajadores en el sector son hombres, el $74.5 \%$ ha alcanzado, a lo más, secundaria completa y sólo el $8.3 \%$ se ha capacitado en algún curso como formación técnico-productiva. Estos bajos niveles de educación constituyen un desafío de política pública si se quiere mejorar la productividad y la competitividad del sector construcción según lo mencionado en el análisis macroeconómico del Sector Construcción en el Perú. 


\section{Capítulo III: Formulación de la visión, misión y valores de la empresa}

\subsection{Visión}

En el desarrollo de muchas organizaciones la visión responde al cuestionamiento en que queremos convertirnos, cuando empleados y directivos dan forma a la declaración de la visión compartida crea una comunión de intereses que puede sacar a los trabajadores de la monotonía y llevarlos a un mundo nuevo de oportunidades y desafíos. (David, 2013).

La visión de una organización es la definición deseada de su futuro, responde a la pregunta ¿Qué queremos ser? lo cual implica un enfoque a largo plazo basado en una precisa evaluación de la situación actual y futura de la Industria, así como el estado actual y futuro de la organización.

Generar la visión implica entender la naturaleza del negocio en que esta la organización, fijar un futuro retador para sí misma y tener la capacidad de difundirla para que sirva de guía y motivación a los empleados. (D’Alessio, 2015).

\subsubsection{Visión actual de la empresa}

"Ser reconocidos como una empresa que brinda comodidad y exclusividad en la implementación de muebles para hogares y ambientes de trabajo".

\subsubsection{Análisis de la visión}

La visión actual de la empresa no cumple con los lineamientos críticos que una visión debería tener para impulsar a la organización. No expresa un ámbito 
desafiante para la empresa que debería incentivar a la mejora continua con el fin de lograr la visión planteada. Existe una ausencia de temporalidad y sin tiempo definido conlleva a no plantear plazos en las acciones a tomar, haciendo casi inalcanzable la visión planteada. Finalmente, el enunciado actual que define la visión no indica el lugar o escenario que se desea alcanzar de forma puntual.

Tabla $\mathrm{N}^{\circ} 12$

Análisis de la visión

\begin{tabular}{cc}
\hline Características & Análisis de la visión actual \\
\hline $\begin{array}{c}\text { Direccional } \\
\text { Centrada }\end{array}$ & No indica de forma específica hacia donde se dirige la \\
empresa. \\
Flexible & Es muy genérica \\
Deseable & Va declaración sí muestra cierto grado de flexibilidad. \\
Desafiante & No plantea un reto para la organización, algo que motive \\
Fácil de Comunicar & Se necesita mayor objetividad en su declaratoria.
\end{tabular}

Nota: Elaboración propia

\subsubsection{Matriz de la visión propuesta}

Tabla $\mathrm{N}^{\circ} 13$

Análisis de la visión propuesta

\begin{tabular}{cc}
\hline Componente & Análisis \\
\hline Breve & Se realizó una visión de solo dos líneas, con el objetivo de que sea \\
firecta & fácil de recordar por los colaboradores y clientes. \\
Inspirada & Directa hacia el objetivo principal al que apunta la compañía. \\
\hline Nota: $:$ Elaboración propia & Inspirada en los clientes y en la gente de la compañía
\end{tabular}




\subsubsection{Visión propuesta}

Ser reconocidos como una empresa de productos y servicios de alta calidad en Lima Metropolitana.

\subsection{Misión}

La misión es un pronunciamiento de actitudes y perspectivas, su alcance es muy amplio, lo que permite la generación y consideración de una variedad de estrategias y objetivos, a su vez la misión responde a la pregunta ¿En qué queremos convertirnos?.(David, 2013).

La misión es el impulsor de la organización hacia la situación futura deseada, es el catalizador que permite que esta trayectoria sea alcanzada por la organización. La misión responde a la interrogante ¿Cuál es nuestro negocio?, y la organización lo debe tener muy claro para hacerlo bien y tener éxito. (D’Alessio, 2015).

\subsubsection{Misión actual de la empresa}

"Satisfacer las expectativas de nuestros clientes y ser su más importante proveedor".

\subsubsection{Análisis de la misión actual}

Se contemplan los siguientes aspectos de la misión, con criterios y se observa el cumplimiento o no de la misma. 
Tabla $\mathrm{N}^{\circ} 14$

Análisis de la Misión

\begin{tabular}{cc}
\hline Criterios & Cumple o No Cumple \\
\hline Clientes & SI \\
Productos y servicios & SI \\
Mercados & NO \\
Tecnología & NO \\
Supervivencia, crecimiento y rentabilidad & SI \\
Filosofía & SI \\
Concepto de sí misma & SI \\
Imagen pública & SI \\
Empleados & SI \\
\hline
\end{tabular}

Nota: Elaboración propia

Tabla $\mathrm{N}^{\circ} 15$

Antecedentes de criterios para la Misión

\begin{tabular}{|c|c|}
\hline Criterios & Interrogante \\
\hline Clientes & ¿Quiénes son ellos? \\
\hline Productos y servicios & $\begin{array}{c}\text { ¿Cuáles son los productos o servicios de la } \\
\text { compañía? }\end{array}$ \\
\hline Mercados & ¿Dónde compite la empresa? \\
\hline Tecnología & ¿Cuál es la tecnología básica de la empresa? \\
\hline $\begin{array}{l}\text { Supervivencia, } \\
\text { crecimiento y rentabilidad }\end{array}$ & $\begin{array}{c}\text { ¿Cuáles son los objetivos económicos de la } \\
\text { compañía? }\end{array}$ \\
\hline Filosofía & $\begin{array}{c}\text { ¿Cuáles son las creencias básicas, valores, } \\
\text { aspiraciones y prioridades filosóficas de la } \\
\text { empresa? }\end{array}$ \\
\hline Concepto de sí misma & $\begin{array}{l}\text { ¿Cuáles son las principales fortalezas y } \\
\text { ventajas competitivas de la compañía? }\end{array}$ \\
\hline Imagen pública & $\begin{array}{c}\text { ¿Cuál es la responsabilidad pública de la } \\
\text { empresa y que imagen desea? }\end{array}$ \\
\hline Empleados & $\begin{array}{c}\text { ¿Cuál es la actitud de la compañía hacia sus } \\
\text { empleados? }\end{array}$ \\
\hline
\end{tabular}

Nota: F. R. David, "How companies define their mission", Long Range Planning, vol 22, número 1, 2015, pp 90-97. 
La misión actual no se enfoca en sus grupos de interés ni en la forma de cómo satisfacer sus necesidades. Esta misión, solo define objetivos a mediano y largo plazo, por lo tanto, se observa un problema de concepto ya que no está enfocado en los elementos que debe tener una misión, no figuran las habilidades que posee la empresa para cumplir con las demandas de los grupos de clientes.

En consecuencia, no se exponen los principios fundamentales para diferenciarse de las demás empresas y constituir su cultura corporativa. Lo cual es un error, pues no se da a conocer cuáles son los valores con que la empresa SF Hermanos cuenta y que son característicos de ella, y con los cuales los empleados se pueden identificar.

Tabla $\mathrm{N}^{\circ} 16$

Prioridad

\begin{tabular}{ccccccccc}
\hline Criterios & Sociedad & Estado & Clientes & Colaborador & Accionistas & Proveedores & Total & Prioridad \\
\hline Clientes & 3 & 2 & 3 & 3 & 3 & 3 & 17 & 2 \\
Productos & 2 & 1 & 3 & 3 & 3 & 3 & 15 & 5 \\
Mercados & 3 & 3 & 3 & 3 & 3 & 3 & 18 & 1 \\
$\begin{array}{c}\text { Super, } \\
\text { Crec. y }\end{array}$ & 3 & 3 & 2 & 3 & 3 & 3 & 17 & 2 \\
$\begin{array}{c}\text { rentabilidad } \\
\text { Filosofía }\end{array}$ & 1 & 1 & 3 & 3 & 3 & 1 & 12 & 6 \\
$\begin{array}{c}\text { Concepto } \\
\text { de sí misma }\end{array}$ & 1 & 1 & 2 & 3 & 3 & 1 & 11 & 7 \\
Empleados & 3 & 3 & 2 & 3 & 3 & 3 & 17 & 2 \\
Total & 16 & 14 & 18 & 21 & 21 & 17 & & \\
\cline { 1 - 4 } Prioridad & 5 & 6 & 3 & 1 & 1 & 4 & &
\end{tabular}

Nota: SF Hermanos, por el Departamento de Marketing. 


\subsubsection{Elementos de la misión propuesta para la empresa}

\section{Grupo de interés}

Accionistas: SF Hermanos S.R.L., se encuentra constituida por tres accionistas, los cuales constituyeron la empresa. Ellos a su vez, exigen un rendimiento creciente, minimización de costos y creación de valor para la compañía; si la empresa no satisface dichas exigencias los accionistas son los más perjudicados y podrían perder lo que se ha venido invirtiendo en los últimos años. Por lo tanto, los accionistas se constituyen como un grupo de interés.

Colaboradores: SF Hermanos S.R.L., da seguridad, estabilidad laboral, estabilidad económica, pago de sueldo a tiempo, motivación, capacitación constante y un buen clima laboral.

Es por esta razón, que al no satisfacer sus demandas hace que no haya una buena productividad y eficiencia en los procesos, el desempeño laboral sería ineficiente y se crearía conflictos entre los colaboradores; en consecuencia, esto podría poner en riesgo a la empresa. De esta manera, los empleados son considerados un grupo de interés.

Clientes: Los clientes de SF Hermanos, son de gran de interés, es por ello que la compañía se preocupa en seguir innovando y satisfacer mejor sus necesidades. Para realizar esto la compañía, entrega un producto de alta calidad utilizando tecnología de punta en sus procesos y alta calidad en los insumos que 
forman parte de la elaboración de los productos, buscando mejorar el producto final y cumplir con las expectativas creadas a los clientes.

\subsubsection{Misión propuesta}

"Somos una empresa dedicada a producir y comercializar muebles de madera, acero, melamine, siguiendo los más altos estándares de calidad, para brindar la plena satisfacción de nuestros clientes, con un personal altamente capacitado. Procuramos alcanzar el máximo desarrollo y rentabilidad en el ámbito en el que nos desenvolvemos, logrando así el óptimo beneficio para nuestros accionistas".

\subsection{Valores}

Los valores de una organización pueden ser considerados como las políticas directrices más importantes, normas que causan el desempeño de sus funcionarios y constituyen el patrón de actuación que guía el proceso de la toma de decisiones, los valores establecen la filosofía de las empresas al representar claramente sus creencias, actitudes, tradiciones y su personalidad. Los valores son indispensables para:

- Moldear los objetivos y propósitos.

- Producir las políticas.

- Definir las intenciones estratégicas. (D’Alessio, 2015).

\subsubsection{Valores actuales de la empresa}

- Responsabilidad. 
- Respeto.

- Confianza.

- Honestidad.

- Justicia.

- Competencia Leal.

- Integridad.

- Limpieza.

- Seguridad.

\subsubsection{Análisis de los valores actuales}

a) Responsabilidad, en sus clientes internos y externos al asumir los deberes y derechos con ellos para cumplirlos y hacer cumplir de acuerdo a las normas emitidas por la empresa.

b) Respeto, hacia las personas que forman parte de la compañía tanto interno como externo.

c) Confianza, visualizado en la convivencia del día a día por parte de los trabajadores.

d) Honestidad, es un valor el cual tiene que prevalecer en la empresa.

e) Compromiso, de los colaboradores de la compañía para conseguir sus objetivos y así mejorar la empresa.

f) Justicia, buscan ser justos en todo momento, ser imparciales al tomar sus decisiones. 
g) Competencia leal, buscan ser correctos con su competencia, buscando nichos en el mercado no atendidos por su competencia.

h) Integridad, mantener los valores que los caracteriza.

i) Limpieza, en el área de trabajo y con sus clientes debido a que sus productos tienen que ser de calidad y con buena presentación.

j) Seguridad, al personal y clientes dentro de su local, al trabajar con la maquinaria y materiales, para evitar los posibles accidentes o incidentes, cumpliendo con las normas actuales de seguridad.

\subsubsection{Elementos de los valores propuestos para la empresa}

Accionistas: SF Hermanos S.R.L., se encuentra constituida por tres accionistas, los cuales constituyeron la empresa. Ellos a su vez, exigen a sus colaboradores un rendimiento creciente, minimización de costos y creación de valor para la compañía; si la empresa no cumple con dichas exigencias los accionistas son los más perjudicados y podrían perder lo que se ha venido invirtiendo en los últimos años. Por lo tanto, los accionistas se constituyen como un grupo de interés.

Colaboradores: SF Hermanos S.R.L. brinda seguridad, estabilidad laboral, estabilidad económica, pago de sueldo a tiempo, motivación, capacitación constante y un buen clima organizacional.

Es por esta razón, que al no satisfacer sus demandas hace que no haya una buena productividad y eficiencia en los procesos, el desempeño laboral sería 
ineficiente y se crearía conflictos entre ellos; en consecuencia, esto podría poner en riesgo a la empresa. De esta manera, los empleados son considerados un grupo de interés.

Clientes: Los clientes de SF Hermanos S.R.L., son de gran de interés, es por ello que realizan notables esfuerzos para seguir innovando y satisfacer mejor sus necesidades. SF Hermanos, entrega un producto de alta calidad utilizando tecnología de punta en sus procesos y alta calidad en los insumos utilizados, buscando mejorar el producto final y que cumpla las expectativas creadas a los clientes.

\subsubsection{Valores propuestos}

a) Calidad: Ofreciendo garantía en la fabricación de muebles hacia los clientes y consumidores, a través de la certificación en los procesos y materiales utilizados.

b) Eficiencia: La capacidad que posee la empresa de la Industria de Muebles para lograr un fin, empleando los mejores medios posibles.

c) Responsabilidad: Las empresas de la Industria de Muebles tratan de cumplir con las obligaciones adquiridas con el cliente.

d) Compromiso: Es el acuerdo contraído de colaboradores de la empresa con su trabajo. 
e) Trabajo en equipo: Los colaboradores de las empresas del mueble son un grupo de personas organizadas para la realización de una tarea o el logro de un objetivo en común.

f) Respeto: Es colaborar para la aplicación de los principios éticos y morales en la realización de productos.

g) Integridad: Todos los involucrados en la Industria de Muebles tratan de ser congruentes entre el pensar, decir y hacer.

h) Innovación: El desarrollar productos en función a las tendencias mundiales. (D’Alessio, 2015).

Alineamiento estratégico de la visión, misión y valores de la empresa. 
Tabla $\mathrm{N}^{\circ} 17$

Alineamiento estratégico de la visión, misión y valores de la empresa SF Hermanos S.R.L.

\begin{tabular}{|c|c|c|}
\hline Valores & $\begin{array}{c}\text { Alineación estratégica con la } \\
\text { misión }\end{array}$ & $\begin{array}{c}\text { Alineación estratégica con la } \\
\text { visión }\end{array}$ \\
\hline Calidad & $\begin{array}{l}\text { Producir productos con los más } \\
\text { altos estándares de diseño }\end{array}$ & $\begin{array}{l}\text { Para lograr el liderazgo se enfoca } \\
\text { el cumplir con los clientes. }\end{array}$ \\
\hline Eficiencia & $\begin{array}{l}\text { Cumplir con los clientes y } \\
\text { proveedores }\end{array}$ & $\begin{array}{c}\text { Se busca lograr el liderazgo } \\
\text { regional }\end{array}$ \\
\hline Responsabilidad & $\begin{array}{c}\text { De orientación a cumplir con } \\
\text { nuestros clientes. }\end{array}$ & $\begin{array}{c}\text { Establecer con los estándares } \\
\text { mundiales. }\end{array}$ \\
\hline Compromiso & $\begin{array}{l}\text { Es en toda la empresa hacia los } \\
\text { clientes proveedores y } \\
\text { accionistas. }\end{array}$ & $\begin{array}{l}\text { Buscando ser los líderes } \\
\text { regionales. }\end{array}$ \\
\hline $\begin{array}{l}\text { Trabajo en } \\
\text { equipo }\end{array}$ & $\begin{array}{l}\text { Estar enfocado en brindar el } \\
\text { mejor servicio a los clientes }\end{array}$ & $\begin{array}{l}\text { Cumplir con los estándares de } \\
\text { clase mundial. }\end{array}$ \\
\hline Respeto & $\begin{array}{l}\text { Estar enfocado en nuestros } \\
\text { colaboradores }\end{array}$ & $\begin{array}{l}\text { Establecer el mejor ambiente } \\
\text { laboral. }\end{array}$ \\
\hline Integridad & $\begin{array}{l}\text { Lograr la comunicación con } \\
\text { todas las áreas de las empresas } \\
\text { en logros de objetivos }\end{array}$ & $\begin{array}{l}\text { Cumplir con el liderazgo de la } \\
\text { comunicación. }\end{array}$ \\
\hline Innovación & $\begin{array}{l}\text { Desarrollar Productos según las } \\
\text { tendencias modernas. }\end{array}$ & $\begin{array}{l}\text { De soluciones en las tendencias al } \\
\text { futuro }\end{array}$ \\
\hline
\end{tabular}

Nota: SF Hermanos 


\section{Capítulo IV: Análisis Externo}

\subsection{Tendencias de las variables del entorno}

Se utiliza el análisis PEST con el objetivo de explorar el macro-entorno externo en el cual se encuentra una empresa, analizando los factores políticos, económicos, sociales, tecnológicos.

Los cuales van a desempeñar en las oportunidades para poder crear valor de una estrategia, pero normalmente se encuentran fuera de control de la compañía y se consideran como oportunidades y amenazas.

\subsubsection{Análisis Político-Gubernamental}

El presidente Pedro Pablo Kuczynski, asumió el cargo el 28 de julio de 2016, Al mismo tiempo, los ciudadanos otorgaron el control del Congreso a los partidos de la oposición. En la elección también se renovó el Parlamento, y actualmente los nuevos parlamentarios representan casi las tres cuartas partes del total. En respuesta a su posición minoritaria, el Gobierno ha puesto en práctica iniciativas para constituir alianzas con las principales fuerzas políticas, incluidas las autoridades subnacionales elegidas en 2014.

En el mandato anterior el sector construcción fue parte importante del incremento en el PBI, a consecuencia de las inversiones realizadas en el sector inmobiliario como resultado de diversos proyectos importantes, construcción de viviendas, obras civiles, programas lanzados por el gobierno del período 2011-2016 como Mi Vivienda, el cual consiste en el financiamiento máximo del 90\% de compras de viviendas nuevas 
(construcción o proyecto) donde los precios oscilaban entre S/ 50,400 y S/180,000 Nuevos soles, de igual forma el programa Techo Propio, el cual está orientado a la compra, construcción o mejoramiento de viviendas de familias de escasos recursos.

El plan de gobierno del presidente actual incorpora gran parte de los programas sociales mencionados, partiendo de la premisa del aumento en la demanda de viviendas y 1.2 millones de familias que desean mejorar o ampliar sus viviendas tanto para las ubicadas en la capital como en provincias, donde solo para Lima y Callao se observa que la demanda es de 142,353 viviendas.

La existencia de los proyectos de construcción de viviendas del nuevo mandato garantiza una oportunidad, debido a que las casas son implementadas de muebles en la cocina, salas y en diversos espacios de los nuevos hogares, lo cual generaría mayores ventas y nuevos clientes.

En el año 2017, se estimó un crecimiento del sector construcción de 3,7\%, impulsado por mayores desembolsos de proyectos de inversión, como la Línea 2 del Metro de Lima". Por otro lado, en los últimos dos o tres años, el sector Construcción se ha dinamizado con mayor fuerza en provincias, y todavía hay mucho por expandirse en el interior del país", pues se venía en negativo, considerando que en el 2015 hubo una caída de $8 \%$ ". Además, los precios de las viviendas se elevarán entre $2 \%$ y $3 \%$, sobre todo en los distritos de Jesús María y Pueblo Libre, que presentan mayor oferta y demanda para el sector inmobiliario (América Económica, 2017). 
La inversión de remodelación garantiza una oportunidad para la empresa, dado que un gran porcentaje del proyecto son los muebles que se encuentran en dichas viviendas.

Por último, hay un crecimiento del sector construcción en el Perú en un 4\%. (Cámara Peruana de la Construcción, 2016).

\subsubsection{Análisis económico}

\section{Producto Bruto Interno (PBI)}

En los últimos diez años el PBI manufacturero registró una tasa de crecimiento anual de $2.3 \%$ habiendo pasado por alzas temporales de algunos precios de alimentos y combustibles, pero manteniéndose a largo plazo el objetivo inflacionario según lo manifestaron representantes del Banco Central de Reserva, donde no se consideran los componentes volátiles de la inflación, siendo su nivel promedio de $2 \%$ en los últimos 10 años. Asimismo, indicaron que el BCR va a actuar de acuerdo a como venga la información de los precios con el objetivo de mantener la inflación bajo control (Diario Gestión, 2016).

En cuanto a la economía peruana el Banco Mundial se mostró optimista en que el Perú crecería para el 2016 y 2017 promovido por el repunte de la minería. Por lo que mencionan que la proyección de crecimiento para la economía peruana será de 3.7\% a 4.2\%. Por otro lado, manifestaron que el 2017 será un buen año para Sudamérica pues será un año de recuperación para todos los países excepto Venezuela y Argentina. Como se puede observar en la siguiente figura: 


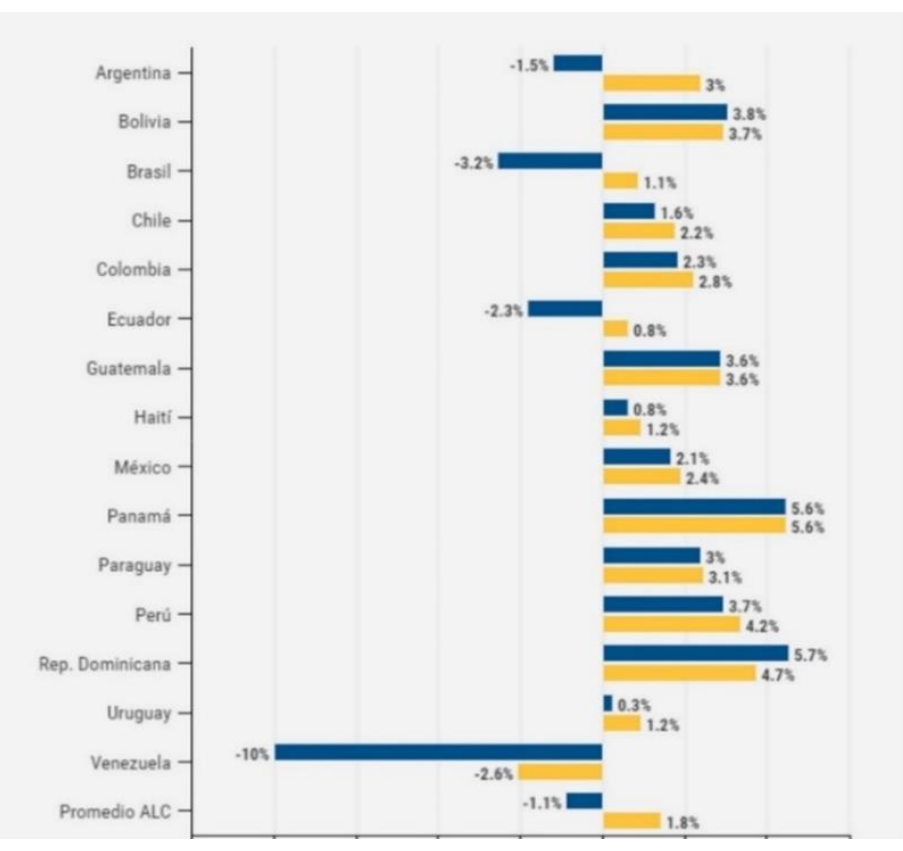

Figura $N^{\circ}$ 17. Perspectivas de crecimiento en América Latina y Caribe: 2016 y 2017. Nota: Fondo Monetario Internacional (FMI)

Para el 2018, se proyecta que Perú y Colombia crecerán en 3.5\% cada uno, este porcentaje de crecimiento estaría por encima de los demás países de la región como Argentina, cuyo crecimiento se proyecta en $2.8 \%$ y Chile en $2.7 \%$.

En cuanto a las estadísticas del PBI para el año 2017 se proyectó un crecimiento de 2.7 \% para el año 2017, según el Ministerio de Economía y Finanzas, por muy debajo de las Proyecciones de los años anteriores.

El sector de manufactura, en tres años consecutivos tuvo una disminución de $2.8 \%$ en el año 2016, revertiéndose esta situación para el año 2017, en 3.9\%. Todo esto se debió al resultado positivo del sector primario sumado al aumento de la producción 
industrial de metales preciosos y ferrosos $(12,9 \%)$ y a la mayor producción de cobre refinado y productos cárnicos $(5,3 \%)$.

En la manufactura no primaria, explicó que responde al buen desempeño de las ramas de fabricación de estructuras metálicas $(9,2 \%)$ y la producción de cemento, cal y yeso $(8,7 \%)$, ligadas directamente al sector de construcción.

Tabla $\mathrm{N}^{\circ} 18$

Variación porcentual del PBI por sectores económicos

\begin{tabular}{ccccc}
\hline Sectores & 2014 & 2015 & 2016 & 2017 \\
\hline PBI & 2.4 & 3.3 & 3.8 & 4.2 \\
Agropecuario & 1.9 & 3.3. & 0.9 & 3.8 \\
Pesca & -27.9 & 15.9 & -9.5 & 15.5 \\
Minería-Hidrocarburo & -0.9 & 9.5 & 15.9 & 7.4 \\
Manufactura & -3.6 & -1.7 & -2.8 & 3.9 \\
Electricidad y agua & 4.9 & 6.1 & 7.7 & 5.4 \\
Construcción & 1.9 & -5.8 & -0.3 & 3.7 \\
Comercio & 4.4. & 3.9 & 2.5 & 3.4 \\
Servicios & 5 & 4.2 & 4.8 & 4.9 \\
\hline
\end{tabular}

Nota: Banco Central de Reserva del Perú

\section{Inflación}

En los últimos 10 años la inflación promedio fue del $2.3 \%$ ocasionada por las alzas temporales en los precios, en 2016 la inflación alcanzó el 0.21\% por mes valor que estuvo por encima de lo estimado por el Banco Central de Reserva, cuyo valor era de 0.15\%. El mismo año, el valor esperado por el mercado fue de $0.16 \%$ tasa que reflejó alzas en los precios de los alimentos y tarifas eléctricas principalmente. También se observa alza en distintos rubros asociados al tipo de cambio como son la compra y venta 
de vehículos. El rango meta para el 2016 fue entre 3\% y 3.2\%, el cual no pudo ser alcanzado principalmente por la reforma tributaria iniciada ese año.

Según las proyecciones del INEI en el horizonte de 2015 - 2017, la inflación pudo haberse incrementado gradualmente a $2.0 \%$, esto se daría por una depreciación nominal mayor a la esperada y la oferta asociada al fenómeno.

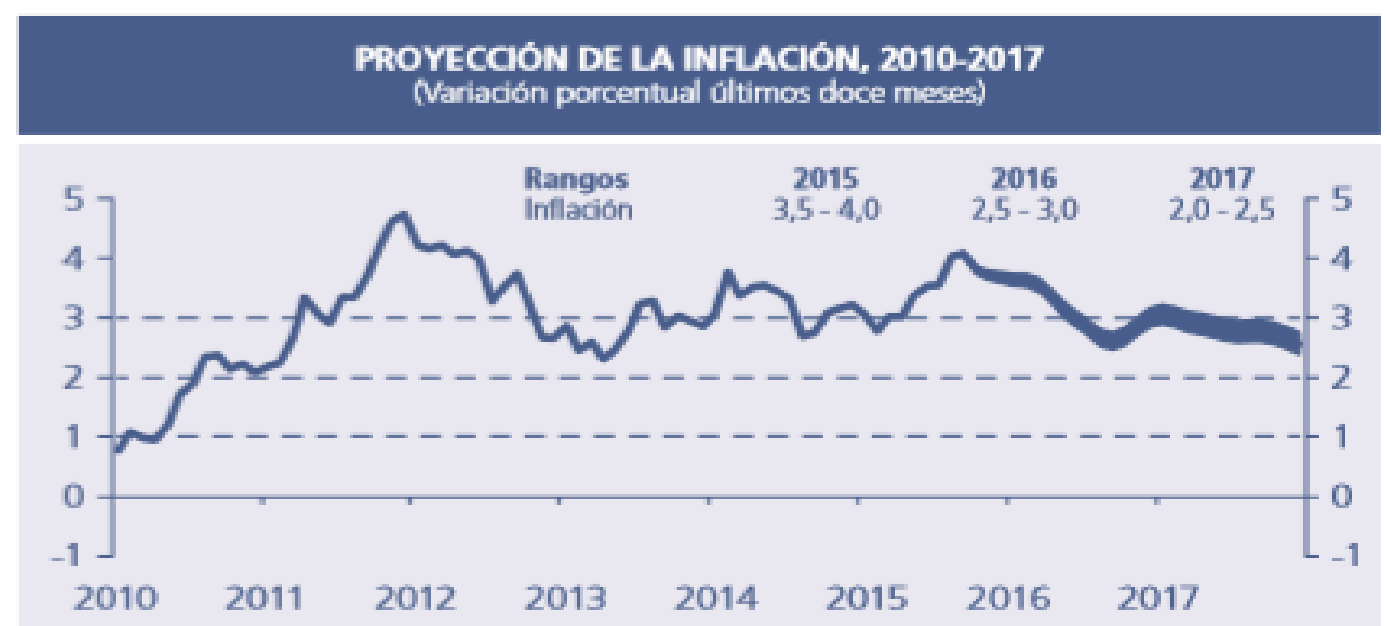

Figura $N^{\circ}$ 18. Proyección de la inflación 2010 - 2017. Nota: Instituto Nacional de Estadística e informática

Con lo observado anteriormente al existir una proyección de la inflación donde se observa disminución en un 2\% SF Hermanos podría aprovechar dicha oportunidad.

\section{Balanza Comercial}

El superávit de la balanza comercial para mediados del 2017 se proyectó por más de US\$ 5.096 millones, superando por mucho el cierre obtenido en el 2016 por 
US\$ 3.879 millones. Con esta proyección la balanza comercial peruana alcanzaba su tercer año consecutivo con cierre positivo.

El superávit para el 2017 se debió principalmente al aumento en las exportaciones por el incremento en los precios de los minerales más exportados del país como el cobre y el oro con aumentos en su cotización en $31 \%$ y $12 \%$ respectivamente. Asimismo, creció el precio del zinc en $29 \%$ y el de la plata en 6\%. Otro factor significativo fue el incremento del volumen de exportaciones no tradicionales, las cuales aumentaron a US\$ 874 millones en dicho año, según detallo el BCRP.

Según el INEI, el mes de noviembre registró exportaciones tradicionales con aumentos en $25,16 \%$ y las exportaciones no tradicionales en 3,66\%. En su conjunto, las exportaciones se incrementaron en 18,64\% en noviembre del 2017.

Por el lado de las importaciones, el BCRP registró para el penúltimo mes del 2017 un incremento en $16.8 \%$ respecto al de noviembre del 2016, principalmente relacionado a las mayores importaciones en insumos $(24.3 \%)$ y bienes de capital (14.3\%). Igualmente, en dicho mes los términos de intercambio crecieron en $10 \%$ en relación al mismo mes del año anterior, debido a los mayores precios de exportación del cobre $(34.7 \%)$, derivados de petróleo $(34.3 \%)$, zinc $(34.6 \%)$ y gas natural $(24.5 \%)$. Con ello, se acumularon 17 meses consecutivos de incremento de este indicador. 


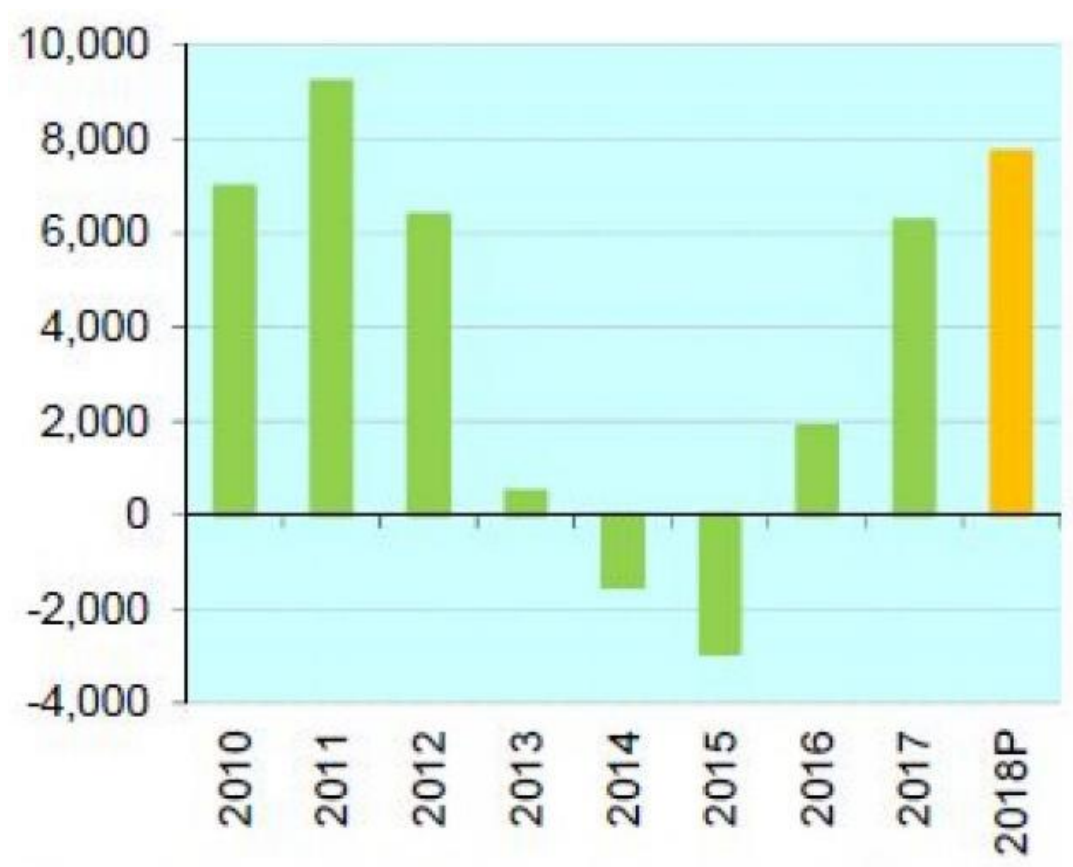

Figura $N^{\circ}$ 19. Balanza Comercial (Millones de US\$). Nota: Estudios EconómicosScotiabank

Finalmente, la balanza comercial reportó un superávit de US\$ 6,266 millones al cierre del 2017, superando por casi US\$ 1,000 millones el monto proyectado.

Este registro es el nivel más alto de los últimos cinco años, según se indicaron en las cifras del Banco Central de Reserva (BCR). Y para el 2018 reportaría un superávit de US\$ 7,700 millones. Cuya composición principal en las exportaciones de productos no tradicionales sería el sector agroexportador. Adicionalmente, el Departamento de Estudios Económicos del Scotiabank prevé que el crecimiento de los precios de los minerales industriales, como el cobre y el zinc continúe en ascenso, debido al aumento que viene presentando la demanda mundial y que, debido a ausencia de grandes proyectos de extracción, la oferta de estos minerales es cada vez menor. 


\section{Tipo de cambio}

El dólar registró una caída en 3,16\% durante los primeros diez meses del 2017 por las mayores exportaciones registradas en ese período, teniendo en cuenta que para fines del 2016 cerró en S/ 3,357.

Las adquisiciones más significativas que tuvo que realizar el BCRP para mitigar la caída del dólar, fueron durante julio y setiembre. Montos que superaron los US\$1,000 millones en agosto y setiembre.

Especialistas en economía monetaria sostienen que un factor relevante en la depreciación de la moneda americana frente al Sol es el mayor flujo de ingresos de divisas al Perú por el incremento de las exportaciones peruanas. Se consideró que sin la intervención constante que el BCRP viene realizando desde el 2016, esta caída seria mayor.

Según responsables de estudios económicos de diversos bancos en Perú, el dólar cerraría el 2018 con un valor frente al sol cercano a S/. 3.40. A continuación se muestra la evolución del dólar durante el presente año: 
Tabla $\mathrm{N}^{\circ} 19$

Tabla oficial del dólar en el 2018

\begin{tabular}{lccl}
\hline \multicolumn{1}{c}{ Mes } & $\begin{array}{c}\text { Promedio para } \\
\text { compra }\end{array}$ & $\begin{array}{c}\text { Promedio } \\
\text { para venta }\end{array}$ & \multicolumn{1}{c}{ Datos } \\
\hline Enero & $\mathrm{S} / 3.215$ & $\mathrm{~S} / 3.218$ & $\begin{array}{l}\text { La cotización más baja fue día 04/01/2018 } \\
\text { La cotización más alta fue día 01/01/2018 }\end{array}$ \\
\hline Febrero & $\mathrm{S} / 3.246$ & $\mathrm{~S} / 3.248$ & $\begin{array}{l}\text { La cotización más baja fue día 01/02/2018 } \\
\text { La cotización más alta fue día 09/02/2018 }\end{array}$ \\
\hline Marzo & $\mathrm{S} / 3.249$ & $\mathrm{~S} / 3.252$ & $\begin{array}{l}\text { La cotización más baja fue día 26/03/2018 } \\
\text { La cotización más alta fue día 19/03/2018 }\end{array}$ \\
\hline Abril & $\mathrm{S} / 3.230$ & $\mathrm{~S} / 3.232$ & $\begin{array}{l}\text { La cotización más baja fue día 18/04/2018 } \\
\text { La cotización más alta fue día 30/04/2018 }\end{array}$ \\
\hline Mayo & $\mathrm{S} / 3.271$ & $\mathrm{~S} / 3.274$ & $\begin{array}{l}\text { La cotización más baja fue día 01/05/2018 } \\
\text { La cotización más alta fue día 09/05/2018 }\end{array}$ \\
\hline Junio & $\mathrm{S} / 3.269$ & $\mathrm{~S} / 3.272$ & $\begin{array}{l}\text { La cotización más baja fue día 06/06/2018 } \\
\text { La cotización más alta fue día 19/06/2018 }\end{array}$ \\
\hline Julio & $\mathrm{S} / 3.274$ & $\mathrm{~S} / 3.278$ & $\begin{array}{l}\text { La cotización más baja fue día 16/07/2018 } \\
\text { La cotización más alta fue día 04/07/2018 }\end{array}$ \\
\hline Agosto & $\mathrm{S} / 3.287$ & $\mathrm{~S} / 3.291$ & $\begin{array}{l}\text { La cotización más baja fue día 07/08/2018 } \\
\text { La cotización más alta fue día 19/08/2018 }\end{array}$ \\
\hline Septiembre & $\mathrm{S} / 3.308$ & $\mathrm{~S} / 3.311$ & $\begin{array}{l}\text { La cotización más baja fue día 23/09/2018 } \\
\text { La cotización más alta fue día 11/09/2018 }\end{array}$ \\
\hline Octubre & $\mathrm{S} / 3.332$ & $\mathrm{~S} / 3.335$ & $\begin{array}{l}\text { La cotización más baja fue día 01/10/2018 } \\
\text { La cotización más alta fue día 31/10/2018 }\end{array}$ \\
\hline Noviembre & $\mathrm{S} / 3.371$ & $\mathrm{~S} / 3.375$ & $\begin{array}{l}\text { La cotización más baja fue día 05/11/2018 } \\
\text { La cotización más alta fue día 15/11/2018 }\end{array}$ \\
\hline Nota: $\mathrm{Recupprado} \mathrm{de} \mathrm{https:/deperu.com/tipo} \mathrm{cambio/historico/2018}$
\end{tabular}

Nota: Recuperado de https://deperu.com/tipo_cambio/historico/2018

Se proyecta que, a pesar de los grandes esfuerzos realizados por el FED de dinamizar el dólar a través del incremento en la tasa de interés, la incertidumbre que genera el gobierno de Donald Trump hace poco atractivo el dólar frente a otras monedas. Adicionalmente se supo que, a inicios de este año, el dólar presentó un mayor valor en relación al euro, caso que no se refleja con la moneda peruana. 
SF Hermanos no está ajeno a estos cambios debido a que importa insumos para la elaboración de sus productos los cuales son comprados en dólares, por tal motivo se realizó un análisis de cómo esta alza y baja de moneda afecta el presupuesto de los productos a elaborar, está información se mostrará en el anexo 18.

\subsubsection{Análisis legal}

En lo relacionado a la legislación vigente peruana, así como su estabilidad se tienen las siguientes leyes:

Ley $\mathrm{N}^{\circ}$ 29245: Ley reguladora de servicios de tercerización y su reglamento (D.S. $\mathrm{N}^{\circ}$ 006-2008 TR): Ley promulgada el 24 de junio del 2008, que hace referencia a lo siguiente:

Artículo 1: "La ley regula los casos en los que se procederá la tercerización, los requisitos, derechos y obligaciones, así como las sanciones aplicables a las empresas que desnaturalizan el uso de este método empresarial”.

Artículo 9: "La empresa principal que contrate la realización de obras o servicios con desplazamiento de personal de la empresa tercerizadora es responsable por el pago de los derechos y beneficios laborales, por las obligaciones de seguridad social, devengados por el tiempo en el que el trabajador estuvo desplazado. Dicha responsabilidad se extiende por un año posterior a la culminación de dicho desplazamiento. 
El objetivo de la ley es que las empresas sean competitivas en un mercado cada vez más cambiante, con el enfoque en su actividad principal y reduciendo costos, y la parte negativa de la ley se aprecia en la responsabilidad del que terceriza debido a que si está empresa no cumple con los contratos y beneficios del trabajador estos van a recaer en la empresa principal, generando una amenaza a los distintos sectores.

Ley de Contrataciones del Estado (D.L. N 1017) Reglamento de Ley de Contrataciones del Estado (DS N 184-2008 -EF): Desde el 4 de junio del 2008 y hasta ahora, la ley y el reglamento que rige las contrataciones que realiza el Estado como el gran comprador de las distintas industrias es la Ley de Contrataciones del Estado según el Decreto Legislativo $\mathrm{N}^{\circ} 1017$ posee los siguientes artículos:

Artículo 33: Las garantías que deben de otorgar los postores adjudicados y/o contratistas son las de fiel cumplimiento del contrato y por los adelantos. Sus modalidades, montos, condiciones y excepciones las cuales son reguladas.

Ley de Productividad y Competitividad Laboral No 728 (DS No 008-2002-TR):

Desde el 2002 las compensaciones por horas extras son reconocidas según los artículos que abarca este Decreto Supremo con respecto la jornada laboral del trabajador y las consideraciones a tener en cuenta.

Artículo 2.- El empleador deberá dar a conocer por medio de carteles colocados en un lugar visible de su establecimiento o por cualquier otro medio adecuado, las horas en 
que se inicia y culmina la jornada de trabajo. Asimismo, el empleador deberá dar a conocer la oportunidad en que se hace efectivo el horario de refrigerio.

Artículo 14.- Horario de refrigerio es el tiempo establecido por la Ley que tiene como finalidad que el trabajador lo destine a la ingesta de su alimentación principal cuando coincida con la oportunidad del desayuno, almuerzo o cena, o de un refrigerio propiamente dicho, y/o al descanso.

Artículo 15.- En el caso de las jornadas que se cumplan en horario corrido según el Artículo 7 de la Ley, el tiempo de refrigerio no podrá ser inferior a cuarenta y cinco (45) minutos y deberá coincidir en lo posible con los horarios habituales del desayuno, almuerzo o cena. El empleador establecerá el tiempo de refrigerio dentro del horario de trabajo, no pudiendo otorgarlo, ni antes ni luego del mismo.

\subsubsection{Análisis social}

Según el XI Censo Nacional de Población del Perú del 2007, la población asciende a 28’220,764 habitantes, la población urbana censada tuvo un incremento en 34,6 \% en los años 1993 y 2007, y la población rural censada se incrementó en $0.2 \%$. Para el año 2020 estiman los especialistas que se tendrán 33 millones de habitantes (Instituto Nacional de Estadística e Informática, 2007).

La población censada para la región de la costa representa un 54.6\%, es decir más de la mitad de la población del país. En relación a los grupos de edad existe reducción en la 
natalidad entre los 0 y 4 años, para los grupos de 25 años se tiene una proporción entre los hombres y mujeres.

El NSE B, según los últimos censos ha estado en crecimiento constante, haciendo este un sector importante de la población a considerar, por su poder adquisitivo y participación en el consumo total por hogares.

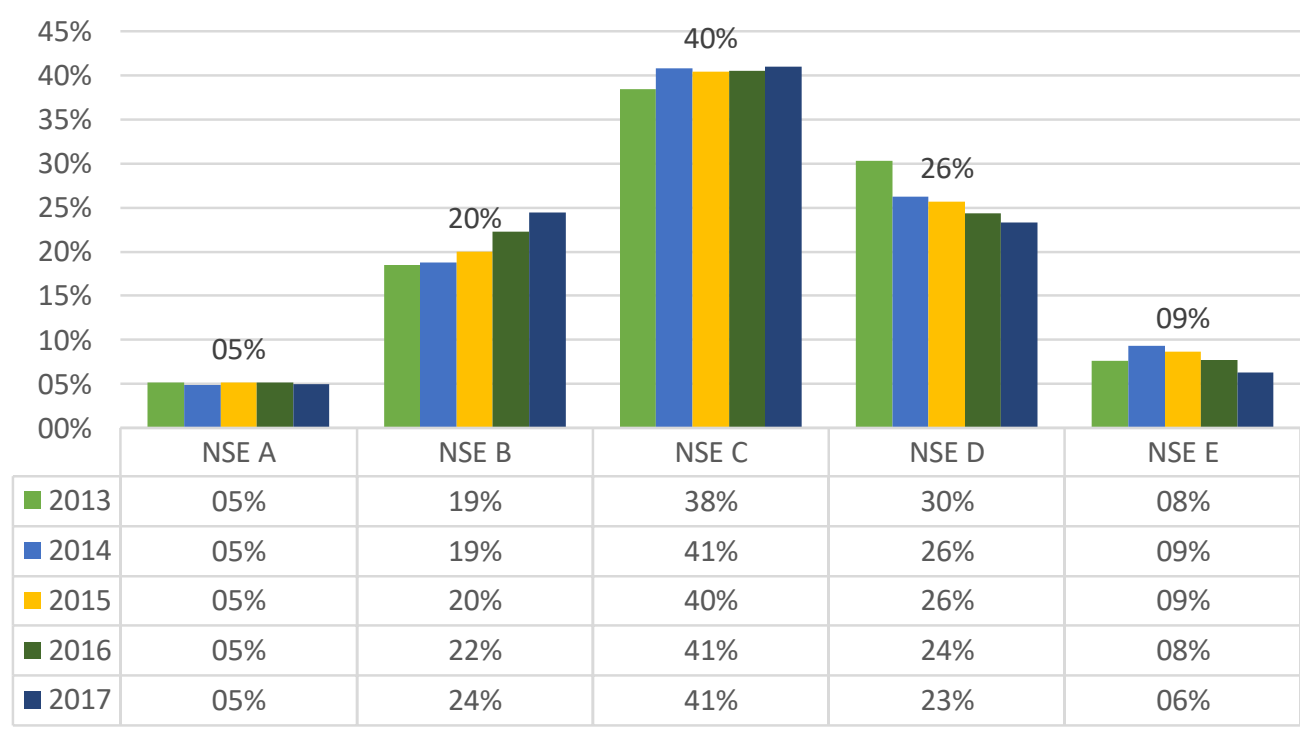

Figura $N^{\circ} 20$. Distribución de hogares según NSE - Lima metropolitana. Nota: ENAHO, elaboración propia.

Por otro lado, el $65 \%$ de los peruanos prefieren muebles de madera dentro de sus hogares entre los que destacan pisos, puertas, ventanas para sus hogares según estudios realizados por el Instituto de Educación Superior Tecnológico Privado de la Construcción - CAPECO.

Además, el incremento del poder adquisitivo de la clase media permite que el mercado local se dinamice, lo cual genera una oportunidad para la empresa SF Hermanos 
S.R.L. debido a que puede enfocarse en este segmento. En consecuencia puede generar una mayor participación de mercado, hecho que se puede lograr replanteando la dirección del mercado meta de los productos principales, así como de los secundarios.

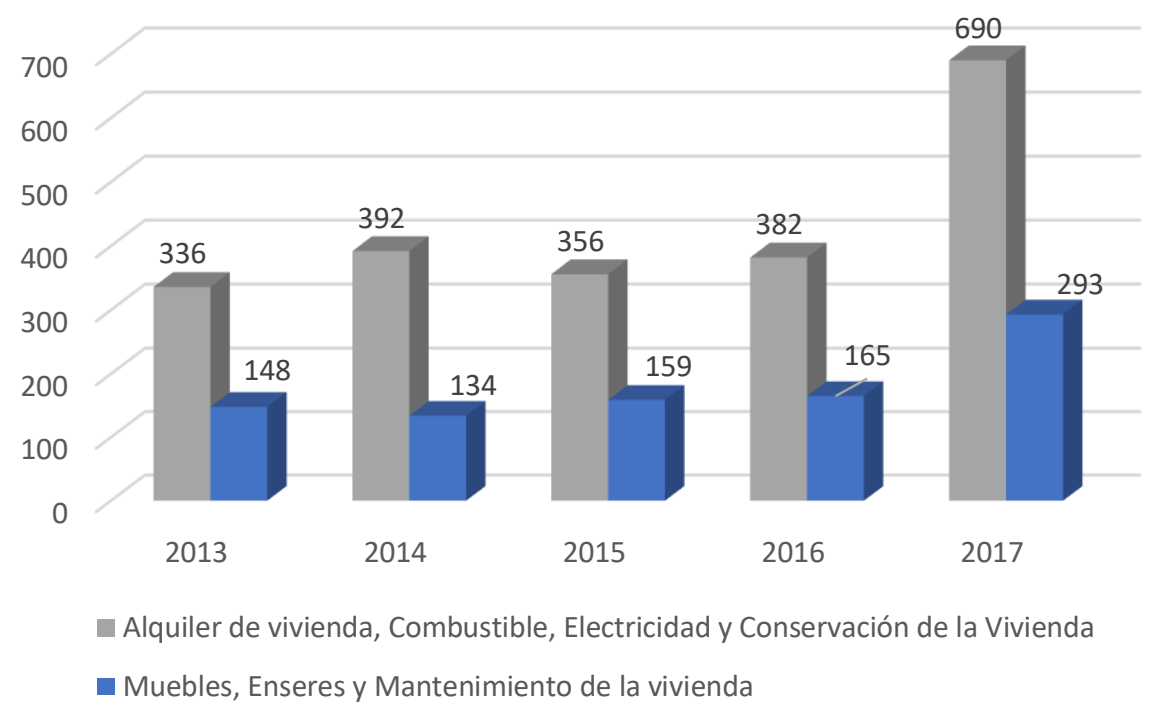

Figura $N^{\circ}$ 21. Evolución de gastos del NSE B - Lima metropolitana. (S/.) Nota: ENAHO, APEIM, elaboración propia.

\subsubsection{Análisis tecnológico}

Debido a la presión del mercado y la mayor exigencia de los clientes las empresas han buscado modernizarse mediante innovaciones tecnológicas lo cual permite mejorar la calidad sea de un bien o de un servicio. Con el progreso tecnológico, se logra un aumento de productividad y estandarización de los productos.

La rápida evolución que se está dando en la tecnología, hace que maquinarias queden cada vez más rápidamente obsoletas y no lleguen a satisfacer las necesidades de los clientes. 


\subsubsection{Análisis ecológico}

El Perú figura entre los tres países más vulnerables a los efectos del cambio climático a nivel global, sumado al retroceso de los glaciares, el incremento de la frecuencia e intensidad del fenómeno de "El Niño” y la elevación del mar, fenómenos que pueden alterar al insumo principal de la empresa, como es la madera, es por eso que SF HERMANOS S.R.L., es una empresa con un fuerte sentido de responsabilidad con el medio ambiente y la sociedad. Para realizar su actividad principal la compañía aprovecha al máximo la luz natural, evitando prender focos durante el día y apaga los que no utiliza, además de concientizar a su personal sobre el cuidado ambiental, los desechos orgánicos e inorgánicos su reducción, reutilización y reciclaje, fomentar la participación del personal en la discusión, reflexión, construcción colectiva sobre temáticas del diagnóstico ambiental y propuestas de acción. Asegurar el conocimiento de los riesgos y las precauciones en el momento de manipular los solventes con peligro de inflamabilidad y contaminación ambiental.

SF Hermanos S.R.L., es una empresa con un fuerte sentido de responsabilidad con el medio ambiente y la sociedad. Para comenzar, la empresa está sujeta al control del reciclaje de todos los residuos de producción esto significa que no permite que nada se quede contaminando el medioambiente.

\subsection{Efecto en la empresa de cada una de las variables del entorno}

\section{Efecto en la empresa}

El análisis externo, permite mostrar los siguientes efectos: 
a) SF Hermanos, necesita proveedores diversos en cantidad y calidad, por tanto, tiene que desarrollar alianzas con proveedores.

b) Necesita desarrollar plataforma digital por web, debe alinear su estrategia de comunicación (P de Publicidad) y llegada a los clientes (P de Plaza), usando plataformas de interacción de comunicación.

c) Necesita cercanía con sus clientes, lo cual se tiene que traducir no solo en garantizar una buena experiencia de compra, sino "predecir" su forma de consumo, tomando las acciones necesarias para mantener su fidelidad.

d) Necesita mejorar procesos, presentar nuevas formas de relación con los clientes, por tanto, tiene que implantar una cultura de innovación constante que tiene que manifestarse en todos los niveles gerenciales, administrativos y operativos.

Tabla $\mathrm{N}^{\circ} 20$

Análisis Político Gubernamental

\begin{tabular}{ccc}
\hline Factor & Impacto Clientes & Impacto Proveedores \\
\hline Elección del nuevo presidente & Alto & Alto \\
El nuevo Plan de Gobierno & Alto & Alto \\
\hline
\end{tabular}

Nota: Elaboración propia

Tabla $\mathrm{N}^{\circ} 21$

Análisis económico

\begin{tabular}{ccc}
\hline Factor & Impacto Clientes & Impacto Proveedores \\
\hline PBI & Alto & Alto \\
\hline Balanza Comercial & Medio & Alto \\
Tipo de cambio & Alto & Alto \\
\hline
\end{tabular}

Nota: Elaboración propia 
Tabla $\mathrm{N}^{\circ} 22$

Análisis tecnológico

\begin{tabular}{ccc}
\hline Factor & Impacto Clientes & Impactos Proveedores \\
\hline Uso de tecnología & Medio & Medio \\
\hline
\end{tabular}

Nota: Elaboración propia

Tabla $\mathrm{N}^{\circ} 23$

Análisis legal

\begin{tabular}{ccc}
\hline Factor & Impacto Clientes & Impactos Proveedores \\
\hline $\begin{array}{c}\text { Ley Reguladora de } \\
\text { Tercerización }\end{array}$ & Bajo & Alto \\
\hline
\end{tabular}

Nota: Elaboración propia

Tabla $\mathrm{N}^{\circ} 24$

Análisis social

\begin{tabular}{ccc}
\hline Factor & Impacto Clientes & Impactos Proveedores \\
\hline Crecimiento de familias & Alto & Alto \\
\hline
\end{tabular}

Nota: Elaboración propia

Tabla $\mathrm{N}^{\circ} 25$

Análisis ecológico

\begin{tabular}{ccc}
\hline Factor & Impacto Clientes & Impactos Proveedores \\
\hline Control de reciclaje & Alto & Alto
\end{tabular}

Nota: Elaboración propia

\subsection{Oportunidades y amenazas}

\section{Oportunidades:}

- Crecimiento del sector construcción en el Perú en un 4\%.

- Crecimiento de capacidad de endeudamiento de los hogares limeños. 
- Existencia de marcas diferenciadas (barrera de entrada).

- Bajo nivel de servicio post venta en el sector.

- La segmentación elegida tiene como preferencia la madera, acero y cueros para la fabricación de sus muebles.

\section{Amenazas:}

- Alto nivel de competencia informal.

- Consumidor cada vez más exigente e influenciado por tendencias mundiales.

- Facilidad en la importación de muebles de procedencia china por retails.

- Estacionalidad de la demanda.

- Existencia de productos sustitutos. 


\subsection{Matriz de evaluación de los factores externos (EFE)}

La matriz EFE, permite que se resuma y evalúe información económica, social, cultural, demográfica, ambiental, política, gubernamental, legal, tecnológica y competitiva. (David, 2013).

Tabla $\mathrm{N}^{\circ} 26$

Matriz de Factores Externos - EFE

\begin{tabular}{|c|c|c|c|c|}
\hline & Factores externos determinantes de éxito & Peso & Calificación & $\begin{array}{c}\text { Total } \\
\text { Ponderado }\end{array}$ \\
\hline \multicolumn{5}{|c|}{ Oportunidades } \\
\hline 1 & $\begin{array}{l}\text { Crecimiento del sector construcción en el Perú en un } \\
\qquad 4 \%\end{array}$ & 0.12 & 3 & 0.36 \\
\hline 2 & $\begin{array}{l}\text { Crecimiento de capacidad de endeudamiento de los } \\
\text { hogares limeños. }\end{array}$ & 0.10 & 3 & 0.30 \\
\hline 3 & $\begin{array}{l}\text { Existencia de marcas diferenciadas (barrera de } \\
\text { entrada) }\end{array}$ & 0.08 & 2 & 0.16 \\
\hline 4 & Bajo nivel de servicio post venta en el sector & 0.10 & 2 & 0.20 \\
\hline \multirow[t]{2}{*}{5} & $\begin{array}{l}\text { La segmentación elegida tiene como preferencia la } \\
\text { madera, acero y cueros para la fabricación de sus } \\
\text { muebles }\end{array}$ & 0.08 & 3 & 0.24 \\
\hline & \multicolumn{4}{|l|}{ Amenazas } \\
\hline 6 & Alto nivel de competencia informal & 0.12 & 2 & 0.24 \\
\hline 7 & $\begin{array}{c}\text { Consumidor cada vez más exigente e influenciado por } \\
\text { tendencias mundiales }\end{array}$ & 0.08 & 3 & 0.24 \\
\hline 8 & $\begin{array}{l}\text { Facilidad en la importación de muebles de } \\
\text { procedencia china por retails }\end{array}$ & 0.10 & 2 & 0.20 \\
\hline 9 & Estacionalidad de la demanda & 0.10 & 2 & 0.20 \\
\hline 10 & Existencia de productos sustitutos & 0.12 & 2 & 0.24 \\
\hline & Total & 1.00 & & 2.38 \\
\hline
\end{tabular}

Nota: Elaboración propia 
Interpretación: El resultado presentado es de 2.38, lo que indica que el conjunto de estrategias y acciones que se han realizado desde la empresa no han sido suficientes para poder lograr una posición estratégica competitiva desde la empresa frente a las diferentes variables externas. 


\section{Capítulo V: Análisis de la industria}

\subsection{Descripción del mercado (demanda) e industria (oferta)}

En el Perú se han registrado importantes cambios debido a que hace tres años, había un comportamiento de desaceleración de oferta de viviendas debido al poco aporte del estado para la construcción de viviendas, pero en el año 2015 presentó indicadores positivos. (BBVA research, 2016).

Desde el año 1998 hasta el presente se aprecia un crecimiento sostenible de la oferta de viviendas, en el cual en el año 2014 representó 29,156 unidades y en el año 2015 de 23,761 unidades (Capeco y BBVA research, 2016).

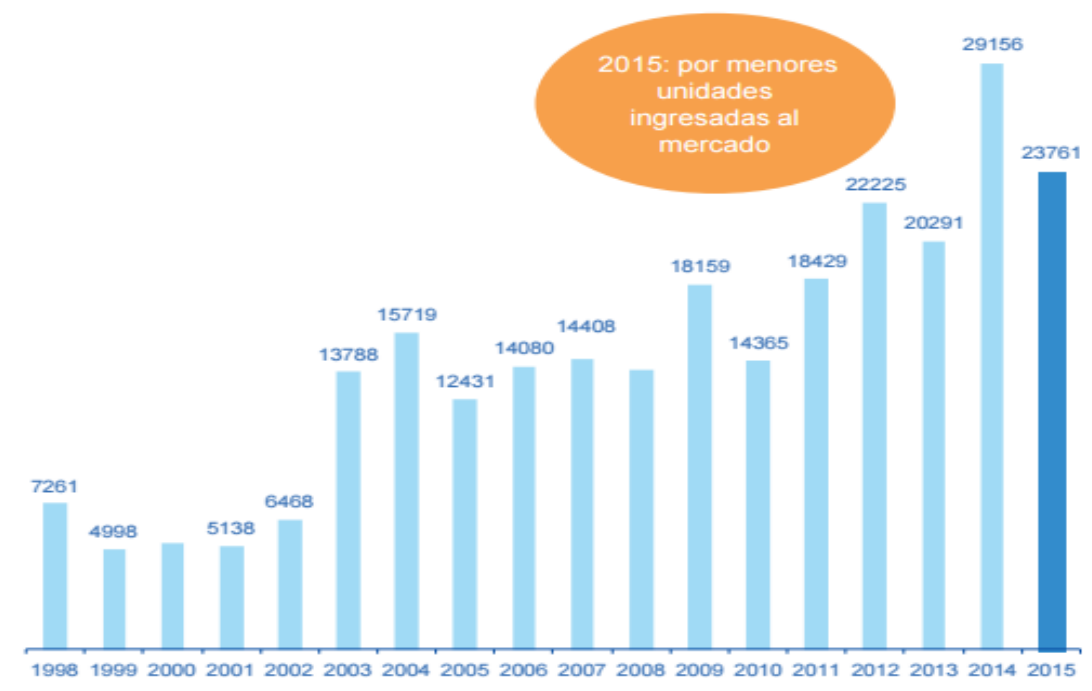

Figura $N^{\circ} 22$ : Ofertas de vivienda. Nota: Cámara Peruana de Construcción 
Por otro lado, la demanda de viviendas entre los años 2012 hasta 2015 representó 89,211 hogares y 153,349 hogares respectivamente lo cual representa un crecimiento considerable en la venta de viviendas (Capeco y BBVA 2016).

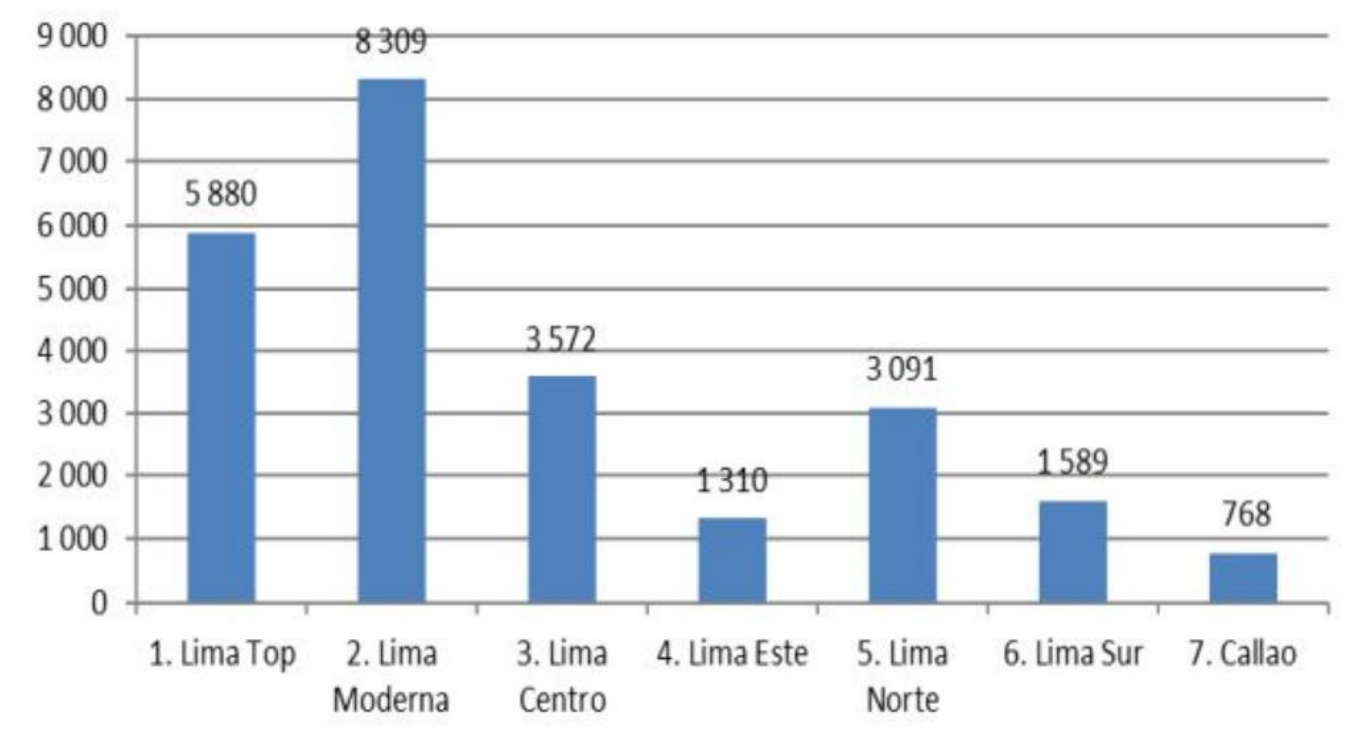

Figura $N^{\circ}$ 23. Demanda de viviendas por sectores urbanos (miles de hogares) al 2016. Nota: Cámara Peruana de Construcción

Se observa que los sectores más demandados en el 2016 fueron las viviendas de los distritos de Lima moderna y Lima Top, zonas cuya composición del NSE A y B son más altas en comparación a otros sectores. La industria de los muebles está entrelazado con la oferta y demanda de las viviendas obtenidas por año, debido a que a la población tiene la necesidad básica de obtener mobiliario para las diferentes áreas que comprende su hogar.

En la siguiente figura podemos observar cómo ha crecido la obtención de viviendas de tipo independiente y departamento en edificios por lo cual no solo hay demanda del consumidor final, sino de las empresas que ofrecen la venta de sus viviendas con el amueblamiento básico de su hogar. 


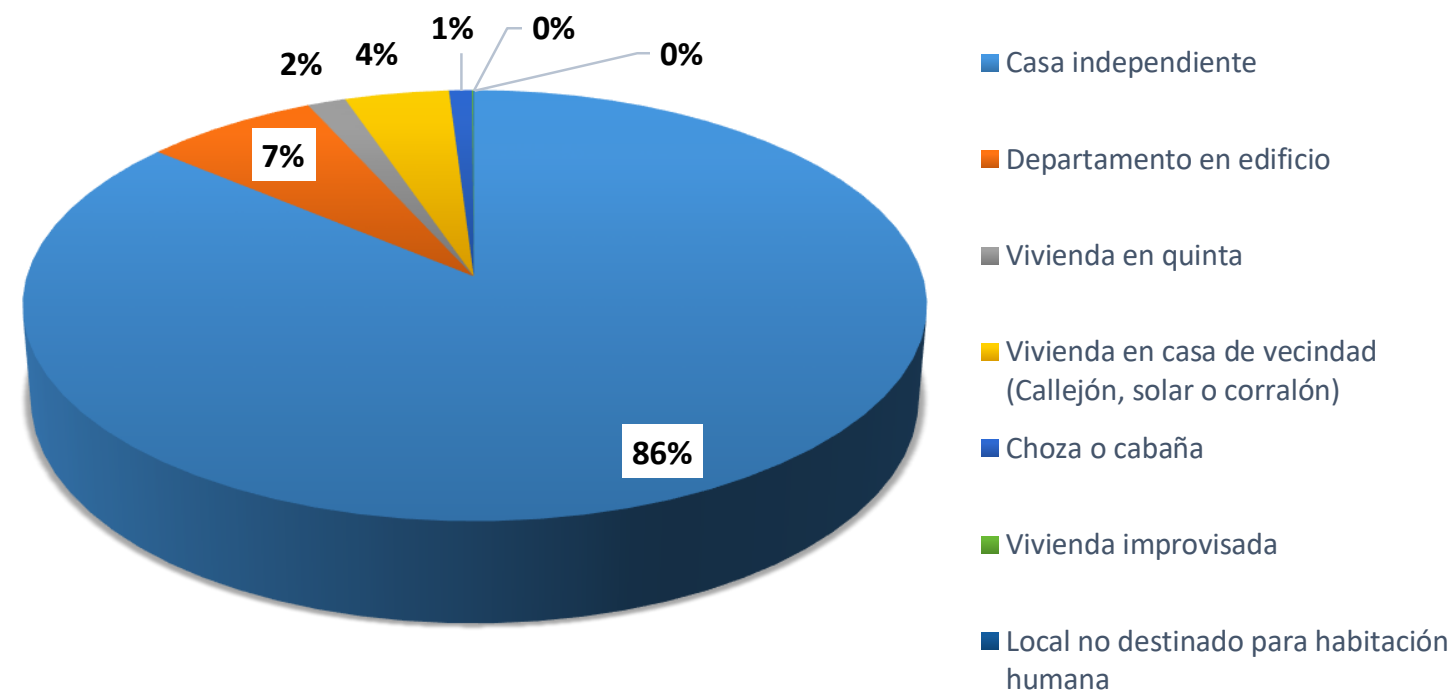

Figura $N^{\circ} 24$. Tipos de viviendas que ocupan los hogares al 2016. Nota: Instituto Nacional de Estadística e Informática, elaboración propia.

Además, el promedio mensual de ingresos por cada poblador va en aumento en estos últimos años, claro ejemplo está en la ciudad de Lima con un promedio de 1,940 soles al 2016, donde los hogares comprenden entre dos a cinco integrantes por cada una de ellas, obteniendo mayor adquisición de bienes para su hogar. 


\section{2,500}

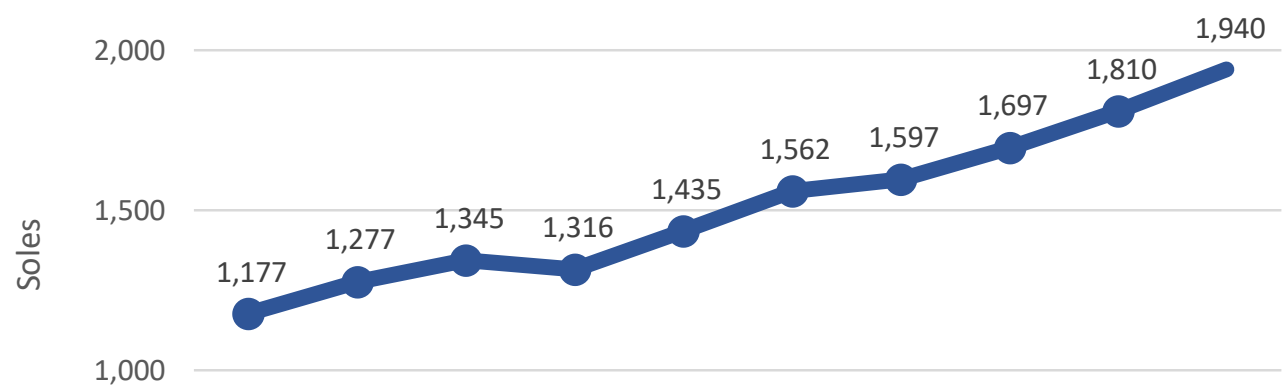

500

\begin{tabular}{|c|c|c|c|c|c|c|c|c|c|c|}
\hline 00 & 2007 & 2008 & 2009 & 2010 & 2011 & 2012 & 2013 & 2014 & 2015 & 2016 \\
\hline Ingreso Mensual & 1,177 & 1,277 & 1,345 & 1,316 & 1,435 & 1,562 & 1,597 & 1,697 & 1,810 & 1,940 \\
\hline
\end{tabular}

Figura $N^{\circ} 25$. Ingreso promedio mensual Lima Metropolitana 2007-2016. Nota: Instituto Nacional de Estadística e Informática, elaboración propia.

\subsection{Descripción de las cinco fuerzas competitivas de la industria}

Se realizará a continuación un análisis del entorno directo a través de las cinco fuerzas de Porter, realizando un análisis para medir al sector de muebles.

\subsubsection{Amenaza de productos sustitutos}

Muchas empresas encuentran productos con características similares a lo que ofrecen, por lo cual compiten entre sí, existe una participación en el mercado importante concluyendo a un tope de precio del producto a ofrecer (David, 2013). 
La industria de los muebles en la que se encuentra la empresa cuenta con dos sustitutos continuación el detalle:

Muebles de lata o cromado: Este mobiliario es utilizado para todas las áreas de la vivienda (sala, cocina, comedor, habitación entre otras), en cuanto al precio de estos productos a comparación de los muebles en acero, son más económicos y de fácil acceso para los clientes, estos pueden ser encontrados no solo en tiendas comerciales dedicadas a vender muebles, sino que ya pueden ser encontrados en supermercados, mayoristas y otros establecimientos a un precio más accesible. En lo referido al promedio de duración de este bien sustituto frente a los productos de acero es demasiado corto, además de depender del uso, condiciones de temperatura del área entre otros factores.

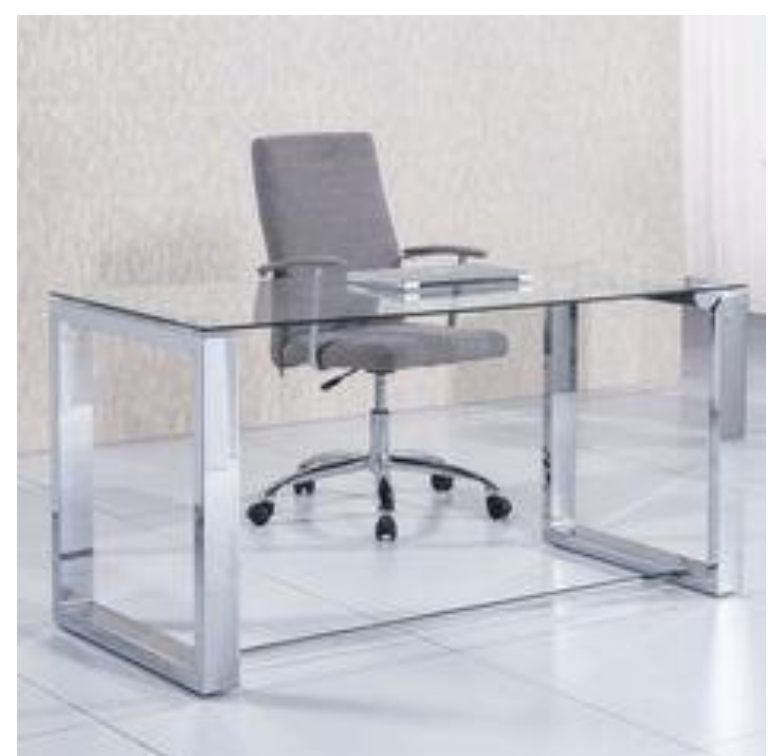

Figura $N^{\circ}$ 26. Muebles de lata o cromado. Nota: Pagina web de SF Hermanos

Muebles de PVC o plástico: El material PVC está abundando en el mercado en los últimos años debido a su facilidad para amoldar diferentes productos que son 
utilizados en la vida diaria y todas las áreas del hogar u oficina, además de ser un material reutilizable para la fabricación de otros productos, en la última década se puede observar que en los grandes retails y mercados mayoristas dichos mobiliarios elaborados con este tipo de material son una opción económica para el consumidor final, estos productos se pueden encontrar en diversidad de colores y con diseñados de última tendencia.

\subsubsection{Amenazas de competidores potenciales}

Son consideradas a las empresas que no están dedicadas al mismo rubro, pero tienen la posibilidad de obtener una mayor participación de mercado insertándose a este rubro (David, 2013).

SF Hermanos S.R.L. considera como competidores potenciales a las empresas que se dedican a la venta de melamine y acero, debido a que tienen el capital suficiente para insertarse a este rubro, considerando que los precios de la materia prima que ellos pueden obtener son demasiado bajos debido a que compran al mismo distribuidor, pero por temas de políticas establecidas por las empresas que fabrican estos productos, prohíben la fabricación y/o comercialización de estos como producto para el consumidor final.

Otro competidor potencial para SF Hermanos S.R.L. son las empresas importadoras de muebles de última tendencia las cuales traen productos con 
similares diseños y formas, pero con menor calidad y poseen un costo menor por la tecnología avanzada que usan para desarrollarlos.

En estos últimos años no se ha visto la importación de muebles de calidad como se menciona anteriormente, sino la importación de muebles de calidad baja y duración mínima bajo el concepto utilizado por las personas como "Esto es temporal", los cuales son provenientes de China.

\subsubsection{Poder de negociación con los clientes}

El poder de negociación con los consumidores es una importante fuerza que afecta la intensidad de la competencia en una industria, pudiendo así afectar a la ventaja competitiva. (David, 2013).

Los clientes en la industria de muebles determinan el $31.6 \%$ de ventas al público en general que abarca el mayor porcentaje de las ventas de SF Hermanos, el segundo lugar, lo ocupan las Empresas Constructoras con un $18.1 \%$ de participación, seguidos de los Ingenieros con 17.4\% y los Arquitectos con una representación de $16.2 \%$ producto de todos los proyectos que realizan con insumos y materiales de la compañía, por lo cual se llega a la conclusión de que la venta que se realiza va al consumidor directo desarrollando ventas por menor. 
Tabla $\mathrm{N}^{\circ} 27$

Ventas según tipo de cliente

\begin{tabular}{cc}
\hline Clientes & $\%$ \\
\hline Público en general & $31.6 \%$ \\
Empresas constructoras & $18.1 \%$ \\
Ingenieros & $17.4 \%$ \\
Arquitectos & $16.2 \%$ \\
Joyeros/artesanos & $7.2 \%$ \\
Fábrica de utensilios & $5.1 \%$ \\
Empresas de embalaje & $3.1 \%$ \\
Fábricas de Calzado & $1.3 \%$ \\
Total & $100.0 \%$ \\
\hline
\end{tabular}

Nota: Estudio de mercado nacional de madera y productos de madera para el sector construcción - CITE MADERA.

Sin embargo, las ventas a las constructoras es un punto esencial en la industria debido a que existe un crecimiento de demanda de obtener departamentos y casas propias, por lo ellos están en la obligación de presentar y/o adicionar a sus productos el amoblado de estos.

SF Hermanos S.R.L. cuenta con diversidad de clientes donde se enfoca en la venta por menor, por consecuencia el proceso de venta se basa en las necesidades y diseños según cliente. A continuación, se detallan algunos de los clientes frecuentes en el último año: 
Tabla $\mathrm{N}^{\circ} 28$

Porcentaje de ventas por Cliente - Año 2018

\begin{tabular}{cc}
\hline Clientes & $\%$ \\
\hline Juan Miguel Raffo & $33 \%$ \\
Fernando Gordillo & $24 \%$ \\
Carla Cabaneix & $12 \%$ \\
Urpi Alosilla & $10 \%$ \\
Antonio Garcia & $8 \%$ \\
Enrique Calmet Augusto & $6 \%$ \\
Jorge Deliot & $4 \%$ \\
Fiorella Ubillus & $3 \%$ \\
\hline
\end{tabular}

Nota: Elaboración propia

\subsubsection{Poder de negociación con proveedores}

El poder de negociación de los proveedores también afecta a intensidad de la competencia industria, sobre todo cuando hay un número grande de proveedores (David, 2013).

En la industria de mueble se listan a los principales proveedores de madera, acero, derivados de madera y accesorios.

Aserraderos: Son empresas que se dedican a la compra de madera de nuestra selva, y le dan los procedimientos adecuados según lo solicita el cliente, los cuales pueden ser tableros, vigas, machihembrados, listones, etc. 


\begin{tabular}{|c|c|}
\hline Novopan del Perú S.A. \\
\cline { 2 - 3 } NOVOPAN & $\begin{array}{r}\text { Empresa de Ecuador dedicada a la venta de derivados de madera, tableros MDF, MDP, MDP colores. Ofrecen } \\
\text { productos de calidad para todo tipo de trabajos marcando la illima tendencia en colores y diseños. La distribución de } \\
\text { sus tableros es a todas las regiones del pás, marca reconocida en calidad y precio debido a que los mobiliarios } \\
\text { realizados con estos tableros presentan mayor duración. }\end{array}$ \\
\hline
\end{tabular}

Figura $N^{\circ}$ 27. Proveedor - Novopan del Perú S.A. Nota: Novopan del Perú S.A.

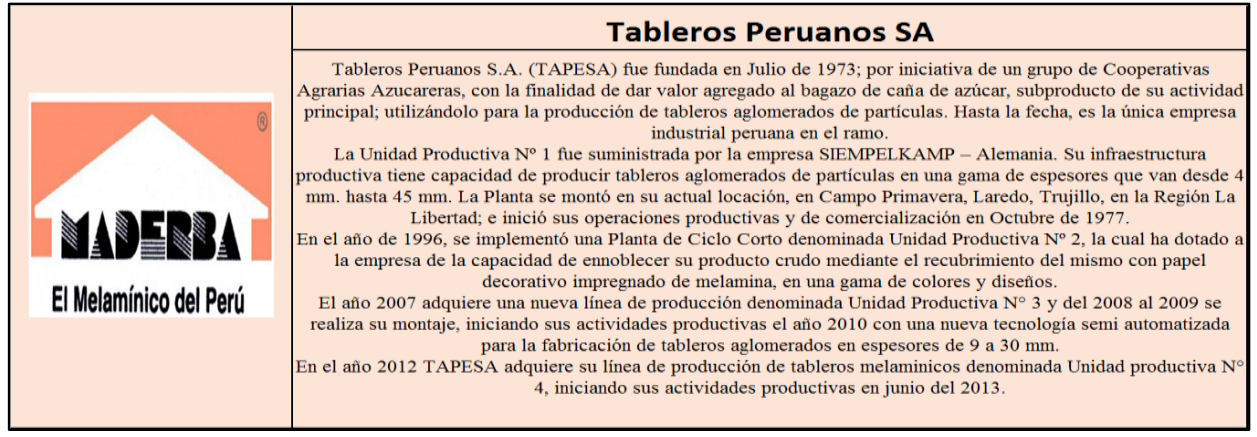

Figura $N^{\circ} 28$. Proveedor - Tableros Peruanos S.A. Nota: Tableros Peruanos S.A.

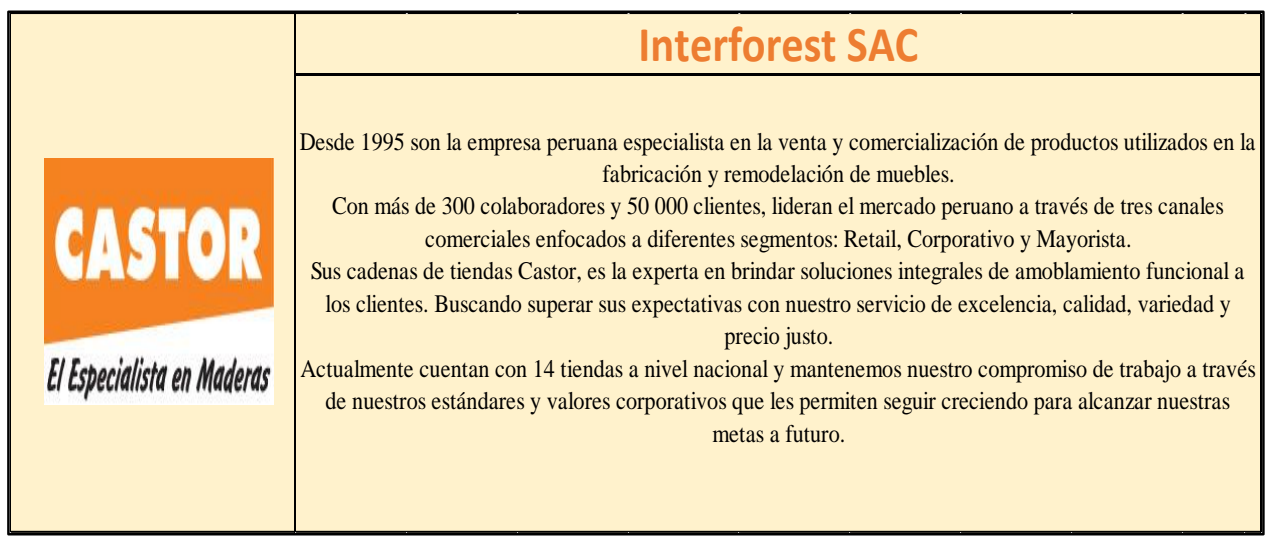

Figura $N^{\circ}$ 29. Proveedor - Interforest S.A.C. Nota: Interforest S.A.C. 


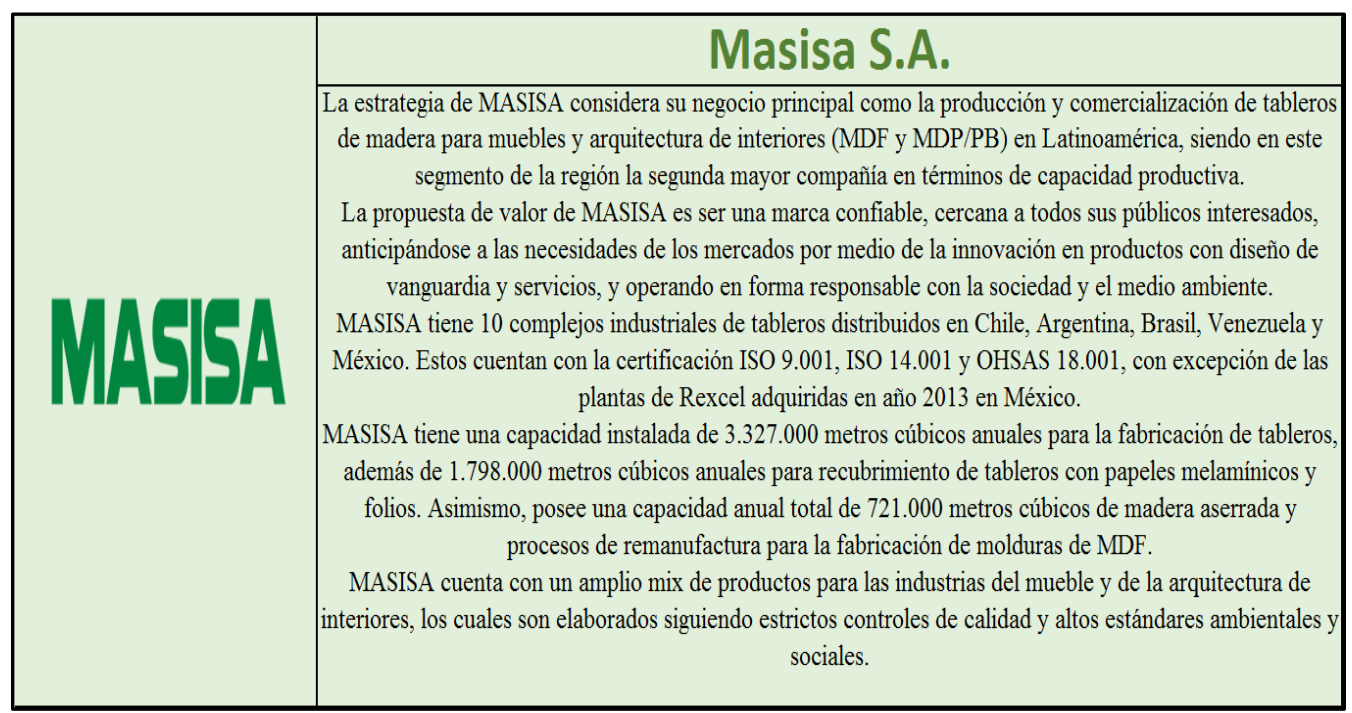

Figura $N^{\circ}$ 30. Proveedor - Masisa S.A. Nota: Masisa S.A.

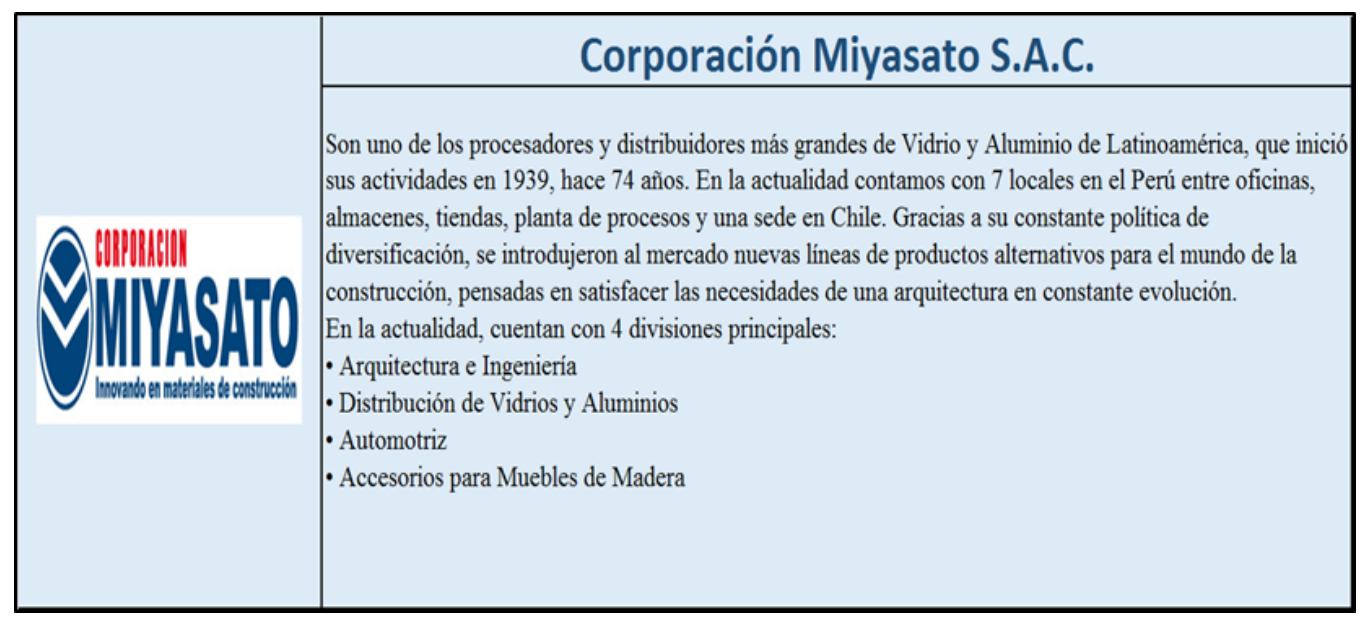

Figura $N^{\circ}$ 31. Proveedor - Miyasato S.A.C. Nota: Miyasato S.A.C.

\section{Dilfas S.A.C.}

Empresa que se dedica a la venta por mayor y menor de todo tipo de fierros y acero inoxidable, su amplia experiencia en estos productos han hecho que ofrezca servicios complementarios que necesita su público objetivo para cumplir sus trabajos con eficiencia y calidad.

Figura $N^{\circ}$ 32. Proveedor-Dilfas S.A.C. Nota: Dilfas S.A.C 


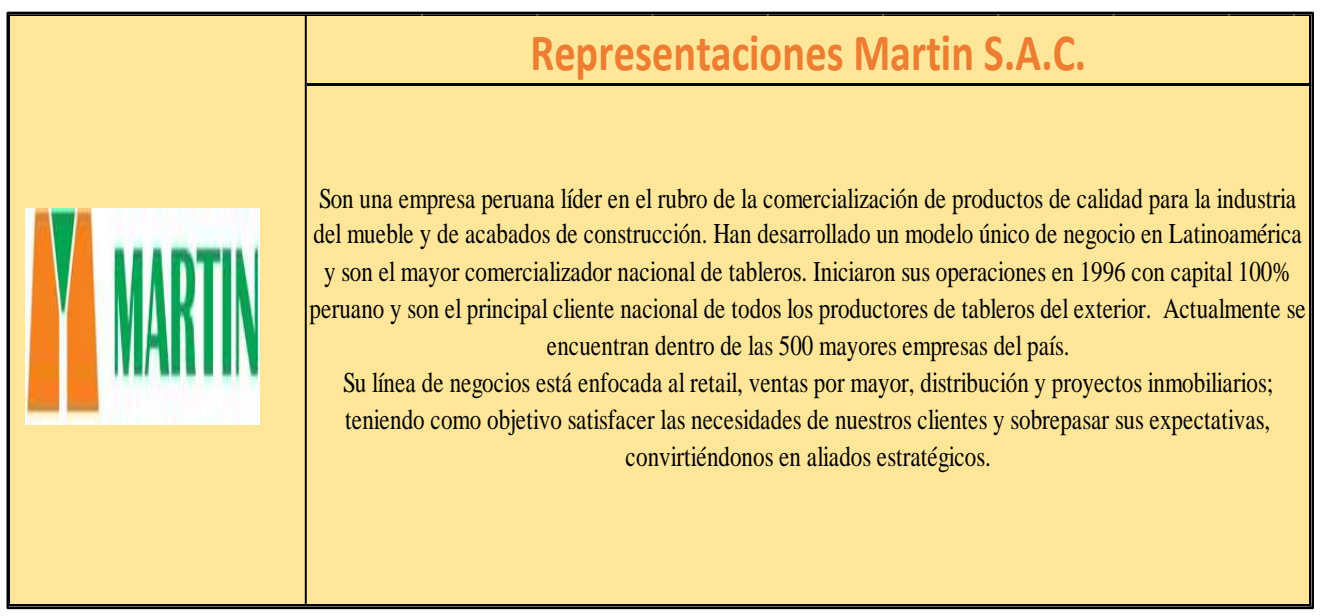

Figura $N^{\circ}$ 33. Proveedor - Representaciones Martin S.A.C. Nota: Representaciones Martin S.A.C.

\subsubsection{Competencia en el mismo sector}

La competencia en el mercado nacional está conformada por empresas informales y formales, así como las tiendas por retail.

Empresas informales:

Estas empresas no están registradas en SUNARP, por lo cual es difícil de identificarlas, sin embargo, son carpinterías, cerrajerías y/o independientes que realizan pequeños trabajos a un menor precio al que se presenta en el mercado. Los trabajos que se desarrollan son económicos pero la calidad puede predominar debido a que no cuentan con la experiencia y técnica suficiente para ofrecer un producto con las condiciones y parámetros correctos.

- Productores de muebles en Villa Salvador y San Juan de Lurigancho:

Conglomerados de microempresas que se dedican a la fabricación de muebles 
de hogar por mayor, ofreciendo precios económicos, modelos y diseños estándares. Estos muebles son vendidos por mayor en el mercado nacional en los puntos comerciales en los conos de Lima y en provincias. Entre los principales el mercado Unicachi, Minka, Decormuebles.

Empresas formales:

- Saga Falabella: La compañía chilena Falabella, creada en 1958, ingresó al mercado peruano en 1995 con la compra de Saga y se ha consolidado en el mercado como una de las comercializadoras y distribuidora de comercio minorista más importante del mercado, atendiendo los segmentos A, B y C. Cuenta con su propia financiera CMR, la cual opera por medio de tarjetas de crédito para las compras de sus clientes.

- Sodimac: Es del grupo Falabella y ofrece productos para el hogar, gran variedad de muebles en melamine con el concepto "listos para armar".

- Ripley: Empresa de origen chileno, creada en 1964, entró al mercado peruano en 1997 con gran fuerza. Al igual que otras compañías su principal negocio es la financiación a los consumidores, otorgándoles créditos a través de su compañía de financiamiento Cordillera. Al igual que Saga Falabella, está compitiendo por el mismo segmento de clientes en el mercado. 
- Promart: Ofreciendo productos de fácil armado, y accesorios para armar "tu propio mueble" para tu propio hogar, con la opción de financiamiento con la tarjeta de la empresa.

- Muebles Ferrini S.A.: Es una empresa constituida hace más de 75 años, dedicada a la fabricación y venta de mobiliario residencial (para salas, comedores, salones de entretenimiento, bares, etc.) e institucional en diversos estilos: desde el clásico moderno al estilo contemporáneo. Esta empresa ofrece alta calidad en sus muebles y opera en una planta de más de 3,000 m2 contando con modernos procesos de fabricación y con materiales de primera calidad.

- Canziani: Muebles Canziani se remonta al año 1925, cuando un joven inmigrante italiano abre un taller dedicado a la elaboración de muebles de estilo, respetando la tradición europea. Con el paso de los años Muebles Canziani se fue afirmando en el mercado peruano del mueble; en el año 1940, se da un cambio a la compañía, ofreciendo las últimas tendencias mundiales en cuanto a estética y funcionalidad para los muebles que fabricaban. Se puede decir que mantiene un diseño clásico en sus muebles.

Actualmente la fábrica de Muebles Canziani cuenta con una planta moderna, equipada con alta tecnología y contando con personal altamente capacitado. Muebles Canziani también exporta sus productos, siendo sus principales destinos Estados Unidos y Europa. 
- Alida S.A: Creada hace 40 años, empezó ofreciendo muebles para el hogar en el mercado local y desde el año 2000 exporta sus productos a Chile y Panamá. Es un proveedor importante de las tiendas por departamento que cuenta con planta propia, ofreciendo productos de alta calidad con diseños modernos y vanguardistas.

- Ibero Perú S.A.C. Empresa con amplia experiencia en el diseño y fabricación de mobiliario oficina, retail y vivienda. Soluciones Integrales en amueblamiento. Fundada en 1996, IBERO PERU S.A.C es una empresa peruana conformada por especialistas de amplia experiencia en el diseño y la fabricación de mobiliario para proyectos de oficina, retail y vivienda. 


\subsection{Matriz de atractividad de cada una de las cinco fuerzas:}

Tabla $\mathrm{N}^{\circ} 29$

Matriz de atractividad: Amenaza de productos sustitutos

\begin{tabular}{cccc}
\hline $\begin{array}{c}\text { Elemento de } \\
\text { análisis }\end{array}$ & $\begin{array}{c}\text { Nivel de la } \\
\text { amenaza }\end{array}$ & $\begin{array}{c}\text { Aspectos que lo hacen } \\
\text { riesgoso }\end{array}$ & $\begin{array}{c}\text { Aspectos que lo hacen } \\
\text { altamente riesgoso }\end{array}$ \\
\hline $\begin{array}{c}\text { Precios relativos } \\
\text { de productos } \\
\text { sustitutos }\end{array}$ & Alta & $\begin{array}{c}\text { Los productos sustitutos } \\
\text { poseen un precio inferior al } \\
\text { del mercado. }\end{array}$ & $\begin{array}{c}\text { La compra en grandes } \\
\text { cantidades por parte de } \\
\text { las empresas de retail a } \\
\text { un precio mucho menor. }\end{array}$ \\
$\begin{array}{c}\text { Calidad de } \\
\text { productos } \\
\text { sustitutos }\end{array}$ & Bajo & $\begin{array}{c}\text { El material utilizado es de } \\
\text { baja calidad y durabilidad }\end{array}$ & $\begin{array}{c}\text { Tendencias de la moda } \\
\text { que hacen que el periodo } \\
\text { de renovación de } \\
\text { muebles sea más corto. }\end{array}$ \\
\hline
\end{tabular}

Nota: Elaboración propia

En base a lo analizado se concluye que esta fuerza es una amenaza alta en el sector

debido a que el sector construcción está creciendo y la tendencia de cambio de muebles son cada vez más constantes. 
Tabla $\mathrm{N}^{\circ} 30$

Matriz de atractividad: Amenaza de competidores potenciales

\begin{tabular}{|c|c|c|c|}
\hline Elemento de análisis & Nivel de la amenaza & $\begin{array}{l}\text { Criterios que lo hacen poco } \\
\text { atractivo }\end{array}$ & $\begin{array}{l}\text { Criterios que lo hacen muy } \\
\text { atractivo }\end{array}$ \\
\hline $\begin{array}{l}\text { Diferenciación por } \\
\text { atributos }\end{array}$ & Alta & $\begin{array}{c}\text { Muchas empresas que son clientes } \\
\text { pero solo se dedican a buscar } \\
\text { precios y no atributos. }\end{array}$ & $\begin{array}{l}\text { Sectores de clientes importantes } \\
\text { que buscan atributos en los } \\
\text { productos. }\end{array}$ \\
\hline Requisito de capital & Bajo & $\begin{array}{l}\text { La informalidad es muy grande en } \\
\text { este sector, lo que reduce el } \\
\text { capital de las pequeñas y } \\
\text { medianas empresas. }\end{array}$ & $\begin{array}{l}\text { La inversión es fuerte por la } \\
\text { necesidad de máquinas para la } \\
\text { producción. }\end{array}$ \\
\hline $\begin{array}{l}\text { Canales de } \\
\text { distribución }\end{array}$ & Alta & $\begin{array}{l}\text { Acceso a la distribución donde } \\
\text { cada empresa lo define. }\end{array}$ & $\begin{array}{c}\text { Se presenta atractiva por esta } \\
\text { variable. }\end{array}$ \\
\hline $\begin{array}{l}\text { Desventaja de } \\
\text { costos }\end{array}$ & Medio & $\begin{array}{c}\text { Las empresas transaccionales } \\
\text { grandes pueden superar estas } \\
\text { barreras. }\end{array}$ & $\begin{array}{c}\text { Empresas con mayor antigüedad } \\
\text { tienen mayor ubicación y acceso a } \\
\text { recurso. }\end{array}$ \\
\hline
\end{tabular}

Nota: Elaboración propia 
Tabla $\mathrm{N}^{\circ} 31$

Matriz de atractividad: Poder de negociación con los clientes

\begin{tabular}{|c|c|c|c|}
\hline Elementos de análisis & $\begin{array}{l}\text { Nivel de la } \\
\text { amenaza }\end{array}$ & $\begin{array}{l}\text { Criterios que lo hacen poco } \\
\text { atractivo }\end{array}$ & $\begin{array}{c}\text { Criterios que lo hacen } \\
\text { muy atractivo }\end{array}$ \\
\hline $\begin{array}{c}\text { Cuando los clientes se encuentran en } \\
\text { un mismo mercado }\end{array}$ & Bajo & $\begin{array}{c}\text { En este sector algunas empresas } \\
\text { están concentradas. }\end{array}$ & $\begin{array}{l}\text { Los clientes no están } \\
\text { concentrados. }\end{array}$ \\
\hline $\begin{array}{l}\text { Cuando los clientes que compran } \\
\text { forman parte de su estructura de } \\
\text { costos }\end{array}$ & Medio & $\begin{array}{l}\text { Algunos costos de producción son } \\
\text { altos, pero no puede afectar al } \\
\text { precio del producto. }\end{array}$ & $\begin{array}{l}\text { Existen clientes cuyos } \\
\text { presupuestos son para la } \\
\text { compra de muebles. }\end{array}$ \\
\hline $\begin{array}{l}\text { Cuando los insumos son } \\
\text { diferenciados }\end{array}$ & Medio & $\begin{array}{l}\text { Muchas empresas compran } \\
\text { muebles para cumplir con los } \\
\text { trabajadores, pero no buscan la } \\
\text { calidad. }\end{array}$ & \\
\hline $\begin{array}{c}\text { Cuando los clientes tienen bajas } \\
\text { utilidades }\end{array}$ & Medio & $\begin{array}{c}\text { Los márgenes de ganancias son } \\
\text { bajos por lo que se esfuerza en la } \\
\text { negociación. }\end{array}$ & $\begin{array}{c}\text { Se cuenta con } \\
\text { presupuestos anuales. }\end{array}$ \\
\hline $\begin{array}{l}\text { Cuando los clientes amenazan con } \\
\text { integrarse verticalmente hacia atrás }\end{array}$ & Bajo & & \\
\hline
\end{tabular}

Nota: Elaboración propia 
Tabla N 32

Matriz de atractividad: Poder de negociación de los proveedores

\begin{tabular}{|c|c|c|c|}
\hline Elementos de análisis & Poder & $\begin{array}{c}\text { Criterios que lo hacen poco } \\
\text { atractivo }\end{array}$ & $\begin{array}{c}\text { Criterios que lo hacen muy } \\
\text { atractivo }\end{array}$ \\
\hline $\begin{array}{c}\text { Cuando sus productos están } \\
\text { diferenciados }\end{array}$ & Alto & $\begin{array}{c}\text { Existen proveedores que } \\
\text { importan productos de muy } \\
\text { buena calidad o les dan un valor } \\
\text { agregado a sus productos. }\end{array}$ & $\begin{array}{l}\text { Si existe concentración de } \\
\text { proveedores }\end{array}$ \\
\hline $\begin{array}{l}\text { Cuando no hay sustitutos en los } \\
\text { productos que venden }\end{array}$ & Alto & $\begin{array}{l}\text { En el mercado se encuentran } \\
\text { proveedores especializados en } \\
\text { materiales que se necesita para } \\
\text { la producción. }\end{array}$ & $\begin{array}{l}\text { Existen proveedores que } \\
\text { tienen buena negociación } \\
\text { con sus clientes }\end{array}$ \\
\hline $\begin{array}{l}\text { Cuando los clientes que atienden no } \\
\text { son importantes porque también } \\
\text { atienden a otros sectores }\end{array}$ & Medio & $\begin{array}{l}\text { Los proveedores atienden a más } \\
\text { de un cliente y muchas veces } \\
\text { prefieren dar prioridad a otros. }\end{array}$ & $\begin{array}{l}\text { Existen clientes más } \\
\text { grandes }\end{array}$ \\
\hline $\begin{array}{c}\text { Cuando el proveedor se puede } \\
\text { integrar para adelante }\end{array}$ & Bajo & & $\begin{array}{c}\text { Existen proveedores que } \\
\text { están fabricando sus propios } \\
\text { productos }\end{array}$ \\
\hline Cuando existen pocos proveedores & Medio & $\begin{array}{c}\text { Cuando los importadores son } \\
\text { escasos. }\end{array}$ & $\begin{array}{c}\text { Existe una variedad } \\
\text { mediana de proveedores }\end{array}$ \\
\hline $\begin{array}{c}\text { Cuando el costo de cambio de } \\
\text { proveedor es alto }\end{array}$ & Alto & $\begin{array}{l}\text { Las economías de escala hacen } \\
\text { que cambiar de proveedor } \\
\text { genere un costo. }\end{array}$ & $\begin{array}{c}\text { Algunos productos son } \\
\text { normados }\end{array}$ \\
\hline
\end{tabular}

Nota: Elaboración propia 
Tabla $N^{\circ} 33$

Matriz de atractividad de la industria

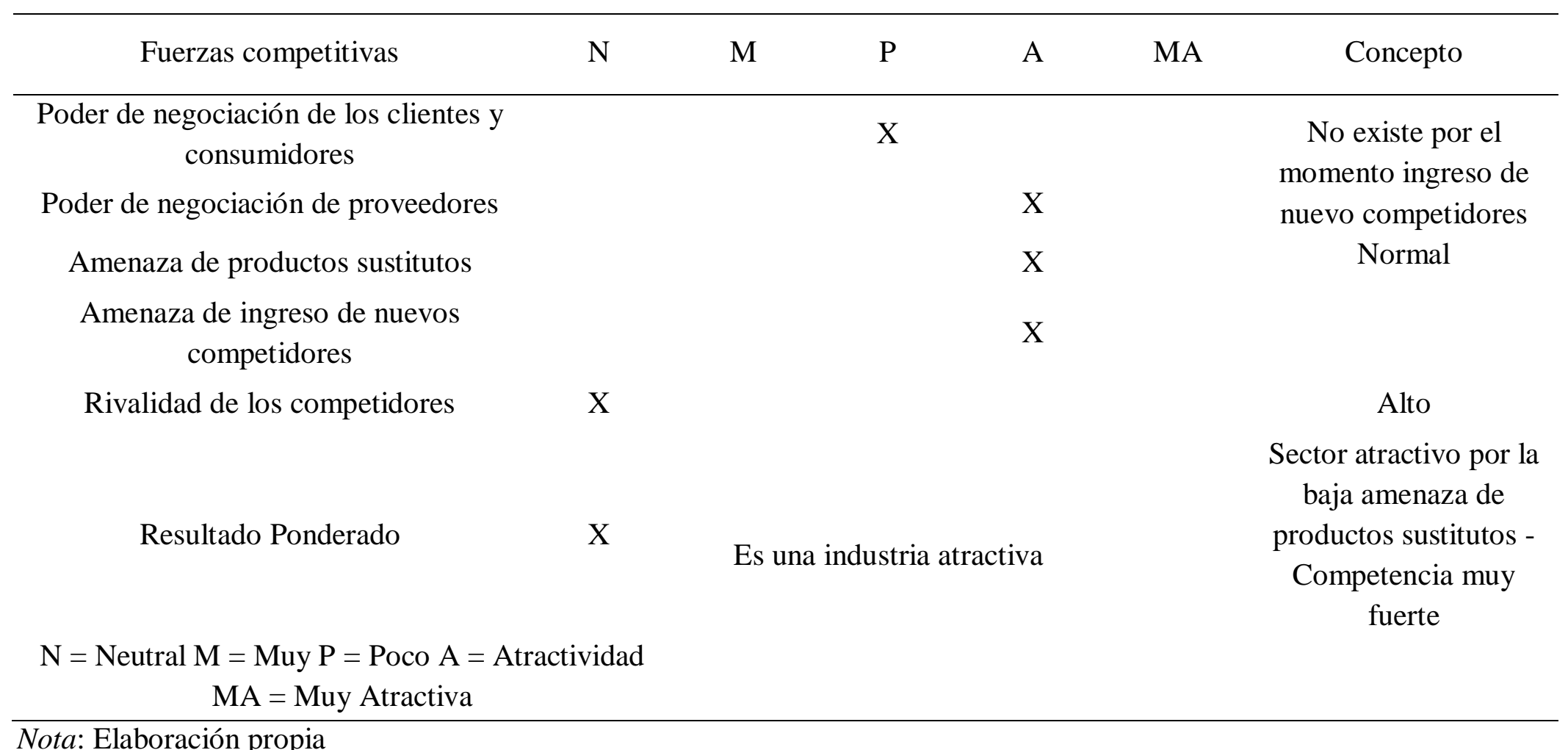

Nota: Elaboración propia 


\subsection{Matriz de perfil competitivo MPC}

La matriz MPC, identifica los principales competidores de la compañía, así como sus fortalezas y debilidades particulares en relación con la posición estratégica de una firma. (David, 2013).

Para la elaboración de está matriz es necesario identificar las fortalezas y debilidades de SF Hermanos en relación a sus principales competidores Ferrini y Canziani; luego de este análisis se encuentran los factores críticos de éxito debido a que dicha competencia ofrece productos similares con los mismos rangos de precios.

Los factores claves críticos de éxito afectan a todos los competidores lo cual será crucial para el avance del sector de muebles en el Perú. Dichos factores se definen como las variables sobre las cuales la gerencia puede influir con sus decisiones y que pueden afectan significativamente la posición competitiva de la empresa en la industria.

\section{Factores críticos de éxito:}

\section{Amplia línea de productos / Personal capacitado en el proceso de producción}

SF Hermanos a lo largo de los años ha ido diversificando los productos y materiales para la elaboración de los muebles, lo cual le ha permitido contar con mano de obra especializada en cada área de sus procesos productivos permitiéndole abrirse campo en el mercado. 


\section{Calidad de producto}

La calidad del producto es símbolo de los muebles y parrillas de SF Hermanos. Cada producto es elaborado con materiales que cumplen altos estándares de calidad como por ejemplo el acero que se encuentra certificado siendo complementado con la mano de obra calificada y especializada para cada línea de producto.

\section{Innovación en las presentaciones}

Las innovaciones son permanentes en la elaboración de muebles y parrillas debido a las exigencias de los clientes y las tendencias que van cambiando (formas y colores).

Se van creando nuevos muebles gracias a la innovación en materiales, como el acabado en poliuretano utilizado para los tableros con incrustaciones de acero; la nueva tendencia plasmada en los catálogos está siendo bastante aceptada por los clientes lo cual respaldaría la estrategia Renuévate.

\section{Conocimiento de los canales de distribución}

Al culminar el diseño de la mano de un profesional, se plasman en diversos programas informáticos como Autocad, para poder enviarle al cliente una muestra y así observe como quedan los muebles en el ambiente a remodelar.

Finalmente, el producto aprobado por parte del cliente es elaborado, para luego pasar por el control de calidad y así poder enviarlo al cliente a través de los medios de transporte de SF Hermanos. 


\section{Poder de negociación de los proveedores}

El poder de negociación de los proveedores impacta en los costos como por ejemplo el acero que es adquirido en grandes volúmenes lo que ayuda a la empresa a reducir los costos en la elaboración de los muebles. Por otro lado, los demás insumos como por ejemplo la madera, el cuero y la tela son comprados a proveedores con los cuales SF Hermanos ya cuenta con años de relación.

\section{Precio}

El precio se considera un factor crítico de éxito debido a que, gracias a este, SF Hermanos se identifica frente a sus competidores en el mercado.

\section{Presencia en puntos de venta}

El punto de venta de SF Hermanos se encuentra ubicado en distrito de Ate Vitarte, se tiene como objetivo abrir un punto de venta en uno de los distritos elegidos por la estrategia renuévate. SF Hermanos no solo se da a conocer por los puntos de venta sino también en las diversas oficinas de diseñadores con prestigio en el país. 
Tabla $N^{\circ} 34$

Matriz Perfil Competitivo - MPC

\begin{tabular}{|c|c|c|c|c|c|c|c|c|}
\hline & \multirow[b]{2}{*}{ Factores Críticos de Éxito } & \multirow[b]{2}{*}{ Peso } & \multicolumn{2}{|c|}{ S F Hermanos } & \multicolumn{2}{|c|}{ Canziani } & \multicolumn{2}{|c|}{ Ferrini } \\
\hline & & & Calificación & $\begin{array}{c}\text { Peso } \\
\text { Ponderado }\end{array}$ & Calificación & $\begin{array}{c}\text { Peso } \\
\text { Ponderado }\end{array}$ & Calificación & Peso Ponderado \\
\hline 1 & Amplia línea de productos & 0.09 & 2 & 0.18 & 3 & 0.27 & 2 & 0.18 \\
\hline 2 & $\begin{array}{l}\text { Personal capacitado en el proceso } \\
\text { de producción }\end{array}$ & 0.09 & 3 & 0.27 & 4 & 0.36 & 3 & 0.27 \\
\hline 3 & Insumos de calidad & 0.12 & 3 & 0.36 & 3 & 0.36 & 3 & 0.36 \\
\hline 4 & Innovación en sus presentaciones & 0.12 & 2 & 0.24 & 3 & 0.36 & 4 & 0.48 \\
\hline 5 & Calidad del Producto & 0.15 & 3 & 0.45 & 3 & 0.45 & 3 & 0.45 \\
\hline 6 & $\begin{array}{c}\text { Conocimiento de los canales de } \\
\text { distribución }\end{array}$ & 0.10 & 2 & 0.20 & 4 & 0.40 & 3 & 0.30 \\
\hline 7 & $\begin{array}{c}\text { Poder de negociación de los } \\
\text { proveedores }\end{array}$ & 0.08 & 2 & 0.16 & 3 & 0.24 & 3 & 0.24 \\
\hline 8 & Precio & 0.15 & 3 & 0.45 & 2 & 0.30 & 2 & 0.30 \\
\hline 9 & Presencia en puntos de ventas & 0.10 & 2 & 0.20 & 4 & 0.40 & 3 & 0.30 \\
\hline
\end{tabular}

Nota: Elaboración propia. Los valores de calificación son los siguientes: 1 = debilidad importante, $2=$ debilidad menor, $3=$ fortaleza menor, 4 = fortaleza importante.

Interpretación: Se puede interpretar de la matriz MPC, donde se plantearon los factores críticos de éxito y los competidores directos, que Canziani logró un puntaje de 3.14 por lo tanto es el competidor con más fuerza en el sector. 


\section{Capítulo VI: Análisis Interno}

\subsection{Descripción de las actividades de la cadena de valor de la empresa}

Logística interna, Operaciones, Logística externa, Mercadotecnia, Servicios.

Adquisiciones, Recursos Humanos, Tecnología, Infraestructura. La cadena de valor es una gráfica que permite describir las actividades de una organización para generar valor al cliente final y a la empresa. Por eso se dice que una empresa tiene ventaja competitiva frente a otra si es capaz de aumentar el margen ya sea bajando costos o incrementando sus ventas. (Muñiz, 2016).

\subsubsection{Cadena de valor actual}

Teniendo en cuenta que SF Hermanos S.R.L.:

- Es una empresa de servicios de remodelación de interiores de casa y departamento.

- Es una empresa comercializadora.

- No va a tercerizar actividades estratégicas

Se tiene la siguiente cadena de valor. 


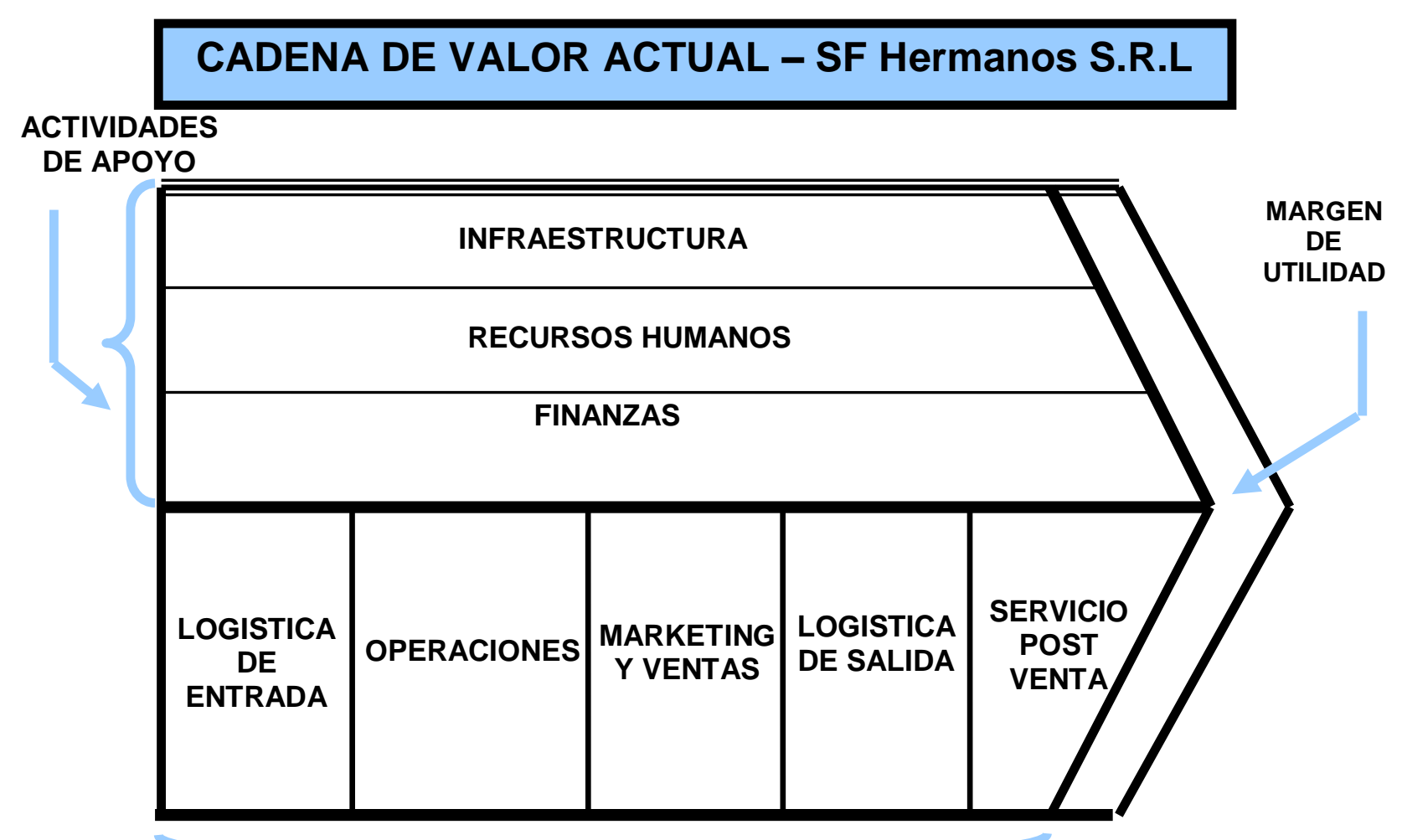

\section{ACTIVIDADES PRIMARIAS}

Figura $N^{\circ}$ 34. Cadena de valor actual - SF Hermanos S.R.L. Nota: Elaboración propia

\subsubsection{Actividades primarias}

\subsubsection{Logística entrada}

Son las actividades que realiza la empresa para desarrollarse en su entorno diario para dar inicio al proceso administrativo y productivo. Las actividades se inician con la llegada de los requerimientos de los materiales y suministros que solicita el área de producción para la elaboración del producto a desarrollar, donde se verifican las cantidades, precio, calidad, entre otras características. Se realiza la recepción de estos materiales y 
suministros, los cuales pasan a ser inspeccionados, con la respuesta de aceptación se procede a la distribución a cada área según sus requerimientos. Responsables:

El área de finanzas y logística.

Indicadores:

Movilidad de inventarios: Este indicador es el resultado de la división de los inventarios y el capital contable, en el cual se determina el valor del porcentaje de la inversión que es utilizada para la obtención de materiales y suministros.

$$
\% \text { Inversión }=\frac{\text { Total de inventarios }}{\text { Total Capital Contable }}
$$

Rotación de inventarios: Es importante para la empresa determinar cuánto es el tiempo y uso de cada material o suministro a utilizar, debido a que el área de producción depende del ingreso de estos para el desarrollo de cada uno de los pedidos realizados.

$$
\begin{aligned}
& \begin{array}{l}
\text { Rotación de } \\
\text { inventario }=
\end{array} \\
&
\end{aligned}
$$

\subsubsection{Operaciones}

Se realizan las actividades que corresponden a la fabricación del producto solicitado, primero se observan los planos, medidas, colores y diseños aprobados por el cliente, luego se procede a fabricar el producto 
solicitado, una vez verificado el stock de los materiales y suministros para elaborarlo. Luego de ser elaborado el producto, el área de control de calidad procede a revisarlo para comprobar si el producto cumple con los estándares requeridos por la empresa y el cliente, una vez aceptado por ellos se procede a programar la instalación o distribución del mismo.

Descripción del proceso del mueble (Melamine):

1. Recepción: En esta operación se reciben las copias de las órdenes de trabajo las cuales se optimizan para la siguiente operación que es el trazado, corte de tableros.

2. Trazado, corte de tableros: En esta operación se recibe del supervisor la optimización de los tableros para el trazado y corte para hacer el armado aquí se realiza una inspección para ver si los tableros están bien cortados de acuerdo a la optimización.

3. Armado de muebles: En esta operación se ensamblan las piezas de los muebles para la siguiente operación. El mueble pasa al lijado en el área correspondiente. El personal después de armar el mueble, debe retirar el pegamento sobrante de este, ya que este retrasa al lijado.

4. Instalación de accesorios: De acuerdo a la orden de trabajo se instalan los accesorios que necesite el mueble como correderas, bisagras cangrejo, etc. Luego se procede a la entrega del mueble e instalación. 
5. Embalaje de muebles: En esta operación se embalan los muebles con cuidado, para evitar quiñes, ralladuras, etc.

Se usa para realizar este proceso, los siguientes elementos:

a) Periódicos.

b) Strech films.

c) Espuma y/o cartón para asegurar los muebles.

d) Se embala el mueble si este ya está listo y terminado en su totalidad (seco la pintura).

6. Transporte: Se debe de considerar lo siguiente:

a) Ubicar los muebles en el carro, de acuerdo al tamaño del mueble.

b) Colocar los muebles entre frazadas, espumas para que no se quiñen entre ellos.

c) Debe tener el mueble una guía de remisión para su transporte.

d) Manejar despacio el carro.

7. Instalación: Bajar los muebles del carro con mucho cuidado evitando que se quiñen las esquinas, arañones u otros. Al cargar los muebles usar el ascensor, escaleras, etc. Instalar los muebles de acuerdo al plano, teniendo cuidado en no quiñar el acabado.

8. Retoque del mueble: Esta operación es opcional, solo se usa si se requiere armar en obra los muebles de acuerdo a la orden de trabajo y planos. El retoque del mueble para el caso de uniones lo debe realizar un 
carpintero con masilla y color, materiales que debe de llevar para toda instalación.

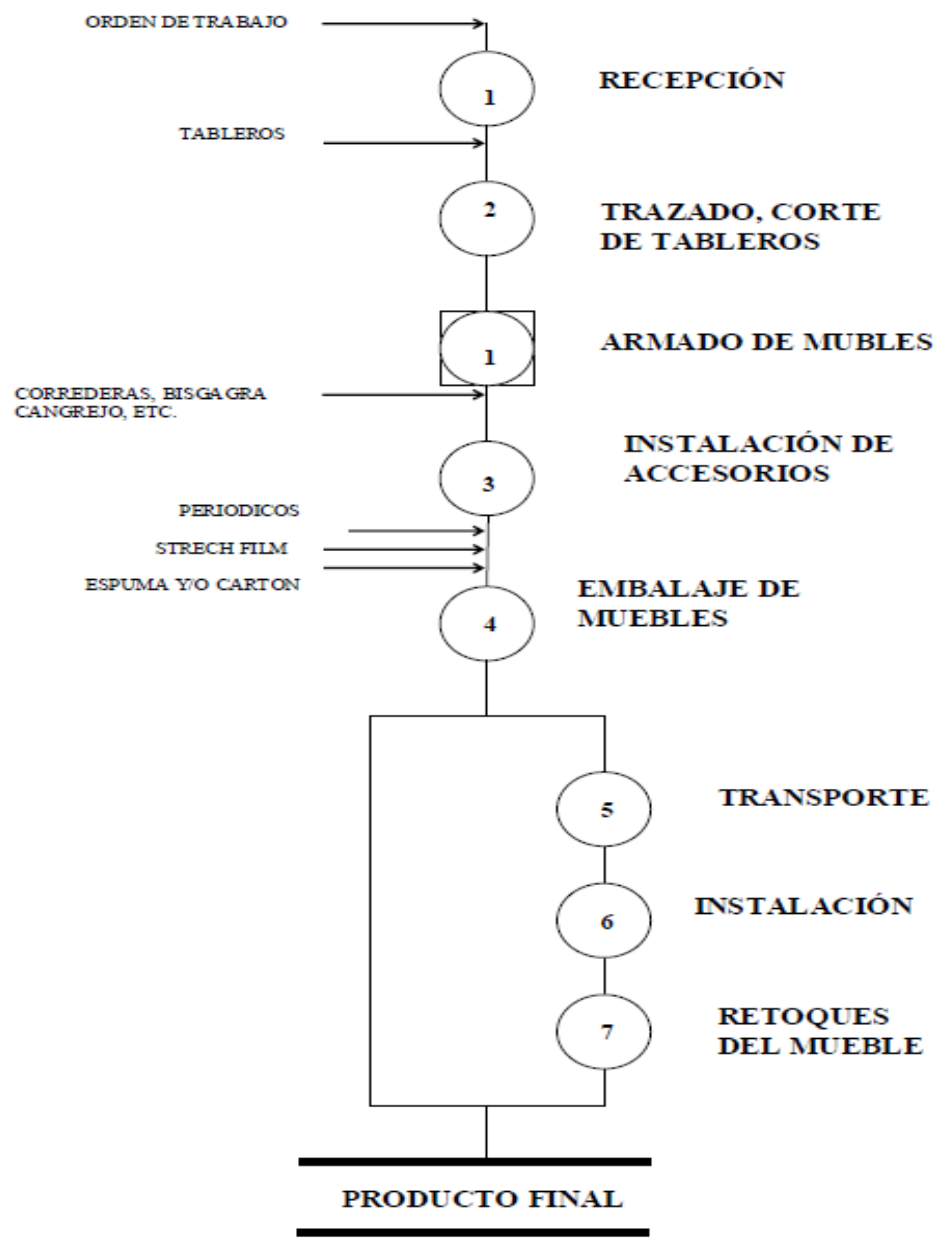

Figura $N^{\circ} 35$. DOP del mueble (Melamine). Nota: Elaboración propia

De la figura DOP del mueble (Melamine):

1. Recepción: En esta operación se reciben las copias de las órdenes de trabajo, las cuales se optimizan para la siguiente operación que es el trazado, corte de tableros. 
2. Trazado, corte de tableros: En esta operación se reciben del supervisor la optimización de los tableros para el trazado y corte para hacer el armado, aquí existe una inspección para ver si los tableros están bien cortados de acuerdo a la optimización.

3. Primer lijado de muebles: Después del enchape de los tableros, se procederá a realizar el primer lijado con una lijadora de banda antes de su armado. Las piezas del mueble, sobre todo las interiores, se deben de lijar utilizando lijas $\mathrm{N}^{\circ} 80,100$.

4. Armado de muebles: En esta operación se ensamblarán las piezas de los muebles para la siguiente operación. El mueble pasa al lijado en el área correspondiente. El personal después de armar el mueble, debe retirar el pegamento sobrante de este, ya que este retrasa al lijado.

5. Segundo lijado de muebles: En esta operación lo que se requiere es un perfecto lijado, el lijado que se hace no debe malograr el enchapado. Esta operación se realiza con el objetivo de que no queden astillas, imperfecciones en el mueble para la siguiente operación. Se utilizará lijas por pliego o lijas en banda de acuerdo al tipo de lijado que se requiera, puede ser a mano o automático. Se realizará una breve inspección para ver si no hay ninguna imperfección o falla en el mueble. 
De acuerdo a la orden de trabajo (mueble enchapado o pintado) se deberá realizar lo siguiente:

1. En el mueble de color oscuro; se usará lija de 80 como primer paso y luego perfeccionar los filos de los muebles con lija fina 220.

2. En los muebles que no llevan color (naturales) utilizar la lija $\mathrm{N}^{\mathrm{o}} 80 \mathrm{y}$ pulir con lija fina de acuerdo a la textura.

3. Lija de banda $\mathrm{N}^{\circ} 60$ y 80 para madera rígida (pumaquiro, huayiuro, tornillo, capirona).

a. Caoba, cedro y palisandro: lija 220

b. Pumaquiro, congona, picus: lijas 120,180

6. Aplicación de parafínico /laca a la piroxilina

a) Aplicación de parafínico (brocha o soplete)

Con brocha; piezas o muebles pequeños, en interiores.

Con soplete: superficies grandes, calculando el secado del parafínico.

Aproximadamente $3 / 8 \mathrm{Gl}$. deparafínico cubre $1 \mathrm{~m}^{2}$ en tres manos. Se aplica el parafínico la primera mano en forma proporcional. Se debe esperar que la superficie con parafínico este en estado coloidal (gelatinoso) para la aplicación de la segunda mano. Y de la misma forma la tercera mano. 
Mueble al duco: Se debe de aplicar el parafínico igual al proceso del mueble enchapado, no masillar las tapas de los tornillos, aplicar directamente el parafínico en esas áreas.

7. Tercer lijado de muebles: En esta operación se debe realizar el lijado para que el mueble quede liso y no contenga imperfecciones para el acabado final. Se hace una breve inspección. En esta etapa se deben utilizar las lijas finas 120, 180,220 y 360 de acuerdo a la superficie. Verificar la perfección de la superficie (no olas) principalmente en las partes exteriores del mueble: frentes, cajas, puertas, tableros de mesas, etc.

Corregir con un taco de madera el pulido de las superficies externas, el lijado se debe realizar utilizando amoladora, vibrador de acuerdo a la superficie. La amoladora se utiliza en las superficies amplias y el vibrador en superficies pequeñas como cajones, interiores, etc. Se procede a lijar hasta llegar casi al pulido, se puede usar lijas circulares N. ${ }^{\circ} 120,180,220$.

8. Instalación de accesorios: De acuerdo a la orden de trabajo se deben de instalar los accesorios que necesite el mueble como correderas, bisagras cangrejo, etc. Luego se procederá a la entrega del mueble e instalación. 
9. Acabado de muebles: Se debe verificar el tercer lijado libre de olas, masillar imperfecciones, pincelar los filos, cantos blancos. Se dará el tono del color al mueble ya sea brillante, mate o satinado de acuerdo a orden de trabajo y muestra.

El acabado se debe realizar de la siguiente manera:

- Preparación de laca con thinner extra acrílico.

- Aplicación de una mano de laca o pintura.

- $\quad$ Lijado de áreas, con lija fina 360.

- Verificación de la uniformidad de color y aplicación de tinte si es necesario.

- Aplicación de la segunda mano de laca o pintura, para sellar el tinte, masilla y/o pincelada.

- $\quad$ Lijado con lija $\mathrm{N}^{\circ} 600$.

- Aplicación de la tercera mano de laca o pintura, lijado del mueble enchapado con lija fina $\mathrm{N}^{\mathrm{o}} 1000$, en caso de acabado acrílico se usa lija No 2000 .

- Pulir el acabado acrílico con pulidor grueso y fino.

10. Embalaje de muebles: En esta operación se embalan los muebles con cuidado, para evitar quiñes, ralladuras, etc. Se usa:
a) Periódicos
b) Strech films
c) Espuma y/o cartón para asegurar los muebles. 
Se embala el mueble si está terminado en su totalidad (secó la pintura al $100 \%)$.

\section{Transporte}

a) Ubicar los muebles en el carro, de acuerdo al tamaño del mueble.

b) Colocar los muebles entre frazadas, espumas para evitar que se dañen entre ellos.

c) El mueble debe de poseer la guía de remisión para su transporte.

d) Manejar despacio el carro.

12. Instalación

a) Bajar los muebles del carro con mucho cuidado evitando que se dañen las esquinas, arañones u otros.

b) Al cargar los muebles se debe usar el ascensor, escaleras, etc. (deben ser cargados con mucho cuidado)

c) Instalar los muebles de acuerdo al plano, teniendo cuidado en no dañar el acabado.

\section{Retoque del mueble}

a) Esta operación es opcional es decir solo se realiza cuando se requiere armar en obra los muebles de acuerdo a la orden de trabajo y planos. 
b) El retoque del mueble en caso de uniones debe ser realizado por el carpintero con masilla y color, materiales que debe de llevar para toda instalación.

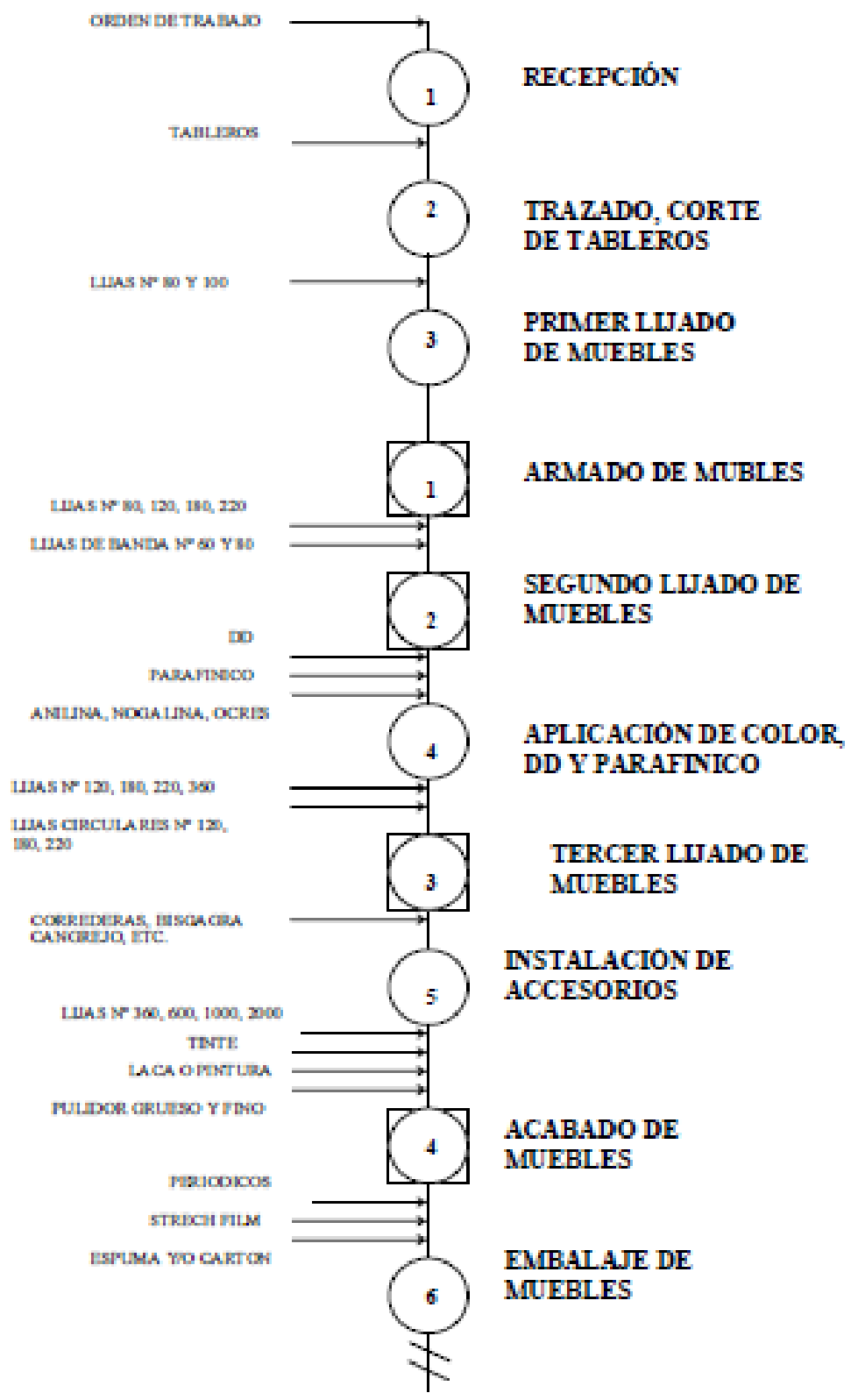

Figura $N^{\circ} 36$ DOP del mueble. Nota: Elaboración propia 


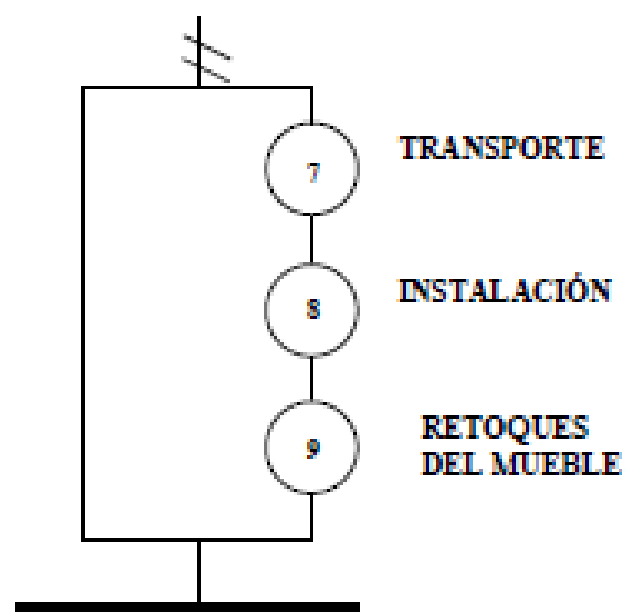

PRODUCTO FINAL

Figura $N^{\circ} 37$ DOP del mueble - producto final. Nota: Elaboración Propia

Responsables:

Área de producción y el área de administración

Indicadores:

Productividad de mano de obra: Cada operación debe tener la medición adecuada en el cual se van a medir las horas de trabajo frente a los productos fabricados en el día.

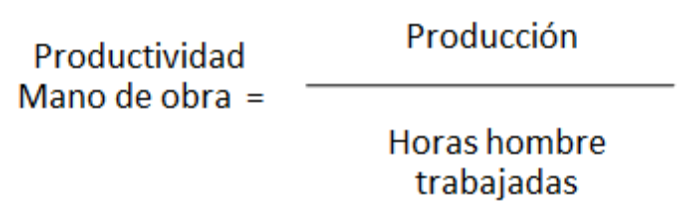

Indicador de mantenimiento: En este caso las maquinarias y equipos deben de pasar un mantenimiento continuo para que en la parte productiva no presente tiempos muertos y retrasos de entrega de productos terminados. 


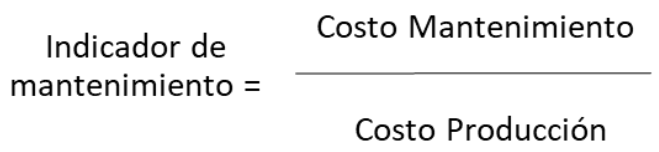

\subsubsection{Logística Salida}

Se procederán a realizar las actividades de almacenamiento, programación y procedimiento de entrega de pedido y distribución de estos. Responsables:

Área de finanzas y logística, Área de producción, Área de ventas.

Indicadores:

Movilidad de Inventarios de productos terminados: Este indicador es muy importante debido que se necesita tener conocimiento de la proporción que pertenece al capital contable, debido a que no debe haber inventarios en almacén por que generan gastos en la empresa.

Costo de unidad despachada: Es importante conocer el costo de cada producto a enviar, debido a que el transporte tiene gastos y costos que se deben cubrir, esto generará que la programación deba ser la adecuada para que este costo no se eleve.

Costo de transportes vs ventas: Este indicador es esencial debido a que el costo de las ventas depende mucho del costo de transporte, si este es 
usado de manera incorrecta ocasionará que el margen obtenido por la empresa se disminuya, hasta puede ocasionar pérdidas.

\subsubsection{Marketing y Ventas}

Actividades que facilitan la compra por parte del cliente y su identificación con el producto y con la marca. La empresa promociona sus productos mediante la red social Facebook y la herramienta Google Adwords, la cual es manejada por campañas. Las ventas se realizan en negociaciones directas con el cliente, o acuerdos telefónicos.

\section{Responsables:}

Área de ventas y área de administración.

Indicadores:

Rentabilidad por producto: Es esencial saber que productos son rentables para su comercialización y promoción, lo cual se ve reflejado en las ventas totales sobre las ventas de cada línea de producto, determinando que línea de productos es en la que conviene invertir generando beneficios para la empresa.

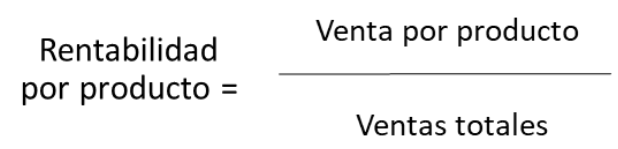

Índice de comercialidad: Está definido por el número de ventas realizadas frente a los otros productos que tiene la empresa, indica que es lo que es más solicitado, pero eso no indica que el producto sea rentable. 
Eficacia: Capacidad para producir el efecto deseado o de ir bien para un determinado producto.

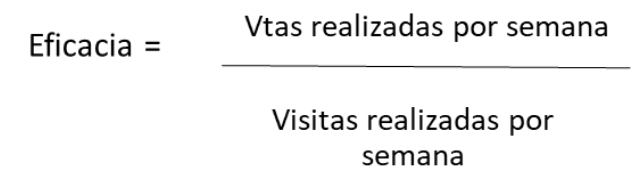

Productividad: Este índice nos indica en cuanto tiempo realizan el producto solicitado.

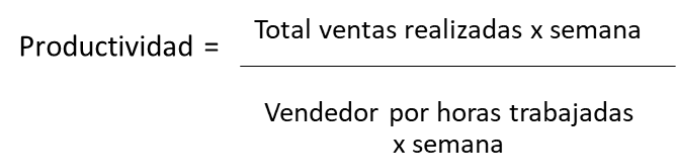

\subsubsection{Servicio post venta}

Realizan el seguimiento de las ventas realizadas consultando al cliente si tiene algún reclamo, observación o sugerencia a realizar.

Responsables:

Área de ventas y área de producción.

Indicadores:

Nivel de calidad: La calidad en cada área de la empresa es esencial, por lo cual es el área post venta la que recibe todas las quejas, devoluciones, comentarios o sugerencia de los clientes, los cuales son categorizados para determinar la calidad del servicio del producto que se está ofreciendo. 
Número de quejas: Es el número de inconformidades que tiene la empresa por el producto elaborado.

Número de devoluciones: Es el número de reprocesos que tiene la empresa por cada producto que no satisface la necesidad del cliente.

\subsection{Indicadores de cada una de las actividades de la cadena de valor}

Los indicadores de cada una de las actividades de la cadena de valor dependen de las necesidades de los clientes, las cuales han sido satisfechas o no en su momento, por lo cual se desarrollan ciertos criterios que nos ayudarán a identificar cuáles son los esenciales para la empresa (David, 2013).

Proceso de Innovacion

\begin{tabular}{|c|}
\hline Las \\
necesidades \\
del cliente \\
han sido \\
identificadas
\end{tabular}

Proceso Operativo

$\begin{array}{cc}\text { Construcción } & \begin{array}{c}\text { Entrega } \\ \text { de los } \\ \text { de los }\end{array} \\ \text { productos } & \text { producto } \\ \text { /servicios } & \text { s/ } \\ & \text { servicios }\end{array}$

Proceso de servicios de post-venta

\begin{tabular}{c|c|}
\cline { 2 - 2 } $\begin{array}{c}\text { Servicio al } \\
\text { cliente } \\
\text { (Mantenimie }\end{array}$ & $\begin{array}{c}\text { Las } \\
\text { necesidades } \\
\text { del cliente } \\
\text { to) }\end{array}$ \\
están \\
satisfechas
\end{tabular}

Figura $N^{\circ} 38$ Identificación de necesidades del cliente. Nota: Elaboración Propia

Estos son los criterios a tomarse en consideración para obtener los indicadores deseados:

Cliente: Satisfacer las necesidades del cliente en forma directa o indirecta y su fidelización con la institución. 
Accionistas o directores: Los accionistas buscan obtener un retorno sostenible de su inversión e imagen del banco, su fin no es obtener el máximo beneficio a corto plazo.

Procesos: Contar con un proceso eficaz y eficientemente óptimo capaz de actualizar e implementar con reducción de tiempo y costos. Producir las características distintivas del producto.

Proveedores: Responsabilidad para asegurar la calidad de la relación con los proveedores, para obtener la puntualidad y que la entrega de los productos sea de calidad y a precios competitivos.

Recursos Humanos: Invertir considerables recursos en la capacitación del personal comprometido con la institución, para crear una motivación. Ambiente de trabajo agradable. 
Tabla $\mathrm{N}^{\circ} 35$

Indicadores de cada una de las actividades de la cadena de valor

\begin{tabular}{|c|c|c|}
\hline Área & Indicador & Índices \\
\hline \multirow{4}{*}{$\begin{array}{l}\text { Logística de } \\
\text { Entrada }\end{array}$} & Movilidad de inventarios & Inventarios \\
\hline & 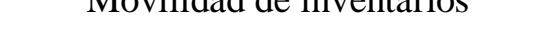 & Capital contable \\
\hline & Rotación de inventarios & $\begin{array}{l}\text { Materia prima empleada en el mes } \\
\text { Inventario de materia prima }\end{array}$ \\
\hline & $\begin{array}{l}\text { Movilidad de inventarios productos } \\
\text { terminados }\end{array}$ & $\begin{array}{l}\text { Inventario productos terminados } \\
\text { Capital contable }\end{array}$ \\
\hline \multirow{4}{*}{ Logística de Salida } & Costo de unidad desnachada & Costo de Bodega \\
\hline & costo ue unnau uespacriana & Total de unidades despachadas \\
\hline & Costo de transporte vs Ventas & $\begin{array}{l}\text { Costo de transporte Total x } 100 \\
\text { Ventas }\end{array}$ \\
\hline & Productividad de mano de obra & $\begin{array}{l}\text { Producción } \\
\text { Horas Hombre trabajadas }\end{array}$ \\
\hline \multirow[t]{4}{*}{ Operaciones } & Indicador de mantenimiento & $\begin{array}{l}\text { Costo de mantenimiento } \\
\text { Costo de producción }\end{array}$ \\
\hline & Ausentismo & Horas hombre ausentes \\
\hline & AUSEIIISIIIO & Horas Hombre trabajadas \\
\hline & Importancia de salarios & $\begin{array}{l}\text { Total de salarios pagados } \\
\text { Costo de producción }\end{array}$ \\
\hline \multirow{4}{*}{$\begin{array}{l}\text { Recursos } \\
\text { Humanos }\end{array}$} & Indicador de rotación de trabajador & Total de trabajadores retirados \\
\hline & IIU⿴囗十⺝ & Número promedio de trabajadores \\
\hline & Indicador ventas-trabajador & $\begin{array}{l}\text { Ventas totales } \\
\text { Número promedio de trabajadores }\end{array}$ \\
\hline & Rentabilidad por producto & $\begin{array}{c}\text { Margen } \\
\text { Total de ventas }\end{array}$ \\
\hline \multirow{4}{*}{$\begin{array}{l}\text { Marketing y } \\
\text { ventas }\end{array}$} & Índice de comercialidad & $\begin{array}{l}\text { Venta producto } \\
\text { Ventas totales }\end{array}$ \\
\hline & Eficacia & $\begin{array}{c}\text { Ventas realizadas por semana } \times 100 \\
\text { Visitas realizadas por semana }\end{array}$ \\
\hline & Productividad & $\begin{array}{l}\text { Total de ventas realizada por semanas } \\
\text { Vendedor por horas trabajadas por semana }\end{array}$ \\
\hline & Nivel de calidad & $\begin{array}{l}\text { Total de productos sin defectos } \\
\text { Total de productos elaborados }\end{array}$ \\
\hline $\begin{array}{l}\text { Seguimiento } \\
\text { Postventa }\end{array}$ & Número de Quejas & \\
\hline
\end{tabular}

Número de Devoluciones

Nota: Elaboración propia 


\subsection{Benchmarking y comparación con los líderes de la industria de cada una de las actividades de la cadena de valor}

Benchmarking es la técnica de mejora continua que busca las mejores prácticas que se realizan dentro y fuera de la empresa (Casadesús, 2005).

Se hace la comparación frente a sus competidores lo cual implica aprender de lo que está haciendo otro y entonces adaptar sus propias prácticas, mejorarlas y buscar la innovación de estos.

Tabla $\mathrm{N}^{\circ} 36$

Indicadores para logística de entrada y salida

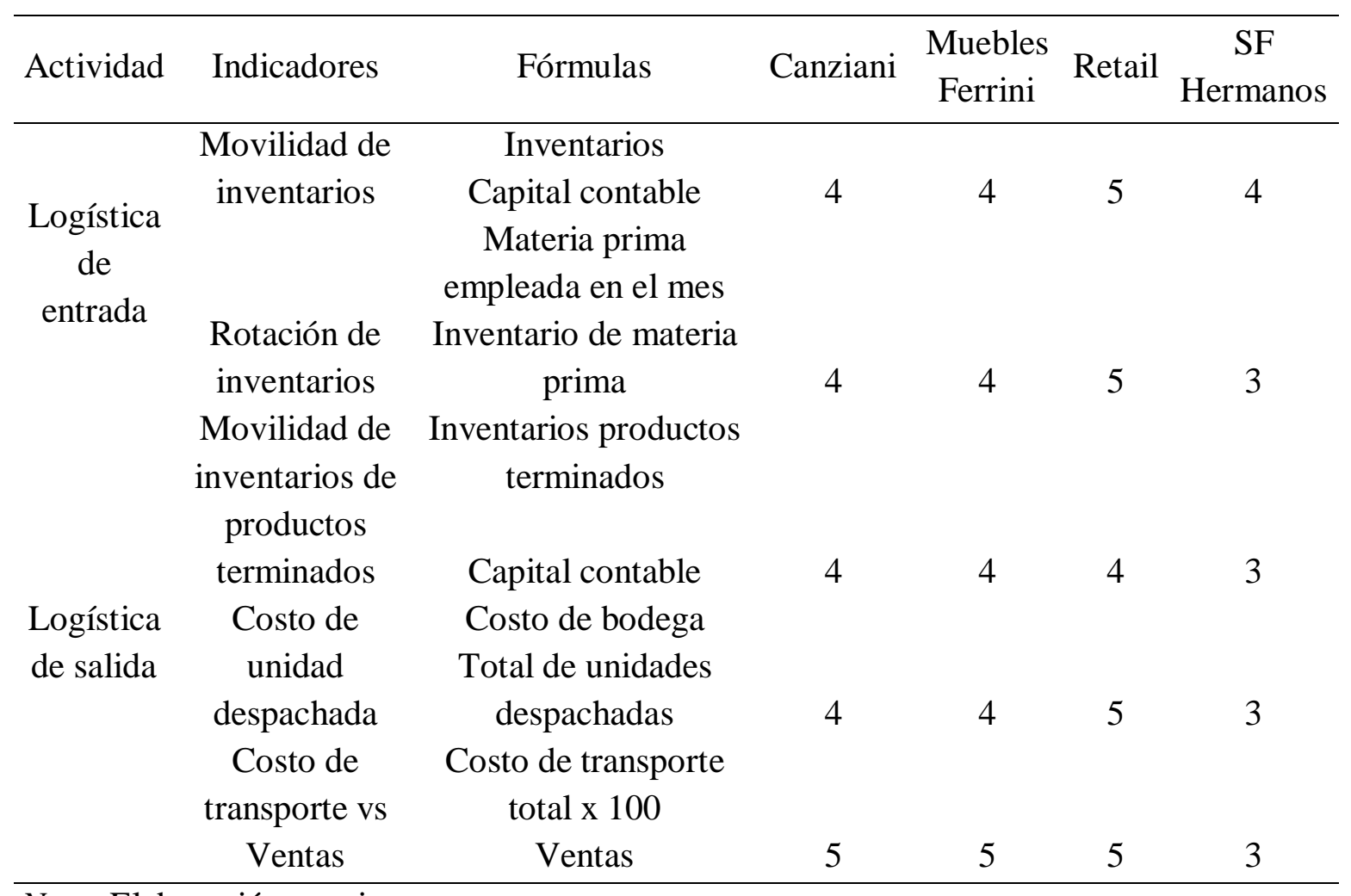

Nota: Elaboración propia 
Tabla $\mathrm{N}^{\circ} 37$

Indicadores para operaciones y recursos humanos

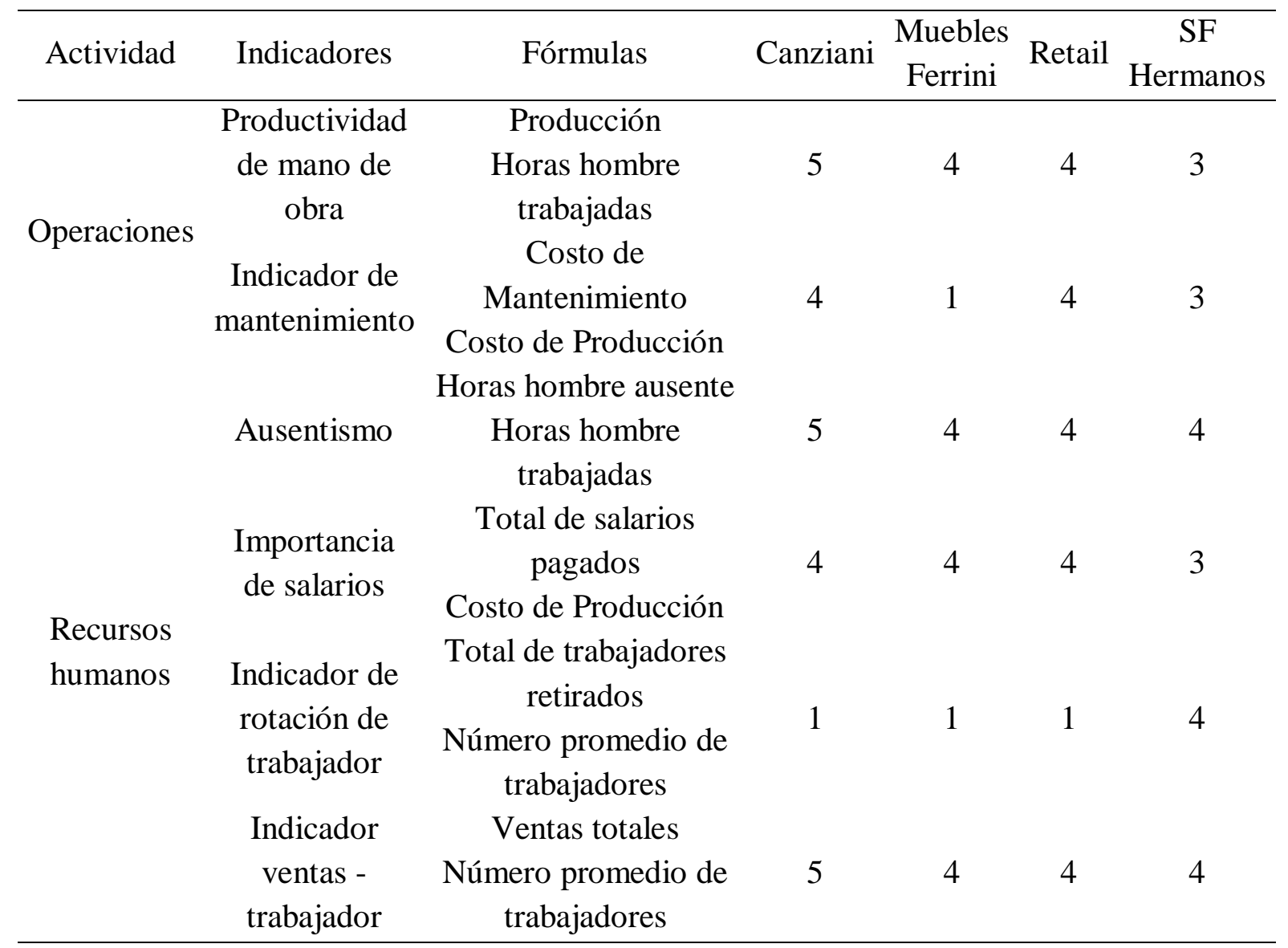

Nota: Elaboración propia 
Tabla $\mathrm{N}^{\circ} 38$

Indicadores para logística de marketing y post venta

\begin{tabular}{|c|c|c|c|c|c|c|}
\hline Actividad & Indicadores & Fórmulas & Canziani & $\begin{array}{l}\text { Muebles } \\
\text { Ferrini }\end{array}$ & Retail & $\begin{array}{c}\text { SF } \\
\text { Hermanos }\end{array}$ \\
\hline \multirow{4}{*}{$\begin{array}{c}\text { Marketing y } \\
\text { ventas }\end{array}$} & $\begin{array}{l}\text { Rentabilidad } \\
\text { por producto }\end{array}$ & $\begin{array}{c}\text { Margen } \\
\text { Total de ventas }\end{array}$ & 5 & 4 & 5 & 4 \\
\hline & $\begin{array}{c}\text { Índice de } \\
\text { comercialidad }\end{array}$ & $\begin{array}{l}\text { Venta producto } \\
\text { Ventas totales }\end{array}$ & 4 & 4 & 4 & 4 \\
\hline & Eficacia & $\begin{array}{l}\text { Ventas realizadas } \\
\text { por semana x } 100 \\
\text { Visitas realizadas } \\
\text { por semana }\end{array}$ & 5 & 4 & 1 & 3 \\
\hline & Productividad & $\begin{array}{l}\text { Total de ventas } \\
\text { realizadas por } \\
\text { semanas } \\
\text { Vendedor por } \\
\text { hora trabajadas } \\
\text { por semana }\end{array}$ & 4 & 4 & 4 & 3 \\
\hline \multirow{3}{*}{$\begin{array}{l}\text { Seguimiento post } \\
\text { venta }\end{array}$} & $\begin{array}{l}\text { Nivel de } \\
\text { calidad }\end{array}$ & $\begin{array}{l}\text { Total de } \\
\text { productos sin } \\
\text { defectos } \\
\text { Número } \\
\text { promedio de } \\
\text { trabajadores }\end{array}$ & 5 & 4 & 3 & 4 \\
\hline & $\begin{array}{l}\text { Número de } \\
\text { quejas }\end{array}$ & & 5 & 4 & 3 & 4 \\
\hline & $\begin{array}{c}\text { Número de } \\
\text { devoluciones }\end{array}$ & & 1 & 1 & 1 & 4 \\
\hline
\end{tabular}

Nota: Elaboración propia 
A continuación, los criterios para la determinación del puntaje de los criterios:

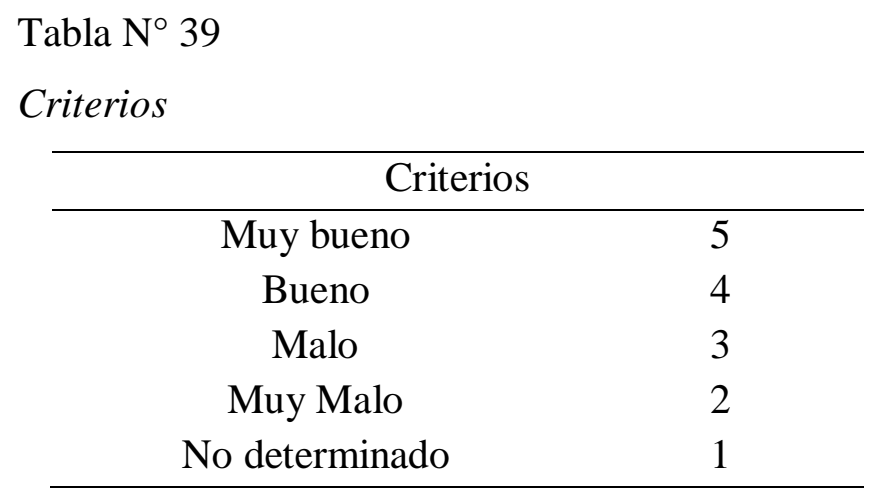

Nota: Elaboración propia

En conclusión, la empresa Canziani es el principal competidor para SF Hermanos, lo cual está determinado por la suma de puntaje de cada indicador de las actividades o proceso de cada una de las empresas competidoras.

Se puede observar que las empresas en rubro de retail se encuentran en el segundo lugar, con calificaciones altas en sus actividades o procesos, pero la calidad del producto es esencial para el sector que estamos dirigidos, a consecuencia de que su público objetivo son del sector b y c, que son productos de baja calidad. Por lo tanto, presenta un nivel de quejas altos sobre estos productos por su menor duración y garantía.

\subsection{Determinar las competencias de la empresa}

Para determinar las competencias de la empresa se toma como referencia el análisis VRIO el cual evalúa los recursos que tiene esta, lo cual la hace diferente frente a las empresas competidoras, en consecuencia, logra el éxito de la estrategia elegida. 
Cada recurso que aporte una ventaja competitiva para la empresa será llamado “recurso VRIO”. Entonces las condiciones que debe cumplir un recurso para ser VRIO serán las siguientes:

1. Valiosos: Permiten nuevas oportunidades en el mercado.

2. Raros, únicos o escasos: Específicos de la empresa, difícil de comprar / obtener en el mercado.

3. Inimitables: Difíciles de copiar por la competencia.

4. Inmersos en la organización de la empresa: Se complementan con otros recursos.

Abreviaremos cada una de estas definiciones en la siguiente tabla:

Tabla $\mathrm{N}^{\circ} 40$

Leyenda de cada recurso VRIO

\begin{tabular}{cc}
\hline & Leyenda \\
\hline $\mathrm{V}$ & Valor \\
$\mathrm{R}$ & Raro \\
$\mathrm{I}$ & Inimitable \\
$\mathrm{O}$ & Organización \\
\hline
\end{tabular}

Nota: “Análisis VRIO y la ventaja competitiva”,2016

Con esta información se realizó el análisis para cada recurso de la empresa con el modelo VRIO:

\section{Recursos tangibles}

Son los recursos más fáciles de identificar en la empresa, porque se pueden ver, se pueden tocar, se pueden valorar. Se distinguen dos tipos: financieros y físicos. 
Tabla $\mathrm{N}^{\circ} 41$

Competencia de la empresa SF hermanos: "Recursos Tangibles"

\begin{tabular}{ccccc}
\hline Recursos Tangibles & $\mathrm{V}$ & $\mathrm{R}$ & $\mathrm{I}$ & $\mathrm{O}$ \\
\hline Financieros & & & & \\
Recursos financieros propios & SI & NO & NO & SI \\
Físicos & SI & NO & NO & SI \\
Capacidad para obtener financiamiento & & & & \\
Equipos e instalaciones modernas & NO & NO & NO & NO \\
Ubicación privilegiada & NO & NO & NO & NO \\
Proceso de producción innovador & SI & NO & NO & SI \\
Patentes, derechos de autor, marcas & NO & NO & NO & NO \\
registradas & NO & NO & NO & NO \\
Sistemas de control de calidad & N
\end{tabular}
Nota: Análisis VRIO y la ventaja competitiva, 2016

Los recursos tangibles de la empresa no presentan aportes esenciales de diferenciación lo cual beneficien a la empresa. No cuentan con la tecnología adecuada y ubicación privilegiada, presentando una gran desventaja frente a los competidores de la empresa, además no haber patentado los productos que realizan ni presentar una marca definida por ellos.

El control de calidad lo realiza el jefe de producción bajo los criterios básicos y necesidades de los clientes a consecuencia de esto, los clientes realizan sus quejas por medio telefónico o por email, realizando la empresa un reproceso, tomando las acciones correctivas y preventivas correspondientes. Podemos resaltar como competencia, el proceso de producción innovador, debido a que la empresa elabora productos según la necesidad del cliente o diseño, siendo productos personalizados y diferenciados frente a otros, por lo 
general son productos que se desarrollan con menor frecuencia frente a los productos comerciales.

\section{Recursos intangibles}

Son muy importantes para las empresas en la actualidad, de hecho, muchas empresas se benefician más de sus recursos intangibles que de los tangibles. Estos recursos no aparecen en los estados contables de la empresa y no es fácil valorarlos.

Tabla $\mathrm{N}^{\circ} 42$

Competencia de la empresa SF hermanos: "Recursos Intangibles"

\begin{tabular}{ccccc}
\hline Recursos Intangibles & V & R & I & O \\
\hline Experiencia en el rubro & & & & \\
Capacidades de sus trabajadores & SI & NO & NO & SI \\
Motivación de tú equipo de trabajo & SI & NO & NO & SI \\
Habilidades gerenciales & SI & NO & NO & SI \\
Procedimientos propios & NO & NO & NO & NO \\
Habilidades técnicas & SI & SI & SI & NO \\
Capacidad de innovación & SI & SI & SI & SI \\
Marca reconocida & SI & NO & SI & SI \\
Buena reputación con los clientes & NO & NO & NO & NO \\
Confianza de proveedores & SI & NO & SI & SI \\
\hline
\end{tabular}

Nota: Análisis VRIO y la ventaja competitiva, 2016

A diferencia del análisis anterior realizado, los recursos intangibles presentan mayores recursos VRIO los cuales traen ventajas competitivas a la empresa, pero todavía existen algunos puntos por mejorar como las habilidades gerenciales y marca reconocida. Según las entrevistas desarrolladas al personal de la empresa determina que la gerencia presenta dificultades al designar funciones, en comprometer al personal en el trabajo diario, y analizar 
los problemas esenciales que tiene la empresa. En el caso de marca reconocida, la empresa no ha desarrollado una marca en especial para los productos que elaboran, trabajan con el logo y el nombre de la empresa para la venta de cada uno de ellos, generando confusión en sus clientes.

Frente a todo lo mencionado anteriormente la empresa tiene la competencia en sus habilidades técnicas, las cuales la diferencian de otras empresas debido a que tienen el know how de cómo solucionar ciertos problemas o requerimientos que necesita el cliente, lo cual es un punto muy esencial para mantener fidelizado al cliente.

\section{Capacidades}

Son aquellos factores que no se miden, pero son de suma importancia debido al gran aporte económico que trae a la empresa.

\section{Tabla $\mathrm{N}^{\circ} 43$}

Competencia de la empresa SF hermanos: "Capacidades"

\begin{tabular}{ccccc}
\hline Capacidades & V & R & I & O \\
\hline $\begin{array}{c}\text { Servicio al cliente } \\
\begin{array}{c}\text { Desarrollo de productos y servicios de } \\
\text { manera eficiente }\end{array}\end{array}$ & NO & NO & NO & SI \\
$\begin{array}{c}\text { Innovación en productos y servicios } \\
\text { Habilidad para contratar, motivar y retener } \\
\text { a tú equipo de trabajo }\end{array}$ & SI & NO & NO & SI \\
& NO & NO & NO & NO
\end{tabular}

Nota: Análisis VRIO y la ventaja competitiva, 2016

En esta tabla se observa que la competencia se da en el servicio al cliente e innovación en productos y servicios, pues la atención al cliente es un proceso principal que debe tener la empresa para captar y mantener a sus clientes, además de la innovación que fue mencionada 
anteriormente, la empresa desarrolla productos según lo requerido por cada uno de ellos, los cuales no son frecuentes, pero dan un plus adicional a la empresa. Por otro lado, la habilidad para contratar, motivar y retener al equipo de trabajo es una desventaja que tiene la empresa debido a que presentan falta de habilidades gerenciales, por lo cual el flujo de comunicación de trabajo se ve interrumpido en consecuencia presenta inconformidades en los procesos y actividades que desarrolla la empresa.

\subsection{Identificación y determinación de las ventajas competitivas de la empresa}

Las ventajas competitivas son las actividades y procesos especializados que realiza la empresa en comparación con empresas rivales (David, 2013).

Por lo tanto, la diferenciación es la clave para asegurar la venta de los productos elaborados por la empresa.

Primero se define la leyenda siguiente:

Tabla $\mathrm{N}^{\circ} 44$

Leyenda de clasificación de ventaja competitiva

\begin{tabular}{cc}
\hline & Leyenda \\
\hline VCS & Ventaja competitiva sostenible \\
VCT & Ventaja competitiva temporal \\
PC & Paridad competitiva \\
DC & Desventaja competitiva \\
\hline
\end{tabular}

Nota: Elaboración propia

1. Ventaja competitiva sostenible: Es aquella que ha perdurado por un espacio de tiempo suficientemente largo.

2. Ventaja competitiva temporal: Es aquella que se presenta en un periodo corto. 
3. Paridad competitiva: Es aquella que es común entre empresa y sus competidores.

4. Desventaja competitiva: Es aquella que no presenta un beneficio a la empresa.

Segundo, se analiza cada recurso que tiene la empresa, así como identificar la ventaja comparativa de cada uno de ellos y en qué fase se encuentra.

\section{Recursos Tangibles}

Tabla $\mathrm{N}^{\circ} 45$

Identificación de ventaja competitiva: "Recursos Tangibles"

\begin{tabular}{|c|c|c|c|c|c|}
\hline Recursos Tangibles & $\mathrm{V}$ & $\mathrm{R}$ & I & $\mathrm{O}$ & $\begin{array}{l}\text { Implicancia } \\
\text { competitiva }\end{array}$ \\
\hline \multicolumn{6}{|l|}{ Financieros } \\
\hline Recursos financieros propios & SI & NO & NO & SI & $\mathrm{PC}$ \\
\hline $\begin{array}{l}\text { Capacidad de obtener } \\
\text { financiamiento }\end{array}$ & SI & NO & $\mathrm{NO}$ & SI & $\mathrm{PC}$ \\
\hline \multicolumn{6}{|l|}{ Físico } \\
\hline $\begin{array}{l}\text { Equipos e instalaciones } \\
\text { modernas }\end{array}$ & NO & NO & NO & NO & DC \\
\hline Ubicación privilegiada & NO & NO & NO & NO & DC \\
\hline $\begin{array}{l}\text { Proceso de producción } \\
\text { innovador }\end{array}$ & SI & NO & $\mathrm{NO}$ & SI & VCT \\
\hline $\begin{array}{c}\text { Patentes, derechos de autor, } \\
\text { marcas registradas }\end{array}$ & NO & $\mathrm{NO}$ & $\mathrm{NO}$ & NO & $\mathrm{DC}$ \\
\hline $\begin{array}{l}\text { Sistemas de control de } \\
\text { calidad }\end{array}$ & NO & NO & NO & NO & DC \\
\hline
\end{tabular}

Nota: “Análisis VRIO y la ventaja competitiva",2016

En esta tabla se muestra que la ventaja competitiva que presenta la empresa es el proceso de producción innovador, pero este viene a ser temporal debido a que estos procesos han sido copiados por las empresas competidoras. 
Además, presentan paridad competitiva y desventaja competitiva lo cual se pueden rescatar empleando las estrategias adecuadas y acciones correctivas que debe tomar la empresa para que estas se vuelvan la fortaleza de la empresa a consecuencia obtener mayor beneficio económico.

\section{Recursos Intangibles}

Tabla $\mathrm{N}^{\circ} 46$

Identificación de ventaja competitiva: "Recursos Intangibles"

\begin{tabular}{|c|c|c|c|c|c|}
\hline \multirow[t]{2}{*}{ Recursos Intangibles } & $\mathrm{V}$ & $\mathrm{R}$ & $\mathrm{I}$ & $\mathrm{O}$ & \multirow{2}{*}{$\begin{array}{l}\text { Implicancia } \\
\text { competitiva }\end{array}$} \\
\hline & & & & & \\
\hline Experiencia en el rubro & SI & NO & NO & SI & $\mathrm{PC}$ \\
\hline $\begin{array}{l}\text { Capacidades de sus } \\
\text { trabajadores }\end{array}$ & SI & $\mathrm{NO}$ & $\mathrm{NO}$ & SI & VCT \\
\hline $\begin{array}{l}\text { Motivación de tú equipo de } \\
\text { trabajo }\end{array}$ & SI & $\mathrm{NO}$ & $\mathrm{NO}$ & SI & PC \\
\hline Habilidades gerenciales & NO & $\mathrm{NO}$ & NO & NO & $\mathrm{DC}$ \\
\hline Procedimientos propios & SI & SI & SI & NO & VCT \\
\hline Habilidades técnicas & SI & SI & SI & SI & VCS \\
\hline Capacidad de innovación & SI & NO & SI & SI & VCT \\
\hline Marcas reconocidas & NO & NO & NO & NO & $\mathrm{DC}$ \\
\hline $\begin{array}{l}\text { Buena reputación con los } \\
\text { clientes }\end{array}$ & SI & NO & SI & SI & VCT \\
\hline Confianza de proveedores & SI & $\mathrm{NO}$ & NO & SI & VCT \\
\hline
\end{tabular}

Nota: Análisis VRIO y la ventaja competitiva",2016

Se aprecia que la empresa presenta ventaja competitiva sostenible en sus habilidades técnicas, lo cual representa el know how de ellos. Desarrollan técnicas las cuales son raras y difíciles de imitar a la hora de elaborar un producto a diseño o personalizado.

También se nota que las ventajas competitivas temporales son esenciales para la empresa obteniendo mayor soporte frente a cualquier competidor del entorno, estas ventajas 
son: capacidad de sus trabajadores, procedimientos propios, capacidad e innovación, buena reputación con los clientes y confianza con los proveedores.

\section{Capacidades}

Tabla $\mathrm{N}^{\circ} 47$

Identificación de ventaja competitiva: "Capacidades"

\begin{tabular}{|c|c|c|c|c|}
\hline Capacidades & $\mathrm{V}$ & $\mathrm{I}$ & $\mathrm{O}$ & $\begin{array}{l}\text { Implicancia } \\
\text { competitiva }\end{array}$ \\
\hline Servicio al cliente & SI NO & $\mathrm{NO}$ & SI & VCT \\
\hline $\begin{array}{l}\text { Desarrollo de productos y servicios } \\
\text { de manera eficiente }\end{array}$ & NO NO & NO & SI & VCT \\
\hline Innovación en productos y servicios & SI NO & $\mathrm{NO}$ & SI & VCT \\
\hline $\begin{array}{l}\text { Habilidad para contratar, motivar y } \\
\text { retener a tú equipo de trabajo }\end{array}$ & NO NO & $\mathrm{NO}$ & NO & $\mathrm{DC}$ \\
\hline
\end{tabular}

Nota: "Análisis VRIO y la ventaja competitiva", 2016 Recuperado:

http://marketingestrategico.pe/el-analisis-vrio-y-la-ventaja-competitiva/

Servicio al cliente, desarrollo de productos y servicios de manera eficiente e innovación en productos y servicios, son ventajas competitivas temporales los cuales necesitan reforzar para que este no sea una oportunidad para nuestros competidores.

La desventaja competitiva que es el retener el equipo de trabajo debe ser de prioridad dentro las estrategias a realizar debido a que es importante tener un flujo de trabajo sostenible, de lo contrario obtendremos pérdida de dinero y de comunicación. 


\subsection{Matriz de Evaluación de los Factores Internos EFI}

Es una herramienta para la formulación de la estrategia que resume y evalúa las fortalezas y debilidades importantes en las áreas funcionales de una empresa y también constituye una base para identificar y evaluar las relaciones entre ellas.

Tabla $N^{\circ} 48$

Matriz de Factores Internos

\begin{tabular}{|c|c|c|c|c|}
\hline \multicolumn{2}{|r|}{ FACTORES INTERNOS DETERMINANTES DE ÉXITO } & \multirow[t]{2}{*}{ Peso } & \multirow[t]{2}{*}{ Calificación } & \multirow[t]{2}{*}{$\begin{array}{c}\text { Total } \\
\text { Ponderado }\end{array}$} \\
\hline & FORTALEZAS & & & \\
\hline 1 & Alta calidad de productos & 0.12 & 3 & 0.36 \\
\hline 2 & $\begin{array}{l}\text { Know How en la realización de productos y servicios que } \\
\text { se ofrecen }\end{array}$ & 0.15 & 3 & 0.45 \\
\hline 3 & Personal altamente capacitado & 0.10 & 3 & 0.3 \\
\hline 4 & Capacidad instalada & 0.08 & 4 & 0.32 \\
\hline 5 & $\begin{array}{l}\text { Flexibilidad en la realización de cualquier producto sobre } \\
\text { medidas o en serie } \\
\text { DEBILIDADES }\end{array}$ & 0.15 & 3 & 0.45 \\
\hline 6 & Informalidad del Sector & 0.08 & 2 & 0.16 \\
\hline 7 & $\begin{array}{l}\text { No contar con una marca que facilite el posicionamiento } \\
\text { en consumidores }\end{array}$ & 0.08 & 1 & 0.08 \\
\hline 8 & Bajo poder de negociación con los proveedores & 0.08 & 2 & 0.16 \\
\hline 9 & Bajo nivel de publicidad y difusión de sus servicios & 0.08 & 2 & 0.16 \\
\hline 10 & Local alejado de mercado objetivo & 0.08 & 1 & 0.08 \\
\hline & TOTAL & 1.00 & & 2.52 \\
\hline
\end{tabular}

Nota: Elaboración propia

Tiene 2.52 de ponderado, del cual aún le falta aplicar nuevas estrategias para que sea una empresa realmente competitiva, y que enfrente el mercado de la mejor manera. 


\section{Capítulo VII: Formulación de los objetivos y diseño de las estrategias}

\subsection{Alcance y planteamiento de los objetivos estratégicos}

Para el desarrollo del alcance y planteamiento de los objetivos estratégicos vamos a considerar lo que la misión y visión proponen, y que se relaciona directamente con las tres características de una organización:

- Propósito definido.

- Estructura.

- Personas.

Estas tres características, estratégicamente definidas, le confieren a la empresa SF HERMANOS S.R.L. para el logro de la ventaja competitiva en su ámbito de competencia.

Por otro lado, la rentabilidad como medio para sustentar el desarrollo de estas tres características, también será base importante para el planteamiento de los objetivos estratégicos.

\subsubsection{Objetivos estratégicos}

Los objetivos planteados por SF Hermanos son los siguientes:

1) Objetivo Estratégico 1

Incrementar la rentabilidad neta en $10 \%$ para el año 2023. 
Los directivos de la empresa SF Hermanos esperan incrementar la rentabilidad de la empresa en un $10 \%$ según la entrevista realizada al Gerente General, donde se establecerán estrategias dirigidas a cada área de la organización de la empresa para obtener resultados óptimos.

\section{2) Objetivo Estratégico 2}

Combinar estrategias de precio, promoción y ventas para obtener 1.8 millones de ingresos adicionales para el año 2023.

El precio de los productos o servicios que oferta la empresa tiene un impacto directo en los resultados financieros.

De forma que, una variación en los precios pueden hacer que las ventas se incrementen pero con una menor ganancia.

Por tanto, establecer una estrategia de precios y promoción adecuada puede suponer la diferencia entre la rentabilidad o tener que cerrar.

\section{3) Objetivo Estratégico 3}

Incrementar la productividad en un $8 \%$ para el año 2023.

Este objetivo es relevante, debido a que es el único camino para que la empresa pueda crecer y aumentar sosteniblemente su competitividad y rentabilidad. Los 
instrumentos fundamentales que originan una mayor productividad son: la mejora de procesos, reducción de tiempos y reducción de reprocesos.

\section{4) Objetivo Estratégico 4}

Potenciar el capital humano con 2 capacitaciones anuales para el año 2021.

Reconocer el papel clave que juegan los trabajadores en la realización de las tareas imprescindibles para el éxito de la empresa. Después de todo, mientras más capaz sea el equipo humano, las labores que se llevan a cabo dentro de una organización serán realizadas con mayor eficiencia y los objetivos que se tengan podrán cumplirse.

El área de recursos humanos es muy importante no solo para el reclutamiento del mejor equipo, sino también para la adaptación y capacitación de los miembros de la organización. Mientras más compenetrados estén los trabajadores con los objetivos y valores de la empresa, mejor será su rendimiento. Es por ello que la gestión de recursos humanos no debe de limitarse a labores administrativas, sino que debe procurar crear un clima laboral agradable que genere un sentido de pertenencia y compromiso entre todos los trabajadores. 


\subsubsection{Análisis de los objetivos estratégicos}

El siguiente análisis consistirá en determinar la relación entre los objetivos estratégicos, la Visión y Misión del plan estratégico. Logrando así que los objetivos estratégicos permitan alcanzar la misión y visión propuesta.

Los diferentes objetivos indicados cumplen con las características propias de su formulación, tal como se puede observar:

- Son medibles en tiempo, todos los objetivos tienen temporalidad de 3 y 5 años, es decir se enuncia claramente a fines del año 2021 y 2023.

- Contiene un indicador claro, todos los objetivos planteados tienen un indicador: rentabilidad neta \% (1), nivel de ventas (2), incremento de productividad (3), capacitación anual (4).

- Tiene una base, todos los objetivos tienen un punto de inicio al presente y se proyecta hacia el futuro. La base de los objetivos es:

○ Participación de mercado actual: $1.2 \%$

○ Rentabilidad neta actual: $9 \%$

○ Ventas actuales al 2017: S/. 2`265,072 
- Es desafiante, todos los objetivos exigen a mejorar diferentes aspectos operativos y administrativos de la empresa, por lo que representan un compromiso y desafío que se debe reflejar en el trabajo cotidiano.

\subsection{Diseño y formulación de estrategias}

\subsubsection{Modelo de Océano Azul}

Las dos situaciones competitivas en las cuales recaen las industrias son los océanos rojos y los océanos azules. La mayoría de las empresas representan los océanos rojos, los océanos azules simbolizan las ideas de negocios que aún son desconocidas o están muy poco desarrolladas (Nieto, 2013).

Para desarrollar el modelo estratégico del Océano Azul, empezaremos definiendo dos océanos: Océano Rojo y Océano Azul.

Océano Rojo. Es el mercado constituido por las empresas descritas anteriormente y el resto de las empresas no consideradas, incluyendo las informales, cuya estructura competitiva es de total amenaza; ya que la competencia es intensa, lo que se traduce en precios cada vez más bajos que no permiten una buena diferenciación.

Océano Azul. Es el espacio de mercado que buscamos encontrar, con una oferta de valor novedosa, en donde no se tiene el efecto de la competencia. 
En este caso se evaluó la entrevista con la gerencia de la empresa y algunos colaboradores, además de la actual situación de la industria, en la cual no nos encontramos en la capacidad de crear un producto innovador que revolucione en el mercado, sino reforzar nuestro el know how y la calidad de los productos que ofrecemos.

Tabla $\mathrm{N}^{\circ} 49$

Análisis situacional de la empresa

\begin{tabular}{|c|c|}
\hline \multicolumn{2}{|c|}{ Análisis situacional } \\
\hline Océano Rojo & Océano azul \\
\hline $\begin{array}{l}\text { Competimos con micro, pequeña, } \\
\text { mediana y empresas } \\
\text { transnacionales. }\end{array}$ & $\begin{array}{l}\text { Fortaleceremos la marca con la diferenciación } \\
\text { de nuestros productos (know how) }\end{array}$ \\
\hline $\begin{array}{l}\text { Buscamos ventaja competitiva } \\
\text { sobre estas empresas Ferrini y } \\
\text { Canziani }\end{array}$ & No nos afectará la presencia de la competencia \\
\hline $\begin{array}{l}\text { Nos enfocamos en los clientes } \\
\text { actuales existentes. }\end{array}$ & $\begin{array}{l}\text { Nos enfocaremos en aumentar nuestra cartera } \\
\text { de clientes. }\end{array}$ \\
\hline $\begin{array}{l}\text { El potencial de utilidades de } \\
\text { nuestro sector es cada vez menor y } \\
\text { el sector crece muy lentamente. }\end{array}$ & $\begin{array}{l}\text { Desarrollaremos oportunidades con } \\
\text { crecimiento y rentabilidad. }\end{array}$ \\
\hline
\end{tabular}

Nota: Elaboración propia

\subsubsection{Lienzo de la estrategia actual de la empresa}

El lienzo de la estrategia es el esquema central de diagnóstico y acción para establecer una estrategia del océano azul convincente. El eje horizontal recopila el rango de factores en el que la empresa compite e invierte, mientras que el eje vertical recopila el nivel de oferta que los compradores reciben. Considerando la realidad actual de la empresa, los aspectos críticos del sector y una calificación de 1 al 6 por cada uno de ellos se puede observar la siguiente clasificación: 


\section{Tabla $\mathrm{N}^{\circ} 50$}

\section{Criterios}

\begin{tabular}{cc}
\hline \multicolumn{1}{c}{ Criterios } \\
\hline Excelente & 6 \\
Muy bueno & 5 \\
Bueno & 4 \\
Regular & 3 \\
Aceptable & 2 \\
Deficiente & 1 \\
\hline
\end{tabular}

Nota: Elaboración propia

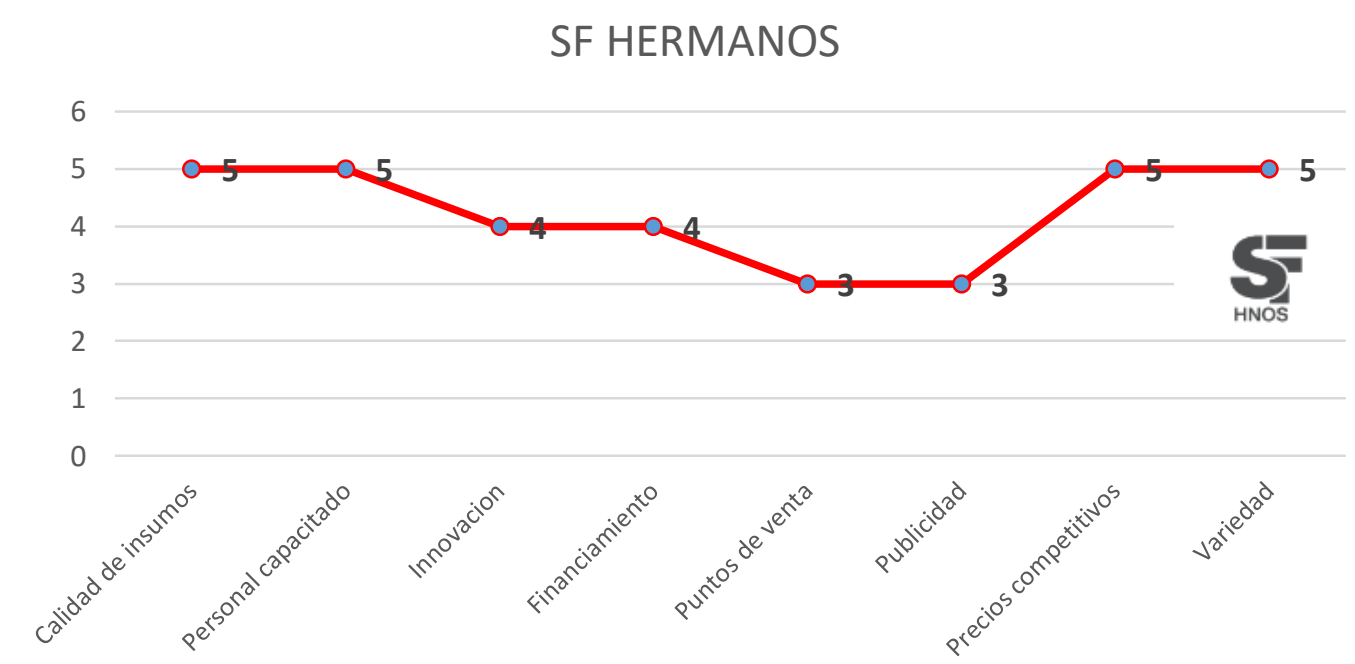

Figura $N^{\circ}$ 39. Estrategia actual para la empresa SF Hermanos S.R.L. Nota: Elaboración propia.

El lienzo de la estrategia para SF Hermanos, según el gráfico, muestra que la compañía trabaja con insumos de calidad, personal bien capacitado, tiene precios competitivos y cuenta con una gran variedad de productos. A su vez, en cuanto a la innovación y al financiamiento, la empresa se encuentra por encima del promedio pues sus productos tienen buena acogida y las tasas de los créditos son buenas. 
Finalmente, SF Hermanos debería poner énfasis en los puntos de venta y su publicidad pues son los factores más bajos de todas las variables analizadas en el lienzo.

\begin{tabular}{lc}
$\begin{array}{l}\text { Tabla } \mathrm{N}^{\circ} 51 \\
\text { Variables }\end{array}$ \\
\hline VARIABLES \\
\hline Calidad de insumos \\
Personal capacitado \\
Innovación \\
Liquidez \\
Puntos de venta \\
Publicidad \\
Precios competitivos \\
Variedad
\end{tabular}

Nota: Elaboración propia

Tabla $\mathrm{N}^{\circ} 52$

Definición de variables

\begin{tabular}{cc}
\hline Variable & Definición \\
\hline Calidad de insumos & $\begin{array}{c}\text { ¿Cuál es la importancia de la empresa que los } \\
\text { insumos sean de calidad alta o baja? } \\
\text { Personal capacitado } \\
\text { La empresa capacita a su personal en todos los } \\
\text { procesos de la fabricación de sus productos } \\
\text { La empresa se preocupa por tener productos } \\
\text { diferenciados frente a diseño, calidad, } \\
\text { procesos, etc. } \\
\text { Liquidez } \\
\text { Luntos de venta } \\
\text { Publicidad } \\
\text { desarrollo de nuevos procesos o proyectos } \\
\text { ¿Tiene puntos de ventas? ¿Cuántos? } \\
\text { Desarrolla campañas de promoción de sus } \\
\text { productos } \\
\text { El precio va de acuerdo al mercado que se } \\
\text { dirige }\end{array}$ \\
¿Cuenta con varios modelos, productos y \\
líneas?
\end{tabular}

Nota: Elaboración propia 
Las variables mostradas determinan que tan buen desempeño presenta S.F. Hermanos S.R.L. en cada uno de los criterios que representan. La calidad de insumos, determina la calidad de los materiales que usan en la elaboración de sus muebles; la capacitación constante del personal que posee las técnicas y conocimientos para el desempeño de sus funciones; la innovación en la producción y gestión de la firma; el grado de liquidez que presenta la empresa; la cantidad de puntos de ventas; la publicidad necesaria y el alcance de la misma; lo precios competitivos que se ajusten al mercado actual, sus requerimientos y la variedad ofertada por línea de producto.

Se puede observar que la empresa se encuentra en un nivel medio - superior, de tal manera que la calidad de insumos, los precios competitivos, el personal capacitado y la variedad de modelos son sus principales atributos competitivos y tienen una calificación 5 .

\subsubsection{Lienzo de la estrategia actual de la industria}

A continuación, se va a mostrar a SF Hermanos frente a la industria. Se muestran los valores de los criterios a mostrar en el gráfico, los cuales van desde 1(Deficiente) y 6 (Excelente). 


\section{Tabla $\mathrm{N}^{\circ} 53$}

\section{Criterios}

\begin{tabular}{cc}
\hline \multicolumn{1}{c}{ Criterios } & \\
\hline Excelente & 6 \\
Muy bueno & 5 \\
Bueno & 4 \\
Regular & 3 \\
Aceptable & 2 \\
Deficiente & 1 \\
\hline
\end{tabular}

Nota: Elaboración propia

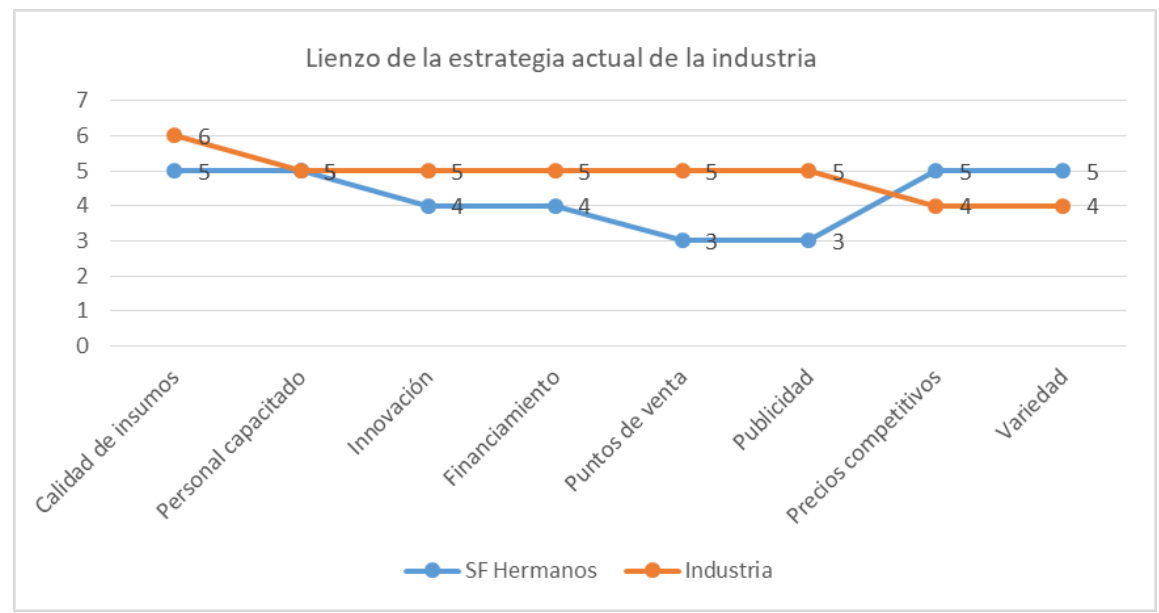

Figura $N^{\circ}$ 40. Estrategia actual para SF Hermanos vs la industria Nota: Elaboración propia

Se observa en la figura que en la industria existen insumos de calidad a disposición de las empresas del rubro. Existe también personal capacitado para realizar los trabajos, a nivel de innovación existen empresas que tienen como prioridad este factor en sus trabajos, existe facilidad en el financiamiento para las empresas del rubro. Por otro lado, es de vital importancia que una empresa tenga puntos de venta donde puedan mostrar sus productos así como la publicidad en medios y redes sociales. En cuanto a los precios se encuentran productos desde muy bajo costo no 
siendo estos precios competitivos y poca variedad de productos debido a productos de procedencia china y los ofrecidos por los retails.

\subsubsection{Matriz (Eliminar, reducir, incrementar, crear)}

La industria en la cual se encuentra SF Hermanos debe de eliminar, reducir, incrementar y crear, los siguientes factores para alcanzar un mejor desempeño competitivo en el sector.

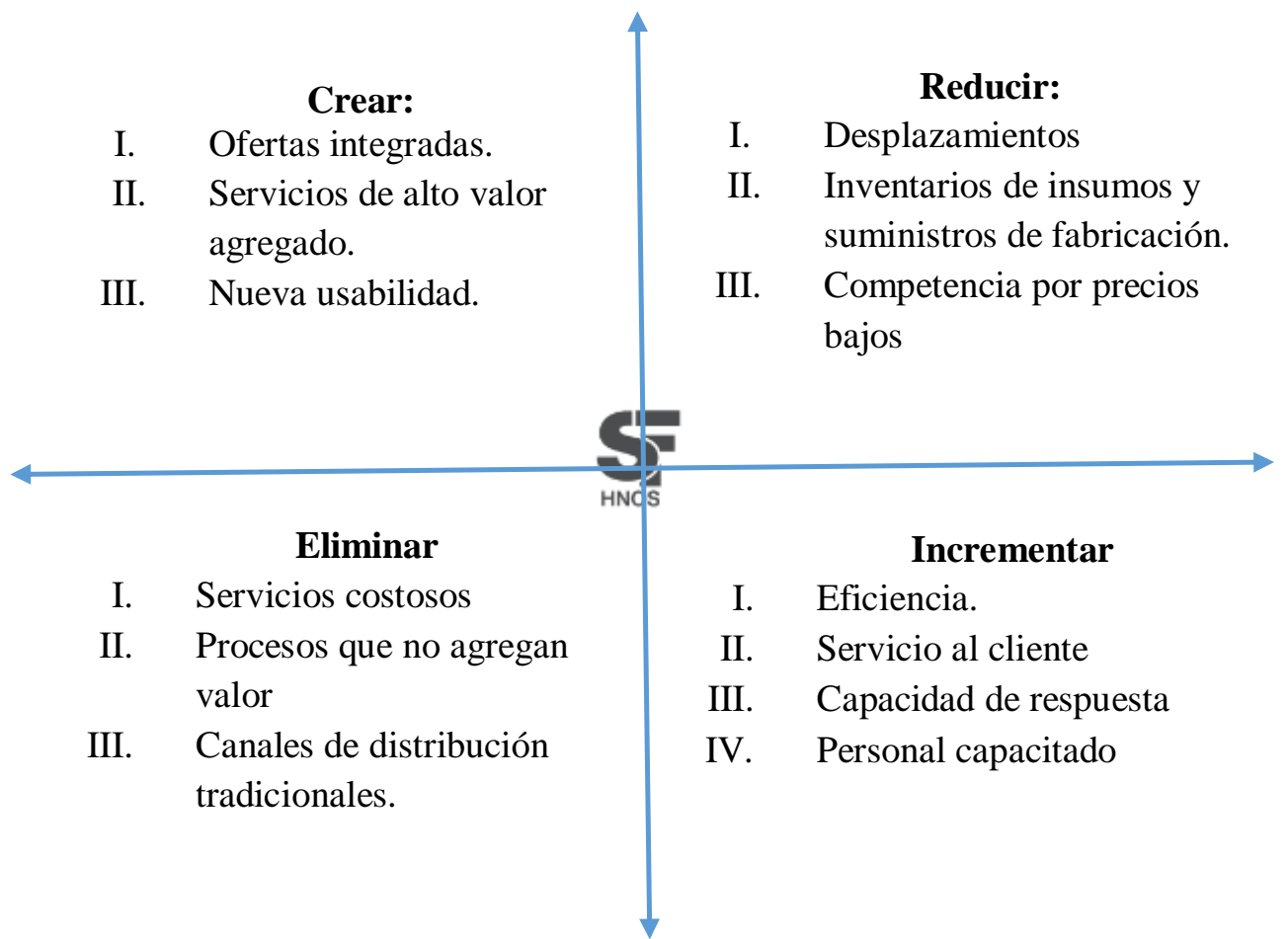

Figura $N^{\circ}$ 41. Matriz ERIC (Eliminar, reducir, incrementar, crear). Nota: Elaboración propia

Tal como se muestra en la industria se debe de realizar lo siguiente:

- Crear: ofertas integradas, que les permita mostrar y hacer llegar su mensaje y oferta a través de las redes sociales. Crear servicios de alto 
valor agregado para sobrepasar la expectativas del cliente. Finalmente crear en los productos una nueva usabilidad de los mismos.

- Reducir: el número de desplazamientos que involucran tiempo y costos asociados, también reducir sus niveles de inventarios para evitar sobre costos, finalmente reducir a la competencia que brinda precios bajos poniendo énfasis en otra característica del producto diferente a un precio bajo.

- Eliminar: Servicios costosos, de manera de que el consumidor final no piense que remodelar espacios o ambientes es una gran inversión, eliminar procesos que no agregan valor en el proceso productivo que puedan provocar cuellos de botella y demoras en la entrega de los productos, así como eliminar los canales de distribución tradicionales que puedan incurrir en costos elevados y demora en las entregas.

- Incrementar: La eficiencia en cada uno de los procesos productivos, mejorar el servicio al cliente, actualmente muchas empresas acuerdan con sus clientes un tiempo de entrega estimado pero no siempre se cumple, así como la capacidad de respuesta ante una queja o reclamo que normalmente no es ágil. Por último la industria requiere personal altamente calificado para el desarrollo de sus productos y a medida según las necesidades de los clientes. 


\subsubsection{Matrices de formulación de estrategias}

En este punto se realizará un análisis de la situación interna y externa de la empresa para la elaboración de las estrategias, tomando como base las siguientes matrices:

\subsubsection{Matriz FODA}

La matriz FODA es una herramienta estratégica de análisis de la situación actual de una empresa, cuyo principal objetivo es ofrecer un claro diagnóstico para poder tomar decisiones estratégicas oportunas y mejorar a futuro. Su nombre viene del acrónimo formado por sus iníciales: Debilidades, amenazas, fortalezas y debilidades. Dicha matriz de análisis permite identificar tanto las oportunidades como las amenazas que se presentan en el mercado, así como identificar las fortalezas y debilidades de la compañía.

Luego de realizar el análisis la empresa debe de aprovechar sus puntos fuertes para sacar el máximo provecho a las oportunidades que ofrece el mercado y reducir las amenazas detectadas, eliminando o corrigiendo sus puntos débiles.

Finalmente, la matriz FODA puede ser utilizada para cualquier empresa independientemente de su actividad o tamaño. (Espinoza, 2013). Para armar la matriz FODA a continuación se ha tomado la matriz de Factores externos EFE del capítulo IV y el análisis de Porter del capítulo V que ha permitido identificar las principales oportunidades y amenazas. 
Asimismo, el análisis de la cadena de valor ha permitido identificar las principales fortalezas y debilidades, las cuales se han presentado en el capítulo VI en la matriz de factores internos (EFI).

Con el cruce de ambas matrices se forma la matriz FODA, de la misma manera se formulan las estrategias y acciones que permitan a la empresa aprovechar las oportunidades y controlar las amenazas. 
Tabla $\mathrm{N}^{\circ} 54$

Matriz FODA

\begin{tabular}{|c|c|c|}
\hline \multirow{6}{*}{ FODA } & FORTALEZAS & DEBILIDADES \\
\hline & F1.-Alta calidad de productos. & D1.- Informalidad del Sector. \\
\hline & $\begin{array}{l}\text { F2.-Know how en la realización de } \\
\text { productos y servicio que se ofrecen. }\end{array}$ & $\begin{array}{l}\text { D2.- No contar con marca que facilite el } \\
\text { posicionamiento en consumidores }\end{array}$ \\
\hline & F3.-Personal altamente capacitado. & $\begin{array}{l}\text { D3.- Bajo poder de negociación con los } \\
\text { proveedores. }\end{array}$ \\
\hline & F4.- Capacidad instalada. & $\begin{array}{c}\text { D4.- Bajo nivel de publicidad y difusión } \\
\text { de servicios. }\end{array}$ \\
\hline & $\begin{array}{l}\text { F5.- Flexibilidad en la realización de } \\
\text { cualquier producto sobre medidas o en serie. }\end{array}$ & D5.- Local alejado del mercado objetivo \\
\hline OPORTUNIDADES & ESTRATEGIAS - FO & ESTRATEGIAS - DO \\
\hline $\begin{array}{l}\text { O1.- Crecimiento del sector } \\
\text { construcción en Perú en un } 4 \%\end{array}$ & \multirow{2}{*}{$\begin{array}{c}\text { F1F203 Aprovechar la existencia de marcas } \\
\text { diferenciadas (Barrera de entrada) para dar a } \\
\text { conocer la alta calidad de los productos que } \\
\text { tiene la empresa }\end{array}$} & \multirow{2}{*}{$\begin{array}{l}\text { D1O305 Fomentar la importancia de } \\
\text { comprar productos de calidad en } \\
\text { empresas formales, indicando los } \\
\text { beneficios que obtendrían, como la } \\
\text { atención personalizada post venta. }\end{array}$} \\
\hline $\begin{array}{l}\text { O2.- Crecimiento de capacidad } \\
\text { de endeudamiento de los } \\
\text { hogares limeños. }\end{array}$ & & \\
\hline $\begin{array}{l}\text { O3.-Existencia de marcas } \\
\text { diferenciadas (barrera de } \\
\text { entrada) }\end{array}$ & $\begin{array}{c}\text { F1F30305 Realizar alianzas estratégicas } \\
\text { con el Ministerio de Producción para el } \\
\text { fomento de la empresa por sus productos de } \\
\text { calidad }\end{array}$ & $\begin{array}{l}\text { D2O5 Implementar un sistema CRM para } \\
\text { la identificación de clientes potenciales } \\
\text { en el sector. }\end{array}$ \\
\hline $\begin{array}{l}\text { O4.- Bajo nivel de servicio } \\
\text { post venta en el sector }\end{array}$ & $\begin{array}{l}\text { F4F301 Expandir la cartera de clientes de la } \\
\text { empresa obteniendo bases de datos de } \\
\text { empresas en el sector inmobiliario }\end{array}$ & D3O1 Implementar sistema SCM \\
\hline $\begin{array}{l}\text { O5.-La segmentación elegida } \\
\text { tiene como preferencia la } \\
\text { madera, acero y cueros para la } \\
\text { fabricación de sus muebles }\end{array}$ & $\begin{array}{l}\text { F2F4O2O5 Realizar encuesta sobre la } \\
\text { adquisición de nuevo producto "Renuévate" }\end{array}$ & $\begin{array}{l}\text { D5O2O5 Instalar puntos de venta en } \\
\text { lugares estratégicos para obtener una } \\
\text { atención directa con el cliente }\end{array}$ \\
\hline AMENAZAS & ESTRATEGIAS - FA & ESTRATEGIAS - DA \\
\hline $\begin{array}{l}\text { A2.- Consumidor cada vez más } \\
\text { exigente e influenciado por } \\
\text { tendencias mundiales }\end{array}$ & $\begin{array}{l}\text { F1F2A1A2A3 Desarrollo de campañas de } \\
\text { publicidad sobre los beneficios y know how } \\
\text { de los productos de la empresa vs los } \\
\text { productos de la competencia. } \\
\text { F1F3A3A5 Realizar capacitaciones } \\
\text { mensuales para los clientes sobre la calidad } \\
\text { de los productos desarrollados, realizados } \\
\text { por personal especializado. }\end{array}$ & $\begin{array}{l}\text { D2A1 Evaluar y rediseñar la marca de la } \\
\text { empresa }\end{array}$ \\
\hline $\begin{array}{l}\text { A3.- Facilidad en la } \\
\text { importación de muebles de } \\
\text { procedencia china por retails }\end{array}$ & $\begin{array}{c}\text { F3F4A2A4 Desarrollar nuevo producto } \\
\text { "Renuévate", del cual su enfoque sea la } \\
\text { remodelación de mobiliario en diferentes } \\
\text { ambientes. }\end{array}$ & $\begin{array}{l}\text { D2D4A1A4 Invertir en publicidad en } \\
\text { diferentes medios de comunicación }\end{array}$ \\
\hline $\begin{array}{l}\text { A4.-Estacionalidad de la } \\
\text { demanda }\end{array}$ & $\begin{array}{l}\text { F5A1A5 Capacitar al área de ventas para } \\
\text { realizar la atención personalizada de los } \\
\text { productos a ofrecer. }\end{array}$ & $\begin{array}{l}\text { D5A1A2 Implementar un módulo digital } \\
\text { de atención al cliente con respuesta de } \\
\text { diseños e imágenes 3D. }\end{array}$ \\
\hline $\begin{array}{l}\text { A5.- Existencia de productos } \\
\text { sustitutos }\end{array}$ & $\begin{array}{l}\text { F2F3A3 Implementar el área de desarrollo } \\
\text { de productos }\end{array}$ & $\begin{array}{l}\text { D4A4 Realizar un plan de ofertas y } \\
\text { promociones }\end{array}$ \\
\hline
\end{tabular}

Nota: Elaboración propia 


\subsubsection{Matriz PEYEA}

La Matriz de Posición Estratégica y Evaluación de la Acción (PEYEA), es una de las matrices más utilizadas en la planificación estratégica de las organizaciones, debido a que ofrece a los especialistas las mejores posibilidades de desempeño en el mercado y la imagen actual de la compañía evaluada. Además de ser una herramienta que define estrategias. En su composición la matriz está formada por un marco de cuatro cuadrantes y va a indicar que tipo de estrategia se debería de utilizar, las cuales pueden ser: Agresivas, conservadoras, defensivas o competitivas según corresponda para cada organización. Los Ejes de la matriz PEYEA van a representar dos dimensiones internas (Fuerza financiera $[\mathrm{FF}]$, la ventaja competitiva [VC], y dos dimensiones externas (Estabilidad del ambiente [EA] y la fuerza de la industria [FI]). (Muñoz, 2013).

\section{Primer paso: Evaluación de fuerzas y componentes}

\section{A.- Fuerza Financiera}

Liquidez. - La empresa posee un alto grado de liquidez para cubrir sus obligaciones de corto plazo debido a que sus clientes pagan en un plazo menor a 80 días después de entregado el trabajo, por tal motivo no sufre de problemas en su flujo de caja diario, su calificación es 4.

Apalancamiento. - La empresa posee alta capacidad de endeudamiento, debido a que cuenta con un buen flujo de caja que permite garantizar sus pagos, asimismo posee acceso a préstamos, por lo que su calificación es de 4. 
Capital de trabajo. - Debido a la liquidez con la que cuenta, puede financiar sus proyectos y servicios encargados, por tanto, su calificación es de 4 .

Rentabilidad Operativa. - La rentabilidad operativa es menor a la del sector, alrededor del 12\%, debido a que arrastra algunos costos fijos y deficiencias en los procesos que tiene que mejorar. Su calificación es de 2.

\section{B.- Estabilidad del ambiente}

Estabilidad económica. - En la actualidad la económica ha alcanzado una estabilidad que permite a las empresas planificar y desarrollarse adecuadamente, se le da una calificación de -1.

Inseguridad y delincuencia. - Este aspecto se considera un aspecto social relevante y trascendente que afecta el desarrollo de las empresas por su impacto en las actividades cotidianas obligando a tomar acciones de prevención, seguro entre otro, y SF hermanos no es ajeno a ello. Se considera una calificación de -4.

Estabilidad política legal. - La clase política del Perú, entendida como los 3 poderes del estado, siempre muestras escaramuzas y conflictos de diferente orden y, al igual el poder judicial (en huelga a diciembre del 2016), no da todas las garantías que debería brindar a las empresas que se desarrollan en el Perú. Es por eso que se da una calificación de -4 . 
Tecnología y acceso a la información. - El actual consumidor moderno, influenciado por la información a la cual accede a través de las diferentes tecnologías de navegación es cada vez más exigente, dado que compara y pide que lo satisfagan permanentemente. Por tanto, se le asigna una calificación de -3.

\section{C.- Ventaja competitiva}

Participación de mercado. - La empresa posee una baja participación de mercado en la actualidad. -4

Calidad del producto. - La calidad de los muebles elaborados por la empresa, demostrados a través de la durabilidad y buenos acabados son aspectos resaltantes y relevantes en la competitividad de la empresa. Se asigna una calificación de -1.

Ubicación. - La accesibilidad de su centro de operaciones y su espacio de trabajo permiten indicar que es un aspecto positivo que fortalece su competitividad, aunque si se ve desde la accesibilidad hacia el segmento de hogares de NSE A y B, ya no es un aspecto positivo. Se califica con -3 .

Inexistencia de marca propia. - Como se indica la empresa no es conocida con una marca específica dentro del sector sino solamente con el nombre SF Hermanos. Se califica con -2 . 


\section{D.- Fuerza de la industria}

Crecimiento en el sector vivienda. - Debido al alto nivel de penetración del sector viviendas, el potencial de crecimiento del sector es alto, lo que va a permitir a SF Hermanos desarrollarse. Ingresar a nuevos segmentos y generar nuevos productos. Se coloca una calificación de 5 .

Alto nivel de informalidad. - El hecho de que existan muchas empresas informales y que se encuentran en diferentes ubicaciones perjudica el desempeño de empresas como SF Hermanos. Se le da una calificación de 2.

Existencia de sustitutos. - En el sector existen una gran cantidad de productos que potencialmente pueden reemplazar el tipo de servicios que ofrece la empresa, el plástico, la melanina con relleno, los muebles pre armados (chinos), los muebles de segunda refaccionados son alguno de ellos. Se considera una calificación de 4 .

Utilización de la capacidad instalada. - En la empresa se tiene una capacidad ociosa por utilizar, por lo cualquier incremento en la demanda puede ser atendida.

\section{Segundo Paso: Suma de promedios}

Con la calificación asignada se puede ordenar como se muestra a continuación: 


\section{Tabla $\mathrm{N}^{\circ} 55$}

Cuadro de calificaciones - Matriz PEYEA

\begin{tabular}{|c|c|c|c|}
\hline Posición estratégica interna & & \multicolumn{2}{|l|}{ Posición estratégica externa } \\
\hline Fuerza financiera $(\mathrm{FF})$ & & \multicolumn{2}{|l|}{ Estabilidad del Ambiente (EA) } \\
\hline Liquidez & 4 & Estabilidad económica & -1 \\
\hline Apalancamiento & 4 & Inseguridad y delincuencia & -4 \\
\hline Capital de trabajo & 4 & Estabilidad política legal & -4 \\
\hline Rentabilidad operativa & 2 & $\begin{array}{c}\text { Tecnología y acceso a la } \\
\text { información }\end{array}$ & -3 \\
\hline Total & 14 & Total & -12 \\
\hline Promedio & 3.50 & Promedio & -3.00 \\
\hline Ventaja Competitiva (VC) & & \multicolumn{2}{|l|}{ Fuerza de la Industria (FI) } \\
\hline Participación en el mercado & -4 & Crecimiento en el sector vivienda & 5 \\
\hline Calidad del producto & -1 & Alto nivel de informalidad & 2 \\
\hline Ubicación & -3 & Existencia de sustitutos & 4 \\
\hline Inexistencia de marca propia & -2 & $\begin{array}{c}\text { Utilización de la capacidad } \\
\text { instalada }\end{array}$ & 4 \\
\hline Total & -10 & Total & 15 \\
\hline Promedio & -2.50 & Promedio & 3.75 \\
\hline
\end{tabular}

Nota: Elaboración propia

Del análisis presentado se obtuvieron los siguientes resultados:

En eje $\mathrm{X}=\mathrm{VC}+\mathrm{FI}=-2.50+3.75=1.25$

En eje $\mathrm{Y}=\mathrm{EA}+\mathrm{FF}=-3.00+3.50=0.50$ 


\section{Tercer paso: Determinación del cuadrante}

Con las coordenadas establecidas en el punto anterior se puede determinar su ubicación en el cuadrante correspondiente en la imagen a continuación:

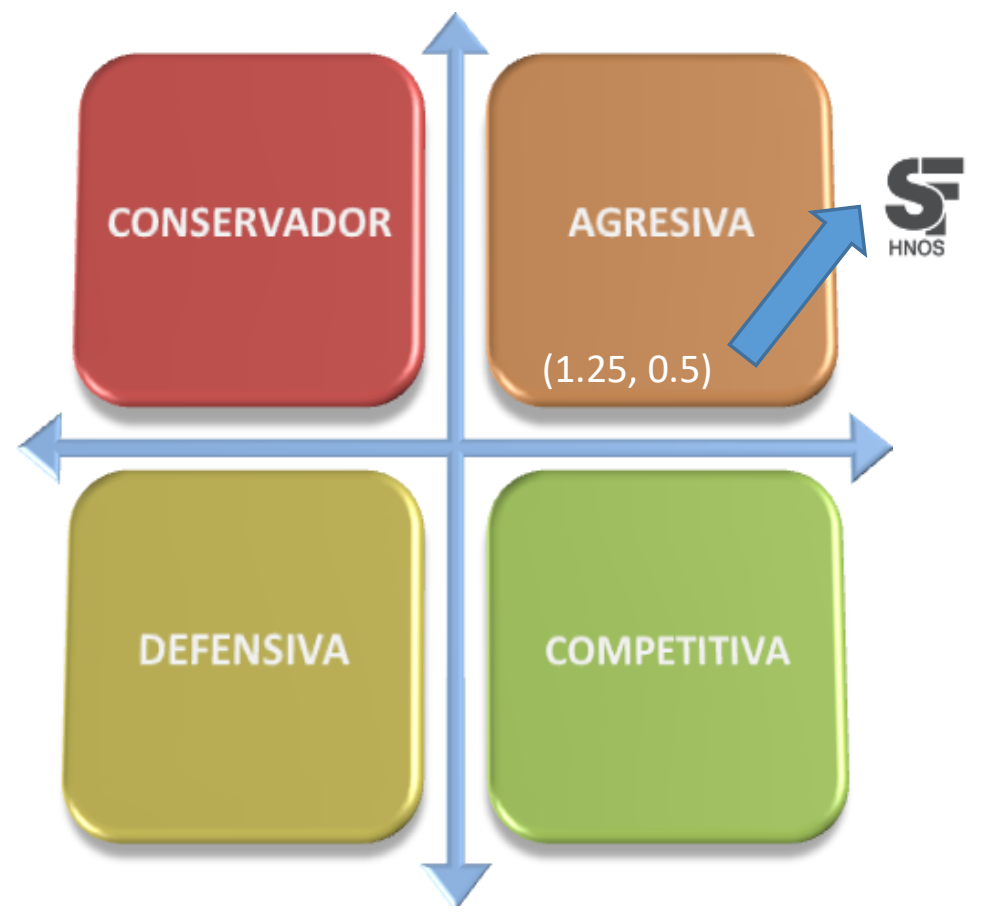

Figura $N^{\circ}$ 42. Matriz PEYEA. Nota: Elaboración propia

\section{Cuarto paso: Selección de la estrategia}

El cuadrante resultante da como opción las siguientes estrategias a implementar:

Penetración de mercado. - Ingresar a un nuevo segmento de mercado con el mismo tipo de servicio a través de acciones que permitan hacer conocido lo que la empresa ofrece o incrementando su frecuencia de consumo.

Desarrollo de mercado. - Ingresar a un nuevo mercado con el mismo tipo de servicio. 
Integración vertical hacia adelante y hacia atrás. - Realizar sociedades con proveedores o distribuidores con el fin de ganar posición competitiva en el mercado.

Diversificación. - Entrar a un nuevo mercado con otro producto o servicio.

\subsubsection{Matriz Interna / Externa}

La matriz de Evaluación Interna es una herramienta de formulación de estrategia, en la cual los especialistas van a resumir y evaluar las debilidades y fortalezas importantes de gerencia, marketing, finanzas, producción, investigación y desarrollo. Además de suministrar una base para analizar las relaciones internas entre las distintas áreas funcionales de la empresa o en simples palabras se puede decir que la matriz interna y externa es una auditoría de la administración estratégica, además de resumir las fuerzas y debilidades importantes dentro de las áreas funcionales del negocio. (Chávez, 2014).

En base a los resultados de la matriz EFE (2.38), que evalúa los factores externos de la empresa teniendo como base el análisis Porter y el análisis Externo (PESTEL). Así mismo se considera la matriz EFI que a través de la cadena de valor y un análisis de la organización determinar el nivel de competitividad de la empresa, y cuya calificación es 2.56, se elabora la matriz interna - externa que da los siguientes resultados: 


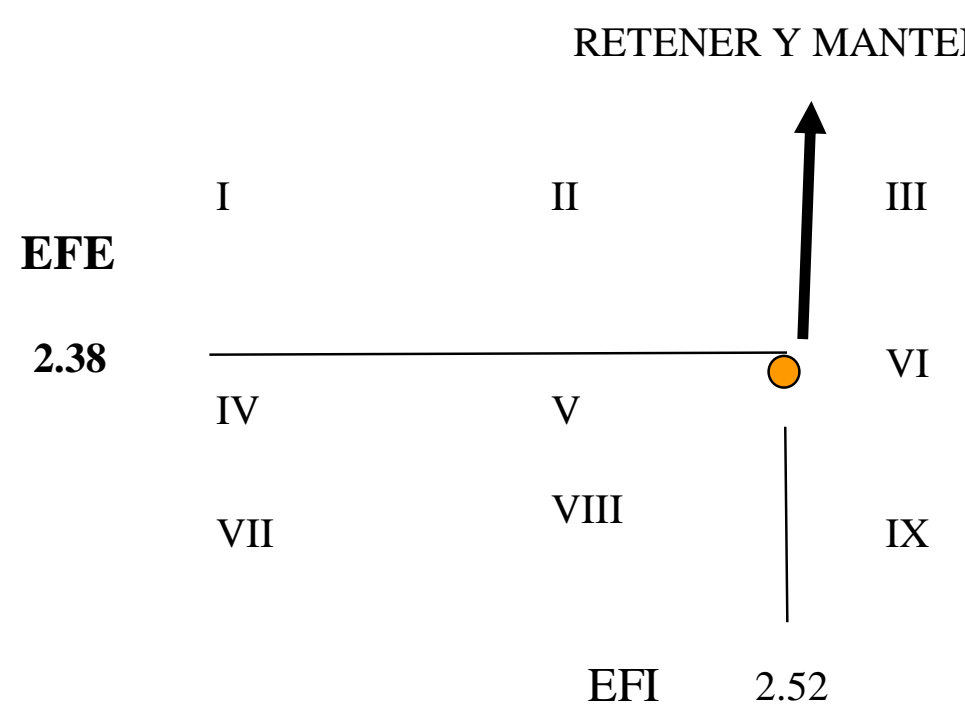

Figura $N^{\circ}$ 43. Matriz interna externa. Nota: Elaboración propia

SF Hermanos posee una posición interna media y una posición externa igual por tanto se ubica en la celda $\mathrm{V}$ (retener y mantener) lo cual indica que debe de utilizar una de las estrategias intensivas como Penetración de Mercado o Desarrollo de Producto.

\subsubsection{Matriz de la Gran Estrategia}

La matriz de la Gran Estrategia, es utilizada para indicar que la empresa tiene una puntuación que demuestra que a pesar de poseer alta calidad en sus productos y poseer competitividad en sus precios no posee un margen aceptable de participación en el mercado, posición financiera y en cuanto al desarrollo del mercado y la lealtad de su clientela la empresa muestra falencias que se necesitan ser atendidas de manera inmediata con el 
objetivo de mejorar estos factores que se aprecian críticos e impiden el éxito de una organización. (Kotler, 2013).

1. Las firmas situadas en el cuadrante I de la matriz de gran estrategia se encuentran en magnífica posición.

2. Las firmas del cuadrante II necesitan evaluar seriamente su actual enfoque con respecto al mercado.

3. Las firmas del cuadrante III compiten en una industria de crecimiento lento y poseen una posición competitiva débil.

4. Las firmas del cuadrante IV poseen una fuerte posición competitiva, pero están en una industria de crecimiento lento.

Para este caso la empresa SF Hermanos S.R.L. se encuentra en el cuadrante 4, ya que tiene una fuerte posición competitiva, del cual va creando nuevos productos y servicios que satisfagan a los clientes.

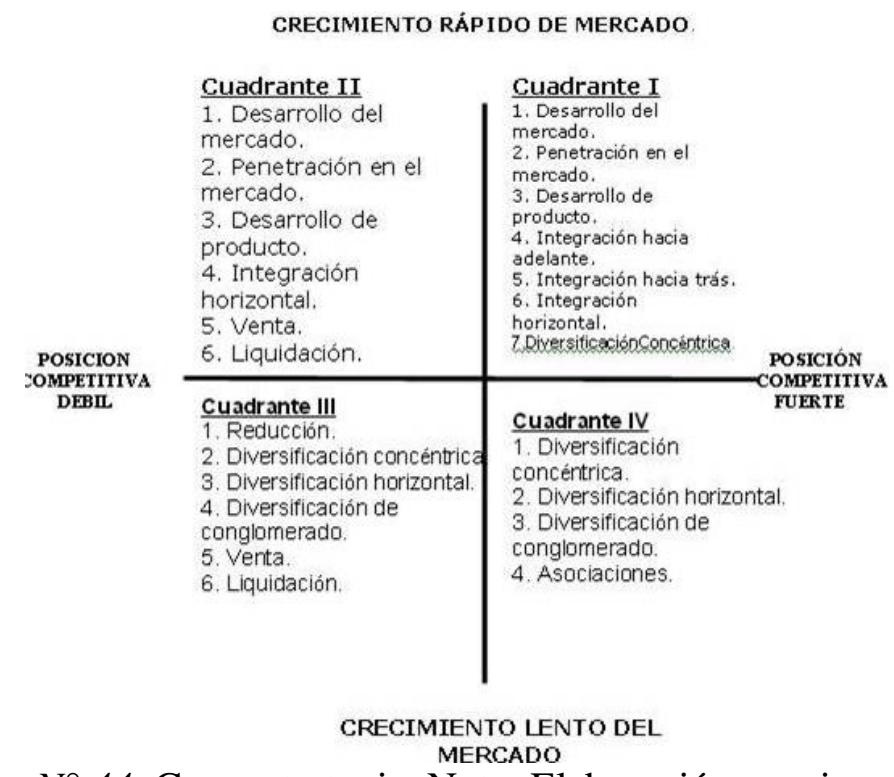

Figura $N^{\circ} 44$. Gran estrategia. Nota: Elaboración propia 


\subsection{Resumen de estrategias formuladas}

Dentro de las estrategias se tiene las siguientes:

Tabla $\mathrm{N}^{\circ} 56$

Cuadro de resumen de las estrategias

\begin{tabular}{|c|c|c|c|c|c|c|}
\hline & Ponderación & \begin{tabular}{|c|} 
Modelo \\
Océano Rojo \\
\end{tabular} & $\begin{array}{r}\text { Matriz FODA } \\
\end{array}$ & Matriz PEYEA & Matriz Interna Externa & Matriz de la Gran Estrategía \\
\hline Penetración del mercado & 7 & & $\begin{array}{l}\text { F1F2A1A2A3 Desarrollo de campañas de publicidad sobre los } \\
\text { beneficios y know how de la empresa frente a sus productos vs los } \\
\text { productos de la competencia. }\end{array}$ & $\begin{array}{l}\text { Penetración de } \\
\text { mercado }\end{array}$ & Penetración de mercado & Diversificación concéntrica \\
\hline Desarrollo del mercado & 2 & & $\begin{array}{l}\text { F3F4A2A4 Desarrollar nuevo producto "Renuévate", el cual su } \\
\text { enfoque es en la remodelacion de mobiliario en diferentes } \\
\text { ambientes inmobiliarios. }\end{array}$ & $\begin{array}{l}\text { Desarrollo de } \\
\text { mercado }\end{array}$ & Desarrollo de producto & Diversificación horizontal \\
\hline Desarrollo de productos & 4 & & F2F3A3 Implementar el área de desarrollo de productos. & $\begin{array}{c}\text { Integración vertical } \\
\text { hacia adelante y } \\
\text { hacia atrás }\end{array}$ & & Diversificación conglomerado \\
\hline Crecimiento integrativo & 2 & & D2A1A2 Evaluar y rediseñar la marca de la empresa. & Diversificación & & Asociaciones \\
\hline \multirow{5}{*}{ Otros } & \multirow{5}{*}{2} & & $\begin{array}{l}\text { F4F3O1 Expandir la cartera de clientes de la empresa obteniendo } \\
\text { base de datos de empresas en el sector inmobiliario. }\end{array}$ & & & \\
\hline & & & $\begin{array}{l}\text { F3F4O4 Implementar sistema de trazabilidad de los productos } \\
\text { realizados y vendidos. }\end{array}$ & & & \\
\hline & & & $\begin{array}{l}\text { D205 Implementar un sistema CRM para la identificación de } \\
\text { clientes potenciales en el sector. }\end{array}$ & & & \\
\hline & & & D3O1 Implentar sistema SCM. & & & \\
\hline & & & $\begin{array}{l}\text { D404 Desarrollar una campaña de promoción por redes sociales, } \\
\text { buscando impulsar y resaltar los productos de la empresa. }\end{array}$ & & & \\
\hline
\end{tabular}

Nota: Elaboración propia 


\section{Capítulo VIII: Selección de la estrategia}

\subsection{Método Factores Estratégicos Claves}

\subsubsection{Criterios de selección}

Se ha considerado los factores más importantes del análisis del entorno directo e indirecto y los considerados después del análisis de la cadena de valor y de toda la organización de la empresa. Es decir, para la elaboración de la Matriz MPEC se va a considerar los factores de la matriz de factores externos (EFE) y factores internos (EFI), dado que son los más representativos e importantes.

\subsubsection{Matriz de selección}

Se elabora la matriz con los siguientes factores del entorno de la empresa, los cuales se pueden observar en el siguiente cuadro, clasificados en oportunidades y amenazas con su respectivo peso:

Tabla $\mathrm{N}^{\circ} 57$

Matriz de Factores Externos

\begin{tabular}{|c|c|c|c|c|}
\hline & FACTORES EXTERNOS DETERMINANTES DE ÉXITO & Peso & Calificación & Total Ponderado \\
\hline \multicolumn{5}{|c|}{ OPORTUNIDADES } \\
\hline 1 & Crecimiento del sector construcción en el Perú en un $4 \%$ & 0.12 & 3 & 0.36 \\
\hline 2 & Crecimiento de capacidad de endeudamiento de los hogares limeños & 0.10 & 3 & 0.30 \\
\hline 3 & Existencia de marcas diferenciadas (barrera de entrada) & 0.08 & 2 & 0.16 \\
\hline 4 & Bajo nivel de servicio post venta en el sector & 0.10 & 2 & 0.20 \\
\hline 5 & $\begin{array}{l}\text { La selección elegida tiene como preferencia la madera, acero y cueros para la } \\
\text { fabricación de sus muebles } \\
\text { AMENAZAS }\end{array}$ & 0.08 & 3 & 0.24 \\
\hline 6 & Alto nivel de competencia informal & 0.12 & 2 & 0.24 \\
\hline 7 & $\begin{array}{c}\text { Consumidor cada vez más exigente e influenciado por tendencias } \\
\text { mundiales }\end{array}$ & 0.08 & 3 & 0.24 \\
\hline 8 & Facilidad en la importación de muebles de procedencia china por retails & 0.10 & 2 & 0.20 \\
\hline 9 & Estacionalidad de la demanda & 0.10 & 2 & 0.20 \\
\hline \multirow[t]{2}{*}{10} & Existencia de productos sustitutos & 0.12 & 2 & 0.24 \\
\hline & TOTAL & 1.00 & & 2.38 \\
\hline
\end{tabular}

Nota: Análisis PEST - Análisis de Porter, elaboración propia 
De la misma manera se ha considerado los factores internos más importantes, como se muestra en el cuadro a continuación:

\section{Tabla $\mathrm{N}^{\circ} 58$}

Matriz de Factores Internos

\begin{tabular}{|c|c|c|c|c|}
\hline & ACTORES INTERNOS DETERMINANTES DE ÉXITO & Peso & Calificación & $\begin{array}{c}\text { Total } \\
\text { Ponderado }\end{array}$ \\
\hline \multicolumn{5}{|c|}{ FORTALEZAS } \\
\hline 1 & Alta calidad de productos & 0.12 & 3 & 0.36 \\
\hline 2 & $\begin{array}{c}\text { Know how en la realización de productos y servicios que se } \\
\text { ofrecen }\end{array}$ & 0.15 & 3 & 0.45 \\
\hline 3 & Personal altamente capacitado & 0.10 & 3 & 0.30 \\
\hline 4 & Capacidad instalada & 0.08 & 4 & 0.32 \\
\hline 5 & $\begin{array}{c}\text { Flexibilidad en la realización de cualquier producto sobre } \\
\text { medidas o en serie } \\
\text { DEBILIDADES }\end{array}$ & 0.15 & 3 & 0.45 \\
\hline 6 & Informalidad del sector & 0.08 & 2 & 0.16 \\
\hline 7 & $\begin{array}{l}\text { No contar con una marca que facilite el posicionamiento en } \\
\text { consumidores }\end{array}$ & 0.08 & 1 & 0.08 \\
\hline 8 & Bajo poder de negociación con los proveedores & 0.08 & 2 & 0.16 \\
\hline 9 & Bajo nivel de publicidad y difusión de sus servicios & 0.08 & 2 & 0.16 \\
\hline \multirow[t]{2}{*}{10} & Local alejado de mercado objetivo de NSE A y B & 0.08 & 1 & 0.08 \\
\hline & TOTAL & 1.00 & & 2.52 \\
\hline
\end{tabular}

Nota: Elaboración propia

\subsection{Método de Escenarios}

\subsubsection{Descripción de escenarios considerados}

Los escenarios que se han contemplado son los siguientes:

Escenario 1 / Positivo.- Se prevé que las ventas sean superiores a las proyectadas, con la premisa de una mayor tasa de crecimiento del mercado de construcción que la registrada en años anteriores. Las necesidades del segmento hogares incrementan producto de la evolución del mercado, donde existen cada vez más casas y departamentos que necesitan mejoras internas en su decoración 
y acabado. Durante el horizonte de evaluación no ingresan nuevos competidores o aparecen nuevos bienes sustitutos. Adicionalmente, en este escenario no se da un incremento en los costos, sobre todo en materiales directo.

Todos estos lineamientos dan como resultado que los valores VAN y TIR del plan estratégico sean elevados, mostrando los alcances positivos de la estrategia.

Escenario 2 / Moderado.- Es el escenario más probable a ocurrir y que se proyecta en la evaluación financiera. Donde el crecimiento del sector construcción está en función al registrado en años anteriores. La empresa mantiene su nivel competitivo y participación de mercado, se mantiene los costos y gastos. La competencia informal sigue presente y los retails incrementan su cobertura de mercado por la apertura de nuevos locales. No hay necesidad de una mayor inversión en activos fijos. Los valores VAN y TIR son viables y con un alto nivel de ocurrencia.

Escenario 3 / Negativo.- Se presenta una desaceleración en el crecimiento del sector; el nivel competitivo se incrementa producto de la aparición de nuevos competidores, la competencia informal aumenta su cobertura y los retail siguen abriendo nuevos locales, la empresa pierde participación de mercado. Registrando ventas menores a las proyectadas de hasta $-30 \%$. El costo de la melamine se incrementa considerablemente, reduciendo el margen precio costo que se proyecta. Esto conlleva a valores de VAN menores de cero y la 
inversión no es recuperable. En este escenario no es recomendable seguir con la estrategia y evaluar otras opciones.

\subsubsection{Comparación de Estrategias con escenarios}

Ante los escenarios indicados se contemplan 3 estrategias, las cuales son las siguientes:

\section{Estrategia 1 - Penetración de mercado}

La estrategia planteada consiste en aumentar la venta de los productos existentes al segmento de construcción, realizando campañas de promoción y publicidad resaltando los beneficios de nuestros productos frente a la de competencia por lo cual se trabajará en reforzar la marca haciendo conocer nuestra experiencia en trabajos personalizados (know how). Se implementará un nuevo punto de venta, así como el lanzamiento de un nuevo producto en la línea de hogares

"Renuevate"

\section{Estrategia 2 - Desarrollo de mercado}

Se espera realizar estudios de mercado de nuevos segmentos en la industria de construcción para ampliar nuestra cartera de clientes, así como también buscar nuevos sectores geográficos, y nuevas líneas para la empresa.

\section{Estrategia 3 - Desarrollo de producto}

Se va a realizar un área de desarrollo de productos en la empresa para aprovechar brechas de mercado en la industria, además de lanzar 2 productos 
por año. Se contratará personal capacitado para encontrar productos innovadores

en el sector $\mathrm{u}$ otro.

Tabla $\mathrm{N}^{\circ} 59$

Escenarios de las estrategias planteadas

\begin{tabular}{|c|c|c|c|}
\hline & \multirow{2}{*}{$\begin{array}{l}\text { Estrategia } 1 \\
\text { Penetración de mercado }\end{array}$} & \multirow{2}{*}{$\begin{array}{l}\text { Estrategia } 2 \\
\text { Desarrollo de mercado }\end{array}$} & \multirow{2}{*}{$\begin{array}{l}\text { Estrategia } 3 \\
\text { Desarrollo de producto }\end{array}$} \\
\hline & & & \\
\hline Escenario 1 Positivo & $\begin{array}{l}\text { Se desarrolla un estudio de } \\
\text { mercado para determinar el } \\
\text { potencial del segmento, se } \\
\text { abre un nuevo local en } \\
\text { Surco, que sirve de local de } \\
\text { exhibición y ventas, se } \\
\text { desarrolla un buen } \\
\text { posicionamiento de la } \\
\text { empresa, el mercado de } \\
\text { vivienda sigue creciendo en } \\
\text { un } 4 \% \text { o más. }\end{array}$ & $\begin{array}{l}\text { Se crea y registra la Marca } \\
\text { "¡Renuévate!", se inicia } \\
\text { una campaña por redes } \\
\text { sociales buscando } \\
\text { posicionar dicha frase en } \\
\text { los segmentos objetivo, el } \\
\text { mercado de vivienda sigue } \\
\text { creciendo en un } 4 \% \text { o más } \\
\text { Se elabora material } \\
\text { impreso y se distribuye. }\end{array}$ & $\begin{array}{l}\text { Se desarrollan } \\
\text { promociones, } \\
\text { liquidaciones y } \\
\text { descuentos en } \\
\text { temporada baja, el } \\
\text { mercado de vivienda } \\
\text { sigue creciendo en un } \\
4 \% \text { o más. }\end{array}$ \\
\hline $\begin{array}{l}\text { Escenario } 2 \\
\text { Moderado }\end{array}$ & $\begin{array}{l}\text { Se abre el nuevo local, a un } \\
\text { costo mayor al esperado, la } \\
\text { aceptación es regular debido } \\
\text { a la competencia y a que la } \\
\text { oferta tiene que mejorar } \\
\text { precios conforme desarrolle } \\
\text { curva de experiencia y se } \\
\text { pueda para bajar los costos } \\
\text { de operación. }\end{array}$ & $\begin{array}{l}\text { Se crea y registra la Marca } \\
\text { ¡Renuévate!", se inicia } \\
\text { una campaña por redes } \\
\text { sociales buscando } \\
\text { posicionar dicha frase en } \\
\text { los segmentos objetivo. La } \\
\text { competencia retail sigue } \\
\text { bien posicionada, el } \\
\text { mercado se estanca y no } \\
\text { crece. }\end{array}$ & $\begin{array}{l}\text { Se desarrollan } \\
\text { promociones, } \\
\text { liquidaciones y } \\
\text { descuentos en } \\
\text { temporada baja, la } \\
\text { competencia sigue } \\
\text { incrementándose, el } \\
\text { mercado de vivienda se } \\
\text { estanca. }\end{array}$ \\
\hline Escenario 3 Negativo & $\begin{array}{l}\text { La competencia se } \\
\text { incrementa, el nuevo local } \\
\text { se abre con retraso y a un } \\
\text { costo mayor debido a los } \\
\text { diferentes permisos por } \\
\text { gestionar y a los costos de } \\
\text { adecuación. La competencia } \\
\text { es intensa y el mercado no } \\
\text { crece. }\end{array}$ & $\begin{array}{l}\text { Se crea y registra la Marca } \\
\text { ¡Renuévate!", se inicia } \\
\text { una campaña por redes } \\
\text { sociales, la competencia } \\
\text { informal y retail sigue } \\
\text { bien posicionada, el } \\
\text { mercado se estanca y no } \\
\text { crece. }\end{array}$ & $\begin{array}{l}\text { Se desarrollan } \\
\text { promociones, } \\
\text { liquidaciones y } \\
\text { descuentos en } \\
\text { temporada baja, la } \\
\text { competencia informal y } \\
\text { retail sigue bien } \\
\text { posicionada, el mercado } \\
\text { se estanca y no crece. }\end{array}$ \\
\hline
\end{tabular}

Nota: Elaboración Propia 


\subsubsection{Matriz de Planeación Estratégica Cuantitativa MPEC}

Con el detalle de cada estrategia y lo que pueda suceder en cada escenario se plantea la matriz de planeación cuantitativa (MPEC) que va a permitir evaluar y decidir sobre una estrategia.

Se puede observar que la estrategia que tiene un mejor ponderado es "Potenciar la venta del segmento A y B". 
Tabla $N^{\circ} 60$

Matriz de Planeación Estratégica Cuantitativa

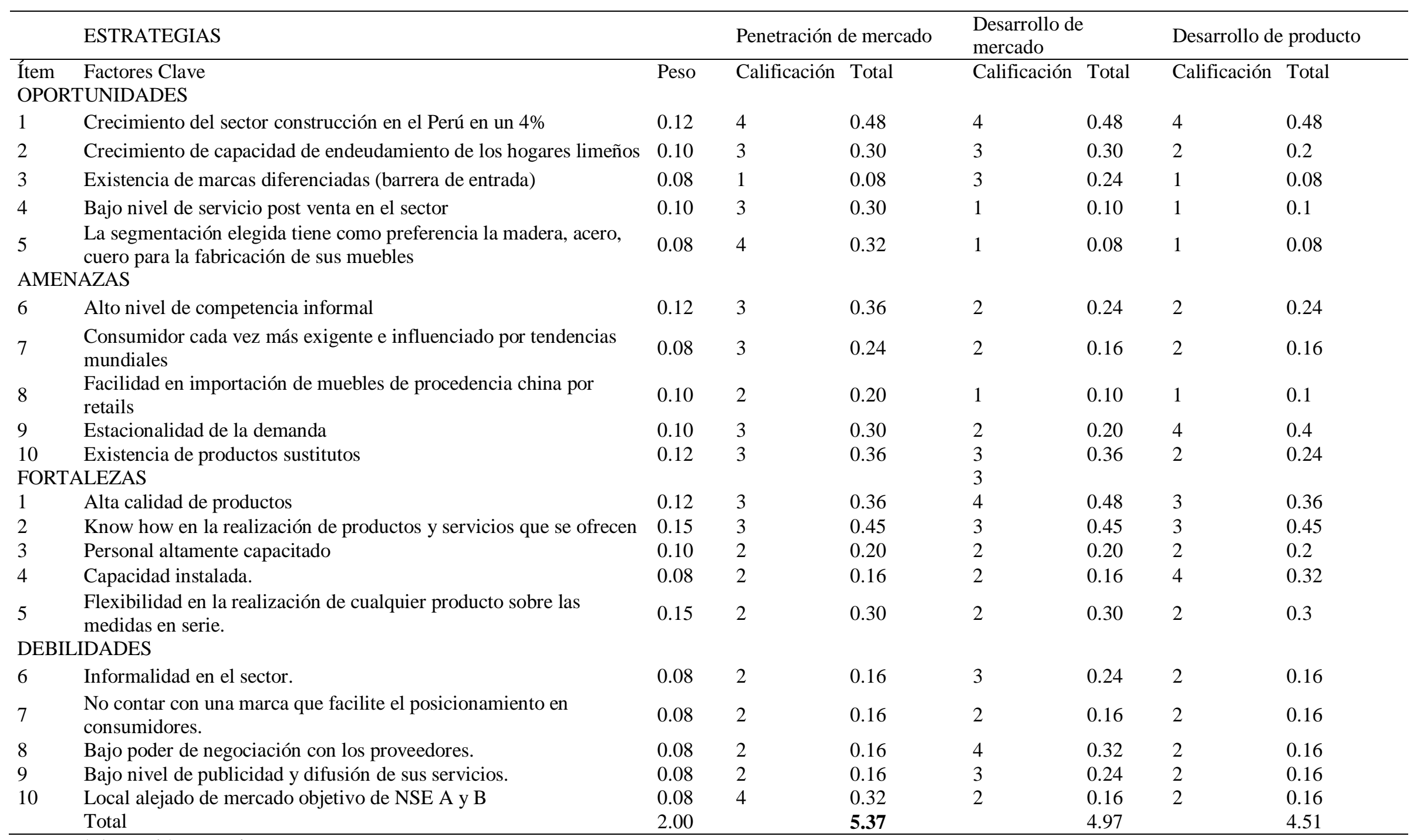

Nota: Elaboración Propia 


\subsubsection{Descripción de estrategia seleccionada}

\section{Estrategia 1 - Penetración de mercado}

Esta estrategia se centra en desarrollar el mercado ya existente, que pertenece en el sector mobiliario de Lima Metropolitana

Se van a realizar las siguientes acciones:

- Buscar y alquilar local por Surco, San Borja o Miraflores, promedio de 400 $500 \mathrm{mts}^{2}$

- Contratar personal para la administración, gestión comercial.

- Capacitar al personal en todas las áreas de la empresa.

- Se va a comprar 1 unidad de transporte para garantizar entrega oportuna.

- Se va a crear y registrar la marca “¡Renuévate!”.

- Se va elaborar un paquete especial que, con diseño, asesoría personalizada, mobiliario post venta.

- Se va a incentivar el posicionamiento de marca.

- Se va a desarrollar piezas gráficas para elaborar material impreso, catálogos, trípticos y usarlas en publicaciones de consumo del segmento objetivo. 


\subsubsection{Descripción de estrategia contingente}

\section{Estrategia 2 - Desarrollo de mercado}

- Se va a crear y registrar la marca “¡Renuévate!”.

- Se va a incentivar el posicionamiento de marca.

- Se va a desarrollar piezas gráficas para elaborar material impreso, catálogos, trípticos y usarlas en publicaciones de consumo del segmento objetivo.

- Se va a desarrollar campaña en redes sociales.

\section{Estrategia 3 - Desarrollo de producto}

- Se van a programar campañas de promoción y ofertas en fechas festivas como fiestas patrias y navidad.

- Se van a desarrollar campañas en temporadas bajas como marzo, abril, setiembre y octubre. 


\section{Capítulo IX: Implantación mediante el Balanced Scorecard}

\subsection{Mapa Estratégico}

Considerando los objetivos estratégicos y su relación con las diferentes dimensiones del balanced scorecard, se procede a elaborar el mapa estratégico para el logro de los objetivos financieros a 3 años. A continuación, se muestra el mapa estratégico.

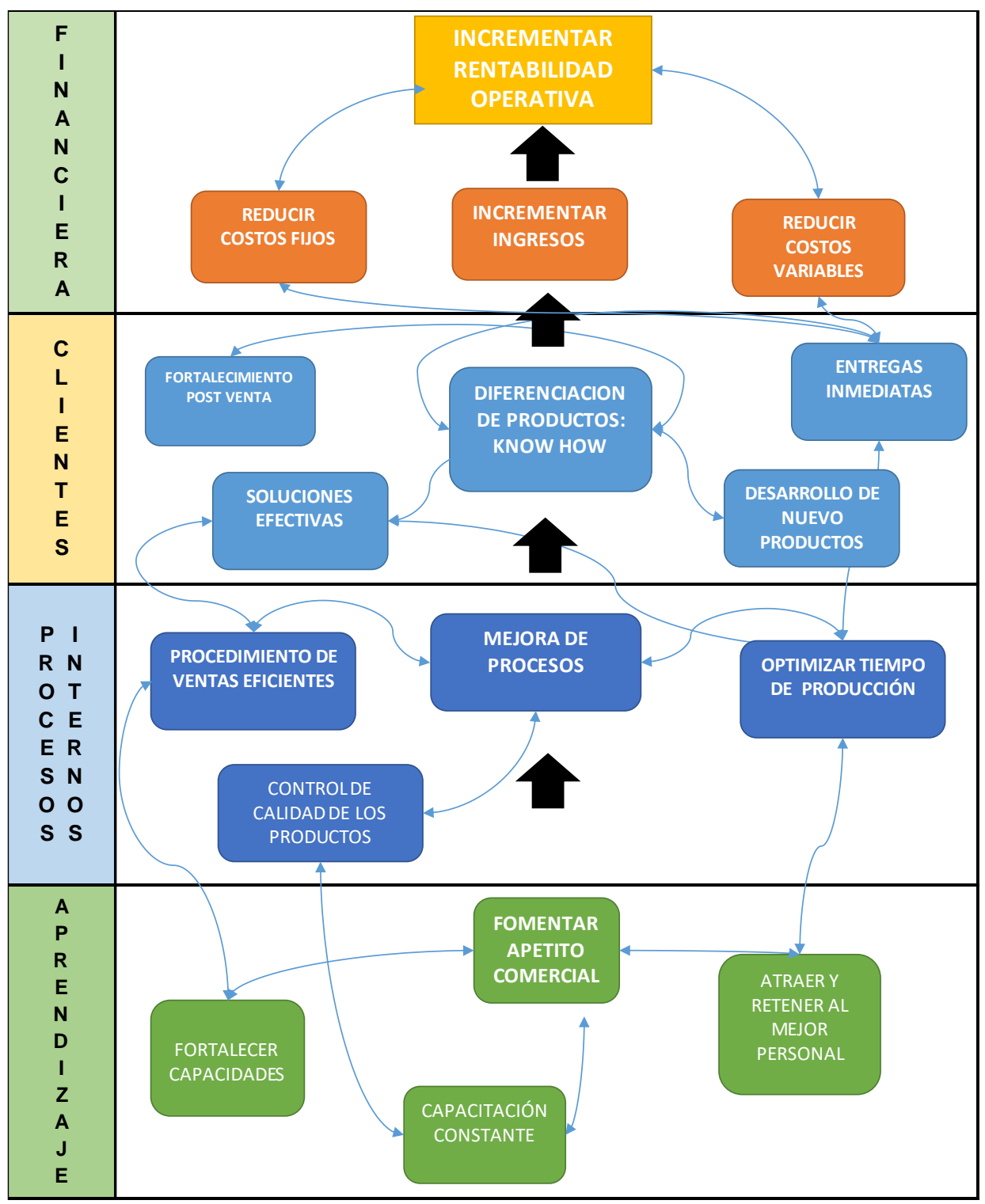

Figura $N^{\circ}$ 45. Mapa Estratégico. Nota: Elaboración propia 


\subsection{Objetivos estratégicos}

Los objetivos estratégicos permitirán a la empresa conocer su direccionamiento estratégico, es decir su visión o propósito empresarial, sin embargo, cada uno de ellos estarán basados bajo dos contextos diferentes, algunos de ellos se formularon a partir de generar valor tangible, es decir, rentabilidad, ingresos, productividad, entre otros. Y otros se enfocarán en el valor intangible, destacando factores como satisfacción del cliente, grado de formación de sus trabajadores, entre otros. Ahora bien los objetivos que se formularon pueden estar destinados a generar valor en factores tangibles como intangibles, sin embargo cada uno de ellos estarán representados con una relación causal provocando que el logro de uno dependerá directamente del otro, es por ello que a continuación se establecerá la descripción de cada uno de los objetivos corporativos previamente establecidos bajo las 4 perspectivas del Balanced Scorecard (Financiera, Cliente, Procesos Internos, Aprendizaje e Innovación).

\subsubsection{Objetivos Estratégicos:}

i. Incrementar la rentabilidad del negocio.

ii. Combinar estrategias de precios, promoción y ventas.

iii. Incrementar la productividad (mejorar los procesos).

iv. Potenciar el capital humano.

La definición de los objetivos específicos, para cada una de las perspectivas, ayudará a la empresa a sustentar cómo logrará la implantación de su estrategia para el horizonte de tiempo indicado. 
Luego de haber fijado los objetivos específicos, y establecido la conexión mediante relaciones causa-efecto, obtenemos el sustento resumido de la estrategia, el cual explica cómo la empresa logrará sus objetivos financieros a través de sus operaciones y procesos, el trabajo del personal, el manejo de los clientes y la habilidad estratégica de la gerencia.

\subsubsection{Objetivos específicos:}

Para el establecimiento de los objetivos estratégicos, hemos evaluado diferentes aspectos del negocio que impactan a cada una de las perspectivas de la estrategia, en el marco del Balanced Scorecard, descritos por los autores Kaplan y Norton:

\section{Perspectiva Financiera}

Los objetivos que se van a formular dentro de la perspectiva financiera serán las directrices finales que la organización espera lograr, es decir los resultados que se obtengan allí serán frutos de las perspectivas anteriores. La empresa debe enfocar sus esfuerzos en el fortalecimiento de las demás perspectivas a fin de generar resultados monetarios como: el aumento de ventas, rentabilidad, ingresos hasta generar valor a los accionistas. Para dicho fin se han formulado una serie de objetivos que garanticen a la compañía su estabilidad financiera y posicionamiento empresarial:

- Incrementar los Ingresos.

- Incrementar la rentabilidad.

- Mejorar la productividad.

- Reducir costos fijos en 5\%. 
- $\quad$ Reducir costos variables en 5\%.

\section{Perspectiva Clientes}

- Incrementar las ventas de cada línea del negocio.

- Desarrollar campañas de promoción y publicidad por redes sociales.

- Implementar un punto de venta céntrico.

- Lanzar nuevo producto.

- Reducir el tiempo de entrega de productos.

- Fortalecer la diferenciación (know how) de sus productos frente a los de la competencia.

\section{Perspectiva de Procesos Internos}

- Optimizar tiempo de producción.

- Optimizar tiempo de respuesta.

- Realizar seguimiento de control de calidad de productos.

- Identificar cuellos de botella en el flujo de producción.

- Implementar procedimientos de ventas eficientes.

\section{Perspectiva Aprendizaje}

- Implementar un plan de capacitación anual.

- Desarrollar habilidades especiales para el personal.

- Implementar sistemas de gestión.

- Formalizar organización y funciones. 
Tabla $\mathrm{N}^{\circ} 61$

Objetivos del Mapa Estratégico de SF Hermanos S.R.L.

\begin{tabular}{|c|}
\hline VISIÓN \\
\hline $\begin{array}{l}\text { "Ser reconocidos como una empresa de productos y servicios de alta calidad } \\
\text { en Lima Metropolitana" }\end{array}$ \\
\hline MISIÓN \\
\hline $\begin{array}{l}\text { "Somos una empresa dedicada a producir y comercializar muebles de } \\
\text { madera, acero, melamine, siguiendo los más altos estándares de calidad, } \\
\text { para brindar la plena satisfacción de nuestros clientes, con un personal } \\
\text { altamente capacitado. Procuramos alcanzar el máximo desarrollo y } \\
\text { rentabilidad en el ámbito en el que nos desenvolvemos, logrando así el } \\
\text { óptimo beneficio para nuestros accionistas". }\end{array}$ \\
\hline MAPA ESTRATÉGICO \\
\hline ¿En que debemos centrarnos para sostener financieramente nuestra $\mathrm{m}$ \\
\hline Incrementar los Ingresos \\
\hline Optimizar los gastos \\
\hline ¿Cómo deben vernos nuestros clientes para sastifacer nuestra visión? \\
\hline $\begin{array}{c}\text { Ser reconocidos por la calidad, diseños y especialización en los proyectos } \\
\text { realizados }\end{array}$ \\
\hline Tener productos variados y personalizados en el sector mobiliario \\
\hline Ser la mejor opción en proyectos mobiliarios \\
\hline $\begin{array}{l}\text { ¿En qué procesos operacionales debemos destacarnos para sastifacer a } \\
\text { nuestros clientes? }\end{array}$ \\
\hline Optimizar los tiempos de despacho \\
\hline Responder inmediatamente consultas y/o cotizaciones \\
\hline Fortalecer los procesos de venta \\
\hline Reducir el tiempo de producción de proyectos personalizados \\
\hline ¿Cómo mantendremos nuestra capacidad de cambiar y mejorar? \\
\hline Estimular el clima laboral \\
\hline Fortalecer capacidades de gestión \\
\hline Mejorar los sistemas de información \\
\hline
\end{tabular}

Nota: Elaboración Propia

En esta tabla se muestra la relación que tienen los objetivos en cada perspectiva y cómo estos han sido identificados a través de preguntas clave para el alineamiento. 
Se definieron los objetivos conectándolos bajo la relación causa-efecto, con las palabras SI y

\section{ENTONCES.}

\subsection{Indicadores}

Los indicadores son los que finalmente revelan si los objetivos trazados se están cumpliendo de acuerdo a la estrategia elegida. Los indicadores se interpretan como herramientas medibles que se han establecido para hacer seguimiento a los resultados, de manera que puedan analizarse, compararse y comunicarse. Los parámetros básicos y necesarios para adoptar un lineamiento de trabajo que busque alcanzar los objetivos propuestos para SF HERMANOS, inevitablemente involucran indicadores, cuyas mediciones deben ser transparentes y entendibles para quienes deberán hacer uso de ellas. Considerando que exista disponibilidad y razonabilidad, los indicadores han sido elaborados tomando en cuenta los siguientes atributos:

- Pertinencia (información conveniente y tomada en cuenta).

- Precisión (exactitud para recoger la información).

- Oportunidad (que es oportuna para el momento requerido).

- Confiabilidad (objetiva y carente de sesgo).

- Economía (eficiencia para obtener y usar la información).

A continuación, se listan los indicadores de cada perspectiva en base a los objetivos planteados, son los siguientes: 


\section{Perspectiva financiera}

\begin{tabular}{|l|c|}
\hline \multicolumn{1}{|c|}{ Objetivo } & Indicador \\
\hline Incrementar los Ingresos & Ventas \\
\hline Incrementar la rentabilidad & ROE \\
\hline Mejorar la productividad & Gastos/Ingresos \\
\hline Reducir costos fijos en un 5\% & Gastos Operativos \\
\hline Reducir costos variables en un 5\% & Gastos Operativos \\
\hline
\end{tabular}

\section{Perspectiva Clientes}

\begin{tabular}{|c|c|}
\hline Objetivo & Indicador \\
\hline $\begin{array}{c}\text { Incrementar las ventas de cada línea del } \\
\text { negocio }\end{array}$ & Porcentaje ventas (\%) \\
\hline $\begin{array}{c}\text { Desarrollar campañas de promoción y } \\
\text { publicidad por redes sociales }\end{array}$ & Encuestas \\
\hline $\begin{array}{c}\text { Implementar un punto de venta } \\
\text { céntrico. }\end{array}$ & Ventas \\
\hline $\begin{array}{c}\text { Lanzar nuevo producto } \\
\text { Reducir el tiempo de entrega de } \\
\text { productos }\end{array}$ & $\begin{array}{c}\text { \#Tiempo de entrega } \\
\text { prospecto }\end{array}$ \\
\hline $\begin{array}{c}\text { Fortalecer la diferenciación (know } \\
\text { anteriompo de entrega } \\
\text { how) de nuestros productos frente a los } \\
\text { de la competencia. }\end{array}$ & Encuestas \\
\hline
\end{tabular}

\section{Perspectiva procesos internos}

\begin{tabular}{|c|c|}
\hline Objetivo & Indicador \\
\hline Optimizar tiempo de producción & $\begin{array}{c}\text { Tiempo de producción } \\
\text { Act./Tiempo de producción } \\
\text { propuesto }\end{array}$ \\
\hline $\begin{array}{c}\text { Tiempo de respuesta } \\
\text { Optimizar tiempo de respuesta }\end{array}$ & $\begin{array}{c}\text { actual/tiempo de respuesta } \\
\text { propuesto }\end{array}$ \\
\hline $\begin{array}{c}\text { Realizar seguimiento de control de } \\
\text { calidad de productos }\end{array}$ & $\begin{array}{c}\text { Porcentaje de quejas y } \\
\text { devoluciones (\%) }\end{array}$ \\
\hline $\begin{array}{c}\text { Identificar cuellos de botella en el flujo } \\
\text { de producción }\end{array}$ & Tiempo de fabricación \\
\hline $\begin{array}{c}\text { Implementar procedimientos de ventas } \\
\text { eficientes }\end{array}$ & \# activaciones \\
\hline
\end{tabular}




\section{Perspectiva aprendizaje}

\begin{tabular}{|c|c|}
\hline Objetivo & Indicador \\
\hline $\begin{array}{c}\text { Implementar un plan de capacitación } \\
\text { anual }\end{array}$ & \# de trabajadores capacitados \\
\hline $\begin{array}{c}\text { Desarrollar habilidades especiales para } \\
\text { el personal }\end{array}$ & Taller de competencias \\
\hline Implementar sistemas de gestión & $\begin{array}{c}\text { \# Cantidad de errores del } \\
\text { sistema }\end{array}$ \\
\hline Formalizar organización y funciones & $\begin{array}{c}\text { Organigrama y manual de } \\
\text { organización y funciones }\end{array}$ \\
\hline
\end{tabular}




\subsection{Metas}

Las metas deben ser alcanzables y medibles las cuales las alineamos de acuerdos a los objetivos estratégicos y específicos:

Tabla $N^{\circ} 62$

Indicadores de SF Hermanos S.R.L.

\begin{tabular}{|c|c|c|}
\hline $\begin{array}{c}\text { Objetivos } \\
\text { Estratégicos }\end{array}$ & Objetivos específicos & Indicador \\
\hline \multirow{5}{*}{$\begin{array}{l}\text { Incrementar } \\
\text { la rentabilidad } \\
\text { del negocio }\end{array}$} & Incrementar los ingresos & Ventas \\
\hline & Incrementar la rentabilidad & ROE \\
\hline & Mejorar la productividad & Gastos/Ingresos \\
\hline & Reducir costos fijos en un 5\% & Gastos Operativos \\
\hline & Reducir costos variables en un $5 \%$ & Gastos Operativos \\
\hline \multirow{6}{*}{$\begin{array}{l}\text { Combinar } \\
\text { estrategias de } \\
\text { precios, } \\
\text { promoción y } \\
\text { ventas. }\end{array}$} & $\begin{array}{c}\text { Incrementar las ventas de cada línea del } \\
\text { negocio }\end{array}$ & $\%$ Ventas \\
\hline & $\begin{array}{c}\text { Desarrollar campañas de promoción y } \\
\text { publicidad por redes sociales }\end{array}$ & Encuestas \\
\hline & Implementar un punto de venta céntrico. & Ventas \\
\hline & Lanzar nuevo producto & Productos actuales/ Producto prospecto \\
\hline & $\begin{array}{l}\text { Reducir el tiempo de entrega de } \\
\text { productos }\end{array}$ & $\begin{array}{c}\text { \#tiempo de entrega anterior/\#tiempo de } \\
\text { entrega actual }\end{array}$ \\
\hline & $\begin{array}{l}\text { Fortalecer la diferenciación (know how) } \\
\text { de nuestros productos frente a los de la } \\
\text { competencia. }\end{array}$ & Encuestas \\
\hline \multirow{5}{*}{$\begin{array}{l}\text { Incrementar } \\
\text { la } \\
\text { productividad } \\
\text { (mejorar los } \\
\text { procesos) }\end{array}$} & Optimizar tiempo de producción & $\begin{array}{l}\text { Tiempo de producción Act./Tiempo de } \\
\text { producción propuesto }\end{array}$ \\
\hline & Optimizar tiempo de respuesta & $\begin{array}{c}\text { Tiempo de respuesta actual/tiempo de } \\
\text { respuesta propuesto }\end{array}$ \\
\hline & $\begin{array}{l}\text { Realizar seguimiento de control de } \\
\text { calidad de productos }\end{array}$ & $\%$ Quejas y devoluciones \\
\hline & $\begin{array}{l}\text { Identificar cuello de botellas en el flujo } \\
\text { de producción }\end{array}$ & Tiempo de fabricación \\
\hline & $\begin{array}{l}\text { Implementar procedimientos de ventas } \\
\text { eficientes }\end{array}$ & \# Activaciones \\
\hline
\end{tabular}




\begin{tabular}{|c|c|c|}
\hline \multirow{4}{*}{$\begin{array}{c}\text { Potenciar el } \\
\text { capital } \\
\text { humano }\end{array}$} & $\begin{array}{c}\text { Implementar un plan de capacitación } \\
\text { anual }\end{array}$ & \# de trabajadores capacitados \\
\cline { 2 - 3 } & $\begin{array}{c}\text { Desarrollar habilidades especiales para el } \\
\text { personal }\end{array}$ & Taller de competencias \\
\cline { 2 - 3 } & $\begin{array}{c}\text { Realizar seguimiento de control de } \\
\text { calidad de productos }\end{array}$ & Check list \\
\cline { 2 - 3 } & Implementar sistemas de gestión & \#cantidad de errores del sistema \\
\cline { 2 - 3 } & Formalizar organización y funciones & Organigrama y manual de organización y \\
& funciones \\
\hline
\end{tabular}

Nota: Elaboración Propia

Según la tabla anterior se define las metas siguientes:

En 3 años:

- Aumentar las ventas a 1.8 millones en todas las áreas.

- $\quad$ Llegar a un ROE de $20 \%$.

- $\quad$ Reducir los costos fijos en 5\%.

- $\quad$ Reducir los costos variables en 5\%.

- Aumentar en 30\% la recordación de la marca.

- Reducir el tiempo de entrega del proyecto un $20 \%$.

- Reducir el tiempo de producción a un $20 \%$.

- $\quad$ Reducir en un $80 \%$ las quejas y devoluciones en la realización del proyecto.

- Implementar el plan de capacitación anual.

- Tener técnicos especializados en cada área.

- Tener el sistema ERP actualizado de acuerdo a las operaciones que tiene la empresa.

En 1 año:

- Implementar el Manual de funciones y organización. 


\subsection{Iniciativas y acciones}

Son todas las actividades que se realizarán con el fin de llegar o superar las metas trazadas. Estas metas, son de alguna manera la razón por la sé cuál elige y evalúa un indicador, de esta forma la gerencia pueda tomar acciones y determinar cuánto se debe invertir para que la estrategia elegida logre resultados favorables.

a) Estudio del Sector A y B.- Se va a realizar un estudio de Mercado de tipo mixto (cualitativo y cuantitativo) a los hogares del sector A y B de los distritos de Lima Moderna, para poder determinar sus diferentes hábitos y costumbres respecto a su consumo de servicios de remodelación de sus viviendas. Se persigue los siguientes objetivos:

- Determinar la frecuencia de consumo.

- Determinar el nivel de gastos.

- Determinar el tipo de material y acabados que prefieren.

- Determina los servicios adicionales o asociados que prefieren.

- Determinar el medio de publicidad que más usan para enterarse de este tipo de servicios.

- Determinar el lugar apropiado para un local de exhibición y ventas.

- Determinar si la marca “¡Renuévate!” es de su agrado.

- Otros relacionados.

b) Contratación de personal para nuevo espacio de exhibición y venta.- Para el nuevo espacio a desarrollar se va a contratar el siguiente personal: 
Tabla $\mathrm{N}^{\circ} 63$

Planilla total

\begin{tabular}{ccc}
\hline Ítem & Puesto & $\begin{array}{c}\text { Sueldo básico } \\
\text { Mensual }\end{array}$ \\
\hline 1 & Administrador & S/. 4,000 \\
2 & Gestor comercial & S/. 2,500 \\
3 & Diseñador gráfico & S/. 2,500 \\
4 & Diseñador de interiores & S/. 4,000 \\
5 & Operarios a tiempo completo & S/. 1,500 \\
6 & Chofer & S/. 1,500 \\
7 & Armadores & S/. 1,200 \\
\hline & TOTAL & S/. 17,200
\end{tabular}

Nota: Elaboración Propia

En el caso del diseñador de interiores deberá encargarse de desarrollar y plantear los espacios que el cliente elija. Deberán cumplir con las siguientes funciones:

- Funciones:

a) Presentar los proyectos decorativos a los clientes, en sus distintas fases, de forma fiel y sugerente, empleando las técnicas más actuales.

b) Distribuir el espacio disponible de forma racional y flexible, buscando el equilibrio entre funcionalidad y estética.

c) Decidir las características técnicas de los revestimientos de suelos y paredes y utilizar los colores y texturas adecuados a la actividad que se vaya a desarrollar. 
Debe de cumplir con los siguientes requisitos:

- Requisitos:

- Experiencia: Mínimo 5 años en diseño de interiores.

- Educación: Egresado de arquitectura, diseño de interiores.

\section{d) Fortalecer las ventas}

- Diseñar un plan para tener presencia en redes sociales, para fortalecer la recordación y presencia de marca, ya que la mayoría de los consumidores actuales sostienen que conocen la marca por recomendaciones de fuentes cercanas.

- $\quad$ Elaborar un plan para impulsar las ventas en supermercados A-B de la marca.

- $\quad$ Mantener una estrategia de precios más asequibles para introducir el producto "Renuévate".

- $\quad$ Hacer campañas de mailing y/o de networking para hacer conocidas a las marcas en sector de Inmobiliarios.

- Diseñar un plan para tener presencia en las principales ferias y eventos que organizan el sector hogar y parrillas.

- Diseño de plan de promoción

El plan promocional constará de las siguientes actividades: 
Tabla $\mathrm{N}^{\circ} 64$

Descripción de la Estrategia

\begin{tabular}{|c|c|c|}
\hline ESTRATEGÍA & DESCRIPCIÓN & ACTIVIDADES \\
\hline Internet & $\begin{array}{l}\text { A través de la página web se } \\
\text { dará información sobre las } \\
\text { ventas corporativas y } \\
\text { promociones. }\end{array}$ & $\begin{array}{l}\text { Dentro de la página web de la empresa } \\
\text { habrá un espacio donde se dará } \\
\text { información de venta corporativa y } \\
\text { datos de contacto. }\end{array}$ \\
\hline $\begin{array}{l}\text { Marketing } \\
\text { Directo } \\
\text { (Relacional) }\end{array}$ & $\begin{array}{l}\text { La gestión de relación con los } \\
\text { clientes se va a formar a partir } \\
\text { de la integración conjunta con } \\
\text { las actividades de la empresa y } \\
\text { las actividades promocionales. } \\
\text { Se elaborará una base de datos } \\
\text { de clientes a través de la página } \\
\text { web, donde los usuarios podrán } \\
\text { registrarse con solo contestar un } \\
\text { mini cuestionario que alimentará } \\
\text { dicha base de datos generando } \\
\text { una retroalimentación. }\end{array}$ & $\begin{array}{l}\text { A los correos electrónicos de esta base } \\
\text { de datos se les enviará información de } \\
\text { esta nueva línea de producto que } \\
\text { ofrecerá SF Hermanos S.R.L. } \\
\text { De la misma manera se creará un "fan } \\
\text { page”, con la marca "iRenuévate!” } \\
\text { Donde se colocará toda la información } \\
\text { necesaria para difundir el nuevo punto } \\
\text { de venta, las ofertas y los diseños que } \\
\text { se ofrecen. }\end{array}$ \\
\hline Venta Personal & $\begin{array}{l}\text { La venta personal estará a cargo } \\
\text { de la fuerza de ventas quienes } \\
\text { serán los encargados de } \\
\text { contactar con los clientes y } \\
\text { ofrecer el producto. }\end{array}$ & $\begin{array}{l}\text { Habrá un personal de ventas que se } \\
\text { encargará de contactar a los clientes y } \\
\text { concertar citas con la finalidad de } \\
\text { ofrecer este nuevo producto } \\
\text { corporativo. } \\
\text { De la misma manera se atenderá en el } \\
\text { espacio de exhibición y venta } \\
\text { alquilado. } \\
\text { En este caso se incluirá lo que son } \\
\text { muestras de materiales y accesorios a } \\
\text { utilizar, así como material impreso } \\
\text { (brochure, tarjetas, catálogos) que se } \\
\text { entregará a los clientes }\end{array}$ \\
\hline
\end{tabular}

Nota: Elaboración Propia 


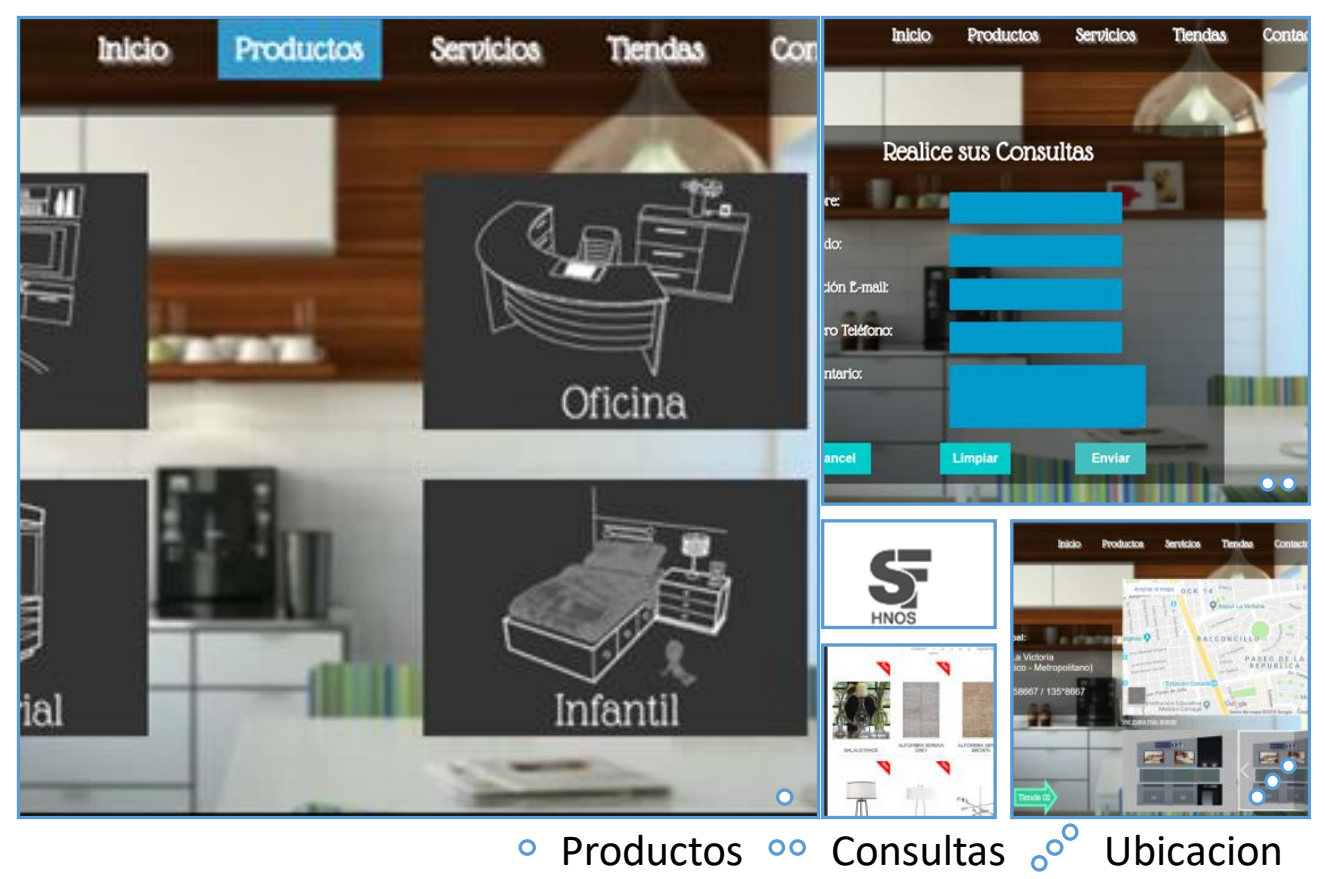

Figura $N^{\circ}$ 46. Diseño potencial de página Web. Nota: Pagina Web Decoart

\section{Compra de una unidad de transporte}

Se adquirirá una unidad de transporte, marca Hyundai, modelo HD 65, con una capacidad de carga de hasta 4 TM, MOTOR EURO III de 3907 CC, con potencia máxima de $2800 \mathrm{hp} / \mathrm{rpm}$, longitud de $6.075 \mathrm{mts}$.
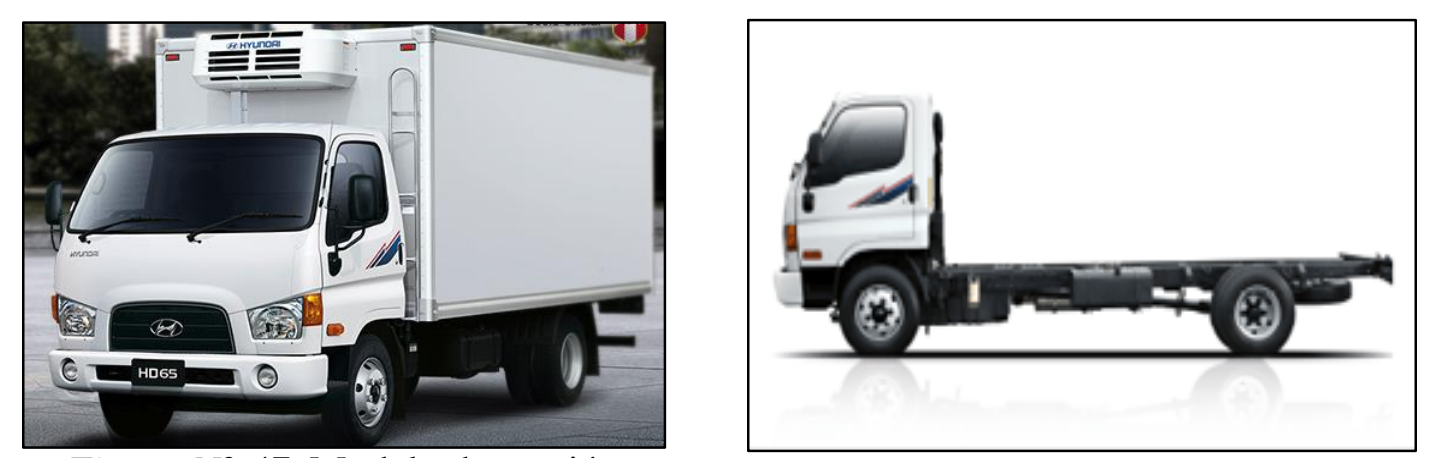

Figura $N^{\circ}$ 47. Modelo de camión a

comprar. Nota: Pagina Web Hyundai

http://www.hyundaicamiones.pe/hd-65-78/ 
e) Elevar la productividad:

- Definir estrategias orientadas a reducir y racionalizar costos de operación.

- Desarrollar herramientas para gestión de negocios (estadísticas e inteligencia de negocios).

f) Mejorar el sistema de gestión

- Evaluar el funcionamiento del Sistema ERP de la empresa.

g) Mejorar el clima laboral.

- Desarrollar el talento humano en un clima laboral armonioso.

- Revisar y proponer un organigrama con su descripción de puestos.

- Elaborar el manual de organización y funciones.

- Desarrollar un plan para programas de capacitación para el personal.

- Desarrollar un plan de actividades de motivación para el personal administrativo y que incorpore e involucre a la actual Dirección.

\subsection{Responsables}

Las actividades descritas tendrán a las siguientes personas como responsables encargadas de su ejecución (si se da en un solo momento) y monitoreo (si es una actividad que dura algún tiempo): 
Tabla $N^{\circ} 65$

Responsabilidades de actividades

\begin{tabular}{|c|c|c|c|}
\hline Ítem & Actividades & Responsable & $\mathrm{Cargo}^{1}$ \\
\hline 1 & $\underset{B}{\text { Estudio de hogares de NSE A y }}$ & Matías Cárdenas & Jefe de ventas \\
\hline 2 & Estimación de la demanda & Matías Cárdenas & Jefe de ventas \\
\hline 3 & $\begin{array}{c}\text { Evaluación de capacidad } \\
\text { operativa }\end{array}$ & $\begin{array}{l}\text { Miguel Sánchez } \\
\text { Silvia Cárdenas. }\end{array}$ & $\begin{array}{c}\text { Jefe de } \\
\text { producción jefe } \\
\text { de logística }\end{array}$ \\
\hline 4 & Contratación de administrador & Lilian Cárdenas C. & Gerente General \\
\hline 5 & Contratación de personal & Personal Nuevo & Administrador $^{2}$ \\
\hline 6 & Evaluación de sistema ERP & Personal Nuevo & Administrador $^{2}$ \\
\hline 7 & $\begin{array}{l}\text { Definición de nuevo tipo de } \\
\text { oferta dirigida }\end{array}$ & Personal Nuevo & Administrador $^{2}$ \\
\hline 8 & Alquiler de local & $\begin{array}{c}\text { Fortunato Cárdenas } \\
\text { A. }\end{array}$ & $\begin{array}{l}\text { Gerente } \\
\text { Financiero }\end{array}$ \\
\hline 9 & Diseño de plan de promoción & $\begin{array}{l}\text { Personal Nuevo } \\
\text { Personal nuevo }\end{array}$ & $\begin{array}{l}\text { Administrador }^{2} \\
\text { Administrador }^{2}\end{array}$ \\
\hline 10 & Compra de unidad & $\begin{array}{l}\text { Fortunato Cárdenas } \\
\text { A. }\end{array}$ & $\begin{array}{l}\text { Gerente } \\
\text { Financiero }\end{array}$ \\
\hline 11 & Implementación de local & $\begin{array}{c}\text { Personal nuevo } \\
\text { Fortunato Cárdenas } \\
\text { A. }\end{array}$ & $\begin{array}{c}\text { Administrador }{ }^{2} \\
\text { Gerente } \\
\text { Financiero }\end{array}$ \\
\hline 12 & Desarrollo de la publicidad & Personal Nuevo & Administrador $^{2}$ \\
\hline 13 & $\begin{array}{l}\text { Lanzamiento del producto } \\
\text { "Renuevate" }\end{array}$ & $\begin{array}{l}\text { Personal Nuevo } \\
\text { Lilian Cárdenas C. }\end{array}$ & $\begin{array}{l}\text { Administrador }^{2} \\
\text { Gerente General }\end{array}$ \\
\hline
\end{tabular}

(2) Cuando hay dos personas es responsabilidad compartida

(3) Nuevo personal de responsabilidad por contratar.

Nota: Elaboración Propia

\subsection{Presupuesto}

El plan para el desarrollo del nuevo segmento A y B contempla los siguientes ítems de inversión: 
Inversión Tangible.- Compuesto por la implementación de la oficina de los nuevos representantes comerciales, las unidades de transporte para la distribución y los espacios de exhibición, se invertirá en total S/ 296,967 soles con el siguiente detalle:

Tabla $\mathrm{N}^{\circ} 66$

Inversión Tangible

\begin{tabular}{cccccc}
\hline Ítem & Descripción & Cantidad & $\begin{array}{c}\text { Pr. Unit } \\
\text { S/ }\end{array}$ & Total S/ & $\begin{array}{c}\text { Total S/. } \\
\text { sin IGV }\end{array}$ \\
\hline 1 & $\begin{array}{c}\text { Implementación de oficina y } \\
\text { call center }\end{array}$ & 1 & S/. 30,000 & S/. 30,000 & S/. 25,424 \\
2 & $\begin{array}{c}\text { Unidad de transporte } \\
\text { Implementación de centro de } \\
\text { exhibición }\end{array}$ & 1 & $\begin{array}{c}\text { S/. 66,967 } \\
\text { S/. }\end{array}$ & S/. 66,967 & S/. 56,751 \\
\hline & Total Inversión Tangible & & S/. 200, 2000,000 & S/. 169,492 \\
\hline
\end{tabular}

Nota: Elaboración Propia

Inversión Intangible.- Compuesto por las autorizaciones e inspecciones para la aprobación de local de almacenaje, los costos de ocupación de local (garantías y adelantos), finalmente el costo de campaña virtual, acondicionamiento de web y material impreso (marketing). Se puede ver el detalle en la siguiente tabla:

Tabla $\mathrm{N}^{\circ} 67$

Inversión Intangible

\begin{tabular}{rlcrrr}
\hline Ítem & Descripción & Cantidad & Pr. Unit S/ & Total S/ & $\begin{array}{c}\text { Total S/. sin } \\
\text { IGV }\end{array}$ \\
\hline 1 & Software y antivirus & 1 & S/. 1,000 & S/. 1,000 & S/. 847 \\
2 & Autorizaciones y licencias & 1 & S/. 2,000 & S/. 2,000 & S/. 2,000 \\
3 & $\begin{array}{l}\text { Garantía de alquiler centro } \\
\text { de exhibición }\end{array}$ & 3 & S/. 13,400 & S/. 40,200 & S/. 34,068 \\
4 & Marketing de lanzamiento & 1 & S/. 11,000 & S/. 11,000 & S/. 9,322 \\
\hline & Total Inversión Intangible & & & S/. 54,200 & S/. 46,237 \\
\hline
\end{tabular}

Nota: Elaboración Propia 
Marketing de lanzamiento.- Durante el mes previo al lanzamiento se van a realizar un conjunto de acciones que van a permitir ingresar y obtener los resultados de venta esperados. El gasto en la campaña de publicidad por Facebook, el gasto operativo en visitas, muestras y otros, así como el material impreso, se puede observar en la siguiente tabla:

Tabla $\mathrm{N}^{\circ} 68$

Marketing de Lanzamiento

\begin{tabular}{ccrrrr}
\hline Item & Actividad & Cantidad & Pr. Unit S/ & \multicolumn{1}{l}{ Total S/ } & $\begin{array}{c}\text { Total S/. sin } \\
\text { IGV }\end{array}$ \\
\hline 1 & Campaña Facebook & 4 & S/. 1,000 & S/. 4,000 & S/. 3,390 \\
2 & Visitas y muestras & 100 & S/. 50 & S/. 5,000 & S/. 4,237 \\
3 & Materiales impresos & 1,000 & S/. 2 & S/. 2,000 & S/. 1,695 \\
\hline & Total de Gastos & & & S/. 11,000 & S/. 9,322 \\
\hline
\end{tabular}

Nota: Elaboración Propia

Capital de trabajo.- Compuesto por el equivalente a 30 días del costo de producción del año previo, según se muestra en la siguiente tabla:

Tabla $\mathrm{N}^{\circ} 69$

Capital de Trabajo Incremental

\begin{tabular}{lrrrr}
\hline \multicolumn{1}{c}{ Concepto } & 2018 & \multicolumn{1}{c}{2019} & \multicolumn{1}{c}{2020} & \multicolumn{1}{c}{2021} \\
\hline Presupuesto anual de materiales & & S/. 796,391 & S/. 830,238 & S/. 866,139 \\
\hline Stock de materiales (cobertura) & & S/. 66,366 & S/. 69,187 & S/. 72,178 \\
\hline KW Incremental & S/. 66,366 & S/. 2,821 & S/. 2,992 & S/. 2,992 \\
\hline
\end{tabular}

Nota: Elaboración Propia

Planilla.- Se contempla la contratación de un equipo adicional de 13 personas para el nuevo espacio de exhibición y venta. Dicho equipo estará a cargo de un administrador que será 
responsable de la gestión y administración de los recursos asignados. Existirán dos gestores comerciales que generarán la base de clientes y se encargarán de concretar las ventas.

Completan el equipo el diseñador especializado en interiores y acabados y un diseñador gráfico. Finalmente, los operarios que se encargaran del traslado y armado de los diferentes espacios. El nivel salarial y el gasto representado para la empresa se muestran en las siguientes tablas:

Tabla $\mathrm{N}^{\circ} 70$

Planilla del proyecto por centro de costos

\begin{tabular}{|c|c|c|c|c|c|}
\hline Área & Puestos & 2019 & 2020 & 2021 & $\begin{array}{l}\text { Remuneración } \\
\text { Mensuales S/. }\end{array}$ \\
\hline Administración & Administrador & 1 & 1 & 1 & $\mathrm{~S} / .4,000$ \\
\hline Ventas & Gestor comercial & 2 & 2 & 2 & $\mathrm{~S} / .2,500$ \\
\hline CIF & Diseñador gráfico & 1 & 1 & 1 & $\mathrm{~S} / .2,500$ \\
\hline CIF & Diseñador de interiores & 2 & 2 & 2 & S/. 4,000 \\
\hline MOD & Operarios a tiempo completo & 3 & 3 & 3 & $\mathrm{~S} / .1,500$ \\
\hline $\mathrm{CIF}$ & Chofer & 1 & 1 & 1 & S/. 1,500 \\
\hline \multirow[t]{2}{*}{ MOD } & Armadores & 3 & 3 & 3 & S/. 1,200 \\
\hline & Total & 13 & 13 & 13 & S/. 17,200 \\
\hline
\end{tabular}

Nota: Elaboración Propia

Tabla $\mathrm{N}^{\circ} 71$

Gasto total por planilla

\begin{tabular}{lrrr}
\hline \multicolumn{1}{c}{ Área } & \multicolumn{1}{c}{2019} & \multicolumn{1}{c}{2020} & \multicolumn{1}{c}{2021} \\
\hline Administración & S/. 67,234 & S/. 67,234 & S/. 67,234 \\
Ventas & S/. 106,402 & S/. 107,413 & S/. 108,343 \\
CIF & S/. 203,231 & S/. 203,231 & S/. 203,231 \\
MOD & S/. 142,222 & S/. 142,222 & S/. 142,222 \\
\hline \multicolumn{1}{c}{ Total } & S/. 519,089 & S/. 520,100 & S/. 521,030 \\
\hline
\end{tabular}

Nota: Elaboración Propia 
Gastos administrativos y de venta.- Para el gasto administrativo se considera el $9.5 \%$ del gasto regular de la empresa, la depreciación de la implementación de la oficina, la amortización del software y licencias además del sueldo del nuevo administrador y del contador. Respecto al gasto de ventas, se considera también el 9.5\% del gasto regular de la empresa, además de la depreciación de la unidad de transporte y el local comercial, la amortización de la garantía y el marketing de lanzamiento, sueldo del personal de ventas y los gastos por visitas y publicidad. Ambos gastos se detallan a continuación:

Tabla $\mathrm{N}^{\circ} 72$

Gastos de administración del proyecto

\begin{tabular}{lcrrr}
\hline \multicolumn{1}{c}{ Concepto } & \multicolumn{1}{c}{2019} & \multicolumn{1}{c}{2020} & \multicolumn{1}{c}{2021} \\
\hline Depreciación Imp. Oficina y call center & $100.0 \%$ & $\mathrm{~S} / .2,542$ & $\mathrm{~S} / .2,542$ & $\mathrm{~S} / .2,542$ \\
Amortización Software y antivirus & $100.0 \%$ & $\mathrm{~S} / .212$ & $\mathrm{~S} / .212$ & $\mathrm{~S} / .212$ \\
Amortización Autorizaciones y licencias & $100.0 \%$ & $\mathrm{~S} / .100$ & $\mathrm{~S} / .100$ & $\mathrm{~S} / .100$ \\
Luz & $9.5 \%$ & $\mathrm{~S} / .285$ & $\mathrm{~S} / .297$ & $\mathrm{~S} / .309$ \\
Agua & $9.5 \%$ & $\mathrm{~S} / .114$ & $\mathrm{~S} / .119$ & $\mathrm{~S} / .124$ \\
Arbitrios & $9.5 \%$ & $\mathrm{~S} / .190$ & $\mathrm{~S} / .190$ & $\mathrm{~S} / .190$ \\
Alquiler & $9.5 \%$ & $\mathrm{~S} / .15,255$ & $\mathrm{~S} / .15,255$ & $\mathrm{~S} / .15,255$ \\
Insumos de mantenimiento y limpieza & $9.5 \%$ & $\mathrm{~S} / .214$ & $\mathrm{~S} / .223$ & $\mathrm{~S} / .233$ \\
Útiles de oficina & $9.5 \%$ & $\mathrm{~S} / .27$ & $\mathrm{~S} / .28$ & $\mathrm{~S} / .29$ \\
Internet y teléfono & $9.5 \%$ & $\mathrm{~S} / .215$ & $\mathrm{~S} / .225$ & $\mathrm{~S} / .234$ \\
Servicio de contabilidad & $100.0 \%$ & $\mathrm{~S} / .18,000$ & $\mathrm{~S} / .18,000$ & $\mathrm{~S} / .18,000$ \\
Sueldos administración & $100.0 \%$ & $\mathrm{~S} / .67,234$ & $\mathrm{~S} / .67,234$ & $\mathrm{~S} / .67,234$ \\
\hline Total de Gastos & & $\mathrm{S} / .104,388$ & $\mathrm{~S} / .104,425$ & $\mathrm{~S} / .104,463$ \\
\hline Nota: Elaboración Propia & & & &
\end{tabular}




\section{Tabla $\mathrm{N}^{\circ} 73$}

Gastos de ventas del proyecto

\begin{tabular}{lcrrr}
\hline \multicolumn{1}{c}{ Concepto } & \multicolumn{1}{c}{2019} & \multicolumn{1}{c}{2020} & \multicolumn{1}{c}{2021} \\
\hline Depreciación Unidad de transporte & $100.0 \%$ & $\mathrm{~S} / .11,350$ & $\mathrm{~S} / .11,350$ & $\mathrm{~S} / .11,350$ \\
Depreciación Centro de exhibición & $100.0 \%$ & $\mathrm{~S} / .16,949$ & $\mathrm{~S} / .16,949$ & $\mathrm{~S} / .16,949$ \\
Amortización Gtía alquiler centro exhib. & $100.0 \%$ & $\mathrm{~S} / .34,068$ & $\mathrm{~S} / .0$ & $\mathrm{~S} / .0$ \\
Amortización Marketing de lanzamiento & $100.0 \%$ & $\mathrm{~S} / .9,322$ & $\mathrm{~S} / .0$ & $\mathrm{~S} / .0$ \\
Luz & $9.5 \%$ & $\mathrm{~S} / .285$ & $\mathrm{~S} / .297$ & $\mathrm{~S} / .309$ \\
Agua & $9.5 \%$ & $\mathrm{~S} / .114$ & $\mathrm{~S} / .119$ & $\mathrm{~S} / .124$ \\
Arbitrios & $9.5 \%$ & $\mathrm{~S} / .190$ & $\mathrm{~S} / .190$ & $\mathrm{~S} / .190$ \\
Alquiler & $9.5 \%$ & $\mathrm{~S} / .15,255$ & $\mathrm{~S} / .15,255$ & $\mathrm{~S} / .15,255$ \\
Insumos de mantenimiento y limpieza & $9.5 \%$ & $\mathrm{~S} / .214$ & $\mathrm{~S} / .223$ & $\mathrm{~S} / .233$ \\
Útiles de oficina & $9.5 \%$ & $\mathrm{~S} / .27$ & $\mathrm{~S} / .28$ & $\mathrm{~S} / .29$ \\
Internet y teléfono & $9.5 \%$ & $\mathrm{~S} / .215$ & $\mathrm{~S} / .225$ & $\mathrm{~S} / .234$ \\
Sueldos ventas & $100.0 \%$ & $\mathrm{~S} / .106,402$ & $\mathrm{~S} / .107,413$ & $\mathrm{~S} / .108,343$ \\
Visitas & $100.0 \%$ & $\mathrm{~S} / .6,000$ & $\mathrm{~S} / .6,000$ & $\mathrm{~S} / .6,000$ \\
Gastos de publicidad & $100.0 \%$ & $\mathrm{~S} / .33,515$ & $\mathrm{~S} / .33,515$ & $\mathrm{~S} / .33,515$ \\
\hline Total de Gastos & & $\mathrm{S} / .233,906$ & $\mathrm{~S} / .191,564$ & $\mathrm{~S} / .192,532$ \\
\hline Nota: Elaboración Propia & & & &
\end{tabular}

\subsection{Cronograma de actividades}

Las actividades descritas en los puntos anteriores serán desarrolladas en el lapso de 4 meses y de manera consecutiva en la mayoría de los casos. Se puede apreciar el detalle de duración de cada una de ellas en la siguiente tabla: 
Tabla $\mathrm{N}^{\circ} 74$

Cronograma de actividades

\begin{tabular}{|c|c|c|c|c|c|c|}
\hline \multirow{2}{*}{$\mathrm{N}^{\circ}$} & $\begin{array}{l}\text { Año } \\
\text { Meses }\end{array}$ & \multicolumn{5}{|l|}{2018} \\
\hline & Actividad / Semana & $\begin{array}{lll}1 & 2 & 3\end{array}$ & 4 & $\begin{array}{llll}1 & 2 & 3 & 4\end{array}$ & $\begin{array}{llll}1 & 2 & 3 & 4\end{array}$ & $\begin{array}{llll}1 & 2 & 3 & 4\end{array}$ \\
\hline 1 & $\begin{array}{l}\text { Estudio de hogares de } \\
\text { NSE A y B }\end{array}$ & & & & & \\
\hline 2 & $\begin{array}{l}\text { Estimación de la } \\
\text { demanda }\end{array}$ & & & & & \\
\hline 3 & $\begin{array}{l}\text { Evaluación de capacidad } \\
\text { operativa }\end{array}$ & & & & & \\
\hline 4 & $\begin{array}{l}\text { Contratación de } \\
\text { administrador }\end{array}$ & & & & & \\
\hline 5 & Contratación de personal & & & & & \\
\hline 6 & $\begin{array}{l}\text { Elaboración de plan de } \\
\text { marketing }\end{array}$ & & & & & \\
\hline 7 & $\begin{array}{l}\text { Definición de nuevo tipo } \\
\text { de oferta dirigida }\end{array}$ & & & & & \\
\hline 8 & Alquiler de local & & & & & \\
\hline 9 & $\begin{array}{l}\text { Diseño de plan de } \\
\text { promoción }\end{array}$ & & & & & \\
\hline 10 & Compra de unidad & & & & & \\
\hline 11 & Implementación de local & & & & & \\
\hline 12 & $\begin{array}{l}\text { Desarrollo de banner y } \\
\text { material impreso }\end{array}$ & & & & & \\
\hline 13 & Lanzamiento & & & & & \\
\hline
\end{tabular}

Nota: Elaboración Propia 


\section{Capítulo X: Evaluación Financiera}

\subsection{Evaluación cualitativa}

\subsubsection{Criterios de evaluación}

Se considera los siguientes factores de evaluación para garantizar la sostenibilidad de la estrategia planteada:

\section{Posicionamiento}

Que a nivel de mercado la marca "Renuévate" sea reconocido ampliamente en el segmento hogares y la marca tenga una recordación positiva en los clientes (posicionamiento de marca) y que tenga un producto de calidad y un excelente servicio (posicionamiento de producto).

\section{Tamaño de segmento}

Que el segmento sea amplio y garantice un espacio de crecimiento con el transcurrir de los años.

\section{Abastecimiento}

Que existan proveedores que garantice el abastecimiento de los insumos y materiales necesarias, a nivel nacional e internacional. 


\section{Financiamiento y Capital de trabajo}

Que exista fuentes de financiamiento (externas e internas), para cubrir el nivel de inversión requerido en activos fijos e intangibles, de igual manera el capital de trabajo necesario para poder tener una producción oportuna.

\subsubsection{Comparación de la estrategia con los criterios}

\section{Posicionamiento}

El nivel de posicionamiento de la empresa SF Hermanos S.R.L. es regular en el sector en general. Dentro del segmento hogares se buscará posicionar la marca "Renuévate" a través de la web, las redes sociales y un buen servicio post venta.

\section{Tamaño de segmento}

El segmento de hogares que tiene un nivel de crecimiento constante en los últimos años, tal como se puede observar en el cuadro continuación:

Tabla $\mathrm{N}^{\circ} 75$

Mercado total

\begin{tabular}{cccccc}
\hline Ítem & Distritos & 2018 & 2019 & 2020 & 2021 \\
\hline 1 & Jesús María & 71,814 & 71,889 & 71,964 & 72,040 \\
2 & Lince & 47,587 & 46,678 & 45,769 & 44,860 \\
3 & Magdalena & 54,928 & 55,018 & 55,108 & 55,198 \\
4 & Pueblo Libre & 75,338 & 75,054 & 74,771 & 74,488 \\
5 & San Miguel & 136,046 & 136,199 & 136,353 & 136,507 \\
6 & Miraflores & 79,654 & 78,846 & 78,038 & 77,230 \\
7 & La Molina & 185,526 & 190,050 & 194,574 & 199,099 \\
8 & San Borja & 112,288 & 112,408 & 112,528 & 112,648 \\
9 & San Isidro & 51,982 & 51,209 & 50,436 & 49,664 \\
10 & Surco & 362,211 & 368,000 & 373,790 & 379,579 \\
\hline \multicolumn{7}{c}{ TOTAL } & $1,177,373$ & $1,185,353$ & $1,193,333$ & $1,201,313$ \\
\hline
\end{tabular}

Nota: Instituto Nacional de Estadística e Informática 
El mercado total es hallado a partir de la totalidad de hogares de los distritos elegidos, hogares que estén dispuestos a remodelar y podrían elegir el servicio renuévate.

Asimismo, el nivel NSE A y B en los distritos objetivos, se puede ver a continuación:

Tabla $\mathrm{N}^{\circ} 76$

NSE en Lima Moderna

\begin{tabular}{ccccc}
\hline Ítem & Distritos & NSE A & NSE B & A + B \\
\hline 1 & Jesús María & $1.70 \%$ & $77.90 \%$ & $79.60 \%$ \\
2 & Lince & $2.40 \%$ & $64.90 \%$ & $67.30 \%$ \\
3 & Magdalena & $19.50 \%$ & $66.70 \%$ & $86.20 \%$ \\
4 & Pueblo Libre & $1.00 \%$ & $88.50 \%$ & $89.50 \%$ \\
5 & San Miguel & $0.80 \%$ & $80.40 \%$ & $81.20 \%$ \\
6 & Miraflores & $52.90 \%$ & $41.90 \%$ & $94.80 \%$ \\
7 & La Molina & $44.10 \%$ & $41.90 \%$ & $86.00 \%$ \\
8 & San Borja & $43.40 \%$ & $54.60 \%$ & $98.00 \%$ \\
9 & San Isidro & $62.40 \%$ & $36.00 \%$ & $98.40 \%$ \\
10 & Surco & $35.90 \%$ & $43.60 \%$ & $79.50 \%$ \\
\hline
\end{tabular}

Nota: Instituto Nacional de Estadística e Informática

Adicionalmente se han determinado las edades de la población de dichos distritos, esto se ve reflejado en el siguiente cuadro:

Tabla $\mathrm{N}^{\circ} 77$

NSE en Lima Moderna

\begin{tabular}{clcccccccc}
\hline & \multicolumn{9}{c}{ Edad } \\
\hline Item & Distritos & $\mathbf{2 5 - 2 9}$ & $\mathbf{3 0}-$ & $\mathbf{3 5}-$ & $\mathbf{4 0 - 4 4}$ & $\mathbf{4 5}-$ & $\mathbf{5 0}-$ & $\mathbf{5 5}$ & TOTAL \\
1 & Jesús María & $7.57 \%$ & $7.66 \%$ & $7.35 \%$ & $6.53 \%$ & $6.79 \%$ & $7.12 \%$ & $1.22 \%$ & $44.2 \%$ \\
2 & Lince & $7.80 \%$ & $7.80 \%$ & $7.42 \%$ & $6.69 \%$ & $6.97 \%$ & $7.09 \%$ & $0.85 \%$ & $44.6 \%$ \\
3 & Magdalena & $7.38 \%$ & $8.01 \%$ & $7.37 \%$ & $6.62 \%$ & $7.16 \%$ & $6.98 \%$ & $0.90 \%$ & $44.4 \%$ \\
4 & Pueblo Libre & $7.20 \%$ & $7.43 \%$ & $7.04 \%$ & $6.66 \%$ & $7.25 \%$ & $6.99 \%$ & $1.25 \%$ & $43.8 \%$ \\
5 & San Miguel & $7.78 \%$ & $7.98 \%$ & $7.71 \%$ & $6.85 \%$ & $7.02 \%$ & $6.50 \%$ & $2.06 \%$ & $45.9 \%$ \\
6 & Miraflores & $7.59 \%$ & $8.30 \%$ & $7.72 \%$ & $6.60 \%$ & $7.35 \%$ & $7.47 \%$ & $1.54 \%$ & $46.6 \%$ \\
7 & La Molina & $7.64 \%$ & $7.69 \%$ & $7.77 \%$ & $6.94 \%$ & $6.98 \%$ & $6.94 \%$ & $2.74 \%$ & $46.7 \%$ \\
8 & San Borja & $7.55 \%$ & $7.87 \%$ & $7.83 \%$ & $6.83 \%$ & $6.88 \%$ & $6.79 \%$ & $1.82 \%$ & $45.6 \%$ \\
9 & San Isidro & $6.74 \%$ & $6.98 \%$ & $7.50 \%$ & $7.24 \%$ & $7.44 \%$ & $7.60 \%$ & $0.99 \%$ & $44.5 \%$ \\
10 & Surco & $7.40 \%$ & $7.89 \%$ & $8.09 \%$ & $7.11 \%$ & $7.21 \%$ & $6.66 \%$ & $5.15 \%$ & $49.5 \%$ \\
\hline
\end{tabular}

Nota: Instituto Nacional de Estadística e Informática 
Con esta información se ha podido determinar el mercado potencial, el cual es producto de restringir el mercado total por nivel socio económico y por edades. Se muestra los hogares que son del NSE A y B:

Tabla $\mathrm{N}^{\circ} 78$

Mercado potencial

\begin{tabular}{cccccc}
\hline Ítem & Distritos & 2018 & 2019 & 2020 & 2021 \\
\hline 1 & Jesús María & 25,279 & 25,305 & 25,331 & 25,358 \\
2 & Lince & 14,290 & 14,017 & 13,744 & 13,472 \\
3 & Magdalena & 21,032 & 21,067 & 21,101 & 21,136 \\
4 & Pueblo Libre & 29,549 & 29,438 & 29,327 & 29,216 \\
5 & San Miguel & 50,692 & 50,749 & 50,806 & 50,864 \\
6 & Miraflores & 35,170 & 34,814 & 34,457 & 34,100 \\
7 & La Molina & 74,525 & 76,342 & 78,160 & 79,977 \\
8 & San Borja & 50,135 & 50,189 & 50,242 & 50,296 \\
9 & San Isidro & 22,761 & 22,423 & 22,084 & 21,746 \\
10 & Surco & 142,569 & 144,848 & 147,127 & 149,405 \\
\hline \multicolumn{7}{c}{ TOTAL } & 466,002 & 469,192 & 472,379 & 475,570 \\
\hline
\end{tabular}

Nota: Instituto Nacional de Estadística e Informática

En la investigación de mercado realizada se ha obtenido la información que indica que el 74\% de los hogares desea refaccionar su hogar, se puede apreciar el dato a continuación:

Tabla $\mathrm{N}^{\circ} 79$

Nivel porcentual de personas que desean remodelar

\begin{tabular}{ccccc}
\hline NRO & Pregunta 7 & SI \% & NO \% & TOTAL \\
\hline & $\begin{array}{c}\text { ¿Considera remodelar } \\
\text { alguno de sus ambientes } \\
\text { en el corto o mediano } \\
\text { plazo? }\end{array}$ & $73.96 \%$ & $26.04 \%$ & $100.0 \%$ \\
& & & & \\
\hline
\end{tabular}

Nota: Elaboración propia 
Tabla $\mathrm{N}^{\circ} 80$

Nivel porcentual de personas que desean contratar una empresa para la remodelación

\begin{tabular}{ccccc}
\hline NRO & Pregunta 8 & SI \% & NO \% & TOTAL \\
\hline 1 & $\begin{array}{c}\text { ¿Considera contratar una } \\
\text { empresa para que se } \\
\text { encargue de dicho } \\
\text { servicio? }\end{array}$ & $71.13 \%$ & $28.87 \%$ & $100.0 \%$ \\
\hline & & & \\
\hline
\end{tabular}

Nota: Elaboración propia

Considerando el criterio anterior se puede ver los hogares que desean remodelar en Lima Moderna.

Tabla $\mathrm{N}^{\circ} 81$

Mercado disponible

\begin{tabular}{ccccccc}
\hline Ítem & Distritos & P7 & P8 & 2019 & 2020 & 2021 \\
\hline 1 & Jesús María & $73.96 \%$ & $71.13 \%$ & 13,311 & 13,325 & 13,339 \\
2 & Lince & $73.96 \%$ & $71.13 \%$ & 7,373 & 7,229 & 7,086 \\
3 & Magdalena & $73.96 \%$ & $71.13 \%$ & 11,082 & 11,100 & 11,118 \\
4 & Pueblo Libre & $73.96 \%$ & $71.13 \%$ & 15,485 & 15,427 & 15,368 \\
5 & San Miguel & $73.96 \%$ & $71.13 \%$ & 26,696 & 26,726 & 26,756 \\
6 & Miraflores & $73.96 \%$ & $71.13 \%$ & 18,313 & 18,125 & 17,938 \\
7 & La Molina & $73.96 \%$ & $71.13 \%$ & 40,159 & 41,115 & 42,071 \\
8 & San Borja & $73.96 \%$ & $71.13 \%$ & 26,401 & 26,429 & 26,457 \\
9 & San Isidro & $73.96 \%$ & $71.13 \%$ & 11,795 & 11,617 & 11,439 \\
10 & Surco & $73.96 \%$ & $71.13 \%$ & 76,196 & 77,394 & 78,593 \\
\hline \multicolumn{7}{c}{ TOTAL } \\
\hline
\end{tabular}

Nota: Elaboración propia

El mercado efectivo considerado por la estrategia planteada es el siguiente: 


\section{Tabla $N^{\circ} 82$}

Hogares dispuestos a solicitar el servicio "Renuévate"

\begin{tabular}{cccc}
\hline & Definitivamente Si & Otras respuestas & TOTAL \\
\hline $\begin{array}{c}\text { ¿Estaría dispuesto a } \\
\text { solicitar los servicios de } \\
\text { "RENUEVATE"? }\end{array}$ & $32.18 \%$ & $67.82 \%$ & $100.0 \%$ \\
\hline
\end{tabular}

Nota: Elaboración propia

Finalmente, para el mercado objetivo, se considera la siguiente información.

Según lo mencionado en el Manual del Emprendedor proporcionado por la Universidad San Ignacio de Loyola, donde en su contenido indica que debemos de compararnos con el porcentaje del mercado objetivo de nuestro competidor más bajo, para este caso Muebles Ferrini (1.2 de participación de mercado) descartando la participación de 3.1 que posee Canziani por ser muy alta.

Tomando como referencia el índice de Mac Daniel y Gates, encontrado en el capítulo 11 del libro Investigación de Mercados Contemporáneos, en cuanto a las escalas de intención de compra para obtener una estimación razonable, pero conservadora se tendrían los siguientes valores para efectuar el ajuste de respuestas:

- $\quad 70 \%$ de los que "Sin duda comprarían"

- 35\% de los que "Probablemente comprarán"

- $\quad 10 \%$ de los que "Probablemente no comprarán"

- $\quad 0 \%$ de los que "Sin duda no comprarán"

En base a los porcentajes mencionados anteriormente y contrastados con los resultados de la encuesta se tendría el cálculo siguiente: 


$$
(0.70)(0.32)+(0.35)(0.40)+(0.10)(0.12)+(0)(0.06)=0.375
$$

Quedando luego de hacer el ajuste del índice el resultado:

$1.2(1-0.375)=0.75 \%$, valor que será el porcentaje del mercado objetivo.

Tabla $\mathrm{N}^{\circ} 83$

Porcentaje del mercado objetivo

\begin{tabular}{cccc}
\hline & 2019 & 2020 & 2021 \\
\hline Crecimiento & $0.75 \%$ & $0.777 \%$ & $0.804 \%$ \\
\hline
\end{tabular}

Nota: Elaboración propia

Se muestra a continuación los hogares a los cuales se dirige la estrategia en los distritos objetivo:

Tabla $\mathrm{N}^{\circ} 84$

Mercado objetivo

\begin{tabular}{ccccc}
\hline Nro. & DISTRITOS & 2019 & 2020 & 2021 \\
\hline 1 & Jesús María & 32 & 33 & 34 \\
2 & Lince & 17 & 18 & 18 \\
3 & Magdalena & 26 & 27 & 28 \\
4 & Pueblo Libre & 37 & 38 & 39 \\
5 & San Miguel & 64 & 66 & 69 \\
6 & Miraflores & 44 & 45 & 46 \\
7 & La Molina & 96 & 102 & 108 \\
8 & San Borja & 63 & 66 & 68 \\
9 & San Isidro & 28 & 29 & 29 \\
10 & Surco & 183 & 193 & 203 \\
\hline & TOTAL & 590 & 617 & 642 \\
\hline
\end{tabular}

Nota: Elaboración propia 


\begin{abstract}
Abastecimiento
La empresa SF Hermanos cuenta con proveedores de insumos y materiales, con los que tienen buenas relaciones a lo largo del tiempo. Se espera que esta situación se mantenga para poder garantizar el abastecimiento continuo y oportuno.
\end{abstract}

\title{
Financiamiento
}

Para poder financiar la estrategia, la empresa va a desembolsar recursos propios equivalentes a $28.88 \%(\mathrm{~S} / \mathrm{120,566)}$ y va a proceder a financiar el $71.12 \%$ a través de un préstamo del Banco de Crédito del Perú, con el cual ya mantiene relaciones financieras anteriormente.

\subsection{Evaluación financiera de la nueva estrategia}

La evaluación financiera requiere poder identificar el total de inversión que necesita la estrategia, los presupuestos de costos, gastos y los ingresos proyectados, dato relevante para la construcción de los estrados financieros del plan estratégico.

\subsubsection{Inversión}

\subsubsection{Inversión Tangible}

La inversión tangible está compuesta por la adquisición de maquinaria, equipos o mueble sólido que ocupe un espacio físico o puedan ser percibidos por los sentidos. Para considerar que un activo es depreciable se debe tomar en cuenta el valor unitario del mismo, el cual debe ser mayor a 1/4 de la Unidad Impositiva Tributaria, mejor conocido como UIT. La UIT para el año 2018 es de S/. 4,150, es decir que, para 
depreciar un activo, debe tener un valor superior a S/.1,037.50 incluido IGV, cuyo equivalente en dólar es \$ 314.23.

Se detalla a continuación, la inversión en activos con dicha condición.

Tabla $\mathrm{N}^{\circ} 85$

Inversión Tangible

\begin{tabular}{cccccc}
\hline Item & Descripción & $\mathrm{Q}$ & $\begin{array}{c}\text { Precio Unit } \\
\text { S/ }\end{array}$ & Total S/ & $\begin{array}{c}\text { Total S/. sin } \\
\text { IGV }\end{array}$ \\
\hline 1 & Implementación de oficina y call & 1 & S/. 30,000 & S/. 30,000 & S/. 25,424 \\
2 & $\begin{array}{c}\text { center } \\
\text { Unidad de transporte }\end{array}$ & 1 & S/. 66,967 & S/. 66,967 & S/. 56,751 \\
3 & $\begin{array}{c}\text { Implementación de centro de } \\
\text { exhibición }\end{array}$ & 1 & S/. 200,000 & S/. 200,000 & S/. 169,492 \\
\hline Total Activos & & & S/. 296,967 & S/. 251,667 \\
\hline
\end{tabular}

Nota: Elaboración propia

En la tabla se observa que la inversión total en activos tangibles asciende a S/. 296,967 incluido el IGV y sin IGV a S/. 251,667. La inversión más relevante es en la implementación de centro de exhibición cuyo desembolso es por S/ 200,000.

\subsubsection{Inversión Intangible}

Con referencia a la inversión en intangibles respecto al proyecto, se tienen los gastos en relación a la obtención de software y sus licencias, campaña de lanzamiento, entre otros. El total de dicha inversión es de S/. 54,200 con IGV, siendo la garantía y adelanto de alquiler de centro de exhibición el monto más significativo por S/. 40,200 con IGV, según se detalla la tabla a continuación: 
Tabla $N^{\circ} 86$

Inversión Intangible

\begin{tabular}{clcccc}
\hline \multirow{2}{*}{ Item } & \multicolumn{1}{c}{ Descripción } & Q & Pr. Unit S/ & Total S/ & Total S/. \\
& & & & & sin IGV \\
\hline 1 & Software y antivirus & 1 & S/. 1,000 & S/. 1,000 & S/. 847 \\
2 & Autorizaciones y licencias & 1 & S/. 2,000 & S/. 2,000 & S/. 2,000 \\
3 & Garantía de alquiler centro de exhibición & 3 & S/. 13,400 & S/. 40,200 & S/. 34,068 \\
4 & Marketing de lanzamiento & 1 & S/. 11,000 & S/. 11,000 & S/. 9,322 \\
\hline & Total Intangibles & & & S/. 54,200 & S/. 46,237 \\
\hline
\end{tabular}

Nota: Elaboración Propia

\subsubsection{Inversión en Capital de Trabajo}

Al calcular el capital de trabajo inicial se consideró el presupuesto en materiales proyectado para el primer año por S/. 796,391. Con lo que se plantea un capital de trabajo incremental que cubra dicho presupuesto por los primeros 30 días de operaciones de cada año. El capital inicial y sus incrementos se muestran en la siguiente tabla:

Tabla $\mathrm{N}^{\circ} 87$

Capital de Trabajo Incremental

\begin{tabular}{lrrrr}
\hline \multicolumn{1}{c}{ Concepto } & 2018 & \multicolumn{1}{c}{2019} & \multicolumn{1}{c}{2020} & \multicolumn{1}{c}{2021} \\
\hline Presupuesto anual de materiales & & S/. 796,391 & S/. 830,238 & S/. 866,139 \\
\hline Stock de materiales (cobertura) & & S/. 66,366 & S/. 69,187 & S/. 72,178 \\
\hline KW Incremental & S/. 66,366 & S/. 2,821 & S/. 2,992 & S/. 2,992 \\
\hline
\end{tabular}

Nota: Elaboración Propia 


\subsubsection{Resumen de inversiones}

\subsubsection{Estructura de Inversiones}

La tabla siguiente resume el total de inversión necesitada por el plan estratégico. Cuyo concepto más significativo es la inversión de activos fijos, que representa el $71.12 \%$ del total, lo que están estrechamente relacionados a la implementación de nuevos ambientes requeridos por la nueva estrategia. Por detrás, como segunda inversión de mayor impacto es la inversión en capital de trabajo que representa el 15.89\%.

Tabla $N^{\circ} 88$

Estructura de inversiones

\begin{tabular}{lcc}
\hline \multicolumn{1}{c}{ Tipo de Inversión } & Monto & Peso \\
\hline Activos fijos & S/. 296,967 & $71.12 \%$ \\
Activos intangibles & S/. 54,200 & $12.98 \%$ \\
Capital de trabajo & S/. 66,366 & $15.89 \%$ \\
\hline \multicolumn{1}{c}{ Total } & S/. 417,532 & $100.00 \%$ \\
\hline
\end{tabular}

Nota: Elaboración Propia

\subsubsection{Estructura de financiamiento}

El aporte de los socios financiará en su totalidad la inversión en intangibles y el capital de trabajo, que representa el $29 \%$ del total de la inversión, por el monto de S/. 120,566. Mientras que la inversión en activos fijo será cubierta por un préstamo bancario de S/. 296,967, cuya participación en la inversión es del 71\%. 


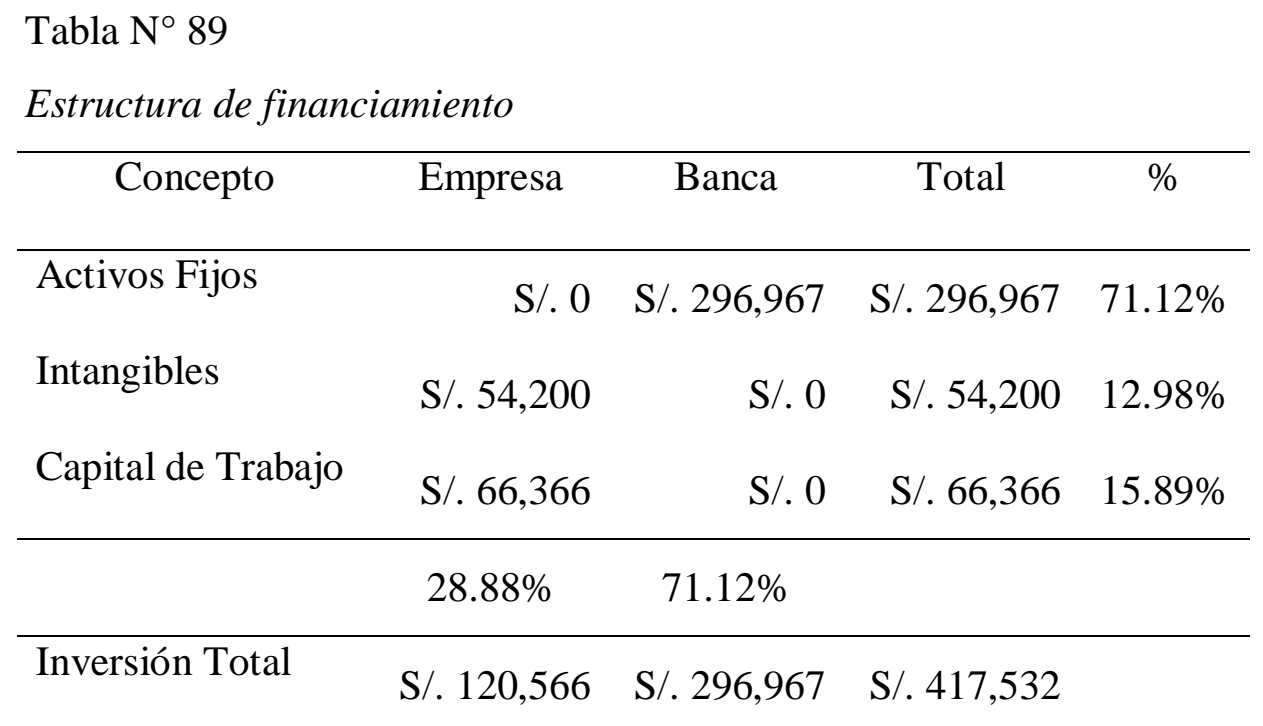

Nota: Elaboración Propia

\subsubsection{Fuente de Financiamiento}

Para financiar los activos fijos se consideró las siguientes opciones:

\section{Financiera CrediScotia}

Se solicita un préstamo a la Financiera CrediScotia para la adquisición de activos fijos, cuyo producto sería dentro del Crédito Negocio el

"Financiamiento para activos e inversión", que ofrece un plazo para cancelar de hasta 36 meses (3 años) con periodo de gracia por 90 días. Para acceder al crédito se solicita:

Documentos personales tales como, DNI del solicitante y del cónyuge si correspondiese, recibo cancelado de servicios, autovalúo y/o título de propiedad. 
Documentos del negocio, sustento de ingresos por ventas, constancia o contrato de alquiler o autovalúo del local comercial, estado de cuenta de los préstamos vigentes o cancelados en el sistema financiero.

La tasa de interés del préstamo no incluye los gastos y comisiones, se detalla a continuación:

\begin{tabular}{|c|c|c|c|c|}
\hline cirearis & MANCIERA & & \multicolumn{2}{|c|}{ CRÉDITOS NEGOCIOS } \\
\hline \multicolumn{3}{|c|}{ Contiene cambios vigentes desde: 03.12 .2015} & \multicolumn{2}{|c|}{ Ültima actualización: 21.12 .2015} \\
\hline \multirow[b]{2}{*}{ Concepto } & \multicolumn{2}{|c|}{ Tarifas } & \multirow{2}{*}{$\begin{array}{l}\text { Forma de } \\
\text { Aplicación }\end{array}$} & \multirow[b]{2}{*}{ Observaciones } \\
\hline & $\begin{array}{l}\text { M. N. } \\
(\mathrm{SI} .)\end{array}$ & $\begin{array}{l}\text { M. E. } \\
\text { (US\$) }\end{array}$ & & \\
\hline \multicolumn{5}{|l|}{ Tasas $\left({ }^{*}\right)$} \\
\hline $\begin{array}{l}\text { Préstamo en Cuotas para } \\
\text { Activo Fijo (T.E.A.) }\end{array}$ & $\begin{array}{l}\operatorname{Min} 21.00 \% \\
\operatorname{Max} 77.00 \%\end{array}$ & $\begin{array}{l}\operatorname{Min} 19.00 \% \\
\operatorname{Max} 36.00 \%\end{array}$ & & $\begin{array}{c}\text { En función del } \\
\text { plazo, monto, } \\
\text { garantia, ventas } \\
\text { declaradas, } \\
\text { moneda y factor } \\
\text { plaza }\end{array}$ \\
\hline $\begin{array}{l}\text { Préstamo para Capital de } \\
\text { Trabajo (Convencional en } \\
\text { Cuotas y Línea de Crédito) } \\
\text { (T.E.A.) }\end{array}$ & $\begin{array}{l}\operatorname{Min} 22.00 \% \\
\operatorname{Max} 77.00 \%\end{array}$ & $\begin{array}{l}\operatorname{Min} 20.00 \% \\
\operatorname{Max} 36.00 \%\end{array}$ & & $\begin{array}{l}\text { En función del } \\
\text { plazo, monto, } \\
\text { garantia, ventas } \\
\text { declaradas, } \\
\text { moneda y factor } \\
\text { plaza } \\
\end{array}$ \\
\hline $\begin{array}{l}\text { Préstamo con Garantía } \\
\text { Liquida (Tasa única) (T.E.A.) }\end{array}$ & $18.00 \%$ & $15.00 \%$ & & \\
\hline $\begin{array}{l}\text { Financiamiento de Proyectos } \\
\text { de Infraestructura (T.E.A.) }\end{array}$ & $19.00 \%$ & $19.00 \%$ & & \\
\hline \begin{tabular}{|l|} 
Autoconstrucción \\
Microempresa (T.E.A.)
\end{tabular} & $\begin{array}{l}\text { Min. } 28.00 \% \\
\text { Máx. } 81.00 \%\end{array}$ & No aplica & & \\
\hline
\end{tabular}

En el gráfico anterior se muestra que el préstamo que financia los

Activos Fijos en moneda nacional (M.N) tiene una TEA mínima de 21\% y máxima de $77 \%$.

\section{Caja Arequipa}

El "Convenio pyme para activo fijo" es un crédito que se otorga a la pequeña y mediana empresa. Cuyo principal requisito es el historial crediticio que tenga el propietario y la capacidad de pago del negocio solicitante. 
El préstamo está disponible en moneda nacional y extranjera. Donde se cobra la tasa efectiva anual (TEA) sin incluir comisiones, intereses y gastos propios del crédito. Las tasas varían según convenio, el cual está en función al monto solicitado, que para el plan estratégico corresponde el convenio B, cuya tasa es de $28.324 \%$.

Tabla $\mathrm{N}^{\circ} 90$

Tarifario de TEA - Convenio activo fijo Caja Arequipa

\begin{tabular}{ccc}
\hline Monto & TEA & Comisiones \\
\hline Convenio A & $26.080 \%$ & \\
Convenio B & $28.324 \%$ & Según Operaciones activas vigentes \\
Convenio C & $30.605 \%$ & \\
\hline \multicolumn{2}{l}{ Nota: Caja Municipal de Ahorro y Crédito de Arequipa, Tarifario WEB }
\end{tabular}

\section{Banco de Crédito del Perú}

Como tercera opción para financiar el activo fijo tenemos el

"Arrendamiento Financiero o Leasing", donde solicitan.

$\checkmark \quad$ Sustento de ingresos del negocio de los últimos 6 meses como mínimo.

$\checkmark \quad$ Fotocopia de DNI titular y socios.

$\checkmark \quad$ Recibo actual de servicios (luz o agua).

$\checkmark \quad$ No tener registro de deudas morosas en ninguna central de riesgo. 
$\checkmark \quad$ Documento de aval con propiedad.

La TEA promedio del Banco de Crédito es de 14\%, la cual excluye los gastos y comisiones.

Tabla $N^{\circ} 91$

Tarifario de Tasa Crédito Leasing - Banco de Crédito

\begin{tabular}{cccc} 
& \multicolumn{3}{c}{ Moneda Nacional (MN) } \\
\hline Concepto & Tasa & Mínimo & Máximo \\
\hline Tasas & & & \\
\hline $\begin{array}{c}\text { 1. Interés Compensatorio Fijo } \\
\text { En Soles (S/.) }\end{array}$ & & $13 \%$ & $20 \%$ \\
2. Interés Moratorio & $10 \%$ & & \\
\hline
\end{tabular}

Nota: Banco de Crédito del Perú

Como resultado de la evaluación de las tres opciones mencionadas anteriormente, se elige el crédito del Banco de Crédito del Perú por tener la tasa más compatible a la magnitud del proyecto en comparación con los otros créditos. Puesto que todos presentan las mismas condiciones de préstamo y requisitos muy similares.

Por lo tanto, se solicita el préstamo al Banco de Crédito del Perú. 
Tabla $\mathrm{N}^{\circ} 92$

Condiciones del préstamo

\begin{tabular}{l|cc}
\multicolumn{1}{c}{ Importe a desembolsar } & S/. 296,967 & \\
\hline Tasa de interés efectiva* & $14.00 \%$ & Anual \\
Plazo de Amortización & 36 & Meses \\
Tipo de amortización & Amortización Variable & \\
Tipo de Cuota & Fija & \\
\hline Valor de la cuota mensual & & S/. 10,031 \\
\hline
\end{tabular}

Nota: Elaboración Propia

Con las condiciones detalladas, se calcula el cronograma con los pagos mensuales que se visualizan en el anexo $\mathrm{N}^{\circ} 5$ cuyos pagos anualizados se muestra en la siguiente tabla:

Tabla $\mathrm{N}^{\circ} 93$

Cronograma de pagos anual

\begin{tabular}{ccccc}
\hline Descripción & 2019 & 2020 & 2021 & Total \\
\hline Principal & S/. 86,338 & S/. 98,425 & S/. 112,204 & S/. 296,967 \\
Intereses & S/. 34,034 & S/. 21,947 & S/. 8,167 & S/. 64,148 \\
\hline Total & S/. 120,372 & S/. 120,372 & S/. 120,372 & S/. 361,115
\end{tabular}

Nota: Elaboración Propia 


\subsubsection{Proyección de Ventas}

Para la determinación del precio de venta se conversó con la gerencia, quienes, a su mejor juicio y conocimiento del negocio, consideran que el margen de contribución debe estar entre un $35 \%$ y $40 \%$. Para ser conservadores se consideró el menor importe, determinándose el precio de venta con la siguiente fórmula:

Donde:

$$
P=\frac{C V}{(1-M C)}
$$

$\mathrm{PV}=$ Precio de venta unitario

$\mathrm{CV}=$ Costo variable unitario

MC = Margen de contribución (porcentaje)

Para la aplicación de esta fórmula es necesario precisar los costos variables, los cuales incluyen los insumos y materia prima, además de diversos gastos, los cuales se detallan a continuación:

Tabla $\mathrm{N}^{\circ} 94$

Determinación de costos variables para servicios Casa

\begin{tabular}{|c|c|c|c|c|c|}
\hline Concepto & Habitaciones & Sala & Comedor & $\begin{array}{l}\text { Zona de } \\
\text { parrillas }\end{array}$ & Cocina \\
\hline Insumos y MP & S/. 3.710 & S/. 3.098 & S/. 3.908 & S/. 2.478 & S/. 3.566 \\
\hline Luz & S/. 134 & S/. 279 & S/. 197 & S/. 497 & S/. 497 \\
\hline Agua & S/. 54 & S/. 112 & S/. 79 & S/. 199 & S/. 199 \\
\hline Insumos de mant. y limpieza & S/. 101 & S/. 210 & S/. 148 & S/. 373 & S/. 373 \\
\hline Útiles de oficina & S/. 13 & S/. 26 & S/. 18 & S/. 47 & S/. 47 \\
\hline Internet y teléfono & S/. 102 & S/. 211 & S/. 149 & S/. 375 & S/. 375 \\
\hline Total Costo Variable & S/. 4.113 & S/. 3.937 & S/. 4.498 & S/. 3.969 & S/. 5.057 \\
\hline
\end{tabular}

Nota: Elaboración propia 
Tabla $\mathrm{N}^{\circ} 95$

Determinación de precio de venta para servicios Casa

\begin{tabular}{crcrrr}
\hline Concepto & Habitaciones & Sala & Comedor & $\begin{array}{c}\text { Zona de } \\
\text { parrillas }\end{array}$ & Cocina \\
\hline Precio de venta & S/. 6.328 & S/. 6.056 & S/. 6.920 & S/. 6.106 & S/. 7.779 \\
Valor de venta & S/. 5.363 & S/. 5.132 & S/. 5.865 & S/. 5.175 & S/. 6.593 \\
\hline
\end{tabular}

Nota: Elaboración propia

Tabla $N^{\circ} 96$

Determinación de costos variables para servicios Departamento

\begin{tabular}{lrrr}
\hline \multicolumn{1}{c}{ Concepto } & Habitaciones & Sala - comedor & \multicolumn{1}{c}{ Cocina } \\
\hline Insumos y MP & $\mathrm{S} / .3 .030$ & $\mathrm{~S} / .2 .797$ & $\mathrm{~S} / .2 .120$ \\
Luz & $\mathrm{S} / .238$ & $\mathrm{~S} / .559$ & $\mathrm{~S} / .600$ \\
Agua & $\mathrm{S} / .95$ & $\mathrm{~S} / .223$ & $\mathrm{~S} / .240$ \\
Insumos de mant. y limpieza & $\mathrm{S} / .179$ & $\mathrm{~S} / .420$ & $\mathrm{~S} / .451$ \\
Útiles de oficina & $\mathrm{S} / .22$ & $\mathrm{~S} / .52$ & $\mathrm{~S} / .56$ \\
Internet y teléfono & $\mathrm{S} / .180$ & $\mathrm{~S} / .422$ & $\mathrm{~S} / .454$ \\
\hline \multicolumn{1}{c}{ Total Costo Variable } & $\mathrm{S} / .3 .744$ & $\mathrm{~S} / .4 .474$ & $\mathrm{~S} / .3 .921$ \\
\hline
\end{tabular}

Nota: Elaboración propia

Tabla $N^{\circ} 97$

Determinación de precio de venta para servicios Departamento

\begin{tabular}{lrrr}
\hline \multicolumn{1}{c}{ Concepto } & Habitaciones & Sala - comedor & \multicolumn{1}{c}{ Cocina } \\
\hline Precio de venta & S/. 5.760 & S/. 6.883 & S/. 6.032 \\
Valor de venta & S/. 4.881 & S/. 5.833 & S/. 5.111 \\
\hline
\end{tabular}

Nota:

Elaboración propia

Para determinar la cantidad de servicios requeridos por tipo de servicio, se realizaron una serie de preguntas a los encuestados sobre la cantidad de servicios requeridos, el tipo de ambiente que renovarán y la frecuencia con la que solicita el 
servicio; todos estos datos recabados ayudan a proyectar la demanda anual de los servicios según área de remodelación.

\begin{tabular}{lccc}
$\begin{array}{l}\text { Tabla No } 98 \\
\text { Programa de ventas anual }\end{array}$ & & & \\
\hline SERVICIOS & $\mathbf{2 0 1 9}$ & $\mathbf{2 0 2 0}$ & $\mathbf{2 0 2 1}$ \\
\hline Servicios Casa & & & \\
Habitaciones & 13 & 13 & 14 \\
Sala & 27 & 28 & 26 \\
Comedor & 19 & 20 & 24 \\
Zona de parrillas & 48 & 53 & 61 \\
Cocina & 48 & 53 & 61 \\
Servicios departamento & & & \\
Habitaciones & 23 & 23 & 22 \\
Sala -Comedor & 54 & 48 & 49 \\
Cocina & 58 & 64 & 72 \\
\hline Total Servicios & $\mathbf{2 9 0}$ & $\mathbf{3 0 2}$ & $\mathbf{3 2 9}$ \\
\hline
\end{tabular}

Nota: Elaboración Propia

Para visualizar el programa de ventas a nivel mensual ver anexo $\mathrm{N}^{\circ} 6$. Con los precios y la demanda proyectada obtenemos la proyección de ventas anual, dichas ventas de manera mensual se pueden ver en el anexo $\mathrm{N}^{\circ} 7$. 
Tabla $\mathrm{N}^{\circ} 99$

Proyección de ventas anual

\begin{tabular}{|c|c|c|c|}
\hline Tipos de venta & 2019 & 2020 & 2021 \\
\hline \multicolumn{4}{|l|}{ Servicios Casa } \\
\hline Habitaciones & S/. 82.269 & S/. 82.269 & S/. 88.597 \\
\hline Sala & S/. 163.519 & S/. 169.575 & S/. 157.463 \\
\hline Comedor & S/. 131.488 & S/. 138.409 & S/. 166.090 \\
\hline Zona de parrillas & S/. 293.090 & S/. 323.621 & S/. 372.469 \\
\hline Cocina & S/. 373.411 & S/. 412.308 & S/. 474.543 \\
\hline \multicolumn{4}{|c|}{ Servicios departamento } \\
\hline Habitaciones & S/. 132.475 & S/. 132.475 & S/. 126.715 \\
\hline Sala-Comedor & S/. 371.708 & S/. 330.407 & S/. 337.291 \\
\hline Cocina & S/. 349.829 & S/. 386.018 & S/. 434.271 \\
\hline Total con IGV & S/. 1.897.791 & S/. 1.975.083 & S/.2.157.440 \\
\hline Total sin IGV & S/. 1.608.297 & S/. 1.673.799 & S/. 1.828.339 \\
\hline
\end{tabular}

Nota: Elaboración Propia 


\subsubsection{Costos y Gastos Anuales}

\subsubsection{Presupuesto de Insumos}

El presupuesto para la compra de insumos necesarios para el servicio "Renuévate", está en función a la lista de componentes necesarios según línea de servicios. El detalle del requerimiento de estos componentes según servicios se encuentra en el anexo $\mathrm{N}^{\circ} 8$. Con el detalle de los costos por componentes se obtiene un promedio de costo por servicio de remodelación.

Tabla $\mathrm{N}^{\circ} 100$

Costo promedio por servicio

\begin{tabular}{ccc}
\hline Líneas / Servicios & Costo promedio & Costo sin IGV \\
\hline A.- Casa & & \\
Habitación & S/. 3,710 & S/. 3,144 \\
Sala & S/. 3,098 & S/. 2,626 \\
Comedor & S/. 3,908 & S/. 3,312 \\
Zona de Parrilla & S/. 2,478 & S/. 2,100 \\
Cocina & S/. 3,566 & S/. 3,022 \\
B.- Departamento & & \\
Habitación & S/. 3,030 & S/. 2,568 \\
Sala - comedor & S/. 2,797 & S/. 2,371 \\
Cocina & S/. 2,120 & S/. 1,796
\end{tabular}

Nota: Elaboración Propia

Con la información de la tabla anterior, se obtiene el presupuesto de insumos, tal presupuesto se encuentra mensualmente en el anexo $\mathrm{N}^{\circ} 9$, la siguiente tabla muestra la proyección anual. 
Tabla $\mathrm{N}^{\circ} 101$

Presupuesto anual de insumos

\begin{tabular}{cccc}
\hline Tipos de venta & 2019 & 2020 & 2021 \\
\hline Servicios Casa & & & \\
Habitaciones & S/. 48.227 & S/. 48.227 & S/. 51.937 \\
Sala & S/. 83.651 & S/. 86.749 & S/. 80.553 \\
Comedor & S/. 74.258 & S/. 78.166 & S/. 93.799 \\
Zona de parrillas & S/. 118.966 & S/. 131.358 & S/. 151.185 \\
Cocina & S/. 171.174 & S/. 189.005 & S/. 217.534 \\
Servicios departamento & & & \\
Habitaciones & S/. 69.683 & S/. 69.683 & S/. 66.653 \\
Sala -Comedor & S/. 151.064 & S/. 134.279 & S/. 137.076 \\
Cocina & S/. 122.931 & S/. 135.648 & S/. 152.604 \\
\hline Total con IGV & S/. 839.952 & S/. 873.114 & S/. 951.341 \\
\hline Total sin IGV & S/. 711.824 & S/. 739.927 & S/. 806.221
\end{tabular}

Nota: Elaboración propia

\subsubsection{Presupuesto de mano de obra}

Del personal requerido para el proyecto, se considera como mano de obra directa a los operarios y armadores, cuyas funciones intervienen directamente en la ejecución e implementación del servicio de remodelación. A continuación, la cantidad de personal por puesto, los sueldo y sus beneficios laborales de acuerdo al régimen laboral, monto que anualmente es igual a S/. 142,222 por los 6 trabajadores. El costo es fijo por los 3 años del proyecto. 
Tabla $N^{\circ} 102$

Presupuesto de mano de obra

\begin{tabular}{|c|c|c|c|c|c|c|c|c|c|}
\hline Puesto & Q & $\begin{array}{l}\text { Sueldo } \\
\text { Básico } \\
\text { Mensual }\end{array}$ & Asig. Lab. & $\begin{array}{l}\text { Sueldo } \\
\text { Básico } \\
\text { Anual }\end{array}$ & $\begin{array}{l}\text { Gratif. (Jul } \\
\text { / Dic) }\end{array}$ & $\begin{array}{c}\text { SUB- } \\
\text { TOTAL }\end{array}$ & ESSALUD & CTS & Total \\
\hline & & & $10 \%$ RMV & & & & $9.00 \%$ & $8.33 \%$ & \\
\hline Operarios & 3 & S/. 1,500 & S/. 93 & S/. 57,348 & S/. 9,558 & S/. 66,906 & S/. 6,022 & S/. 5,576 & S/. 78,503 \\
\hline Armadores & 3 & S/. 1,200 & S/. 93 & S/. 46,548 & S/. 7,758 & S/. 54,306 & S/. 4,888 & S/. 4,526 & S/. 63,719 \\
\hline TOTAL & 6 & S/. 2,700 & & S/. 103,896 & S/. 17,316 & S/. 121,212 & S/. 10,909 & S/. 10,101 & S/. 142,222 \\
\hline
\end{tabular}

Nota: Elaboración propia

\subsubsection{Presupuesto CIF}

Los costos relacionados indirectamente al desarrollo del servicio ofertado por el proyecto "Renuévate", está compuesto principalmente por los servicios comunes asignados directamente al área de operaciones para lo cual se expone en la tabla siguiente la distribución de área total. Donde se muestra que el $81 \%$ del local es ocupado por el área de operaciones.

Tabla $\mathrm{N}^{\circ} 103$

Distribución de las áreas del local por función en $m^{2}$

\begin{tabular}{lccc}
\hline \multicolumn{1}{c}{ ÁREA } & MEDIDA & UNIDAD & $\%$ \\
\hline Administración & 44.4 & $\mathrm{~m} 2$ & $9.5 \%$ \\
Ventas & 44.4 & $\mathrm{~m} 2$ & $9.5 \%$ \\
Operaciones & 379.2 & $\mathrm{~m} 2$ & $81.0 \%$ \\
\hline \multicolumn{1}{c}{ TOTAL } & 468.00 & $\mathrm{~m} 2$ & $100 \%$ \\
\hline
\end{tabular}

Nota: Elaboración propia 
Con la distribución del área se asignan los servicios que no participan de forma directa en la producción del servicio pero que igualmente es consumido en el área de operaciones. 
Tabla $N^{\circ} 104$

Distribución de costos comunes

\begin{tabular}{|c|c|c|c|c|}
\hline Año & Porcentaje $^{2}$ & 2019 & 2020 & 2021 \\
\hline Luz & & S/. 3,000 & S/. 3,124 & S/. 3,403 \\
\hline Administrativa & $9.5 \%$ & S/. 285 & S/. 296 & S/. 323 \\
\hline Ventas & $9.5 \%$ & S/. 285 & S/. 296 & S/. 323 \\
\hline Operaciones & $81.0 \%$ & S/. 2,431 & S/. 2,531 & S/. 2.758 \\
\hline Agua & & S/. 1.200 & S/. 1.250 & S/. 1.361 \\
\hline Administrativa & $9.5 \%$ & S/. 114 & S/. 119 & S/. 129 \\
\hline Ventas & $9.5 \%$ & S/. 114 & S/. 119 & S/. 129 \\
\hline Operaciones & $81.0 \%$ & S/. 972 & S/. 1.013 & S/. 1.103 \\
\hline Arbitrios & & S/. 2.000 & S/. 2.000 & S/. 2.000 \\
\hline Administrativa & $9.5 \%$ & S/. 190 & S/. 190 & S/. 190 \\
\hline Ventas & $9.5 \%$ & S/. 190 & S/. 190 & S/. 190 \\
\hline Operaciones & $81.0 \%$ & S/. 1.621 & S/. 1.621 & S/. 1.621 \\
\hline Alquiler del Local & & S/. 160.800 & S/. 160.800 & S/. 160.800 \\
\hline Administrativa & $9.5 \%$ & S/. 15.255 & S/. 15.255 & S/. 15.255 \\
\hline Ventas & $9.5 \%$ & S/. 15.255 & S/. 15.255 & S/. 15.255 \\
\hline Operaciones & $81.0 \%$ & S/. 130.289 & S/. 130.289 & S/. 130.289 \\
\hline Insumos de mantenimiento & & S/. 2.256 & S/. 2.349 & S/. 2.559 \\
\hline Administrativa & $9.5 \%$ & S/. 214 & S/. 223 & S/. 243 \\
\hline Ventas & $9.5 \%$ & S/. 214 & S/. 223 & S/. 243 \\
\hline Operaciones & $81.0 \%$ & S/. 1.828 & S/. 1.904 & S/. 2.074 \\
\hline Útiles de oficina & & S/. 281 & S/. 293 & S/. 319 \\
\hline Administrativa & $9.5 \%$ & S/. 27 & S/. 28 & S/. 30 \\
\hline Ventas & $9.5 \%$ & S/. 27 & $\mathrm{~S} / .28$ & S/. 30 \\
\hline Operaciones & $81.0 \%$ & S/. 228 & S/. 237 & S/. 258 \\
\hline Internet y teléfono & & S/. 2.268 & S/. 2.362 & S/. 2.573 \\
\hline Administrativa & $9.5 \%$ & S/. 215 & S/. 224 & S/. 244 \\
\hline Ventas & $9.5 \%$ & S/. 215 & S/. 224 & S/. 244 \\
\hline Operaciones & $81.0 \%$ & S/. 1.838 & S/. 1.914 & S/. 2.085 \\
\hline
\end{tabular}

${ }^{1} \mathrm{Se}$ ha contemplado un crecimiento en función al nivel de producción.

$2 \%$ Asignado de acuerdo al nivel de ocupación del área, respecto al total.

Nota: Elaboración propia 
Adicionalmente, también se considera el uso de combustible usado en el transporte de insumos y materiales a las casas y departamentos. Se utiliza el transporte adquirido para el proyecto con un consumo de 10 galones semanal.

Tabla $\mathrm{N}^{\circ} 105$

Consumo anual de combustible

\begin{tabular}{cccc}
\hline Año & 2019 & 2020 & 2021 \\
\hline Unidades & 1 & 1 & 1 \\
Galones por semana & 10 & 10 & 10 \\
Costo por galón 97 & S/. 15.78 & S/. 15.78 & S/. 15.78 \\
Semanas & 52 & 52 & 52 \\
\hline Costo por distribución & S/. 8,206 & S/. 8,206 & S/. 8,206
\end{tabular}

Nota: Elaboración propia

Con las tablas anteriores se elabora el presupuesto anual de costos indirectos. El detalle de estos desembolsos se aprecia en la tabla siguiente:

Tabla $\mathrm{N}^{\circ} 106$

Costos Indirectos de Fabricación

\begin{tabular}{|c|c|c|c|c|}
\hline Concepto & $\%$ & 2019 & 2020 & 2021 \\
\hline Combustible & $100.0 \%$ & S/. 8,206 & S/. 8,206 & S/. 8,206 \\
\hline Luz & $81.0 \%$ & S/. 2,431 & S/. 2,531 & S/. 2,758 \\
\hline Agua & $81.0 \%$ & S/. 972 & $\mathrm{~S} / .1,013$ & S/. 1,103 \\
\hline Arbitrios & $81.0 \%$ & S/. 1,621 & $\mathrm{~S} / .1,621$ & S/. 1,621 \\
\hline Alquiler & $81.0 \%$ & S/. 130,289 & S/. 130,289 & S/. 130,289 \\
\hline Insumos de mantenimiento $\mathrm{y}$ & $81.0 \%$ & S/. 1,828 & S/. 1,904 & S/. 2,074 \\
\hline Útiles de Oficina & $81.0 \%$ & S/. 228 & S/. 237 & S/. 258 \\
\hline Internet y teléfono & $81.0 \%$ & S/. 1,838 & S/. 1,914 & S/. 2,085 \\
\hline Mano de Obra Indirecta & $100.0 \%$ & S/. 203,231 & S/. 203,231 & S/. 203,231 \\
\hline \multicolumn{2}{|c|}{ Total de Gastos } & $\mathrm{S} / . \mathbf{3 5 0 , 6 4 2}$ & $\mathrm{S} / . \mathbf{3 5 0 , 9 6 1}$ & S/. 350,944 \\
\hline \multicolumn{2}{|c|}{ Total de Gastos - sin IGV } & $\mathrm{S} / . \mathbf{3 2 8 , 4 0 3}$ & S/. 328,673 & S/. 328,659 \\
\hline
\end{tabular}

Nota: Elaboración propia 


\subsubsection{Presupuesto de gastos de administración}

Para el presupuesto de gastos administrativos se tiene en cuenta el sueldo del administrador, la depreciación de la oficina y call center, la amortización de las licencias que en su totalidad corresponden al área administrativa. Igualmente, los costos comunes donde se aplican el criterio de asignación del área del local, los insumos de limpieza y los útiles requeridos para oficina. Finalmente se considera el servicio de contabilidad que se encuentra tercerizado.

Tabla $N^{\circ} 107$

Gastos de administración

\begin{tabular}{ccccc}
\hline Concepto & $\%$ & 2019 & 2020 & 2021 \\
\hline Depreciación oficina y call center & $100.0 \%$ & $\mathrm{~S} / .2,542$ & $\mathrm{~S} / .2,542$ & $\mathrm{~S} / .2,542$ \\
Amortización de software y licencias & $100.0 \%$ & $\mathrm{~S} / .212$ & $\mathrm{~S} / .212$ & $\mathrm{~S} / .212$ \\
Luz & $9.5 \%$ & $\mathrm{~S} / .100$ & $\mathrm{~S} / .100$ & $\mathrm{~S} / .100$ \\
Agua & $9.5 \%$ & $\mathrm{~S} / .285$ & $\mathrm{~S} / .296$ & $\mathrm{~S} / .323$ \\
Arbitrios & $9.5 \%$ & $\mathrm{~S} / .114$ & $\mathrm{~S} / .119$ & $\mathrm{~S} / .129$ \\
Alquiler & $9.5 \%$ & $\mathrm{~S} / .190$ & $\mathrm{~S} / .190$ & $\mathrm{~S} / .190$ \\
Insumos de mantenimiento y limpieza & $9.5 \%$ & $\mathrm{~S} / .15,255$ & $\mathrm{~S} / .15,255$ & $\mathrm{~S} / .15,255$ \\
Útiles de oficina & $9.5 \%$ & $\mathrm{~S} / .214$ & $\mathrm{~S} / .223$ & $\mathrm{~S} / .243$ \\
Internet y teléfono & $9.5 \%$ & $\mathrm{~S} / .27$ & $\mathrm{~S} / .28$ & $\mathrm{~S} / .30$ \\
Servicio de contabilidad & $100.0 \%$ & $\mathrm{~S} / .215$ & $\mathrm{~S} / .224$ & $\mathrm{~S} / .244$ \\
Sueldos administración & $100.0 \%$ & $\mathrm{~S} / .18,000$ & $\mathrm{~S} / .18,000$ & $\mathrm{~S} / .18,000$ \\
\hline Total de Gastos & & $\mathrm{S} / . \mathbf{1 0 4 , 3 8 8}$ & $\mathrm{S} / . \mathbf{6 7 , 2 3 4}$ & $\mathrm{S} / . \mathbf{6 7 , 2 3 4}$ \\
\hline Total de Gastos- sin IGV & & $\mathrm{S} / . \mathbf{1 0 1 , 9 3 7}$ & $\mathrm{S} / . \mathbf{1 0 4 , 3 8 8}$ & S/. 104,423 \\
\hline
\end{tabular}

Nota: Elaboración propia 


\subsubsection{Presupuesto de gastos de ventas}

El presupuesto de gastos de venta está compuesto por la depreciación y amortización de los equipos y adelantos designados al área de ventas, los gastos de publicidad, al igual que los gastos comunes distribuidos según asignación del área.

Incluidos dentro de este presupuesto se encuentra la comisión por ventas (dentro de la planilla) y las visitas a las áreas de exhibición. Todos los gastos mencionados están ordenados en la siguiente tabla:

Tabla $\mathrm{N}^{\circ} 108$

Gastos de ventas

\begin{tabular}{ccccc}
\hline & $\%$ & 2019 & 2020 & 2021 \\
\hline Depreciación unidad de transporte & $100.0 \%$ & S/. 11,350 & S/. 11,350 & S/. 11,350 \\
Depreciación centro de exhibición & $100.0 \%$ & S/. 16,949 & S/. 16,949 & S/. 16,949 \\
Amortización garantía local & $100.0 \%$ & S/. 34,068 & S/. 0 & S/. 0 \\
Amortización marketing lanzamiento & $100.0 \%$ & S/. 9,322 & S/. 0 & S/. 0 \\
Luz & $9.5 \%$ & S/. 285 & S/. 296 & S/. 323 \\
Agua & $9.5 \%$ & S/. 114 & S/. 119 & S/. 129 \\
Arbitrios & $9.5 \%$ & S/. 190 & S/. 190 & S/. 190 \\
Alquiler & $9.5 \%$ & S/. 15,255 & S/. 15,255 & S/. 15,255 \\
Insumos de mantenimiento y limpieza & $9.5 \%$ & S/. 214 & S/. 223 & S/. 243 \\
Útiles de oficina & $9.5 \%$ & S/. 27 & S/. 28 & S/. 30 \\
Internet y teléfono & $9.5 \%$ & S/. 215 & S/. 224 & S/. 244 \\
Sueldos ventas & $100.0 \%$ & S/. 107,521 & S/. 108,473 & S/. 110,666 \\
Visitas & $100.0 \%$ & S/. 6,000 & S/. 6,000 & S/. 6,000 \\
Gastos de publicidad & $100.0 \%$ & S/. 33,515 & S/. 33,515 & S/. 33,515 \\
\hline Total de Gastos & & S/. 235,024 & S/. 192,622 & S/. 194,895 \\
\hline Total de Gastos - sin IGV & & S/. 226,539 & S/. 184,132 & S/. 186,392 \\
\hline Nota: Elaboracion propia & & &
\end{tabular}

Nota: Elaboración propia 
A continuación, se muestra de forma más detallada las distintas actividades que comprenden los gastos en publicidad que corresponden exclusivamente a los gastos en ventas.

Tabla $\mathrm{N}^{\circ} 109$

Gastos de promoción y publicidad

\begin{tabular}{crrr}
\hline & \multicolumn{1}{c}{2019} & \multicolumn{1}{c}{2020} & \multicolumn{1}{c}{2021} \\
\hline Actividad & & & \\
\hline Participación en Ferias & S/. 10,000 & S/. 10,000 & S/. 10,000 \\
Suscripción a página Web Urbania & S/. 6,000 & S/. 6,000 & S/. 6,000 \\
Rediseño de página Web & S/. 3,000 & S/. 3,000 & S/. 3,000 \\
Pago de hosting y dominio & S/. 455 & S/. 455 & S/. 455 \\
Catálogos & S/. 1,500 & S/. 1,500 & S/. 1,500 \\
Publicidad en Facebook & S/. 8,000 & S/. 8,000 & S/. 8,000 \\
Diseño de los volantes & S/. 320 & S/. 320 & S/. 320 \\
Impresión de los volantes & S/. 240 & S/. 240 & S/. 240 \\
Repartidor de volantes & S/. 4,000 & S/. 4,000 & S/. 4,000 \\
\hline TOTAL & S/. 33,515 & S/. 33,515 & S/. 33,515
\end{tabular}

Nota: Elaboración propia

\subsubsection{Estado de Resultados (proyectado y con la nueva estrategia)}

Con la información recopilada se presenta el siguiente estado de resultados para la estrategia planteada. Se pueden observar las ventas a detalle en el anexo $\mathrm{N}^{\circ} 7$. Asimismo, los gastos de planilla, gastos administrativos y gastos de ventas del presente documento, alimentan este estado de resultados. En la siguiente tabla, se muestra que la utilidad operativa de la estrategia en el año 2019 representa el 4\% del total de ventas del mismo año. 
Tabla $\mathrm{N}^{\circ} 110$

Estado de Resultado de la Estrategia (soles)

\begin{tabular}{lrrrrr}
\hline & $\mathbf{2 0 1 9}$ & $\mathbf{2 0 2 0}$ & $\mathbf{2 0 2 1}$ & \multicolumn{1}{c}{$\mathbf{2 0 2 2}$} & \multicolumn{1}{c}{$\mathbf{2 0 2 3}$} \\
\hline Ventas & $4,070,295$ & $4,240,590$ & $4,504,384$ & $4,739,924$ & $4,988,405$ \\
Costo de ventas & $2,719,228$ & $2,814,539$ & $2,951,276$ & $3,074,789$ & $3,203,480$ \\
\hline Ganancia (Pérdida) & $\mathbf{1 , 3 5 1 , 0 6 7}$ & $\mathbf{1 , 4 2 6 , 0 5 1}$ & $\mathbf{1 , 5 5 3 , 1 0 8}$ & $\mathbf{1 , 6 6 5 , 1 3 6}$ & $\mathbf{1 , 7 8 4 , 9 2 5}$ \\
Bruta & 324,770 & 334,269 & 345,463 & 357,093 & 369,182 \\
\hline Gasto de ventas* & 383,142 & 406,557 & 419,710 & 433,386 & 447,642 \\
$\begin{array}{l}\text { Gasto de administración* } \\
\text { Depreciación y }\end{array}$ & 149,270 & 81,977 & 75,096 & 75,096 & 74,884 \\
amortización & $\mathbf{4 9 3 , 8 8 4}$ & $\mathbf{6 0 3 , 2 4 9}$ & $\mathbf{7 1 2 , 8 3 9}$ & $\mathbf{7 9 9 , 5 6 0}$ & $\mathbf{8 9 3 , 2 1 7}$ \\
\hline Utilidad Operativa & 36,290 & 26,260 & 17,918 & 23,537 & 15,843 \\
\hline Gastos financieros & $\mathbf{4 5 7 , 5 9 4}$ & $\mathbf{5 7 6 , 9 8 9}$ & $\mathbf{6 9 4 , 9 2 1}$ & $\mathbf{7 7 6 , 0 2 4}$ & $\mathbf{8 7 7 , 3 7 4}$ \\
\hline Utilidad antes de & 22,880 & 28,849 & 34,746 & 38,801 & 43,869 \\
Impuestos & 128,241 & 161,701 & 194,752 & 217,481 & 245,884 \\
\hline Participación de & $\mathbf{3 0 6 , 4 7 4}$ & $\mathbf{3 8 6 , 4 3 8}$ & $\mathbf{4 6 5 , 4 2 3}$ & $\mathbf{5 1 9 , 7 4 2}$ & $\mathbf{5 8 7 , 6 2 1}$ \\
trabajadores & Impuesto a la renta & & & & \\
\hline Utilidad / Pérdida Neta & & & &
\end{tabular}

* No incluye depreciación ni amortización

Nota: Elaboración propia

Para la correcta evaluación del plan estratégico se compara los estados de resultados proyectados y el estado de resultados integrado con la nueva estrategia.

En la actualidad SF Hermanos S.R.L. ha estado vendiendo alrededor de 4 millones de soles al año. En los últimos años ha mostrado un crecimiento promedio de $6.86 \%$ en las ventas.

A continuación, mostramos el estado de resultados histórico que presentó la empresa en los últimos años. Con tal información se calcula la tasa de crecimiento promedio que presentó cada rubro en su registro histórico. 
Tabla $\mathrm{N}^{\circ} 111$

Estado de Resultados Histórico (soles)

\begin{tabular}{lrrrrrc}
\hline & 2013 & 2014 & 2015 & 2016 & 2017 & $\begin{array}{c}\text { Crecimiento } \\
\text { Promedio }\end{array}$ \\
\hline Ventas & $1,777,345$ & $1,897,629$ & $2,005,235$ & $2,163,626$ & $2,265,072$ & $6.86 \%$ \\
Costo de venta & $1,114,395$ & $1,163,246$ & $1,251,267$ & $1,345,776$ & $1,424,730$ & $6.96 \%$ \\
\hline Utilidad Bruta & $\mathbf{6 6 2 , 9 5 0}$ & $\mathbf{7 3 4 , 3 8 2}$ & $\mathbf{7 5 3 , 9 6 8}$ & $\mathbf{8 1 7 , 8 5 1}$ & $\mathbf{8 4 0 , 3 4 2}$ & $\mathbf{6 . 6 9 \%}$ \\
\hline Gastos de ventas & 122,360 & 127,254 & 142,525 & 141,100 & 159,443 & $7.58 \%$ \\
Gastos de & 177,735 & 153,708 & 228,998 & 283,435 & 241,683 & $8.99 \%$ \\
administración & 71,155 & 71,155 & 71,155 & 85,638 & 74,727 & $1.26 \%$ \\
Deprec. y amortiz. & $\mathbf{2 9 1 , 7 0 1}$ & $\mathbf{3 8 2 , 2 6 5}$ & $\mathbf{3 1 1 , 2 9 1}$ & $\mathbf{3 0 7 , 6 7 9}$ & $\mathbf{3 6 4 , 4 8 9}$ & $\mathbf{6 . 2 4 \%}$ \\
\hline Utilidad Operativa & 6,646 & 4,503 & 1,759 & 14,730 & 9,931 & $12.36 \%$ \\
\hline Gastos financieros & $\mathbf{2 8 5 , 0 5 4}$ & $\mathbf{3 7 7 , 7 6 3}$ & $\mathbf{3 0 9 , 5 3 3}$ & $\mathbf{2 9 2 , 9 4 8}$ & $\mathbf{3 5 4 , 5 5 8}$ & $\mathbf{6 . 1 0 \%}$ \\
\hline Utilidad antes Impto & 14,253 & 18,888 & 15,477 & 14,647 & 17,728 & $6.10 \%$ \\
\hline Participación trab. & 81,241 & 107,662 & 82,336 & 77,924 & 99,365 & $5.58 \%$ \\
Impuesto a la renta & $\mathbf{1 8 9 , 5 6 1}$ & $\mathbf{2 5 1 , 2 1 2}$ & $\mathbf{2 1 1 , 7 2 0}$ & $\mathbf{2 0 0 , 3 7 7}$ & $\mathbf{2 3 7 , 4 6 5}$ & $\mathbf{6 . 3 2 \%}$ \\
\hline Utilidad Neta & & & & &
\end{tabular}

Nota: Elaboración propia

Con la tasa promedio de crecimiento obtenida, se proyecta el estado de resultados para los años de evaluación del proyecto.

Para ser conservadores se ha tomado dicho promedio reducido en 2 puntos porcentuales ya que el crecimiento del año 2017 es menor que lo presentado en años anteriores. Los gastos y costos operacionales se determinan según los siguientes drivers: 
Tabla $N^{\circ} 112$

Drivers

\begin{tabular}{|c|c|c|c|c|c|c|c|c|c|c|}
\hline $\begin{array}{l}\text { Drivers de } \\
\text { Resultados }\end{array}$ & 2013 & 2014 & 2015 & 2016 & 2017 & & 2018 & 2019 & 2020 & 2021 \\
\hline Concepto & \multicolumn{4}{|c|}{ Histórico } & & Promedio & \multicolumn{4}{|c|}{ Proyectado } \\
\hline $\begin{array}{l}\text { Costo de ventas / } \\
\text { Ventas } \\
\text { Gastos de ventas / }\end{array}$ & $62.70 \%$ & $61.30 \%$ & $62.40 \%$ & $62.20 \%$ & $62.90 \%$ & $62.30 \%$ & $62.36 \%$ & $62.42 \%$ & $62.48 \%$ & $62.54 \%$ \\
\hline $\begin{array}{l}\text { Ventas } \\
\text { Gastos de adm. / }\end{array}$ & $6.88 \%$ & $6.71 \%$ & $7.11 \%$ & $6.52 \%$ & $7.04 \%$ & $6.85 \%$ & $6.85 \%$ & $6.90 \%$ & $6.95 \%$ & $7.00 \%$ \\
\hline Ventas & $10.00 \%$ & $8.10 \%$ & $11.42 \%$ & $13.10 \%$ & $10.67 \%$ & $10.66 \%$ & $11.10 \%$ & $11.54 \%$ & $11.98 \%$ & $11.98 \%$ \\
\hline
\end{tabular}

Tabla N ${ }^{\circ} 113$

Estado de Resultados Proyectado (soles)

\begin{tabular}{lrrrrrr}
\hline & \multicolumn{1}{c}{2018} & \multicolumn{1}{c}{2019} & \multicolumn{1}{c}{2020} & \multicolumn{1}{c}{2021} & \multicolumn{1}{c}{2022} & \multicolumn{1}{c}{2023} \\
\hline Ventas & $2,361,483$ & $2,461,998$ & $2,566,791$ & $2,676,045$ & $2,789,949$ & $2,908,701$ \\
Costo de venta & $1,472,621$ & $1,536,779$ & $1,603,731$ & $1,673,599$ & $1,746,508$ & $1,822,592$ \\
\hline Utilidad Bruta & $\mathbf{8 8 8 , 8 6 2}$ & $\mathbf{9 2 5 , 2 1 9}$ & $\mathbf{9 6 3 , 0 6 0}$ & $\mathbf{1 , 0 0 2 , 4 4 6}$ & $\mathbf{1 , 0 4 3 , 4 4 1}$ & $\mathbf{1 , 0 8 6 , 1 0 9}$ \\
\hline Gastos de ventas & 161,803 & 169,921 & 178,436 & 187,370 & 196,740 & 206,568 \\
Gastos de administración & 262,077 & 284,065 & 307,450 & 320,537 & 334,180 & 348,404 \\
Depreciación y amortización & 74,727 & 74,727 & 50,823 & 43,943 & 43,943 & 43,943 \\
\hline Utilidad Operativa & $\mathbf{3 9 0 , 2 5 5}$ & $\mathbf{3 9 6 , 5 0 6}$ & $\mathbf{4 2 6 , 3 5 0}$ & $\mathbf{4 5 0 , 5 9 8}$ & $\mathbf{4 6 8 , 5 7 9}$ & $\mathbf{4 8 7 , 1 9 4}$ \\
\hline Gastos financieros & 3,860 & 0 & 0 & 0 & 0 & 0 \\
\hline Utilidad antes Impuesto & $\mathbf{3 8 6 , 3 9 5}$ & $\mathbf{3 9 6 , 5 0 6}$ & $\mathbf{4 2 6 , 3 5 0}$ & $\mathbf{4 5 0 , 5 9 8}$ & $\mathbf{4 6 8 , 5 7 9}$ & $\mathbf{4 8 7 , 1 9 4}$ \\
\hline Participación trabajadores & 19,320 & 19,825 & 21,318 & 22,530 & 23,429 & 24,360 \\
Impuesto a la renta & 108,287 & 111,121 & 119,485 & 126,280 & 131,319 & 136,536 \\
\hline Utilidad Neta & $\mathbf{2 5 8 , 7 8 8}$ & $\mathbf{2 6 5 , 5 6 0}$ & $\mathbf{2 8 5 , 5 4 8}$ & $\mathbf{3 0 1 , 7 8 8}$ & $\mathbf{3 1 3 , 8 3 1}$ & $\mathbf{3 2 6 , 2 9 8}$ \\
\hline
\end{tabular}

Nota: Elaboración propia

Finalmente se puede observar que, si se agrupan tanto el estado de resultados

proyectado de la empresa y el de la estrategia a desarrollar, se puede obtener el

estado de resultados integrado, donde se puede observar que las ventas superan los

2.9 millones de soles y la utilidad operativa llega al $15.67 \%$ de las ventas al 2023

(5to año). 
Tabla $\mathrm{N}^{\circ} 114$

Estados de Resultados Proyectado más Estrategia (soles)

\begin{tabular}{lrrrrr}
\hline & \multicolumn{1}{c}{2019} & \multicolumn{1}{c}{2020} & \multicolumn{1}{c}{2021} & \multicolumn{1}{c}{2022} & \multicolumn{1}{c}{2023} \\
\hline Ventas & 4.070 .295 & 4.240 .590 & 4.504 .384 & 4.739 .924 & 4.988 .405 \\
Costo de venta & 2.719 .228 & 2.814 .539 & 2.951 .276 & 3.074 .789 & 3.203 .480 \\
\hline Ganancia (Pérdida) Bruta & $\mathbf{1 . 3 5 1 . 0 6 7}$ & $\mathbf{1 . 4 2 6 . 0 5 1}$ & $\mathbf{1 . 5 5 3 . 1 0 8}$ & $\mathbf{1 . 6 6 5 . 1 3 6}$ & $\mathbf{1 . 7 8 4 . 9 2 5}$ \\
\hline Gasto de ventas & 324.770 & 334.269 & 345.463 & 357.093 & 369.182 \\
Gasto de administración & 383.142 & 406.557 & 419.710 & 433.386 & 447.642 \\
Depreciación y amortización & 149.270 & 81.977 & 75.096 & 75.096 & 74.884 \\
\hline Utilidad Operativa & $\mathbf{4 9 3 . 8 8 4}$ & $\mathbf{6 0 3 . 2 4 9}$ & $\mathbf{7 1 2 . 8 3 9}$ & $\mathbf{7 9 9 . 5 6 0}$ & $\mathbf{8 9 3 . 2 1 7}$ \\
\hline Gastos financieros & 36.290 & 26.260 & 17.918 & 23.537 & 15.843 \\
\hline Utilidad antes Impuesto & $\mathbf{4 5 7 . 5 9 4}$ & $\mathbf{5 7 6 . 9 8 9}$ & $\mathbf{6 9 4 . 9 2 1}$ & $\mathbf{7 7 6 . 0 2 4}$ & $\mathbf{8 7 7 . 3 7 4}$ \\
\hline Participación trabajadores & 22.880 & 28.849 & 34.746 & 38.801 & 43.869 \\
Impuesto a la renta & 128.241 & 161.701 & 194.752 & 217.481 & 245.884 \\
\hline Utilidad / Pérdida Neta & $\mathbf{3 0 6 . 4 7 4}$ & $\mathbf{3 8 6 . 4 3 8}$ & $\mathbf{4 6 5 . 4 2 3}$ & $\mathbf{5 1 9 . 7 4 2}$ & $\mathbf{5 8 7 . 6 2 1}$ \\
\hline Nota: Elaboración propia & & & & &
\end{tabular}

Nota: Elaboración propia

\subsubsection{Balance General (con la nueva estrategia)}

Continuando con la evaluación financiera, analizaremos la estructura del balance general de SF Hermanos.

Inicialmente observaremos el balance histórico de la firma registrado en los últimos 5 años (2013 - 2017), donde se observa un total de activos por S/. 1’364,007 en el año 2013 y asciende a S/. 1’373,310 para el 2017. Se observa que la empresa opera con créditos en la compra de insumos y en la venta de los productos. Para el último año registrado se observa un patrimonio por S/. 885,459. 
Tabla $N^{\circ} 115$

Balance General Histórico

\begin{tabular}{|c|c|c|c|c|c|}
\hline & 2013 & 2014 & 2015 & 2016 & 2017 \\
\hline \multicolumn{6}{|l|}{ ACTIVO } \\
\hline \multicolumn{6}{|l|}{ Activo Corriente } \\
\hline Caja y bancos & S/. 39,102 & S/. 37,953 & S/. 36,094 & S/. 32,454 & S/. 27,181 \\
\hline Cuentas por cobrar comerciales & S/. 414,121 & S/. 480,100 & S/. 461,204 & S/. 454,362 & S/. 498,316 \\
\hline Existencias & S/. 289,743 & S/. 325,709 & S/. 375,380 & S/. 390,275 & S/. 398,924 \\
\hline Otras cuentas del activo & S/. 4,503 & S/. 1,759 & S/. 14,730 & S/. 9,931 & S/. 3,860 \\
\hline Total Activo Corriente & S/. 747,468 & $\mathrm{S} / . \mathbf{8 4 5 , 5 2 0}$ & S/. 887,409 & S/. 887,022 & $\mathrm{S} / . \mathbf{9 2 8 , 2 8 1}$ \\
\hline \multicolumn{6}{|l|}{ Activo no Corriente } \\
\hline Propiedad, planta y equipo, neto & S/. 614,780 & S/. 543,626 & S/. 472,471 & S/. 519,756 & S/. 445,029 \\
\hline Activos intangibles, neto & S/. 0 & S/. 0 & S/. 0 & S/. 0 & S/. 0 \\
\hline Otros activos & S/. 1,759 & $\mathrm{~S} / .0$ & S/. 13,791 & S/. 3,860 & S/. 0 \\
\hline Total Activo no Corriente & S/. 616,539 & $\mathrm{S} / . \mathbf{5 4 3 , 6 2 6}$ & S/. 486,263 & S/. 523,616 & S/. 445,029 \\
\hline TOTAL ACTIVO & S/. 1,364,007 & S/. 1,389,146 & S/. 1,373,671 & $\mathrm{S} / . \mathbf{1 , 4 1 0 , 6 3 8}$ & $\mathrm{S} / . \mathbf{1 , 3 7 3 , 3 1 0}$ \\
\hline \multicolumn{6}{|l|}{ PASIVO Y PATRIMONIO } \\
\hline \multicolumn{6}{|l|}{ Pasivo Corriente } \\
\hline Préstamos bancarios & S/. 14,302 & S/. 14,302 & S/. 32,841 & S/. 32,841 & S/. 32,841 \\
\hline Cuentas por pagar comerciales & S/. 367,750 & S/. 372,239 & S/. 387,893 & S/. 403,733 & S/. 413,172 \\
\hline $\begin{array}{l}\text { Tributos, remuneraciones y otras } \\
\text { cuentas por pagar }\end{array}$ & S/. 197,822 & S/. 195,093 & S/. 54,339 & S/. 84,261 & S/. 41,839 \\
\hline Total Pasivo Corriente & S/. 579,875 & S/. 581,634 & S/. 475,072 & S/. 520,834 & $\mathrm{S} / . \mathbf{4 8 7 , 8 5 1}$ \\
\hline \multicolumn{6}{|l|}{ Pasivo no Corriente } \\
\hline $\begin{array}{l}\text { Obligaciones financieras a largo } \\
\text { plazo }\end{array}$ & S/. 14,302 & S/. 0 & S/. 65,681 & S/. 32,841 & $\mathrm{~S} / .0$ \\
\hline Total Pasivo no Corriente & $\mathrm{S} / . \mathbf{1 4 , 3 0 2}$ & $\mathrm{S} / .0$ & S/. 65,681 & S/. 32,841 & S/. 0 \\
\hline TOTAL PASIVO & S/.594,177 & $\mathrm{S} / .581,634$ & S/. 540,753 & S/. 553,675 & $\mathrm{S} / .487,851$ \\
\hline \multicolumn{6}{|l|}{ Patrimonio } \\
\hline Capital social & S/. 134,800 & S/. 134,800 & S/. 134,800 & S/. 134,800 & S/. 134,800 \\
\hline Reserva de capital & S/. 0 & S/. 0 & S/. 0 & S/. 0 & S/. 0 \\
\hline Resultado del ejercicio & S/. 28,434 & S/. 37,682 & S/. 25,406 & S/. 24,045 & S/. 28,496 \\
\hline Resultados acumulados & S/. 606,596 & S/. 635,030 & S/. 672,712 & S/. 698,118 & S/. 722,163 \\
\hline TOTAL PATRIMONIO & $\mathrm{S} / . \mathbf{7 6 9 , 8 3 0}$ & $\mathrm{S} / . \mathbf{8 0 7 , 5 1 2}$ & S/. 832,918 & S/. 856,963 & S/. 885,459 \\
\hline $\begin{array}{l}\text { TOTAL PASIVO Y } \\
\text { PATRIMONIO }\end{array}$ & S/. 1,364,007 & S/. 1,389,146 & S/. 1,373,671 & S/. 1,410,638 & $\mathrm{S} / . \mathbf{1 , 3 7 3 , 3 1 0}$ \\
\hline
\end{tabular}

Nota: Área de contabilidad de SF Hermanos

Cabe precisar que la compañía viene aplicando una política de reparto de dividendos año a año, por tal motivo es que su cuenta Caja y Bancos no es muy elevada. Dicha política se detalla en la siguiente tabla: 
Tabla $\mathrm{N}^{\circ} 116$

Reparto de Dividendos

\begin{tabular}{lccccc}
\hline & 2013 & 2014 & 2015 & 2016 & 2017 \\
\hline Utilidad del periodo & S/. 189,561 & S/. 251,212 & S/. 211,720 & S/. 200,377 & S/. 237,465 \\
Tasa de reparto & $85 \%$ & $85 \%$ & $88 \%$ & $88 \%$ & $88 \%$ \\
Dividendos pagados & S/. 161,127 & S/. 213,530 & S/. 186,314 & S/. 176,331 & S/. 208,969 \\
\hline
\end{tabular}

Nota: Área de contabilidad de SF Hermanos

Entre las acciones planteadas por la empresa para llevar a cabo los nuevos servicios se tienen la adquisición de una unidad de transporte adicional, la implementación de un nuevo centro de exhibición, la contratación de nuevo personal, entre otras actividades.

Para la elaboración del balance general incluida la estrategia, se utilizan los ratios promedios de cobro, inventario y pago, así como la cobertura de caja (en resumen, el ciclo operativo del negocio). A estos datos se le adicionan las inversiones realizadas para la implementación de la estrategia, tanto en activos fijos como en intangibles, la obtención del préstamo requerido y el incremento en el capital social.

Cabe mencionar que se mantiene la política de distribución de dividendos y en función a estas proyecciones, en algunos casos se obtuvo un efectivo adicional o se requirió un mayor financiamiento.

El balance general incluida la estrategia del proyecto se muestra a continuación: 


\section{Tabla $N^{\circ} 117$}

\section{Balance General con Estrategia}

\begin{tabular}{|c|c|c|c|c|c|c|}
\hline & 2018 & 2019 & 2020 & 2021 & 2022 & 2023 \\
\hline \multicolumn{7}{|l|}{ ACTIVO } \\
\hline \multicolumn{7}{|l|}{ Activo Corriente } \\
\hline Caja y bancos & 1.582 & 82.712 & 112.701 & 195.297 & 441.607 & 737.963 \\
\hline Efectivo y equivalente de efectivo & 187.501 & 0 & 0 & 0 & 0 & 0 \\
\hline Cuentas por cobrar comerciales & 526.086 & 906.771 & 944.709 & 1.003 .477 & 1.055 .950 & 1.111 .306 \\
\hline Existencias & 480.729 & 774.376 & 793.700 & 832.260 & 867.090 & 903.381 \\
\hline Otras cuentas del activo & 34.034 & 21.947 & 8.167 & 0 & 0 & 0 \\
\hline Total Activo Corriente & 1.229.932 & 1.785 .806 & 1.859.278 & 2.031.034 & 2.364.647 & 2.752.650 \\
\hline \multicolumn{7}{|l|}{ Activo no Corriente } \\
\hline Propiedad, planta y equipo, neto & 621.969 & 516.400 & 434.735 & 359.951 & 285.166 & 210.382 \\
\hline Activos intangibles, neto & 46.237 & 2.536 & 2.224 & 1.912 & 1.600 & 1.500 \\
\hline Otros activos & 30.114 & 8.167 & 0 & 0 & 0 & 0 \\
\hline Total Activo no Corriente & 698.320 & 527.103 & 436.959 & 361.863 & 286.766 & 211.882 \\
\hline TOTAL ACTIVO & 1.928.252 & 2.312.909 & 2.296.237 & 2.392 .896 & 2.651 .414 & 2.964 .533 \\
\hline \multicolumn{7}{|l|}{ PASIVO Y PATRIMONIO } \\
\hline \multicolumn{7}{|l|}{ Pasivo Corriente } \\
\hline Préstamos bancarios & 120.372 & 120.372 & 120.372 & 0 & 0 & 0 \\
\hline Necesidades de financiamiento & 0 & 32.230 & 29.380 & 109.908 & 226.328 & 382.549 \\
\hline Cuentas por pagar comerciales & 441.786 & 808.215 & 836.544 & 877.185 & 913.896 & 952.145 \\
\hline $\begin{array}{l}\text { Tributos, remuneraciones y otras } \\
\text { cuentas por pagar }\end{array}$ & 66.526 & 114.666 & 119.463 & 126.894 & 133.530 & 140.530 \\
\hline Total Pasivo Corriente & 628.684 & 1.075 .482 & 1.105 .758 & 1.113 .988 & 1.273.754 & 1.475 .225 \\
\hline \multicolumn{7}{|l|}{ Pasivo no Corriente } \\
\hline Obligaciones financieras a largo plazo & 240.743 & 120.372 & 0 & 0 & 0 & 0 \\
\hline Total Pasivo no Corriente & 240.743 & 120.372 & $\mathbf{0}$ & $\mathbf{0}$ & $\mathbf{0}$ & $\mathbf{0}$ \\
\hline TOTAL PASIVO & 869.427 & $\mathbf{1 . 1 9 5 . 8 5 4}$ & $\mathbf{1 . 1 0 5 . 7 5 8}$ & 1.113.988 & $\mathbf{1 . 2 7 3 . 7 5 4}$ & 1.475.225 \\
\hline \multicolumn{7}{|l|}{ Patrimonio } \\
\hline Capital social & 258.996 & 258.996 & 258.996 & 258.996 & 258.996 & 258.996 \\
\hline Reserva de capital & $\mathrm{S} / .0$ & $\mathrm{~S} / .0$ & S/. 0 & $\mathrm{~S} / .0$ & S/. 0 & $\mathrm{~S} / .0$ \\
\hline Resultado del ejercicio & 49.170 & 58.230 & 73.423 & 88.430 & 98.751 & 111.648 \\
\hline Resultados acumulados & 750.659 & 799.829 & 858.059 & 931.482 & 1.019 .913 & 1.118 .664 \\
\hline TOTAL PATRIMONIO & 1.058 .825 & 1.117.055 & 1.190 .478 & 1.278 .909 & 1.377 .660 & 1.489 .308 \\
\hline TOTAL, PASIVO Y PATRIMONIO & 1.928.252 & 2.312.909 & 2.296.237 & 2.392 .896 & 2.651 .414 & 2.964 .533 \\
\hline
\end{tabular}

Nota: Elaboración propia 


\subsubsection{Flujo de Caja (de nueva estrategia)}

Para la elaboración del flujo de caja operativo del producto se consideran los ingresos y egresos generados por la ejecución de la estrategia elegida a lo largo de los tres años. Asimismo, se debe tomar en cuenta que en este flujo no se encuentran considerados los gastos financieros (intereses del préstamo) para la determinación de la participación de los trabajadores y el impuesto a la renta, pero si se incluye la liquidación de IGV, que se detalla en el anexo $\mathrm{N}^{\circ} 10$.

Tabla $\mathrm{N}^{\circ} 118$

Flujo de Caja Operativo (estrategia)

\begin{tabular}{lccccc}
\hline & $\mathbf{2 0 1 9}$ & $\mathbf{2 0 2 0}$ & $\mathbf{2 0 2 1}$ & $\mathbf{2 0 2 2}$ & $\mathbf{2 0 2 3}$ \\
\hline Ventas & 1.608 .297 & 1.673 .799 & 1.828 .339 & 1.949 .975 & 2.079 .703 \\
Costo de ventas & 1.182 .449 & 1.210 .808 & 1.277 .678 & 1.328 .281 & 1.380 .887 \\
Utilidad Bruta & $\mathbf{4 2 5 . 8 4 8}$ & $\mathbf{4 6 2 . 9 9 1}$ & $\mathbf{5 5 0 . 6 6 1}$ & $\mathbf{6 2 1 . 6 9 5}$ & $\mathbf{6 9 8 . 8 1 6}$ \\
Gastos de ventas & 154.850 & 155.833 & 158.093 & 160.353 & 162.614 \\
Gastos de administración & 99.076 & 99.106 & 99.174 & 99.206 & 99.238 \\
Depreciación y & 74.543 & 31.154 & 31.154 & 31.154 & 30.942 \\
amortización & $\mathbf{9 7 . 3 7 8}$ & $\mathbf{1 7 6 . 8 9 9}$ & $\mathbf{2 6 2 . 2 4 1}$ & $\mathbf{3 3 0 . 9 8 2}$ & $\mathbf{4 0 6 . 0 2 3}$ \\
Utilidad Operativa & 4.869 & 8.845 & 13.112 & 16.549 & 20.301 \\
Participación de & 27.290 & 49.576 & 73.493 & 92.758 & 113.788 \\
trabajadores & $\mathbf{6 5 . 2 1 9}$ & $\mathbf{1 1 8 . 4 7 8}$ & $\mathbf{1 7 5 . 6 3 6}$ & $\mathbf{2 2 1 . 6 7 5}$ & $\mathbf{2 7 1 . 9 3 4}$ \\
Impuesto a la renta & 74.543 & 31.154 & 31.154 & 31.154 & 30.942 \\
\hline Utilidad / Pérdida Neta & $\mathrm{S} / .53,263$ & $\mathrm{~S} / .0$ & $\mathrm{~S} / .0$ & $\mathrm{~S} / .0$ & $\mathrm{~S} / .0$ \\
\hline Depreciación y & $\mathbf{1 3 9 . 7 6 3}$ & $\mathbf{1 4 9 . 6 3 1}$ & $\mathbf{2 0 6 . 7 8 9}$ & $\mathbf{2 5 2 . 8 2 9}$ & $\mathbf{3 0 2 . 8 7 5}$ \\
amortización & & & & & \\
Liquidación de IGV & & & &
\end{tabular}

Nota: Elaboración propia

A continuación, se muestra el flujo de inversiones, el cual incluye la inversión en capital de trabajo incremental (ver tabla $\mathrm{N}^{\circ} 78$ ) y la inversión en activos fijos e intangibles (ver tablas $\mathrm{N}^{\circ} 76$ y $\mathrm{N}^{\circ} 77$ respectivamente). La perpetuidad de este último se muestra en el anexo $\mathrm{N}^{\circ} 11$. 
Tabla $\mathrm{N}^{\circ} 119$

Flujo de Inversiones

\begin{tabular}{lcccccc}
\hline & $\mathbf{2 0 1 8}$ & $\mathbf{2 0 1 9}$ & $\mathbf{2 0 2 0}$ & $\mathbf{2 0 2 1}$ & $\mathbf{2 0 2 2}$ & $\mathbf{2 0 2 3}$ \\
\hline Inversión en KT & -69.996 & -2.763 & -6.519 & -6.519 & -6.519 & -6.519 \\
Inversión en activos fijos & $\mathrm{S} / .-296,967$ & & & & & \\
Inversión en intangibles & $\mathrm{S} / .-54,200$ & & & & & \\
\hline Flujo de Inversiones & $\mathbf{- 4 2 1 . 1 6 3}$ & $\mathbf{- 2 . 7 6 3}$ & $\mathbf{- 6 . 5 1 9}$ & $\mathbf{- 6 . 5 1 9}$ & $\mathbf{- 6 . 5 1 9}$ & $\mathbf{- 6 . 5 1 9}$ \\
\hline Nota: Elaboración propia & & & & & &
\end{tabular}

Con ambos flujos se elabora el flujo de caja económico (FCE) teniendo en cuenta que se debe incluir la perpetuidad del flujo de caja operativo (descontados al WACC) y la perpetuidad de las inversiones (ver anexo $\mathrm{N}^{\circ} 11$ ). Con el FCE se obtiene el Valor Actual Neto económico (VANE) y la Tasa Interna de Retorno económica (TIRE) de la inversión.

Tabla $N^{\circ} 120$

Flujo de Caja Económico (FCE)

\begin{tabular}{lcccccc}
\hline & $\mathbf{2 0 1 8}$ & $\mathbf{2 0 1 9}$ & $\mathbf{2 0 2 0}$ & $\mathbf{2 0 2 1}$ & $\mathbf{2 0 2 2}$ & $\mathbf{2 0 2 3}$ \\
\hline Flujo de Caja Operativo & 0 & 193.025 & 149.631 & 206.789 & 252.829 & 302.875 \\
Perpetuidad de FDC & & & & -6.461 .973 \\
Flujo de Inversiones & -421.163 & -2.763 & -6.519 & -6.519 & -6.519 & -6.519 \\
Perpetuidad de Inversiones & & & & & -342.944 \\
\hline Flujo de Caja Económico & $\mathbf{- 4 2 1 . 1 6 3}$ & $\mathbf{1 9 0 . 2 6 2}$ & $\mathbf{1 4 3 . 1 1 3}$ & $\mathbf{2 0 0 . 2 7 1}$ & $\mathbf{2 4 6 . 3 1 0}$ & $\mathbf{2 . 4 1 5 . 3 8 6}$ \\
\hline
\end{tabular}

Nota: Elaboración propia

Del financiamiento proyectado con el banco a la tasa de $14 \%$ a cancelar en el plazo de 3 años que dura el proyecto, se genera el siguiente flujo de deuda de la estrategia: 
Tabla $N^{\circ} 121$

Flujo de la Deuda Neto

\begin{tabular}{|c|c|c|c|c|c|c|}
\hline & 2018 & 2019 & 2020 & 2021 & 2022 & 2023 \\
\hline Préstamo & S/. 296,967 & & & & & \\
\hline Servicio de la Deuda & & S/. $-120,372$ & S/. $-120,372$ & S/. $-120,372$ & S/. 0 & $\mathrm{~S} / .0$ \\
\hline Escudo Tributario & & S/. 11,240 & S/. 7,248 & S/. 2,697 & S/. 0 & S/. 0 \\
\hline Flujo de Deuda Neto & S/. 296,967 & S/. -109,132 & S/. -113,124 & S/. -117,674 & $\mathrm{S} / .0$ & $\mathrm{~S} / .0$ \\
\hline
\end{tabular}

Como último flujo se tiene el flujo de caja financiero (FCF), que integra el flujo de caja económico (FCE) y el flujo de la deuda neto. Con el FCF se obtiene el Valor Actual Neto financiero (VANF) y la Tasa Interna de Retorno financiero (TIRF) de la inversión.

Tabla $\mathrm{N}^{\circ} 122$

Flujo de Caja Financiero (FCF)

\begin{tabular}{|c|c|c|c|c|c|c|}
\hline & 2018 & 2019 & 2020 & 2021 & 2022 & 2023 \\
\hline Flujo de Caja Económico & $-421,163$ & 190,262 & 143,113 & 200,271 & 246,310 & $2,415,386$ \\
\hline Flujo de la Deuda Neto & 296,967 & $-109,132$ & $-113,124$ & $-117,674$ & 0 & 0 \\
\hline Flujo de Caja Financiero & $-124,196$ & 81,130 & 29,989 & 82,596 & 246,310 & $2,415,386$ \\
\hline
\end{tabular}

\subsubsection{Evaluación Financiera}

Con la información presentada anteriormente, en especial los flujos de caja, se obtienen los indicadores económicos de la estrategia implementada (VAN y TIR). El VANE del proyecto arroja un valor positivo por S/. 569,777 y con respecto al TIRE se observa que este es mayor que la tasa de descuento $(58.30 \%>12.30 \%)$; lo cual indica que es viable desarrollar la estrategia. La tasa de descuento utilizada es el WACC. 
Tabla $\mathrm{N}^{\circ} 123$

Indicadores de Rentabilidad - Evaluación Económica

\begin{tabular}{lc}
\hline \multicolumn{2}{l}{ Evaluación Económica } \\
\hline WACC & $12.30 \%$ \\
VANE & S/. 569,777 \\
TIRE & $58.30 \%$
\end{tabular}

Nota: Elaboración propia

En relación a los indicadores financieros, que se elaboran a partir del flujo de caja financiero (incluida la deuda) y se descuentan al costo de oportunidad que presenta el accionista de la empresa en la ejecución de la nueva estrategia (COK).

Se observa que el VANF es positivo y por un importe de S/. 480,239 y que la TIRF es superior a la tasa de descuento $(115.38 \%>19.51 \%)$ con lo que se reafirma la viabilidad de la estrategia que se extiende también para el accionista.

\begin{tabular}{lc} 
Tabla $\mathrm{N}^{\circ} 124$ & \\
\hline \multicolumn{2}{c}{ Indicadores de Rentabilidad - Evaluación Financiera } \\
\hline Evaluación Financiera \\
\hline COK & $19.51 \%$ \\
VANF & $\mathrm{S} / .480,239$ \\
TIRF & $115.38 \%$ \\
\hline
\end{tabular}

Nota: Elaboración propia 
Tabla $\mathrm{N}^{\circ} 125$

Cálculo de tasa de descuento

\begin{tabular}{lcc}
\hline \multicolumn{1}{c}{ Concepto } & Datos & \\
\hline Tasa Libre de Riesgo E.E.U.U. & RF & Tasa \\
Rendimiento del Mercado E.E.U.U. & RM & $5.03 \%$ \\
Beta desapalancada & $\beta$ & $8.64 \%$ \\
Beta apalancada & $\beta$ & 0.73 \\
Riesgo País Perú (Tasa \%)* & & 1.93 \\
Tasa Impositiva Perú (IR) & & $1.01 \%$ \\
Participación de los trabajadores & & $29.50 \%$ \\
(PT) & & $5.00 \%$ \\
Costo Deuda (Kd) & & $14.00 \%$ \\
D/K promedio & & 2.4631 \\
\hline
\end{tabular}

Nota: Elaboración propia

Tabla $N^{\circ} 126$

Cálculo del Koa

\begin{tabular}{cc}
\hline \multicolumn{2}{c}{ Cálculo del Koa } \\
\hline Koa Nominal & $7.66 \%$ \\
Koa Nominal + Riesgo País & $8.67 \%$ \\
Koa apalancado del proyecto & $\mathbf{8 . 6 7 \%}$ \\
Riesgo del proyecto & $4.33 \%$ \\
Koa del proyecto & $\mathbf{1 3 . 0 0 \%}$ \\
\hline
\end{tabular}

Nota: Elaboración propia

Tabla $\mathrm{N}^{\circ} 127$

Costo de oportunidad del accionista

Costo de Oportunidad del Accionista (COK) Cálculo del COK apalancado

COK Nominal $12.00 \%$

COK Nominal + Riesgo País $13.01 \%$

COK apalancado del proyecto $13.01 \%$

Riesgo del proyecto $6.50 \%$

COK del proyecto $19.51 \%$

Nota: Elaboración propia 
Tabla $\mathrm{N}^{\circ} 128$

Costo de capital promedio ponderado

\begin{tabular}{lr}
\multicolumn{2}{c}{ Costo de capital promedio ponderado (WACC) } \\
\hline \multicolumn{1}{c}{ Descripción } & Valor \\
\hline COK propio & $19.51 \%$ \\
Costo Deuda ( Kd ) & $14.00 \%$ \\
Razón Capital (\% K) & $28.88 \%$ \\
Razón Endeudamiento (\%D) & $71.12 \%$ \\
Impuesto a la renta & $29.50 \%$ \\
Participación de los trabajadores (PT) & $5.00 \%$ \\
\hline WACC & $\mathbf{1 2 . 3 0 \%}$ \\
\hline
\end{tabular}

\subsubsection{Punto de Equilibrio}

Como parte de la evaluación de la estrategia se considera el punto de equilibrio, que exhibe la cantidad de unidades de servicios que se debe comercializar para cubrir en su totalidad los costos y gastos que se generan en el ejercicio. Para tal propósito se toma el margen de contribución, que es la diferencia entre el precio de venta unitario y su costo variable unitario, el cálculo de estos se muestra en el Anexo $\mathbf{N}^{\circ} 15$. 
Tabla N ${ }^{\circ} 129$

Margen de Contribución

\begin{tabular}{llll}
\hline \multicolumn{1}{c}{ Servicios } & $\mathbf{2 0 1 9}$ & $\mathbf{2 0 2 0}$ & $\mathbf{2 0 2 1}$ \\
\hline A.- Casa & & & \\
Habitación & $\mathrm{S} / .2,193$ & $\mathrm{~S} / .2,192$ & $\mathrm{~S} / .2,192$ \\
Sala & $\mathrm{S} / .2,481$ & $\mathrm{~S} / .2,481$ & $\mathrm{~S} / .2,480$ \\
Comedor & $\mathrm{S} / .2,527$ & $\mathrm{~S} / .2,526$ & $\mathrm{~S} / .2,525$ \\
Zona de Parrilla & $\mathrm{S} / .3,049$ & $\mathrm{~S} / .3,049$ & $\mathrm{~S} / .3,048$ \\
Cocina & $\mathrm{S} / .3,545$ & $\mathrm{~S} / .3,545$ & $\mathrm{~S} / .3,544$ \\
B.- Departamento & & & \\
Habitación & $\mathrm{S} / .2,288$ & $\mathrm{~S} / .2,287$ & $\mathrm{~S} / .2,287$ \\
Sala - comedor & $\mathrm{S} / .3,437$ & $\mathrm{~S} / .3,437$ & $\mathrm{~S} / .3,436$ \\
Cocina & $\mathrm{S} / .3,290$ & $\mathrm{~S} / .3,289$ & $\mathrm{~S} / .3,288$ \\
\hline
\end{tabular}

Nota: Elaboración propia

También se agrupan todos los costos fijos de la estrategia, tal como se observa en la siguiente tabla:

\begin{tabular}{|c|c|c|c|}
\hline \multicolumn{4}{|l|}{ Costos Fijos } \\
\hline Concepto & 2019 & 2020 & 2021 \\
\hline Mano de obra & S/. 520,208 & S/. 521,160 & S/. 523,353 \\
\hline Gasto de administración & S/. 31,118 & S/. 31,118 & S/. 31,118 \\
\hline Gasto de ventas & S/. 46,605 & S/. 46,605 & S/. 46,605 \\
\hline Costos indirectos fabricación & S/. 118,989 & S/. 118,989 & S/. 118,989 \\
\hline Depreciación y amortización & S/. 74,543 & S/. 31,154 & S/. 31,154 \\
\hline Gastos financieros & S/. 34,034 & S/. 21,947 & S/. 8,167 \\
\hline TOTAL & $\mathrm{S} / . \mathbf{8 2 5 , 4 9 8}$ & S/. 770,973 & S/. 759,387 \\
\hline
\end{tabular}

Nota: Elaboración propia

En la siguiente tabla se presenta el punto de equilibrio en unidades de servicio, donde la empresa obtiene una utilidad antes de impuestos igual a cero. Es decir que con esa cantidad de servicios vendidos no hay pérdida ni ganancia, porque solo se cubre los costos y gastos. 
Tabla $N^{\circ} 131$

Punto de equilibrio (servicios)

\begin{tabular}{lccc}
\hline \multicolumn{1}{c}{ Servicios } & $\mathbf{2 0 1 9}$ & $\mathbf{2 0 2 0}$ & $\mathbf{2 0 2 1}$ \\
\hline Punto de Equilibrio (unidades) & $\mathbf{2 6 7}$ & $\mathbf{2 4 9}$ & $\mathbf{2 4 6}$ \\
\hline A.- Casa & $\mathbf{1 4 7}$ & $\mathbf{1 3 7}$ & $\mathbf{1 3 5}$ \\
Habitación & 12 & 11 & 11 \\
Sala & 23 & 21 & 21 \\
Comedor & 19 & 17 & 17 \\
Zona de Parrilla & 41 & 39 & 38 \\
Cocina & 53 & 49 & 48 \\
B.- Departamento & $\mathbf{1 2 0}$ & $\mathbf{1 1 2}$ & $\mathbf{1 1 1}$ \\
Habitación & 19 & 17 & 17 \\
Sala - comedor & 52 & 49 & 48 \\
Cocina & 49 & 46 & 45 \\
\hline
\end{tabular}

Nota: Elaboración propia

Para tener un mejor enfoque del punto de equilibrio, se muestra la cantidad de ingresos generados con la venta de las cantidades mencionadas en la tabla anterior.

Tabla $\mathrm{N}^{\circ} 132$

Punto de equilibrio (soles)

\begin{tabular}{|c|c|c|c|}
\hline & 2019 & 2020 & 2021 \\
\hline \multicolumn{4}{|l|}{ A.- Casa } \\
\hline Habitación & S/. 62,078 & S/. 57,980 & S/. 57,129 \\
\hline Sala & S/. 118,082 & S/. 110,286 & S/. 108,667 \\
\hline Comedor & S/. 108,500 & S/. 101,337 & S/. 99,849 \\
\hline Zona de Parrilla & S/. 213,389 & S/. 199,301 & S/. 196,375 \\
\hline Cocina & S/. 346,373 & S/. 323,505 & S/. 318,756 \\
\hline \multicolumn{4}{|l|}{ B.- Departamento } \\
\hline Habitación & S/. 90,981 & S/. 84,975 & S/. 83,727 \\
\hline Sala - comedor & S/. 305,086 & S/. 284,944 & S/. 280,761 \\
\hline Cocina & S/. 251,591 & S/. 234,981 & S/. 231,531 \\
\hline Total Ventas (soles) & $\mathrm{S} / . \mathbf{1 , 4 9 6 , 0 8 0}$ & S/. 1,397,308 & S/. 1,376,795 \\
\hline
\end{tabular}

Nota: Elaboración propia 
Del total de ingresos proyectados, el $96.5 \%$ se asigna para cubrir el total de gastos y costos de la empresa con la estrategia implementada para el año 2019, tal como se muestra a continuación.

Tabla $N^{\circ} 133$

Participación del punto de equilibro en las ventas

\begin{tabular}{cccc}
\hline & 2019 & 2020 & 2021 \\
\hline VENTAS & $100 \%$ & $100 \%$ & $100 \%$ \\
\hline Cantidad proyectada & 297 & 308 & 322 \\
Pervicios del Punto de equilibrio & 267 & 249 & 246 \\
\hline
\end{tabular}

Nota: Elaboración propia

\subsubsection{Análisis de Sensibilidad}

\subsubsection{Unidimensional}

El análisis de sensibilidad ayuda a ver los cambios que supondrían los indicadores VAN y TIR al modificar una variable incluida en el flujo de caja financiero. Las variables por modificar son consideradas variables de entrada y los indicadores resultantes son las variables de salida.

En el análisis unidimensional se cambia una variable de entrada a la vez y se observa los resultados en los indicadores. Para la primera evaluación se toma como variable de entrada a las ventas. 
Tabla $\mathrm{N}^{\circ} 134$

Sensibilidad de Ventas

\begin{tabular}{crrrrc}
\hline \multirow{2}{*}{ Var. \% } & \multirow{2}{*}{ Ventas } & \multicolumn{1}{c}{ VANE } & TIRE & VANF & \multicolumn{1}{c}{ TIRF } \\
\cline { 3 - 6 } & & $\mathrm{S} / 856,841$ & $51.56 \%$ & $\mathrm{~S} / 632,877$ & $83.81 \%$ \\
\hline $30 \%$ & $\mathrm{~S} / 1,988,241$ & $\mathrm{~S} / 1,130,476$ & $79.90 \%$ & $\mathrm{~S} / 890,013$ & $219.38 \%$ \\
$20 \%$ & $\mathrm{~S} / 1,835,300$ & $\mathrm{~S} / 1,039,264$ & $68.93 \%$ & $\mathrm{~S} / 804,301$ & $156.52 \%$ \\
$10 \%$ & $\mathrm{~S} / 1,682,358$ & $\mathrm{~S} / 948,052$ & $59.56 \%$ & $\mathrm{~S} / 718,589$ & $112.12 \%$ \\
$0 \%$ & $\mathrm{~S} / 1,529,416$ & $\mathrm{~S} / 856,841$ & $51.56 \%$ & $\mathrm{~S} / 632,877$ & $83.81 \%$ \\
$-10 \%$ & $\mathrm{~S} / 1,376,475$ & $\mathrm{~S} / 765,629$ & $44.72 \%$ & $\mathrm{~S} / 547,166$ & $65.41 \%$ \\
$-20 \%$ & $\mathrm{~S} / 1,223,533$ & $\mathrm{~S} / 674,417$ & $38.82 \%$ & $\mathrm{~S} / 461,454$ & $52.63 \%$ \\
$-30 \%$ & $\mathrm{~S} / 1,070,592$ & $\mathrm{~S} / 583,206$ & $33.71 \%$ & $\mathrm{~S} / 375,742$ & $43.19 \%$ \\
\hline
\end{tabular}

Nota: Elaboración propia

Se observa que, si las ventas caen en un $30 \%$, tanto el VANE como el VANF siguen siendo positivos. Esto supone que el proyecto sigue siendo viable ante una caída en las ventas, siempre y cuando las demás variables se mantengan constantes.

En relación al TIRE y TIRF, estos van reduciéndose a una mayor caída en las ventas, a pesar de ello, soportan una caída del 30\% con lo cual siguen siendo superior a su tasa de descuento.

La siguiente variable de entrada es el costo de ventas, el cual se compone principalmente por el costo de los materiales. Esta variable afecta directamente a las ventas y a la utilidad bruta del proyecto. 
Tabla $\mathrm{N}^{\circ} 135$

Sensibilidad de Costo de Ventas

\begin{tabular}{cccccc}
\hline \multirow{2}{*}{ Var. \% } & Costo de & VANE & TIRE & VANF & TIRF \\
\cline { 3 - 6 } & Ventas & S/856,841 & $51.56 \%$ & $S / 632,877$ & $83.81 \%$ \\
\hline $30 \%$ & $-S / 1,489,193$ & $S / 651,888$ & $37.49 \%$ & $S / 440,283$ & $50.05 \%$ \\
$20 \%$ & $-S / 1,374,640$ & $S / 720,205$ & $41.67 \%$ & $S / 504,481$ & $58.52 \%$ \\
$10 \%$ & $-S / 1,260,086$ & $S / 788,523$ & $46.34 \%$ & $S / 568,679$ & $69.38 \%$ \\
$0 \%$ & $-S / 1,145,533$ & $S / 856,841$ & $51.56 \%$ & $S / 632,877$ & $83.81 \%$ \\
$-10 \%$ & $-S / 1,030,980$ & $S / 925,158$ & $57.43 \%$ & $S / 697,076$ & $103.75 \%$ \\
$-20 \%$ & $-S / 916,427$ & $S / 993,476$ & $64.04 \%$ & $S / 761,274$ & $131.86 \%$ \\
$-30 \%$ & $-S / 801,873$ & $S / 1,061,793$ & $71.49 \%$ & $S / 825,472$ & $170.46 \%$ \\
\hline
\end{tabular}

Nota: Elaboración propia

Como se muestra en el cuadro, ante un aumento del costo de ventas

del 30\% se obtiene un VANE positivo de S/. 651,888; lo que

representa casi las dos terceras partes del VANE original. Por otro

lado, el VANF sigue siendo positivo como es de esperarse.

En cuanto a la TIRE y TIRF, ambas caen a un poco más de la mitad

pero aun así están por encima de las tasas de descuento para cada tipo

de evaluación. Por lo tanto, una reducción del $30 \%$ del costo de ventas

no produce que el negocio deje de ser rentable.

Como última variable de entrada se tienen los gastos de ventas y administración. Al igual que la variable anterior, un incremento de estos gastos hasta en un $30 \%$ produce que tanto el VANE como el VANF disminuyan en casi un 5\%, por lo tanto su efecto no es tan impactante como la variación en el costo de ventas. Caso similar ocurre con la TIRE y TIRF, ambas caen, pero siguen siendo superior a las tasas de descuento para cada una. 
Tabla $\mathrm{N}^{\circ} 136$

Sensibilidad de Gastos de Ventas y Administración

\begin{tabular}{cccccc}
\hline \multirow{2}{*}{ Var. \% } & Gastos de & VANE & TIRE & VANF & TIRF \\
\cline { 3 - 6 } & Vtas y Adm. & S/856,841 & $51.56 \%$ & S/632,877 & $83.81 \%$ \\
\hline $30 \%$ & $-S / 328,650$ & $\mathrm{~S} / 811,610$ & $48.04 \%$ & $\mathrm{~S} / 590,374$ & $73.78 \%$ \\
$20 \%$ & $-\mathrm{S} / 303,369$ & $\mathrm{~S} / 826,687$ & $49.18 \%$ & $\mathrm{~S} / 604,542$ & $76.90 \%$ \\
$10 \%$ & $-\mathrm{S} / 278,089$ & $\mathrm{~S} / 841,764$ & $50.36 \%$ & $\mathrm{~S} / 618,710$ & $80.24 \%$ \\
$0 \%$ & $-\mathrm{S} / 252,808$ & $\mathrm{~S} / 856,841$ & $51.56 \%$ & $\mathrm{~S} / 632,877$ & $83.81 \%$ \\
$-10 \%$ & $-\mathrm{S} / 227,527$ & $\mathrm{~S} / 871,918$ & $52.80 \%$ & $\mathrm{~S} / 647,045$ & $87.66 \%$ \\
$-20 \%$ & $-\mathrm{S} / 202,246$ & $\mathrm{~S} / 886,995$ & $54.07 \%$ & $\mathrm{~S} / 661,213$ & $91.79 \%$ \\
$-30 \%$ & $-\mathrm{S} / 176,965$ & $\mathrm{~S} / 902,072$ & $55.37 \%$ & $\mathrm{~S} / 675,381$ & $96.24 \%$ \\
\hline
\end{tabular}

Nota: Elaboración propia

\subsubsection{Bidimensional}

Se continua con el mismo criterio de ver cuánto afecta las variables a los indicadores VANE y TIRE, pero esta vez se aplica con un enfoque de doble entrada, es decir que se modificarán los valores de dos variables al mismo tiempo.

Como primeras variables, se utilizan las variaciones en las ventas y el costo de ventas, ambas variables afectan a la utilidad bruta del proyecto y se observará la sensibilidad del VANE ante estas variaciones. 
Tabla $N^{\circ} 137$

Sensibilidad del VANE según Ventas y Costo de Ventas

\begin{tabular}{|c|c|c|c|c|c|c|c|c|}
\hline & \multirow[b]{2}{*}{ VANE } & \multicolumn{7}{|c|}{ Costo de Ventas } \\
\hline & & $30 \%$ & $20 \%$ & $10 \%$ & $0 \%$ & $-10 \%$ & $-20 \%$ & $-30 \%$ \\
\hline & $\mathrm{S} / 856,841$ & $-\mathrm{S} / 1,489,193$ & $-\mathrm{S} / 1,374,640$ & $-\mathrm{S} / 1,260,086$ & $-\mathrm{S} / 1,145,533$ & $-\mathrm{S} / 1,030,980$ & -S/916,427 & $-\mathrm{S} / 801,873$ \\
\hline \multirow{7}{*}{ 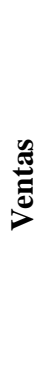 } & $30 \%$ & $\mathrm{~S} / 925,523$ & $\mathrm{~S} / 993,841$ & $\mathrm{~S} / 1,062,158$ & $\mathrm{~S} / 1,130,476$ & $\mathrm{~S} / 1,198,793$ & $\mathrm{~S} / 1,267,111$ & $\mathrm{~S} / 1,335,428$ \\
\hline & $20 \%$ & $\mathrm{~S} / 834,311$ & $\mathrm{~S} / 902,629$ & S/970,946 & $\mathrm{S} / 1,039,264$ & $\mathrm{~S} / 1,107,582$ & S/1,175,899 & $\mathrm{S} / 1,244,217$ \\
\hline & $10 \%$ & $\mathrm{~S} / 743,100$ & $\mathrm{~S} / 811,417$ & $\mathrm{~S} / 879,735$ & $\mathrm{~S} / 948,052$ & $\mathrm{~S} / 1,016,370$ & $\mathrm{~S} / 1,084,687$ & $\mathrm{~S} / 1,153,005$ \\
\hline & $0 \%$ & $\mathrm{~S} / 651,888$ & $\mathrm{~S} / 720,205$ & $\mathrm{~S} / 788,523$ & $\mathrm{~S} / 856,841$ & $\mathrm{~S} / 925,158$ & $\mathrm{~S} / 993,476$ & $\mathrm{~S} / 1,061,793$ \\
\hline & $-10 \%$ & $S / 560,676$ & S/628,994 & $\mathrm{S} / 697,311$ & $\mathrm{~S} / 765,629$ & $\mathrm{~S} / 833,946$ & S/902,264 & S/970,582 \\
\hline & $-20 \%$ & $\mathrm{~S} / 469,465$ & $\mathrm{~S} / 537,782$ & S/606,100 & $\mathrm{S} / 674,417$ & $\mathrm{~S} / 742,735$ & $\mathrm{~S} / 811,052$ & $\mathrm{~S} / 879,370$ \\
\hline & $-30 \%$ & $\mathrm{~S} / 378,253$ & $\mathrm{~S} / 446,570$ & $\mathrm{~S} / 514,888$ & S/583,206 & $\mathrm{S} / 651,523$ & $\mathrm{~S} / 719,841$ & $\mathrm{~S} / 788,158$ \\
\hline
\end{tabular}

Nota: Elaboración propia

En la tabla anterior se observa cómo se comporta el VANE mientras varían las ventas y el costo de ventas, cuando las ventas caen y el costo de ventas aumenta, el VANE tiende a bajar, sin llegar a ser negativo en ningún caso.

En la tabla siguiente se aprecia cómo se comporta la TIRE para el mismo escenario.

Tabla $N^{\circ} 138$

Sensibilidad del TIRE según Ventas y Costo de Ventas

\begin{tabular}{|c|c|c|c|c|c|c|c|c|}
\hline & \multirow[b]{2}{*}{ TIRE } & \multicolumn{7}{|c|}{ Costo de Ventas } \\
\hline & & $30 \%$ & $20 \%$ & $10 \%$ & $0 \%$ & $-10 \%$ & $-20 \%$ & $-30 \%$ \\
\hline & $51.56 \%$ & -S/1,489,193 & -S/1,374,640 & -S/1,260,086 & -S/1,145,533 & -S/1,030,980 & -S/916,427 & -S/801,873 \\
\hline \multirow{7}{*}{ 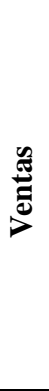 } & $30 \%$ & $57.47 \%$ & $64.08 \%$ & $71.53 \%$ & $79.90 \%$ & $89.27 \%$ & $99.68 \%$ & $111.14 \%$ \\
\hline & $20 \%$ & $49.77 \%$ & $55.42 \%$ & $61.77 \%$ & $68.93 \%$ & $76.99 \%$ & $86.02 \%$ & $96.08 \%$ \\
\hline & $10 \%$ & $43.18 \%$ & $48.02 \%$ & $53.45 \%$ & $59.56 \%$ & $66.44 \%$ & $74.18 \%$ & $82.88 \%$ \\
\hline & $0 \%$ & $37.49 \%$ & $41.67 \%$ & $46.34 \%$ & $51.56 \%$ & $57.43 \%$ & $64.04 \%$ & $71.49 \%$ \\
\hline & $-10 \%$ & $32.55 \%$ & $36.18 \%$ & $40.22 \%$ & $44.72 \%$ & $49.74 \%$ & $55.39 \%$ & $61.74 \%$ \\
\hline & $-20 \%$ & $28.21 \%$ & $31.40 \%$ & $34.92 \%$ & $38.82 \%$ & $43.15 \%$ & $47.99 \%$ & $53.42 \%$ \\
\hline & $-30 \%$ & $24.38 \%$ & $27.21 \%$ & $30.30 \%$ & $33.71 \%$ & $37.47 \%$ & $41.65 \%$ & $46.31 \%$ \\
\hline
\end{tabular}

Nota: Elaboración propia 
Para el caso de la TIRE, se mantiene la misma lógica. A menores ventas y mayor costo de ventas, la TIRE baja a casi la mitad de su valor original pero no llega a ser menor que el WACC, por lo tanto el proyecto sigue siendo viable.

Como se ha podido apreciar, el proyecto se ve afectado si el escenario es desfavorable en ingresos y costos, para el siguiente análisis se utilizan como variables de entrada el costo de ventas y los gastos de ventas y administración y se nota cómo afectan al proyecto.

Tabla $N^{\circ} 139$

Sensibilidad del VANE según Costo de Ventas y Gastos de Ventas y Administración

\begin{tabular}{|c|c|c|c|c|c|c|c|c|}
\hline & \multirow[b]{2}{*}{ VANE } & \multicolumn{7}{|c|}{ Gastos de Ventas y Administración } \\
\hline & & $30 \%$ & $20 \%$ & $10 \%$ & $0 \%$ & $-10 \%$ & $-20 \%$ & $-30 \%$ \\
\hline & $\mathrm{S} / 856,841$ & $-\mathrm{S} / 328,650$ & $-S / 303,369$ & $-\mathrm{S} / 278,089$ & $-S / 252,808$ & $-\mathrm{S} / 227,527$ & $-\mathrm{S} / 202,246$ & $-\mathrm{S} / 176,965$ \\
\hline \multirow{7}{*}{ 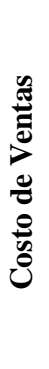 } & $30 \%$ & S/606,657 & $\mathrm{S} / 621,734$ & $\mathrm{~S} / 636,811$ & $\mathrm{~S} / 651,888$ & S/666,965 & $\mathrm{S} / 682,042$ & $\mathrm{~S} / 697,119$ \\
\hline & $20 \%$ & $\mathrm{~S} / 674,974$ & $\mathrm{~S} / 690,051$ & $\mathrm{~S} / 705,128$ & $\mathrm{~S} / 720,205$ & $\mathrm{~S} / 735,282$ & $\mathrm{~S} / 750,359$ & $S / 765,437$ \\
\hline & $10 \%$ & $\mathrm{~S} / 743,292$ & $\mathrm{~S} / 758,369$ & $\mathrm{~S} / 773,446$ & $\mathrm{~S} / 788,523$ & $\mathrm{~S} / 803,600$ & $\mathrm{~S} / 818,677$ & $\mathrm{~S} / 833,754$ \\
\hline & $0 \%$ & $\mathrm{~S} / 811,610$ & $\mathrm{~S} / 826,687$ & $\mathrm{~S} / 841,764$ & $\mathrm{~S} / 856,841$ & $\mathrm{~S} / 871,918$ & $\mathrm{~S} / 886,995$ & $\mathrm{~S} / 902,072$ \\
\hline & $-10 \%$ & $\mathrm{~S} / 879,927$ & $\mathrm{~S} / 895,004$ & $\mathrm{~S} / 910,081$ & $\mathrm{~S} / 925,158$ & $\mathrm{~S} / 940,235$ & $\mathrm{~S} / 955,312$ & S/970,389 \\
\hline & $-20 \%$ & $\mathrm{~S} / 948,245$ & $\mathrm{~S} / 963,322$ & S/978,399 & $\mathrm{S} / 993,476$ & $\mathrm{~S} / 1,008,553$ & $\mathrm{~S} / 1,023,630$ & $\mathrm{~S} / 1,038,707$ \\
\hline & $-30 \%$ & $\mathrm{~S} / 1,016,562$ & $\mathrm{~S} / 1,031,639$ & $\mathrm{~S} / 1,046,716$ & $\mathrm{~S} / 1,061,793$ & $\mathrm{~S} / 1,076,870$ & $\mathrm{~S} / 1,091,947$ & $\mathrm{~S} / 1,107,024$ \\
\hline
\end{tabular}

Nota: Elaboración propia

En la tabla anterior se observa como ante un aumento del $30 \%$ del costo de ventas y los gastos de ventas y administración, el VANE baja considerablemente, sin llegar a ser negativo. Esto demuestra que ambos egresos tienen un fuerte impacto, pero no tanto como una variación en las ventas, como lo hemos visto en la tabla 138.

En la tabla siguiente se muestra cómo se comporta la TIRE para el mismo escenario. 
Tabla $\mathrm{N}^{\circ} 140$

Sensibilidad del TIRE según Costo de Ventas y Gastos de Ventas y Administración

\begin{tabular}{|c|c|c|c|c|c|c|c|c|}
\hline & \multirow[b]{2}{*}{ TIRE } & \multicolumn{7}{|c|}{ Gastos de Ventas y Administración } \\
\hline & & $30 \%$ & $20 \%$ & $10 \%$ & $0 \%$ & $-10 \%$ & $-20 \%$ & $-30 \%$ \\
\hline & $51.56 \%$ & $-\mathrm{S} / 328,650$ & $-S / 303,369$ & -S/278,089 & -S/252,808 & -S/227,527 & -S/202,246 & $-S / 176,965$ \\
\hline \multirow{7}{*}{ 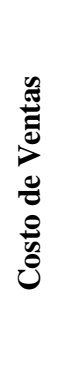 } & $30 \%$ & $34.95 \%$ & $35.78 \%$ & $36.63 \%$ & $37.49 \%$ & $38.38 \%$ & $39.28 \%$ & $40.21 \%$ \\
\hline & $20 \%$ & $38.85 \%$ & $39.77 \%$ & $40.71 \%$ & $41.67 \%$ & $42.66 \%$ & $43.67 \%$ & $44.70 \%$ \\
\hline & $10 \%$ & $43.19 \%$ & $44.21 \%$ & $45.26 \%$ & $46.34 \%$ & $47.44 \%$ & $48.57 \%$ & $49.73 \%$ \\
\hline & $0 \%$ & $48.04 \%$ & $49.18 \%$ & $50.36 \%$ & $51.56 \%$ & $52.80 \%$ & $54.07 \%$ & $55.37 \%$ \\
\hline & $-10 \%$ & $53.47 \%$ & $54.76 \%$ & $56.08 \%$ & $57.43 \%$ & $58.82 \%$ & $60.25 \%$ & $61.72 \%$ \\
\hline & $-20 \%$ & $59.58 \%$ & $61.03 \%$ & $62.51 \%$ & $64.04 \%$ & $65.61 \%$ & $67.22 \%$ & $68.87 \%$ \\
\hline & $-30 \%$ & $66.46 \%$ & $68.09 \%$ & $69.77 \%$ & $71.49 \%$ & $73.25 \%$ & $75.06 \%$ & $76.92 \%$ \\
\hline
\end{tabular}

Nota: Elaboración propia

Para concluir el análisis de sensibilidad bidimensional, se muestra que la sensibilidad de la TIRE ante variaciones en el costo de ventas y gastos de ventas y administración. Ante un incremento de ambos egresos en un 30\%, la TIRE disminuye a 34.95\% siendo todavía mayor al WACC (12.30\%) por lo tanto se puede afirmar que el proyecto sigue siendo viable. Es muy probable que, ante un incremento mayor de ambos o cualquiera de estos egresos, esta situación cambie y el proyecto deje de ser atractivo.

Tanto para el análisis unidimensional y bidimensional, el detalle del cálculo se muestra en el Anexo $\mathbf{N}^{\circ} 16$. 


\section{Capítulo XI. Conclusiones y Recomendaciones}

\subsection{Conclusiones}

1. Los principales aspectos que generan oportunidad del sector son: el crecimiento del sector construcción y la disponibilidad de recursos de las familias para financiar remodelaciones en las familias de los segmentos A y B.

2. La estrategia a desarrollar es penetración de mercados, la cual debe de ser desarrollada enfocada en el segmento de hogares del NSE A y B.

3. Se financiará el proyecto a través de capital propio de los accionistas por un total de S/. 120,566 que representa el $28.88 \%$ de la inversión total y será asignado para los activos intangibles y capital de trabajo. La diferencia de inversión (71.12\%) será financiada a través de un préstamo por S/. 296,967 para la adquisición de activos fijos con una tasa de interés efectiva del $14 \%$.

4. El proyecto es rentable al obtenerse un VANE de S/. 569,777 y un TIRE de $58.30 \%$, el cual es mayor al WACC de $12.30 \%$. Se hace mención que el proyecto presenta flujos positivos desde su primer año.

5. En relación al análisis financiero, vemos que también resulta rentable ya que se obtendría un VANF de S/. 480,239 y un TIRF de $115.38 \%$, el cual es mayor al COK de $19.51 \%$ con flujos positivos para todo el horizonte de evaluación.

6. Se cumple el objetivo estratégico de ventas superior a 1.8 millones de soles al quinto año de implementada la estrategia.

7. El plan estratégico fue presentado a la gerencia, teniendo el total apoyo de los altos directivos para poder ejecutarlo. 


\subsection{Recomendaciones}

1. Se recomienda desarrollar un estudio complementario que identifique los atributos más valorados por el mercado en la remodelación del área de la cocina (distribución del área, decoración, calidad de los materiales, exclusividad en diseños, etc.) siendo este el servicio más demandado.

2. Se debería evaluar alianzas con empresas con servicios complementarios, tales como constructoras medianas o nuevas en el mercado que no estén enfocadas al diseño de interiores, para complementar ambos servicios.

3. Es conveniente ampliar la línea de productos con el servicio de remodelación de baños.

4. Complementar el servicio de remodelación con servicios de garantía extendida que incluya reparación, cambio de color y capacitación para el mantenimiento.

5. Se debe considerar abrir un local más en San Borja o San Isidro, después de terminado el periodo de evaluación actual.

6. El monitoreo de las necesidades de mercado debe ser permanente.

7. La marca "Renuévate" puede auspiciar eventos de interés para el segmento objetivo.

8. Mantener la publicidad por redes sociales y ampliar la publicidad a través de AdWords, servicio de pago por preferencia de búsquedas en Google.

9. El servicio post venta debe ser manejado de cerca para poder generar el marketing boca a boca, dado que ese tipo de servicio requiere confianza que solo te la pueden dar los recomendados.

10. Sugerimos implementar el plan estratégico debido a que se acopla a las necesidades de la empresa y tiene la aprobación de los altos directivos. 


\section{REFERENCIAS}

1. Sector vivienda crecería 5\% al cierre del 2016, Diario El comercio, 2016 http://elcomercio.pe/economia/peru/capeco-sector-vivienda-creceria-5-al-cierre-2016$\underline{\text { noticia- } 1929450}$

2. Ivonne Barreto, Violeta Gamero y Mónica Sánchez, 2011, "Plan de negocios de una empresa comercializadora de muebles para departamentos" (Tesis de posgrado), UPC, Perú http://repositorioacademico.upc.edu.pe/upc/bitstream/10757/324390/11/Barreto_I.pdf

3. Sistema de clasificación, DIGESTYC, salvador, 2016 http://aplicaciones.digestyc.gob.sv/Clasificadores/Sistema/Documentos/DocumentoCLAEE $\underline{\text { S.pdf }}$

4. Kotler \& Armstrong, 2013, Fundamentos de Marketing, México, Pearson Hall 11edicion.

5. Kotler \& Armstrong, 2013, Fundamentos de Marketing, México, Pearson Hall 6ta edición. https://profdariomarketing.files.wordpress.com/2014/03/marketing kotler-armstrong.pdf

6. Franklin Benjamín, 2009, Organización de empresas, Italia, Pearson Hall Tercera edición

7. Producción Nacional, INEI, 2007 https://www.inei.gob.pe/media/MenuRecursivo/boletines/01-produccion-nacional-ene2014.pdf

8. David Mayorga, La ventaja competitiva, 2014 http://marketingestrategico.pe/el-analisis-vrio-y-la-ventaja-competitiva/

9. Sector construcción se recuperará este año y creció hasta 4\%, Diario Gestión, 2016 http://gestion.pe/economia/capeco-sector-construccion-se-recuperara-este-ano-y-crecerahasta-4-2161062 
10. 400 mil hogares en Lima quieren y pueden comprar una vivienda, Diario Gestión, 2013 http://gestion.pe/inmobiliaria/viviendas-capeco-400-mil-hogares-lima-quieren-y-puedencomprar-vivienda-2080129

11. Ingreso por habitante frente a los países de la región, Diario Gestión, 2013 http://gestion.pe/economia/pbicomo-esta-nuestro-ingreso-habitante-frente-paises-region$\underline{2176291}$

12. Hay una guerra de precios en el mercado de muebles, Biznews, 2014 http://biznews.pe/noticias-empresariales-nacionales/hay-guerra-precios-mercado-muebles

13. El $65 \%$ de los limeños prefieren productos de madera para sus hogares, Diario Gestión, 2015 http://gestion.pe/economia/65-limenos-prefieren-productos-madera-sus-hogares-2126136

14. Elsa del Águila, 2008, Línea de Desarrollo Económico del Programa Urbano de Desco, situación de la industria maderera en lima sur http://www.academia.edu/7203733/Situacion_Industria_maderera_Lima_sur

15. El 65\% de todas las empresas en el Perú son informales, Diario El comercio, 2014 http://elcomercio.pe/economia/peru/65-todas-empresas-peru-son-informales-noticia1720484

16. Servicios e industrias news, ADEX, 2016

17. Plan de Gobierno, peruanos por el Kambio, 2016

18. Evolución de los indicadores de empleo e ingresos por departamentos 2004 - 2014, INEI, 2014 
19. Página web, SF Hermanos

http://sfhnos.com/la-empresa/

20. Novopan del Perú S.A.

http://www.novopan.com.pe/

21. Tableros Peruanos S.A

http://www.maderba.com/tableros-peruanos-sa/

22. Masisa S.A

http://www.masisa.com/

23. Interforest $\mathrm{SAC}$

http://compuempresa.com/info/interforest-sac-20136226631

24. Corporación Miyasato

http://www.miyasato.com.pe/

25. Representaciones Martin S.A.C

http://www.guiademateriales.com/?REPRESENTACIONES-MARTIN-S-A-C

26. Dilfas S.A.C

http://compuempresa.com/info/dilfas-sac-20101612318 


\section{ANEXOS \\ Anexo $\mathbf{N}^{\circ} 1$ - Entrevista de Profundidad \\ Entrevista al Gerente General}

Nombre de la empresa: SF HERMANOS S.R.L.

Nombre del entrevistado: Elba Lilian Cárdenas Cerrón

1. ¿En qué fecha se fundó SF HERMANOS S.R.L. y con qué línea de producto se estableció para ofrecer a sus clientes?

La empresa SF HERMANOS S.R.L. fue fundada el año 1990 y empezamos con el rubro de seguridad y fierro, con el tiempo vimos que había demanda insatisfecha con los productos elaborados en madera y fierro, es en ese momento donde decidimos cambiar de rubro, y con la experiencia fuimos expandiendo las líneas que ahora ofrecemos.

2. ¿Qué fue lo que motivo para crear la empresa?

Los fundadores habían llegado a Lima con muchas expectativas de crecimiento, es así que cuando empiezan a hacer más contactos en el rubro en el cual estaban laborando se deciden a tomar el riesgo de hacer su negocio propio.

3. ¿Actualmente SF HERMANOS S.R.L. que es lo que busca mejorar e implementar?

Buscamos mejorar la parte de la Publicidad y Marketing de la empresa, debido a que tenemos más de 28 años en el mercado, tiempo en el cual hemos realizado trabajos muy importantes y participado en proyectos de ingenieros y arquitectos reconocidos en el medio 
inmobiliario, más no hemos sido capaces de poder trabajar paralelamente el reconocimiento de la calidad de nuestros trabajos. La falta de capacitación y el uso de diferentes medios para promocionarnos, ha hecho que sea difícil ampliar nuestro mercado aún más.

\section{4. ¿Con que método de administración de su mercadería y ventas cuenta la empresa?}

Nosotros llevamos la administración de la mercadería y ventas mediante un programa llamado "Ventor", en el cual realizamos las facturaciones por ese medio. Nuestros procesos de ventas están definidos por cada línea de cada producto, que por lo general lo resumimos a venta inmediata, y venta mediante pedido.

Las ventas inmediatas son los productos que tenemos en stock, las cuales por lo general son las líneas hogar y la tienda de acero inoxidable, en cambio las ventas por pedido son los servicios, muebles comerciales, oficinas y hogar, donde primero precisamos de una visita técnica, definimos medidas, diseños y colores que el cliente desea, pasamos a una cotización, luego la aprobación y facturación del pedido.

El proceso del manejo de mercadería lo realizamos mediante los documentos de facturación que realizamos y el ingreso de documentos de compra.

\section{5. ¿Cuál es su opinión sobre la estrategia a implementar "Renuévate"?}

La estrategia "Renuévate" nos ha llamado mucho la atención porque ha tocado varios puntos débiles de la empresa que queremos fortalecer. 
La estrategia nos va a ayudar a atraer clientes a la empresa, y esta sea reconocida por su trayectoria que tiene, por la experiencia y calidad de los productos que elaboramos.

El aumento de nuestra capacidad operativa, debido a que esta estrategia nos va a ayudar a aprovechar los tiempos muertos que se generan debido a la espera que se produce al obtener un nuevo pedido de nuestra cartera de clientes y las recomendaciones de estos.

Mejora de nuestra imagen, posición de nuestra marca para lo cual causaría representar o pertenecer al top 10 de las empresas especializadas en la fabricación de muebles, dándonos mayor competitividad frente a las otras empresas que se dedican al mismo rubro.

\section{6. ¿En su empresa se realiza capacitaciones a su personal?}

La capacitación al personal es constante pues eso nos ayuda a producir productos de buena calidad e innovadores modelos.

\section{7. ¿Qué opina sobre la capacitación del personal?}

La capacitación del personal es muy esencial en una empresa, porque proporciona herramientas importantes para cada uno de ellos en su puesto de trabajo, obteniendo por parte de ellos productividad y eficiencia.

Además de brindar mejor calidad de los productos, toma de decisiones rápidas y adecuadas frente a un problema. 


\title{
8. ¿Por qué medios se dio a conocer SF HERMANOS S.R.L. a los clientes actuales?
}

SF HERMANOS se da a conocer por la cartera de clientes que maneja desde sus inicios, lo cual ha generado una publicidad de boca a boca llegando a clientes que han sido recomendados por los clientes de nuestra cartera.

\section{9. ¿Qué beneficios van a existir a las líneas de productos de la empresa SF HERMANOS} implementando la estrategia "Renuévate"?

\begin{abstract}
Al implementar la estrategia "Renuévate", las líneas de hogar, carpintería en obra y tienda de acero inoxidable, van a obtener mayores ingresos debido a que al remodelar los espacios con nuevas tendencias hace que el cliente piense en obtener productos nuevos, como muebles en madera y acero, y trabajos en estructuras, barandas, decoración en madera y acero, lo cual está conectado también con la tienda de acero inoxidable,
\end{abstract}

\section{0. ¿Por qué Renuévate se enfoca en la línea de hogar y no de oficinas?}

Porque la línea de hogar ha mostrado un crecimiento en los últimos años debido a que nos proporciona más trabajos, los cuales se realizan en casas y departamentos, mientras los trabajos en oficina se han hecho más ausentes porque en el mercado ha ingresado productos de importación con grandes tendencias en modelos y colores, además del reemplazo de la madera ya cero por el pvc y aluminio, lo cual ha hecho que varios clientes nos desplacen en los trabajos de amueblamiento de oficinas. 


\section{1. ¿Por qué la empresa eligió trabajar con el segmento Ay B?}

Los fundadores siempre han tenido el principio que todo lo que realizan deben ser la mejor calidad y satisfacción del cliente, por lo cual nuestros productos son desarrollados con procesos detallados y minuciosos para la creación de estos, el ingenio al realizar diseños complejos, asesoramiento en los proyectos a realizar, y sobre todo el costo de los materiales A1 para la fabricación de nuestros productos. Por lo cual los precios de nuestros productos no son accesibles para el segmento $\mathrm{C}$ y D, en cambio en el segmento Ay B son apreciados por la calidad de cada uno.

12. ¿Estás satisfecho con las utilidades que te está generando tu negocio en estos?

No estoy satisfecha debido a que nosotros no estamos explotando todos nuestros recursos, nuestra planta no llega a su máxima capacidad de producción.

13. ¿Cuentas con una estrategia que permita aumentar las ventas en un $50 \%$ en los próximos dos años?

Si, la estrategia "Renuévate".

\section{4. ¿Se han estancado las ventas o no puedes ajustar los precios?}

Las ventas en la mayoría de las líneas se están estacando debido a que no estamos siendo reconocidos por nuestro trabajo, el precio que manejamos está acorde al mercado. 
15. ¿Consideras que han bajado los márgenes de ganancia?

Si en algunas líneas estamos presentado que los márgenes de ganancia están disminuyendo por ejemplo la línea de muebles de oficina debido a que los pedidos son reducidos.

16. ¿Sientes que los gastos fijos y los gastos financieros están consumiendo las ganancias de tu negocio?

En estos momentos no, pero analizando a la situación que podemos llegar si no implementamos la nueva estrategia, va a llegar un momento que estos nos consuman.

17. ¿Sabes usted cuál es el punto de equilibrio operativo y financiero de tu negocio?

Manejo cuadros internos en el cual tengo un punto de equilibrio financiero por cada línea, mas no es un cuadro especifico y detallado en el cual pueda ser exacto debido a la forma de trabajo.

18. ¿Dónde quisieras que se encuentre tu empresa dentro de uno año y dentro de 5 años?

Dentro de un año y medio, deseamos ser reconocidos en Lima Metropolitana como una empresa top en la fabricación de muebles en madera y acero inoxidable. Y en 5 años una empresa reconocida a nivel nacional por nuestros productos de calidad. 
19. ¿Si lograras duplicar tus ganancias en menos de un año te sentirías satisfecha?

Por supuesto.

20. ¿Has visto empresas en tu mismo giro de negocio que han crecido de manera espectacular y tu quisieras saber cómo lo han hecho para lograr eso y más?

Así es, hemos visto empresas con los mismos años de trayectoria que nosotros, y queremos mejorar para llegar a competir con ellos.

21. ¿Quisieras llevar tu empresa al siguiente nivel de crecimiento?

Claro, por ese motivo estamos muy entusiasmado en implementar la nueva estrategia. 
ENTREVISTA REALIZADA AL VENDEDOR DE LA EMPRESA SF HERMANOS S.R.L.

Nombre de la empresa: SF HERMANOS SRL

Nombre del entrevistado: Joseph Pancorbo

Puesto que ocupa: Vendedor

\section{1. ¿Cuál sería la visión a un futuro de la empresa?}

La visión de la empresa ser reconocida a nivel nacional como especialistas en la fabricación de muebles en, madera y acero inoxidable.

\section{En cuanto a la competencia ¿Qué problemas se les ha presentado?}

La falta información de los productos que tenemos, la calidad y los procesos que se realizan para tener un producto de calidad. Por lo general hay empresas que son nuevas en el rubro, además de tener profesionales que recién están empezando su vida laboral, por lo cual los desconocimientos de la complejidad de trabajo hacen que elijan opciones rápidas y de menor precio. Los que conocen sobre nuestro trabajo siempre vuelven y nos recomiendan a otras empresas.

\section{Para aumentar su clientela que estaría dispuesta hacer}

Estaría dispuesto a capacitarme más sobre los procesos de producción de cada línea de trabajo, realizar seguimiento post venta de nuestros productos, asesorar, e incentivar al cliente a que nos recomienden. 
4. ¿Qué fortaleza piensa que tiene la empresa SF HERMANOS SRL?

La calidad de sus productos, y el ingenio para resolver los problemas complicados que tiene los clientes al desarrollar sus proyectos.

5. ¿Ha recibido alguna capacitación para atención al cliente?

No, aun no. 


\section{ENTREVISTA REALIZADA AL JEFE DE PRODUCCION DE LA EMPRESA SF HERMANOS S.R.L.}

Nombre de la empresa: SF HERMANOS SRL

Nombre del entrevistado: Ing. Jaime Canchan

Puesto que ocupa: Jefe de producción

1. ¿Cuál es la función principal que desempeña en la empresa?

Mi función principal es velar por la fabricación de los productos que labora la empresa, supervisar e inspeccionar que todo esté de acuerdo a lo establecido por la empresa o el cliente.

2. ¿Cuántas personas están a su cargo?

25 Personas.

3. ¿Cómo maneja a su personal para asignarles tareas?

Primero hago un cronograma de todos los trabajos a realizar, veo los materiales si tenemos en stock, y procedo a designar a cada uno su tarea por las habilidades y conocimientos que tiene cada uno de ellos.

4. ¿Ud. Tiene almacenes asignados para cada tipo de producto?

$\mathrm{Si}$, tenemos almacenes para nuestros materiales y suministros. 


\section{5. ¿Hay almacen para productos terminados?}

$\mathrm{Si}$, contamos con un almacen.

\section{Capacita a su personal para llevar a cabo sus tareas?}

Claro, para cada trabajo que tenemos que realizar deben estar informados y capacitados para cumplir con los estándares de calidad planteados.

7. ¿Brevemente explíquenos como es el proceso actual que se lleva en su empresa?

Primero realizamos visitas a los clientes para saber los requerimientos que tienen, se toman medias, colores, diseños y planos de los clientes, se realiza la cotización respectiva, una vez aprobada se realiza la orden de pedido, es donde empezamos a producir el producto designado.

8. ¿Este proceso que menciono lo utiliza para todos sus productos?

No se utiliza en la tienda de acero inoxidable, en las demás líneas si se utiliza. 


\section{ENTREVISTA REALIZADA A LA ADMINISTRACION DE LA EMPRESA SF \\ HERMANOS S.R.L.}

Nombre de la empresa: SF HERMANOS S.R.L.

Nombre del entrevistado: Katya Cardenas Waidhofer.

Puesto que ocupa: Administradora.

1. ¿Cuáles son las principales actividades que lleva a cabo la empresa?

Velar por la gestión administrativa y productiva de la empresa con el fin de obtener utilidades.

2. ¿Qué línea de productos maneja?

Manejamos varias líneas, línea de hogar, de oficinas, carpintería metálica, servicios y tienda de acero inoxidable.

3. ¿Cómo manejan la calidad de sus productos?

Realizamos revisión y supervisión de nuestros trabajos estén de acuerdo con las especificaciones establecidas por cada producto y las especificaciones del cliente.

4. ¿Ofrecen garantía a sus clientes?

Claro, ofrecemos 12 meses de garantía de nuestros productos.

5. ¿La venta de sus productos es únicamente en este local? 
$\mathrm{Si}$, solo contamos con nuestro local para venta de nuestros productos.

6. ¿Qué canales utiliza para la distribución de sus productos?

Solo manejamos un canal de distribución que es fabrica a cliente directamente.

7. ¿Realiza actividades de publicidad?

Solo publicamos nuestros productos por página web y facebook.

8. ¿Cómo establece el precio de sus productos?

Dependiendo de cada línea se determina el precio, según diseño, modelo y material para la fabricación del producto.

9. ¿Qué políticas de venta lleva a cabo?

Antes de realizar la fabricación del producto debe haber la cotización aprobada, y el 50\% de adelanto.

10. ¿Qué políticas de pago lleva a cabo?

El pago debe ser $50 \%$ de adelanto y el otro $50 \%$ después de finalizar el trabajo.

\section{1. ¿Qué margen de utilidad maneja?}

Dependiendo de la línea de producto entre 10 a $30 \%$ de margen de utilidad. 


\section{2. ¿Tiene algún perfil de clientes?}

No, para nosotros todos los clientes son importantes.

13. ¿Cuenta con alguna base de datos o un registro para clasificar a sus clientes?

Antes no lo teníamos, recién este año estamos empezando armar nuestra base de datos y registro de clientes.

14. ¿Además de su mercado actual, piensa usted abarcar otro tipo de clientes? Así es, por eso queremos implementar la estrategia "Renuévate".

15. ¿Cuál cree que sean las principales fortalezas y debilidades de su empresa?

La fortaleza de la empresa es la experiencia en los trabajos especializados en madera y en acero, los clientes fidelizados por la calidad y eficiencia en nuestros productos.

La debilidad es la falta de promoción de nuestros productos, lo cual no nos permite a llegar a más clientes, y conocer nuestro trabajo.

\section{6. ¿Cuáles considera que son las amenazas y oportunidades del sector?}

La amenaza son los productos importados que han llegado a nuestro país, los cuales tienen diseño y estilo, pero calidad y durabilidad no lo tiene.

El crecimiento de proyectos inmobiliarios en el país, desarrollo de departamentos y casas que se expanden en lugares que antes no eran habitados. 


\section{Anexo $\mathbf{N}^{\circ} 2$ - Cuestionario aplicado a clientes}

\begin{tabular}{|c|c|c|c|c|}
\hline & Alicorp & Sunat & $\begin{array}{c}\text { AM \&M } \\
\text { Construccio } \\
\text { nes }\end{array}$ & $\begin{array}{c}\text { Edificaciones y } \\
\text { Construcciones } \\
\text { Chacarrilla S.A.C. }\end{array}$ \\
\hline $\begin{array}{l}\text { ¿Ha usado en algún momento nuestros } \\
\text { servicios? Alguna vez/ } 6 \text { meses/ 1-3 } \\
\text { años/nunca }\end{array}$ & Alguna vez & $1-3$ años & Alguna vez & 1-3 años \\
\hline $\begin{array}{c}\text { ¿Con qué frecuencia Ud. remodela } \\
\text { algún espacio físico de su domicilio? } \\
\text { 1año/3años/5años/10años/nunca }\end{array}$ & 5 años & 5 años & 10 años & 5 años \\
\hline $\begin{array}{l}\text { ¿Cuán satisfecho se encuentra con el } \\
\text { producto o servicio? } \\
\text { Muy } \\
\text { satisfecho/Satisfecho/Neutral/Insatisfe } \\
\text { cho/Muy satisfecho }\end{array}$ & Satisfecho & Satisfecho & $\begin{array}{l}\text { Muy } \\
\text { satisfecho }\end{array}$ & Insatisfecho \\
\hline $\begin{array}{c}\text { ¿Qué lo impresionó más acerca de } \\
\text { nuestro producto o servicio? } \\
\text { Calidad/ Precio/ Experiencia de } \\
\text { compra/ Instalación o Primer uso/uso } \\
\text { servicio al cliente. }\end{array}$ & Calidad & $\begin{array}{l}\text { Experienci } \\
\text { a de } \\
\text { compra }\end{array}$ & $\begin{array}{l}\text { Instalación o } \\
\text { Primer uso }\end{array}$ & Precio \\
\hline $\begin{array}{c}\text { ¿Qué lo decepcionó de nuestro } \\
\text { producto o servicio? } \\
\text { Calidad/ Precio/ Experiencia de } \\
\text { compra/ Instalación o Primer uso/uso } \\
\text { servicio al cliente. }\end{array}$ & $\begin{array}{l}\text { Instalación } \\
\text { o primer } \\
\text { uso }\end{array}$ & $\begin{array}{l}\text { Instalació } \\
\text { n o primer } \\
\text { uso }\end{array}$ & $\begin{array}{l}\text { Uso servicio } \\
\text { al cliente }\end{array}$ & $\begin{array}{l}\text { Instalación o } \\
\text { primer uso }\end{array}$ \\
\hline $\begin{array}{l}\text { ¿Qué es lo que le gusta de nuestro } \\
\text { producto o servicio? }\end{array}$ & La calidad & El diseño & $\begin{array}{c}\text { La } \\
\text { innovación }\end{array}$ & No hay nada \\
\hline $\begin{array}{l}\text { ¿Qué es lo que no le gusta de nuestro } \\
\text { producto o servicio? }\end{array}$ & La demora & La demora & El material & La demora \\
\hline $\begin{array}{c}\text { Comparado con productos similares } \\
\text { ofrecidos por otras compañías, ¿cómo } \\
\text { considera nuestro producto o servicio? } \\
\text { Mucho mejor/Algo mejor/ más o } \\
\text { menos igual/ algo peor/mucho peor/ } \\
\text { no opina }\end{array}$ & Algo mejor & $\begin{array}{l}\text { Mucho } \\
\text { mejor }\end{array}$ & $\begin{array}{l}\text { Más o menos } \\
\text { igual }\end{array}$ & Más o menos igual \\
\hline $\begin{array}{c}\text { ¿Usaría nuestro producto o servicio en } \\
\text { el futuro? } \\
\text { Definitivamente/ Probablemente/No } \\
\text { estoy seguro//Probablemente } \\
\text { no/Definitivamente no }\end{array}$ & $\begin{array}{l}\text { Probableme } \\
\text { nte }\end{array}$ & $\begin{array}{l}\text { Definitiva } \\
\text { mente }\end{array}$ & $\begin{array}{l}\text { Probablemen } \\
\text { te }\end{array}$ & Probablemente no \\
\hline $\begin{array}{c}\text { ¿Recomendaría nuestro producto o } \\
\text { servicio a otra gente? } \\
\text { Definitivamente/ Probablemente/No } \\
\text { estoy seguro//Probablemente } \\
\text { no/Definitivamente no }\end{array}$ & $\begin{array}{l}\text { Probableme } \\
\text { nte }\end{array}$ & $\begin{array}{l}\text { Definitiva } \\
\text { mente }\end{array}$ & $\begin{array}{l}\text { Probablemen } \\
\text { te }\end{array}$ & Probablemente no \\
\hline
\end{tabular}


Anexo $\mathbf{N}^{\circ} 3$ - Competidores

SF HERMANOS

\begin{tabular}{|c|c|}
\hline RUC: & 20101250653 - S.F. HERMANOS S.R.L. \\
\hline Tipo Contribuyente: & SOC.COM.RESPONS. LTDA \\
\hline Nombre Comercial: & - \\
\hline Fecha de Inscripción: & $27 / 01 / 1893$ \\
\hline Estado: & ACTIVO \\
\hline Condición: & HABIDO \\
\hline Domicilio Fiscal: & MZA. K LOTE. 2 P.I. EL ASESOR LIMA - LIMA - ATE \\
\hline Actividad(es) Económica(s): & Principal - CIIU 38104 - FAB. DE MUEBLES. \\
\hline \multirow[t]{5}{*}{$\begin{array}{l}\text { Comprobantes de Pago c/aut. de impresión } \\
\text { (F. } 806 \text { u } 816) \text { : }\end{array}$} & FACTURA \\
\hline & BOLETA DE VENTA \\
\hline & NOTA DE CREDITO \\
\hline & NOTA DE DEBITO \\
\hline & GUIA DE REMISION - REMITENTE \\
\hline Sistema de Emisión Electrónica: & - \\
\hline Afiliado al PLE desde: & $01 / 01 / 2015$ \\
\hline Padrones: & NINGUNO \\
\hline
\end{tabular}




\section{CANZIANI S.A.C}

\begin{tabular}{|ll|}
\hline RUC: & 20100639492 - CANZIANI MUEBLES Y DECORACIONES S A \\
\hline Tipo Contribuyente: & SOCIEDAD ANONIMA \\
\hline Nombre Comercial: & CANZIANI MUEBLES Y DECORACIONE \\
\hline Fecha de Inscripción: & 27/01/1983 \\
\hline Estado: & ACTIVO \\
Condición: & HABIDO \\
\hline Domicilio Fiscal: & AV. VENEZUELA NRO. 2305 LIMA - LIMA - LIMA \\
\hline Actividad(es) Económica(s): & Principal - CIIU 52301 - OTROS TIPOS DE VENTA AL POR MENOR. \\
\hline $\begin{array}{l}\text { Comprobantes de Pago claut. de impresión } \\
\text { (F. 806 u 816): }\end{array}$ & NINGUNO \\
\hline Sistema de Emisión Electrónica: & - \\
\hline Afiliado al PLE desde: & - \\
\hline Padrones: & \\
\hline
\end{tabular}


MUEBLES FERRINI

\begin{tabular}{|c|c|}
\hline RUC: & 20100359961 - MUEBLES FERRINI S.A. \\
\hline Tipo Contribuyente: & SOCIEDAD ANONIMA \\
\hline Nombre Comercial: & FERRINI \\
\hline Fecha de Inscripción: & $27 / 01 / 1993$ \\
\hline Estado: & ACTIVO \\
\hline Condición: & HABIDO \\
\hline Domicilio Fiscal: & $\begin{array}{l}\text { CAL.LOS TALLERES NRO. } 4897 \text { ZI. EL NARANJAL LIMA - LIMA - } \\
\text { INDEPENDENCIA }\end{array}$ \\
\hline \multirow[t]{2}{*}{ Actividad(es) Económica(s): } & Principal - CIIU 36104 - FAB. DE MUEBLES. \\
\hline & Secundaria 1 - CIIU 52335 - VTA. MIN. EQUIPO DE USO DOMESTICO. \\
\hline \multirow[t]{6}{*}{$\begin{array}{l}\text { Comprobantes de Pago c/aut. de } \\
\text { impresión (F. } 806 \text { u 816): }\end{array}$} & FACTURA \\
\hline & BOLETA DE VENTA \\
\hline & CARTA DE PORTE AEREO \\
\hline & NOTA DE CREDITO \\
\hline & NOTA DE DEBITO \\
\hline & GUIA DE REMISION - REMITENTE \\
\hline Sistema de Emisión Electrónica: & - \\
\hline Afiliado al PLE desde: & $01 / 01 / 2013$ \\
\hline Padrones: & NINGUNO \\
\hline
\end{tabular}


Anexo 4 - Proveedores

NOVOPAN DEL PERÚ S.A.

\begin{tabular}{|c|c|}
\hline RUC: & 20381034071 - NOVOPAN PERU S.A.C. \\
\hline Tipo Contribuyente: & SOCIEDAD ANONIMA CERRADA \\
\hline Nombre Comercial: & - \\
\hline Fecha de Inscripción: & $17 / 12 / 1997$ \\
\hline Estado: & ACTIVO \\
\hline Condición: & HABIDO \\
\hline Domicilio Fiscal: & $\begin{array}{l}\text { AN. EUCALIPTOS LOTE. } 3 \text { INT. D } 2 B \text { URB. SANTA GENOVEVA (ALT. KM. } 40 \\
\text { ANTIGUA PANAMERICANA SUR) LIMA - LIMA - LURIN }\end{array}$ \\
\hline \multirow[t]{2}{*}{ Actividad(es) Económica(s): } & Principal - CIIU 51430 - VTA. MAY. MATERIALES DE CONSTRUCCION. \\
\hline & Secundaria 1 - CIIU 93098 - OTRAS ACTIVID.DE TIPO SERVICIO NCP \\
\hline \multirow{6}{*}{$\begin{array}{l}\text { Comprobantes de Pago c/aut. de impresión } \\
\text { (F. } 806 \text { u } 816) \text { : }\end{array}$} & FACTURA \\
\hline & BOLETA DE VENTA \\
\hline & NOTA DE CREDITO \\
\hline & NOTA DE DEBITO \\
\hline & GUIA DE REMISION - REMITENTE \\
\hline & COMPROBANTE DE RETENCION \\
\hline Sistema de Emisión Electrónica: & $\begin{array}{l}\text { DESDE LOS SISTEMAS DEL CONTRIBUYENTE. AUTORIZ DESDE } \\
12 / 03 / 2016\end{array}$ \\
\hline Afiliado al PLE desde: & $01 / 01 / 2013$ \\
\hline Padrones: & $\begin{array}{l}\text { Incorporado al Régimen de Agentes de Retención de IGV (R.S.378-2013) a } \\
\text { partir del 01/03/2014 }\end{array}$ \\
\hline
\end{tabular}


TABLEROS PERUANOS S.A

\begin{tabular}{|c|c|}
\hline RUC: & 20165544995 - TABLEROS PERUANOS S.A. \\
\hline Tipo Contribuyente: & SOCIEDAD ANONIMA \\
\hline Nombre Comercial: & TABLEROS PERUANOS S.A. \\
\hline Fecha de Inscripción: & $07 / 08 / 1983$ \\
\hline Estado: & ACTIVO \\
\hline Condición: & HABIDO \\
\hline Domicilio Fiscal: & $\begin{array}{l}\text { CAR.INDUSTRIAL KM. } 8 \text { Z.I. CAMPO PRIMAVERA (COOPERATIVA LAREDO) } \\
\text { LA LIBERTAD - TRUJILLO - LAREDO }\end{array}$ \\
\hline \multirow[t]{2}{*}{ Actividad(es) Económica(s): } & Principal - CIIU 20211 - FAB. DE HOJAS DE MADERA. \\
\hline & Secundaria 1 - CIIU 93098 - OTRAS ACTIVID.DE TIPO SERVICIO NCP \\
\hline \multirow{7}{*}{$\begin{array}{l}\text { Comprobantes de Pago claut. de impresión } \\
\text { (F. } 806 \text { u 816): }\end{array}$} & FACTURA \\
\hline & BOLETA DE VENTA \\
\hline & LIQUIDACION DE COMPRA \\
\hline & NOTA DE CREDITO \\
\hline & NOTA DE DEBITO \\
\hline & GUIA DE REMISION - REMITENTE \\
\hline & COMPROBANTE DE RETENCION \\
\hline Sistema de Emisión Electrónica: & - \\
\hline Afiliado al PLE desde: & $30 / 10 / 2012$ \\
\hline Padrones: & $\begin{array}{l}\text { Incorporado al Régimen de Agentes de Retención de IGV (R.S.395-2014) a } \\
\text { partir del 01/02/2015 }\end{array}$ \\
\hline
\end{tabular}




\section{MASISA S.A.C}

\begin{tabular}{|c|c|}
\hline RUC: & 20546199445 - PLACACENTROS MASISA PERU S.A.C. \\
\hline Tipo Contribuyente: & SOCIEDAD ANONIMA CERRADA \\
\hline Nombre Comercial: & PLACACENTRO MASISA \\
\hline Fecha de Inscripción: & 28/12/2011 \\
\hline Estado: & ACTIVO \\
\hline Condición: & HABIDO \\
\hline Domicilio Fiscal: & $\begin{array}{l}\text { AV. REPUBLICA DE PANAMA NRO. } 3533 \text { DPTO. } 401 \text { LIMA - LIMA - SAN } \\
\text { ISIDRO }\end{array}$ \\
\hline Actividad(es) Económica(s): & Principal - CIIU 52190 - VTA. MIN. OTROS PRODUCTOS EN ALMACEN. \\
\hline \multirow{6}{*}{$\begin{array}{l}\text { Comprobantes de Pago c/aut. de } \\
\text { impresión (F. } 806 \text { u 816): }\end{array}$} & FACTURA \\
\hline & BOLETA DE VENTA \\
\hline & NOTA DE CREDITO \\
\hline & NOTA DE DEBITO \\
\hline & GUIA DE REMISION - REMITENTE \\
\hline & COMPROBANTE DE RETENCION \\
\hline Sistema de Emisión Electrónica: & - \\
\hline Afiliado al PLE desde: & 01/01/2014 \\
\hline Padrones: & Excluido del Régimen de Agentes de Retención de IGV a partir del 01/09/ \\
\hline
\end{tabular}


INTERFOREST S.A.C.

\begin{tabular}{|c|c|}
\hline RUC: & 20136226631 - INTERFOREST S.A.C. \\
\hline Tipo Contribuyente: & SOCIEDAD ANONIMA CERRADA \\
\hline Nombre Comercial: & INTERFOREST \\
\hline Fecha de Inscripción: & $13 / 05 / 1803$ \\
\hline Estado: & ACTIVO \\
\hline Condición: & HABIDO \\
\hline Domicilio Fiscal: & AN. REPUBLICA DE PANAMA NRO. 4613 LIMA - LIMA - SURQUILLO \\
\hline \multirow[t]{3}{*}{ Actividad(es) Económica(s): } & Principal - CIIU 52583 - OTROS TIPOS DE VENTA POR MENOR. \\
\hline & Secundaria 1 - CIIU 51906 - VTA. MAY. DE OTROS PRODUCTOS. \\
\hline & Secundaria 2 - CIIU 74986 - OTRAS ACTIVIDADES EMPRESARIALES NCP. \\
\hline \multirow{8}{*}{$\begin{array}{l}\text { Comprobantes de Pago c/aut. de impresión } \\
\text { (F. } 806 \text { u } 816 \text { ): }\end{array}$} & FACTURA \\
\hline & BOLETA DE VENTA \\
\hline & LIQUIDACION DE COMPRA \\
\hline & NOTA DE CREDITO \\
\hline & NOTA DE DEBITO \\
\hline & GUIA DE REMISION - REMITENTE \\
\hline & COMPROBANTE DE RETENCION \\
\hline & GUIA DE REMISION - TRANSPORTISTA \\
\hline Sistema de Emisión Electrónica: & $\begin{array}{l}\text { DESDE LOS SISTEMAS DEL CONTRIBUYENTE. AUTORIZ DESDE } \\
03 / 08 / 2016\end{array}$ \\
\hline Afiliado al PLE desde: & $01 / 01 / 2013$ \\
\hline
\end{tabular}


CORPORACIÓN MIYASATO

\begin{tabular}{|c|c|}
\hline RUC: & 20100083877 - CORPORACION MIYASATO S.A.C. \\
\hline Tipo Contribuyente: & SOCIEDAD ANONIMA CERRADA \\
\hline Nombre Comercial: & CORPORACION MIYASATO \\
\hline Fecha de Inscripción: & $08 / 10 / 1982$ \\
\hline Estado: & ACTIVO \\
\hline Condición: & HABIDO \\
\hline Domicilio Fiscal: & AV. IQUITOS NRO. 1174 LIMA - LIMA - LA VICTORIA \\
\hline Actividad(es) Económica(s): & Principal - CIIU 51008 - VTA. MAY. DE OTROS PRODUCTOS. \\
\hline \multirow{7}{*}{$\begin{array}{l}\text { Comprobantes de Pago c/aut. de impresión } \\
\text { (F. } 806 \text { u 816): }\end{array}$} & FACTURA \\
\hline & BOLETA DE VENTA \\
\hline & NOTA DE CREDITO \\
\hline & NOTA DE DEBITO \\
\hline & GUIA DE REMISION - REMITENTE \\
\hline & COMPROBANTE DE RETENCION \\
\hline & COMPROBANTE DE PERCEPCION VENTA INTERNA \\
\hline Sistema de Emisión Electrónica: & $\begin{array}{l}\text { DESDE LOS SISTEMAS DEL CONTRIBUYENTE. AUTORIZ DESDE } \\
04 / 07 / 2015\end{array}$ \\
\hline Afiliado al PLE desde: & $14 / 01 / 2013$ \\
\hline \multirow[t]{2}{*}{ Padrones: } & $\begin{array}{l}\text { Incorporado al Régimen de Agentes de Retención de IGV (R.S.037-2002) a } \\
\text { partir del 01/08/2002 }\end{array}$ \\
\hline & $\begin{array}{l}\text { Incorporado al Régimen de Agentes de Percepción de IGV - Venta Interna } \\
\text { (R.S. 058-2008) a partir del 01/04/2008 }\end{array}$ \\
\hline
\end{tabular}


REPRESENTACIONES MARTIN S.A.C.

\begin{tabular}{|c|c|}
\hline RUC: & 20306637305 - REPRESENTACIONES MARTIN S.A.C \\
\hline Tipo Contribuyente: & SOCIEDAD ANONIMA CERRADA \\
\hline Nombre Comercial: & REPRESENTACIONES MARTIN SAC \\
\hline Fecha de Inscripción: & 05/08/1896 \\
\hline Estado: & ACTIVO \\
\hline Condición: & HABIDO \\
\hline Domicilio Fiscal: & $\begin{array}{l}\text { PQ. INDUSTRIAL NRO. K-2 INT. } 11 \text { PARCELA II (ENTRE AN.PACHACUTEC Y } \\
\text { J.VELASCO ALVARADO) LIMA - LIMA - VILLA EL SALVADOR }\end{array}$ \\
\hline \multirow[t]{2}{*}{ Actividad(es) Económica(s): } & Principal - CIIU 51430 - VTA. MAY. MATERIALES DE CONSTRUCCION. \\
\hline & Secundaria 1 - CIIU 51502 - VTA. MAY. MAQUINARIA, EQUIPO Y MATER. \\
\hline \multirow{7}{*}{$\begin{array}{l}\text { Comprobantes de Pago c/aut. de impresión } \\
\text { (F. } 806 \text { u } 816 \text { ): }\end{array}$} & FACTURA \\
\hline & BOLETA DE VENTA \\
\hline & NOTA DE CREDITO \\
\hline & NOTA DE DEBITO \\
\hline & GUIA DE REMISION - REMITENTE \\
\hline & COMPROBANTE DE RETENCION \\
\hline & COMPROBANTE DE PERCEPCION VENTA INTERNA \\
\hline Sistema de Emisión Electrónica: & $\begin{array}{l}\text { DESDE LOS SISTEMAS DEL CONTRIBUYENTE. AUTORIZ DESDE } \\
\text { 16/05/2015 }\end{array}$ \\
\hline Afiliado al PLE desde: & $01 / 01 / 2013$ \\
\hline Padrones: & $\begin{array}{l}\text { Incorporado al Régimen de Agentes de Retención de IGV (R.S.101-2003) a } \\
\text { partir del 01/08/2003 }\end{array}$ \\
\hline
\end{tabular}




\section{DILFAS S.A.C}

\begin{tabular}{|c|c|}
\hline RUC: & 20101612318 - DILFAS S.A.C. \\
\hline Tipo Contribuyente: & SOCIEDAD ANONIMA CERRADA \\
\hline Nombre Comercial: & DILFAS SAC \\
\hline Fecha de Inscripción: & $09 / 03 / 1893$ \\
\hline Estado: & ACTIVO \\
\hline Condición. & Hapun \\
\hline Domicilio Fiscal: & $\begin{array}{l}\text { AN. NICOLAS AYLLON NRO. } 3340 \text { COO. } 27 \text { DE ABRIL (A } 3 \text { CDRAS OVALO STA } \\
\text { ANITA-KM } 4.5 \text { C.CENTR) LIMA - LIMA - ATE }\end{array}$ \\
\hline \multirow[t]{3}{*}{ Actividad(es) Económica(s): } & Principal - CIIU 51430 - VTA. MAY. MATERIALES DE CONSTRUCCION. \\
\hline & Secundaria 1 - CIIU 71118 - ALQUILER EQUIPO TRANSPORTE V. TERRES. \\
\hline & Secundaria 2 - CIIU 71221 - ALQUILER MAQUI. Y EQUIP.CONSTRUCCION. \\
\hline \multirow{6}{*}{$\begin{array}{l}\text { Comprobantes de Pago c/aut. de impresión } \\
\text { (F. } 806 \text { u 816): }\end{array}$} & FACTURA \\
\hline & BOLETA DE VENTA \\
\hline & NOTA DE CREDITO \\
\hline & NOTA DE DEBITO \\
\hline & GUIA DE REMISION - REMITENTE \\
\hline & COMPROBANTE DE PERCEPCION VENTA INTERNA \\
\hline Sistema de Emisión Electrónica: & - \\
\hline Afiliado al PLE desde: & $01 / 01 / 2013$ \\
\hline Padrones: & $\begin{array}{l}\text { Excluido del Régimen de Agentes de Percepción de IGV - Venta Interna a partir } \\
\text { del } 01 / 07 / 2013\end{array}$ \\
\hline
\end{tabular}


Anexo $N^{\circ} 5$ - Pagos mensuales del préstamo

\begin{tabular}{|c|c|c|c|c|c|}
\hline Mes & $\begin{array}{c}\text { Préstamo } \\
\text { Total }\end{array}$ & $\begin{array}{c}\text { Amortización } \\
\text { Mensual } \\
\end{array}$ & $\begin{array}{c}\text { Intereses } \\
1.10 \% \\
\end{array}$ & $\begin{array}{c}\text { Cuota } \\
\text { Mensual }\end{array}$ & $\begin{array}{c}\text { Saldo } \\
\text { Préstamo } \\
\end{array}$ \\
\hline 1 & S/. 296,967 & S/. 6,771 & $\mathrm{S} / .3,260$ & S/. 10,031 & S/. 290,196 \\
\hline 2 & S/. 290,196 & S/. 6,845 & S/. 3,186 & S/. 10,031 & S/. 283,351 \\
\hline 3 & S/. 283,351 & S/. 6,920 & S/. 3,111 & S/. 10,031 & S/. 276,431 \\
\hline 4 & S/. 276,431 & S/. 6,996 & S/. 3,035 & S/. 10,031 & S/. 269,435 \\
\hline 5 & S/. 269,435 & S/. 7,073 & S/. 2,958 & S/. 10,031 & S/. 262,362 \\
\hline 6 & S/. 262,362 & S/. 7,151 & S/. 2,880 & S/. 10,031 & S/. 255,211 \\
\hline 7 & S/. 255,211 & S/. 7,229 & S/. 2,802 & S/. 10,031 & S/. 247,982 \\
\hline 8 & S/. 247,982 & S/. 7,308 & S/. 2,723 & S/. 10,031 & S/. 240,674 \\
\hline 9 & S/. 240,674 & S/. 7,389 & S/. 2,642 & S/. 10,031 & S/. 233,285 \\
\hline 10 & S/. 233,285 & S/. 7,470 & S/. 2,561 & S/. 10,031 & S/. 225,815 \\
\hline 11 & S/. 225,815 & S/. 7,552 & S/. 2,479 & S/. 10,031 & S/. 218,264 \\
\hline 12 & S/. 218,264 & S/. 7,365 & S/. 2,396 & S/. 10,031 & S/. 210,629 \\
\hline 13 & S/. 210,629 & S/. 7,719 & S/. 2,312 & S/. 10,031 & S/. 202,910 \\
\hline 14 & S/. 202,910 & S/. 7,803 & S/. 2,228 & S/. 10,031 & S/. 195,107 \\
\hline 15 & S/. 195,107 & S/. 7,889 & S/. 2,142 & S/. 10,031 & S/. 187,218 \\
\hline 16 & S/. 187,218 & S/. 7,976 & S/. 2,055 & S/. 10,031 & S/. 179,243 \\
\hline 17 & S/. 179,243 & S/. 8,063 & S/. 1,968 & S/. 10,031 & S/. 171,180 \\
\hline 18 & S/. 171,180 & S/. 8,152 & S/. 1,879 & S/. 10,031 & S/. 163,028 \\
\hline 19 & S/. 163,028 & S/. 8,241 & S/. 1,790 & S/. 10,031 & S/. 154,787 \\
\hline 20 & S/. 154,787 & S/. 8,332 & S/. 1,699 & S/. 10,031 & S/. 146,455 \\
\hline 21 & S/. 146,455 & S/. 8,423 & S/. 1,608 & S/. 10,031 & S/. 138,032 \\
\hline 22 & S/. 138,032 & S/. 8,516 & S/. 1,515 & S/. 10,031 & S/. 129,517 \\
\hline 23 & S/. 129,517 & S/. 8,609 & S/. 1,422 & S/. 10,031 & S/. 120,908 \\
\hline 24 & S/. 120,908 & S/. 8,704 & S/. 1,327 & S/. 10,031 & S/. 112,204 \\
\hline 25 & S/. 112,204 & S/. 8,799 & S/. 1,232 & S/. 10,031 & S/. 103,405 \\
\hline 26 & S/. 103,405 & S/. 8,896 & S/. 1,135 & S/. 10,031 & S/. 94,509 \\
\hline 27 & S/. 94,509 & S/. 8,993 & S/. 1,038 & S/. 10,031 & S/. 85,516 \\
\hline 28 & S/. 85,516 & S/. 9,092 & S/. 939 & S/. 10,031 & S/. 76,424 \\
\hline 29 & S/. 76,424 & S/. 9,192 & S/. 839 & S/. 10,031 & S/. 67,232 \\
\hline 30 & S/. 67,232 & S/. 9,293 & S/. 738 & S/. 10,031 & S/. 57,939 \\
\hline 31 & S/. 57,939 & S/. 9,395 & S/. 636 & S/. 10,031 & S/. 48,544 \\
\hline 32 & S/. 48,544 & S/. 9,498 & S/. 533 & S/. 10,031 & S/. 39,046 \\
\hline 33 & S/. 39,046 & S/. 9,602 & S/. 429 & S/. 10,031 & S/. 29,444 \\
\hline 34 & S/. 29,444 & S/. 9,708 & S/. 323 & S/. 10,031 & S/. 19,736 \\
\hline 35 & S/. 19,736 & S/. 9,814 & S/. 217 & S/. 10,031 & S/. 9,922 \\
\hline 36 & S/. 9,922 & S/. 9,922 & S/. 109 & S/. 10,031 & S/. 0 \\
\hline
\end{tabular}


Anexo $N^{\circ} 6$ - Programa de ventas mensual

PROGRAMA DE VENTAS POR MESES - 2019

\begin{tabular}{|c|c|c|c|c|c|c|c|c|c|c|c|c|c|}
\hline \multirow[b]{3}{*}{ Estacionalidad \% } & \multicolumn{13}{|c|}{ Meses } \\
\hline & Enero & Febrero & Marzo & Abril & Mayo & Junio & Julio & Agosto & Sept. & Oct. & Nov. & Dic. & Total \\
\hline & $3.30 \%$ & $3.30 \%$ & $3.30 \%$ & $8.42 \%$ & $8.42 \%$ & $8.42 \%$ & $11.72 \%$ & $11.72 \%$ & $11.72 \%$ & $9.90 \%$ & $9.90 \%$ & $9.90 \%$ & $100.0 \%$ \\
\hline \multicolumn{14}{|l|}{ Servicios Casa } \\
\hline Habitaciones & 0 & 0 & 1 & 1 & 1 & 1 & 2 & 2 & 2 & 1 & 1 & 1 & 13 \\
\hline Sala & 1 & 1 & 1 & 2 & 2 & 2 & 3 & 3 & 3 & 3 & 3 & 3 & 27 \\
\hline Comedor & 1 & 1 & 0 & 2 & 2 & 1 & 2 & 2 & 2 & 2 & 2 & 2 & 19 \\
\hline Zona de parrillas & 2 & 1 & 2 & 4 & 4 & 4 & 5 & 6 & 6 & 5 & 5 & 4 & 48 \\
\hline Cocina & 2 & 1 & 2 & 4 & 4 & 4 & 5 & 6 & 6 & 5 & 5 & 4 & 48 \\
\hline \multicolumn{14}{|c|}{ Servicios departamento } \\
\hline Habitaciones & 0 & 1 & 1 & 2 & 2 & 2 & 3 & 3 & 3 & 2 & 2 & 2 & 23 \\
\hline Sala-Comedor & 2 & 2 & 3 & 4 & 4 & 4 & 6 & 7 & 6 & 5 & 6 & 5 & 54 \\
\hline Cocina & 2 & 2 & 2 & 4 & 5 & 5 & 7 & 7 & 6 & 6 & 6 & 6 & 58 \\
\hline Total & 10 & 9 & 12 & 23 & 24 & 23 & 33 & 36 & 34 & 29 & 30 & 27 & 290 \\
\hline
\end{tabular}


PROGRAMA DE VENTAS POR MESES - 2020

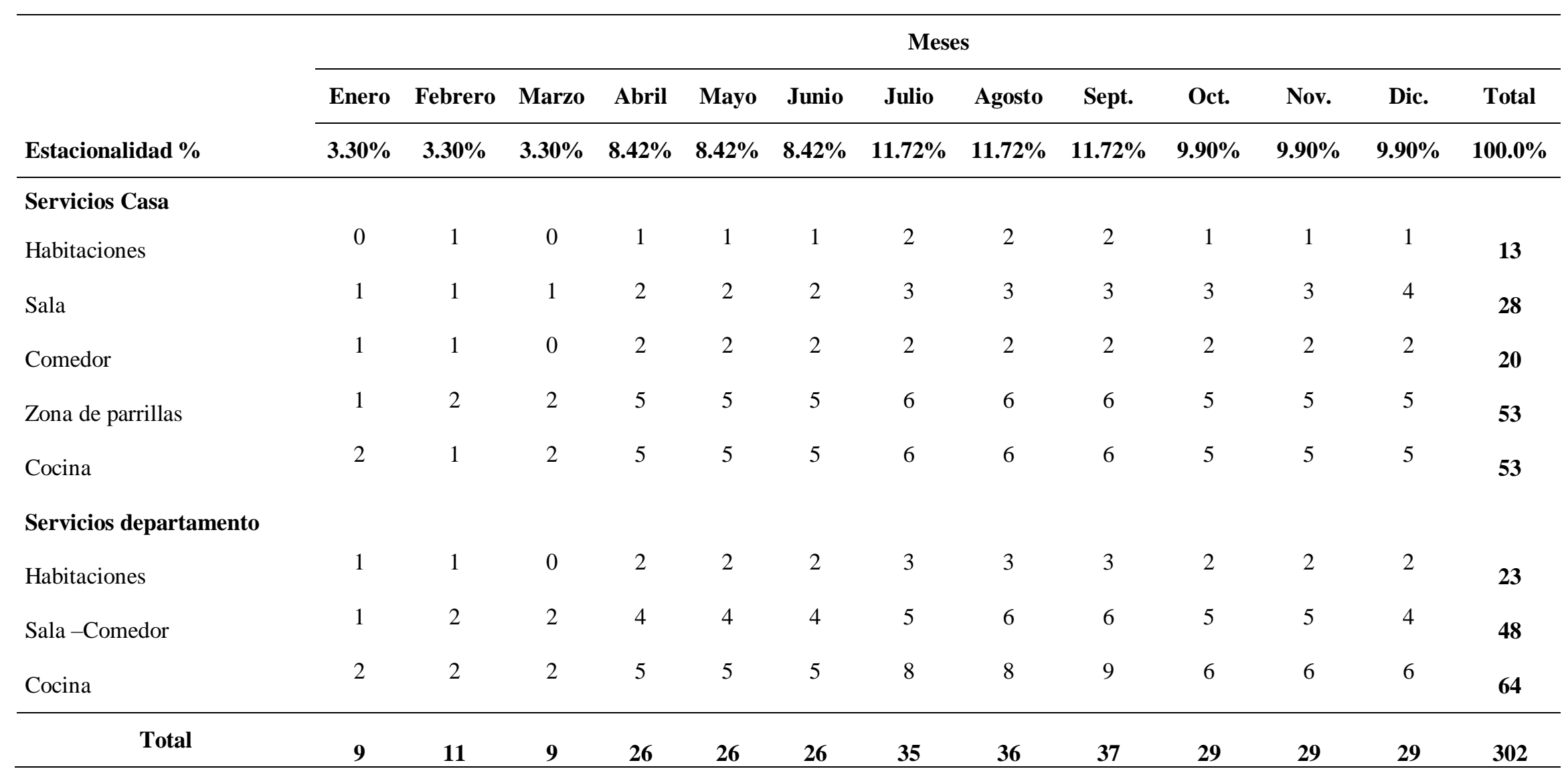


PROGRAMA DE VENTAS POR MESES - 2021

\begin{tabular}{|c|c|c|c|c|c|c|c|c|c|c|c|c|c|}
\hline \multirow[b]{3}{*}{ Estacionalidad \% } & \multicolumn{13}{|c|}{ Meses } \\
\hline & Enero & Febrero & Marzo & Abril & Mayo & Junio & Julio & Agosto & Sept. & Oct. & Nov. & Dic. & Total \\
\hline & $3.30 \%$ & $3.30 \%$ & $3.30 \%$ & $8.42 \%$ & $8.42 \%$ & $8.42 \%$ & $11.72 \%$ & $11.72 \%$ & $11.72 \%$ & $9.90 \%$ & $9.90 \%$ & $9.90 \%$ & $100.0 \%$ \\
\hline \multicolumn{14}{|l|}{ Servicios Casa } \\
\hline Habitaciones & 0 & 0 & 1 & 1 & 1 & 2 & 2 & 2 & 2 & 1 & 1 & 1 & 14 \\
\hline Sala & 1 & 1 & 1 & 2 & 2 & 2 & 3 & 2 & 3 & 3 & 3 & 3 & 26 \\
\hline Comedor & 1 & 1 & 1 & 2 & 2 & 2 & 3 & 3 & 3 & 2 & 2 & 2 & 24 \\
\hline Zona de parrillas & 1 & 2 & 2 & 6 & 5 & 5 & 7 & 7 & 7 & 6 & 7 & 6 & 61 \\
\hline Cocina & 1 & 2 & 2 & 6 & 5 & 5 & 7 & 7 & 7 & 6 & 7 & 6 & 61 \\
\hline \multicolumn{14}{|c|}{ Servicios departamento } \\
\hline Habitaciones & 1 & 1 & 0 & 2 & 2 & 2 & 2 & 3 & 3 & 2 & 2 & 2 & 22 \\
\hline Sala-Comedor & 2 & 1 & 2 & 4 & 4 & 4 & 6 & 6 & 5 & 5 & 5 & 5 & 49 \\
\hline Cocina & 2 & 2 & 2 & 6 & 7 & 6 & 9 & 8 & 8 & 8 & 7 & 7 & 72 \\
\hline Total & 9 & 10 & 11 & 29 & 28 & 28 & 39 & 38 & 38 & 33 & 34 & 32 & 329 \\
\hline
\end{tabular}


Anexo $N^{\circ} 7$ - Proyección de ingresos mensual

\begin{tabular}{|c|c|c|c|c|c|c|c|c|c|c|c|c|c|}
\hline \multicolumn{14}{|c|}{ PROYECCIÓN DE INGRESOS POR MESES - 2019} \\
\hline \multirow[b]{3}{*}{$\begin{array}{c}\text { Estacionalidad } \\
\%\end{array}$} & \multicolumn{13}{|c|}{ Meses } \\
\hline & Enero & Febrero & Marzo & Abril & Mayo & Junio & Julio & Agosto & Sept. & Oct. & Nov. & Dic. & Total \\
\hline & $\mathbf{3 . 3 0 \%}$ & $3.30 \%$ & $\mathbf{3 . 3 0 \%}$ & $8.42 \%$ & $8.42 \%$ & $8.42 \%$ & $11.72 \%$ & $11.72 \%$ & $11.72 \%$ & $9.90 \%$ & $9.90 \%$ & $9.90 \%$ & $100.0 \%$ \\
\hline \multicolumn{14}{|l|}{ Servicios Casa } \\
\hline Habitaciones & S/. 0 & $\mathrm{~S} / .0$ & S/. 6,328 & S/. 6,328 & S/. 6,328 & S/. 6,328 & S/. 12,657 & S/. 12,657 & S/. 12,657 & S/. 6,328 & S/. 6,328 & S/. 6,328 & S/. 0 \\
\hline Sala & S/. 6,056 & S/. 6,056 & S/. 6,056 & S/. 12,113 & S/. 12,113 & S/. 12,113 & S/. 18,169 & S/. 18,169 & S/. 18,169 & S/. 18,169 & S/. 18,169 & S/. 18,169 & S/. 6,056 \\
\hline Comedor & S/. 6,920 & S/. 6,920 & S/. 0 & S/. 13,841 & S/. 13,841 & S/. 6,920 & S/. 13,841 & S/. 13,841 & S/. 13,841 & S/. 13,841 & S/. 13,841 & S/. 13,841 & S/. 6,920 \\
\hline Zona de parrillas & S/. 12,212 & S/. 6,106 & S/. 12,212 & S/. 24,424 & S/. 24,424 & S/. 24,424 & S/. 30,530 & S/. 36,636 & S/. 36,636 & S/. 30,530 & S/. 30,530 & S/. 24,424 & S/. 12,212 \\
\hline Cocina & S/. 15,559 & S/. 7,779 & S/. 15,559 & S/. 31,118 & S/. 31,118 & S/. 31,118 & S/. 38,897 & S/. 46,676 & S/. 46,676 & S/. 38,897 & S/. 38,897 & S/. 31,118 & S/. 15,559 \\
\hline \multicolumn{14}{|l|}{$\begin{array}{c}\text { Servicios } \\
\text { departamento }\end{array}$} \\
\hline Habitaciones & S/. 0 & S/. 5,760 & S/. 5,760 & S/. 11,520 & S/. 11,520 & S/. 11,520 & S/. 17,279 & S/. 17,279 & S/. 17,279 & S/. 11,520 & S/. 11,520 & S/. 11,520 & S/. 0 \\
\hline Sala - Comedor & S/. 13,767 & S/. 13,767 & S/. 20,650 & S/. 27,534 & S/. 27,534 & S/. 27,534 & S/. 41,301 & S/. 48,184 & S/. 41,301 & S/. 34,417 & S/. 41,301 & S/. 34,417 & S/. 13,767 \\
\hline Cocina & S/. 12,063 & S/. 12,063 & S/. 12,063 & S/. 24,126 & S/. 30,158 & S/. 30,158 & S/. 42,221 & S/. 42,221 & S/. 36,189 & S/. 36,189 & S/. 36,189 & S/. 36,189 & S/. 12,063 \\
\hline Total con IGV & S/. 66,578 & $\mathrm{S} / . \mathbf{5 8 , 4 5 2}$ & S/. 78,629 & S/. 151,003 & S/.157,035 & S/.150,114 & S/.214,895 & S/.235,664 & S/.222,749 & S/. 189,892 & S/. 196,775 & S/.176,006 & S/. 66,578 \\
\hline Total sin IGV & S/. 56,422 & S/. 49,536 & S/. 66,635 & S/.127,969 & $\mathrm{S} / . \mathbf{1 3 3 , 0 8 0}$ & S/.127,216 & S/.182,114 & S/. 199,715 & S/. 188,770 & S/.160,925 & S/. 166,758 & S/. 149,158 & S/. 56,422 \\
\hline
\end{tabular}


PROYECCIÓN DE INGRESOS POR MESES - 2020

\begin{tabular}{|c|c|c|c|c|c|c|c|c|c|c|c|c|c|}
\hline \multirow[b]{3}{*}{$\begin{array}{c}\text { Estacionalidad } \\
\%\end{array}$} & \multicolumn{13}{|c|}{ Meses } \\
\hline & Enero & Febrero & Marzo & Abril & Mayo & Junio & Julio & Agosto & Sept. & Oct. & Nov. & Dic. & Total \\
\hline & $3.30 \%$ & $3.30 \%$ & $3.30 \%$ & $8.42 \%$ & $8.42 \%$ & $8.42 \%$ & $11.72 \%$ & $11.72 \%$ & $11.72 \%$ & $9.90 \%$ & $9.90 \%$ & $9.90 \%$ & $100.0 \%$ \\
\hline \multicolumn{14}{|l|}{ Servicios Casa } \\
\hline Habitaciones & S/. 0 & S/. 6,328 & S/. 0 & S/. 6,328 & S/. 6,328 & S/. 6,328 & S/. 12,657 & S/. 12,657 & S/. 12,657 & S/. 6,328 & S/. 6,328 & S/. 6,328 & S/. 0 \\
\hline Sala & S/. 6,056 & S/. 6,056 & S/. 6,056 & S/. 12,113 & S/. 12,113 & S/. 12,113 & S/. 18,169 & S/. 18,169 & S/. 18,169 & S/. 18,169 & S/. 18,169 & S/. 24,225 & S/. 6,056 \\
\hline Comedor & S/. 6,920 & S/. 6,920 & S/. 0 & S/. 13,841 & S/. 13,841 & S/. 13,841 & S/. 13,841 & S/. 13,841 & S/. 13,841 & S/. 13,841 & S/. 13,841 & S/. 13,841 & S/. 6,920 \\
\hline Zona de parrillas & S/. 6,106 & S/. 12,212 & S/. 12,212 & S/. 30,530 & S/. 30,530 & S/. 30,530 & S/. 36,636 & S/. 36,636 & S/. 36,636 & S/. 30,530 & S/. 30,530 & S/. 30,530 & S/. 6,106 \\
\hline Cocina & S/. 15,559 & S/. 7,779 & S/. 15,559 & S/. 38,897 & S/. 38,897 & S/. 38,897 & S/. 46,676 & S/. 46,676 & S/. 46,676 & S/. 38,897 & S/. 38,897 & S/. 38,897 & S/. 15,559 \\
\hline \multicolumn{14}{|l|}{$\begin{array}{c}\text { Servicios } \\
\text { departamento }\end{array}$} \\
\hline Habitaciones & S/. 5,760 & S/. 5,760 & S/. 0 & S/. 11,520 & S/. 11,520 & S/. 11,520 & S/. 17,279 & S/. 17,279 & S/. 17,279 & S/. 11,520 & S/. 11,520 & S/. 11,520 & S/. 5,760 \\
\hline Sala - Comedor & S/. 6,883 & S/. 13,767 & S/. 13,767 & S/. 27,534 & S/. 27,534 & S/. 27,534 & S/. 34,417 & S/. 41,301 & S/. 41,301 & S/. 34,417 & S/. 34,417 & S/. 27,534 & S/. 6,883 \\
\hline Cocina & S/. 12,063 & S/. 12,063 & S/. 12,063 & S/. 30,158 & S/. 30,158 & S/. 30,158 & S/. 48,252 & S/. 48,252 & S/. 54,284 & S/. 36,189 & S/. 36,189 & S/. 36,189 & S/. 12,063 \\
\hline Total con IGV & S/.59,348 & S/.70,886 & S/.59,657 & S/.170,920 & S/.170,920 & S/.170,920 & S/.227,928 & $\mathrm{S} / . \mathbf{2 3 4 , 8 1 2}$ & S/.240,843 & S/. 189,892 & S/. 189,892 & S/. 189,064 & S/.59,348 \\
\hline Total sin IGV & S/.50,295 & S/. 60,073 & S/. 50,557 & S/. 144,848 & S/. 144,848 & S/. 144,848 & $\mathrm{S} / .193,160$ & S/. 198,993 & S/. 204,104 & S/. 160,925 & S/. 160,925 & S/.160,224 & S/.50,295 \\
\hline
\end{tabular}




\section{PROYECCIÓN DE INGRESOS POR MESES - 2021}

\begin{tabular}{|c|c|c|c|c|c|c|c|c|c|c|c|c|c|}
\hline \multirow[b]{3}{*}{$\begin{array}{c}\text { Estacionalidad } \\
\% \\
\end{array}$} & \multicolumn{13}{|c|}{ Meses } \\
\hline & Enero & Febrero & Marzo & Abril & Mayo & Junio & Julio & Agosto & Sept. & Oct. & Nov. & Dic. & Total \\
\hline & $3.30 \%$ & $3.30 \%$ & $3.30 \%$ & $8.42 \%$ & $8.42 \%$ & $8.42 \%$ & $11.72 \%$ & $11.72 \%$ & $11.72 \%$ & $9.90 \%$ & $9.90 \%$ & $9.90 \%$ & $100.0 \%$ \\
\hline \multicolumn{14}{|l|}{ Servicios Casa } \\
\hline Habitaciones & S/. 0 & S/. 0 & S/. 6,328 & S/. 6,328 & S/. 6,328 & S/. 12,657 & S/. 12,657 & S/. 12,657 & S/. 12,657 & S/. 6,328 & S/. 6,328 & S/. 6,328 & $\mathrm{S} / .0$ \\
\hline Sala & S/. 6,056 & S/. 6,056 & S/. 6,056 & S/. 12,113 & S/. 12,113 & S/. 12,113 & S/. 18,169 & S/. 12,113 & S/. 18,169 & S/. 18,169 & S/. 18,169 & S/. 18,169 & S/. 6,056 \\
\hline Comedor & S/. 6,920 & S/. 6,920 & S/. 6,920 & S/. 13,841 & S/. 13,841 & S/. 13,841 & S/. 20,761 & S/. 20,761 & S/. 20,761 & S/. 13,841 & S/. 13,841 & S/. 13,841 & S/. 6,920 \\
\hline $\begin{array}{l}\text { Zona de } \\
\text { parrillas }\end{array}$ & S/. 6,106 & S/. 12,212 & S/. 12,212 & S/. 36,636 & S/. 30,530 & S/. 30,530 & S/. 42,742 & S/. 42,742 & S/. 42,742 & S/. 36,636 & S/. 42,742 & S/. 36,636 & S/. 6,106 \\
\hline Cocina & S/. 7,779 & S/. 15,559 & S/. 15,559 & S/. 46,676 & S/. 38,897 & S/. 38,897 & S/. 54,456 & S/. 54,456 & S/. 54,456 & S/. 46,676 & S/. 54,456 & S/. 46,676 & S/. 7,779 \\
\hline \multicolumn{14}{|l|}{$\begin{array}{c}\text { Servicios } \\
\text { departamento } \\
\text { Habitaciones }\end{array}$} \\
\hline Sala - Comedor & S/. 13,767 & S/. 6,883 & S/. 13,767 & S/. 27,534 & S/. 27,534 & S/. 27,534 & S/. 41,301 & S/. 41,301 & S/. 34,417 & S/. 34,417 & S/. 34,417 & S/. 34,417 & S/. 13,767 \\
\hline Cocina & S/. 12,063 & S/. 12,063 & S/. 12,063 & S/. 36,189 & S/. 42,221 & S/. 36,189 & S/. 54,284 & S/. 48,252 & S/. 48,252 & S/. 48,252 & S/. 42,221 & S/. 42,221 & S/. 12,063 \\
\hline Total con IGV & $\mathrm{S} / . \mathbf{5 8 , 4 5 2}$ & S/. 65,454 & S/. 72,906 & S/. 190,837 & S/. 182,983 & $\mathrm{S} / \mathrm{183}, \mathbf{2 8 0}$ & S/.255,889 & S/. 249,561 & S/.248,734 & S/.215,840 & S/.223,694 & S/.209,809 & S/. 58,452 \\
\hline Total sin IGV & S/. 49,536 & S/. 55,469 & S/. 61,785 & S/. 161,726 & S/. 155,071 & S/. 155,322 & S/.216,855 & $\mathrm{S} / .211,493$ & S/.210,792 & S/. 182,915 & S/. 189,571 & S/.177,804 & S/. 49,536 \\
\hline
\end{tabular}




\section{Anexo $\mathbf{N}^{\circ} 8$ - Requerimiento de componentes por servicio}

\begin{tabular}{|c|c|c|c|c|c|c|}
\hline \multicolumn{7}{|c|}{ Línea: Casas } \\
\hline \multicolumn{7}{|c|}{ Servicio: Habitación - Tipo 1} \\
\hline Ítem & Material & Cantidad & Unidad & $\begin{array}{c}\text { Precio } \\
\text { Unitario } \\
\end{array}$ & $\begin{array}{c}\text { Precio Total } \\
\text { IGV }\end{array}$ & $\begin{array}{l}\text { Precio Sin } \\
\text { IGV }\end{array}$ \\
\hline 1 & $\begin{array}{l}\text { Lámina de melamine } \\
\text { (Toscana } 18 \mathrm{~mm} \text { ) }\end{array}$ & 12 & $\mathrm{~m} 2$ & S/. 186.90 & S/. 2,242.80 & S/. $1,900.68$ \\
\hline 2 & Madera Tornillo & 5 & $\mathrm{~m} 2$ & S/. 26.90 & S/. 134.50 & S/. 113.98 \\
\hline 3 & Laca Selladora & 1 & Litro & S/. 42.00 & S/. 42.00 & S/. 35.59 \\
\hline 4 & Corredera metálica & 8 & Unidad & S/. 66.90 & S/. 535.20 & S/. 453.56 \\
\hline 5 & Thinner acrílico & 1 & Litro & S/. 9.40 & S/. 9.40 & S/. 7.97 \\
\hline 6 & Clavos $1 \frac{1}{1 / 2}$ & 20 & Unidad & S/. 1.40 & S/. 28.00 & S/. 23.73 \\
\hline 7 & Pegamento Cola & 2 & Litro & $\mathrm{S} / .2 .80$ & S/. 5.60 & S/. 4.75 \\
\hline 8 & Lija & 2 & Pliego & $\mathrm{S} / .2 .30$ & S/. 4.60 & S/. 3.90 \\
\hline 9 & Etiquetas (Pack) & 1 & Unidad & S/. 12.00 & S/. 12.00 & S/. 10.17 \\
\hline 10 & Waype & 0.25 & Kilo & S/. 4.00 & S/. 1.00 & S/. 0.85 \\
\hline 11 & Otros & 1 & Unidad & S/. 100.00 & S/. 100.00 & S/. 84.75 \\
\hline \multicolumn{5}{|c|}{ Total } & S/. 3,115.1 & S/. 2,639.92 \\
\hline
\end{tabular}

\section{Línea: Casas}

\begin{tabular}{|c|c|c|c|c|c|c|}
\hline \multicolumn{7}{|c|}{ Servicio: Habitación - Tipo 2} \\
\hline Ítem & Material & Cantidad & Unidad & $\begin{array}{c}\text { Precio } \\
\text { Unitario }\end{array}$ & $\begin{array}{c}\text { Precio Total } \\
\text { IGV }\end{array}$ & $\begin{array}{c}\text { Precio Sin } \\
\text { IGV }\end{array}$ \\
\hline 1 & $\begin{array}{l}\text { Lámina de melamine } \\
\text { (Toscana } 18 \mathrm{~mm} \text { ) }\end{array}$ & 15 & $\mathrm{~m} 2$ & S/. 186.90 & S/. $2,803.50$ & S/. $2,375.85$ \\
\hline 2 & Madera Tornillo & 7 & $\mathrm{~m} 2$ & S/. 26.90 & S/. 188.30 & S/. 159.58 \\
\hline 3 & Laca Selladora & 1 & Litro & S/. 42.00 & S/. 42.00 & S/. 35.59 \\
\hline 4 & Corredera metálica & 14 & Unidad & S/. 66.90 & S/. 936.60 & S/. 793.73 \\
\hline 5 & Thinner acrílico & 1 & Litro & S/. 9.40 & S/. 9.40 & S/. 7.97 \\
\hline 6 & Clavos $1 \frac{1}{2}$ & 35 & Unidad & S/. 1.40 & S/. 49.00 & S/. 41.53 \\
\hline 7 & Pegamento Cola & 2 & Litro & $\mathrm{S} / .2 .80$ & S/. 5.60 & S/. 4.75 \\
\hline 8 & Lija & 4 & Pliego & $\mathrm{S} / .2 .30$ & S/. 9.20 & S/. 7.80 \\
\hline 9 & Etiquetas (Pack) & 1 & Unidad & S/. 12.00 & S/. 12.00 & S/. 10.17 \\
\hline 10 & Waype & 0.5 & Kilo & S/. 4.00 & S/. 2.00 & S/. 1.69 \\
\hline 11 & Otros & 1 & Unidad & S/. 100.00 & S/. 100.00 & S/. 84.75 \\
\hline \multicolumn{5}{|c|}{ Total } & S/. 4,157.6 & $\mathrm{S} / . \mathbf{3 , 5 2 3 . 3 9}$ \\
\hline
\end{tabular}




\begin{tabular}{|c|c|c|c|c|c|c|}
\hline \multicolumn{7}{|c|}{ Línea: Casas } \\
\hline \multicolumn{7}{|c|}{ Servicio: Habitación - Tipo 3} \\
\hline Ítem & Material & Cantidad & Unidad & $\begin{array}{c}\text { Precio } \\
\text { Unitario } \\
\end{array}$ & $\begin{array}{c}\text { Precio Total } \\
\text { IGV }\end{array}$ & Precio Sin IGV \\
\hline 1 & $\begin{array}{l}\text { Lámina de melamine } \\
\text { (Toscana } 18 \mathrm{~mm})\end{array}$ & 12 & $\mathrm{~m} 2$ & S/. 186.90 & S/. $2,242.80$ & S/. $1,900.68$ \\
\hline 2 & Madera Tornillo & 3 & $\mathrm{~m} 2$ & S/. 26.90 & S/. 80.70 & S/. 68.39 \\
\hline 3 & Laca Selladora & 1 & Litro & S/. 42.00 & S/. 42.00 & S/. 35.59 \\
\hline 4 & Corredera metálica & 10 & Unidad & S/. 66.90 & S/. 669.00 & S/. 566.95 \\
\hline 5 & Thinner acrílico & 1 & Litro & S/. 9.40 & S/. 9.40 & S/. 7.97 \\
\hline 6 & Clavos $1 \frac{1}{2}$ & 20 & Unidad & S/. 1.40 & S/. 28.00 & S/. 23.73 \\
\hline 7 & Pegamento Cola & 2 & Litro & $\mathrm{S} / .2 .80$ & S/. 5.60 & S/. 4.75 \\
\hline 8 & Lija & 4 & Pliego & $\mathrm{S} / .2 .30$ & S/. 9.20 & S/. 7.80 \\
\hline 9 & Etiquetas (Pack) & 6 & Unidad & S/. 12.00 & S/. 72.00 & S/. 61.02 \\
\hline 10 & Waype & 0.25 & Kilo & $\mathrm{S} / .4 .00$ & S/. 1.00 & S/. 0.85 \\
\hline 11 & Otros & 1 & Unidad & S/. 50.00 & S/. 50.00 & S/. 42.37 \\
\hline \multicolumn{5}{|c|}{ Total } & $\mathrm{S} / . \mathbf{3 , 2 1 0}$ & $\mathrm{S} / .2,720$ \\
\hline
\end{tabular}

\begin{tabular}{|c|c|c|c|c|c|c|}
\hline \multicolumn{7}{|c|}{ Línea: Casas } \\
\hline \multicolumn{7}{|c|}{ Servicio: Habitación - Tipo 4} \\
\hline Ítem & Material & Cantidad & Unidad & $\begin{array}{c}\text { Precio } \\
\text { Unitario } \\
\end{array}$ & $\begin{array}{c}\text { Precio Total } \\
\text { IGV } \\
\end{array}$ & Precio Sin IGV \\
\hline 1 & $\begin{array}{l}\text { Lámina de melamine } \\
\quad \text { (Toscana } 18 \mathrm{~mm} \text { ) }\end{array}$ & 18 & $\mathrm{~m} 2$ & S/. 186.90 & S/. 3,364.20 & S/. 2,851.02 \\
\hline 2 & Madera Tornillo & 6 & $\mathrm{~m} 2$ & S/. 26.90 & S/. 161.40 & S/. 136.78 \\
\hline 3 & Laca Selladora & 1 & Litro & S/. 42.00 & S/. 42.00 & S/. 35.59 \\
\hline 4 & Corredera metálica & 8 & Unidad & S/. 66.90 & S/. 535.20 & S/. 453.56 \\
\hline 5 & Thinner acrílico & 1 & Litro & S/. 9.40 & S/. 9.40 & S/. 7.97 \\
\hline 6 & Clavos 1 1⁄2 & 40 & Unidad & S/. 1.40 & S/. 56.00 & S/. 47.46 \\
\hline 7 & Pegamento Cola & 2 & Litro & S/. 2.80 & S/. 5.60 & S/. 4.75 \\
\hline 8 & Lija & 3 & Pliego & $\mathrm{S} / .2 .30$ & S/. 6.90 & S/. 5.85 \\
\hline 9 & Etiquetas (Pack) & 6 & Unidad & S/. 12.00 & S/. 72.00 & S/. 61.02 \\
\hline 10 & Waype & 1 & Kilo & S/. 4.00 & S/. 4.00 & S/. 3.39 \\
\hline 11 & Otros & 1 & Unidad & S/. 100.00 & S/. 100.00 & S/. 84.75 \\
\hline \multicolumn{5}{|c|}{ Total } & $\mathrm{S} / .4,356.7$ & $\mathrm{~S} / .3,692.1$ \\
\hline
\end{tabular}




\begin{tabular}{|c|c|c|c|c|c|c|}
\hline \multicolumn{7}{|c|}{ Línea: Casas } \\
\hline \multicolumn{7}{|c|}{ Servicio: Sala - Tipo 1} \\
\hline Ítem & Material & Cantidad & Unidad & $\begin{array}{c}\text { Precio } \\
\text { Unitario } \\
\end{array}$ & $\begin{array}{c}\text { Precio Total } \\
\text { IGV } \\
\end{array}$ & Precio Sin IGV \\
\hline 1 & $\begin{array}{c}\text { Lámina de melamine } \\
\text { (Tropicalizado blanco } \\
18 \mathrm{~mm} \text { ) }\end{array}$ & 12 & $\mathrm{~m} 2$ & S/. 195.00 & S/. 2,340.00 & S/. 1,983.05 \\
\hline 2 & Madera Tornillo & 5 & $\mathrm{~m} 2$ & S/. 26.90 & S/. 134.50 & S/. 113.98 \\
\hline 3 & Laca Selladora & 1 & Litro & S/. 42.00 & S/. 42.00 & S/. 35.59 \\
\hline 4 & Manija & 4 & Unidad & S/. 66.90 & S/. 267.60 & S/. 226.78 \\
\hline 5 & Thinner acrílico & 1 & Litro & S/. 9.40 & S/. 9.40 & S/. 7.97 \\
\hline 6 & Tornillos & 20 & Unidad & S/. 4.00 & S/. 80.00 & S/. 67.80 \\
\hline 7 & Pegamento Cola & 2 & Unidad & $\mathrm{S} / .2 .80$ & S/. 5.60 & S/. 4.75 \\
\hline 8 & Lija & 2 & Pliego & $\mathrm{S} / .2 .30$ & S/. 4.60 & $\mathrm{~S} / .3 .90$ \\
\hline 9 & Etiquetas (Pack) & 1 & Unidad & S/. 12.00 & $\mathrm{~S} / .12 .00$ & S/. 10.17 \\
\hline 10 & Waype & 0.25 & Kilo & S/. 4.00 & S/. 1.00 & S/. 0.85 \\
\hline 11 & Otros & 1 & Unidad & S/. 100.00 & S/. 100.00 & S/. 84.75 \\
\hline \multicolumn{5}{|c|}{ Total } & S/. 2,997 & S/. 2,540 \\
\hline
\end{tabular}

\section{Línea: Casas}

\begin{tabular}{|c|c|c|c|c|c|c|}
\hline \multicolumn{7}{|c|}{ Servicio: Sala - Tipo 2} \\
\hline Ítem & Material & Cantidad & Unidad & $\begin{array}{c}\text { Precio } \\
\text { Unitario } \\
\end{array}$ & $\begin{array}{c}\text { Precio Total } \\
\text { IGV } \\
\end{array}$ & Precio Sin IGV \\
\hline 1 & $\begin{array}{l}\text { Lámina de melamine } \\
\text { (Raucantex Melaminico } \\
\text { Tapacanto pre encolado } \\
22 \mathrm{~mm} \text { x } 30 \mathrm{~m} \text { cedro) }\end{array}$ & 12 & $\mathrm{~m} 2$ & S/. 195.00 & S/. 2,340.00 & S/. $1,983.05$ \\
\hline 2 & Madera Tornillo & 5 & $\mathrm{~m} 2$ & S/. 26.90 & S/. 134.50 & S/. 113.98 \\
\hline 3 & Laca Selladora & 1 & Litro & S/. 42.00 & S/. 42.00 & S/. 35.59 \\
\hline 4 & Manija & 4 & Unidad & S/. 66.90 & S/. 267.60 & S/. 226.78 \\
\hline 5 & Thinner acrílico & 1 & Litro & S/. 9.40 & S/. 9.40 & S/. 7.97 \\
\hline 6 & Tornillos & 20 & Unidad & S/. 4.00 & S/. 80.00 & S/. 67.80 \\
\hline 7 & Pegamento Cola & 2 & Unidad & S/. 2.80 & S/. 5.60 & S/. 4.75 \\
\hline 8 & Lija & 2 & Pliego & $\mathrm{S} / .2 .30$ & S/. 4.60 & S/. 3.90 \\
\hline 9 & Etiquetas (Pack) & 1 & Unidad & S/. 12.00 & S/. 12.00 & S/. 10.17 \\
\hline 10 & Waype & 0.25 & Kilo & S/. 4.00 & S/. 1.00 & S/. 0.85 \\
\hline 11 & Otros & 1 & Unidad & S/. 100.00 & S/. 100.00 & S/. 84.75 \\
\hline \multicolumn{5}{|c|}{ Total } & S/. 2,996.70 & S/. 2,539.58 \\
\hline
\end{tabular}




\begin{tabular}{|c|c|c|c|c|c|c|}
\hline \multicolumn{7}{|c|}{ Línea: Casas } \\
\hline \multicolumn{7}{|c|}{ Servicio: Sala - Tipo 3} \\
\hline Ítem & Material & Cantidad & Unidad & $\begin{array}{c}\text { Precio } \\
\text { Unitario } \\
\end{array}$ & $\begin{array}{c}\text { Precio Total } \\
\text { IGV } \\
\end{array}$ & Precio Sin IGV \\
\hline 1 & $\begin{array}{c}\text { Lámina de melamine } \\
\text { (Tropicalizado blanco } \\
18 \mathrm{~mm} \text { ) }\end{array}$ & 12 & $\mathrm{~m} 2$ & S/. 195.00 & S/. 2,340.00 & S/. 1,983.05 \\
\hline 2 & Madera Tornillo & 5 & $\mathrm{~m} 2$ & S/. 26.90 & S/. 134.50 & S/. 113.98 \\
\hline 3 & Laca Selladora & 1 & Litro & S/. 42.00 & S/. 42.00 & S/. 35.59 \\
\hline 4 & Manija & 1 & Unidad & S/. 66.90 & S/. 66.90 & S/. 56.69 \\
\hline 5 & Thinner acrílico & 1 & Litro & S/. 9.40 & S/. 9.40 & S/. 7.97 \\
\hline 6 & Tornillos & 24 & Unidad & S/. 1.40 & S/. 33.60 & S/. 28.47 \\
\hline 7 & Pegamento Cola & 2 & Unidad & $\mathrm{S} / .2 .80$ & S/. 5.60 & S/. 4.75 \\
\hline 8 & Lija & 2 & Pliego & $\mathrm{S} / .2 .30$ & S/. 4.60 & $\mathrm{~S} / .3 .90$ \\
\hline 9 & Etiquetas (Pack) & 1 & Unidad & S/. 12.00 & S/. 12.00 & S/. 10.17 \\
\hline 10 & Waype & 0.25 & Kilo & S/. 4.00 & S/. 1.00 & S/. 0.85 \\
\hline 11 & Otros & 1 & Unidad & S/. 100.00 & S/. 100.00 & S/. 84.75 \\
\hline \multicolumn{5}{|c|}{ Total } & $\mathrm{S} / .2,749.60$ & S/. 2,330.17 \\
\hline
\end{tabular}

\begin{tabular}{|c|c|c|c|c|c|c|}
\hline \multicolumn{7}{|c|}{ Línea: Casas } \\
\hline \multicolumn{7}{|c|}{ Servicio: Sala - Tipo 4} \\
\hline Ítem & Material & Cantidad & Unidad & $\begin{array}{c}\text { Precio } \\
\text { Unitario }\end{array}$ & $\begin{array}{c}\text { Precio Total } \\
\text { IGV }\end{array}$ & $\begin{array}{l}\text { Precio Sin } \\
\text { IGV }\end{array}$ \\
\hline 1 & $\begin{array}{l}\text { Lámina de melamine } \\
\text { (Tropicalizado blanco } \\
18 \mathrm{~mm} \text { ) }\end{array}$ & 15 & $\mathrm{~m} 2$ & S/. 195.00 & S/. 2,925.00 & S/. 2,478.81 \\
\hline 2 & Madera Tornillo & 5 & $\mathrm{~m} 2$ & S/. 26.90 & S/. 134.50 & S/. 113.98 \\
\hline 3 & Laca Selladora & 1 & Litro & S/. 42.00 & S/. 42.00 & S/. 35.59 \\
\hline 4 & Manija & 4 & Unidad & S/. 66.90 & S/. 267.60 & S/. 226.78 \\
\hline 5 & Thinner acrílico & 1 & Litro & S/. 9.40 & S/. 9.40 & S/. 7.97 \\
\hline 6 & Tornillos & 20 & Unidad & S/. 1.40 & S/. 28.00 & S/. 23.73 \\
\hline 7 & Pegamento Cola & 2 & Unidad & $\mathrm{S} / .2 .80$ & S/. 5.60 & S/. 4.75 \\
\hline 8 & Lija & 2 & Pliego & $\mathrm{S} / .2 .30$ & S/. 4.60 & S/. 3.90 \\
\hline 9 & Etiquetas (Pack) & 1 & Unidad & S/. 12.00 & $\mathrm{~S} / .12 .00$ & S/. 10.17 \\
\hline 10 & Waype & 0.25 & Kilo & S/. 4.00 & S/. 1.00 & S/. 0.85 \\
\hline 11 & Lámina de Cristal & 1 & Unidad & S/. 120.00 & S/. 120.00 & S/. 101.69 \\
\hline \multicolumn{5}{|c|}{ Total } & $\mathrm{S} / . \mathbf{3 , 6 4 9 . 7 0}$ & S/. 3,092.97 \\
\hline
\end{tabular}




\begin{tabular}{|c|c|c|c|c|c|c|}
\hline \multicolumn{7}{|c|}{ Línea: Casas } \\
\hline \multicolumn{7}{|c|}{ Servicio: Comedor - Tipo 1} \\
\hline Ítem & Material & Cantidad & Unidad & $\begin{array}{c}\text { Precio } \\
\text { Unitario } \\
\end{array}$ & $\begin{array}{c}\text { Precio Total } \\
\text { IGV } \\
\end{array}$ & Precio Sin IGV \\
\hline 1 & Lámina de melamine & 15 & $\mathrm{~m} 2$ & S/. 195.00 & S/. 2,925.00 & S/. 2,478.81 \\
\hline 2 & Madera Tornillo & 16 & $\mathrm{~m} 2$ & S/. 26.90 & S/. 430.40 & S/. 364.75 \\
\hline 3 & Laca Selladora & 1 & Litro & S/. 42.00 & S/. 42.00 & S/. 35.59 \\
\hline 4 & Corredera metálica & 6 & Unidad & S/. 66.90 & S/. 401.40 & S/. 340.17 \\
\hline 5 & Thinner acrílico & 1 & Litro & S/. 9.40 & S/. 9.40 & S/. 7.97 \\
\hline 6 & Clavos $1 \frac{1}{2}$ & 60 & Unidad & S/. 4.00 & S/. 240.00 & S/. 203.39 \\
\hline 7 & Pegamento Cola & 2 & Unidad & $\mathrm{S} / .2 .80$ & S/. 5.60 & S/. 4.75 \\
\hline 8 & Lija & 2 & Pliego & $\mathrm{S} / .2 .30$ & S/. 4.60 & $\mathrm{~S} / .3 .90$ \\
\hline 9 & Etiquetas (Pack) & 1 & Unidad & S/. 12.00 & S/. 12.00 & S/. 10.17 \\
\hline 10 & Waype & 0.25 & Kilo & S/. 4.00 & S/. 1.00 & S/. 0.85 \\
\hline 11 & Otros & 1 & Unidad & S/. 100.00 & S/. 100.00 & S/. 84.75 \\
\hline \multicolumn{5}{|c|}{ Total } & S/. 4,171.40 & S/. 3,535.08 \\
\hline
\end{tabular}

\section{Línea: Casas}

\begin{tabular}{ccccccc}
\hline \multicolumn{7}{c}{ Servicio: Comedor - Tipo 2 } \\
\hline Ítem & Material & Cantidad & Unidad & $\begin{array}{c}\text { Precio } \\
\text { Unitario }\end{array}$ & $\begin{array}{c}\text { Precio Total } \\
\text { IGV }\end{array}$ & Precio Sin IGV \\
\hline 1 & Lámina de melamine & 12 & $\mathrm{~m} 2$ & $\mathrm{~S} / .195 .00$ & $\mathrm{~S} / .2,340.00$ & $\mathrm{~S} / .1,983.05$ \\
2 & Madera Tornillo & 14 & $\mathrm{~m} 2$ & $\mathrm{~S} / .26 .90$ & $\mathrm{~S} / .376 .60$ & $\mathrm{~S} / .319 .15$ \\
3 & Laca Selladora & 1 & Litro & $\mathrm{S} / .42 .00$ & $\mathrm{~S} / .42 .00$ & $\mathrm{~S} / .35 .59$ \\
4 & Corredera metálica & 6 & Unidad & $\mathrm{S} / .66 .90$ & $\mathrm{~S} / .401 .40$ & $\mathrm{~S} / .340 .17$ \\
5 & Thinner acrílico & 1 & Litro & $\mathrm{S} / .9 .40$ & $\mathrm{~S} / .9 .40$ & $\mathrm{~S} / .7 .97$ \\
6 & Clavos 1 1/2 & 4 & Unidad & $\mathrm{S} / .140 .00$ & $\mathrm{~S} / .560 .00$ & $\mathrm{~S} / .474 .58$ \\
7 & Pegamento Cola & 2 & Unidad & $\mathrm{S} / .2 .80$ & $\mathrm{~S} / .5 .60$ & $\mathrm{~S} / .4 .75$ \\
8 & Lija & 2 & Pliego & $\mathrm{S} / .2 .30$ & $\mathrm{~S} / .4 .60$ & $\mathrm{~S} / .3 .90$ \\
9 & Etiquetas (Pack) & 1 & Unidad & $\mathrm{S} / .12 .00$ & $\mathrm{~S} / .12 .00$ & $\mathrm{~S} / .10 .17$ \\
10 & Waype & 0.25 & Kilo & $\mathrm{S} / .4 .00$ & $\mathrm{~S} / .1 .00$ & $\mathrm{~S} / .0 .85$ \\
11 & Otros & 1 & Unidad & $\mathrm{S} / .100 .00$ & $\mathrm{~S} / .100 .00$ & $\mathrm{~S} / .84 .75$ \\
\hline & & Total & & & S/. 3,852.60 & S/. 3,264.92 \\
\hline
\end{tabular}




\begin{tabular}{|c|c|c|c|c|c|c|}
\hline \multicolumn{7}{|c|}{ Línea: Casas } \\
\hline \multicolumn{7}{|c|}{ Servicio: Comedor - Tipo 3} \\
\hline Ítem & Material & Cantidad & Unidad & $\begin{array}{c}\text { Precio } \\
\text { Unitario }\end{array}$ & $\begin{array}{c}\text { Precio Total } \\
\text { IGV }\end{array}$ & Precio Sin IGV \\
\hline 1 & Lámina de melamine & 14 & $\mathrm{~m} 2$ & S/. 195.00 & S/. 2,730.00 & S/. 2,313.56 \\
\hline 2 & Madera Tornillo & 12 & $\mathrm{~m} 2$ & S/. 26.90 & S/. 322.80 & S/. 273.56 \\
\hline 3 & Laca Selladora & 1 & Litro & S/. 42.00 & S/. 42.00 & S/. 35.59 \\
\hline 4 & Corredera metálica & 6 & Unidad & S/. 66.90 & S/. 401.40 & S/. 340.17 \\
\hline 5 & Thinner acrílico & 1 & Litro & S/. 9.40 & S/. 9.40 & S/. 7.97 \\
\hline 6 & Clavos $1 \frac{1}{2}$ & 60 & Unidad & S/. 1.40 & S/. 84.00 & S/. 71.19 \\
\hline 7 & Pegamento Cola & 2 & Unidad & $\mathrm{S} / .2 .80$ & S/. 5.60 & S/. 4.75 \\
\hline 8 & Lija & 2 & Pliego & $\mathrm{S} / .2 .30$ & S/. 4.60 & S/. 3.90 \\
\hline 9 & Etiquetas (Pack) & 1 & Unidad & S/. 12.00 & S/. 12.00 & S/. 10.17 \\
\hline 10 & Waype & 0.25 & Kilo & S/. 4.00 & S/. 1.00 & S/. 0.85 \\
\hline 11 & Otros & 1 & Unidad & S/. 100.00 & S/. 100.00 & S/. 84.75 \\
\hline \multicolumn{5}{|c|}{ Total } & $\mathrm{S} / . \mathbf{3 , 7 1 2 . 8 0}$ & S/. 3,146.44 \\
\hline
\end{tabular}

Línea: Casas

\begin{tabular}{|c|c|c|c|c|c|c|}
\hline \multicolumn{7}{|c|}{ Servicio: Comedor - Tipo 4} \\
\hline Ítem & Material & Cantidad & Unidad & $\begin{array}{c}\text { Precio } \\
\text { Unitario }\end{array}$ & $\begin{array}{c}\text { Precio Total } \\
\text { IGV }\end{array}$ & $\begin{array}{c}\text { Precio Sin } \\
\text { IGV }\end{array}$ \\
\hline 1 & Lámina de melamine & 14 & $\mathrm{~m} 2$ & S/. 195.00 & S/. 2,730.00 & S/. 2,313.56 \\
\hline 2 & Madera Tornillo & 16 & $\mathrm{~m} 2$ & S/. 26.90 & S/. 430.40 & S/. 364.75 \\
\hline 3 & Laca Selladora & 1 & Litro & $\mathrm{S} / .42 .00$ & $\mathrm{~S} / .42 .00$ & $\mathrm{~S} / .35 .59$ \\
\hline 4 & Corredera metálica & 6 & Unidad & S/. 66.90 & S/. 401.40 & S/. 340.17 \\
\hline 5 & Thinner acrílico & 1 & Litro & S/. 9.40 & S/. 9.40 & S/. 7.97 \\
\hline 6 & Clavos $1 \frac{1}{2}$ & 40 & Unidad & S/. 4.00 & S/. 160.00 & S/. 135.59 \\
\hline 7 & Pegamento Cola & 2 & Unidad & $\mathrm{S} / .2 .80$ & S/. 5.60 & S/. 4.75 \\
\hline 8 & Lija & 2 & Pliego & $\mathrm{S} / .2 .30$ & S/. 4.60 & S/. 3.90 \\
\hline 9 & Etiquetas (Pack) & 1 & Unidad & S/. 12.00 & S/. 12.00 & S/. 10.17 \\
\hline 10 & Waype & 0.25 & Kilo & S/. 4.00 & S/. 1.00 & S/. 0.85 \\
\hline 11 & Otros & 1 & Unidad & S/. 100.00 & S/. 100.00 & S/. 84.75 \\
\hline \multicolumn{5}{|c|}{ Total } & S/. 3,896.40 & $\mathrm{S} / . \mathbf{3 , 3 0 2 . 0 3}$ \\
\hline
\end{tabular}




\begin{tabular}{|c|c|c|c|c|c|c|}
\hline \multicolumn{7}{|c|}{ Línea: Casas } \\
\hline \multicolumn{7}{|c|}{ Servicio: Zona de parrillas- Tipo 1} \\
\hline Ítem & Material & Cantidad & Unidad & $\begin{array}{c}\text { Precio } \\
\text { Unitario }\end{array}$ & $\begin{array}{c}\text { Precio Total } \\
\text { IGV }\end{array}$ & $\begin{array}{l}\text { Precio S/ } \\
\text { IGV }\end{array}$ \\
\hline 1 & Lámina de melamine & 10 & $\mathrm{~m} 2$ & S/. 186.90 & S/. $1,869.00$ & S/. $1,583.90$ \\
\hline 2 & Barras de hierro & 12 & $\mathrm{~m} 2$ & S/. 27.00 & S/. 324.00 & S/. 274.58 \\
\hline 3 & Laca Selladora & 1 & Litro & S/. 42.00 & S/. 42.00 & S/. 35.59 \\
\hline 4 & Thinner acrílico & 1 & Litro & S/. 9.40 & S/. 9.40 & S/. 7.97 \\
\hline 5 & Clavos $1 \frac{1}{2}$ & 4 & Unidad & S/. 1.40 & S/. 5.60 & S/. 4.75 \\
\hline 6 & Pegamento Cola & 1 & Unidad & $\mathrm{S} / .2 .80$ & $\mathrm{~S} / .2 .80$ & S/. 2.37 \\
\hline 7 & Lija & 2 & Pliego & $\mathrm{S} / .2 .30$ & S/. 4.60 & S/. 3.90 \\
\hline 8 & Etiquetas (Pack) & 1 & Unidad & S/. 12.00 & S/. 12.00 & S/. 10.17 \\
\hline 9 & Waype & 0.25 & Kilo & S/. 4.00 & S/. 1.00 & S/. 0.85 \\
\hline 10 & Otros & 1 & Unidad & S/. 100.00 & S/. 100.00 & S/. 84.75 \\
\hline 11 & Lámina de melamine & 10 & $\mathrm{~m} 2$ & S/. 186.90 & S/. 1,869.00 & S/. $1,583.90$ \\
\hline \multicolumn{5}{|c|}{ Total } & S/. 2,370.40 & S/. 2,008.81 \\
\hline
\end{tabular}

\section{Línea: Casas}

\begin{tabular}{|c|c|c|c|c|c|c|}
\hline \multicolumn{7}{|c|}{ Servicio: Zona de parrillas- Tipo 2} \\
\hline Ítem & Material & Cantidad & Unidad & $\begin{array}{c}\text { Precio } \\
\text { Unitario }\end{array}$ & $\begin{array}{c}\text { Precio Total } \\
\text { IGV }\end{array}$ & $\begin{array}{c}\text { Precio Sin } \\
\text { IGV }\end{array}$ \\
\hline 1 & Lámina de melamine & 10 & $\mathrm{~m} 2$ & S/. 186.90 & S/. $1,869.00$ & S/. $1,583.90$ \\
\hline 2 & Barras de hierro & 4 & $\mathrm{~m} 2$ & S/. 27.00 & S/. 108.00 & S/. 91.53 \\
\hline 3 & Laca Selladora & 1 & Litro & S/. 42.00 & S/. 42.00 & S/. 35.59 \\
\hline 4 & Thinner acrílico & 1 & Litro & S/. 9.40 & S/. 9.40 & S/. 7.97 \\
\hline 5 & Clavos $1 \frac{1}{2}$ & 4 & Unidad & S/. 1.40 & S/. 5.60 & S/. 4.75 \\
\hline 6 & Pegamento Cola & 1 & Unidad & $\mathrm{S} / .2 .80$ & $\mathrm{~S} / .2 .80$ & S/. 2.37 \\
\hline 7 & Lija & 2 & Pliego & $\mathrm{S} / .2 .30$ & S/. 4.60 & S/. 3.90 \\
\hline 8 & Etiquetas (Pack) & 1 & Unidad & S/. 12.00 & $\mathrm{~S} / .12 .00$ & S/. 10.17 \\
\hline 9 & Waype & 0.25 & Kilo & S/. 4.00 & S/. 1.00 & S/. 0.85 \\
\hline 10 & Otros & 1 & Unidad & S/. 100.00 & S/. 100.00 & S/. 84.75 \\
\hline 11 & Lámina de melamine & 10 & $\mathrm{~m} 2$ & S/. 186.90 & S/. $1,869.00$ & S/. 1,583.90 \\
\hline \multicolumn{5}{|c|}{ Total } & S/. 2,154.40 & S/. 1,825.76 \\
\hline
\end{tabular}




\section{Línea: Casas}

Servicio: Zona de parrillas- Tipo 3

\begin{tabular}{|c|c|c|c|c|c|c|}
\hline Ítem & Material & Cantidad & Unidad & $\begin{array}{c}\text { Precio } \\
\text { Unitario }\end{array}$ & $\begin{array}{c}\text { Precio Total } \\
\text { IGV }\end{array}$ & $\begin{array}{l}\text { Precio S/ } \\
\text { IGV }\end{array}$ \\
\hline 1 & Lámina de melamine & 10 & $\mathrm{~m} 2$ & S/. 186.90 & S/. 1,869.00 & S/. $1,583.90$ \\
\hline 2 & Barras de hierro & 12 & $\mathrm{~m} 2$ & S/. 27.00 & S/. 324.00 & S/. 274.58 \\
\hline 3 & Laca Selladora & 1 & Litro & S/. 42.00 & S/. 42.00 & S/. 35.59 \\
\hline 4 & Thinner acrílico & 1 & Litro & S/. 9.40 & S/. 9.40 & S/. 7.97 \\
\hline 5 & Clavos $1 \frac{1}{2}$ & 2 & Unidad & S/. 25.00 & S/. 50.00 & S/. 42.37 \\
\hline 6 & Pegamento Cola & 50 & Unidad & S/. 3.70 & S/. 185.00 & S/. 156.78 \\
\hline 7 & Lija & 2 & Pliego & S/. 2.30 & S/. 4.60 & S/. 3.90 \\
\hline 8 & Etiquetas (Pack) & 1 & Unidad & $\mathrm{S} / .12 .00$ & $\mathrm{~S} / .12 .00$ & S/. 10.17 \\
\hline 9 & Waype & 0.25 & Kilo & S/. 4.00 & S/. 1.00 & S/. 0.85 \\
\hline 10 & Otros & 1 & Unidad & S/. 50.00 & S/. 50.00 & S/. 42.37 \\
\hline 11 & Lámina de melamine & 10 & $\mathrm{~m} 2$ & S/. 186.90 & S/. $1,869.00$ & S/. $1,583.90$ \\
\hline \multicolumn{5}{|c|}{ Total } & S/. 2,547.00 & S/. 2,158.47 \\
\hline
\end{tabular}

\section{Línea: Casas}

\begin{tabular}{ccccccc}
\hline \multicolumn{7}{c}{ Servicio: Zona de parrillas - Tipo 4 } \\
\hline Ítem & Material & Cantidad & Unidad & $\begin{array}{c}\text { Precio } \\
\text { Unitario }\end{array}$ & $\begin{array}{c}\text { Precio Total } \\
\text { IGV }\end{array}$ & Precio Sin IGV \\
\hline 1 & Lámina de melamine & 10 & $\mathrm{~m} 2$ & $\mathrm{~S} / .186 .90$ & $\mathrm{~S} / .1,869.00$ & $\mathrm{~S} / .1,583.90$ \\
2 & Barras de hierro & 12 & $\mathrm{~m} 2$ & $\mathrm{~S} / .27 .00$ & $\mathrm{~S} / .324 .00$ & $\mathrm{~S} / .274 .58$ \\
3 & Laca Selladora & 1 & Litro & $\mathrm{S} / .42 .00$ & $\mathrm{~S} / .42 .00$ & $\mathrm{~S} / .35 .59$ \\
4 & Thinner acrílico & 1 & Litro & $\mathrm{S} / .9 .40$ & $\mathrm{~S} / .9 .40$ & $\mathrm{~S} / .7 .97$ \\
5 & Clavos 1 1/2 & 2 & Unidad & $\mathrm{S} / .25 .00$ & $\mathrm{~S} / .50 .00$ & $\mathrm{~S} / .42 .37$ \\
6 & Pegamento Cola & 100 & Unidad & $\mathrm{S} / .3 .70$ & $\mathrm{~S} / .370 .00$ & $\mathrm{~S} / .313 .56$ \\
7 & Lija & 2 & Pliego & $\mathrm{S} / .2 .30$ & $\mathrm{~S} / .4 .60$ & $\mathrm{~S} / .3 .90$ \\
8 & Etiquetas (Pack) & 6 & Unidad & $\mathrm{S} / .12 .00$ & $\mathrm{~S} / .72 .00$ & $\mathrm{~S} / .61 .02$ \\
9 & Waype & 0.25 & Kilo & $\mathrm{S} / .4 .00$ & $\mathrm{~S} / .1 .00$ & $\mathrm{~S} / .0 .85$ \\
10 & Otros & 1 & Unidad & $\mathrm{S} / .100 .00$ & $\mathrm{~S} / .100 .00$ & $\mathrm{~S} / .84 .75$ \\
11 & Lámina de melamine & 10 & $\mathrm{~m} 2$ & $\mathrm{~S} / .186 .90$ & $\mathrm{~S} / .1,869.00$ & $\mathrm{~S} / .1,583.90$ \\
\hline & & Total & & & S/. 2,842.00 & S/. 2,408.47 \\
\hline
\end{tabular}




\begin{tabular}{|c|c|c|c|c|c|c|}
\hline \multicolumn{7}{|c|}{ Línea: Casas } \\
\hline \multicolumn{7}{|c|}{ Servicio: Cocina - Tipo 1} \\
\hline Ítem & Material & Cantidad & Unidad & $\begin{array}{c}\text { Precio } \\
\text { Unitario }\end{array}$ & $\begin{array}{c}\text { Precio Total } \\
\text { IGV }\end{array}$ & Precio Sin IGV \\
\hline 1 & Lámina de melamine & 12 & $\mathrm{~m} 2$ & S/. 186.90 & S/. 2,242.80 & S/. 1,900.68 \\
\hline 2 & Madera Tornillo & 5 & $\mathrm{~m} 2$ & S/. 26.90 & S/. 134.50 & S/. 113.98 \\
\hline 3 & Laca Selladora & 1 & Litro & S/. 42.00 & S/. 42.00 & S/. 35.59 \\
\hline 4 & Corredera metálica & 6 & Unidad & S/. 66.90 & S/. 401.40 & S/. 340.17 \\
\hline 5 & Thinner acrílico & 1 & Litro & S/. 9.40 & S/. 9.40 & S/. 7.97 \\
\hline 6 & Clavos 1 1/2 & 10 & Unidad & S/. 1.40 & S/. 14.00 & S/. 11.86 \\
\hline 7 & Pegamento Cola & 2 & Unidad & $\mathrm{S} / .2 .80$ & S/. 5.60 & S/. 4.75 \\
\hline 8 & Lija & 2 & Pliego & $\mathrm{S} / .2 .30$ & S/. 4.60 & S/. 3.90 \\
\hline 9 & Etiquetas (Pack) & 1 & Unidad & S/. 12.00 & S/. 12.00 & S/. 10.17 \\
\hline 10 & Waype & 0.25 & Kilo & S/. 4.00 & S/. 1.00 & S/. 0.85 \\
\hline 11 & Manijas de acero & 20 & Unidad & S/. 16.00 & S/. 320.00 & S/. 271.19 \\
\hline 12 & Otros & 1 & Unidad & S/. 100.00 & S/. 100.00 & S/. 84.75 \\
\hline \multicolumn{5}{|c|}{ Total } & S/. 3,287.3 & S/. 2,785.8 \\
\hline
\end{tabular}

\begin{tabular}{|c|c|c|c|c|c|c|}
\hline \multicolumn{7}{|c|}{ Línea: Casas } \\
\hline \multicolumn{7}{|c|}{ Servicio: Cocina - Tipo 2} \\
\hline Ítem & Material & Cantidad & Unidad & $\begin{array}{c}\text { Precio } \\
\text { Unitario }\end{array}$ & $\begin{array}{c}\text { Precio Total } \\
\text { IGV }\end{array}$ & Precio Sin IGV \\
\hline 1 & Lámina de melamine & 13 & $\mathrm{~m} 2$ & S/. 186.90 & S/. 2,429.70 & S/. 2,059.07 \\
\hline 2 & Madera Tornillo & 5 & $\mathrm{~m} 2$ & S/. 26.90 & $\mathrm{~S} / .134 .50$ & S/. 113.98 \\
\hline 3 & Laca Selladora & 1 & Litro & S/. 42.00 & S/. 42.00 & S/. 35.59 \\
\hline 4 & Corredera metálica & 6 & Unidad & S/. 66.90 & S/. 401.40 & S/. 340.17 \\
\hline 5 & Thinner acrílico & 1 & Litro & S/. 9.40 & S/. 9.40 & S/. 7.97 \\
\hline 6 & Clavos $1 \frac{1}{2}$ & 15 & Unidad & S/. 1.40 & S/. 21.00 & S/. 17.80 \\
\hline 7 & Pegamento Cola & 2 & Unidad & S/. 2.80 & S/. 5.60 & S/. 4.75 \\
\hline 8 & Lija & 2 & Pliego & $\mathrm{S} / .2 .30$ & S/. 4.60 & S/. 3.90 \\
\hline 9 & Etiquetas (Pack) & 1 & Unidad & S/. 12.00 & S/. 12.00 & S/. 10.17 \\
\hline 10 & Waype & 0.25 & Kilo & S/. 4.00 & S/. 1.00 & S/. 0.85 \\
\hline 11 & Manijas de acero & 20 & Unidad & S/. 16.00 & S/. 320.00 & S/. 271.19 \\
\hline 12 & Otros & 1 & Unidad & S/. 100.00 & S/. 100.00 & S/. 84.75 \\
\hline \multicolumn{5}{|c|}{ Total } & $\mathrm{S} / . \mathbf{3 , 4 8 1 . 2 0}$ & S/. 2,950.17 \\
\hline
\end{tabular}




\begin{tabular}{|c|c|c|c|c|c|c|}
\hline \multicolumn{7}{|c|}{ Línea: Casas } \\
\hline \multicolumn{7}{|c|}{ Servicio: Cocina - Tipo 3} \\
\hline Ítem & Material & Cantidad & Unidad & $\begin{array}{c}\text { Precio } \\
\text { Unitario } \\
\end{array}$ & $\begin{array}{c}\text { Precio Total } \\
\text { IGV }\end{array}$ & $\begin{array}{c}\text { Precio Sin } \\
\text { IGV }\end{array}$ \\
\hline 1 & Lámina de melamine & 14 & $\mathrm{~m} 2$ & S/. 186.90 & S/. 2,616.60 & S/. 2,217.46 \\
\hline 2 & Madera Tornillo & 5 & $\mathrm{~m} 2$ & S/. 26.90 & S/. 134.50 & S/. 113.98 \\
\hline 3 & Laca Selladora & 1 & Litro & S/. 42.00 & $\mathrm{~S} / .42 .00$ & S/. 35.59 \\
\hline 4 & Corredera metálica & 6 & Unidad & S/. 66.90 & S/. 401.40 & S/. 340.17 \\
\hline 5 & Thinner acrílico & 1 & Litro & S/. 9.40 & S/. 9.40 & S/. 7.97 \\
\hline 6 & Clavos $1 \frac{1}{2}$ & 10 & Unidad & S/. 1.40 & S/. 14.00 & S/. 11.86 \\
\hline 7 & Pegamento Cola & 2 & Unidad & $\mathrm{S} / .2 .80$ & S/. 5.60 & S/. 4.75 \\
\hline 8 & Lija & 2 & Pliego & $\mathrm{S} / .2 .30$ & S/. 4.60 & S/. 3.90 \\
\hline 9 & Etiquetas (Pack) & 1 & Unidad & S/. 12.00 & S/. 12.00 & S/. 10.17 \\
\hline 10 & Waype & 0.25 & Kilo & S/. 4.00 & S/. 1.00 & S/. 0.85 \\
\hline 11 & Manijas de acero & 8 & Unidad & S/. 15.00 & S/. 120.00 & S/. 101.69 \\
\hline 12 & Otros & 1 & Unidad & S/. 100.00 & S/. 100.00 & S/. 84.75 \\
\hline \multicolumn{5}{|c|}{ Total } & $\mathrm{S} / . \mathbf{3 , 4 6 1 . 1 0}$ & S/. 2,933.14 \\
\hline
\end{tabular}

\section{Línea: Casas}

\begin{tabular}{|c|c|c|c|c|c|c|}
\hline \multicolumn{7}{|c|}{ Servicio: Cocina - Tipo 4} \\
\hline Ítem & Material & Cantidad & Unidad & $\begin{array}{c}\text { Precio } \\
\text { Unitario }\end{array}$ & $\begin{array}{c}\text { Precio Total } \\
\text { IGV }\end{array}$ & Precio Sin IGV \\
\hline 1 & Lámina de melamine & 16 & $\mathrm{~m} 2$ & S/. 186.90 & S/. 2,990.40 & S/. 2,534.24 \\
\hline 2 & Madera Tornillo & 5 & $\mathrm{~m} 2$ & S/. 26.90 & S/. 134.50 & S/. 113.98 \\
\hline 3 & Laca Selladora & 1 & Litro & S/. 42.00 & S/. 42.00 & S/. 35.59 \\
\hline 4 & Corredera metálica & 6 & Unidad & S/. 66.90 & S/. 401.40 & S/. 340.17 \\
\hline 5 & Thinner acrílico & 1 & Litro & S/. 9.40 & S/. 9.40 & S/. 7.97 \\
\hline 6 & Clavos 1 1⁄2 & 10 & Unidad & $\mathrm{S} / .1 .40$ & S/. 14.00 & S/. 11.86 \\
\hline 7 & Pegamento Cola & 2 & Unidad & $\mathrm{S} / .2 .80$ & S/. 5.60 & S/. 4.75 \\
\hline 8 & Lija & 2 & Pliego & S/. 2.30 & S/. 4.60 & $\mathrm{~S} / .3 .90$ \\
\hline 9 & Etiquetas (Pack) & 1 & Unidad & S/. 12.00 & S/. 12.00 & S/. 10.17 \\
\hline 10 & Waype & 0.25 & Kilo & S/. 4.00 & S/. 1.00 & S/. 0.85 \\
\hline 11 & Manijas de acero & 20 & Unidad & S/. 16.00 & S/. 320.00 & S/. 271.19 \\
\hline 12 & Otros & 1 & Unidad & S/. 100.00 & S/. 100.00 & S/. 84.75 \\
\hline \multicolumn{5}{|c|}{ Total } & $\mathrm{S} / . \mathbf{4 , 0 3 4 . 9 0}$ & $\mathrm{S} / . \mathbf{3 , 4 1 9 . 4 1}$ \\
\hline
\end{tabular}




\begin{tabular}{|c|c|c|c|c|c|c|}
\hline \multicolumn{7}{|c|}{ Línea: Departamento } \\
\hline \multicolumn{7}{|c|}{ Servicio: Habitación - Tipo 1} \\
\hline Ítem & Material & Cantidad & Unidad & $\begin{array}{c}\text { Precio } \\
\text { Unitario }\end{array}$ & $\begin{array}{c}\text { Precio Total } \\
\text { IGV }\end{array}$ & $\begin{array}{l}\text { Precio Sin } \\
\text { IGV }\end{array}$ \\
\hline 1 & Lámina de melamine & 10 & $\mathrm{~m} 2$ & S/. 186.90 & S/. $1,869.00$ & S/. $1,583.90$ \\
\hline 2 & Madera Tornillo & 4 & $\mathrm{~m} 2$ & S/. 26.90 & S/. 107.60 & S/. 91.19 \\
\hline 3 & Laca Selladora & 1 & Litro & S/. 42.00 & S/. 42.00 & S/. 35.59 \\
\hline 4 & Corredera metálica & 8 & Unidad & S/. 66.90 & S/. 535.20 & S/. 453.56 \\
\hline 5 & Thinner acrílico & 1 & Litro & S/. 9.40 & S/. 9.40 & S/. 7.97 \\
\hline 6 & Clavos $1 \frac{1 / 2}{2}$ & 16 & Unidad & S/. 1.40 & S/. 22.40 & S/. 18.98 \\
\hline 7 & Pegamento Cola & 2 & Litro & $\mathrm{S} / .2 .80$ & S/. 5.60 & S/. 4.75 \\
\hline 8 & Lija & 2 & Pliego & S/. 2.30 & S/. 4.60 & S/. 3.90 \\
\hline 9 & Etiquetas (Pack) & 1 & Unidad & S/. 12.00 & S/. 12.00 & S/. 10.17 \\
\hline 10 & Waype & 0.25 & Kilo & S/. 4.00 & S/. 1.00 & S/. 0.85 \\
\hline 11 & Otros & 1 & Unidad & S/. 100.00 & S/. 100.00 & S/. 84.75 \\
\hline \multicolumn{5}{|c|}{ Total } & S/. 2,708.8 & S/. 2,295.6 \\
\hline
\end{tabular}

Línea: Departamento

\begin{tabular}{|c|c|c|c|c|c|c|}
\hline \multicolumn{7}{|c|}{ Servicio: Habitación - Tipo 2} \\
\hline Ítem & Material & Cantidad & Unidad & $\begin{array}{c}\text { Precio } \\
\text { Unitario }\end{array}$ & $\begin{array}{c}\text { Precio Total } \\
\text { IGV }\end{array}$ & $\begin{array}{l}\text { Precio Sin } \\
\text { IGV }\end{array}$ \\
\hline 1 & $\begin{array}{l}\text { Lámina de melamine } \\
\text { (Toscana } 18 \mathrm{~mm} \text { ) }\end{array}$ & 15 & $\mathrm{~m} 2$ & S/. 186.90 & S/. 2,803.50 & S/. 2,375.85 \\
\hline 2 & Madera Tornillo & 7 & $\mathrm{~m} 2$ & S/. 26.90 & S/. 188.30 & S/. 159.58 \\
\hline 3 & Laca Selladora & 1 & Litro & S/. 42.00 & S/. 42.00 & S/. 35.59 \\
\hline 4 & Corredera metálica & 14 & Unidad & S/. 66.90 & S/. 936.60 & S/. 793.73 \\
\hline 5 & Thinner acrílico & 1 & Litro & S/. 9.40 & S/. 9.40 & S/. 7.97 \\
\hline 6 & Clavos $1 \frac{1}{2}$ & 35 & Unidad & S/. 1.40 & S/. 49.00 & S/. 41.53 \\
\hline 7 & Pegamento Cola & 2 & Litro & $\mathrm{S} / .2 .80$ & S/. 5.60 & S/. 4.75 \\
\hline 8 & Lija & 4 & Pliego & $\mathrm{S} / .2 .30$ & S/. 9.20 & S/. 7.80 \\
\hline 9 & Etiquetas (Pack) & 1 & Unidad & S/. 12.00 & S/. 12.00 & S/. 10.17 \\
\hline 10 & Waype & 0.5 & Kilo & S/. 4.00 & S/. 2.00 & S/. 1.69 \\
\hline 11 & Otros & 1 & Unidad & S/. 100.00 & S/. 100.00 & S/. 84.75 \\
\hline \multicolumn{5}{|c|}{ Total } & S/. 4,157.6 & S/. 3,523.4 \\
\hline
\end{tabular}


Línea: Departamento

Servicio: Habitación - Tipo 3

\begin{tabular}{ccccccc}
\hline Ítem & Material & Cantidad & Unidad & $\begin{array}{c}\text { Precio } \\
\text { Unitario }\end{array}$ & $\begin{array}{c}\text { Precio Total } \\
\text { IGV }\end{array}$ & $\begin{array}{c}\text { Precio Sin } \\
\text { IGV }\end{array}$ \\
\hline 1 & Lámina de melamine & 10 & $\mathrm{~m} 2$ & $\mathrm{~S} / .186 .90$ & $\mathrm{~S} / .1,869.00$ & $\mathrm{~S} / .1,583.90$ \\
2 & Madera Tornillo & 12 & $\mathrm{~m} 2$ & $\mathrm{~S} / .26 .90$ & $\mathrm{~S} / .322 .80$ & $\mathrm{~S} / .273 .56$ \\
3 & Laca Selladora & 1 & Litro & $\mathrm{S} / .42 .00$ & $\mathrm{~S} / .42 .00$ & $\mathrm{~S} / .35 .59$ \\
4 & Corredera metálica & 8 & Unidad & $\mathrm{S} / .66 .90$ & $\mathrm{~S} / .535 .20$ & $\mathrm{~S} / .453 .56$ \\
5 & Thinner acrílico & 1 & Litro & $\mathrm{S} / .9 .40$ & $\mathrm{~S} / .9 .40$ & $\mathrm{~S} / .7 .97$ \\
6 & Clavos 1 1/2 & 4 & Unidad & $\mathrm{S} / .1 .40$ & $\mathrm{~S} / .5 .60$ & $\mathrm{~S} / .4 .75$ \\
7 & Pegamento Cola & 2 & Litro & $\mathrm{S} / .2 .80$ & $\mathrm{~S} / .5 .60$ & $\mathrm{~S} / .4 .75$ \\
8 & Lija & 2 & Pliego & $\mathrm{S} / .2 .30$ & $\mathrm{~S} / .4 .60$ & $\mathrm{~S} / .3 .90$ \\
9 & Etiquetas (Pack) & 1 & Unidad & $\mathrm{S} / .12 .00$ & $\mathrm{~S} / .12 .00$ & $\mathrm{~S} / .10 .17$ \\
10 & Waype & 0.25 & Kilo & $\mathrm{S} / .4 .00$ & $\mathrm{~S} / .1 .00$ & $\mathrm{~S} / .0 .85$ \\
11 & Otros & 1 & Unidad & $\mathrm{S} / .100 .00$ & $\mathrm{~S} / .100 .00$ & $\mathrm{~S} / .84 .75$ \\
\hline & & Total & & & S/. 2,907.2 & S/. 2,463.7 \\
\hline
\end{tabular}

Línea: Departamento

\begin{tabular}{|c|c|c|c|c|c|c|}
\hline \multicolumn{7}{|c|}{ Servicio: Habitación - Tipo 4} \\
\hline Ítem & Material & Cantidad & Unidad & $\begin{array}{c}\text { Precio } \\
\text { Unitario } \\
\end{array}$ & $\begin{array}{c}\text { Precio Total } \\
\text { IGV } \\
\end{array}$ & $\begin{array}{c}\text { Precio Sin } \\
\text { IGV }\end{array}$ \\
\hline 1 & Lámina de melamine & 8 & $\mathrm{~m} 2$ & S/. 186.90 & S/. 1,495.20 & S/. $1,267.12$ \\
\hline 2 & Madera Tornillo & 5 & $\mathrm{~m} 2$ & S/. 26.90 & S/. 134.50 & S/. 113.98 \\
\hline 3 & Laca Selladora & 1 & Litro & $\mathrm{S} / .42 .00$ & $\mathrm{~S} / .42 .00$ & S/. 35.59 \\
\hline 4 & Corredera metálica & 8 & Unidad & S/. 66.90 & S/. 535.20 & S/. 453.56 \\
\hline 5 & Thinner acrílico & 1 & Litro & S/. 9.40 & S/. 9.40 & S/. 7.97 \\
\hline 6 & Clavos $1 \frac{1}{2}$ & 4 & Unidad & S/. 1.40 & S/. 5.60 & S/. 4.75 \\
\hline 7 & Pegamento Cola & 2 & Litro & $\mathrm{S} / .2 .80$ & S/. 5.60 & S/. 4.75 \\
\hline 8 & Lija & 2 & Pliego & $\mathrm{S} / .2 .30$ & S/. 4.60 & $\mathrm{~S} / .3 .90$ \\
\hline 9 & Etiquetas (Pack) & 1 & Unidad & $\mathrm{S} / .12 .00$ & $\mathrm{~S} / .12 .00$ & S/. 10.17 \\
\hline 10 & Waype & 0.25 & Kilo & S/. 4.00 & S/. 1.00 & S/. 0.85 \\
\hline 11 & Otros & 1 & Unidad & S/. 100.00 & S/. 100.00 & S/. 84.75 \\
\hline \multicolumn{5}{|c|}{ Total } & S/. 2,345.1 & S/. 1,987.4 \\
\hline
\end{tabular}




\begin{tabular}{|c|c|c|c|c|c|c|}
\hline \multicolumn{7}{|c|}{ Línea: Departamento } \\
\hline \multicolumn{7}{|c|}{ Servicio: Sala-Comedor - Tipo 1} \\
\hline Ítem & Material & Cantidad & Unidad & $\begin{array}{c}\text { Precio } \\
\text { Unitario } \\
\end{array}$ & $\begin{array}{c}\text { Precio Total } \\
\text { IGV } \\
\end{array}$ & Precio Sin IGV \\
\hline 1 & $\begin{array}{l}\text { Lámina de melamine } \\
\text { (Tropicalizado blanco } \\
18 \mathrm{~mm} \text { ) }\end{array}$ & 14 & $\mathrm{~m} 2$ & S/. 195.00 & S/. 2,730.00 & S/. 2,313.56 \\
\hline 2 & Madera Tornillo & 1 & $\mathrm{~m} 2$ & S/. 26.90 & S/. 26.90 & S/. 22.80 \\
\hline 3 & Laca Selladora & 1 & Litro & S/. 42.00 & S/. 42.00 & S/. 35.59 \\
\hline 4 & Manija & 4 & Unidad & S/. 66.90 & S/. 267.60 & S/. 226.78 \\
\hline 5 & Thinner acrílico & 1 & Litro & S/. 9.40 & S/. 9.40 & S/. 7.97 \\
\hline 6 & Tornillos & 12 & Unidad & S/. 4.00 & S/. 48.00 & S/. 40.68 \\
\hline 7 & Pegamento Cola & 2 & Unidad & $\mathrm{S} / .2 .80$ & S/. 5.60 & S/. 4.75 \\
\hline 8 & Lija & 2 & Pliego & $\mathrm{S} / .2 .30$ & S/. 4.60 & S/. 3.90 \\
\hline 9 & Etiquetas (Pack) & 1 & Unidad & S/. 12.00 & S/. 12.00 & S/. 10.17 \\
\hline 10 & Waype & 0.25 & Kilo & S/. 4.00 & S/. 1.00 & S/. 0.85 \\
\hline 11 & Otros & 1 & Unidad & S/. 100.00 & S/. 100.00 & S/. 84.75 \\
\hline \multicolumn{5}{|c|}{ Total } & S/. 3,147.1 & S/. 2,667.0 \\
\hline
\end{tabular}

\section{Línea: Departamento}

Servicio: Sala-Comedor - Tipo 2

\begin{tabular}{|c|c|c|c|c|c|c|}
\hline Ítem & Material & Cantidad & Unidad & $\begin{array}{c}\text { Precio } \\
\text { Unitario }\end{array}$ & $\begin{array}{c}\text { Precio Total } \\
\text { IGV }\end{array}$ & $\begin{array}{c}\text { Precio Sin } \\
\text { IGV }\end{array}$ \\
\hline 1 & $\begin{array}{l}\text { Lámina de melamine } \\
\text { (Tropicalizado blanco } 18 \\
\mathrm{~mm} \text { ) }\end{array}$ & 12 & $\mathrm{~m} 2$ & S/. 195.00 & S/. 2,340.00 & S/. 1,983.05 \\
\hline 2 & Madera Tornillo & 2 & $\mathrm{~m} 2$ & S/. 26.90 & S/. 53.80 & S/. 45.59 \\
\hline 3 & Laca Selladora & 1 & Litro & S/. 42.00 & S/. 42.00 & S/. 35.59 \\
\hline 4 & Manija & 4 & Unidad & S/. 66.90 & S/. 267.60 & S/. 226.78 \\
\hline 5 & Thinner acrílico & 1 & Litro & S/. 9.40 & S/. 9.40 & S/. 7.97 \\
\hline 6 & Tornillos & 8 & Unidad & S/. 4.00 & S/. 32.00 & S/. 27.12 \\
\hline 7 & Pegamento Cola & 2 & Unidad & S/. 2.80 & S/. 5.60 & S/. 4.75 \\
\hline 8 & Lija & 2 & Pliego & S/. 2.30 & S/. 4.60 & S/. 3.90 \\
\hline 9 & Etiquetas (Pack) & 1 & Unidad & S/. 12.00 & S/. 12.00 & S/. 10.17 \\
\hline 10 & Waype & 0.25 & Kilo & S/. 4.00 & S/. 1.00 & S/. 0.85 \\
\hline 11 & Otros & 1 & Unidad & S/. 100.00 & S/. 100.00 & S/. 84.75 \\
\hline \multicolumn{5}{|c|}{ Total } & S/. 2,768.0 & S/. 2,345.8 \\
\hline
\end{tabular}


Línea: Departamento

\begin{tabular}{|c|c|c|c|c|c|c|}
\hline \multicolumn{7}{|c|}{ Servicio: Sala-Comedor - Tipo 3} \\
\hline Ítem & Material & Cantidad & Unidad & $\begin{array}{c}\text { Precio } \\
\text { Unitario }\end{array}$ & $\begin{array}{c}\text { Precio Total } \\
\text { IGV }\end{array}$ & $\begin{array}{c}\text { Precio Sin } \\
\text { IGV }\end{array}$ \\
\hline 1 & $\begin{array}{c}\text { Lámina de melamine } \\
\text { (Tropicalizado blanco } \\
18 \mathrm{~mm} \text { ) }\end{array}$ & 10 & $\mathrm{~m} 2$ & S/. 195.00 & S/. 1,950.00 & S/. 1,652.54 \\
\hline 2 & Madera Tornillo & 3 & $\mathrm{~m} 2$ & S/. 26.90 & S/. 80.70 & S/. 68.39 \\
\hline 3 & Laca Selladora & 1 & Litro & $\mathrm{S} / .42 .00$ & $\mathrm{~S} / .42 .00$ & S/. 35.59 \\
\hline 4 & Manija & 4 & Unidad & S/. 66.90 & S/. 267.60 & S/. 226.78 \\
\hline 5 & Thinner acrílico & 1 & Litro & S/. 9.40 & S/. 9.40 & S/. 7.97 \\
\hline 6 & Tornillos & 10 & Unidad & S/. 4.00 & S/. 40.00 & S/. 33.90 \\
\hline 7 & Pegamento Cola & 1 & Unidad & S/. 2.80 & S/. 2.80 & S/. 2.37 \\
\hline 8 & Lija & 2 & Pliego & $\mathrm{S} / .2 .30$ & S/. 4.60 & S/. 3.90 \\
\hline 9 & Etiquetas (Pack) & 1 & Unidad & S/. 12.00 & S/. 12.00 & S/. 10.17 \\
\hline 10 & Waype & 0.25 & Kilo & S/. 4.00 & S/. 1.00 & S/. 0.85 \\
\hline 11 & Otros & 1 & Unidad & S/. 100.00 & S/. 100.00 & S/. 84.75 \\
\hline \multicolumn{5}{|c|}{ Total } & $\mathrm{S} / . \mathbf{2 , 4 1 0 . 1}$ & S/. 2,042.5 \\
\hline
\end{tabular}

Línea: Departamento

\begin{tabular}{|c|c|c|c|c|c|c|}
\hline \multicolumn{7}{|c|}{ Servicio: Sala-Comedor - Tipo 4} \\
\hline Ítem & Material & Cantidad & Unidad & $\begin{array}{c}\text { Precio } \\
\text { Unitario }\end{array}$ & $\begin{array}{c}\text { Precio Total } \\
\text { IGV }\end{array}$ & $\begin{array}{l}\text { Precio Sin } \\
\text { IGV }\end{array}$ \\
\hline 1 & $\begin{array}{c}\text { Lámina de melamine } \\
\text { (Tropicalizado blanco } \\
18 \mathrm{~mm} \text { ) }\end{array}$ & 12 & $\mathrm{~m} 2$ & S/. 195.00 & S/. 2,340.00 & S/. 1,983.05 \\
\hline 2 & Madera Tornillo & 5 & $\mathrm{~m} 2$ & S/. 26.90 & S/. 134.50 & S/. 113.98 \\
\hline 3 & Laca Selladora & 1 & Litro & S/. 42.00 & S/. 42.00 & S/. 35.59 \\
\hline 4 & Manija & 4 & Unidad & S/. 66.90 & S/. 267.60 & S/. 226.78 \\
\hline 5 & Thinner acrílico & 1 & Litro & S/. 9.40 & S/. 9.40 & S/. 7.97 \\
\hline 6 & Tornillos & 12 & Unidad & S/. 4.00 & S/. 48.00 & S/. 40.68 \\
\hline 7 & Pegamento Cola & 2 & Unidad & S/. 2.80 & S/. 5.60 & S/. 4.75 \\
\hline 8 & Lija & 2 & Pliego & S/. 2.30 & S/. 4.60 & S/. 3.90 \\
\hline 9 & Etiquetas (Pack) & 1 & Unidad & S/. 12.00 & S/. 12.00 & S/. 10.17 \\
\hline 10 & Waype & 0.25 & Kilo & S/. 4.00 & S/. 1.00 & S/. 0.85 \\
\hline 11 & Otros & 1 & Unidad & S/. 100.00 & S/. 100.00 & S/. 84.75 \\
\hline \multicolumn{5}{|c|}{ Total } & S/. 2,864.7 & S/. 2,427.7 \\
\hline
\end{tabular}




\begin{tabular}{|c|c|c|c|c|c|c|}
\hline \multicolumn{7}{|c|}{ Línea: Departamento } \\
\hline \multicolumn{7}{|c|}{ Servicio: Cocina - Tipo 1} \\
\hline Ítem & Material & Cantidad & Unidad & $\begin{array}{c}\text { Precio } \\
\text { Unitario }\end{array}$ & $\begin{array}{c}\text { Precio Total } \\
\text { IGV }\end{array}$ & Precio Sin IGV \\
\hline 1 & $\begin{array}{c}\text { Lámina de melamine } \\
\text { (Tropicalizado blanco } \\
18 \mathrm{~mm} \text { ) }\end{array}$ & 8 & $\mathrm{~m} 2$ & S/. 195.00 & S/. $1,560.00$ & S/. 1,322.03 \\
\hline 2 & Madera Tornillo & 5 & $\mathrm{~m} 2$ & S/. 66.90 & S/. 334.50 & S/. 283.47 \\
\hline 3 & Laca Selladora & 1 & Litro & S/. 9.40 & S/. 9.40 & S/. 7.97 \\
\hline 4 & Manija & 2 & Unidad & S/. 4.00 & S/. 8.00 & S/. 6.78 \\
\hline 5 & Thinner acrílico & 1 & Litro & $\mathrm{S} / .2 .80$ & $\mathrm{~S} / .2 .80$ & S/. 2.37 \\
\hline 6 & Tornillos & 12 & Unidad & S/. 4.00 & S/. 48.00 & S/. 40.68 \\
\hline 7 & Pegamento Cola & 2 & Unidad & S/. 12.00 & S/. 24.00 & S/. 20.34 \\
\hline 8 & Lija & 2 & Pliego & S/. 4.00 & S/. 8.00 & S/. 6.78 \\
\hline 9 & Etiquetas (Pack) & 1 & Unidad & S/. 12.00 & S/. 12.00 & S/. 10.17 \\
\hline 10 & Waype & 0.25 & Kilo & S/. 0.00 & S/. 0.00 & S/. 0.00 \\
\hline 11 & Otros & 1 & Unidad & S/. 100.00 & S/. 100.00 & S/. 84.75 \\
\hline \multicolumn{5}{|c|}{ Total } & S/. 2,006.7 & S/. 1,700.6 \\
\hline
\end{tabular}

\begin{tabular}{|c|c|c|c|c|c|c|}
\hline \multicolumn{7}{|c|}{ Línea: Departamento } \\
\hline \multicolumn{7}{|c|}{ Servicio: Cocina - Tipo 2} \\
\hline Ítem & Material & Cantidad & Unidad & $\begin{array}{c}\text { Precio } \\
\text { Unitario }\end{array}$ & $\begin{array}{c}\text { Precio Total } \\
\text { IGV }\end{array}$ & Precio S/ IGV \\
\hline 1 & $\begin{array}{c}\text { Lámina de melamine } \\
\text { (Tropicalizado blanco } \\
18 \mathrm{~mm} \text { ) }\end{array}$ & 9 & $\mathrm{~m} 2$ & S/. 195.00 & S/. $1,755.00$ & S/. 1,487.29 \\
\hline 2 & Madera Tornillo & 5 & $\mathrm{~m} 2$ & S/. 66.90 & $\mathrm{~S} / .334 .50$ & S/. 283.47 \\
\hline 3 & Laca Selladora & 1 & Litro & S/. 9.40 & S/. 9.40 & S/. 7.97 \\
\hline 4 & Manija & 10 & Unidad & S/. 4.00 & S/. 40.00 & S/. 33.90 \\
\hline 5 & Thinner acrílico & 1 & Litro & $\mathrm{S} / .2 .80$ & $\mathrm{~S} / .2 .80$ & $\mathrm{~S} / .2 .37$ \\
\hline 6 & Tornillos & 6 & Unidad & $\mathrm{S} / .4 .00$ & S/. 24.00 & S/. 20.34 \\
\hline 7 & Pegamento Cola & 2 & Unidad & S/. 12.00 & S/. 24.00 & S/. 20.34 \\
\hline 8 & Lija & 2 & Pliego & $\mathrm{S} / .4 .00$ & $\mathrm{~S} / .8 .00$ & S/. 6.78 \\
\hline 9 & Etiquetas (Pack) & 1 & Unidad & S/. 12.00 & S/. 12.00 & S/. 10.17 \\
\hline 10 & Waype & 0.25 & Kilo & S/. 0.00 & S/. 0.00 & S/. 0.00 \\
\hline 11 & Otros & 1 & Unidad & S/. 100.00 & S/. 100.00 & S/. 84.75 \\
\hline \multicolumn{5}{|c|}{ Total } & $\mathrm{S} / .2,209.7$ & S/. 1,872.6 \\
\hline
\end{tabular}




\begin{tabular}{|c|c|c|c|c|c|c|}
\hline \multicolumn{7}{|c|}{ Línea: Departamento } \\
\hline \multicolumn{7}{|c|}{ Servicio: Cocina - Tipo 3} \\
\hline Ítem & Material & Cantidad & Unidad & $\begin{array}{c}\text { Precio } \\
\text { Unitario }\end{array}$ & $\begin{array}{c}\text { Precio Total } \\
\text { IGV }\end{array}$ & Precio Sin IGV \\
\hline 1 & $\begin{array}{l}\text { Lámina de melamine } \\
\text { (Tropicalizado blanco } \\
18 \mathrm{~mm} \text { ) }\end{array}$ & 8 & $\mathrm{~m} 2$ & S/. 195.00 & S/. $1,560.00$ & S/. 1,322.03 \\
\hline 2 & Madera Tornillo & 5 & $\mathrm{~m} 2$ & S/. 66.90 & S/. 334.50 & S/. 283.47 \\
\hline 3 & Laca Selladora & 1 & Litro & S/. 9.40 & S/. 9.40 & S/. 7.97 \\
\hline 4 & Manija & 4 & Unidad & S/. 4.00 & S/. 16.00 & S/. 13.56 \\
\hline 5 & Thinner acrílico & 1 & Litro & $\mathrm{S} / .2 .80$ & $\mathrm{~S} / .2 .80$ & S/. 2.37 \\
\hline 6 & Tornillos & 12 & Unidad & S/. 4.00 & $\mathrm{~S} / .48 .00$ & S/. 40.68 \\
\hline 7 & Pegamento Cola & 2 & Unidad & S/. 12.00 & S/. 24.00 & S/. 20.34 \\
\hline 8 & Lija & 2 & Pliego & $\mathrm{S} / .4 .00$ & S/. 8.00 & S/. 6.78 \\
\hline 9 & Etiquetas (Pack) & 1 & Unidad & S/. 12.00 & $\mathrm{~S} / .12 .00$ & S/. 10.17 \\
\hline 10 & Waype & 0.25 & Kilo & S/. 0.00 & S/. 0.00 & S/. 0.00 \\
\hline 11 & Otros & 1 & Unidad & S/. 100.00 & S/. 100.00 & S/. 84.75 \\
\hline \multicolumn{5}{|c|}{ Total } & S/. 2,014.7 & S/. 1,707.4 \\
\hline
\end{tabular}

\begin{tabular}{|c|c|c|c|c|c|c|}
\hline \multicolumn{7}{|c|}{ Línea: Departamento } \\
\hline \multicolumn{7}{|c|}{ Servicio: Cocina - Tipo 4} \\
\hline Ítem & Material & Cantidad & Unidad & $\begin{array}{c}\text { Precio } \\
\text { Unitario }\end{array}$ & $\begin{array}{c}\text { Precio Total } \\
\text { IGV }\end{array}$ & Precio Sin IGV \\
\hline 1 & $\begin{array}{c}\text { Lámina de melamine } \\
\text { (Tropicalizado blanco } \\
18 \mathrm{~mm} \text { ) }\end{array}$ & 10 & $\mathrm{~m} 2$ & S/. 195.00 & S/. 1,950.00 & S/. 1,652.54 \\
\hline 2 & Madera Tornillo & 3 & $\mathrm{~m} 2$ & S/. 66.90 & S/. 200.70 & S/. 170.08 \\
\hline 3 & Laca Selladora & 1 & Litro & S/. 9.40 & S/. 9.40 & S/. 7.97 \\
\hline 4 & Manija & 4 & Unidad & S/. 4.00 & S/. 16.00 & $\mathrm{~S} / .13 .56$ \\
\hline 5 & Thinner acrílico & 1 & Litro & S/. 2.80 & $\mathrm{~S} / .2 .80$ & S/. 2.37 \\
\hline 6 & Tornillos & 6 & Unidad & S/. 4.00 & S/. 24.00 & S/. 20.34 \\
\hline 7 & Pegamento Cola & 2 & Unidad & S/. 12.00 & S/. 24.00 & S/. 20.34 \\
\hline 8 & Lija & 2 & Pliego & S/. 4.00 & S/. 8.00 & S/. 6.78 \\
\hline 9 & Etiquetas (Pack) & 1 & Unidad & S/. 12.00 & S/. 12.00 & S/. 10.17 \\
\hline 10 & Waype & 0.25 & Kilo & S/. 0.00 & S/. 0.00 & S/. 0.00 \\
\hline 11 & Otros & 1 & Unidad & S/. 100.00 & S/. 100.00 & S/. 84.75 \\
\hline \multicolumn{5}{|c|}{ Total } & S/. 2,246.9 & $\mathrm{S} / .1,904.2$ \\
\hline
\end{tabular}




\section{Anexo $\mathbf{N}^{\circ} 9$ - Presupuesto de compras mensual}

\section{PRESUPUESTO DE COMPRAS POR MESES - 2019}

\begin{tabular}{|c|c|c|c|c|c|c|c|c|c|c|c|c|c|}
\hline & Enero & Febrero & Marzo & Abril & Mayo & Junio & Julio & Agosto & Sept. & Oct. & Nov. & Dic. & Total \\
\hline Estacionalidad \% & $3.30 \%$ & $3.30 \%$ & $3.30 \%$ & $8.42 \%$ & $8.42 \%$ & $8.42 \%$ & $11.72 \%$ & $11.72 \%$ & $11.72 \%$ & $9.90 \%$ & $9.90 \%$ & $9.90 \%$ & $100.0 \%$ \\
\hline \multicolumn{14}{|l|}{ A.- Casa } \\
\hline Habitación & $\mathrm{S} / .0$ & $\mathrm{~S} / .0$ & S/. 3,710 & S/. 3,710 & S/. 3,710 & S/. 3,710 & S/. 7,420 & S/. 7,420 & S/. 7,420 & S/. 3,710 & S/. 3,710 & S/. 3,710 & S/. 48,227 \\
\hline Sala & S/. 3,098 & S/. 3,098 & S/. 3,098 & S/. 6,196 & S/. 6,196 & S/. 6,196 & S/. 9,295 & S/. 9,295 & S/. 9,295 & S/. 9,295 & S/. 9,295 & S/. 9,295 & S/. 83,651 \\
\hline Comedor & S/. 3,908 & S/. 3,908 & S/. 0 & S/. 7,817 & S/. 7,817 & S/. 3,908 & S/. 7,817 & S/. 7,817 & S/. 7,817 & S/. 7,817 & S/. 7,817 & S/. 7,817 & S/. 74,258 \\
\hline Zona de Parrilla & S/. 4,957 & S/. 2,478 & S/. 4,957 & S/. 9,914 & S/. 9,914 & S/. 9,914 & S/. 12,392 & S/. 14,871 & S/. 14,871 & S/. 12,392 & S/. 12,392 & S/. 9,914 & S/. 118,966 \\
\hline Cocina & S/. 7,132 & S/. 3,566 & S/. 7,132 & S/. 14,265 & S/. 14,265 & S/. 14,265 & S/. 17,831 & S/. 21,397 & S/. 21,397 & S/. 17,831 & S/. 17,831 & S/. 14,265 & S/. 171,174 \\
\hline \multicolumn{14}{|l|}{ B.- Departamento } \\
\hline Habitación & S/. 0 & $\mathrm{~S} / .3,030$ & S/. 3,030 & S/. 6,059 & S/. 6,059 & S/. 6,059 & S/. 9,089 & S/. 9,089 & S/. 9,089 & S/. 6,059 & S/. 6,059 & S/. 6,059 & S/. 69,683 \\
\hline Sala - comedor & S/. 5,595 & S/. 5,595 & S/. 8,392 & S/. 11,190 & S/. 11,190 & S/. 11,190 & S/. 16,785 & S/. 19,582 & S/. 16,785 & S/. 13,987 & S/. 16,785 & S/. 13,987 & S/. 151,064 \\
\hline Cocina & S/. 4,239 & S/. 4,239 & S/. 4,239 & S/. 8,478 & S/. 10,598 & S/. 10,598 & S/. 14,837 & S/. 14,837 & S/. 12,717 & S/. 12,717 & S/. 12,717 & S/. 12,717 & S/. 122,931 \\
\hline Total con IGV & $\mathrm{S} / . \mathbf{2 8 , 9 3 0}$ & S/.25,915 & S/. 34,558 & S/. 67,628 & S/. 69,748 & S/. 65,839 & S/.95,464 & S/. 104,306 & S/.99,389 & S/. 83,808 & S/.86,605 & $\mathrm{S} / . \mathbf{7 7 , 7 6 3}$ & S/. 839,952 \\
\hline Total sin IGV & S/. 24,517 & S/. 21,962 & S/. 29,287 & S/. 57,312 & S/. 59,108 & S/.55,796 & $\mathrm{S} / .80,902$ & S/. 88,395 & S/. 84,228 & S/. 71,023 & S/. 73,394 & S/. 65,901 & S/. 711,824 \\
\hline
\end{tabular}


PRESUPUESTO DE COMPRAS POR MESES - 2020

\begin{tabular}{|c|c|c|c|c|c|c|c|c|c|c|c|c|c|}
\hline & Enero & Febrero & Marzo & Abril & Mayo & Junio & Julio & Agosto & Sept. & Oct. & Nov. & Dic. & Total \\
\hline Estacionalidad \% & $3.30 \%$ & $3.30 \%$ & $3.30 \%$ & $8.42 \%$ & $8.42 \%$ & $8.42 \%$ & $11.72 \%$ & $11.72 \%$ & $11.72 \%$ & $9.90 \%$ & $9.90 \%$ & $9.90 \%$ & $100.0 \%$ \\
\hline \multicolumn{14}{|l|}{ A.- Casa } \\
\hline Habitación & $\mathrm{S} / .0$ & S/. 3,710 & $\mathrm{S} / .0$ & S/. 3,710 & S/. 3,710 & S/. 3,710 & S/. 7,420 & S/. 7,420 & S/. 7,420 & S/. 3,710 & S/. 3,710 & S/. 3,710 & S/. 48,227 \\
\hline Sala & S/. 3,098 & S/. 3,098 & S/. 3,098 & S/. 6,196 & S/. 6,196 & S/. 6,196 & S/. 9,295 & S/. 9,295 & S/. 9,295 & S/. 9,295 & S/. 9,295 & S/. 12,393 & S/. 86,749 \\
\hline Comedor & S/. 3,908 & S/. 3,908 & S/. 0 & S/. 7,817 & S/. 7,817 & S/. 7,817 & S/. 7,817 & S/. 7,817 & S/. 7,817 & S/. 7,817 & S/. 7,817 & S/. 7,817 & S/. 78,166 \\
\hline Zona de Parrilla & S/. 2,478 & S/. 4,957 & S/. 4,957 & S/. 12,392 & S/. 12,392 & S/. 12,392 & S/. 14,871 & S/. 14,871 & S/. 14,871 & S/. 12,392 & S/. 12,392 & S/. 12,392 & S/. 131,358 \\
\hline Cocina & S/. 7,132 & S/. 3,566 & S/. 7,132 & S/. 17,831 & S/. 17,831 & S/. 17,831 & S/. 21,397 & S/. 21,397 & S/. 21,397 & S/. 17,831 & S/. 17,831 & S/. 17,831 & S/. 189,005 \\
\hline \multicolumn{14}{|l|}{ B.- Departamento } \\
\hline Habitación & S/. 3,030 & S/. 3,030 & S/. 0 & S/. 6,059 & S/. 6,059 & S/. 6,059 & S/. 9,089 & S/. 9,089 & S/. 9,089 & S/. 6,059 & S/. 6,059 & S/. 6,059 & S/. 69,683 \\
\hline Sala - comedor & S/. 2,797 & S/. 5,595 & S/. 5,595 & S/. 11,190 & S/. 11,190 & S/. 11,190 & S/. 13,987 & S/. 16,785 & S/. 16,785 & S/. 13,987 & S/. 13,987 & S/. 11,190 & S/. 134,279 \\
\hline Cocina & S/. 4,239 & S/. 4,239 & S/. 4,239 & S/. 10,598 & S/. 10,598 & S/. 10,598 & S/. 16,956 & S/. 16,956 & S/. 19,076 & S/. 12,717 & S/. 12,717 & S/. 12,717 & S/. 135,648 \\
\hline Total con IGV & $\mathrm{S} / . \mathbf{2 6 , 6 8 3}$ & $\mathrm{S} / . \mathbf{3 2 , 1 0 3}$ & S/. 25,021 & S/. 75,792 & S/. 75,792 & S/. 75,792 & $\mathrm{S} / . \mathbf{1 0 0 , 8 3 1}$ & $\mathrm{S} / . \mathbf{1 0 3 , 6 2 8}$ & S/.105,748 & $\mathrm{S} / . \mathbf{8 3 , 8 0 8}$ & $\mathrm{S} / . \mathbf{8 3 , 8 0 8}$ & $\mathrm{S} / .84,108$ & S/.873,114 \\
\hline Total sin IGV & S/.22,613 & S/.27,206 & S/.21,204 & S/. 64,231 & S/. 64,231 & S/. 64,231 & S/. 85,450 & S/. 87,820 & S/. 89,617 & S/. 71,023 & S/. 71,023 & S/. 71,278 & S/. 739,927 \\
\hline
\end{tabular}




\begin{tabular}{|c|c|c|c|c|c|c|c|c|c|c|c|c|c|}
\hline \multicolumn{14}{|c|}{ PRESUPUESTO DE COMPRAS POR MESES - 2021} \\
\hline & Enero & Febrero & Marzo & Abril & Mayo & Junio & Julio & Agosto & Sept. & Oct. & Nov. & Dic. & Total \\
\hline Estacionalidad \% & $3.30 \%$ & $3.30 \%$ & $3.30 \%$ & $8.42 \%$ & $8.42 \%$ & $8.42 \%$ & $11.72 \%$ & $11.72 \%$ & $11.72 \%$ & $9.90 \%$ & $9.90 \%$ & $9.90 \%$ & $100.0 \%$ \\
\hline \multicolumn{14}{|l|}{ A.- Casa } \\
\hline Habitación & $\mathrm{S} / .0$ & S/. 0 & S/. 3,710 & S/. 3,710 & S/. 3,710 & S/. 7,420 & S/. 7,420 & S/. 7,420 & S/. 7,420 & S/. 3,710 & S/. 3,710 & S/. 3,710 & S/. 51,937 \\
\hline Sala & S/. 3,098 & S/. 3,098 & S/. 3,098 & S/. 6,196 & S/. 6,196 & S/. 6,196 & S/. 9,295 & S/. 6,196 & S/. 9,295 & S/. 9,295 & S/. 9,295 & S/. 9,295 & S/. 80,553 \\
\hline Comedor & S/. 3,908 & S/. 3,908 & S/. 3,908 & S/. 7,817 & S/. 7,817 & S/. 7,817 & S/. 11,725 & S/. 11,725 & S/. 11,725 & S/. 7,817 & S/. 7,817 & S/. 7,817 & S/. 93,799 \\
\hline Zona de Parrilla & S/. 2,478 & S/. 4,957 & S/. 4,957 & S/. 14,871 & S/. 12,392 & S/. 12,392 & S/. 17,349 & S/. 17,349 & S/. 17,349 & S/. 14,871 & S/. 17,349 & S/. 14,871 & S/. 151,185 \\
\hline Cocina & S/. 3,566 & S/. 7,132 & S/. 7,132 & S/. 21,397 & S/. 17,831 & S/. 17,831 & S/. 24,963 & S/. 24,963 & S/. 24,963 & S/. 21,397 & S/. 24,963 & S/. 21,397 & S/. 217,534 \\
\hline \multicolumn{14}{|l|}{ B.- Departamento } \\
\hline Habitación & S/. 3,030 & S/. 3,030 & $\mathrm{S} / .0$ & S/. 6,059 & S/. 6,059 & S/. 6,059 & S/. 6,059 & S/. 9,089 & S/. 9,089 & S/. 6,059 & S/. 6,059 & S/. 6,059 & S/. 66,653 \\
\hline Sala - comedor & S/. 5,595 & S/. 2,797 & S/. 5,595 & S/. 11,190 & S/. 11,190 & S/. 11,190 & S/. 16,785 & S/. 16,785 & S/. 13,987 & S/. 13,987 & S/. 13,987 & S/. 13,987 & S/. 137,076 \\
\hline Cocina & S/. 4,239 & S/. 4,239 & S/. 4,239 & S/. 12,717 & S/. 14,837 & S/. 12,717 & S/. 19,076 & S/. 16,956 & S/. 16,956 & S/. 16,956 & S/. 14,837 & S/. 14,837 & S/. 152,604 \\
\hline Total con IGV & S/. 25,915 & S/. 29,162 & S/. 32,639 & S/. 83,956 & $\mathrm{S} / .80,031$ & S/. 81,622 & S/.112,671 & S/. 110,483 & $\mathrm{S} / \mathbf{1 1 0 , 7 8 3}$ & S/.94,091 & S/.98,016 & S/.91,972 & S/.951,341 \\
\hline Total sin IGV & S/. 21,962 & $\mathrm{S} / .24,713$ & $\mathrm{~S} / .27,660$ & S/. 71,150 & S/. 67,823 & S/. 69,171 & S/. 95,484 & S/. 93,629 & S/. 93,884 & S/. 79,738 & S/. 83,065 & S/. 77,942 & S/. 806,221 \\
\hline
\end{tabular}




\section{Anexo $N^{\circ} 10$ - Liquidación del IGV}

\begin{tabular}{|c|c|c|c|c|}
\hline Concepto & 2018 & 2019 & 2020 & 2021 \\
\hline IGV de los Ingresos & & 289,493 & 301,284 & 329,101 \\
\hline IGV de Materia Prima & & $-128,128$ & $-133,187$ & $-145,120$ \\
\hline IGV de Gastos & & $-33,182$ & $-33,239$ & $-33,367$ \\
\hline IGV de Inversiones & S/. $-53,263$ & & & \\
\hline IGV Neto & S/. - -53,263 & 128,183 & 134,858 & 150,615 \\
\hline Crédito Fiscal del IGV & S/. $-53,263$ & 0 & 0 & 0 \\
\hline Pago de IGV a SUNAT & $\mathrm{S} / .0$ & 74,921 & 134,858 & 150,615 \\
\hline Liquidación del IGV & S/. -53,263 & 53,263 & $\mathbf{0}$ & $\mathbf{0}$ \\
\hline
\end{tabular}




\section{Anexo $\mathbf{N}^{\circ} 11$ - Perpetuidad de las Inversiones}

\begin{tabular}{lrrrrr}
\hline \multicolumn{1}{c}{ Perpetuidad de Inversiones } & Importe S/ & Vida útil & K Vida útil & VP Vida útil & VP al 2023 \\
\hline Propiedad, planta y equipo & & & & & \\
Implementación de oficina y call center & $-30,000$ & 10 & $219.07 \%$ & $-13,695$ & $-24,462$ \\
Unidad de transporte & $-66,967$ & 5 & $78.62 \%$ & $-85,173$ & $-152,139$ \\
Implementación de centro de exhibición & $-200,000$ & 10 & $219.07 \%$ & $-91,297$ & $-163,078$ \\
& & & & & \\
Activos intangibles & $-1,000$ & 4 & $59.06 \%$ & $-1,693$ & $-3,025$ \\
Software y antivirus & $-2,000$ & 20 & $918.03 \%$ & -218 & -389 \\
Autorizaciones y licencias & & & & & $\mathbf{- 3 4 3 , 0 9 3}$ \\
\hline Total & & & & &
\end{tabular}




\section{Anexo $\mathrm{N}^{\circ} 12$ - Imágenes de línea de productos} SF Hermanos

\section{1.- MUEBLES PARA EL HOGAR}

PARRILLAS
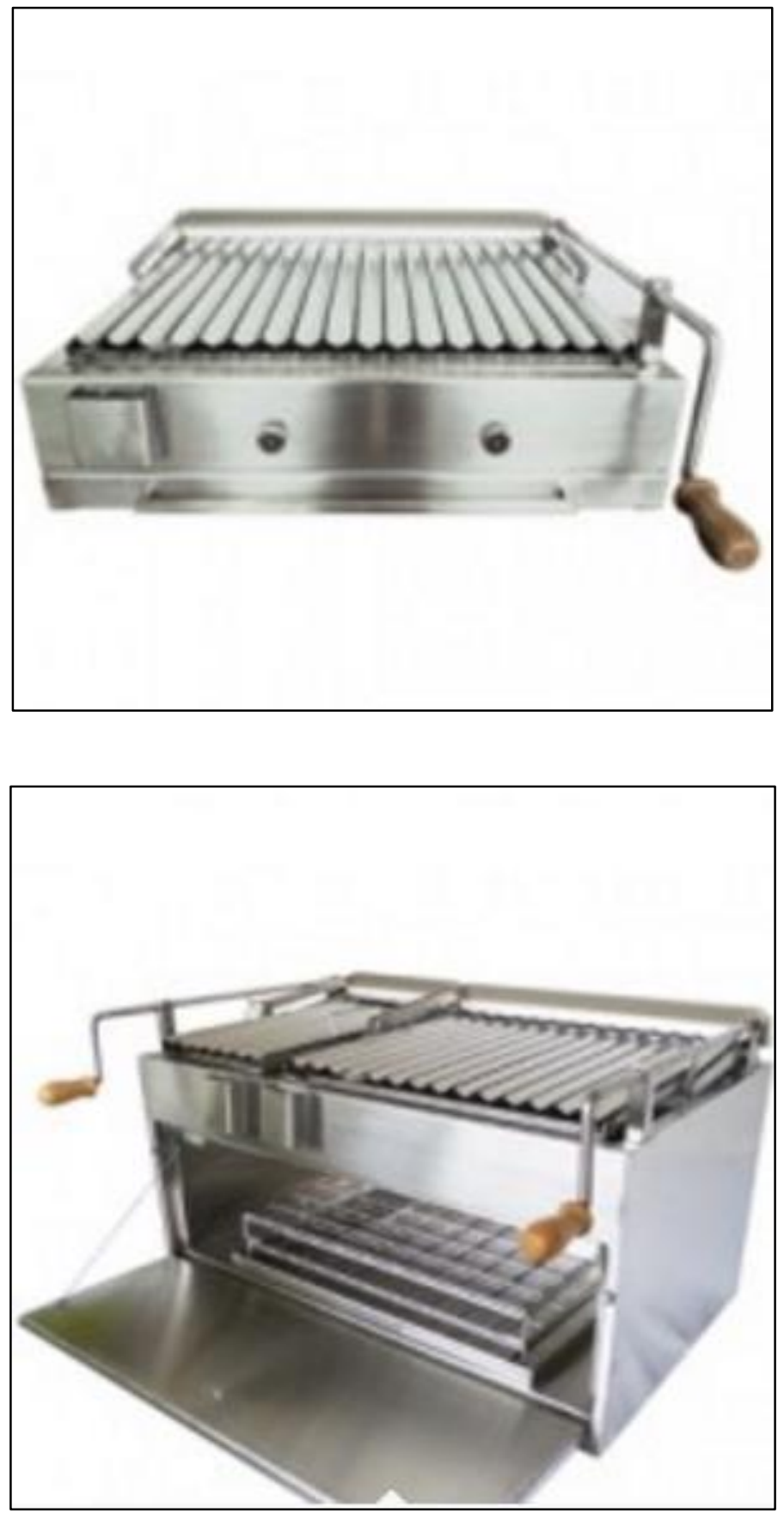
ACCESORIOS PARA LA PARRILLA
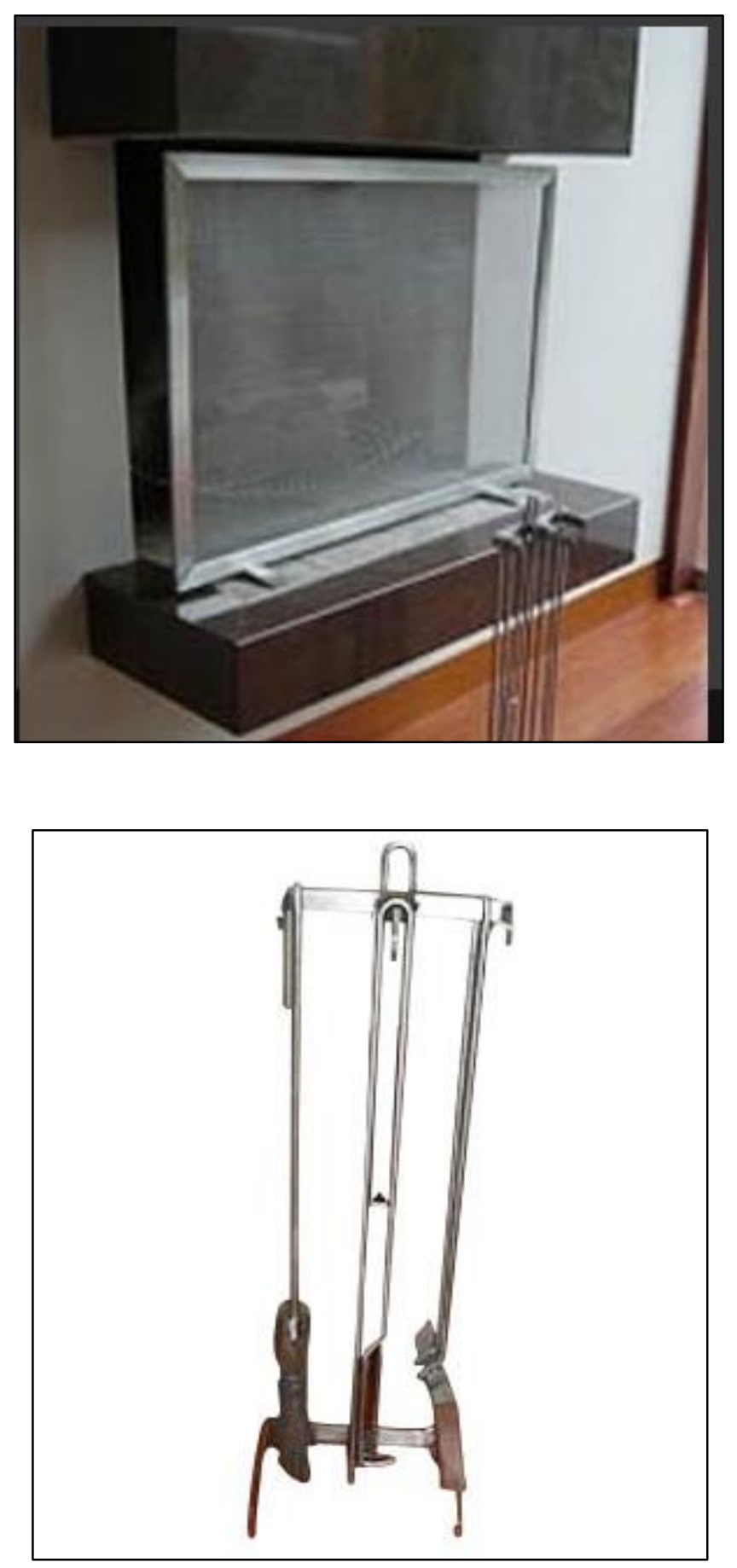


\section{BARES}
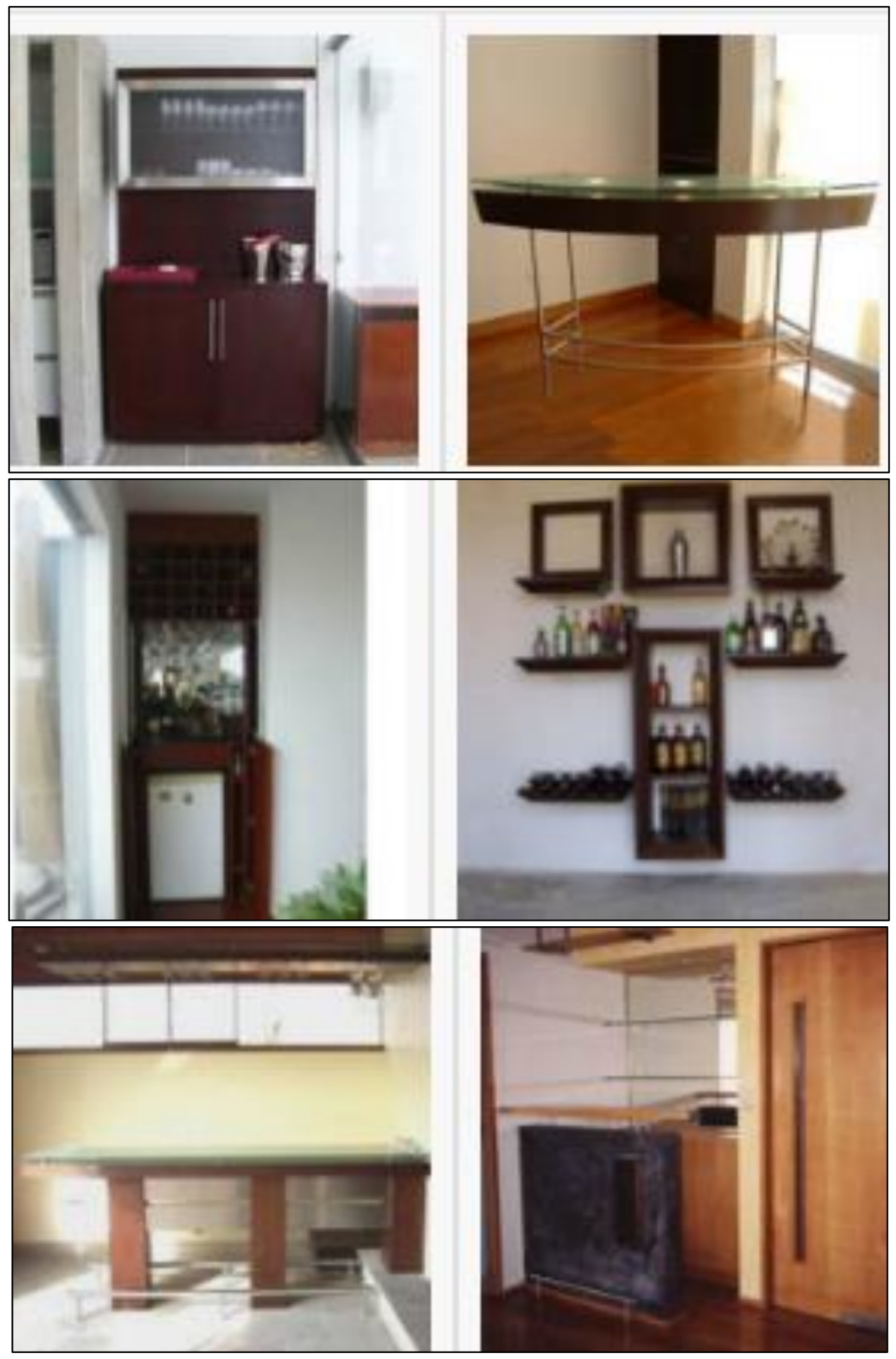


\section{COCINAS}
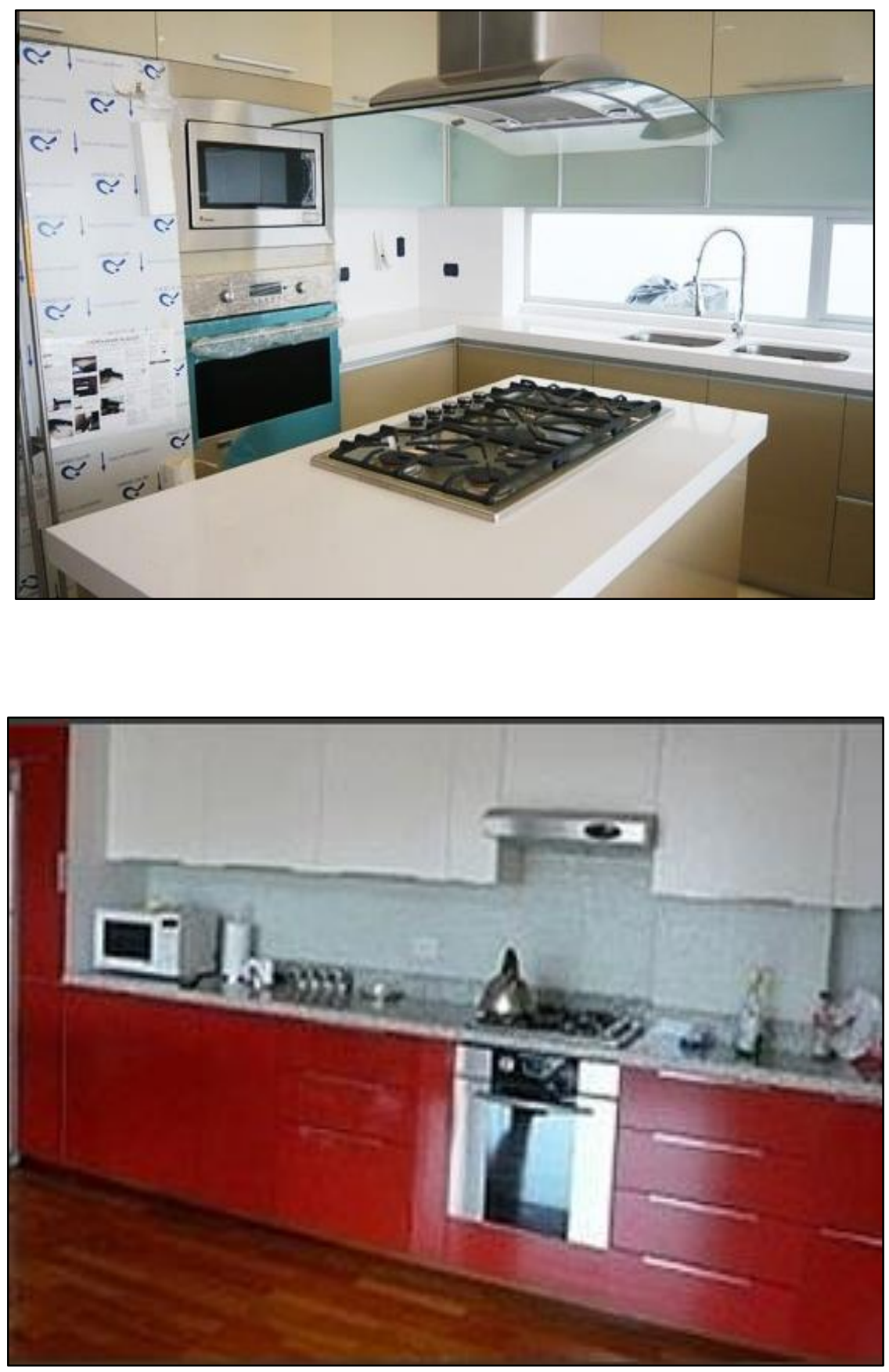


\section{COMEDORES}

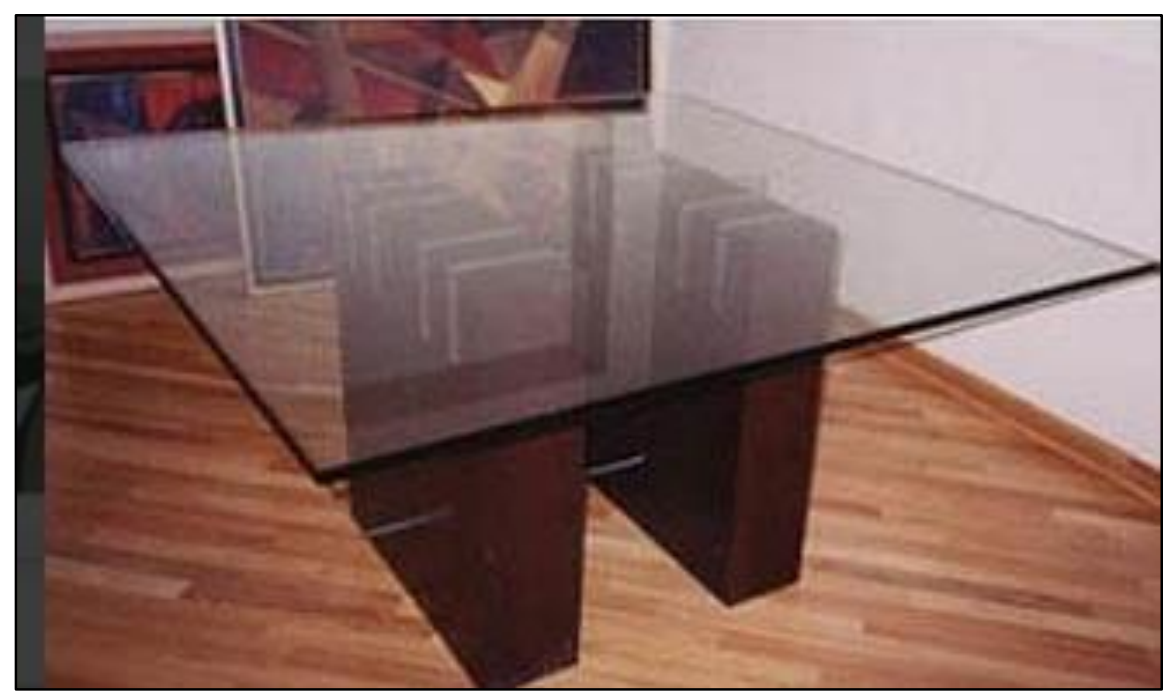

DORMITORIOS

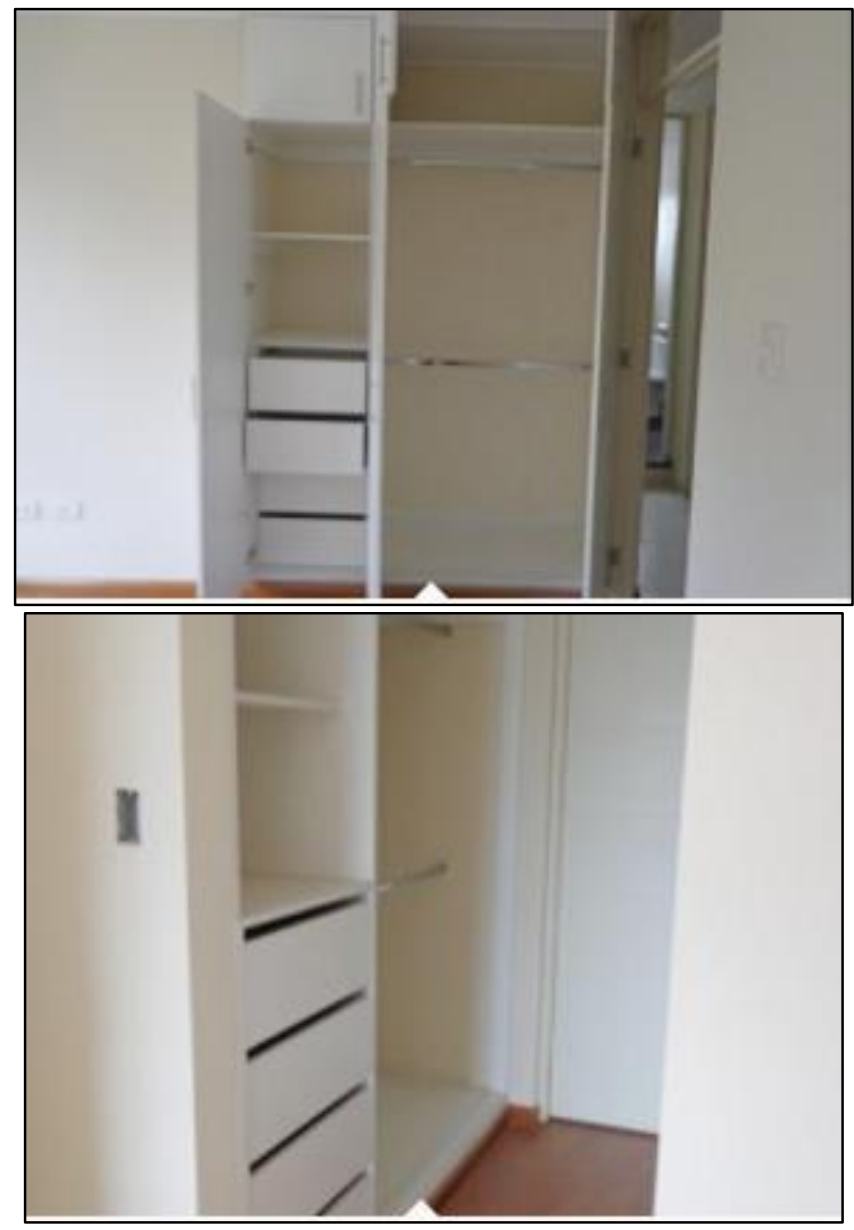




\section{BAÑOS}

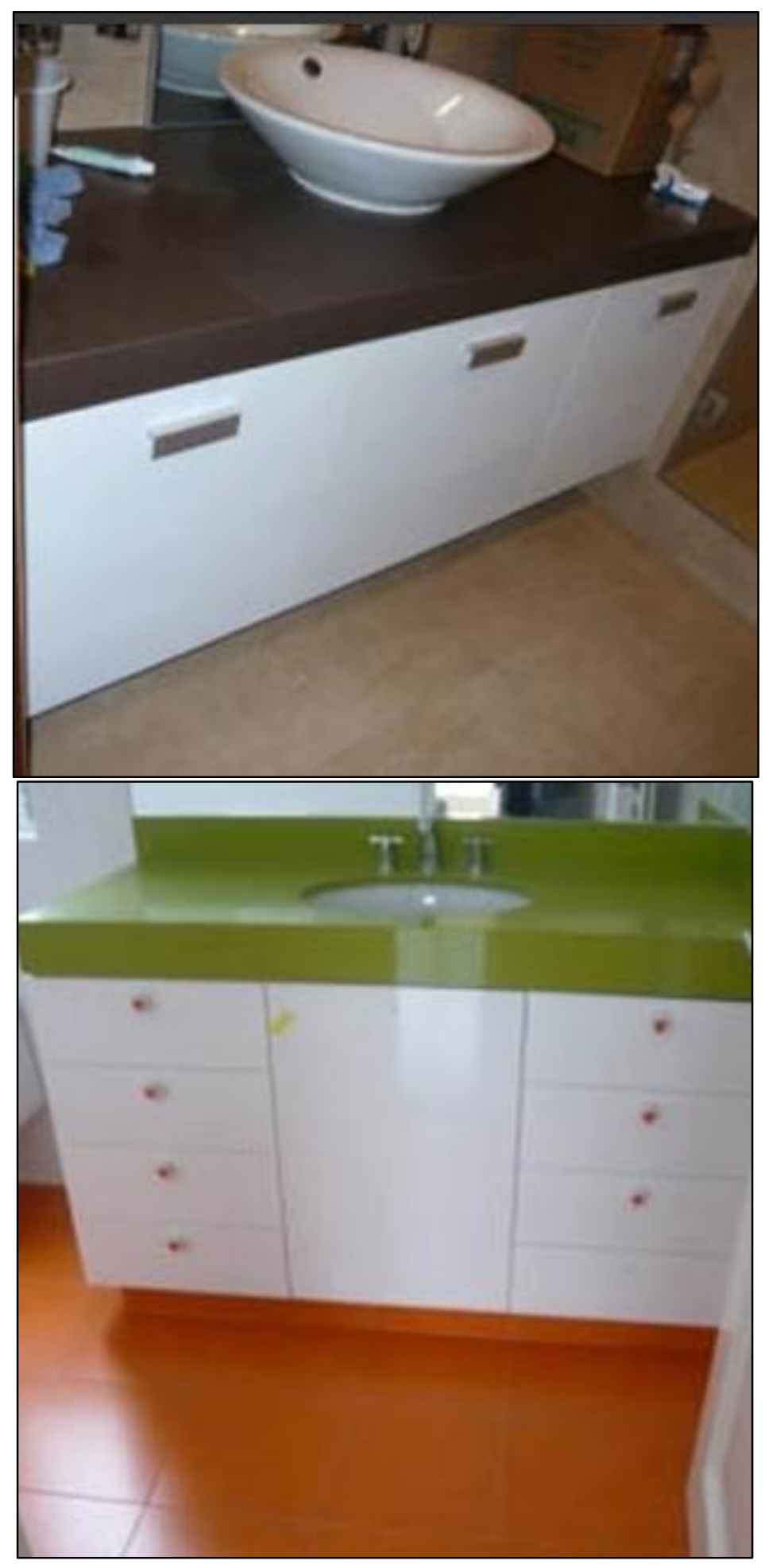




\section{SALAS}
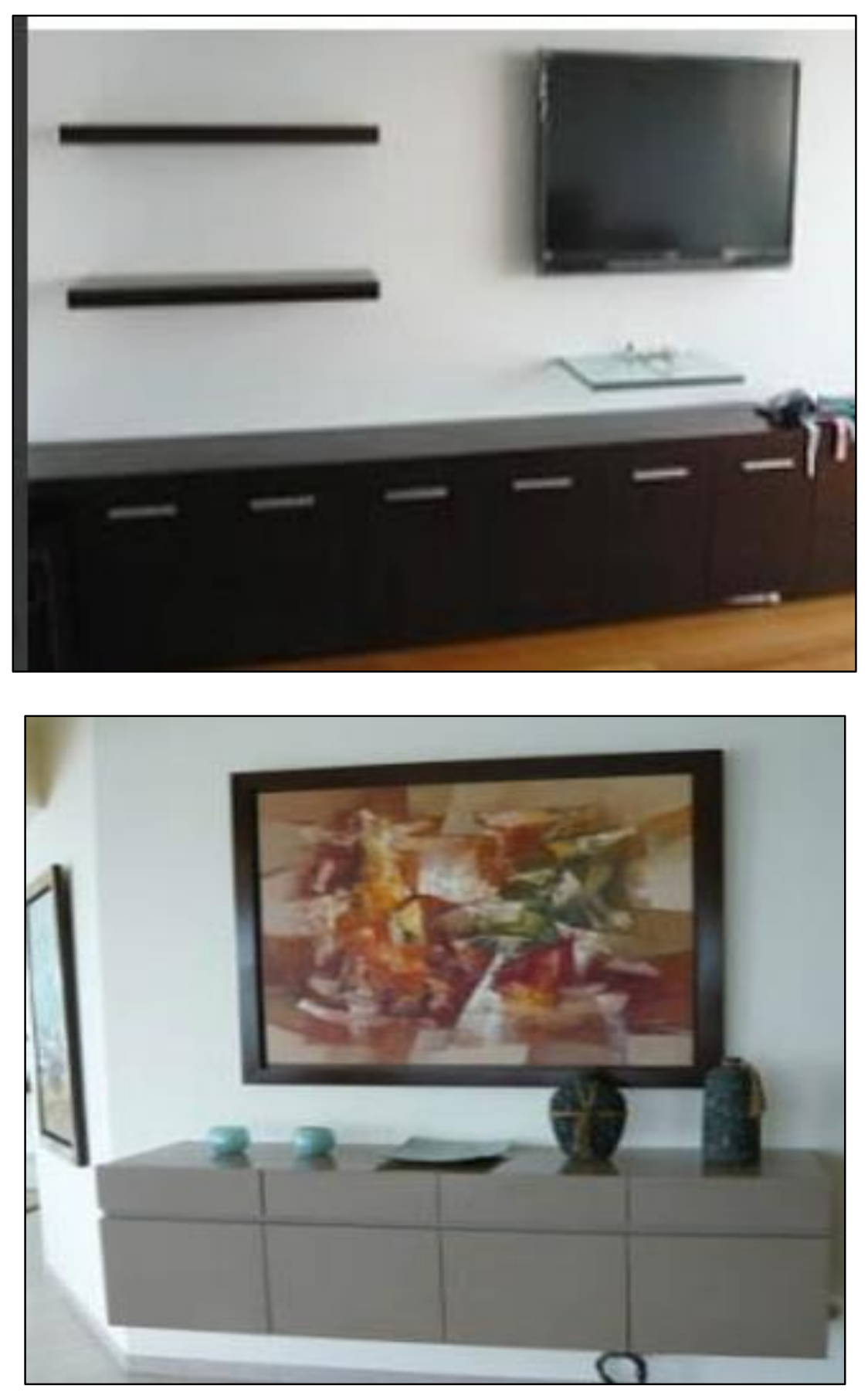


\section{TERRAZAS}
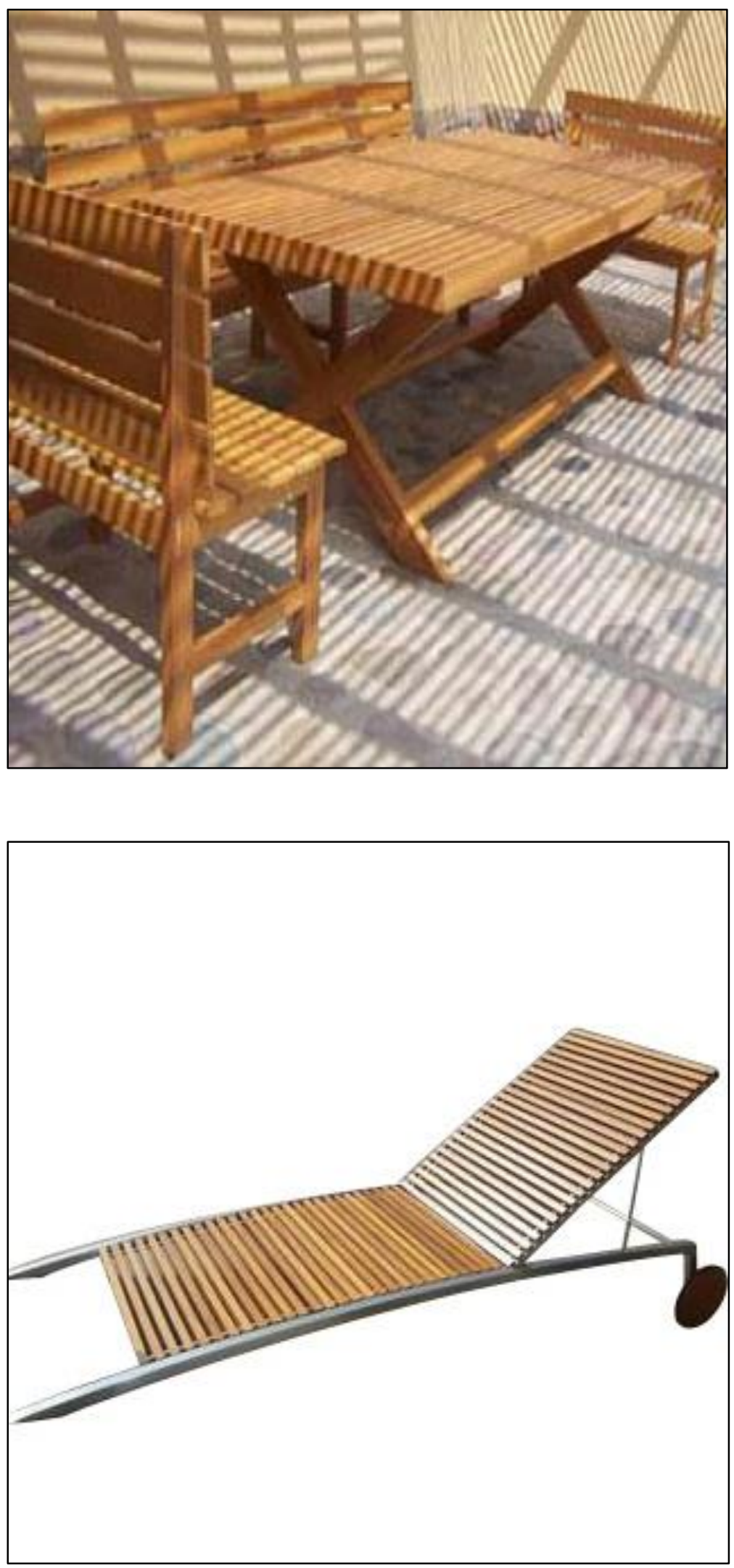


\section{2.- MUEBLES PARA OFICINA}

ARMARIOS
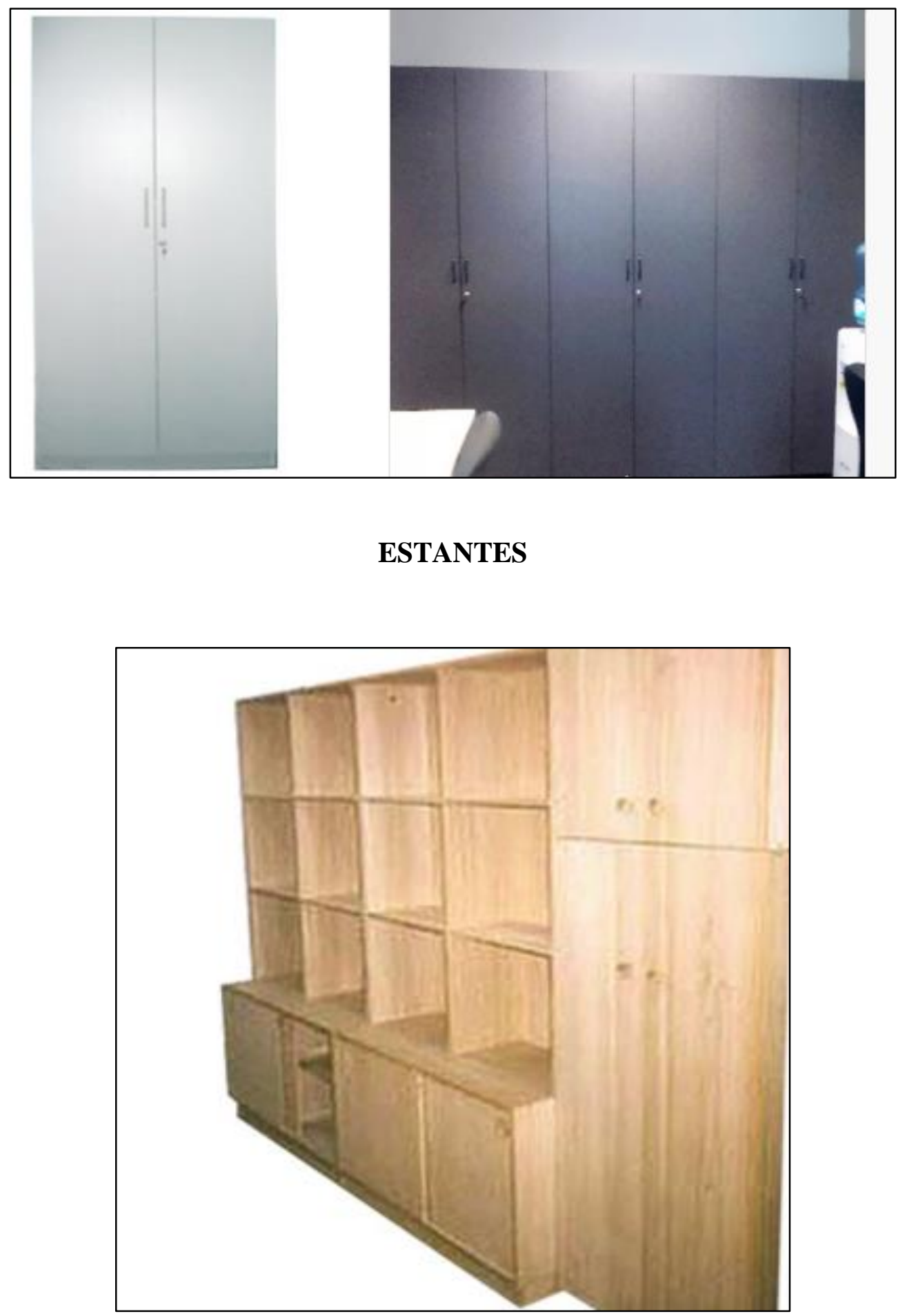


\section{ESCRITORIOS}
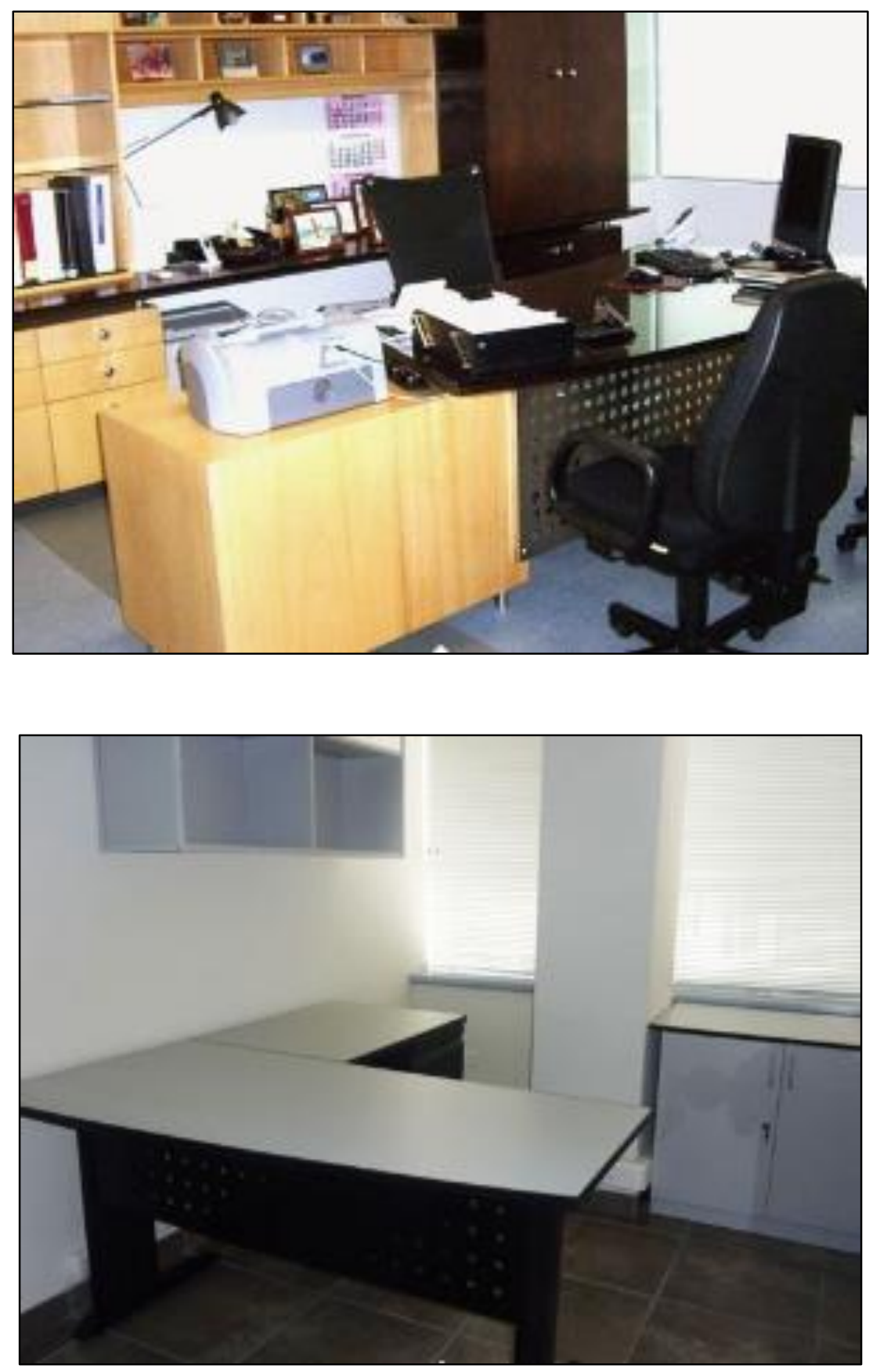


\section{MUEBLES COMPLEMENTARIOS}
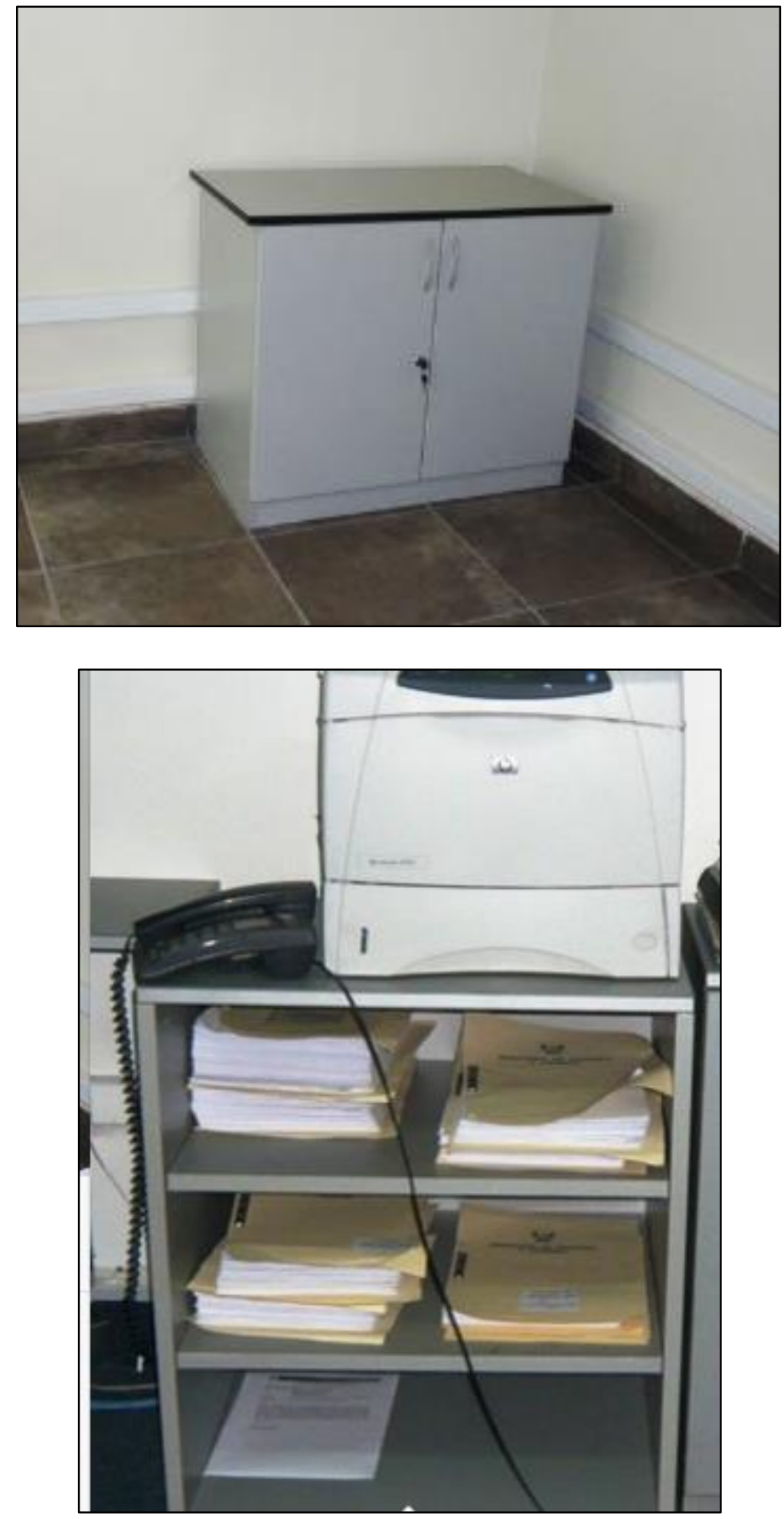


\section{3.- MUEBLES COMERCIALES}

COUNTERS

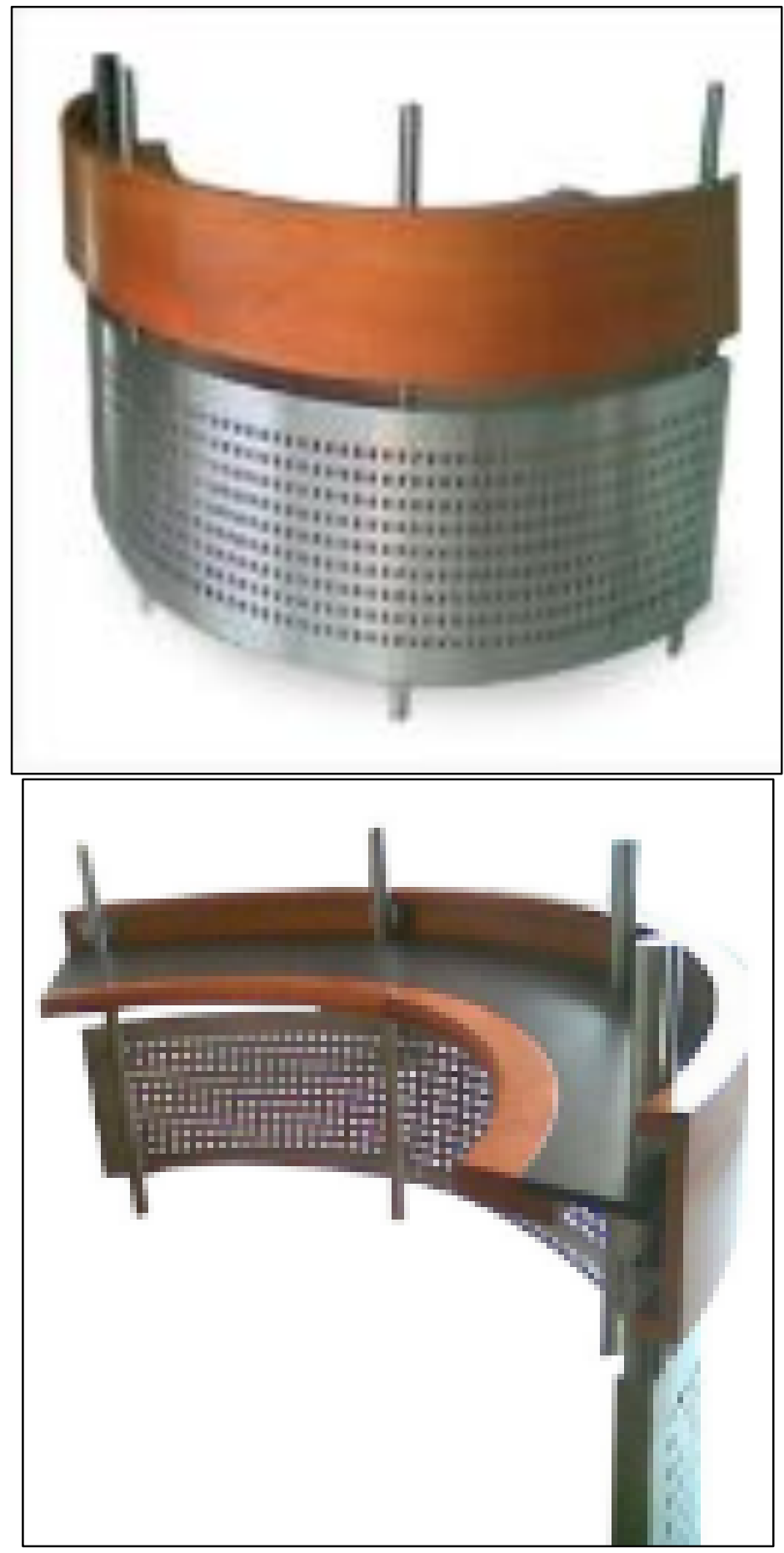


GANDOLAS

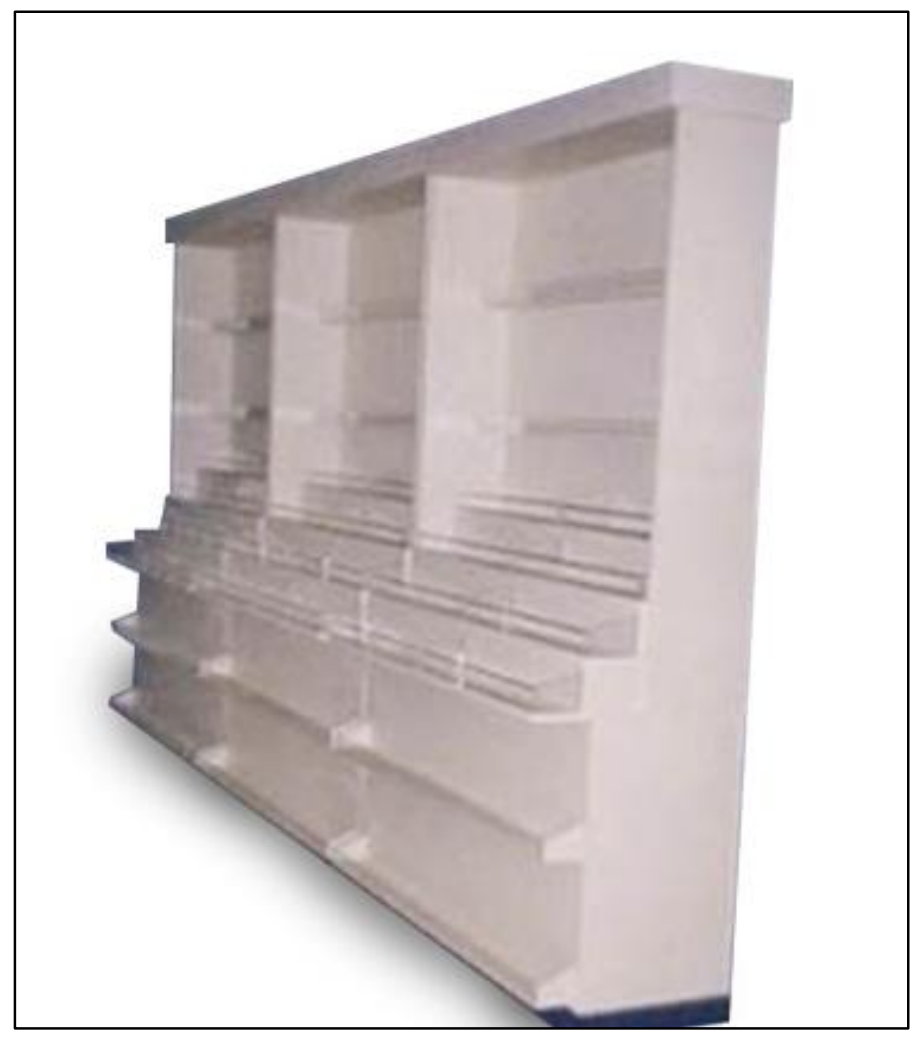

MESAS

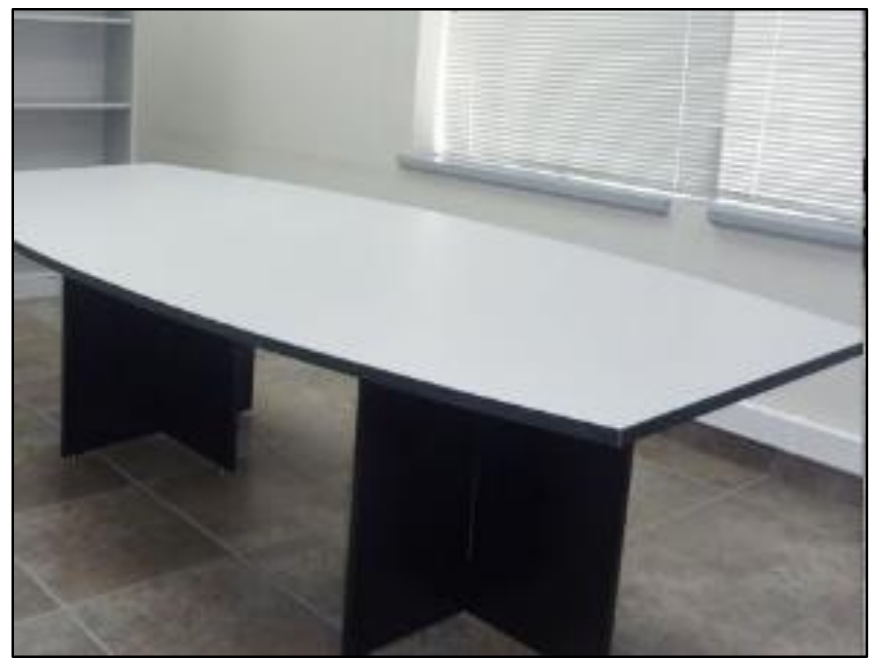


AMOBLAMIENTO

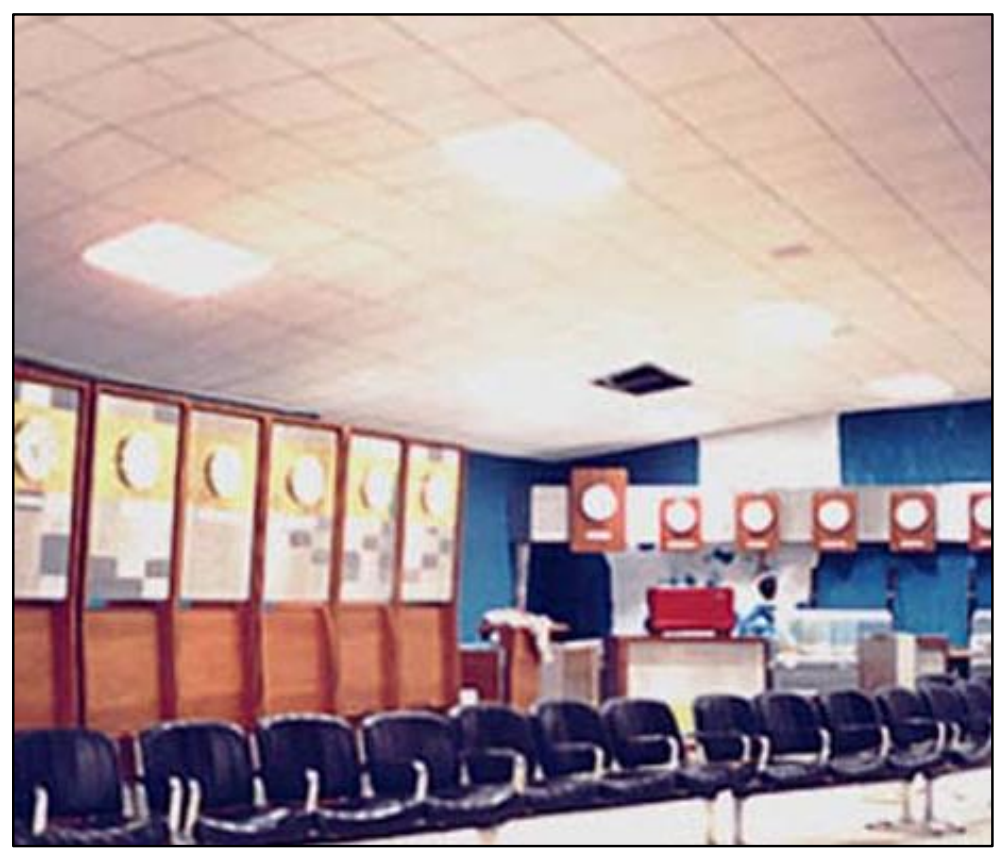

MÓDULOS

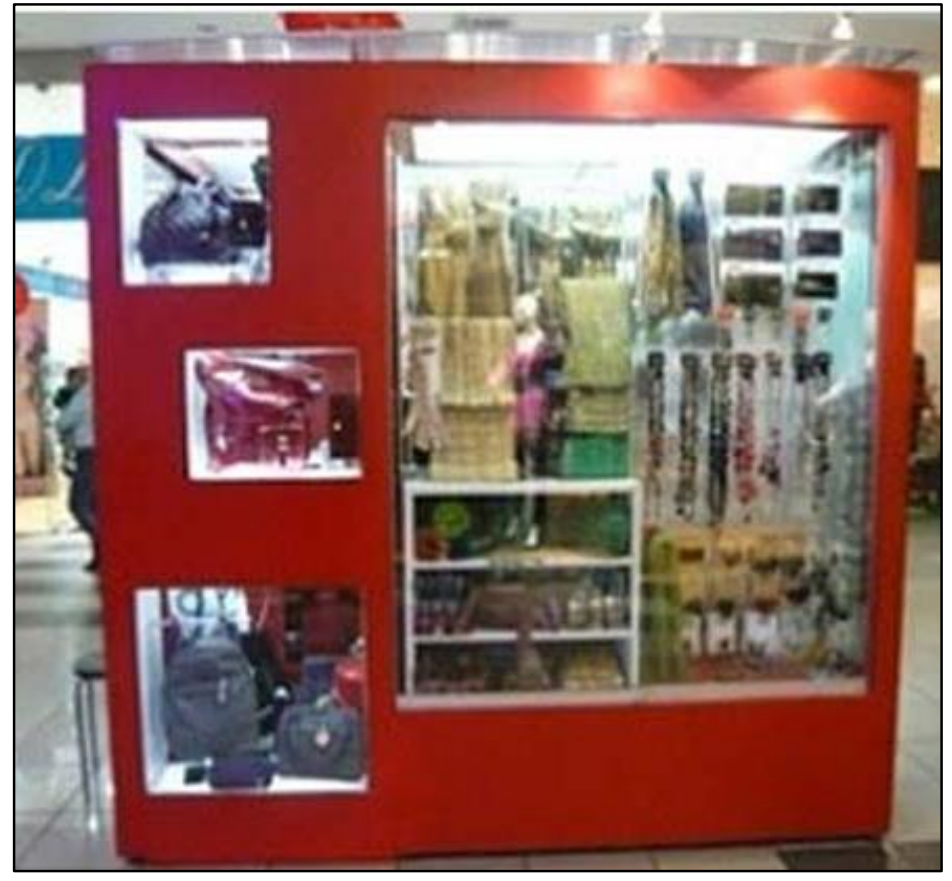




\section{4.- CARPINTERÍA EN OBRA}

ESCALERA
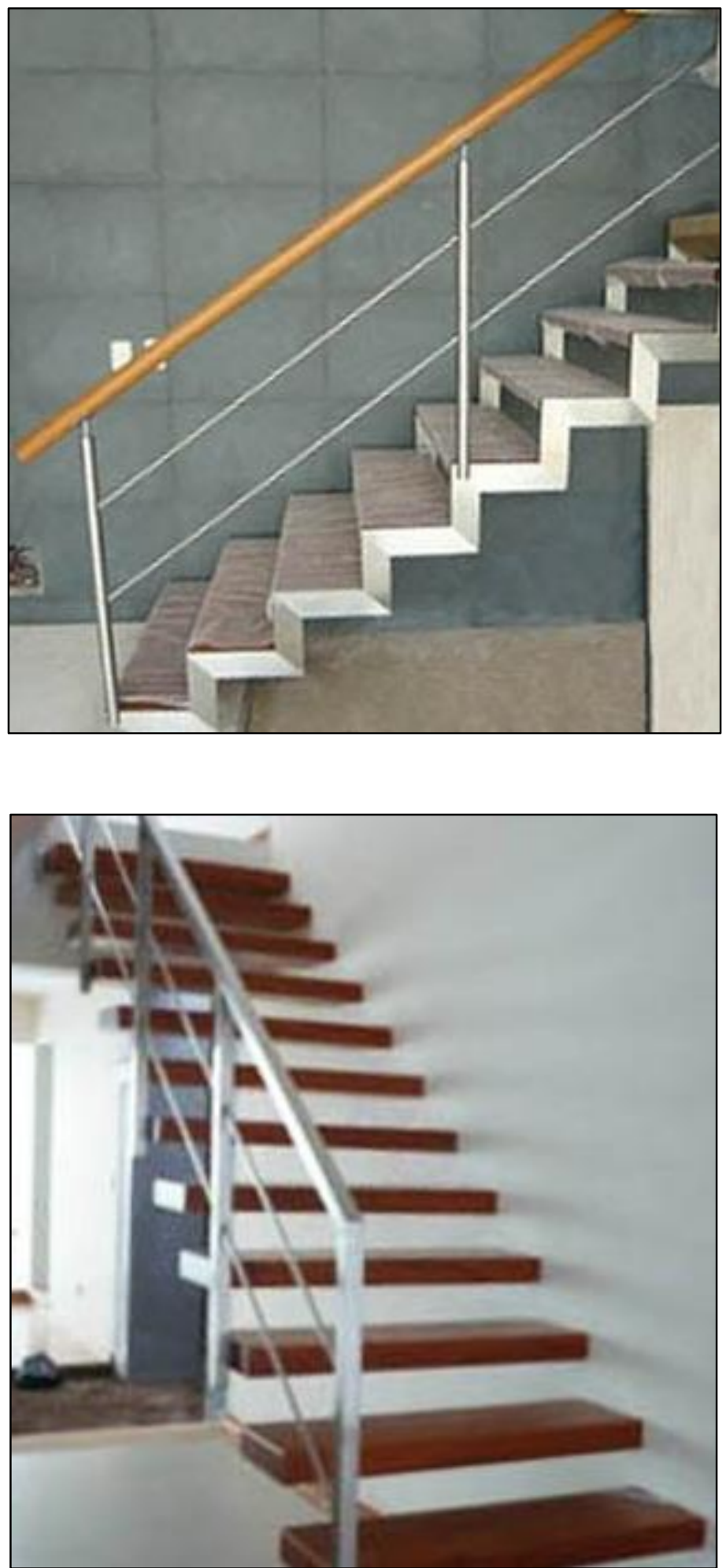
BARANDAS
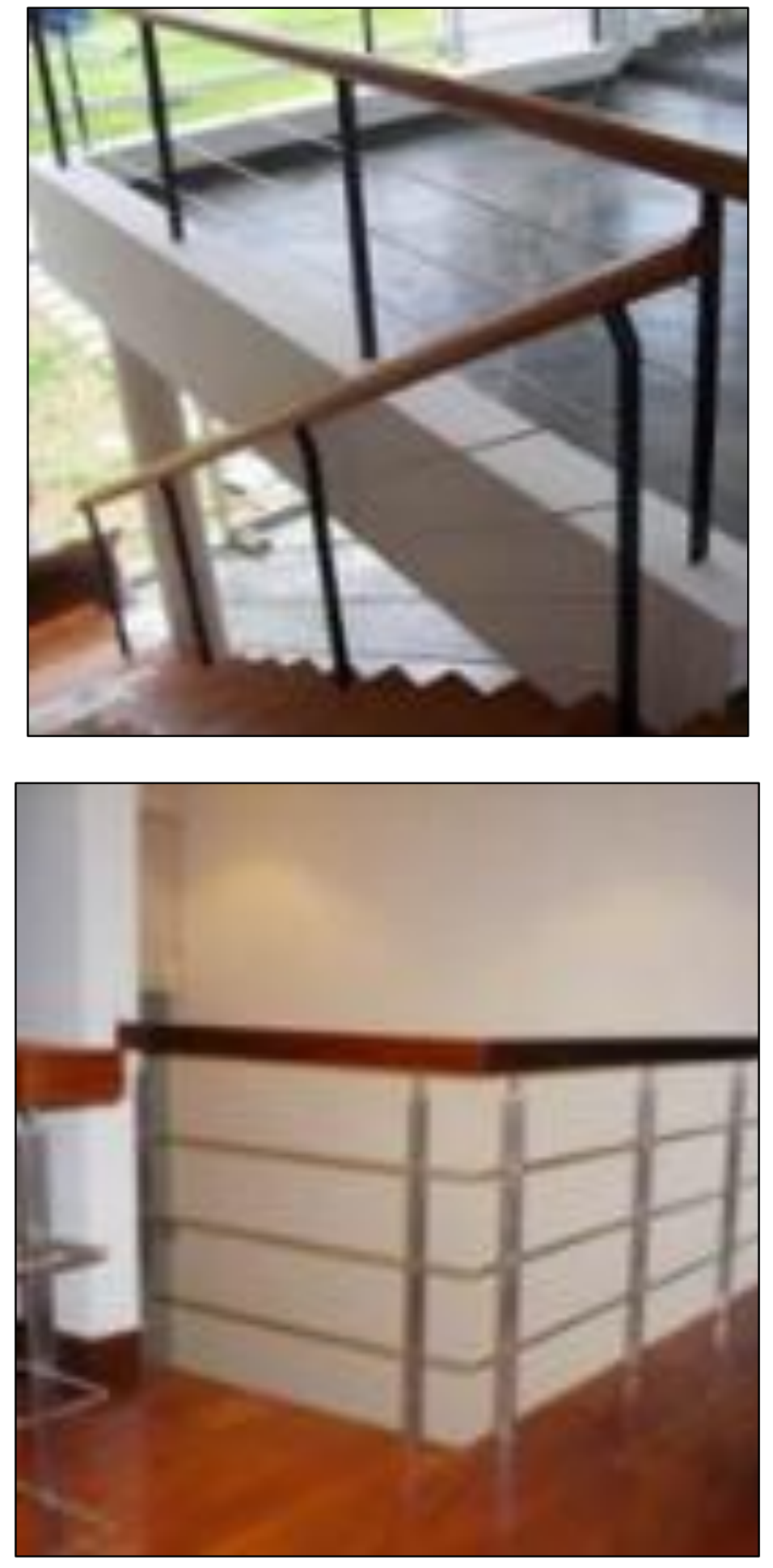
PUERTAS Y PORTONES
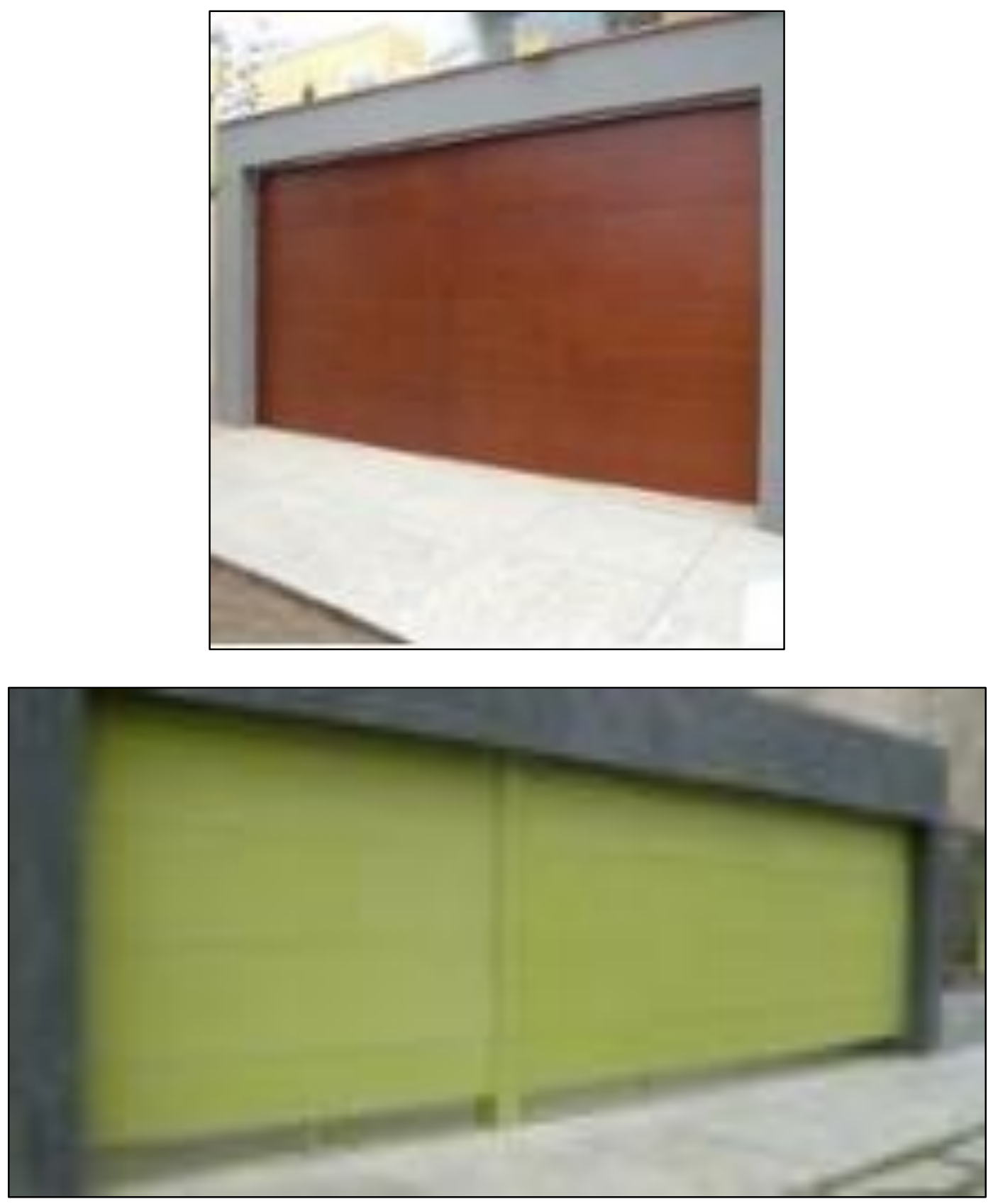
TECHOS Y ENCHAPADOS
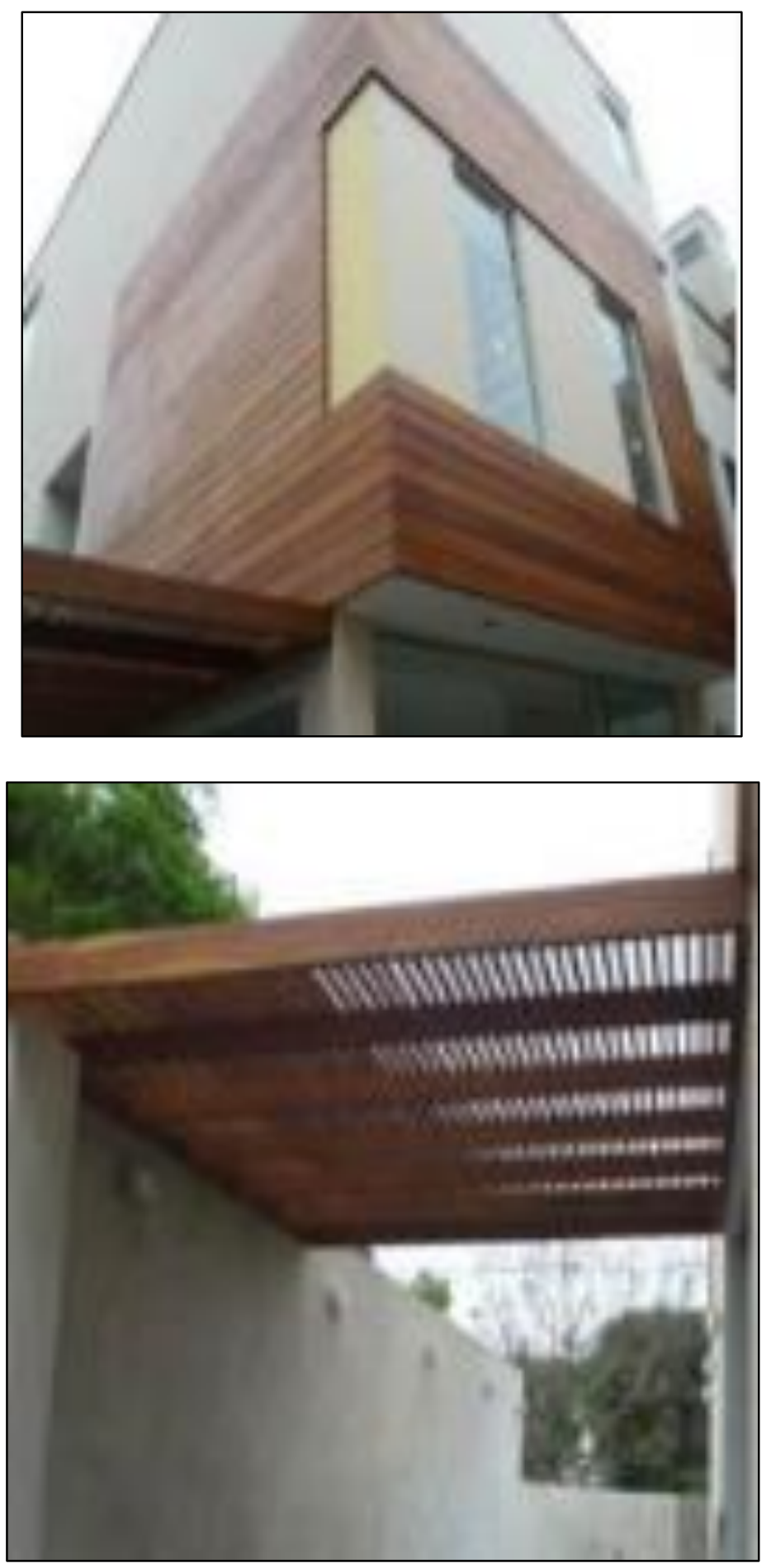


\section{ELEVADORES PARA DISCAPACITADOS}
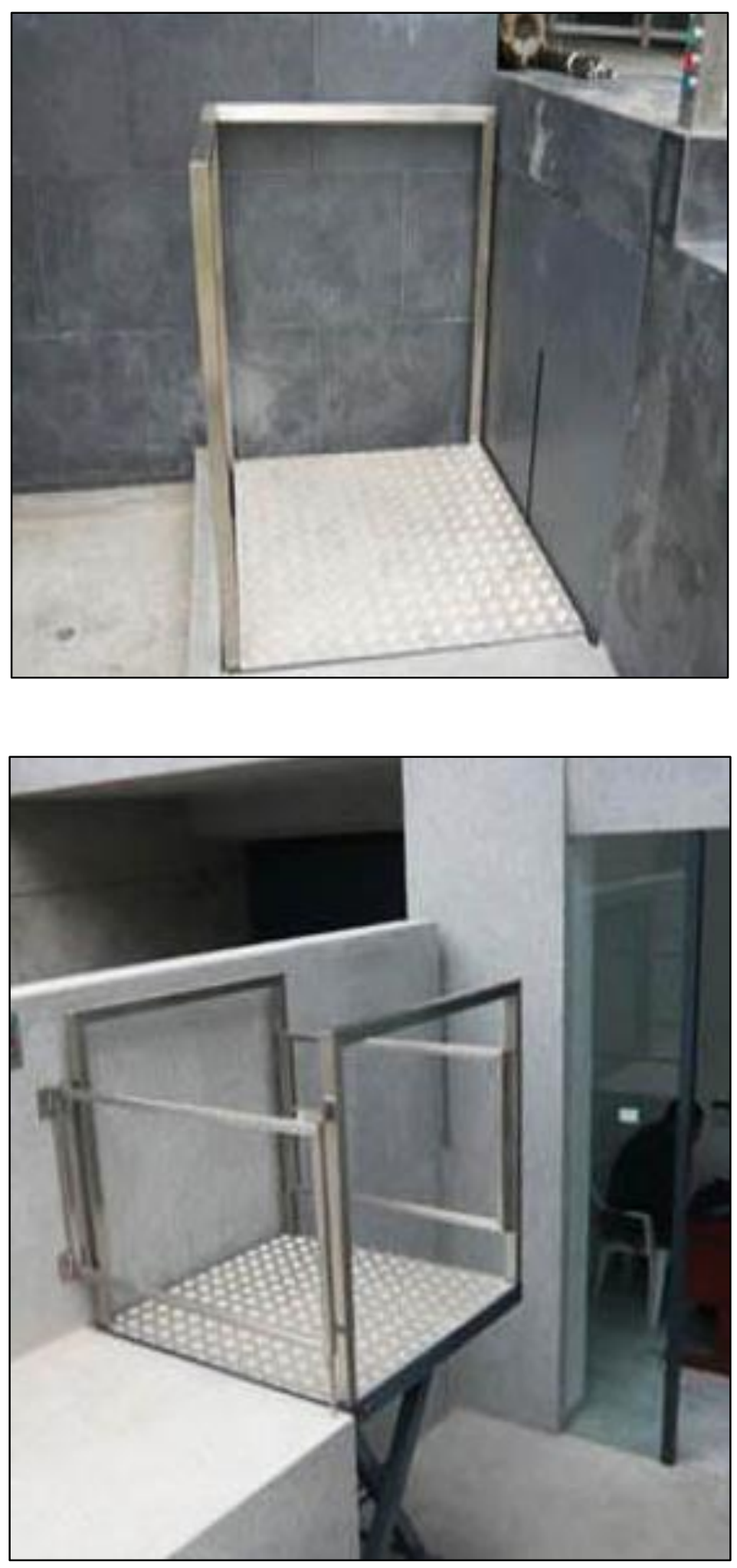


\section{Anexo $N^{\circ} 13$ - Encuestas de Campo}

\section{$\underline{\text { Cuestionario }}$}

Instrucciones: Un cordial saludo y gracias por participar en nuestra encuesta. Estamos realizando un trabajo de investigación acerca de la preferencia de dulces y postres. Por tanto agradecemos responda con total sinceridad a las preguntas a formular. Muchas gracias.

\section{I.- Pregunta filtro y perfil}

P1) ¿Tiene vivienda propia?
a) $\mathrm{Si}$
b) No (fin de la encuesta)

P2) ¿Qué tipo de vivienda ocupa?
a) Casa independiente
b) Departamento en edificio
c) Casa en condominio
d) Casa en quinta (fin de la encuesta)
e) Otros (fin de la encuesta)

P3) ¿En cuánto estima su ingreso familiar al mes?
a) Menos a S/ 4815 (fin de la encuesta)
b) Mayor a S/. 4815 a S/. 7800
c) Mayor a S/. 7800

P4) Género
a) Masculino
b) Femenino

P5) ¿Cuántos años tiene?
a) Menos de 25 años
b) De 25 a 29 años
c) De 30 a 34 años
d) De 35 a 39 años
e) De 40 a 44 años
f) De 45 a 50 años
g) Más de 50 años

P6) ¿Cuántos miembros son en su familia?
a) 2 personas
b) 3 personas
c) 4 personas
d) 5 personas
e) 6 personas
f) Más de 6 personas

\section{II.- Perfil de consumidor}

P7) ¿Considera remodelar alguno de sus ambientes en el corto o mediano plazo?
a) $\mathrm{Si}$
b) No (fin de la encuesta)

P8) ¿Considera contratar una empresa para que se encargue de dicho servicio?
a) $\mathrm{Si}$
b) No (fin de la encuesta)

P9) Si tiene casa ¿Cuánto gasta aproximadamente en una remodelación?
a) Menos de $\mathrm{S} / 5000$
b) De S/ 5000 a S/ 6500
c) De $S / 6500$ a $S / 16500$
d) $\mathrm{De} S / 16500$ a S/ 20000
e) Más de S/ 20000

P10) Si tiene departamento ¿Cuánto gasta aproximadamente en una remodelación?
a) Menos de $\mathrm{S} / 5000$
b) De $S / 5000$ a S/ 6500
c) De $S / 6500$ a $S / 16500$
d) $\mathrm{De} \mathrm{S} / 16500$ a S/ 20000
e) Más de S/ 20000

P11) Mayormente ¿Qué tipo de material usa normalmente en sus trabajos de remodelación?
a) Melamine
b) Madera
c) Metal
d) Vidrio
e) Otros

P12) ¿Cada cuánto tiempo la realiza?
a) 2 veces al año o más
b) 1 vez al año
c) Cada 2 años
d) Cada 3 años
e) Cada 4 años
f) Cada 5 años 
P13) ¿En qué mes del año le es conveniente renovar?
a) Enero - Marzo
b) Abril - Junio
c) Julio - Setiembre
d) Octubre - Diciembre

P14) ¿Qué opciones de proveedores maneja para remodelar sus interiores?
a) Sodimac - Maestro
b) Decor center.
c) Saga - Ripley
d) PROMART
e) Ferrini
f) Canziani
g) Parque Villa El Salvador
h) Mercado Unicachi
i) Maestros independientes
j) Otros

\section{III.- Validación de producto}

"RENUEVATE es un servicio de diseño, optimización y remodelación de espacios a medida que se pondrá a disponibilidad de las familias que deseen mejorar o remodelar sus espacios internos. Se tendrá a disposición un servicio de pre diseño digital para que las personas sepan cómo van a quedar sus espacios al final del servicio, asimismo se tendrá mano de obra calificada y garantía sobre los muebles y espacios diseñados, de tal manera que se logre la idoneidad del servicio y la satisfacción del cliente. Las propuestas se adaptarán al presupuesto del cliente y se podrán financiar a 120, 180 y 240 días sin intereses.

P15) ¿Estaría dispuesto a solicitar los servicios de "RENUEVATE"?
a) Definitivamente si
b) $\mathrm{Si}$
c) Indiferente
d) No
e) Definitivamente no

P16) ¿Con que frecuencia lo realizaría?
a) $1 \mathrm{vez}$ al año
b) 1 vez cada 2 años
c) 1 vez cada 3 años
d) 1 vez cada 4 años
e) 1 vez cada 5 años

P17) ¿Qué tipo de vivienda renovaría?
a) Casa propia
b) Departamento

P18) En casa ¿Qué tipo de ambiente renovaría?
a) Habitaciones
b) Sala
c) Comedor
d) Zona de parrilla
e) Cocina
f) Otros

P19) En Dpto. ¿Qué tipo de ambiente renovaría?

a) Habitaciones

b) Sala-Comedor

c) Cocina

d) Otros

P20) ¿Cuánto gastaría en dicha renovación?

\begin{tabular}{|l|l|l|l|l|l|}
\hline & $\begin{array}{c}\text { Menos de } \\
\text { S/.5000 }\end{array}$ & $\begin{array}{c}\text { De S/.5000 a } \\
\text { S/.6500 }\end{array}$ & $\begin{array}{c}\text { De S/.6500 a } \\
\text { S/.16 500 }\end{array}$ & $\begin{array}{c}\text { De S/.16500 a } \\
\text { S/.20 000 }\end{array}$ & $\begin{array}{c}\text { Más de } \\
\text { S/.20 000 }\end{array}$ \\
\hline A.- Casa & & & & & \\
\hline Habitación & & & & & \\
\hline Sala & & & & & \\
\hline Comedor & & & & & \\
\hline Zona de Parrilla & & & & & \\
\hline Cocina & & & & & \\
\hline B.- Departamento & & & & & \\
\hline Habitaciones & & & & & \\
\hline Sala - comedor & & & & & \\
\hline Cocina & & & & & \\
\hline
\end{tabular}

P21) ¿Cómo lo pagaría?
a) $\mathrm{Al}$ contado
b) $\mathrm{Al}$ crédito

P22) Si accede al crédito de la empresa, ¿a cuántos días le parece adecuado?
a) A 120 días
b) A 180 días
c) A 240 días
d) A 360 días

P23) ¿Qué tipo de material solicitaría?
a) Melamine
b) Madera
c) Metal
Vidrio 
P24) ¿Qué opina de la Marca "RENUÉVATE"?
a) Muy Buena
b) Buena
c) Indiferente
d) Mala
e) Muy mala

P25) ¿A través de qué medio(s) le gustaría de las promociones, novedades o sorteos?
a) Revistas/Periódico
b) Volantes, impresos
c) Fan Page (Facebook)
d) Instagram
e) Página web
f) Radio
g) $\mathrm{TV}$
h) Otros

P26) ¿Qué servicios complementarios le gustaría aparte del diseño, la elaboración, la instalación y la garantía?
a) La reparación
b) El cambio de color
c) El reemplazo
d) Venta de accesorios complementarios
e) La capacitación para el mantenimiento
f) Otros 


\section{Anexo $N^{\circ} 14$ - Resultados de Cuestionario}

\section{Pregunta 1}

\begin{tabular}{|c|c|c|}
\hline \multicolumn{3}{|c|}{ 1) ¿Tiene vivienda propia? } \\
\hline Respuesta & Cantidad & \% \\
\hline $\mathrm{Si}$ & 408 & $75 \%$ \\
\hline No $^{*}$ & 136 & $25 \%$ \\
\hline Total & $\mathbf{5 4 4}$ & $\mathbf{1 0 0 \%}$ \\
\hline
\end{tabular}

* Fin de la encuesta

\section{P1) ¿Tiene vivienda propia?}

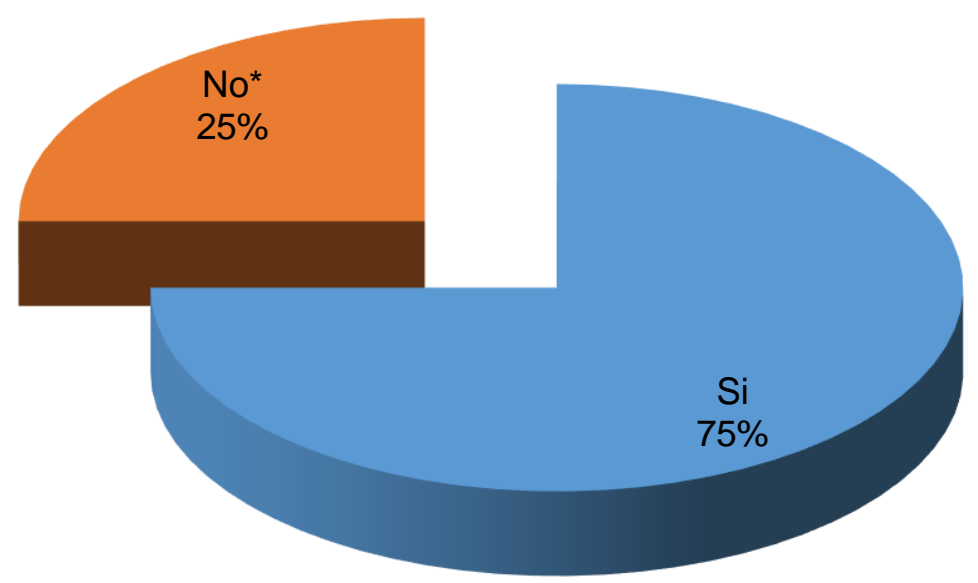

Interpretación: Del total de encuestados un 75\% tienen vivienda propia y un 25\% no cuentan con vivienda propia. 


\section{Pregunta 2}

\begin{tabular}{|l|c|c|}
\hline \multicolumn{2}{|c|}{ 2) ¿Qué tipo de vivienda ocupa? } \\
\hline \multicolumn{1}{|c|}{ Respuestas } & Cantidad & \% \\
\hline Casa independiente & 184 & $45 \%$ \\
\hline Departamento en edificio & 163 & $40 \%$ \\
\hline Casa en condominio & 49 & $12 \%$ \\
\hline Casa en quinta* & 4 & $1 \%$ \\
\hline Otros* & 8 & $2 \%$ \\
\hline \multicolumn{1}{|c|}{ Total } & $\mathbf{4 0 8}$ & $\mathbf{1 0 0 \%}$ \\
\hline
\end{tabular}

* Fin de la encuesta

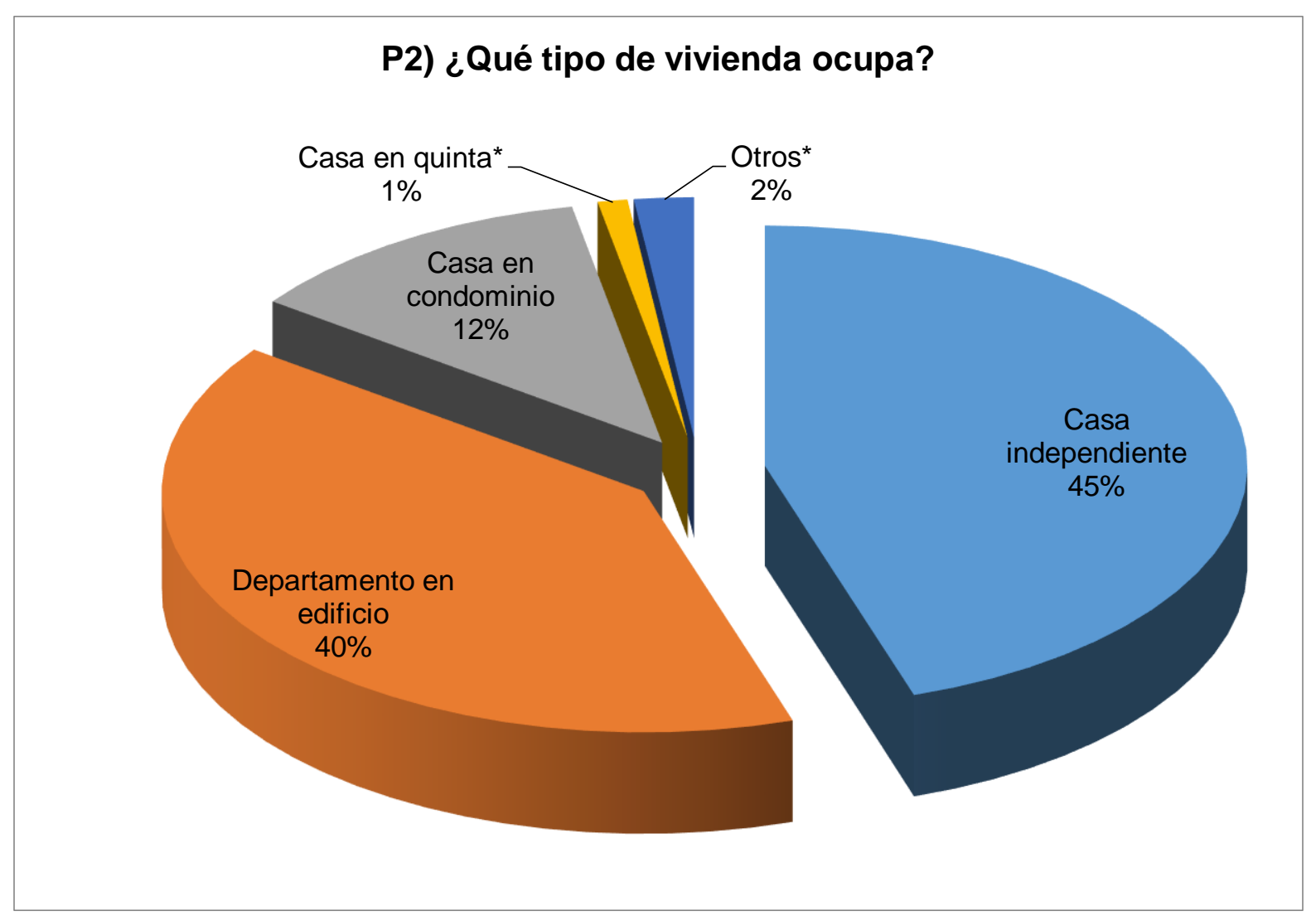

Interpretación: Del total de personas que cuentan con vivienda propia, un 45\% ocupa una casa independiente, un $40 \%$ ocupa un departamento en edificio, seguido de un $12 \%$ que ocupa una casa en condominio, un $1 \%$ ocupa casa en quinta y finalmente un $2 \%$ ocupa otro tipo de viviendas. 


\section{Pregunta 3}

\begin{tabular}{|c|c|c|}
\hline \multicolumn{3}{|c|}{ 3) ¿En cuánto estima su ingreso familiar al mes? } \\
\hline Respuestas & Cantidad & $\%$ \\
\hline Menos a S/. $4815^{*}$ & 12 & $3 \%$ \\
\hline Entre S/. 4815 a S/. 7800 & 257 & $65 \%$ \\
\hline Mayor a S/. 7800 & 127 & $32 \%$ \\
\hline Total & 396 & $100 \%$ \\
\hline
\end{tabular}

* Fin de la encuesta

\section{P3) ¿En cuánto estima su ingreso familiar al mes?}

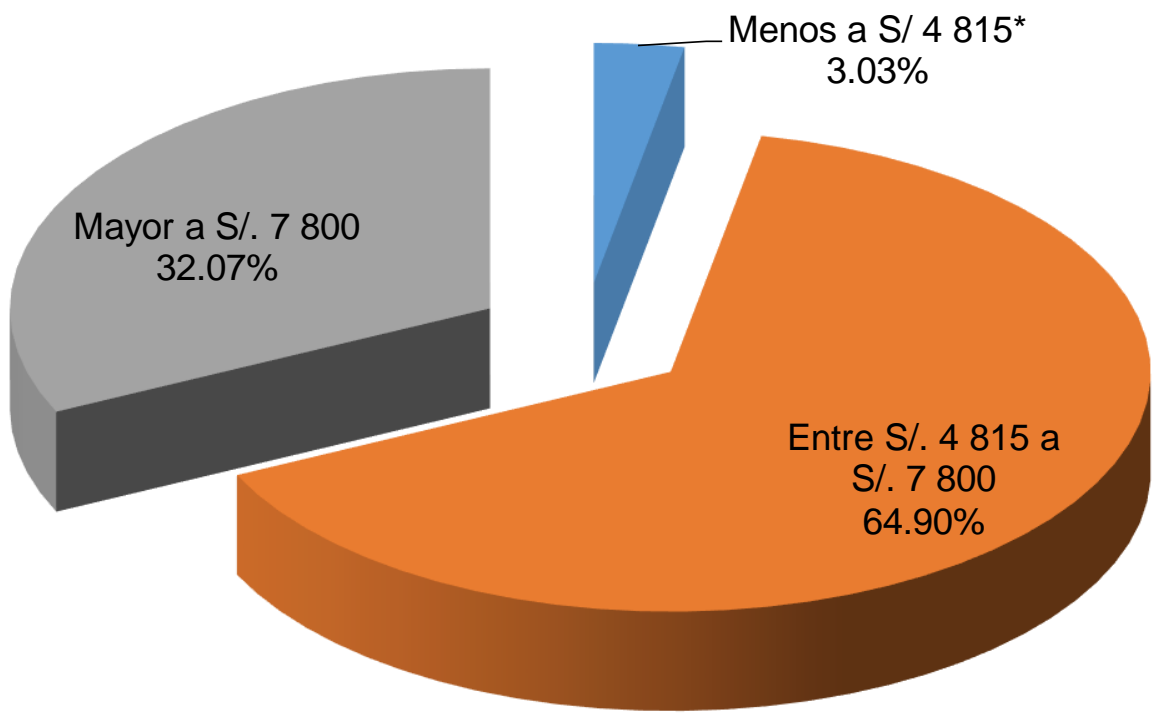

Interpretación: Del total de personas, un 3\% tiene ingresos familiares menores a S/. 4 815, el 65\% cuenta con un ingresos entre S/. 4815 y S/. 7800 y el 32\% cuenta con un ingreso mayor a S/. 7 800. 


\section{Pregunta 4}

\begin{tabular}{|cc|c|c|}
\hline \multicolumn{3}{|c|}{ 4) Género } \\
\hline Respuestas & Cantidad & \% \\
\hline Masculino & 184 & $48 \%$ \\
\hline Femenino & 200 & $52 \%$ \\
\hline \multicolumn{2}{|c|}{ Total } & $\mathbf{3 8 4}$ & $\mathbf{1 0 0 \%}$ \\
\hline
\end{tabular}

\section{P4) Género}
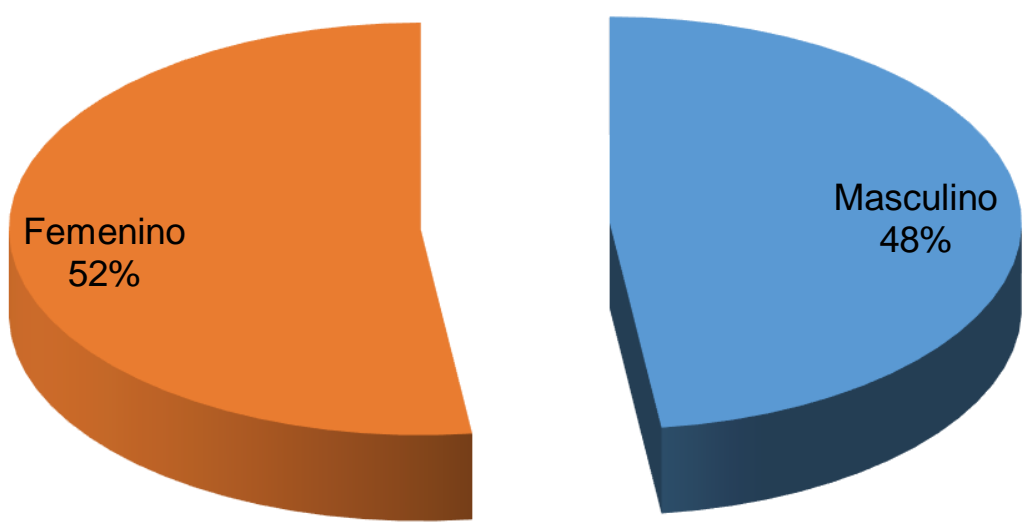

Interpretación: Del total de personas que cuentan con un ingreso mayor a S/. 4 815, el 48\% son varones y el $52 \%$ son mujeres. 


\section{$\underline{\text { Pregunta } 5}$}

\begin{tabular}{|c|c|c|}
\hline \multicolumn{3}{|c|}{ 5) ¿Cuántos años tiene? } \\
\hline Respuestas & Cantidad & $\%$ \\
\hline De 25 a 29 años & 38 & $10 \%$ \\
\hline De 30 a 34 años & 46 & $12 \%$ \\
\hline De 35 a 39 años & 119 & $31 \%$ \\
\hline De 40 a 44 años & 88 & $23 \%$ \\
\hline De 45 a 50 años & 69 & $18 \%$ \\
\hline De 50 a 55 años & 23 & $6 \%$ \\
\hline Total & 384 & $100 \%$ \\
\hline
\end{tabular}

\section{P5) ¿Cuántos años tiene?}

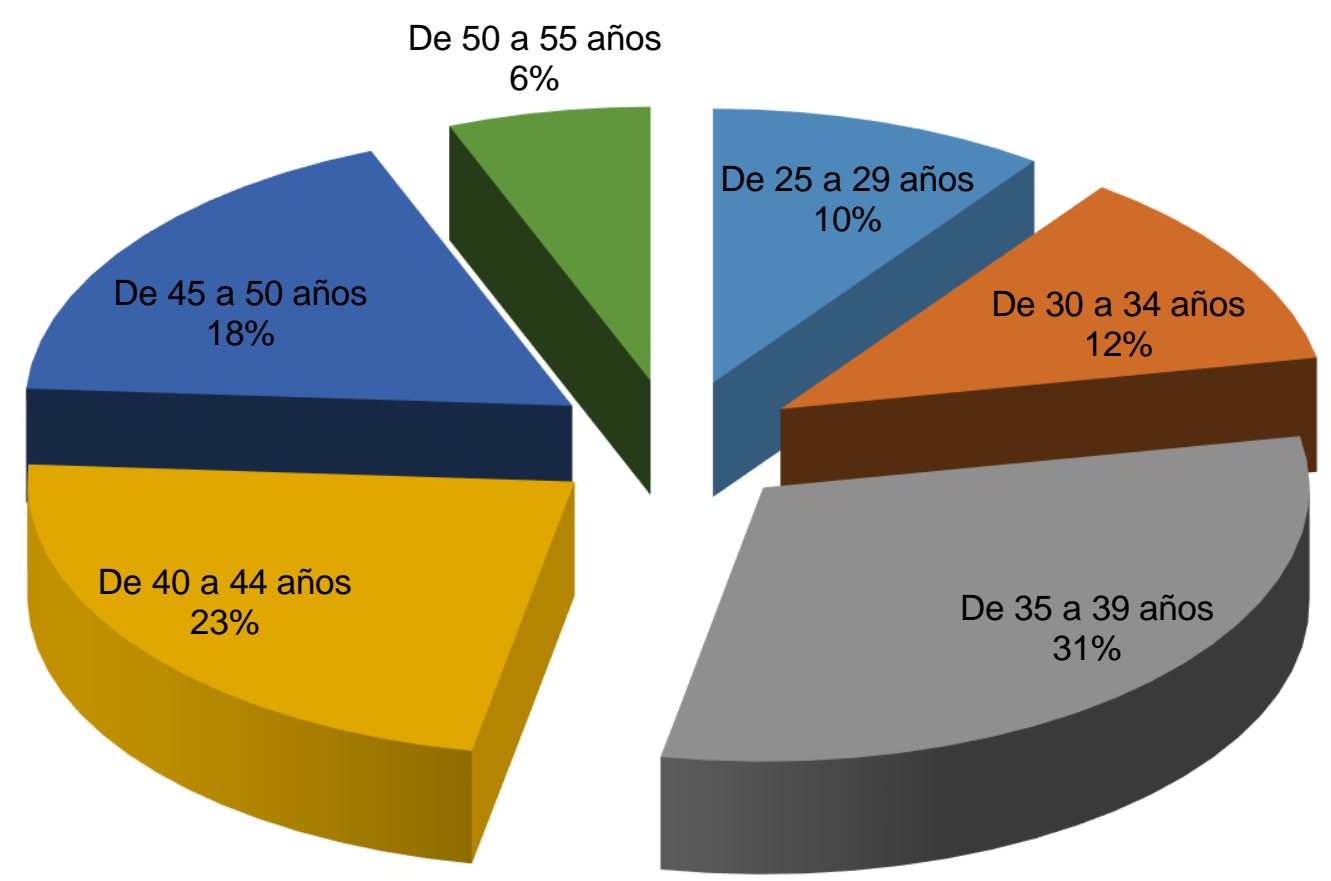

Interpretación: Del total de encuestados, el 10\% tiene entre 25 y 29 años de edad, el $12 \%$ tiene entre 30 y 34 años, un $31 \%$ oscila de 35 a 39 años, un $23 \%$ oscila de 40 a 44 años, un $18 \%$ de 45 a 49 años, y por último un $6 \%$ tiene más de 50 años. 


\section{$\underline{\text { Pregunta } 6}$}

\begin{tabular}{|c|c|c|}
\hline \multicolumn{3}{|c|}{ 6) ¿Cuántos miembros son en su familia? } \\
\hline Respuestas & Cantidad & $\%$ \\
\hline 2 personas & 31 & $8 \%$ \\
\hline 3 personas & 46 & $12 \%$ \\
\hline 4 personas & 223 & $58 \%$ \\
\hline 5 personas & 46 & $12 \%$ \\
\hline 6 personas & 23 & $6 \%$ \\
\hline Más de 6 personas & 15 & $4 \%$ \\
\hline Total & 384 & $100 \%$ \\
\hline
\end{tabular}

* Fin de la encuesta

\section{P6) ¿Cuántos miembros son en su familia?}

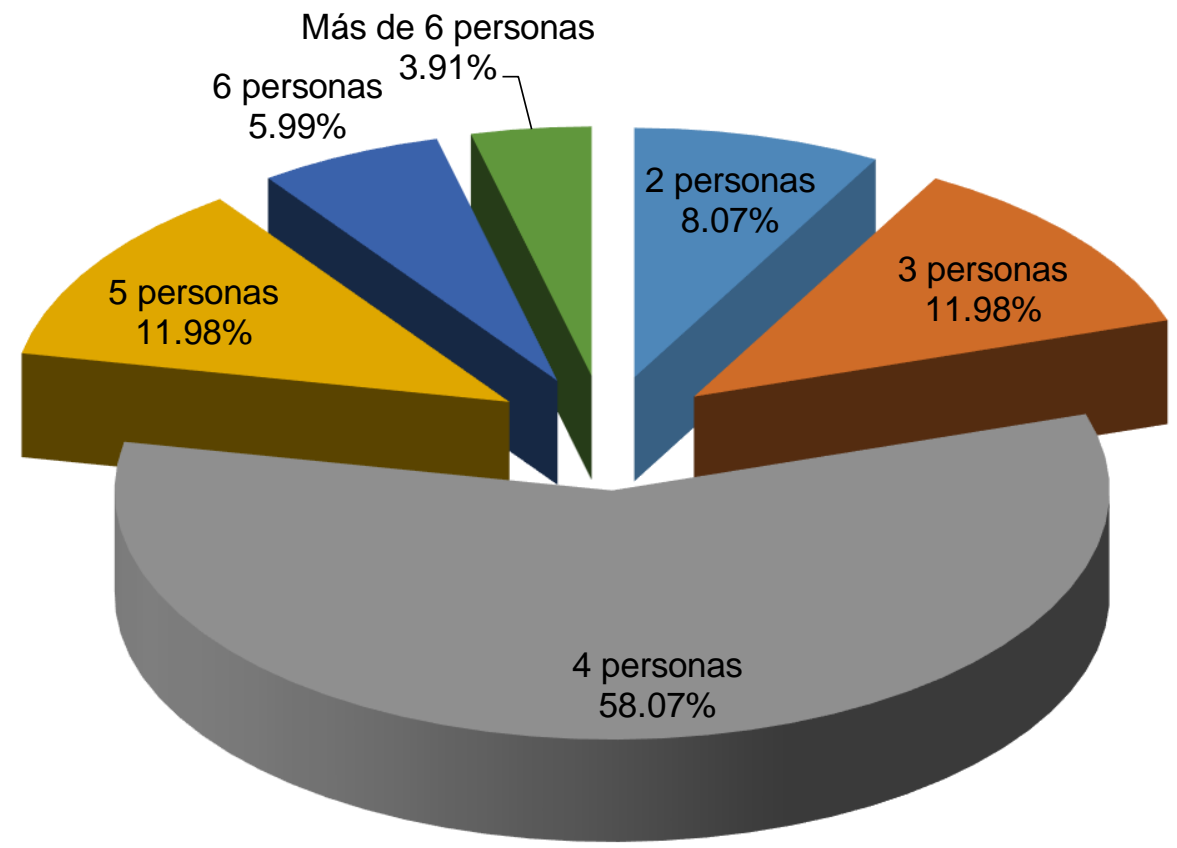

Interpretación: Del total de encuestados, el 8\% tiene 2 miembros en su familia, un 12\% tiene 3 miembros en su familia, el 58\% tiene 4 miembros en su familia, el 12\% tiene 5 miembros en su familia, el $6 \%$ tiene 6 miembros en su familia y por último el $4 \%$ tiene más de 6 personas como miembros en su familia. 


\section{Pregunta 7}

\begin{tabular}{|lc|c|c|}
\hline \multicolumn{3}{|c|}{$\begin{array}{c}\text { 7) ¿Considera remodelar alguno de sus ambientes en el corto o } \\
\text { mediano plazo? }\end{array}$} \\
\hline & Respuestas & Cantidad & \% \\
\hline $\mathrm{Si}$ & 284 & $74 \%$ \\
\hline $\mathrm{No}^{*}$ & 100 & $26 \%$ \\
\hline \multicolumn{2}{|c|}{ Total } & $\mathbf{3 8 4}$ & $\mathbf{1 0 0 \%}$ \\
\hline
\end{tabular}

* Fin de la encuesta

P7) ¿Considera remodelar alguno de sus ambientes en el corto o mediano plazo?

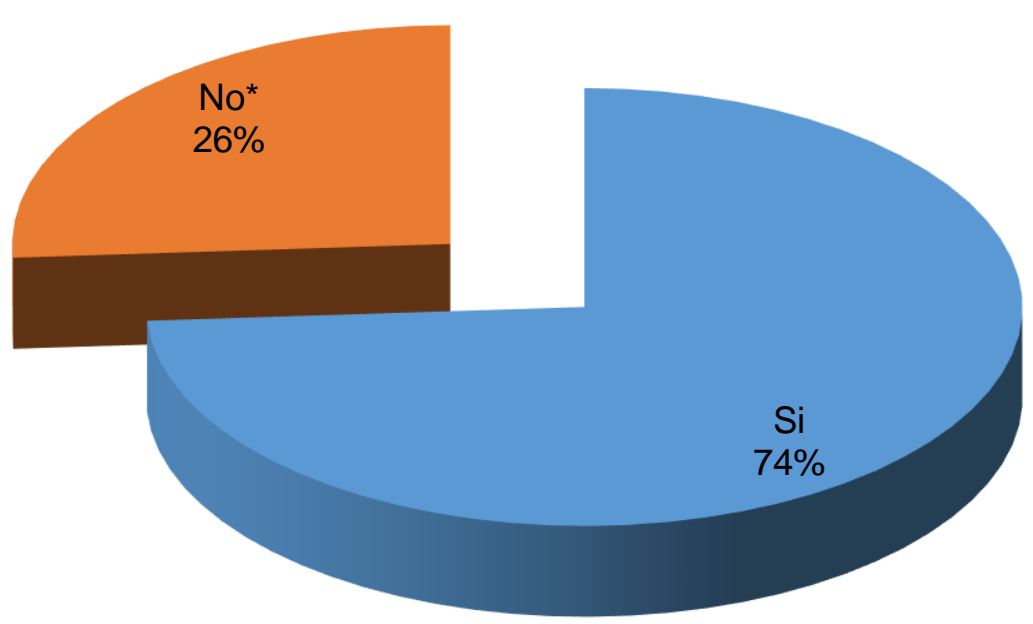

Interpretación: Del total del mercado, el 74\% considera remodelar alguno de sus ambientes en el corto o mediano plazo mientras que el $26 \%$ no lo está considerando. 


\section{Pregunta 8}

\begin{tabular}{|c|c|c|}
\hline \multicolumn{3}{|c|}{$\begin{array}{l}\text { 8) ¿Considera contratar una empresa para que se encargue de } \\
\text { dicho servicio? }\end{array}$} \\
\hline Respuestas & Cantidad & $\%$ \\
\hline $\mathrm{Si}$ & 202 & $71 \%$ \\
\hline No* & 82 & $29 \%$ \\
\hline Total & 284 & $100 \%$ \\
\hline
\end{tabular}

* Fin de la encuesta

\section{P8) ¿Considera contratar una empresa para que se encargue de dicho servicio?}

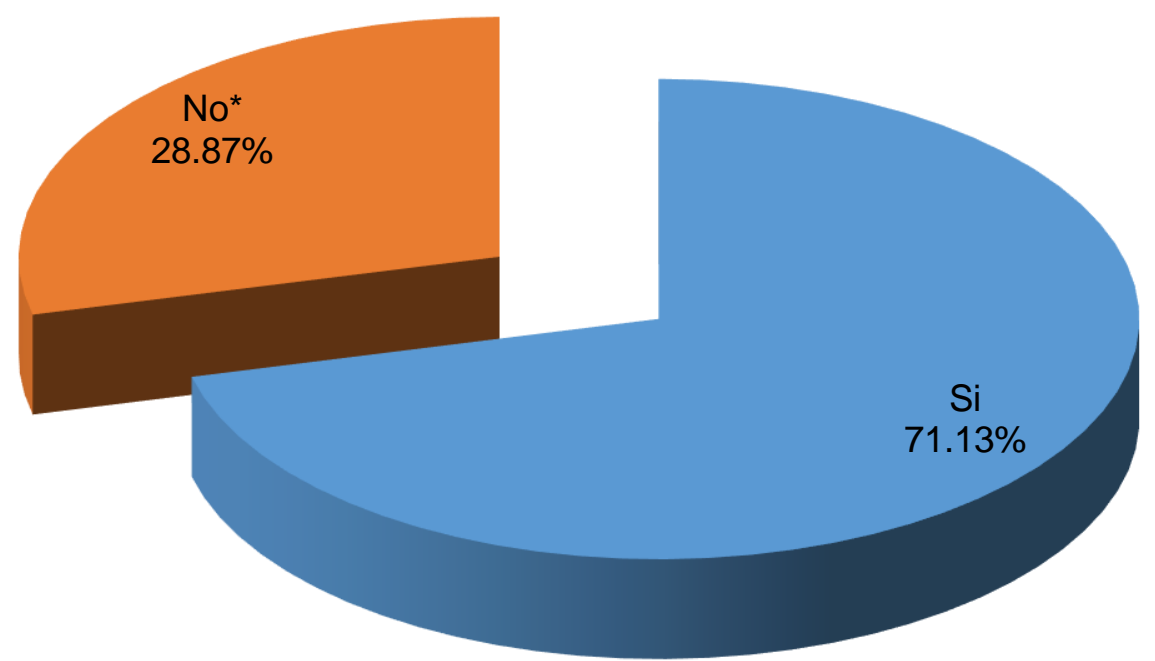

Interpretación: Del total de encuestados, el 71\% considera contratar una empresa para que se encargue de dicho servicio, el 29\% no lo considera. 


\section{Pregunta 9}

\begin{tabular}{|c|c|c|}
\hline \multicolumn{3}{|c|}{$\begin{array}{l}\text { 9) Si tiene casa ¿Cuánto gasta aproximadamente en una } \\
\text { remodelación? }\end{array}$} \\
\hline Respuestas & Cantidad & $\%$ \\
\hline Menos de S/ 5000 & 20 & $10 \%$ \\
\hline De S/ 5000 a S/ 6500 & 67 & $33 \%$ \\
\hline De S/ 6500 a S/ 16500 & 85 & $42 \%$ \\
\hline De $S / 16500$ a S/ 20000 & 20 & $10 \%$ \\
\hline Más de S/ 20000 & 10 & $5 \%$ \\
\hline Total & 202 & $100 \%$ \\
\hline
\end{tabular}

\section{P9) Si tiene casa ¿Cuánto gasta aproximadamente en una remodelación?}

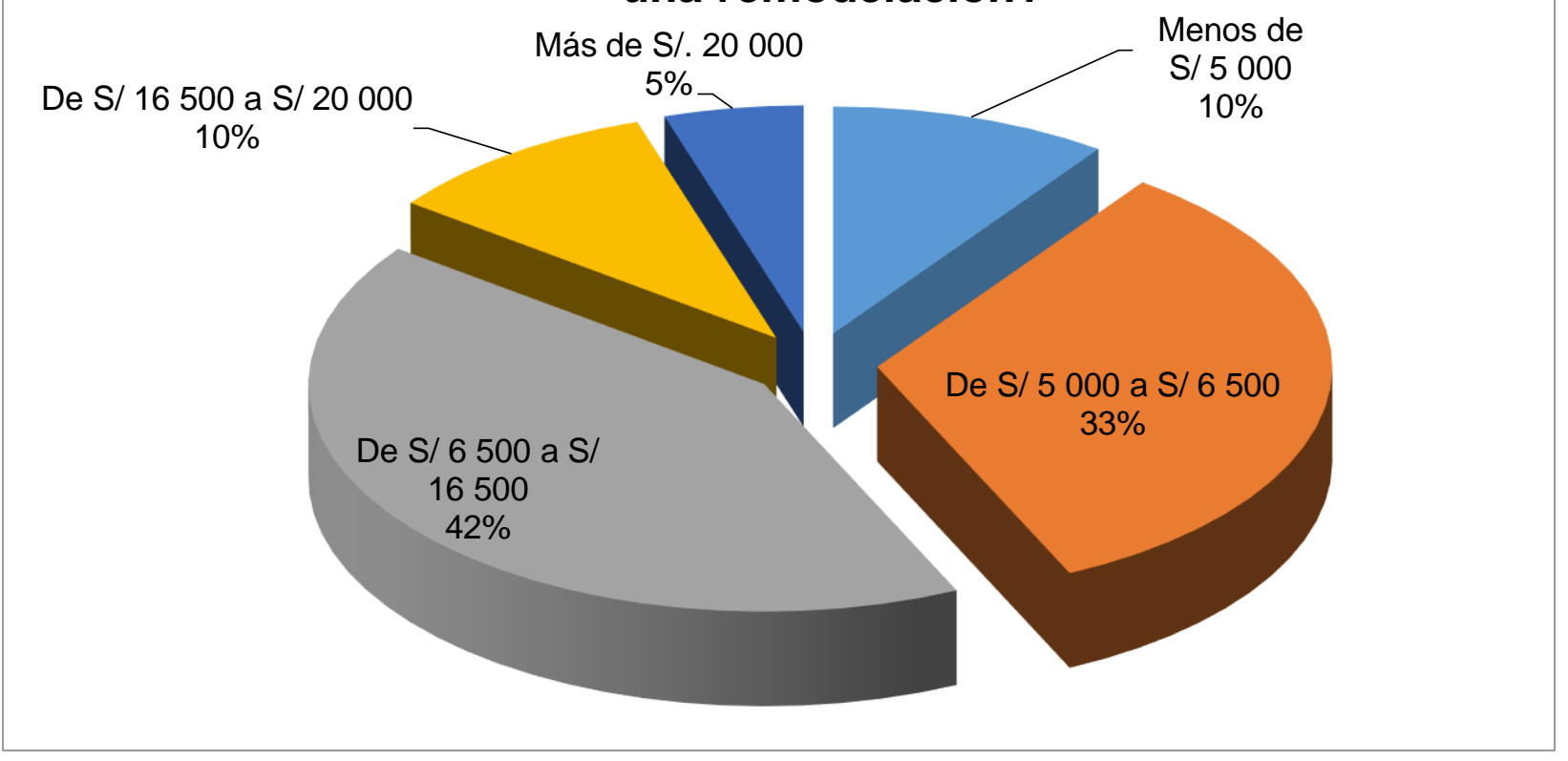

Interpretación: Del total, un 10\% gasta menos de S/ 5000 en una remodelación, un 33\% gasta de S/ 5000 a S/ 6500 en una remodelación, un 42\% gasta de S/ 6500 a S/ 16500 en una remodelación, un 10\% gasta de S/ 16500 a S/ 20000 en una remodelación, y por último un 5\% gasta más de S/ 20000 en una remodelación. 


\section{Pregunta 10}

\begin{tabular}{|l|c|c|}
\hline \multicolumn{3}{|c|}{$\begin{array}{c}\text { 10) Si tiene departamento ¿Cuánto gasta aproximadamente en } \\
\text { una remodelación? }\end{array}$} \\
\hline \multicolumn{1}{|c|}{ Respuestas } & Cantidad & $\%$ \\
\hline Menos de S/ 5 000 & 34 & $17 \%$ \\
\hline De S/ 5 000 a S/ 6 500 & 119 & $59 \%$ \\
\hline De S/ 6 500 a S/ 16 500 & 36 & $18 \%$ \\
\hline De S/ 16 500 a S/ 20 000 & 7 & $3 \%$ \\
\hline Más de S/ 20 000 Total & 6 & $3 \%$ \\
\hline \multicolumn{2}{|c|}{} & \\
\hline
\end{tabular}

\section{P10) Si tiene departamento ¿Cuánto gasta aproximadamente en una remodelación?}

De S/ 16500 a S/ 20000.

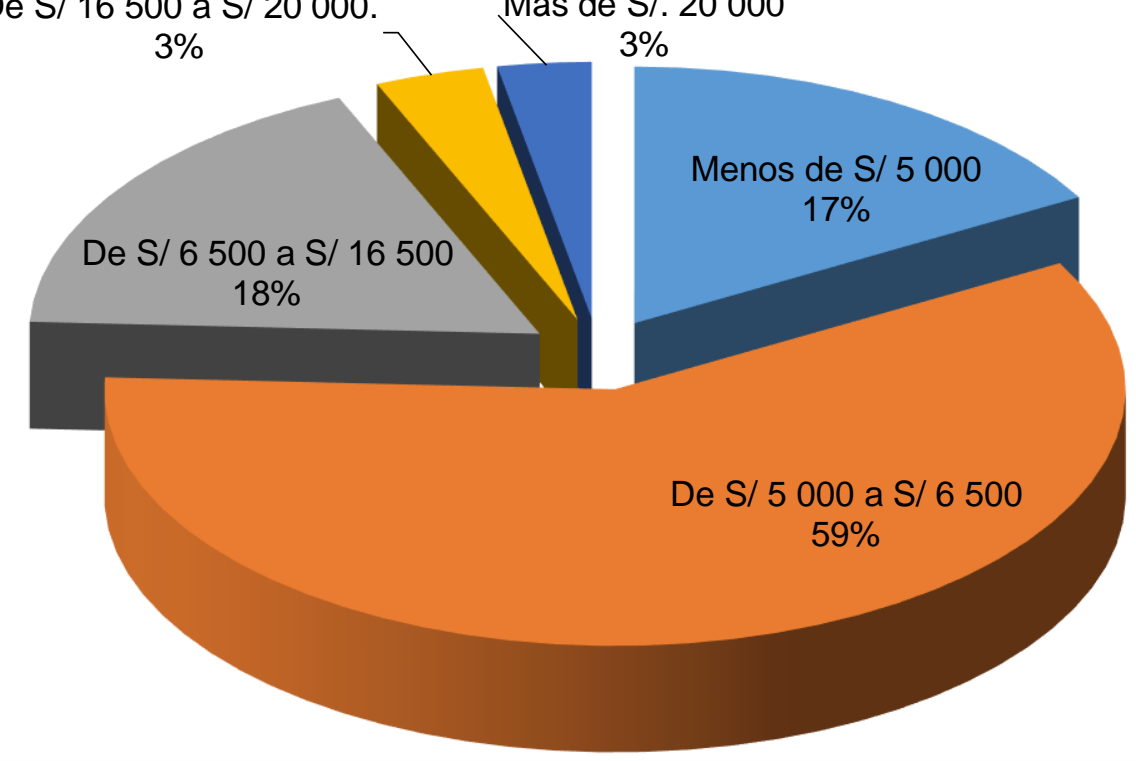

Interpretación: Del total, un 17\% gasta menos de S/ 5000 en una remodelación, un 59\% gasta de S/ 5000 a S/ 6500 en una remodelación, un 18\% gasta de S/ 6500 a S/ 16500 en una remodelación, un 3\% gasta de S/ 16500 a S/ 20000 en una remodelación, y por último un 3\% gasta más de S/ 20000 en una remodelación. 


\section{Pregunta 11}

11) Mayormente ¿Qué tipo de material usa normalmente en sus trabajos de remodelación?

\begin{tabular}{|l|c|c|}
\hline \multicolumn{1}{|c|}{ Respuesta } & Cantidad & \% \\
\hline Melamine & 91 & $45 \%$ \\
\hline Madera & 77 & $38 \%$ \\
\hline Metal & 22 & $11 \%$ \\
\hline Vidrio & 8 & $4 \%$ \\
\hline Otros $\quad$ Total & 4 & $2 \%$ \\
\hline \multicolumn{2}{|c|}{ 202 } & $\mathbf{1 0 0 \%}$ \\
\hline
\end{tabular}

P11) Mayormente ¿Qué tipo de material usa normalmente en sus trabajos de remodelación?

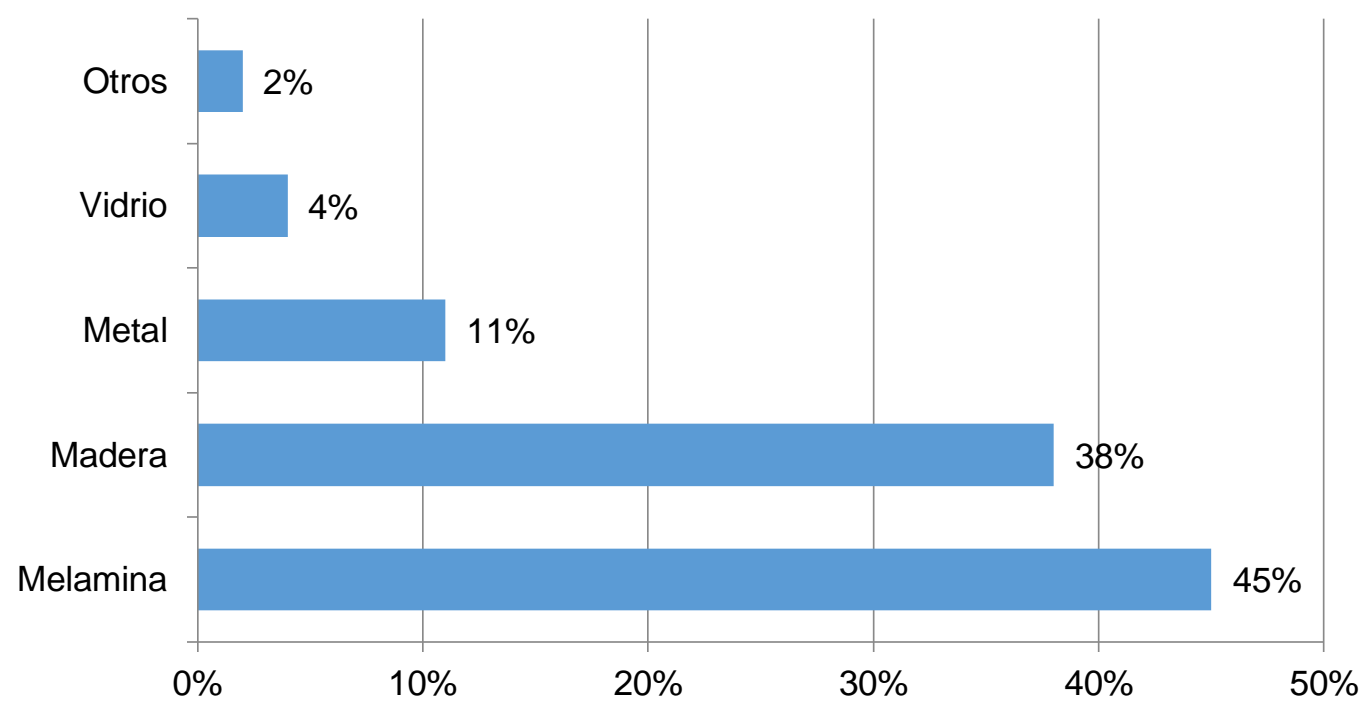

Interpretación: Del total de encuestados, el $45 \%$ utiliza melamine para remodelación de su vivienda, el 38\% utiliza madera para la remodelación de su vivienda, el 11\% utiliza metal para la remodelación, el $4 \%$ utiliza vidrio y por último el $2 \%$ otros. 


\section{Pregunta 12}

\begin{tabular}{|c|c|c|}
\hline \multicolumn{3}{|c|}{ 12) ¿Cada cuánto tiempo la realiza? } \\
\hline Respuesta & Cantidad & $\%$ \\
\hline 2 veces al año o más & 2 & $1 \%$ \\
\hline 1 vez al año & 20 & $10 \%$ \\
\hline Cada 2 años & 71 & $35 \%$ \\
\hline Cada 3 años & 51 & $25 \%$ \\
\hline Cada 4 años & 38 & $19 \%$ \\
\hline Cada 5 años & 20 & $10 \%$ \\
\hline Total & 202 & $100 \%$ \\
\hline
\end{tabular}

\section{P12) ¿Cada cuánto tiempo la realiza?}

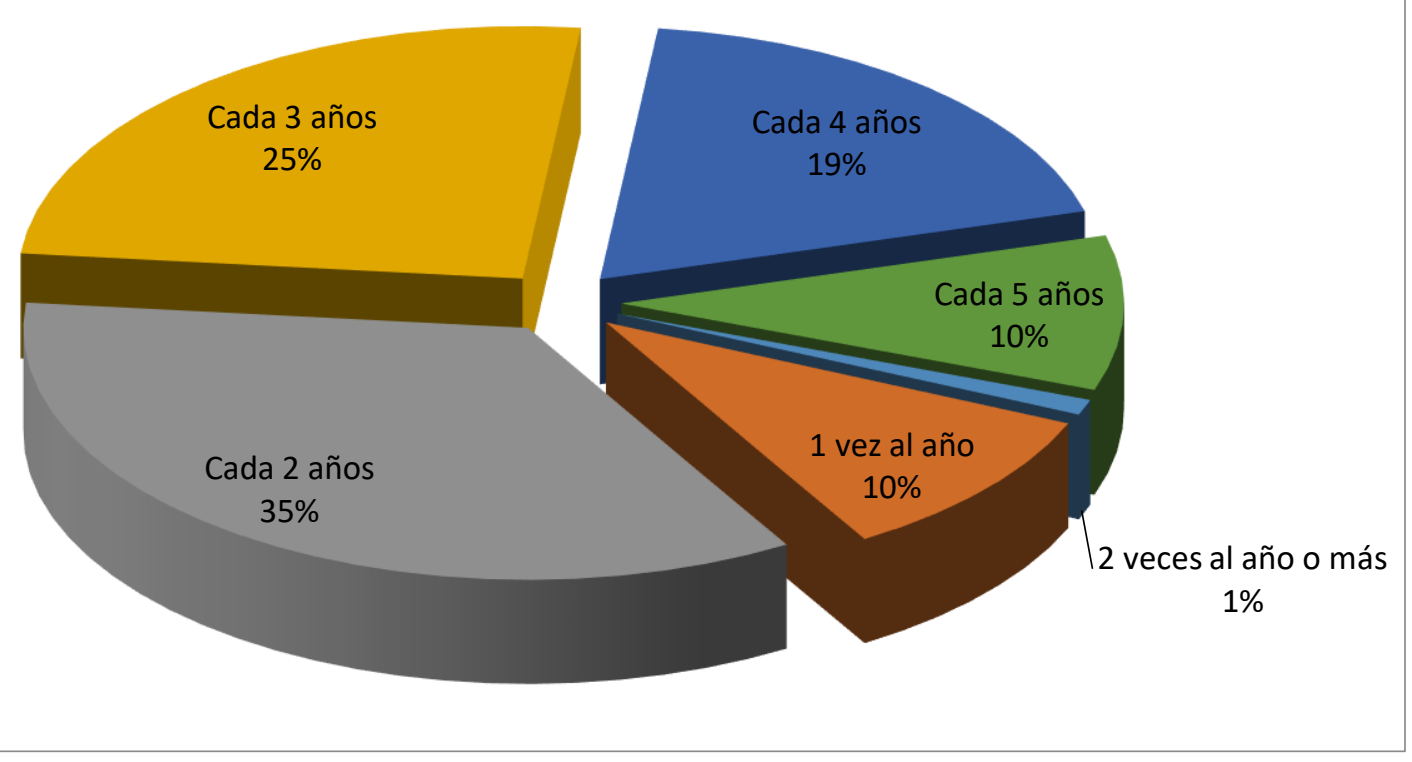

Interpretación: Del total de mercado, el 1\% realiza remodelación 2 veces al año o más, el 10\% la realiza 1 vez al año, el 35\% la realiza cada dos años, el 25\% realiza remodelación cada tres años, el $19 \%$ la realiza cada cuatro años y por último, el 10\% realiza cada cinco años una remodelación en su vivienda. 


\section{$\underline{\text { Pregunta } 13}$}

\begin{tabular}{|c|c|c|}
\hline \multicolumn{3}{|c|}{ 13) ¿En qué mes del año le es conveniente renovar? } \\
\hline Respuesta & Cantidad & $\%$ \\
\hline Enero - Marzo & 20 & $10 \%$ \\
\hline Abril - Junio & 51 & $25 \%$ \\
\hline Julio - Setiembre & 71 & $35 \%$ \\
\hline Octubre - Diciembre & 60 & $30 \%$ \\
\hline Total & 202 & $100 \%$ \\
\hline
\end{tabular}

\section{P13) ¿En qué mes del año le es conveniente renovar?}

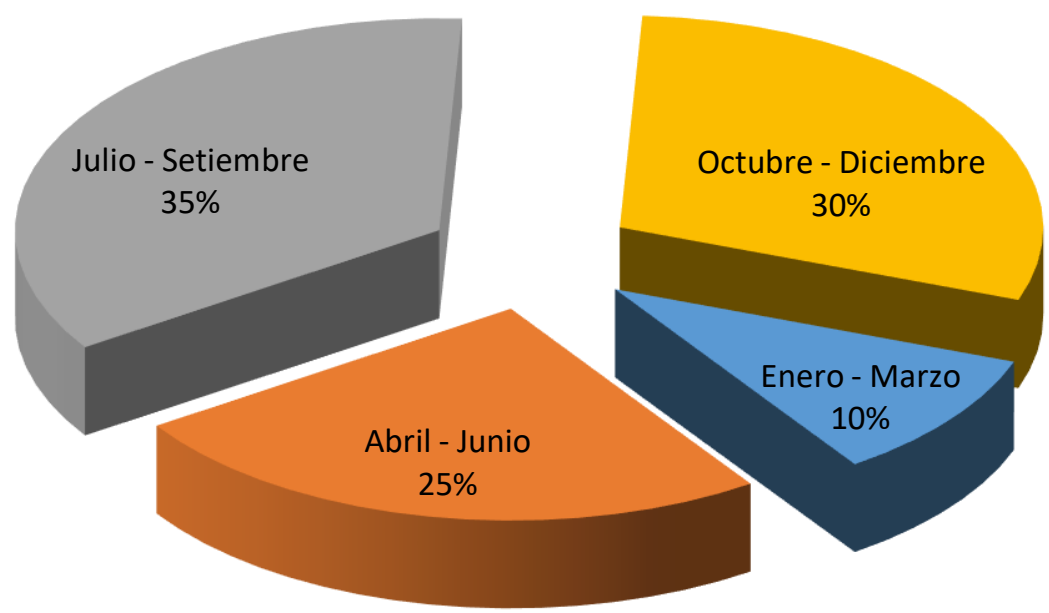

Interpretación: Del total de encuestados, el 10\% señala que es conveniente renovar entre los meses de enero y marzo, el 25\% señala que es conveniente renovar entre los meses de abril y junio, el 35\% señala que es conveniente renovar entre los meses de julio y setiembre, y por último, el 30\% señala que renovaría entre octubre y diciembre. 


\section{Pregunta 14}

\begin{tabular}{|c|c|c|}
\hline \multicolumn{3}{|c|}{$\begin{array}{l}\text { 14) ¿Qué opciones de proveedores maneja para remodela } \\
\text { sus interiores? }\end{array}$} \\
\hline Respuesta & Cantidad & $\%$ \\
\hline Sodimac - Maestro & 24 & $12 \%$ \\
\hline Decor Center & 18 & $9 \%$ \\
\hline Saga - Ripley & 26 & $13 \%$ \\
\hline PROMART & 22 & $11 \%$ \\
\hline Ferrini & 18 & $9 \%$ \\
\hline Canziani & 15 & $7 \%$ \\
\hline Parque Villa El Salvador & 17 & $8 \%$ \\
\hline Mercado Unicachi & 16 & $8 \%$ \\
\hline Maestros independientes & 28 & $14 \%$ \\
\hline Otros & 18 & $9 \%$ \\
\hline Total & 202 & $100 \%$ \\
\hline
\end{tabular}

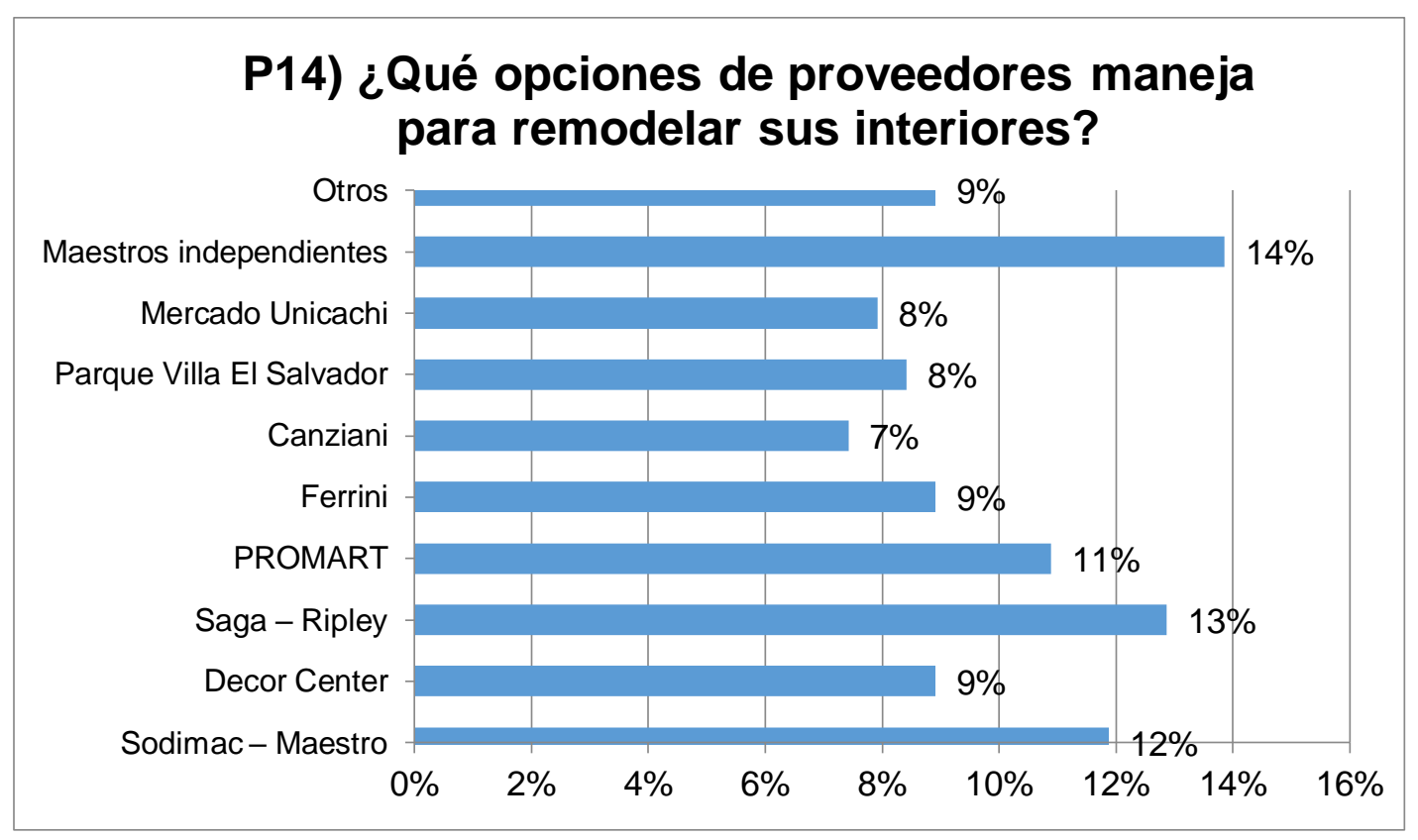

Interpretación: Del total de encuestados, el 12\% tiene como proveedor para remodelar sus interiores a Sodimac - Maestro, el 9\% tiene como proveedor para remodelar sus interiores a Decor Center, el 13\% tiene como proveedor para remodelar sus interiores a Saga - Ripley, el 11\% tiene como proveedor para remodelar sus interiores a Promart, el 14\% tiene como proveedor para remodelar sus interiores a maestros independientes. 
"RENUEVATE es un servicio de diseño, optimización y remodelación de espacios a medida que se pondrá a disponibilidad de las familias que deseen mejorar o remodelar sus espacios internos. Se tendrá a disposición un servicio de pre diseño digital para que las personas sepan cómo van a quedar sus espacios al final del servicio, asimismo se tendrá mano de obra calificada y garantía sobre los muebles y espacios diseñados, de tal manera que se logre la idoneidad del servicio y la satisfacción del cliente. Las propuestas se adaptarán al presupuesto del cliente y se podrán financiar a 120, 180 y 240 días sin intereses.

\section{$\underline{\text { Pregunta } 15}$}

\begin{tabular}{|l|c|c|}
\hline \multicolumn{3}{|c|}{ 15) ¿Estaría dispuesto a solicitar los servicios de } \\
"RENUEVATE"?
\end{tabular}

* Fin de la encuesta

\section{P15) ¿Estaría dispuesto a solicitar los servicios de "RENUEVATE"?}

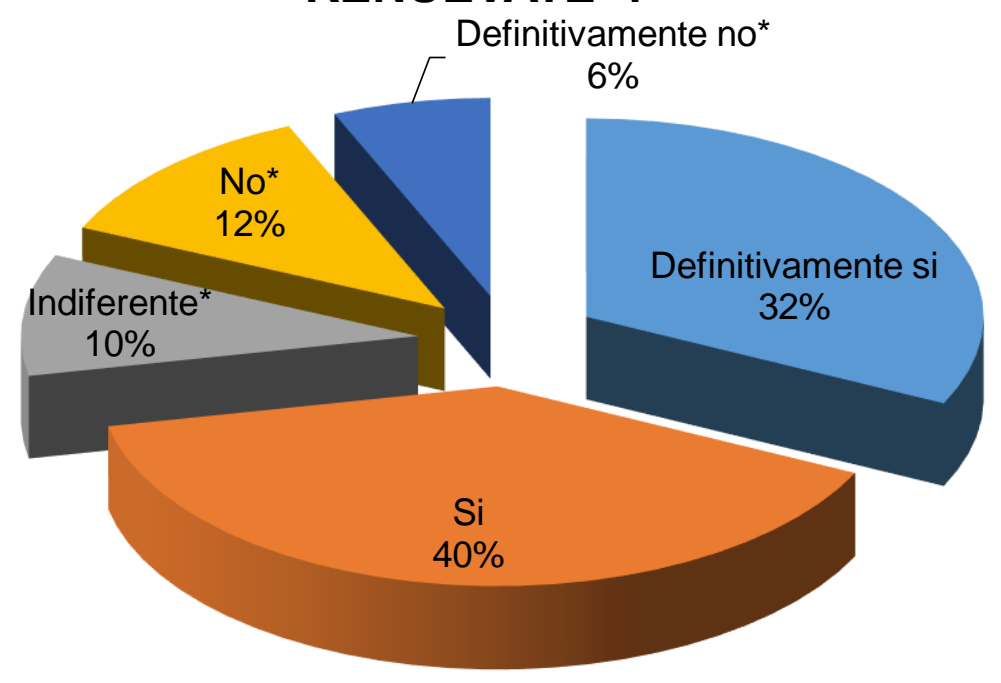


Interpretación: Del total de encuestados, el 32\% definitivamente sí solicitaría los servicios de RENUEVATE y el 40\% respondieron también que sí. Asimismo un $10 \%$ es indiferente a la oferta descrita y un $18 \%$ no solicitaría los servicios.

\section{Pregunta 16}

\begin{tabular}{|l|c|c|}
\hline \multicolumn{2}{|c|}{ 16) ¿Con que frecuencia lo realizaría? } \\
\hline \multicolumn{1}{|c|}{ Respuesta } & Cantidad & $\mathbf{\%}$ \\
\hline 1 vez al año & 22 & $15 \%$ \\
\hline 1 vez cada 2 años & 71 & $49 \%$ \\
\hline 1 vez cada 3 años & 33 & $23 \%$ \\
\hline 1 vez cada 4 años & 16 & $11 \%$ \\
\hline 1 vez cada 5 años & 3 & $2 \%$ \\
\hline Total & $\mathbf{1 4 5}$ & $\mathbf{1 0 0 \%}$ \\
\hline
\end{tabular}

\section{P16) ¿Con que frecuencia lo realizaría?}

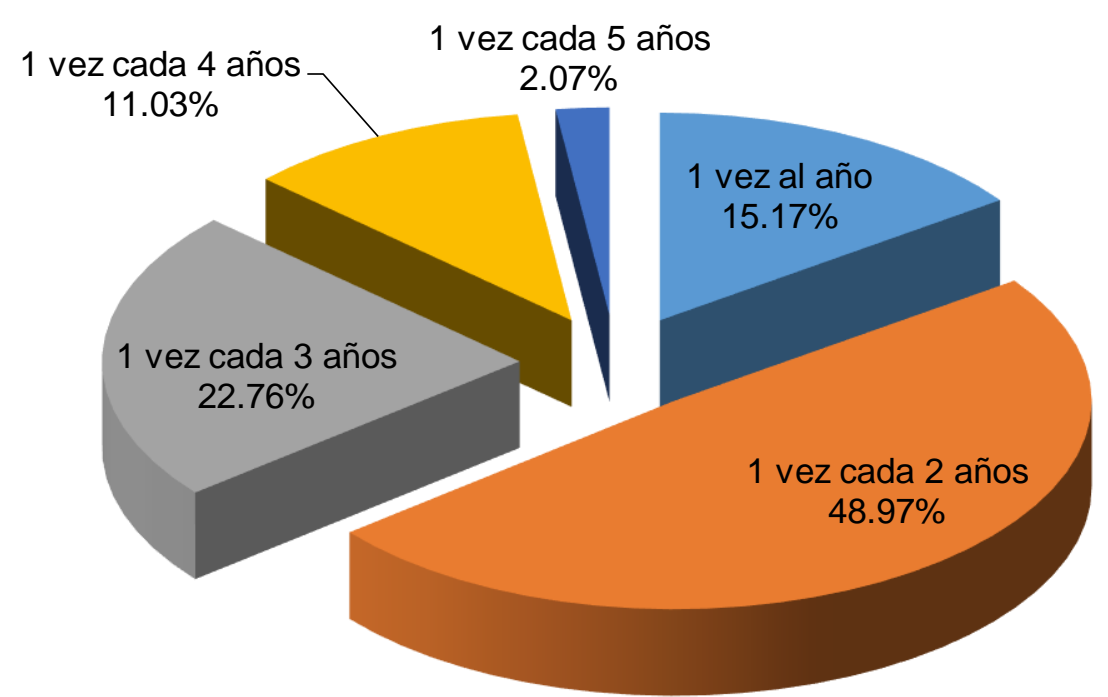

Interpretación: Del total de encuestados, el 15\% realiza remodelación una vez al año, el 49\% lo realiza cada dos años, el $23 \%$ lo realiza cada tres años, el $11 \%$ lo realiza cada cuatro años y por último el $2 \%$ lo realiza cada cinco años. 


\section{Pregunta 17}

\begin{tabular}{|l|c|c|}
\hline \multicolumn{3}{|c|}{ 17) ¿Qué tipo de vivienda renovaría? } \\
\hline \multicolumn{1}{|c|}{ Respuesta } & Cantidad & $\mathbf{\%}$ \\
\hline Casa Propia & 80 & $55 \%$ \\
\hline Departamento & 65 & $45 \%$ \\
\hline Total & $\mathbf{1 4 5}$ & $\mathbf{1 0 0 \%}$ \\
\hline
\end{tabular}

\section{P17) ¿Qué tipo de vivienda renovaría?}
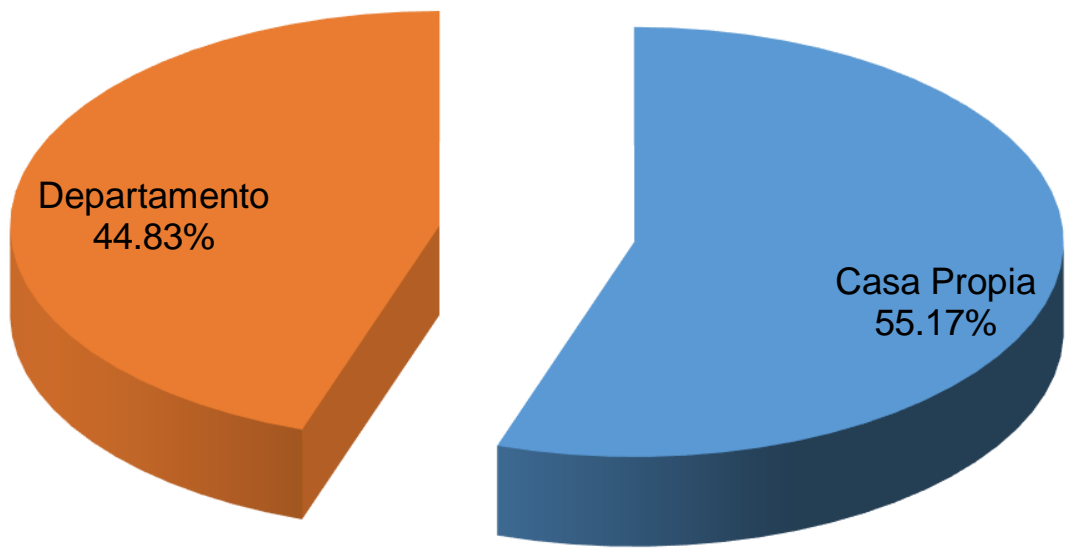

Interpretación: Un 55\% indica que renovaría su casa propia y un $45 \%$ indica que renovaría su departamento. 


\section{Pregunta 18}

\begin{tabular}{|c|c|c|}
\hline \multicolumn{3}{|c|}{ 18) En casa ¿Qué tipo de ambiente renovaría? } \\
\hline Respuesta & Cantidad & $\%$ \\
\hline Habitaciones & 6 & $8 \%$ \\
\hline Sala & 12 & $15 \%$ \\
\hline Comedor & 10 & $13 \%$ \\
\hline Zona de parrilla & 24 & $30 \%$ \\
\hline Cocina & 24 & $30 \%$ \\
\hline Otros & 4 & $5 \%$ \\
\hline Total & 80 & $100 \%$ \\
\hline
\end{tabular}

\section{P18) En casa ¿Qué tipo de ambiente renovaría?}

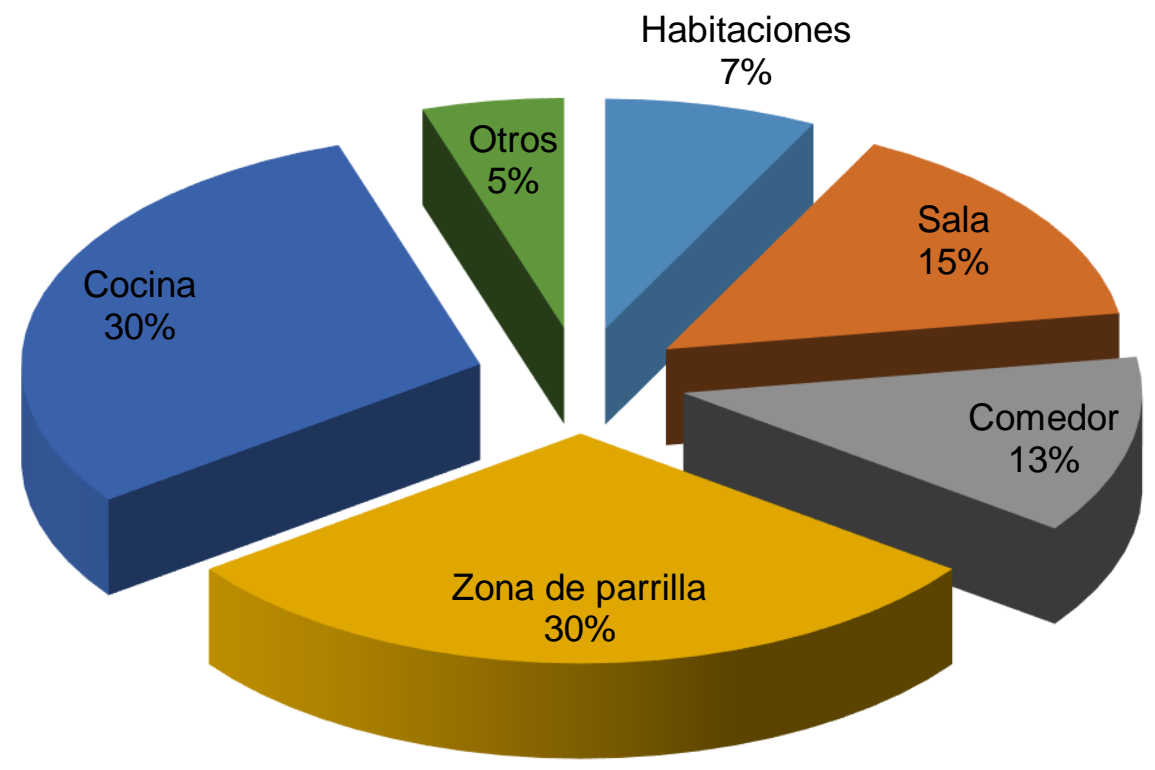

Interpretación: Del total de encuestados, $8 \%$ renovarían sus habitaciones, un $15 \%$ renovaría su sala, un $13 \%$ renovaría su comedor, un $30 \%$ renovaría su zona de parrilla, otro $30 \%$ renovaría su cocina y por último un $5 \%$ renovaría otro ambiente no especificado. 


\section{$\underline{\text { Pregunta } 19}$}

\begin{tabular}{|c|c|c|}
\hline \multicolumn{3}{|c|}{ 19) En Dpto. ¿Qué tipo de ambiente renovaría? } \\
\hline Respuesta & Cantidad & $\%$ \\
\hline Habitaciones & 10 & $15 \%$ \\
\hline Sala - Comedor & 23 & $35 \%$ \\
\hline Cocina & 29 & $45 \%$ \\
\hline Otros & 3 & $5 \%$ \\
\hline Total & 65 & $100 \%$ \\
\hline
\end{tabular}

\section{P19) En Dpto. ¿Qué tipo de ambiente renovaría?}

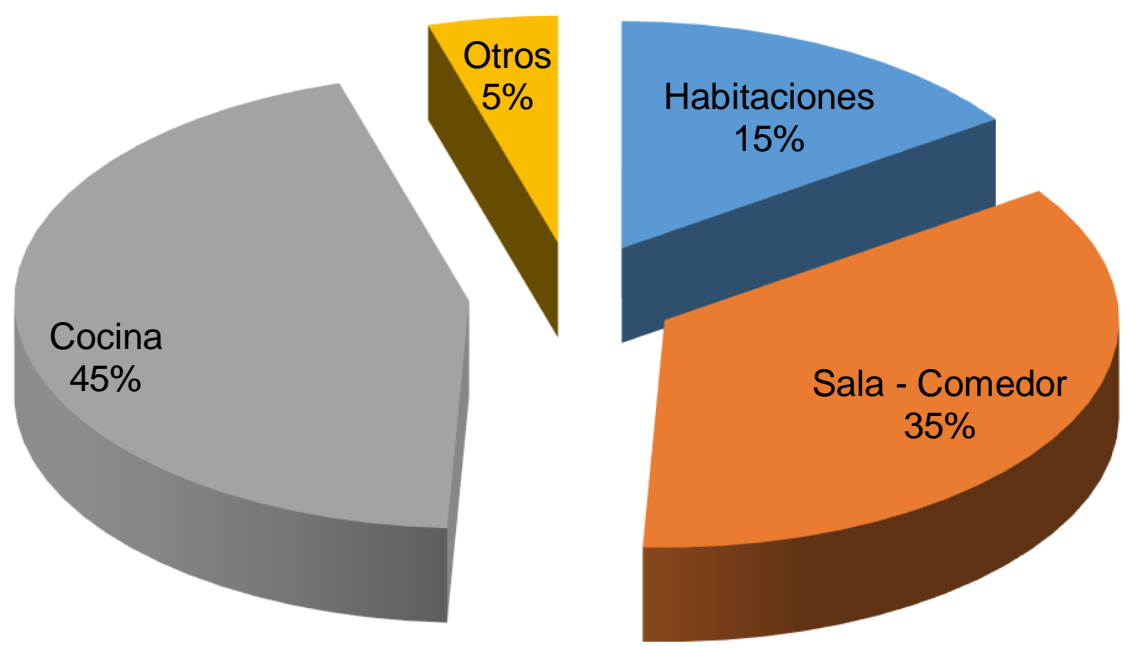

Interpretación: Del total de encuestados, un 15\% renovarían sus habitaciones, un 35\% renovaría su sala - comedor, un $45 \%$ renovaría su cocina y por último un $5 \%$ renovarían otros ambientes. 


\section{Pregunta 20}

\begin{tabular}{|l|c|c|c|c|c|}
\hline \multicolumn{7}{|c|}{$\mathbf{2 0 )}$ ¿Cuánto gastaría en dicha renovación? } \\
\hline & $\begin{array}{c}\text { Menos de } \\
\text { S/. 5,000 }\end{array}$ & $\begin{array}{c}\text { De S/. 5,000 } \\
\text { a S/. 6,500 }\end{array}$ & $\begin{array}{c}\text { De S/. 6,500 } \\
\text { a S/. 16,500 }\end{array}$ & $\begin{array}{c}\text { De S/. 16,500 } \\
\text { a S/. 20,000 }\end{array}$ & $\begin{array}{c}\text { Más de } \\
\text { S/. 20,000 }\end{array}$ \\
\hline A.- Casa & & & & & \\
\hline Habitación & $24 \%$ & $70 \%$ & $3 \%$ & $2 \%$ & $1 \%$ \\
\hline Sala & $2 \%$ & $68 \%$ & $21 \%$ & $8 \%$ & $1 \%$ \\
\hline Comedor & $1 \%$ & $55 \%$ & $37 \%$ & $5 \%$ & $2 \%$ \\
\hline Zona de parrilla & $20 \%$ & $65 \%$ & $10 \%$ & $3 \%$ & $2 \%$ \\
\hline Cocina & $1 \%$ & $46 \%$ & $50 \%$ & $2 \%$ & $1 \%$ \\
\hline B.- Departamento & & & & & \\
\hline Habitación & $43 \%$ & $52 \%$ & $2 \%$ & $2 \%$ & $1 \%$ \\
\hline Sala - comedor & $28 \%$ & $55 \%$ & $12 \%$ & $4 \%$ & $1 \%$ \\
\hline Cocina & $33 \%$ & $46 \%$ & $15 \%$ & $4 \%$ & $2 \%$ \\
\hline
\end{tabular}

20 A ¿Cuánto gastaría en dicha renovación?

Casa - Habitación

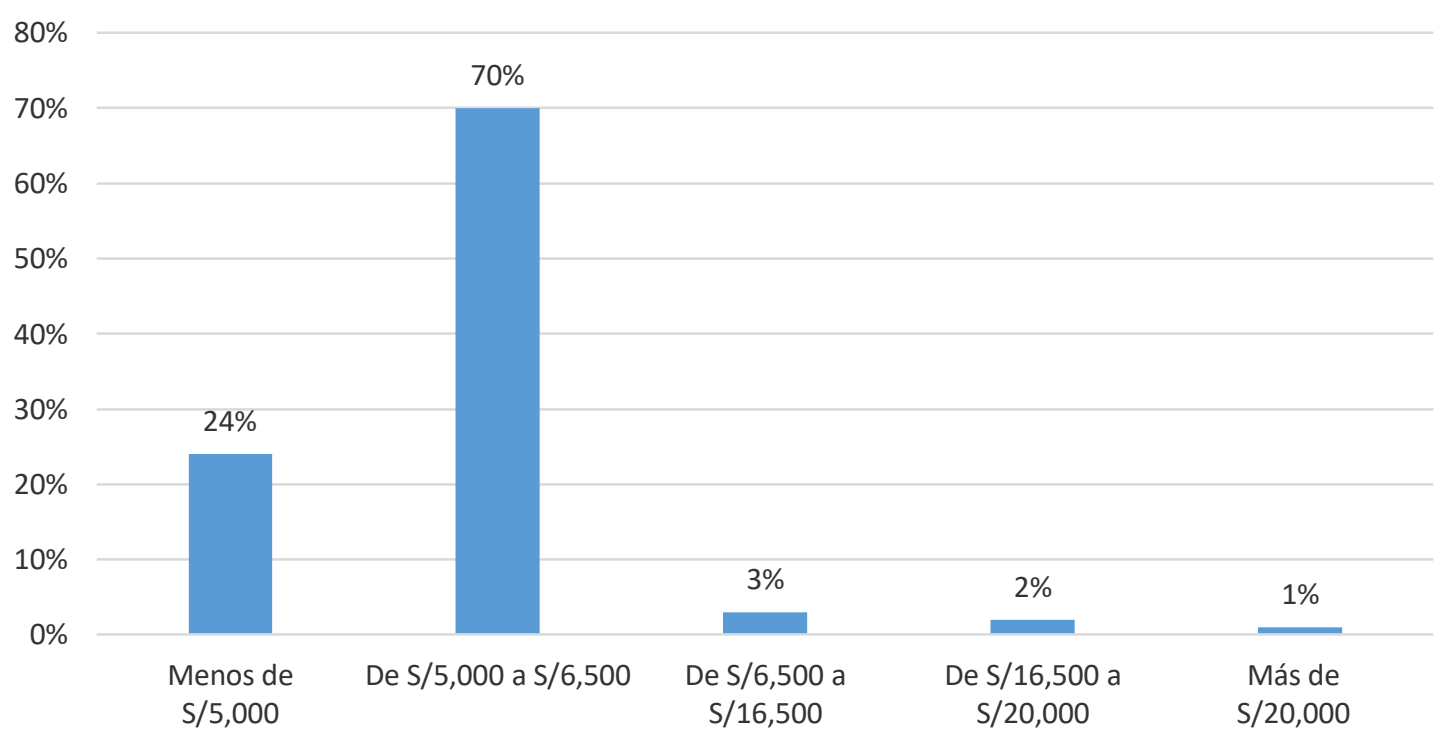



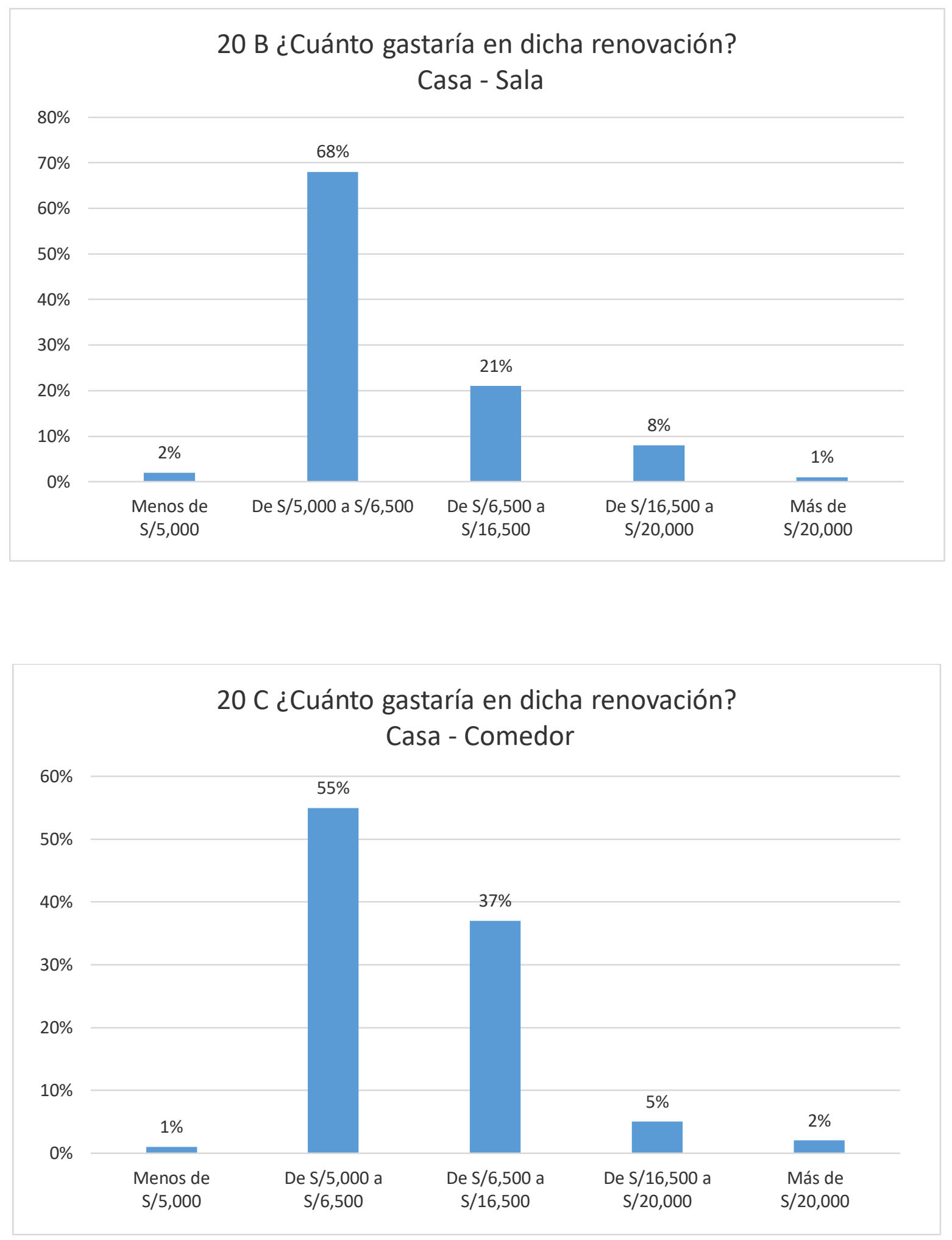

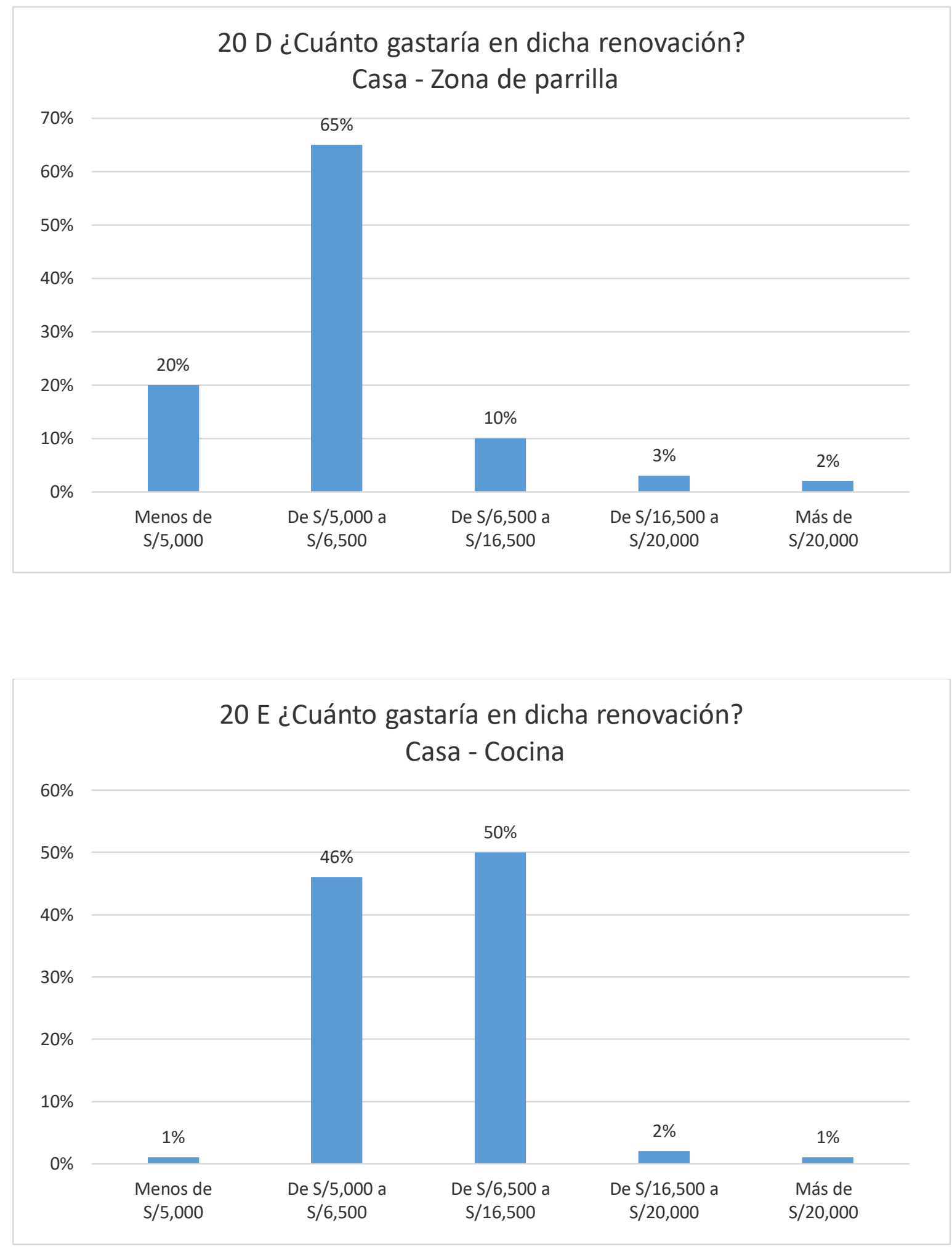

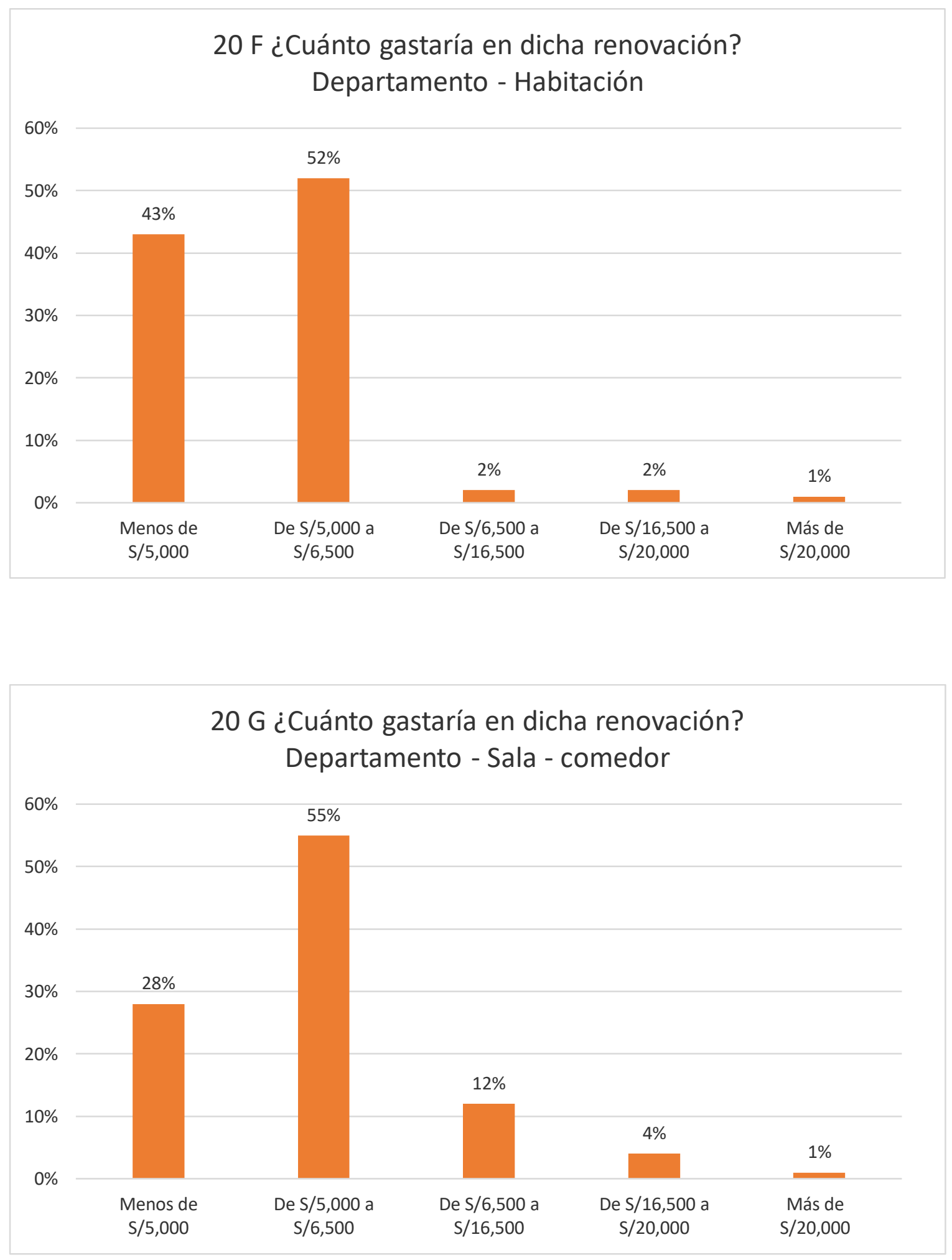


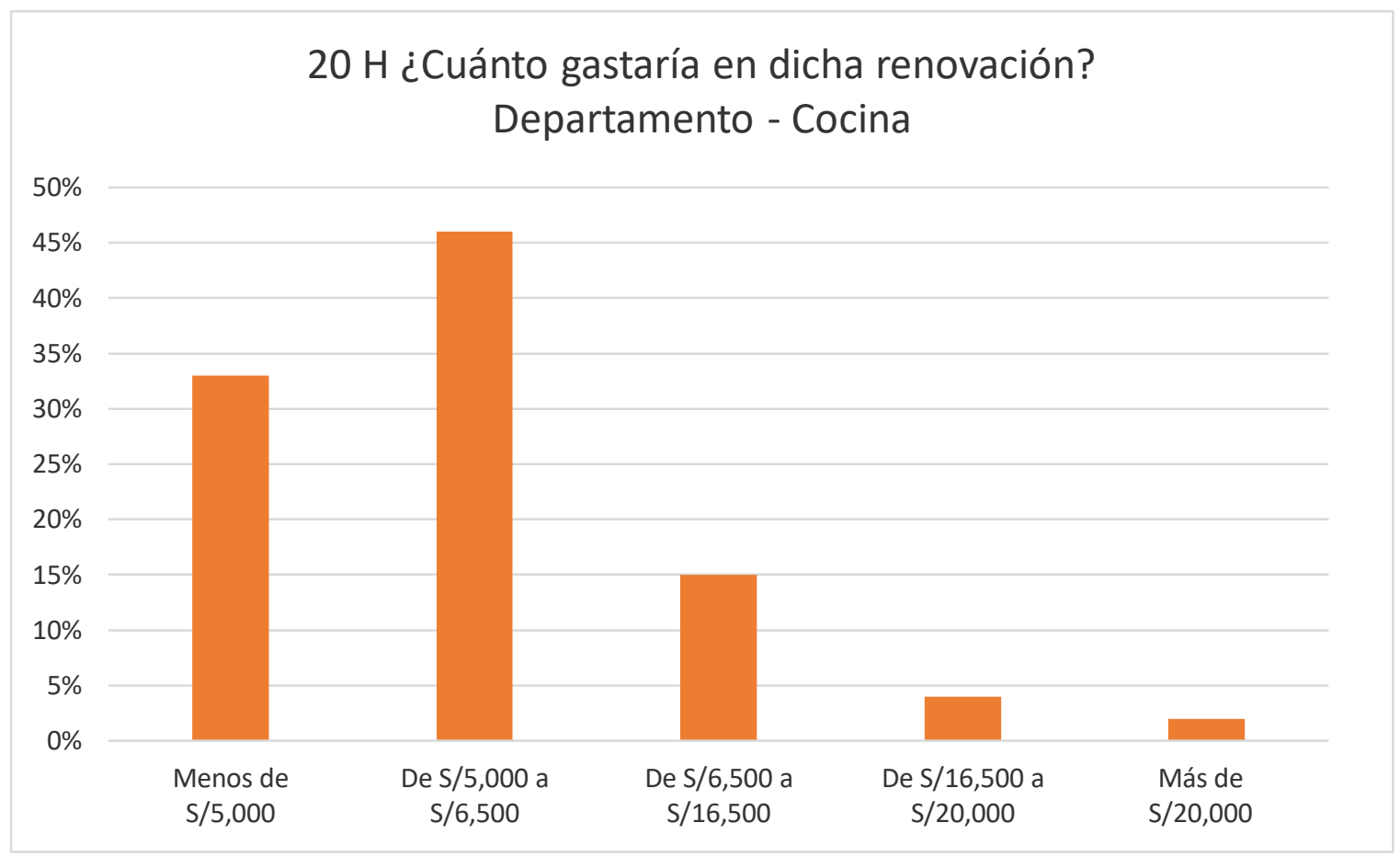




\section{Pregunta 21}

\begin{tabular}{|c|c|c|}
\hline \multicolumn{3}{|c|}{ 21) ¿Cómo lo pagaría? } \\
\hline Respuesta & Cantidad & $\%$ \\
\hline Al contado & 51 & $35 \%$ \\
\hline Al crédito & 94 & $65 \%$ \\
\hline Total & 145 & $100 \%$ \\
\hline
\end{tabular}

\section{P21) ¿Cómo lo pagaría?}

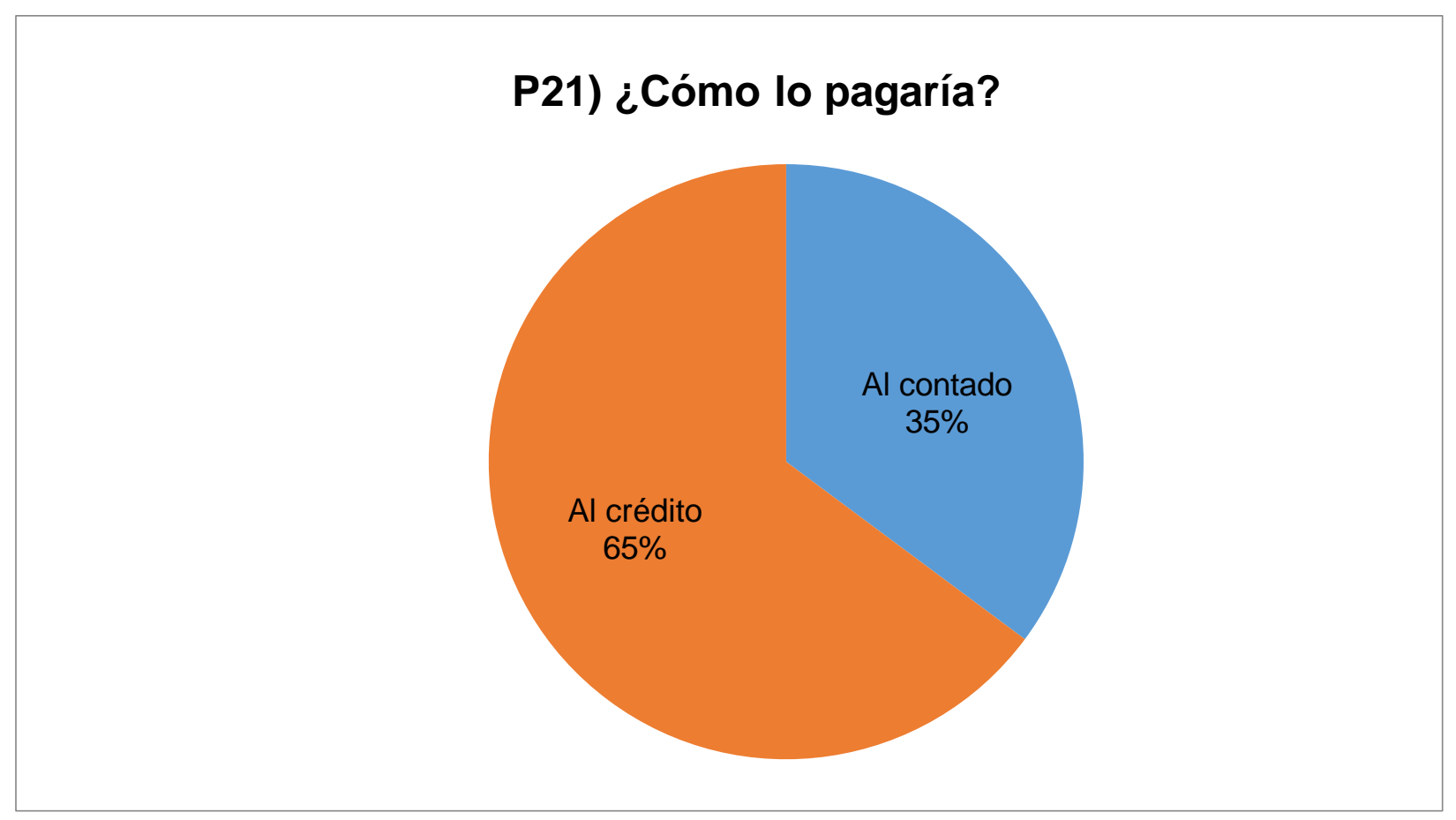

Interpretación: Del total, un 35\% pagaría al contado la remodelación de sus interiores y un $65 \%$ lo pagaría al crédito. 


\section{Pregunta 22}

\begin{tabular}{|c|c|c|}
\hline \multicolumn{3}{|c|}{ 22) Si accede al crédito de la empresa, ia cuántos días le } \\
parece adecuado?
\end{tabular}

\section{P22) Si accede al crédito de la empresa, ¿a cuántos días le parece adecuado?}

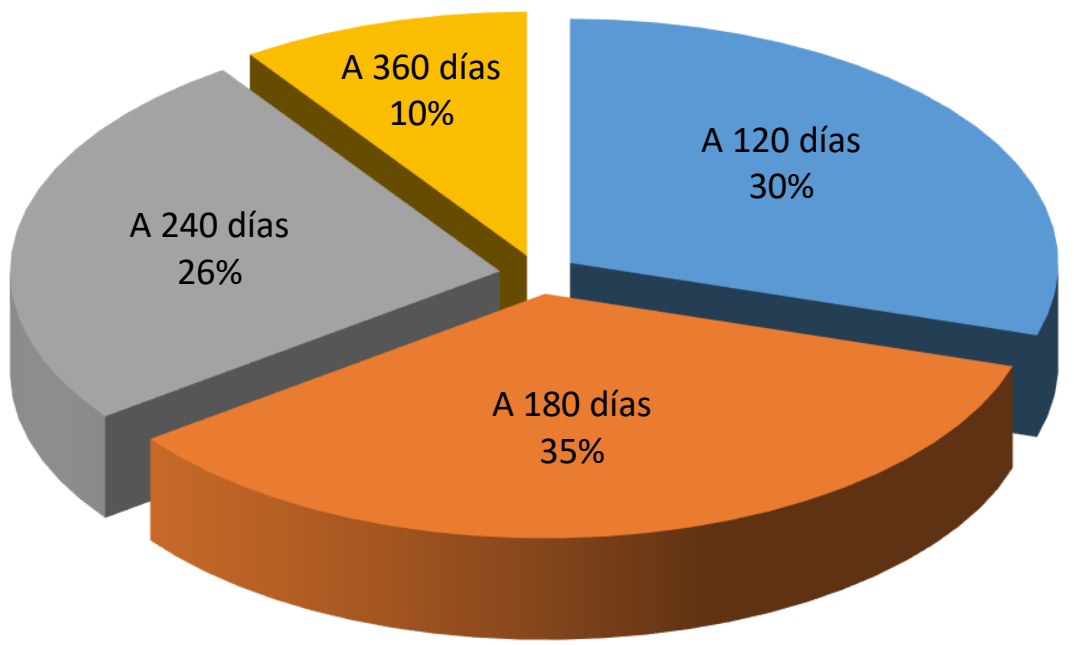

Interpretación: De todas las personas encuestadas que pagarían al crédito la remodelación, un $30 \%$ lo pagaría a 120 días, un 35\% lo pagaría a 180 días, un $26 \%$ lo pagaría a 240 días y por último un $10 \%$ lo pagaría a 360 días. 


\section{Pregunta 23}

\begin{tabular}{|l|c|c|}
\hline \multicolumn{3}{|c|}{$23)$ ¿Qué tipo de material solicitaría? } \\
\hline \multicolumn{1}{|c|}{ Respuesta } & Cantidad & $\%$ \\
\hline Melamine & 65 & $45 \%$ \\
\hline Madera & 58 & $40 \%$ \\
\hline Metal & 15 & $10 \%$ \\
\hline Vidrio & 7 & $5 \%$ \\
\hline \multicolumn{1}{|c|}{ Total } & $\mathbf{1 4 5}$ & $\mathbf{1 0 0 \%}$ \\
\hline
\end{tabular}

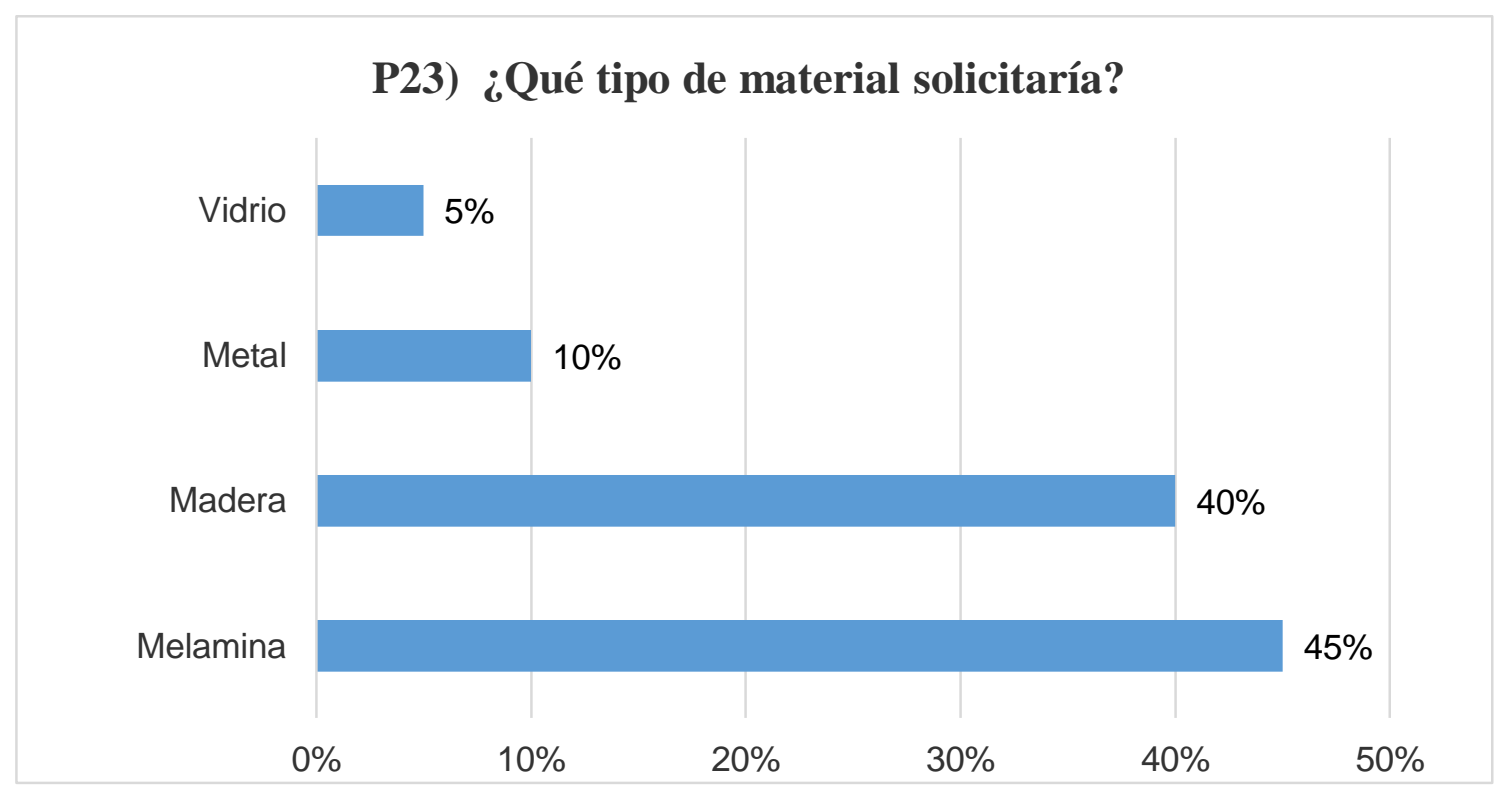

Interpretación: Un 45\% solicitaría melamine, un 40\% solicitaría madera, un 10\% solicitaría metal y por último un 5\% solicitaría vidrio, para la remodelación de sus interiores. 


\section{Pregunta 24}

\begin{tabular}{|l|c|c|}
\hline \multicolumn{3}{|c|}{ 24) ¿Qué opina de la marca "RENUÉVATE"? } \\
\hline \multicolumn{1}{|c|}{ Respuesta } & Cantidad & $\%$ \\
\hline Muy buena & 39 & $27 \%$ \\
\hline Buena & 92 & $63 \%$ \\
\hline Indiferente & 10 & $7 \%$ \\
\hline Mala & 3 & $2 \%$ \\
\hline Muy mala & 1 & $1 \%$ \\
\hline \multicolumn{1}{|c|}{ Total } & $\mathbf{1 4 5}$ & $\mathbf{1 0 0 \%}$ \\
\hline
\end{tabular}

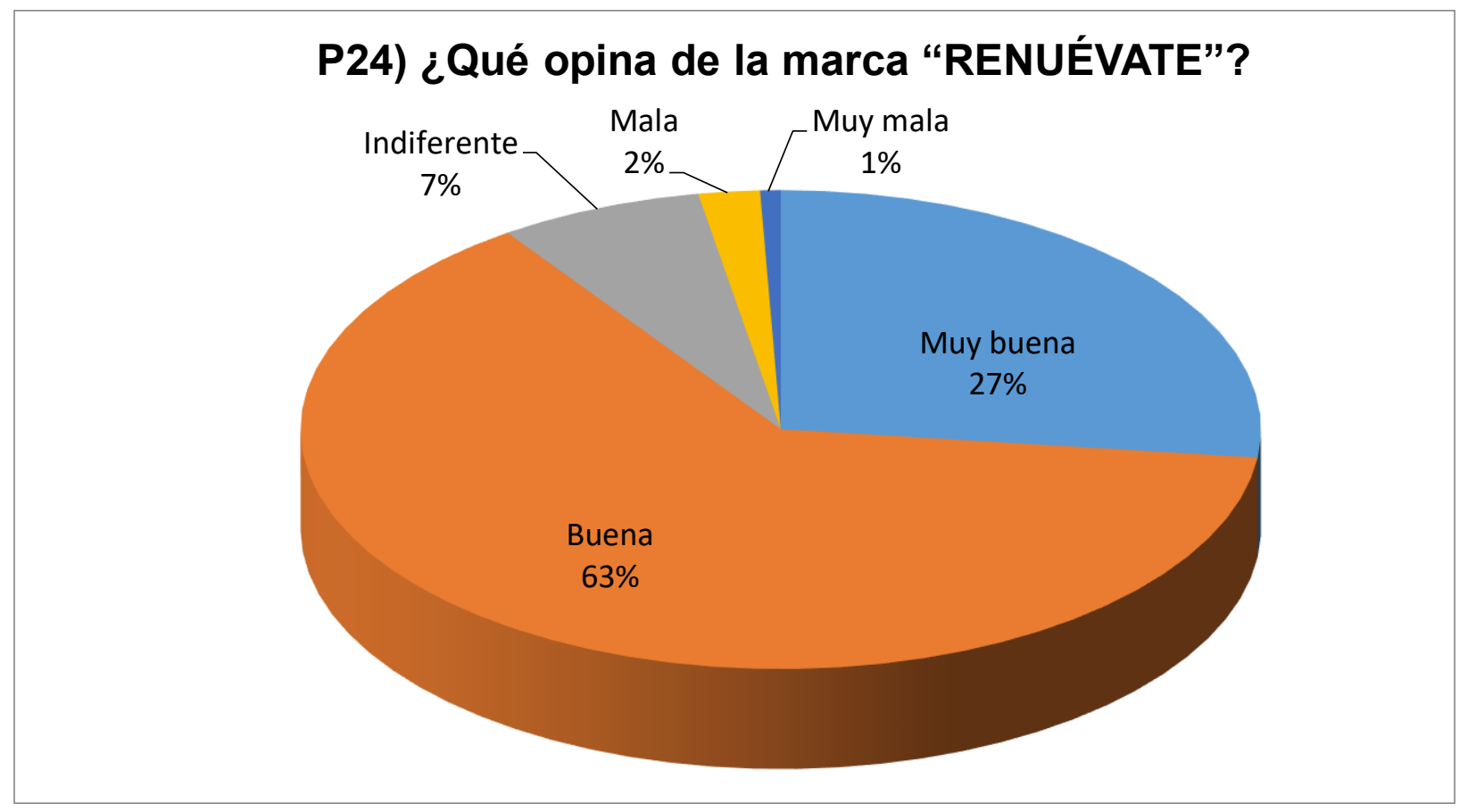

Interpretación: Un 27\% tiene una opinión muy buena de la marca RENUEVATE, un 63\% opina que es buena, para un $7 \%$ es indiferente y un $3 \%$ la considera mala. 


\section{Pregunta 25}

\begin{tabular}{|c|c|c|}
\hline \multicolumn{3}{|c|}{$\begin{array}{c}\text { 25) ¿A través de qué medio(s) le gustaría enterarse de las } \\
\text { promociones, novedades o sorteos? }\end{array}$} \\
\hline Respuesta & Cantidad & $\%$ \\
\hline Revistas / Periódico & 7 & $5 \%$ \\
\hline Volantes / Impresos & 15 & $10 \%$ \\
\hline Fan Page (Facebook) & 36 & $25 \%$ \\
\hline Instagram & 28 & $19 \%$ \\
\hline Página web & 36 & $25 \%$ \\
\hline Radio & 4 & $3 \%$ \\
\hline TV & 15 & $10 \%$ \\
\hline Otros & 4 & $3 \%$ \\
\hline Total & 145 & $100 \%$ \\
\hline
\end{tabular}

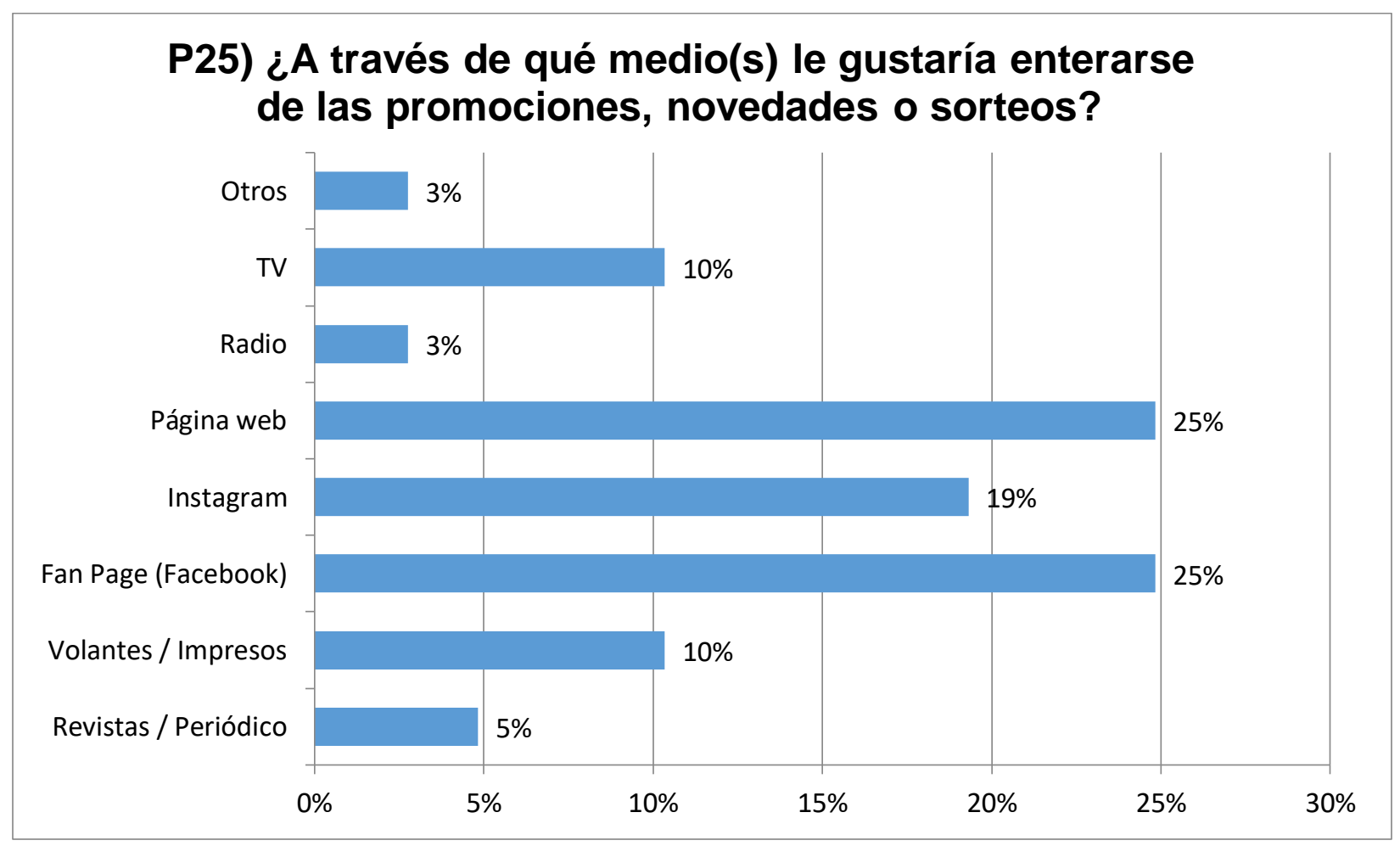

Interpretación: Del total de personas encuestadas, a un 25\% le gustaría ver las promociones, novedades o sorteos por Fan Page (Facebook) y Página Web, un 19\% prefiere el Instagram y el $10 \%$ lo haría por TV o volantes. 


\section{Pregunta 26}

\begin{tabular}{|c|c|c|}
\hline \multicolumn{3}{|c|}{$\begin{array}{l}\text { 26) ¿Qué servicios complementarios le gustaría aparte del } \\
\text { diseño, la elaboración, la instalación y la garantía? }\end{array}$} \\
\hline Respuesta & Cantidad & $\%$ \\
\hline La reparación & 22 & $15 \%$ \\
\hline El cambio de color & 15 & $10 \%$ \\
\hline El reemplazo & 7 & $5 \%$ \\
\hline Venta de accesorios complementarios & 22 & $15 \%$ \\
\hline La capacitación para el mantenimiento & 65 & $45 \%$ \\
\hline Otros & 15 & $10 \%$ \\
\hline Total & 145 & $100 \%$ \\
\hline
\end{tabular}

\section{P26) ¿Qué servicios complementarios le gustaría aparte del diseño, la elaboración, la instalación y la garantía?}

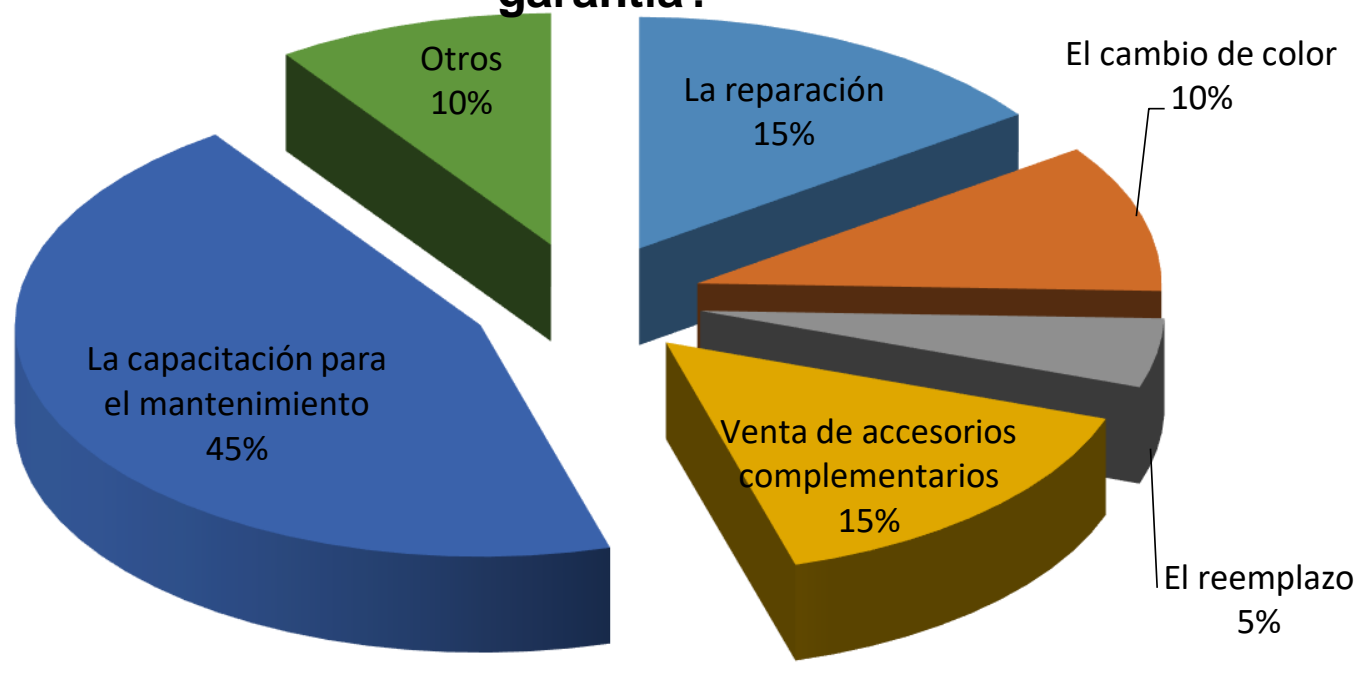

Interpretación: Del total de personas encuestadas, a un 45\% le gustaría recibir capacitación para el mantenimiento, a un $15 \%$ le gustaría poder comprar accesorios complementarios y tener el servicio de la reparación, a un $10 \%$ le gustaría que cambien de color los muebles y solo al 5\% le preocupa el reemplazo. 


\section{Anexo $N^{\circ} 15$ - Determinación del Margen de Contribución}

\begin{tabular}{lccc}
\hline \multicolumn{4}{c}{ Costo de Producción Unitario promedio } \\
\hline \multicolumn{1}{c}{ Concepto } & $\mathbf{2 0 1 9}$ & $\mathbf{2 0 2 0}$ & \multicolumn{2}{c}{$\mathbf{2 0 2 1}$} \\
\hline Materia Prima e insumos & $\mathrm{S} / .674,908$ & $\mathrm{~S} / .703,592$ & $\mathrm{~S} / .734,016$ \\
Mano de Obra Directa & $\mathrm{S} / .142,222$ & $\mathrm{~S} / .142,222$ & $\mathrm{~S} / .142,222$ \\
Costos Indirectos & $\mathrm{S} / .328,403$ & $\mathrm{~S} / .328,673$ & $\mathrm{~S} / .328,943$ \\
Total Costo de Producción & $\mathrm{S} / \mathbf{1 , 1 4 5 , 5 3 3}$ & $\mathrm{S} / \mathbf{1 , 1 7 4 , 4 8 7}$ & $\mathrm{S} / \mathbf{1 , 2 0 5 , 1 8 1}$ \\
Servicios & 275 & 287 & 299 \\
\hline Costo de producción por unidad & $\mathrm{S} / \mathbf{4 , 1 6 6}$ & $\mathrm{S} / \mathbf{4 , 0 9 2}$ & $\mathrm{S} / \mathbf{4 , 0 3 1}$ \\
\hline
\end{tabular}

\begin{tabular}{|c|c|c|c|}
\hline \multicolumn{4}{|c|}{ Costo Total Unitario promedio } \\
\hline Concepto & 2019 & 2020 & 2021 \\
\hline \multicolumn{4}{|l|}{ Costos Variables } \\
\hline Materia Prima e insumos & S/. 674,908 & S/. 703,592 & S/. 734,016 \\
\hline Luz & S/. 2,542 & S/. 2,653 & S/. 2,764 \\
\hline Agua & S/. 1,017 & S/. 1,061 & S/. 1,106 \\
\hline Insumos de mantenimiento y limpieza & S/. 1,912 & S/. 1,995 & S/. 2,079 \\
\hline Útiles de oficina & S/. 238 & S/. 249 & S/. 259 \\
\hline Internet y teléfono & S/. 1,922 & S/. 2,006 & S/. 2,090 \\
\hline \multicolumn{4}{|l|}{ Costos Fijos } \\
\hline Planilla & S/. 519,089 & S/. 520,100 & S/. 521,030 \\
\hline Arbitrios & S/. 2,000 & S/. 2,000 & S/. 2,000 \\
\hline Alquiler del local & S/. 136,271 & S/. 136,271 & S/. 136,271 \\
\hline Depreciación y amortización & S/. 74,543 & S/. 31,154 & S/. 31,154 \\
\hline Servicio de contabilidad & S/. 18,000 & S/. 18,000 & S/. 18,000 \\
\hline Visitas & S/. 5,085 & S/. 5,085 & S/. 5,085 \\
\hline Gastos de publicidad & S/. 28,403 & S/. 28,403 & S/. 28,403 \\
\hline Combustible & S/. 6,954 & S/. 6,954 & S/. 6,954 \\
\hline Gastos Financieros & S/. 34,034 & S/. 21,947 & S/. 8,167 \\
\hline Total & S/. 1,506,919 & $S / .1,481,469$ & S/. 1,499,377 \\
\hline Servicios & 275 & 287 & 299 \\
\hline Costo Total Unitario & $\mathrm{S} / . \mathbf{5 , 4 8 0}$ & $\mathrm{S} / .5,162$ & $\mathrm{~S} / . \mathbf{5 , 0 1 5}$ \\
\hline
\end{tabular}




\begin{tabular}{lcc}
\hline \multicolumn{3}{c}{ Costo variable promedio por servicios } \\
\hline \multicolumn{1}{c}{ Líneas / } & $\begin{array}{c}\text { Precio de compra } \\
\text { promedio }\end{array}$ & $\begin{array}{c}\text { Precio de } \\
\text { compra sin IGV }\end{array}$ \\
\hline A.- Casa & & \\
Habitación & $\mathrm{S} / .3,710$ & $\mathrm{~S} / .3,144$ \\
Sala & $\mathrm{S} / .3,098$ & $\mathrm{~S} / .2,626$ \\
Comedor & $\mathrm{S} / .3,908$ & $\mathrm{~S} / .3,312$ \\
Zona de Parrilla & $\mathrm{S} / .2,478$ & $\mathrm{~S} / .2,100$ \\
Cocina & $\mathrm{S} / .3,566$ & $\mathrm{~S} / .3,022$ \\
B.- & & \\
Departamento & & \\
Habitación & $\mathrm{S} / .3,030$ & $\mathrm{~S} / .2,568$ \\
Sala - comedor & $\mathrm{S} / .2,797$ & $\mathrm{~S} / .2,371$ \\
Cocina & $\mathrm{S} / .2,120$ & $\mathrm{~S} / .1,796$ \\
\hline
\end{tabular}

\begin{tabular}{|c|c|c|c|c|c|}
\hline \multirow[b]{2}{*}{$\%$ por Clase } & \multicolumn{5}{|c|}{ PROGRAMA DE VENTAS - SERVICIO } \\
\hline & LINEA & $\%$ & 2019 & 2020 & 2021 \\
\hline $100.0 \%$ & A.- Casa & $55 \%$ & 152 & 158 & 165 \\
\hline $8.6 \%$ & Habitación & $5 \%$ & 13 & 13 & 14 \\
\hline $15.8 \%$ & Sala & $9 \%$ & 24 & 25 & 26 \\
\hline $12.5 \%$ & Comedor & $7 \%$ & 19 & 20 & 21 \\
\hline $31.6 \%$ & Zona de Parrilla & $17 \%$ & 48 & 50 & 52 \\
\hline $31.6 \%$ & Cocina & $17 \%$ & 48 & 50 & 52 \\
\hline $100.0 \%$ & B.- Departamento & $45 \%$ & 123 & 129 & 134 \\
\hline $16.3 \%$ & Habitación & $7 \%$ & 20 & 20 & 22 \\
\hline $36.6 \%$ & Sala - comedor & $16 \%$ & 45 & 48 & 49 \\
\hline \multirow[t]{2}{*}{$47.2 \%$} & Cocina & $21 \%$ & 58 & 61 & 63 \\
\hline & TOTAL & $100 \%$ & 275 & 287 & 299 \\
\hline
\end{tabular}

\begin{tabular}{lrrr}
\hline \multicolumn{5}{c}{ Concepto } & \multicolumn{1}{c}{ 2019 } & \multicolumn{1}{c}{$\mathbf{2 0 2 0}$} & \multicolumn{1}{c}{$\mathbf{2 0 2 1}$} \\
\hline Materia prima e insumos & S/. 3,144 & S/. 3,144 & S/. 3,144 \\
Costo de Insumo y Mp & S/. 3,144 & S/. 3,144 & S/. 3,144 \\
Mano de Obra Directa & S/. 517 & S/. 517 & S/. 480 \\
Costos Indirectos & S/. 1,194 & S/. 1,195 & S/. 1,111 \\
Costo de Producción Unitario & S/. 4,855 & S/. 4,856 & S/. 4,735 \\
Gastos Administrativos & S/. 371 & S/. 371 & S/. 344 \\
Gastos de Ventas & S/. 820 & S/. 666 & S/. 621 \\
Gastos Financieros & S/. 124 & S/. 80 & S/. 28 \\
\hline Costo Total Unitario S/. & S/. 6,169 & S/.5,973 & S/.5,728 \\
\hline
\end{tabular}




\begin{tabular}{|c|c|c|c|}
\hline \multicolumn{4}{|c|}{ A.- CASA - Sala } \\
\hline Concepto & 2019 & 2020 & 2021 \\
\hline Materia prima e insumos & S/. 2,626 & S/. 2,626 & S/. 2,626 \\
\hline Costo de Insumo y Mp & $\mathrm{S} / . \mathbf{2 , 6 2 6}$ & $\mathrm{S} / .2,626$ & $S / .2,626$ \\
\hline Mano de Obra Directa & S/. 517 & S/. 496 & S/. 477 \\
\hline Costos Indirectos & S/. 1,194 & S/. 1,147 & S/. 1,104 \\
\hline Costo de Producción Unitario & S/. 4,337 & S/. 4,269 & S/. 4,207 \\
\hline Gastos Administrativos & S/. 371 & S/. 356 & S/. 342 \\
\hline Gastos de Ventas & S/. 820 & S/. 639 & S/. 618 \\
\hline Gastos Financieros & S/. 124 & S/. 77 & S/. 27 \\
\hline Costo Total Unitario S/. & $\mathrm{S} / . \mathbf{5 , 6 5 1}$ & S/. 5,341 & S/. 5,195 \\
\hline
\end{tabular}

\begin{tabular}{lrrr}
\hline \multicolumn{5}{c}{ A.- CASA - Comedor } \\
\hline \multicolumn{1}{c}{ Concepto } & \multicolumn{1}{c}{$\mathbf{2 0 1 9}$} & \multicolumn{1}{c}{$\mathbf{2 0 2 0}$} & \multicolumn{1}{c}{$\mathbf{2 0 2 1}$} \\
\hline Materia prima e insumos & $\mathrm{S} / .3,312$ & $\mathrm{~S} / .3,312$ & $\mathrm{~S} / .3,312$ \\
Costo de Insumo y Mp & $\mathrm{S} / . \mathbf{3 , 3 1 2}$ & $\mathrm{S} / . \mathbf{3 , 3 1 2}$ & $\mathrm{S} / . \mathbf{3 , 3 1 2}$ \\
Mano de Obra Directa & $\mathrm{S} / .517$ & $\mathrm{~S} / .491$ & $\mathrm{~S} / .468$ \\
Costos Indirectos & $\mathrm{S} / .1,194$ & $\mathrm{~S} / .1,135$ & $\mathrm{~S} / .1,082$ \\
Costo de Producción Unitario & $\mathrm{S} / . \mathbf{5 , 0 2 3}$ & $\mathrm{S} / . \mathbf{4 , 9 3 9}$ & $\mathrm{S} / . \mathbf{4 , 8 6 2}$ \\
Gastos Administrativos & $\mathrm{S} / .371$ & $\mathrm{~S} / .352$ & $\mathrm{~S} / .336$ \\
Gastos de Ventas & $\mathrm{S} / .820$ & $\mathrm{~S} / .632$ & $\mathrm{~S} / .605$ \\
Gastos Financieros & $\mathrm{S} / .124$ & $\mathrm{~S} / .76$ & $\mathrm{~S} / .27$ \\
\hline Costo Total Unitario S/. & $\mathrm{S} / . \mathbf{6 , 3 3 8}$ & $\mathrm{S} / . \mathbf{5 , 9 9 9}$ & $\mathrm{S} / . \mathbf{5 , 8 3 0}$ \\
\hline
\end{tabular}

\begin{tabular}{|c|c|c|c|}
\hline \multicolumn{4}{|c|}{ A.- CASA - Zona de Parrillas } \\
\hline Concepto & 2019 & 2020 & 2021 \\
\hline Materia prima e insumos & $\mathrm{S} / .2,100$ & S/. 2,100 & $\mathrm{S} / .2,100$ \\
\hline Costo de Insumo y Mp & $\mathrm{S} / . \mathbf{2 , 1 0 0}$ & S/. 2,100 & $\mathrm{S} / .2,100$ \\
\hline Mano de Obra Directa & S/. 517 & S/. 496 & S/. 477 \\
\hline Costos Indirectos & S/. 1,194 & S/. 1,147 & S/. 1,104 \\
\hline Costo de Producción Unitario & S/. 3,812 & S/. 3,744 & $\mathrm{S} / . \mathbf{3 , 6 8 2}$ \\
\hline Gastos Administrativos & S/. 371 & S/. 356 & S/. 342 \\
\hline Gastos de Ventas & S/. 820 & S/. 639 & S/. 618 \\
\hline Gastos Financieros & S/. 124 & S/. 77 & S/. 27 \\
\hline Costo Total Unitario S/. & S/. 5,126 & S/. 4,816 & $S / .4,669$ \\
\hline
\end{tabular}




\begin{tabular}{lrrr}
\hline \multicolumn{5}{c}{ A.- CASA - Cocina } \\
\hline \multicolumn{1}{c}{ Concepto } & \multicolumn{1}{c}{ 2019 } & \multicolumn{1}{c}{$\mathbf{2 0 2 0}$} & \multicolumn{1}{c}{$\mathbf{2 0 2 1}$} \\
\hline Materia prima e insumos & S/. 3,022 & S/. 3,022 & S/. 3,022 \\
Costo de Insumo y Mp & S/. 3,022 & S/. 3,022 & S/. 3,022 \\
Mano de Obra Directa & $\mathrm{S} / .517$ & $\mathrm{~S} / .496$ & $\mathrm{~S} / .477$ \\
Costos Indirectos & $\mathrm{S} / .1,194$ & $\mathrm{~S} / .1,147$ & $\mathrm{~S} / .1,104$ \\
Costo de Producción Unitario & $\mathrm{S} / \mathbf{4 , 7 3 4}$ & $\mathrm{S} / \mathbf{4 , 6 6 6}$ & $\mathrm{S} / \mathbf{4 , 6 0 4}$ \\
Gastos Administrativos & $\mathrm{S} / .371$ & $\mathrm{~S} / .356$ & $\mathrm{~S} / .342$ \\
Gastos de Ventas & $\mathrm{S} / .820$ & $\mathrm{~S} / .639$ & $\mathrm{~S} / .618$ \\
Gastos Financieros & $\mathrm{S} / .124$ & $\mathrm{~S} / .77$ & $\mathrm{~S} / .27$ \\
\hline Costo Total Unitario S/. & S/. 6,048 & S/. 5,738 & S/.5,591 \\
\hline
\end{tabular}

\begin{tabular}{|c|c|c|c|}
\hline \multicolumn{4}{|c|}{ B.- DEPARTAMENTO -Habitación } \\
\hline Concepto & 2019 & 2020 & 2021 \\
\hline Materia prima e insumos & $\mathrm{S} / .2,568$ & $\mathrm{~S} / .2,568$ & S/. 2,568 \\
\hline Costo de Insumo y Mp & S/. 2,568 & $\mathrm{S} / . \mathbf{2 , 5 6 8}$ & S/. 2,568 \\
\hline Mano de Obra Directa & S/. 517 & S/. 517 & S/. 470 \\
\hline Costos Indirectos & S/. 1,194 & S/. 1,195 & S/. 1,087 \\
\hline Costo de Producción Unitario & S/. 4,279 & $\mathrm{S} / .4,280$ & $\mathrm{~S} / . \mathbf{4 , 1 2 5}$ \\
\hline Gastos Administrativos & S/. 371 & S/. 371 & S/. 337 \\
\hline Gastos de Ventas & S/. 820 & S/. 666 & S/. 608 \\
\hline Gastos Financieros & S/. 124 & S/. 80 & S/. 27 \\
\hline Costo Total Unitario S/. & $\mathrm{S} / . \mathbf{5 , 5 9 3}$ & $\mathrm{S} / . \mathbf{5 , 3 9 6}$ & S/. 5,098 \\
\hline
\end{tabular}




\begin{tabular}{|c|c|c|c|}
\hline \multicolumn{4}{|c|}{ B.- DEPARTAMENTO - Cocina } \\
\hline Concepto & 2019 & 2020 & 2021 \\
\hline Materia prima e insumos & S/. 1,796 & S/. 1,796 & S/. 1,796 \\
\hline Costo de Insumo y Mp & S/. 1,796 & S/. 1,796 & S/. 1,796 \\
\hline Mano de Obra Directa & S/. 517 & S/. 492 & S/. 476 \\
\hline Costos Indirectos & S/. 1,194 & S/. 1,136 & S/. 1,101 \\
\hline Costo de Producción Unitario & $\mathrm{S} / . \mathbf{3 , 5 0 8}$ & S/. 3,424 & S/. 3,374 \\
\hline Gastos Administrativos & S/. 371 & S/. 353 & S/. 341 \\
\hline Gastos de Ventas & S/. 820 & S/. 633 & S/. 616 \\
\hline Gastos Financieros & S/. 124 & S/. 76 & S/. 27 \\
\hline Costo Total Unitario S/. & S/. 4,822 & $\mathrm{S} / . \mathbf{4 , 4 8 6}$ & $\mathrm{S} / . \mathbf{4 , 3 5 8}$ \\
\hline
\end{tabular}

\section{COSTO TOTAL UNITARIO POR PRODUCTO}

\begin{tabular}{llll}
\hline \multicolumn{1}{c}{ Concepto } & $\mathbf{2 0 1 9}$ & $\mathbf{2 0 2 0}$ & $\mathbf{2 0 2 1}$ \\
\hline A.- Casa & & & \\
Habitación & S/. 6,169 & S/. 5,973 & S/. 5,728 \\
Sala & S/. 5,651 & S/. 5,341 & S/. 5, 195 \\
Comedor & S/. 6,338 & S/. 5,999 & S/. 5,830 \\
Zona de Parrilla & S/. 5,126 & S/. 4,816 & S/. 4,669 \\
Cocina & S/. 6,048 & S/. 5,738 & S/. 5,591 \\
B.- Departamento & & & \\
Habitación & S/. 5,593 & S/. 5,396 & S/. 5, 098 \\
Sala - comedor & S/. 5,396 & S/. 5,023 & S/. 4,927 \\
Cocina & S/. 4,822 & S/. 4,486 & S/. 4,358 \\
\hline
\end{tabular}

\begin{tabular}{|c|c|c|c|}
\hline \multicolumn{4}{|c|}{ B.- DEPARTAMENTO - Sala - Comedor } \\
\hline Concepto & 2019 & 2020 & 2021 \\
\hline Materia prima e insumos & S/. 2,371 & $\mathrm{S} / .2,371$ & S/. 2,371 \\
\hline Costo de Insumo y Mp & S/. 2,371 & S/. 2,371 & S/. 2,371 \\
\hline Mano de Obra Directa & S/. 517 & S/. 485 & S/. 475 \\
\hline Costos Indirectos & S/. 1,194 & $\mathrm{~S} / .1,120$ & S/. 1,099 \\
\hline Costo de Producción Unitario & $\mathrm{S} / .4,082$ & S/. 3,976 & S/. 3,944 \\
\hline Gastos Administrativos & S/. 371 & S/. 348 & S/. 341 \\
\hline Gastos de Ventas & S/. 820 & S/. 624 & S/. 615 \\
\hline Gastos Financieros & S/. 124 & S/. 75 & S/. 27 \\
\hline Costo Total Unitario S/. & $\mathrm{S} / . \mathbf{5 , 3 9 6}$ & $\mathrm{S} / . \mathbf{5 , 0 2 3}$ & S/. 4,927 \\
\hline
\end{tabular}




\begin{tabular}{|c|c|c|c|}
\hline \multicolumn{4}{|c|}{ Estructura de precios } \\
\hline Servicios & $\mathbf{V V}$ & IGV & PV \\
\hline \multicolumn{4}{|l|}{ A.- Casa } \\
\hline Habitación & S/. 5,392 & S/. 971 & S/. 6,362 \\
\hline Sala & S/. 5,064 & S/. 912 & S/. 5,975 \\
\hline Comedor & S/. 5,907 & S/. 1,063 & S/. 6,970 \\
\hline Zona de Parrilla & S/. 5,281 & S/. 951 & S/. 6,231 \\
\hline Cocina & S/. 6,699 & S/. 1,206 & S/. 7,904 \\
\hline \multicolumn{4}{|l|}{ B.- Departamento } \\
\hline Habitación & S/. 4,804 & S/. 865 & S/. 5,669 \\
\hline Sala - comedor & S/. 5,568 & S/. 1,002 & S/. 6,571 \\
\hline Cocina & S/. 5,240 & S/. 943 & S/. 6,183 \\
\hline Precio Ponderado & S/. 5,622 & $\mathrm{S} / . \mathbf{1 , 0 1 2}$ & S/. 6,634 \\
\hline
\end{tabular}

\begin{tabular}{lccc}
\hline \multicolumn{4}{c}{ Costo Variable Unitario } \\
\hline A.- Casa & $\mathbf{2 0 1 9}$ & $\mathbf{2 0 2 0}$ & $\mathbf{2 0 2 1}$ \\
Habitación & & & \\
Sala & $\mathrm{S} / .3,172$ & $\mathrm{~S} / .3,173$ & $\mathrm{~S} / .3,172$ \\
Comedor & $\mathrm{S} / .2,653$ & $\mathrm{~S} / .2,653$ & $\mathrm{~S} / .2,653$ \\
Zona de Parrilla & $\mathrm{S} / .3,340$ & $\mathrm{~S} / .3,340$ & $\mathrm{~S} / .3,339$ \\
Cocina & $\mathrm{S} / .2,128$ & $\mathrm{~S} / .2,128$ & $\mathrm{~S} / .2,128$ \\
B.- Departamento & $\mathrm{S} / .3,050$ & $\mathrm{~S} / .3,050$ & $\mathrm{~S} / .3,050$ \\
Habitación & & & \\
Sala - comedor & $\mathrm{S} / .2,595$ & $\mathrm{~S} / .2,596$ & $\mathrm{~S} / .2,595$ \\
Cocina & $\mathrm{S} / .2,398$ & $\mathrm{~S} / .2,398$ & $\mathrm{~S} / .2,398$ \\
\hline Costo Variable Unitario Ponderado & $\mathrm{S} / .1,824$ & $\mathrm{~S} / .1,824$ & $\mathrm{~S} / .1,824$ \\
\hline
\end{tabular}


Anexo $\mathbf{N}^{\circ} 16$ - Cálculo del análisis de sensibilidad

\begin{tabular}{lccc}
\hline \multicolumn{4}{c}{ Variables de entrada } \\
\hline \multicolumn{1}{c}{ Concepto } & $\mathbf{2 0 1 9}$ & Var (2020/2019) & Var (2021/2020) \\
\hline Ventas & $\mathrm{S} / 1,529,416$ & $4.40 \%$ & $4.13 \%$ \\
Costo de ventas & - & $2.53 \%$ & $2.61 \%$ \\
Gastos de ventas y administración & $\mathrm{S} / 1,145,533$ & & $0.39 \%$ \\
\hline
\end{tabular}

\begin{tabular}{|c|c|c|c|c|}
\hline \multicolumn{5}{|c|}{ Flujo de Caja Financiero } \\
\hline & 2018 & 2019 & 2020 & 2021 \\
\hline Ventas & & $S / 1,529,416$ & $S / 1,596,770$ & $S / 1,662,746$ \\
\hline Costo de venta & & $-S / 1,145,533$ & $-S / 1,174,487$ & $-S / 1,205,181$ \\
\hline Utilidad Bruta & & $S / 383,883$ & $S / 422,283$ & $S / 457,565$ \\
\hline Gastos de vtas y adm. & & $-S / 252,808$ & $-S / 253,882$ & $-S / 254,875$ \\
\hline Deprec. y amortiz. & & $-S / 74,543$ & $-S / 31,154$ & $-S / 31,154$ \\
\hline Utilidad Operativa & & $S / 56,532$ & $S / 137,248$ & $S / 171,536$ \\
\hline Partic. de los trab. & & $-S / 2,827$ & $-S / 6,862$ & $-S / 8,577$ \\
\hline Impuesto a la renta & & $-S / 15,843$ & $-S / 38,464$ & $-S / 48,073$ \\
\hline Utilidad Neta & & $S / 37,862$ & $S / 91,922$ & $S / 114,886$ \\
\hline Deprec. y amortiz. & & $S / 74,543$ & $S / 31,154$ & $\mathrm{~S} / 31,154$ \\
\hline Flujo de Caja Operat. & & $S / 112,406$ & $S / 123,075$ & $S / 146,040$ \\
\hline Liquidación del IGV & & $S / 53,263$ & & \\
\hline Perpetuidad de FDC & & & & $S / 1,187,112$ \\
\hline$(+/-)$ Inv. en KT & $-S / 66,366$ & $-S / 2,821$ & $-S / 2,992$ & $-S / 2,992$ \\
\hline Inversión en AF & $-S / 296,967$ & & & \\
\hline Inversión en Intang. & $-S / 54,200$ & & & \\
\hline Perpetuidad de Inv. & & & & $-S / 184,957$ \\
\hline Flujo de Caja Econ. (FCE) & $-S / 417,532$ & $S / 162,848$ & $S / 120,084$ & $S / 1,145,203$ \\
\hline Préstamo & $S / 296,967$ & & & \\
\hline Servicio de la Deuda & & $-S / 137,062$ & $-S / 137,062$ & $-S / 137,062$ \\
\hline Escudo Trib. de Intereses & & $S / 19,541$ & $S / 13,109$ & $\mathrm{~S} / 5,071$ \\
\hline Flujo de Caja Finan. (FCF) & $-S / 120,566$ & $S / 45,327$ & $-S / 3,869$ & $S / 1,013,212$ \\
\hline
\end{tabular}

\section{VARIABLES DE SALIDA}

\begin{tabular}{crcr} 
WACC & $12.30 \%$ & COK propio & $19.51 \%$ \\
VANE & $\mathrm{S} / 631,263$ & VANF & $\mathrm{S} / 508,270$ \\
TIRE & $61.69 \%$ & TIRF & $116.09 \%$ \\
\hline
\end{tabular}




\section{Anexo $N^{\circ} 17$ - Efecto por variación en el tipo de cambio}

Para un incremento en el tipo de cambio del 1\% tenemos un incremento en las ventas de S/ 3,333.57 y un incremento en las compras de insumos en $\mathrm{S} / 708.55$.

\begin{tabular}{lrrrrrr}
\multicolumn{2}{c}{ VENTAS } \\
ENERO & \multicolumn{7}{c}{ Variación en el tipo de camb } \\
\hline Producto & \multicolumn{3}{c}{ Cantidad } & V. Vta Unit. \$ V. Vta Total \$ & \multicolumn{1}{l}{ TC } & V. Vta Total S/ \\
\hline Caja china mediana (Tapa trapez) & 4 & 270.00 & $1,080.00$ & 3.389 & $3,659.63$ \\
Base fija & 4 & 180.00 & 720.00 & 3.389 & $2,439.76$ \\
Parrilla con caja china (Parrilla con c & 1 & $1,380.00$ & $1,380.00$ & 3.389 & $4,676.20$ \\
Parrilla dual (Parrilla a gas con tapa & 1 & $1,130.00$ & $1,130.00$ & 3.389 & $3,829.06$ \\
Parrilla Std grande (Parrilla con caja & 1 & $1,550.00$ & $1,550.00$ & 3.389 & $5,252.25$ \\
Parrilla Std mediana (Parrilla a gas Ca & 2 & 960.00 & $1,920.00$ & 3.378 & $6,486.62$ \\
Parrilla Std pequeña (Parrilla dual (gi & 1 & 810.00 & 810.00 & 3.376 & $2,734.91$ \\
Varios (3 bases fijas) & 1 & 550.00 & 550.00 & 3.378 & $1,858.15$ \\
\hline & & & & $\mathbf{9 , 1 4 0 . 0 0}$ & & $\mathbf{3 0 , 9 3 6 . 5 8}$
\end{tabular}
$1 \%$

\section{FEBRERO}

\begin{tabular}{lrrrrr}
\hline Producto & Cantidad & V. Vta Unit. \$ V. Vta Total \$ & TC & V. Vta Total S/ \\
\hline Caja china mediana (Tapa trapez) & 9 & 270.00 & $2,430.00$ & 3.392 & $8,241.54$ \\
Caja china grande (base + fondo par & 4 & 350.00 & $1,400.00$ & 3.392 & $4,748.21$ \\
Caja china pequeña (Base fija) & 6 & 180.00 & $1,080.00$ & 3.392 & $3,662.91$ \\
Parrilla Std mediana (Parrilla STD co & 2 & 895.00 & $1,790.00$ & 3.392 & $6,070.93$ \\
Parrilla Std mediana (Parrilla a gas C & 1 & 970.00 & 970.00 & 3.392 & $3,289.83$ \\
Parrilla Std (Parrilla a gas) & 1 & 740.00 & 740.00 & 3.392 & $2,509.77$ \\
Parrilla + caja china & 1 & 989.00 & 989.00 & 3.392 & $3,354.27$ \\
Tapa plana (Parrilla doble sistema) & 1 & 700.00 & 700.00 & 3.392 & $2,374.11$ \\
Wok (Parrilla a gas) & 1 & 711.00 & 711.00 & 3.392 & $2,411.41$ \\
\hline & & & $\mathbf{1 0 , 8 1 0 . 0 0}$ & & $\mathbf{3 6 , 6 6 2 . 9 8}$
\end{tabular}

$30,630.34 \quad 306.24$

MARZO

\begin{tabular}{lrrrrr}
\hline Producto & Cantidad V. Vta Unit. \$ V. Vta Total \$ & \multicolumn{1}{l}{ TC } & V. Vta Total S \\
\hline Caja china mediana (Tapa trapez) & 5 & 270.00 & $1,350.00$ & 3.378 & $4,560.91$ \\
Caja china pequeña (Base fija) & 3 & 180.00 & 540.00 & 3.389 & $1,829.82$ \\
Caja china grande (base + fondo par & 1 & 350.00 & 350.00 & 3.378 & $1,182.46$ \\
Parrilla std (parrilla a gas) & 4 & 711.00 & $2,844.00$ & 3.378 & $9,608.31$ \\
Parrilla doble + wok y hornilla (parril & 1 & $1,740.00$ & $1,740.00$ & 3.378 & $5,878.50$ \\
Parrilla + tapa trapez (parrilla std co & 1 & $1,153.00$ & $1,153.00$ & 3.378 & $3,895.35$ \\
Puerta para horno y ducto (parrilla s & 1 & 597.00 & 597.00 & 3.389 & $2,022.96$ \\
\hline
\end{tabular}

$36,301.00 \quad 361.98$

\section{ABRIL}

\begin{tabular}{lrrrrr}
\hline Producto & Cantidad & V. Vta Unit. \$ V. Vta Total\$ & TC & V. Vta Total S \\
\hline Caja china pequeña (Base fija) & 3 & 183.00 & 549.00 & 3.396 & $1,864.20$ \\
Caja china mediana (Tapa trapez) & 1 & 285.00 & 285.00 & 3.396 & 967.75 \\
Caja china grande (base + fondo par & 2 & 353.00 & 706.00 & 3.396 & $2,397.31$ \\
Caja china de acero inox con parrille & 1 & $1,093.00$ & $1,093.00$ & 3.396 & $3,711.41$ \\
Caja china de acero inox y parrilla (F & 2 & $1,029.00$ & $2,058.00$ & 3.396 & $6,988.19$ \\
Parrilla uruguaya (Parrilla STD con té & 1 & 882.00 & 882.00 & 3.396 & $2,994.94$ \\
Parrilla con caja china con tapa (Par & 1 & $1,298.00$ & $1,298.00$ & 3.396 & $4,407.51$ \\
Parrilla std (parrilla a gas) & 2 & 711.00 & $1,422.00$ & 3.399 & $4,832.88$ \\
Parrilla Std con tapa (Parrilla a gas C & 1 & $1,096.00$ & $1,096.00$ & 3.399 & $3,724.92$ \\
\hline
\end{tabular}

$\begin{array}{rrr}9,389.00 & 31,889.11\end{array}$

MAYO

\begin{tabular}{lcrrrr}
\hline Producto & Cantidad V. Vta Unit. \$ V. Vta Total \$ & TC & V. Vta Total S/ \\
\hline Caja china pequeña (Base fija) & 8 & 183.00 & $1,464.00$ & 3.363 & $4,923.87$ \\
Caja china mediana (Tapa trapez) & 8 & 285.00 & $2,280.00$ & 3.363 & $7,668.32$ \\
Caja china grande (base + fondo par & 1 & 353.00 & 353.00 & 3.363 & $1,187.24$ \\
Wok (Fondo parrilla x 3) & 3 & 170.00 & 510.00 & 3.361 & $1,714.25$ \\
Parrilla Std (parrilla a gas) & 2 & 711.00 & $1,422.00$ & 3.363 & $4,782.61$ \\
Parrilla a gas dual (Parrilla dual) & 1 & 811.00 & $811.00^{-2}$ & 3.363 & $\mathbf{2 , 7 2 7 . 6 4}$ \\
\hline
\end{tabular}

\begin{tabular}{|c|c|c|c|c|c|}
\hline Producto & Cantidad & V. Vta Unit. \$ & V. Vta Total\$ & TC & V. Vta Total S/ \\
\hline Caja china pequeña (Base fija) & 11 & 183.00 & $2,013.00^{\prime}$ & 3.346 & $6,735.76$ \\
\hline Caja china mediana (Tapa trapez) & 8 & 285.00 & $2,280.00^{\circ}$ & 3.346 & $7,629.18$ \\
\hline Caja china grande (base + fondo par & 2 & 353.00 & $706.00^{\circ}$ & 3.346 & $2,362.37$ \\
\hline (04) Silla de madera con base de ac€ & 3 & 139.00 & $417.00^{\circ}$ & 3.346 & $1,395.34$ \\
\hline Parrilla con caja china (Parrilla con c & 2 & $1,274.00$ & $2,548.00^{\circ}$ & 3.345 & $8,523.37$ \\
\hline Parrilla Std (Parrilla dual) & 2 & 811.00 & $1,622.00^{\circ}$ & 3.346 & $5,427.42$ \\
\hline Parrilla con caja china y tapa trapez & 1 & $1,421.00$ & $1,421.00^{\top}$ & 3.346 & $4,754.85$ \\
\hline Parrilla doble sistema con tapa (Parı & 1 & $1,274.00$ & $1,274.00^{\prime}$ & 3.346 & $4,262.97$ \\
\hline
\end{tabular}


JULIO

\begin{tabular}{lrrrrr}
\hline Producto & Cantidad V. Vta Unit. \$ V. Vta Total \$ & TC & V. Vta Total S/ \\
\hline Caja china pequeña (Base fija) & 4 & 183.00 & 732.00 & 3.358 & $2,458.24$ \\
Caja china mediana (Tapa trapez) & 6 & 285.00 & $1,710.00$ & 3.358 & $5,742.61$ \\
Caja china grande (base + fondo par & 1 & 353.00 & 353.00 & 3.356 & $1,184.75$ \\
Parrilla con caja china + tapa (Parrill & 2 & $1,421.00$ & $2,842.00$ & 3.358 & $9,544.15$ \\
Parrilla Std (parrilla a gas) & 2 & 711.00 & $1,422.00$ & 3.358 & $4,775.43$ \\
Parrilla con caja china y base (Parrill & 1 & $1,553.00$ & $1,553.00$ & 3.358 & $5,215.36$ \\
Parrilla con caja china (Parrilla con c & 1 & 989.00 & 989.00 & 3.358 & $3,321.31$ \\
\hline
\end{tabular}

\section{AGOSTO}

\begin{tabular}{lrrrrr}
\hline Producto & Cantidad V. Vta Unit. \$ V. Vta Total \$ & TC & V. Vta Total S/ \\
\hline Caja china pequeña (Base fija) & 1 & 183.00 & 183.00 & 3.399 & 621.95 \\
Caja china mediana (Tapa trapez) & 2 & 285.00 & 570.00 & 3.399 & $1,937.23$ \\
Caja china grande (base + fondo par & 2 & 353.00 & 706.00 & 3.399 & $2,399.45$ \\
Caja china full (Parrilla con caja chin & 3 & 989.00 & $2,967.00$ & 3.399 & $10,083.79$ \\
Mesas y repisas (Parrilla con caja ch & 1 & $1,121.00$ & $1,121.00$ & 3.399 & $3,809.89$ \\
Freidor de acero inox (Base plegabl€ & 2 & 132.00 & 264.00 & 3.399 & 897.24 \\
Parrilla full (Parrilla full + base fija) & 2 & $1,276.00$ & $2,552.00$ & 3.399 & $8,673.35$ \\
Parrilla Std con tapa (Parrilla dual) & 1 & 811.00 & 811.00 & 3.399 & $2,756.31$ \\
Parrilla gas dual (Parrilla a gas con ti & 1 & $1,096.00$ & $1,096.00$ & 3.399 & $3,724.92$ \\
Parrilla Std (parrilla a gas) & 1 & 711.00 & 711.00 & 3.397 & $2,415.00$ \\
Parrilla con caja china (Parrilla con c & 1 & 989.00 & 989.00 & 3.399 & $3,361.26$ \\
\hline
\end{tabular}

$40,278.00 \quad 402.40$

\section{SETIEMBRE}

\begin{tabular}{lrrrrr}
\hline Producto & Cantidad V. Vta Unit. \$ V. Vta Total \$ & TC & V. Vta Total S/ \\
\hline Caja china pequeña (Base fija) & 8 & 183.00 & $1,464.00$ & 3.363 & $4,923.87$ \\
Caja china mediana (Tapa trapez) & 8 & 285.00 & $2,280.00$ & 3.363 & $7,668.32$ \\
Caja china grande (base + fondo par & 1 & 353.00 & 353.00 & 3.361 & $1,186.53$ \\
Wok (Fonde parrilla x 3) & 3 & 170.00 & 510.00 & 3.363 & $1,715.28$ \\
Parrilla Std (parrilla a gas) & 2 & 711.00 & $1,422.00$ & 3.363 & $4,782.61$ \\
Parrilla a gas dual (Parrilla dual) & 1 & 811.00 & 811.00 & 3.363 & $\mathbf{2 , 7 2 7 . 6 4}$ \\
\hline
\end{tabular}

$22,776.00 \quad 228.26$

\section{OCTUBRE}

\section{Producto}

$6,840.00$
$31,922.00 \quad 319.85$

\begin{tabular}{lrrrrr} 
& Cantidad V. Vta Unit. $\mathbf{~ V . V t a ~ T o t a l ~}$ & \multicolumn{2}{c}{ TC. Vta Total S/ } \\
\hline Caja china mediana (Tapa trapez) & 5 & 270.00 & $1,350.00$ & 3.378 & $4,560.91$ \\
Caja china pequeña (Base fija) & 3 & 180.00 & 540.00 & 3.389 & $1,829.82$ \\
Caja china grande (base + fondo par & 1 & 350.00 & 350.00 & 3.378 & $1,182.46$ \\
Parrilla std (parrilla a gas) & 4 & 711.00 & $2,844.00$ & 3.378 & $9,608.31$ \\
Parrilla doble + wok y hornilla (parril & 1 & $1,740.00$ & $1,740.00$ & 3.378 & $5,878.50$ \\
Parrilla + tapa trapez (parrilla std co & 1 & $1,153.00$ & $1,153.00$ & 3.378 & $3,895.35$ \\
Puerta para horno y ducto (parrilla s & 1 & 597.00 & 597.00 & 3.389 & $2,022.96$ \\
\hline
\end{tabular}

$28,691.32 \quad 286.99$

\section{DICIEMBRE}

\begin{tabular}{lrrrrr}
\hline Producto & Cantidad V. Vta Unit. \$ V. Vta Total \$ & TC & \multicolumn{1}{r}{ V. Vta Total S/ } \\
\hline Caja china mediana (Tapa trapez) & 5 & 270.00 & $1,350.00$ & 3.376 & $4,558.18$ \\
Caja china pequeña (Base fija) & 3 & 180.00 & 540.00 & 3.378 & $1,824.36$ \\
Caja china grande (base + fondo par & 1 & 350.00 & 350.00 & 3.376 & $1,181.75$ \\
Parrilla std (parrilla a gas) & 4 & 711.00 & $2,844.00$ & 3.376 & $9,602.57$ \\
Puerta para horno y ducto (parrilla 5 & 1 & 597.00 & 597.00 & 3.378 & $\mathbf{2 , 0 1 6 . 9 3}$ \\
\hline
\end{tabular}

$18,994.42 \quad 189.38$ 
ENERO

COMPRAS

Variación en el tipo de cambio $1 \%$

\begin{tabular}{lrrrrrr}
\hline Producto & Cantidad & Costo M.P. \$ & Costo M.O. y GRAL \$ & TC 1 & TC 2 & Costo Total S/ \\
\hline Caja china mediana (Tapa trapı & 4 & 33.41 & 117.60 & 3.389 & 3.355 & $2,031.03$ \\
Base fija & 4 & 67.82 & 29.40 & 3.389 & 3.355 & $1,313.82$ \\
Parrilla con caja china (Parrilla & 1 & 295.04 & 441.00 & 3.389 & 3.355 & $2,479.30$ \\
Parrilla dual (Parrilla a gas con & 1 & 183.14 & 444.55 & 3.389 & 3.355 & $2,112.05$ \\
Parrilla Std grande (Parrilla con & 1 & 325.63 & 488.04 & 3.389 & 3.355 & $2,740.77$ \\
Parrilla Std mediana (Parrilla a & 2 & 183.14 & 344.55 & 3.378 & 3.345 & $3,542.50$ \\
Parrilla Std pequeña (Parrilla di & 1 & 149.73 & 326.95 & 3.376 & 3.343 & $1,598.55$ \\
Varios (3 bases fijas) & 1 & 203.47 & 88.20 & 3.378 & 3.345 & 982.43 \\
\hline
\end{tabular}

$16,735.84 \quad 64.62$

FEBRERO

\begin{tabular}{lrrrrrr}
\hline Producto & Cantidad & Costo M.P. \$ & Costo M.O. y GRAL \$ & TC 1 & TC 2 & Costo Total S / \\
\hline Caja china mediana (Tapa trapı & 9 & 33.41 & 117.60 & 3.392 & 3.358 & $4,573.91$ \\
Caja china grande (base + fond & 4 & 99.33 & 88.20 & 3.392 & 3.358 & $2,532.30$ \\
Caja china pequeña (Base fija) & 6 & 67.82 & 29.40 & 3.392 & 3.358 & $1,972.49$ \\
Parrilla Std mediana (Parrilla ST & 2 & 164.34 & 294.00 & 3.392 & 3.358 & $3,089.27$ \\
Parrilla Std mediana (Parrilla a & 1 & 183.14 & 344.55 & 3.392 & 3.358 & $1,778.13$ \\
Parrilla Std (Parrilla a gas) & 1 & 149.73 & 226.95 & 3.392 & 3.358 & $1,269.92$ \\
Parrilla + caja china & 1 & 220.83 & 294.00 & 3.392 & 3.358 & $1,736.22$ \\
Tapa plana (Parrilla doble sistel & 1 & 156.51 & 205.80 & 3.392 & 3.358 & $1,221.89$ \\
Wok (Parrilla a gas) & 1 & 149.73 & 226.95 & 3.392 & 3.358 & $1,269.92$ \\
\hline
\end{tabular}

$1,224.85 \quad 1,827.45 \quad 19,444.06$

$19,367.04 \quad 77.02$

MARZO

\begin{tabular}{lrrrrrr}
\hline Producto & Cantidad & Costo M.P. \$ & Costo M.O. y GRAL \$ & TC 1 & TC 2 & Costo Total S/ \\
\hline Caja china mediana (Tapa trapı & 5 & 33.41 & 117.60 & 3.378 & 3.345 & $2,531.23$ \\
Caja china pequeña (Base fija) & 3 & 67.82 & 29.40 & 3.389 & 3.355 & 985.37 \\
Caja china grande (base + fond & 1 & 99.33 & 88.20 & 3.378 & 3.345 & 630.62 \\
Parrilla std (parrilla a gas) & 4 & 149.73 & 226.95 & 3.378 & 3.345 & $5,060.02$ \\
Parrilla doble + wok y hornilla & 1 & 344.66 & 567.99 & 3.378 & 3.345 & $3,064.35$ \\
Parrilla + tapa trapez (parrilla s & 1 & 234.89 & 367.50 & 3.378 & 3.345 & $2,022.84$ \\
Puerta para horno y ducto (par & 1 & 130.93 & 176.40 & 3.389 & 3.355 & $1,035.50$ \\
\hline
\end{tabular}

$15,270.36 \quad 59.55$

ABRIL

\begin{tabular}{lrrrrrr}
\hline Producto & Cantidad & Costo M.P. \$ & Costo M.O. y GRAL \$ & TC 1 & TC 2 & Costo Total S/ \\
\hline Caja china pequeña (Base fija) & 3 & 67.82 & 29.40 & 3.396 & 3.362 & 987.42 \\
Caja china mediana (Tapa trap & 1 & 33.41 & 117.60 & 3.396 & 3.362 & 508.82 \\
Caja china grande (base + fond & 2 & 99.33 & 88.20 & 3.396 & 3.362 & $1,267.66$ \\
Caja china de acero inox con pi & 1 & 246.41 & 323.40 & 3.396 & 3.362 & $1,923.98$ \\
Caja china de acero inox y parr & 2 & 194.93 & 341.04 & 3.396 & 3.362 & $3,616.98$ \\
Parrilla uruguaya (Parrilla STD c & 1 & 164.34 & 294.00 & 3.396 & 3.362 & $1,546.47$ \\
Parrilla con caja china con tapa & 1 & 282.09 & 396.90 & 3.396 & 3.362 & $2,292.24$ \\
Parrilla std (parrilla a gas) & 2 & 149.73 & 226.95 & 3.399 & 3.365 & $2,545.14$ \\
Parrilla Std con tapa (Parrilla a & 1 & 183.14 & 444.55 & 3.399 & 3.365 & $2,118.34$ \\
\hline
\end{tabular}

$16,739.76 \quad 67.28$

MAYO

\begin{tabular}{lrrrrrr}
\hline Producto & Cantidad & Costo M.P. \$ & Costo M.O. y GRAL \$ & TC 1 & TC 2 & Costo Total S/ \\
\hline Caja china pequeña (Base fija) & 8 & 67.82 & 29.40 & 3.363 & 3.330 & $2,608.06$ \\
Caja china mediana (Tapa trap & 8 & 33.41 & 117.60 & 3.363 & 3.330 & $4,031.80$ \\
Caja china grande (base + fond & 1 & 99.33 & 88.20 & 3.363 & 3.330 & 627.80 \\
Wok (Fondo parrilla x 3) & 3 & 31.51 & 58.80 & 3.361 & 3.328 & 904.82 \\
Parrilla Std (parrilla a gas) & 2 & 149.73 & 226.95 & 3.363 & 3.330 & $2,518.66$ \\
Parrilla a gas dual (Parrilla dual', & 1 & 149.73 & 326.95 & 3.363 & 3.330 & $1,592.33$ \\
\hline & & $\mathbf{5 3 1 . 5 4}$ & $\mathbf{8 4 7 . 9 0}$ & & & $\mathbf{1 2 , 2 8 3 . 4 7}$
\end{tabular}

$12,235.09 \quad 48.38$

JUNIO

\begin{tabular}{lrrrrrr}
\hline Producto & Cantidad & Costo M.P. \$ & Costo M.O. y GRAL \$ & TC 1 & TC 2 & Costo Total S/ \\
\hline Caja china pequeña (Base fija) & 11 & 67.82 & 29.40 & 3.346 & 3.313 & $3,567.78$ \\
Caja china mediana (Tapa trapı & 8 & 33.41 & 117.60 & 3.346 & 3.313 & $4,011.22$ \\
Caja china grande (base + fond & 2 & 99.33 & 88.20 & 3.346 & 3.313 & $1,249.18$ \\
(04) Silla de madera con base d & 3 & 29.75 & 44.10 & 3.346 & 3.313 & 736.91 \\
Parrilla con caja china (Parrilla & 2 & 254.24 & 411.60 & 3.345 & 3.312 & $4,427.37$ \\
Parrilla Std (Parrilla dual) & 2 & 149.73 & 326.95 & 3.346 & 3.313 & $3,168.41$ \\
Parrilla con caja china y tapa tr & 1 & 284.83 & 458.64 & 3.346 & 3.313 & $2,472.55$ \\
Parrilla doble sistema con tapa & 1 & $\mathbf{2 5 4 . 2 4}$ & 411.60 & 3.346 & 3.313 & $2,214.35$ \\
\hline & & $\mathbf{1 , 1 7 3 . 3 5}$ & $\mathbf{1 , 8 8 8 . 0 9}$ & & & $\mathbf{2 1 , 8 4 7 . 7 7}$
\end{tabular}


JULIO

\begin{tabular}{lrrrrrr}
\hline Producto & Cantidad & Costo M.P. \$ & Costo M.O. y GRAL \$ & TC 1 & TC 2 & Costo Total S/ \\
\hline Caja china pequeña (Base fija) & 4 & 67.82 & 29.40 & 3.358 & 3.325 & $1,302.07$ \\
Caja china mediana (Tapa trapı & 6 & 33.41 & 117.60 & 3.358 & 3.325 & $3,019.31$ \\
Caja china grande (base + fond & 1 & 99.33 & 88.20 & 3.356 & 3.323 & 626.48 \\
Parrilla con caja china + tapa (F & 2 & 284.83 & 458.64 & 3.358 & 3.325 & $4,963.01$ \\
Parrilla Std (parrilla a gas) & 2 & 149.73 & 226.95 & 3.358 & 3.325 & $2,514.88$ \\
Parrilla con caja china y base (F & 1 & 325.63 & 488.04 & 3.358 & 3.325 & $2,716.27$ \\
Parrilla con caja china (Parrilla & 1 & 220.83 & 294.00 & 3.358 & 3.325 & $1,719.16$ \\
\hline & & $\mathbf{1 , 1 8 1 . 5 8}$ & $\mathbf{1 , 7 0 2 . 8 3}$ & & & $\mathbf{1 6 , 8 6 1 . 1 8}$
\end{tabular}

$16,795.12 \quad 66.05$

\section{AGOSTO}

\begin{tabular}{lrrrrrr}
\hline Producto & Cantidad & Costo M.P. \$ & Costo M.O. y GRAL \$ & TC 1 & TC 2 & Costo Total S/ \\
\hline Caja china pequeña (Base fija) & 1 & 67.82 & 29.40 & 3.399 & 3.365 & 329.43 \\
Caja china mediana (Tapa trapı & 2 & 33.41 & 117.60 & 3.399 & 3.365 & $1,018.54$ \\
Caja china grande (base + fond & 2 & 99.33 & 88.20 & 3.399 & 3.365 & $1,268.79$ \\
Caja china full (Parrilla con caja & 3 & 220.83 & 294.00 & 3.399 & 3.365 & $5,219.51$ \\
Mesas y repisas (Parrilla con ca & 1 & 261.63 & 323.40 & 3.399 & 3.365 & $1,977.42$ \\
Freidor de acero inox (Base ple & 2 & 40.80 & 29.40 & 3.399 & 3.365 & 475.17 \\
Parrilla full (Parrilla full + base f & 2 & 314.23 & 352.80 & 3.399 & 3.365 & $4,510.26$ \\
Parrilla Std con tapa (Parrilla di & 1 & 149.73 & 326.95 & 3.399 & 3.365 & $1,609.07$ \\
Parrilla gas dual (Parrilla a gas c & 1 & 183.14 & 444.55 & 3.399 & 3.365 & $2,118.34$ \\
Parrilla Std (parrilla a gas) & 1 & 149.73 & 226.95 & 3.397 & 3.363 & $1,271.81$ \\
Parrilla con caja china (Parrilla & 1 & $\mathbf{2 2 0 . 8 3}$ & $\mathbf{2 9 4 . 0 0}$ & 3.399 & 3.365 & $1,739.84$ \\
\hline & & $\mathbf{1 , 7 4 1 . 4 8}$ & $\mathbf{2 , 5 2 7 . 2 5}$ & & $\mathbf{2 1 , 5 3 8 . 1 9}$
\end{tabular}

$21,448.32 \quad 89.87$

\section{SETIEMBRE}

\begin{tabular}{lrrrrrr}
\hline Producto & Cantidad & Costo M.P. \$ & Costo M.O. y GRAL \$ & TC 1 & TC 2 & Costo Total S/ \\
\hline Caja china pequeña (Base fija) & 8 & 67.82 & 29.40 & 3.363 & 3.330 & $2,608.06$ \\
Caja china mediana (Tapa trapı & 8 & 33.41 & 117.60 & 3.363 & 3.330 & $4,031.80$ \\
Caja china grande (base + fond & 1 & 99.33 & 88.20 & 3.363 & 3.330 & 627.80 \\
Wok (Fondo parrilla x 3) & 3 & 31.51 & 58.80 & 3.361 & 3.328 & 904.82 \\
Parrilla Std (parrilla a gas) & 2 & 149.73 & 226.95 & 3.363 & 3.330 & $2,518.66$ \\
Parrilla a gas dual (Parrilla dual'; & 1 & 149.73 & 326.95 & 3.363 & 3.330 & $1,592.33$ \\
\hline & & $\mathbf{5 3 1 . 5 4}$ & $\mathbf{8 4 7 . 9 0}$ & & & $\mathbf{1 2 . 2 8 3 . 4 7}$
\end{tabular}

$12,235.09 \quad 48.38$

\section{OCTUBRE}

\begin{tabular}{lrrrrrr}
\hline Producto & Cantidad & Costo M.P. $\mathbf{~}$ & Costo M.O. y GRAL \$ & TC 1 & TC 2 & Costo Total S/ \\
\hline Caja china mediana (Tapa trapı & 5 & 33.41 & 117.60 & 3.378 & 3.345 & $2,531.23$ \\
Caja china pequeña (Base fija) & 3 & 67.82 & 29.40 & 3.389 & 3.355 & 985.37 \\
Caja china grande (base + fon & 1 & 99.33 & 88.20 & 3.378 & 3.345 & 630.62 \\
Parrilla std (parrilla a gas) & 4 & 149.73 & 226.95 & 3.378 & 3.345 & $5,060.02$ \\
Parrilla doble + wok y hornilla & 1 & 344.66 & 567.99 & 3.378 & 3.345 & $3,064.35$ \\
Parrilla + tapa trapez (parrilla s & 1 & 234.89 & 367.50 & 3.378 & 3.345 & $2,022.84$ \\
Puerta para horno y ducto (par & 1 & 130.93 & 176.40 & 3.389 & 3.355 & $1,035.50$ \\
\hline
\end{tabular}

$1,060.78 \quad 1,574.04 \quad 15,329.91$

DICIEMBRE

\begin{tabular}{lrrrrrr}
\hline Producto & Cantidad & Costo M.P. \$ & Costo M.O. y GRAL \$ & TC 1 & TC 2 & Costo Total S/ \\
\hline Caja china mediana (Tapa trap & 5 & 33.41 & 117.60 & 3.376 & 3.343 & $2,529.71$ \\
Caja china pequeña (Base fija) & 3 & 67.82 & 29.40 & 3.378 & 3.345 & 982.43 \\
Caja china grande (base + fond & 1 & 99.33 & 88.20 & 3.376 & 3.343 & 630.25 \\
Parrilla std (parrilla a gas) & 4 & 149.73 & 226.95 & 3.376 & 3.343 & $5,056.99$ \\
Puerta para horno y ducto (par & 1 & 130.93 & 176.40 & 3.378 & 3.345 & $1,032.41$ \\
\hline & & $\mathbf{4 8 1 . 2 3}$ & $\mathbf{6 3 8 . 5 5}$ & & & $\mathbf{1 0 , 2 3 1 . 7 9}$
\end{tabular}


Para un incremento en el tipo de cambio del $0.5 \%$ tenemos un incremento en las ventas de S/ 1,666.98 y un incremento en las compras de insumos en S/ 354.27.

\begin{tabular}{lrrrrrr}
\multicolumn{2}{c}{ VENTAS } \\
ENERO & \multicolumn{3}{c}{ Variación en el tipo de camb } \\
\hline Producto & \multicolumn{3}{c}{ Cantidad } & V. Vta Unit. \$ V. Vta Total \$ & \multicolumn{1}{l}{ TC } & V. Vta Total S/ \\
\hline Caja china mediana (Tapa trapez) & 4 & 270.00 & $1,080.00$ & 3.372 & $3,641.52$ \\
Base fija & 4 & 180.00 & 720.00 & 3.372 & $2,427.68$ \\
Parrilla con caja china (Parrilla con c & 1 & $1,380.00$ & $1,380.00$ & 3.372 & $4,653.05$ \\
Parrilla dual (Parrilla a gas con tapa & 1 & $1,130.00$ & $1,130.00$ & 3.372 & $3,810.11$ \\
Parrilla Std grande (Parrilla con caja & 1 & $1,550.00$ & $1,550.00$ & 3.372 & $5,226.25$ \\
Parrilla Std mediana (Parrilla a gas C1 & 2 & 960.00 & $1,920.00$ & 3.362 & $6,454.51$ \\
Parrilla Std pequeña (Parrilla dual (gi & 1 & 810.00 & 810.00 & 3.360 & $2,721.37$ \\
Varios (3 bases fijas) & 1 & 550.00 & 550.00 & 3.362 & $1,848.95$ \\
\hline & & & & $\mathbf{9 , 1 4 0 . 0 0}$ & & $\mathbf{3 0 , 7 8 3 . 4 3}$
\end{tabular}

\section{FEBRERO}

\begin{tabular}{lrrrrr}
\hline Producto & Cantidad V. Vta Unit. \$ V. Vta Total \$ & \multicolumn{1}{l}{ TC } & V. Vta Total S/ \\
\hline Caja china mediana (Tapa trapez) & 9 & 270.00 & $2,430.00$ & 3.375 & $8,200.74$ \\
Caja china grande (base + fondo par & 4 & 350.00 & $1,400.00$ & 3.375 & $4,724.71$ \\
Caja china pequeña (Base fija) & 6 & 180.00 & $1,080.00$ & 3.375 & $3,644.77$ \\
Parrilla Std mediana (Parrilla STD co & 2 & 895.00 & $1,790.00$ & 3.375 & $6,040.87$ \\
Parrilla Std mediana (Parrilla a gas C1 & 1 & 970.00 & 970.00 & 3.375 & $3,273.55$ \\
Parrilla Std (Parrilla a gas) & 1 & 740.00 & 740.00 & 3.375 & $2,497.34$ \\
Parrilla + caja china & 1 & 989.00 & 989.00 & 3.375 & $3,337.67$ \\
Tapa plana (Parrilla doble sistema) & 1 & 700.00 & 700.00 & 3.375 & $2,362.35$ \\
Wok (Parrilla a gas) & 1 & 711.00 & 711.00 & 3.375 & $2,399.48$ \\
\hline
\end{tabular}

\section{MARZO}

\section{Producto} $10,810.00$

\begin{tabular}{lrrrrr}
\hline Producto & Cantidad V. Vta Unit. \$ V. Vta Total \$ & \multicolumn{1}{c}{ TC } & V. Vta Total S \\
\hline Caja china mediana (Tapa trapez) & 5 & 270.00 & $1,350.00$ & 3.362 & $4,538.33$ \\
Caja china pequeña (Base fija) & 3 & 180.00 & 540.00 & 3.372 & $1,820.76$ \\
Caja china grande (base + fondo par & 1 & 350.00 & 350.00 & 3.362 & $1,176.60$ \\
Parrilla std (parrilla a gas) & 4 & 711.00 & $2,844.00$ & 3.362 & $9,560.75$ \\
Parrilla doble + wok y hornilla (parril & 1 & $1,740.00$ & $1,740.00$ & 3.362 & $5,849.40$ \\
Parrilla + tapa trapez (parrilla std co & 1 & $1,153.00$ & $1,153.00$ & 3.362 & $3,876.07$ \\
Puerta para horno y ducto (parrilla s & 1 & 597.00 & 597.00 & 3.372 & $2,012.95$ \\
\hline
\end{tabular}

\section{ABRIL}

\begin{tabular}{lrrrrr}
\hline Producto & Cantidad V. Vta Unit. \$ V. Vta Total \$ & TC & V. Vta Total S/ \\
\hline Caja china pequeña (Base fija) & 3 & 183.00 & 549.00 & 3.379 & $1,854.97$ \\
Caja china mediana (Tapa trapez) & 1 & 285.00 & 285.00 & 3.379 & 962.96 \\
Caja china grande (base + fondo par & 2 & 353.00 & 706.00 & 3.379 & $2,385.44$ \\
Caja china de acero inox con parrillá & 1 & $1,093.00$ & $1,093.00$ & 3.379 & $3,693.04$ \\
Caja china de acero inox y parrilla (F & 2 & $1,029.00$ & $2,058.00$ & 3.379 & $6,953.59$ \\
Parrilla uruguaya (Parrilla STD con tc & 1 & 882.00 & 882.00 & 3.379 & $2,980.11$ \\
Parrilla con caja china con tapa (Par & 1 & $1,298.00$ & $1,298.00$ & 3.379 & $4,385.70$ \\
Parrilla std (parrilla a gas) & 2 & 711.00 & $1,422.00$ & 3.382 & $4,808.96$ \\
Parrilla Std con tapa (Parrilla a gas C & 1 & $1,096.00$ & $1,096.00$ & 3.382 & $3,706.48$ \\
\hline
\end{tabular}

MAYO

\begin{tabular}{|c|c|c|c|c|c|}
\hline Producto & Cantidad & V. Vta Unit. \$ & V. Vta Total \$ & TC & V. Vta Total S/ \\
\hline Caja china pequeña (Base fija) & 8 & 183.00 & $1,464.00^{\prime \prime}$ & 3.347 & $4,899.50$ \\
\hline Caja china mediana (Tapa trapez) & 8 & 285.00 & $2,280.00^{\prime \prime}$ & 3.347 & $7,630.36$ \\
\hline Caja china grande (base + fondo par & 1 & 353.00 & $353.00^{\prime}$ & 3.347 & $1,181.37$ \\
\hline Wok (Fondo parrilla × 3 ) & 3 & 170.00 & $510.00^{\prime}$ & 3.345 & $1,705.77$ \\
\hline Parrilla Std (parrilla a gas) & 2 & 711.00 & $1,422.00^{\prime}$ & 3.347 & $4,758.94$ \\
\hline Parrilla a gas dual (Parrilla dual) & 1 & 811.00 & $811.00^{\prime}$ & 3.347 & $2,714.13$ \\
\hline
\end{tabular}

\section{JUNIO}

\begin{tabular}{|c|c|c|c|c|c|}
\hline Producto & Cantidad & V. Vta Unit. \$ & V. Vta Total \$ & TC & V. Vta Total S/ \\
\hline Caja china pequeña (Base fija) & 11 & 183.00 & $2,013.00^{\prime}$ & 3.330 & $6,702.41$ \\
\hline Caja china mediana (Tapa trapez) & 8 & 285.00 & $2,280.00^{\prime}$ & 3.330 & $7,591.41$ \\
\hline Caja china grande (base + fondo par & 2 & 353.00 & $706.00^{\prime}$ & 3.330 & $2,350.67$ \\
\hline (04) Silla de madera con base de act & 3 & 139.00 & $417.00^{\top}$ & 3.330 & $1,388.43$ \\
\hline Parrilla con caja china (Parrilla con c & 2 & $1,274.00$ & $2,548.00^{\prime \prime}$ & 3.329 & $8,481.17$ \\
\hline Parrilla Std (Parrilla dual) & 2 & 811.00 & $1,622.00^{\prime \prime}$ & 3.330 & $5,400.55$ \\
\hline Parrilla con caja china y tapa trapez & 1 & $1,421.00$ & $1,421.00^{\prime}$ & 3.330 & $4,731.31$ \\
\hline Parrilla doble sistema con tapa (Parı & 1 & $1,274.00$ & $1,274.00^{\prime \prime}$ & 3.330 & $4,241.87$ \\
\hline
\end{tabular}


JULIO

\begin{tabular}{lrrrrr}
\hline Producto & Cantidad V. Vta Unit. \$ V. Vta Total \$ & \multicolumn{1}{c}{ TC } & V. Vta Total S/ \\
\hline Caja china pequeña (Base fija) & 4 & 183.00 & 732.00 & 3.342 & $2,446.07$ \\
Caja china mediana (Tapa trapez) & 6 & 285.00 & $1,710.00$ & 3.342 & $5,714.18$ \\
Caja china grande (base + fondo par & 1 & 353.00 & 353.00 & 3.340 & $1,178.88$ \\
Parrilla con caja china + tapa (Parrill & 2 & $1,421.00$ & $2,842.00$ & 3.342 & $9,496.90$ \\
Parrilla Std (parrilla a gas) & 2 & 711.00 & $1,422.00$ & 3.342 & $4,751.79$ \\
Parrilla con caja china y base (Parrill & 1 & $1,553.00$ & $1,553.00$ & 3.342 & $5,189.54$ \\
Parrilla con caja china (Parrilla con c & 1 & 989.00 & 989.00 & 3.342 & $3,304.87$ \\
\hline
\end{tabular}

$31,922.00 \quad 160.23$

AGOSTO

Producto

TC V. Vta Total S/

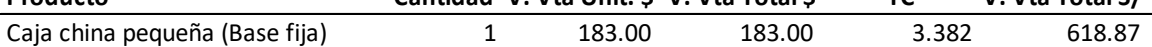

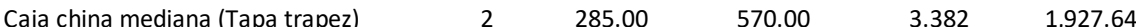

$\begin{array}{llllll}\text { Caja china grande (base + fondo par } & 2 & 353.00 & 706.00 & 3.382 & 2,387.57\end{array}$

$\begin{array}{llllll}\text { Caja china full (Parrilla con caja chin } & 3 & 989.00 & 2,967.00 & 3.382 & 10,033.87\end{array}$

$\begin{array}{llllll}\text { Mesas y repisas (Parrilla con caja ch } & 1 & 1,121.00 & 1,121.00 & 3.382 & 3,791.03\end{array}$

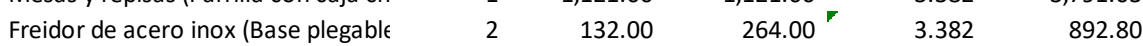

$\begin{array}{llllll}\text { Parrilla full (Parrilla full + base fija) } & 2 & 1,276.00 & 2,552.00 & 3.382 & 8,630.42\end{array}$

$\begin{array}{llrrrr}\text { Parrilla Std con tapa (Parrilla dual) } & 1 & 811.00 & 811.00 & 3.382 & 2,742.66\end{array}$

$\begin{array}{llllll}\text { Parrilla gas dual (Parrilla a gas con ti } & 1 & 1,096.00 & 1,096.00 & 3.382 & 3,706.48\end{array}$

$\begin{array}{llllll}\text { Parrilla Std (parrilla a gas) } & 1 & 711.00 & 711.00^{\vee} & 3.380 & 2,403.05\end{array}$

\begin{tabular}{lllllr} 
Parrilla con caja china (Parrilla con c & 1 & 989.00 & 989.00 & 3.382 & $3,344.62$ \\
\hline
\end{tabular}

$11,970.00 \quad 40,479.02$

$40,278.00 \quad 201.02$

SETIEMBRE

\begin{tabular}{lrrrrr}
\hline Producto & Cantidad V. Vta Unit. \$ V. Vta Total \$ & TC & V. Vta Total S/ \\
\hline Caja china pequeña (Base fija) & 8 & 183.00 & $1,464.00$ & 3.347 & $4,899.50$ \\
Caja china mediana (Tapa trapez) & 8 & 285.00 & $2,280.00$ & 3.347 & $7,630.36$ \\
Caja china grande (base + fondo par & 1 & 353.00 & 353.00 & 3.345 & $1,180.66$ \\
Wok (Fonde parrilla x 3) & 3 & 170.00 & 510.00 & 3.347 & $1,706.79$ \\
Parrilla Std (parrilla a gas) & 2 & 711.00 & $1,422.00$ & 3.347 & $4,758.94$ \\
Parrilla a gas dual (Parrilla dual) & 1 & 811.00 & 811.00 & 3.347 & $\mathbf{2 , 7 1 4 . 1 3}$ \\
\hline
\end{tabular}

$22,776.00 \quad 114.38$

\section{OCTUBRE}

\begin{tabular}{lrrrrr}
\hline Producto & Cantidad & V. Vta Unit. \$ & V. Vta Total \$ & \multicolumn{1}{c}{ TC } & V. Vta Total S/ \\
\hline Caja china mediana (Tapa trapez) & 5 & 270.00 & $1,350.00$ & 3.362 & $4,538.33$ \\
Caja china pequeña (Base fija) & 3 & 180.00 & 540.00 & 3.372 & $1,820.76$ \\
Caja china grande (base + fondo par & 1 & 350.00 & 350.00 & 3.362 & $1,176.60$ \\
Parrilla std (parrilla a gas) & 4 & 711.00 & $2,844.00$ & 3.362 & $9,560.75$ \\
Parrilla doble + wok y hornilla (parri & 1 & $1,740.00$ & $1,740.00$ & 3.362 & $5,849.40$ \\
Parrilla + tapa trapez (parrilla std co & 1 & $1,153.00$ & $1,153.00$ & 3.362 & $3,876.07$ \\
Puerta para horno y ducto (parrilla s & 1 & 597.00 & 597.00 & 3.372 & $\mathbf{2 , 0 1 2 . 9 5}$ \\
\hline
\end{tabular}

DICIEMBRE

\begin{tabular}{lrrrrr}
\hline Producto & Cantidad V. Vta Unit. \$ V. Vta Total \$ & TC & V. Vta Total S/ \\
\hline Caja china mediana (Tapa trapez) & 5 & 270.00 & $1,350.00$ & 3.360 & $4,535.62$ \\
Caja china pequeña (Base fija) & 3 & 180.00 & 540.00 & 3.362 & $1,815.33$ \\
Caja china grande (base + fondo par & 1 & 350.00 & 350.00 & 3.360 & $1,175.90$ \\
Parrilla std (parrilla a gas) & 4 & 711.00 & $2,844.00$ & 3.360 & $9,555.03$ \\
Puerta para horno y ducto (parrilla & 1 & 597.00 & 597.00 & 3.362 & $\mathbf{2 , 0 0 6 . 9 5}$ \\
\hline
\end{tabular}


ENERO

Producto Cantidad
Caja china mediana (Tapa trapı
Base fija
Parrilla con caja china (Parrilla
Parrilla dual (Parrilla a gas con
Parrilla Std grande (Parrilla con
Parrilla Std mediana (Parrilla a:
Parrilla Std pequeña (Parrilla dı
Varios (3 bases fijas)

\section{FEBRERO}

\section{Producto}

Caja china grande (base + fond

Caja china pequeña (Base fija)

Parrilla Std mediana (Parrilla ST

Parrilla Std mediana (Parrilla a

Parrilla Std (Parrilla a gas)

Parrilla + caja china

Tapa plana (Parrilla doble siste

Wok (Parrilla a gas)
Caja china mediana (Tapa trapı

COMPRAS

Variación en el tipo de cambio

$0.50 \%$

\begin{tabular}{rrrrrr} 
ad & Costo M.P. $\mathbf{\text { C }}$ & Costo M.O. y GRAL \$ & TC 1 & TC 2 & Costo Total S/ \\
\hline 4 & 33.41 & 117.60 & 3.372 & 3.355 & $2,028.79$ \\
4 & 67.82 & 29.40 & 3.372 & 3.355 & $1,309.27$ \\
1 & 295.04 & 441.00 & 3.372 & 3.355 & $2,474.36$ \\
1 & 183.14 & 444.55 & 3.372 & 3.355 & $2,108.97$ \\
1 & 325.63 & 488.04 & 3.372 & 3.355 & $2,735.31$ \\
2 & 183.14 & 344.55 & 3.362 & 3.345 & $3,536.37$ \\
1 & 149.73 & 326.95 & 3.360 & 3.343 & $1,596.05$ \\
1 & 203.47 & 88.20 & 3.362 & 3.345 & 979.03 \\
\hline \multicolumn{7}{r}{} & $\mathbf{1 , 4 4 1 . 3 7}$ & $\mathbf{2 , 2 8 0 . 2 9}$ & & & $\mathbf{1 6 , 7 6 8 . 1 5}$
\end{tabular}

$16,735.84 \quad 32.31$

$19,367.04 \quad 38.51$

MARZO

Producto

Caja china mediana (Tapa trapi

Caja china pequeña (Base fija)

Caja china grande (base + fond

Parrilla std (parrilla a gas)

Parrilla doble + wok y hornilla (

Parrilla + tapa trapez (parrilla $s$

Puerta para horno y ducto (par

Cantidad Costo M.P. \$ Costo M.O. y GRAL \$

GRAL \$ TC 1

TC 2

\begin{tabular}{lr}
2 & Costo Total S/ \\
\hline 3.358 & $4,568.86$
\end{tabular}

88.20

3.375

3.375

3.358

$\begin{array}{lll}29.40 & 3.375 & 3.358\end{array}$

294.00

3.375

3.358

344.55

3.375

3.358

3.358

$226.95 \quad 3.375$

294.00

3.375

3.358

3.358

205.80
226.95

3.375

3.358

$2,525.63$

$1,965.66$

$3,083.75$

$1,775.06$

$1,267.41$

$1,732.51$

$1,219.26$

$\begin{array}{llr}1,224.85 & 1,827.45 & 19,405.55\end{array}$

$15,270.36 \quad 29.77$

ABRIL

\section{Producto}

Caja china pequeña (Base fija)

Caja china mediana (Tapa trapı

Caja china grande (base + fond

Caja china de acero inox con $p$

Caja china de acero inox y parr

Parrilla uruguaya (Parrilla STD c

Parrilla con caja china con tape

Parrilla std (parrilla a gas)

Parrilla Std con tapa (Parrilla a Cantidad Costo M.P. \$ Costo M.O. y GRAL \$

TC 1

$\begin{array}{ll}3.362 & \text { TC 2 } \\ 3.372 & 3.345\end{array}$

$3.345 \quad 2,528.43$

$\begin{array}{llll}29.40 & 3.372 & 3.355 & 981.95\end{array}$

\subsection{2}

99.33

149.73

344.66

234.89

130.93

88.20

226.95

567.99

3.362

3.362

3.345

3.345

628.96
$5,050.00$

$\begin{array}{llll}367.50 & 3.362 & 3.345 & 2,018.91\end{array}$

\begin{tabular}{llll}
176.40 & 3.372 & 3.355 & $1,033.30$ \\
\hline
\end{tabular}

$1,574.04$

$5,300.14$

MAYO

Producto

Caja china pequeña (Base fija)

Caja china mediana (Tapa trapı

Caja china grande (base + fond

Wok (Fondo parrilla $\times 3$ )

Parrilla Std (parrilla a gas)

Parrilla a gas dual (Parrilla dual
Cantidad Costo M.P. \$ Costo M.O. y GRAL \$ M.P.\$

33.41

99.33

246.41

194.93

164.34

282.09

149.73

183.14

$1,421.21$

2,262.04

\begin{tabular}{rcrr} 
y GRAL \$ & TC 1 & TC 2 & Costo Total S/ \\
\hline 29.40 & 3.379 & 3.362 & 984.00 \\
117.60 & 3.379 & 3.362 & 508.26 \\
88.20 & 3.379 & 3.362 & $1,264.32$ \\
323.40 & 3.379 & 3.362 & $1,919.84$ \\
341.04 & 3.379 & 3.362 & $3,610.42$ \\
294.00 & 3.379 & 3.362 & $1,543.71$ \\
396.90 & 3.379 & 3.362 & $2,287.50$ \\
226.95 & 3.382 & 3.365 & $2,540.10$ \\
444.55 & 3.382 & 3.365 & $2,115.26$ \\
\hline $\mathbf{2 , 2 6 2 . 0 4}$ & & & $\mathbf{1 6 , 7 7 3 . 4 1}$
\end{tabular}

$16,773.41$
$16,739.76 \quad 33.64$

$12,235.09 \quad 24.19$

JUNIO

Producto

Caja china pequeña (Base fija)

Caja china mediana (Tapa trap

Caja china grande (base + fond

(04) Silla de madera con base

Parrilla con caja china (Parrilla

Parrilla Std (Parrilla dual)

Parrilla con caja china y tapa tr

Cantidad

dad Costo M

M.P. \$ Costo M.O. y

GRAL \$

RAL \$ TC 1

C 1 TC 2

$\begin{array}{llll}117.60 & 3.347 & 3.330 & 4,027.35\end{array}$

3.347

$\begin{array}{llll}117.60 & 3.347 & 3.330 & 4,027.35\end{array}$

2 Costo Total S/

$\begin{array}{lllll}99.33 & 88.20 & 3.347 & 3.330 & 626.14\end{array}$

$\begin{array}{lllll}31.51 & 58.80 & 3.345 & 3.328 & 903.25\end{array}$

$\begin{array}{lllll}149.73 & 226.95 & 3.347 & 3.330 & 2,513.68\end{array}$

149.73

\begin{tabular}{llll}
326.95 & 3.347 & 3.330 & $1,589.84$ \\
\hline
\end{tabular}

$847.90 \quad 12,259.28$

Cantidad Costo M.P. \$ Costo M.O. y GRAL \$ TC 1

67.82

33.41

33.41
99.33

29.75

254.24

149.73

284.83

254.24

$1,173.35$

\begin{tabular}{rcrr} 
y GRAL \$ & TC 1 & TC 2 & Costo Total S/ \\
\hline 29.40 & 3.330 & 3.313 & $3,555.42$ \\
117.60 & 3.330 & 3.313 & $4,006.79$ \\
88.20 & 3.330 & 3.313 & $1,245.89$ \\
44.10 & 3.330 & 3.313 & 735.43 \\
411.60 & 3.329 & 3.312 & $4,418.95$ \\
326.95 & 3.330 & 3.313 & $3,163.45$ \\
458.64 & 3.330 & 3.313 & $2,467.83$ \\
411.60 & 3.330 & 3.313 & $2,210.14$ \\
\hline $1,888.09$ & & & $\mathbf{2 1 , 8 0 3 . 9 0}$
\end{tabular}


JULIO

\begin{tabular}{lrrrrrr}
\hline Producto & Cantidad & Costo M.P. \$ & Costo M.O. y GRAL \$ & TC 1 & TC 2 & Costo Total S/ \\
\hline Caja china pequeña (Base fija) & 4 & 67.82 & 29.40 & 3.342 & 3.325 & $1,297.56$ \\
Caja china mediana (Tapa trapi & 6 & 33.41 & 117.60 & 3.342 & 3.325 & $3,015.98$ \\
Caja china grande (base + fond & 1 & 99.33 & 88.20 & 3.340 & 3.323 & 624.83 \\
Parrilla con caja china + tapa (F & 2 & 284.83 & 458.64 & 3.342 & 3.325 & $4,953.54$ \\
Parrilla Std (parrilla a gas) & 2 & 149.73 & 226.95 & 3.342 & 3.325 & $2,509.90$ \\
Parrilla con caja china y base (F & 1 & 325.63 & 488.04 & 3.342 & 3.325 & $2,710.85$ \\
Parrilla con caja china (Parrilla & 1 & $\mathbf{2 2 0 . 8 3}$ & $\mathbf{2 9 4 . 0 0}$ & 3.342 & 3.325 & $1,715.49$ \\
\hline & & $\mathbf{1 , 1 8 1 . 5 8}$ & $\mathbf{1 , 7 0 2 . 8 3}$ & & & $\mathbf{1 6 , 8 2 8 . 1 5}$
\end{tabular}

\section{AGOSTO}

Producto Caja china pequeña (Base fija)

Caja china mediana (Tapa trap

Caja china grande (base + fond

Caja china full (Parrilla con caja

Mesas y repisas (Parrilla con ca

Freidor de acero inox (Base ple

Parrilla full (Parrilla full + base

Parrilla Std con tapa (Parrilla de

Parrilla gas dual (Parrilla a gas $c$

Parrilla Std (parrilla a gas)

Parrilla con caja china (Parrilla

\begin{tabular}{rrrrrr} 
Cantidad & Costo M.P. \$ & Costo M.O. y GRAL \$ & TC 1 & TC 2 & Costo Total S/ \\
\hline 1 & 67.82 & 29.40 & 3.382 & 3.365 & 328.29 \\
2 & 33.41 & 117.60 & 3.382 & 3.365 & $1,017.42$ \\
2 & 99.33 & 88.20 & 3.382 & 3.365 & $1,265.45$ \\
3 & 220.83 & 294.00 & 3.382 & 3.365 & $5,208.37$ \\
1 & 261.63 & 323.40 & 3.382 & 3.365 & $1,973.02$ \\
2 & 40.80 & 29.40 & 3.382 & 3.365 & 473.80 \\
2 & 314.23 & 352.80 & 3.382 & 3.365 & $4,499.69$ \\
1 & 149.73 & 326.95 & 3.382 & 3.365 & $1,606.55$ \\
1 & 183.14 & 444.55 & 3.382 & 3.365 & $2,115.26$ \\
1 & 149.73 & 226.95 & 3.380 & 3.363 & $1,269.29$ \\
1 & 220.83 & 294.00 & 3.382 & 3.365 & $1,736.12$ \\
\hline
\end{tabular}

$1,741.48$

$16,795.12 \quad 33.03$

$21,448.32 \quad 44.94$

\section{SETIEMBRE}

\begin{tabular}{lrrrrrr}
\hline Producto & Cantidad & Costo M.P. \$ & Costo M.O. y GRAL \$ & TC 1 & TC 2 & Costo Total S/ \\
\hline Caja china pequeña (Base fija) & 8 & 67.82 & 29.40 & 3.347 & 3.330 & $2,599.03$ \\
Caja china mediana (Tapa trap & 8 & 33.41 & 117.60 & 3.347 & 3.330 & $4,027.35$ \\
Caja china grande (base + fond & 1 & 99.33 & 88.20 & 3.347 & 3.330 & 626.14 \\
Wok (Fondo parrilla x 3) & 3 & 31.51 & 58.80 & 3.345 & 3.328 & 903.25 \\
Parrilla Std (parrilla a gas) & 2 & 149.73 & 226.95 & 3.347 & 3.330 & $2,513.68$ \\
Parrilla a gas dual (Parrilla dual & 1 & 149.73 & 326.95 & 3.347 & 3.330 & $1,589.84$ \\
\hline
\end{tabular}

$12,235.09 \quad 24.19$

\section{OCTUBRE}

\section{Producto}

Caja china mediana (Tapa trap

Caja china pequeña (Base fija)

Caja china grande (base + fond

Parrilla std (parrilla a gas)

Parrilla doble + wok y hornilla

Parrilla + tapa trapez (parrilla $s$

Puerta para horno y ducto (par

Cantidad

\begin{tabular}{cr} 
ad & Costo M.P. \\
3 & 33 \\
1 & 67 \\
4 & 99 \\
1 & 149 \\
1 & 2344 \\
1 & 130 \\
\hline
\end{tabular}

\begin{tabular}{rr} 
M.P. \$ & Costo M.O. y GRAL \\
\hline 33.41 & 117.60 \\
67.82 & 29.4 \\
99.33 & 88.2 \\
149.73 & 226.9 \\
344.66 & 567.9 \\
234.89 & 367.5 \\
130.93 & 176.4 \\
\hline $\mathbf{0 6 0 . 7 8}$ & $\mathbf{1 , 5 7 4 . 0}$
\end{tabular}

$\begin{array}{r}\text { GRAL \$ } \\ 117.60 \\ 29.40 \\ 88.20 \\ 226.95 \\ 567.99 \\ 367.50 \\ 176.40 \\ \hline, 574.04\end{array}$

TC 1

1

3.362

3.372

3.362

3.362

3.362

3.362 3.372

TC 2

C 2

$3.345 \quad 2,528.43$

$3.355 \quad 981.95$

$3.345 \quad 628.96$

$3.345 \quad 5,050.00$

$3.345 \quad 3,058.58$

$3.345 \quad 2,018.91$ 3.355 $1,033.30$

$15,300.14$

$15,270.36 \quad 29.77$

\section{DICIEMBRE}

\begin{tabular}{lrrrrrr}
\hline Producto & Cantidad & Costo M.P. \$ & Costo M.O. y GRAL \$ & TC 1 & TC 2 & Costo Total S/ \\
\hline Caja china mediana (Tapa trapı & 5 & 33.41 & 117.60 & 3.360 & 3.343 & $2,526.92$ \\
Caja china pequeña (Base fija) & 3 & 67.82 & 29.40 & 3.362 & 3.345 & 979.03 \\
Caja china grande (base + fon & 1 & 99.33 & 88.20 & 3.360 & 3.343 & 628.59 \\
Parrilla std (parrilla a gas) & 4 & 149.73 & 226.95 & 3.360 & 3.343 & $5,046.98$ \\
Puerta para horno y ducto (par & 1 & 130.93 & 176.40 & 3.362 & 3.345 & $1,030.22$ \\
\hline
\end{tabular}

$10,191.68 \quad 20.06$ 
Anexo $N^{\circ} 18$ - Proyección de ingresos de productos comercializados actualmente por SF Hermanos E.I.R.L.

Muebles Hogar

\begin{tabular}{lccc} 
& \multicolumn{3}{c}{$\mathbf{2 0 1 8}$} \\
\cline { 2 - 4 } & Precio & Cantidad & PxQ \\
\cline { 2 - 4 } Enero & $5,301.33$ & 3 & $15,903.99$ \\
Enero & $3,043.28$ & 7 & $21,302.96$ \\
Enero & $3,524.87$ & 8 & $28,198.96$ \\
Febrero & $2,875.25$ & 4 & $11,501.00$ \\
Febrero & $3,047.00$ & 5 & $15,235.00$ \\
Febrero & $3,073.33$ & 6 & $18,439.98$ \\
Marzo & $5,402.50$ & 2 & $10,805.00$ \\
Marzo & $3,230.40$ & 5 & $16,152.00$ \\
Abril & $3,485.00$ & 4 & $13,940.00$ \\
Abril & $3,450.00$ & 5 & $17,250.00$ \\
Mayo & $3,292.60$ & 5 & $16,463.00$ \\
Mayo & $2,662.37$ & 8 & $21,298.96$ \\
Mayo & $3,313.22$ & 9 & $29,818.98$ \\
Junio & $3,128.50$ & 4 & $12,514.00$ \\
Junio & $3,530.60$ & 5 & $17,653.00$ \\
Junio & $3,182.22$ & 9 & $28,639.98$ \\
Julio & $3,254.00$ & 6 & $19,524.00$ \\
Julio & $3,873.67$ & 6 & $23,242.02$ \\
Julio & $3,384.42$ & 7 & $23,690.94$ \\
Julio & $4,547.33$ & 6 & $27,283.98$ \\
Agosto & $3,527.80$ & 5 & $17,639.00$ \\
Agosto & $3,012.33$ & 6 & $18,073.98$ \\
Agosto & $3,736.00$ & 6 & $22,416.00$ \\
Agosto & $3,672.62$ & 8 & $29,380.96$ \\
Setiembre & $2,547.50$ & 4 & $10,190.00$ \\
Setiembre & $3,201.17$ & 6 & $19,207.02$ \\
Octubre & $3,437.00$ & 3 & $10,311.00$ \\
Octubre & $4,155.80$ & 5 & $20,779.00$ \\
Noviembre & $4,044.50$ & 6 & $24,267.00$ \\
Noviembre & $3,213.83$ & 6 & $19,282.98$ \\
Noviembre & $5,980.80$ & 5 & $29,904.00$ \\
Diciembre & $3,114.71$ & 7 & $21,802.97$ \\
Diciembre & $4,451.66$ & 6 & $26,709.96$ \\
Diciembre & $4,488.50$ & 6 & $26,931.00$ \\
Diciembre & $4,067.00$ & 7 & $28,469.00$ \\
\cline { 2 - 4 } & & & $\mathbf{7 1 4 , 2 2 1 . 6 2}$
\end{tabular}

\begin{tabular}{ccc}
\hline & 2019 & \\
\hline Precio & Cantidad & PxQ \\
\hline $5,301.33$ & 5 & $26,506.65$ \\
$3,543.28$ & 7 & $24,802.96$ \\
$3,524.87$ & 8 & $28,198.96$ \\
$2,875.25$ & 4 & $11,501.00$ \\
$3,547.00$ & 5 & $17,735.00$ \\
$3,573.33$ & 6 & $21,439.98$ \\
$5,402.50$ & 4 & $21,610.00$ \\
$3,230.40$ & 5 & $16,152.00$ \\
$3,485.00$ & 4 & $13,940.00$ \\
$3,450.00$ & 5 & $17,250.00$ \\
$3,292.60$ & 5 & $16,463.00$ \\
$2,662.37$ & 8 & $21,298.96$ \\
$3,313.22$ & 9 & $29,818.98$ \\
$3,128.50$ & 6 & $18,771.00$ \\
$3,530.60$ & 5 & $17,653.00$ \\
$3,182.22$ & 9 & $28,639.98$ \\
$3,254.00$ & 6 & $19,524.00$ \\
$3,873.67$ & 6 & $23,242.02$ \\
$3,384.42$ & 7 & $23,690.94$ \\
$4,547.33$ & 6 & $27,283.98$ \\
$3,527.80$ & 5 & $17,639.00$ \\
$3,012.33$ & 6 & $18,073.98$ \\
$3,736.00$ & 6 & $22,416.00$ \\
$3,672.62$ & 8 & $29,380.96$ \\
$2,547.50$ & 6 & $15,285.00$ \\
$3,201.17$ & 6 & $19,207.02$ \\
$3,437.00$ & 6 & $20,622.00$ \\
$4,655.80$ & 5 & $23,279.00$ \\
$4,544.50$ & 6 & $27,267.00$ \\
$3,213.83$ & 6 & $19,282.98$ \\
$5,980.80$ & 5 & $29,904.00$ \\
$3,109.80$ & 7 & $21,768.60$ \\
$4,451.66$ & 6 & $26,709.96$ \\
$4,488.50$ & 6 & $26,931.00$ \\
$4,500.00$ & 7 & $31,500.00$ \\
\hline & & $774,788.91$ \\
& & \\
\hline
\end{tabular}

\begin{tabular}{|c|c|c|}
\hline \multicolumn{3}{|c|}{2020} \\
\hline Precio & Cantidad & $P \times Q$ \\
\hline $5,301.33$ & 6 & $31,807.98$ \\
\hline $3,543.28$ & 7 & $24,802.96$ \\
\hline $3,524.87$ & 8 & $28,198.96$ \\
\hline $3,196.00$ & 4 & $12,784.00$ \\
\hline $3,547.00$ & 5 & $17,735.00$ \\
\hline $3,573.33$ & 6 & $21,439.98$ \\
\hline $5,402.50$ & 6 & $32,415.00$ \\
\hline $3,230.40$ & 5 & $16,152.00$ \\
\hline $3,485.00$ & 4 & $13,940.00$ \\
\hline $3,450.00$ & 5 & $17,250.00$ \\
\hline $3,292.60$ & 5 & $16,463.00$ \\
\hline $2,662.37$ & 8 & $21,298.96$ \\
\hline $3,313.22$ & 9 & $29,818.98$ \\
\hline $3,128.50$ & 6 & $18,771.00$ \\
\hline $3,530.60$ & 7 & $24,714.20$ \\
\hline $3,182.22$ & 9 & $28,639.98$ \\
\hline $3,254.00$ & 6 & $19,524.00$ \\
\hline $3,873.67$ & 6 & $23,242.02$ \\
\hline $3,384.42$ & 7 & $23,690.94$ \\
\hline $4,547.33$ & 9 & $40,925.97$ \\
\hline $3,527.80$ & 5 & $17,639.00$ \\
\hline $3,012.33$ & 6 & $18,073.98$ \\
\hline $3,736.00$ & 6 & $22,416.00$ \\
\hline $3,672.62$ & 8 & $29,380.96$ \\
\hline $2,547.50$ & 8 & $20,380.00$ \\
\hline $3,201.17$ & 8 & $25,609.36$ \\
\hline $3,437.00$ & 6 & $20,622.00$ \\
\hline $4,655.80$ & 5 & $23,279.00$ \\
\hline $4,544.50$ & 6 & $27,267.00$ \\
\hline $3,213.83$ & 6 & $19,282.98$ \\
\hline $5,980.80$ & 7 & $41,865.60$ \\
\hline $3,109.80$ & 7 & $21,768.60$ \\
\hline $4,451.66$ & 6 & $26,709.96$ \\
\hline $4,488.50$ & 6 & $26,931.00$ \\
\hline $4,500.00$ & 7 & $31,500.00$ \\
\hline
\end{tabular}

\begin{tabular}{lcc}
\hline & $\mathbf{2 0 2 1}$ & \\
\hline Precio & Cantidad & PxQ \\
\hline $5,301.33$ & 6 & $31,807.98$ \\
$3,543.28$ & 7 & $24,802.96$ \\
$3,524.87$ & 8 & $28,198.96$ \\
$3,196.00$ & 6 & $19,176.00$ \\
$3,547.00$ & 5 & $17,735.00$ \\
$3,573.33$ & 6 & $21,439.98$ \\
$5,402.50$ & 6 & $32,415.00$ \\
$3,230.40$ & 5 & $16,152.00$ \\
$3,485.00$ & 5 & $17,425.00$ \\
$3,890.00$ & 5 & $19,450.00$ \\
$3,292.60$ & 5 & $16,463.00$ \\
$3,262.37$ & 8 & $26,098.96$ \\
$3,313.22$ & 10 & $33,132.20$ \\
$3,128.50$ & 6 & $18,771.00$ \\
$3,530.60$ & 7 & $24,714.20$ \\
$3,182.22$ & 9 & $28,639.98$ \\
$3,254.00$ & 8 & $26,032.00$ \\
$3,873.67$ & 6 & $23,242.02$ \\
$4,084.42$ & 7 & $28,590.94$ \\
$4,547.33$ & 9 & $40,925.97$ \\
$3,527.80$ & 7 & $24,694.60$ \\
$3,012.33$ & 6 & $18,073.98$ \\
$3,736.00$ & 7 & $26,152.00$ \\
$3,672.62$ & 8 & $29,380.96$ \\
$2,547.50$ & 8 & $20,380.00$ \\
$3,701.17$ & 8 & $29,609.36$ \\
$3,437.00$ & 6 & $20,622.00$ \\
$4,655.80$ & 7 & $32,590.60$ \\
$4,544.50$ & 6 & $27,267.00$ \\
$3,213.83$ & 6 & $19,282.98$ \\
$6,140.80$ & 7 & $42,985.60$ \\
$3,109.80$ & 7 & $21,768.60$ \\
$5,003.46$ & 6 & $30,020.76$ \\
$4,488.50$ & 6 & $26,931.00$ \\
$4,500.00$ & 8 & $36,000.00$ \\
\hline & & $900,972.59$ \\
& & \\
\hline
\end{tabular}


Muebles Oficina

\begin{tabular}{llcc} 
& \multicolumn{3}{c}{$\mathbf{2 0 1 8}$} \\
\cline { 2 - 4 } Enero & Precio & Cantidad & PxQ \\
\cline { 2 - 4 } Febrero & $1,164.00$ & 2 & $2,328.00$ \\
Febrero & $1,910.00$ & 1 & $1,910.00$ \\
Marzo & $1,422.50$ & 2 & $2,845.00$ \\
Marzo & $1,287.66$ & 3 & $3,862.98$ \\
Abril & $1,333.00$ & 2 & $2,666.00$ \\
Abril & $1,024.00$ & 2 & $2,048.00$ \\
Mayo & $1,544.33$ & 3 & $4,632.99$ \\
Mayo & $1,524.00$ & 3 & $4,572.00$ \\
Junio & $1,727.00$ & 2 & $3,454.00$ \\
Junio & $1,234.00$ & 2 & $2,468.00$ \\
Julio & $1,652.33$ & 3 & $4,956.99$ \\
Julio & $1,577.00$ & 1 & $1,577.00$ \\
Agosto & $1,265.50$ & 2 & $2,531.00$ \\
Agosto & $1,181.00$ & 3 & $3,543.00$ \\
Setiembre & $2,068.50$ & 2 & $4,137.00$ \\
Setiembre & $2,444.50$ & 2 & $4,889.00$ \\
Octubre & $1,485.33$ & 3 & $4,455.99$ \\
Octubre & $1,286.66$ & 3 & $3,859.98$ \\
Noviembre & $2,218.00$ & 1 & $2,218.00$ \\
Noviembre & $1,291.00$ & 3 & $3,873.00$ \\
Diciembre & $1,025.00$ & 1 & $1,025.00$ \\
\cline { 2 - 4 } & $1,332.50$ & 2 & $2,665.00$ \\
\hline
\end{tabular}

\begin{tabular}{ccc}
\hline \multicolumn{3}{c}{$\mathbf{2 0 1 9}$} \\
\hline Precio & Cantidad & PxQ \\
\hline $1,164.00$ & 2 & $2,328.00$ \\
$1,910.00$ & 1 & $1,910.00$ \\
$1,422.50$ & 2 & $2,845.00$ \\
$1,287.66$ & 3 & $3,862.98$ \\
$1,333.00$ & 2 & $2,666.00$ \\
$1,024.00$ & 2 & $2,048.00$ \\
$1,544.33$ & 3 & $4,632.99$ \\
$1,524.00$ & 3 & $4,572.00$ \\
$1,727.00$ & 2 & $3,454.00$ \\
$1,234.00$ & 2 & $2,468.00$ \\
$1,652.33$ & 2 & $3,304.66$ \\
$1,577.00$ & 1 & $1,577.00$ \\
$1,265.50$ & 1 & $1,265.50$ \\
$1,181.00$ & 3 & $3,543.00$ \\
$2,068.50$ & 1 & $2,068.50$ \\
$2,444.50$ & 2 & $4,889.00$ \\
$1,485.33$ & 2 & $2,970.66$ \\
$1,286.66$ & 1 & $1,286.66$ \\
$2,218.00$ & 1 & $2,218.00$ \\
$1,291.00$ & 4 & $5,164.00$ \\
$1,025.00$ & 1 & $1,025.00$ \\
$1,332.50$ & 2 & $2,665.00$ \\
\hline & & $62,763.95$
\end{tabular}

\begin{tabular}{lcc}
\hline \multicolumn{3}{c}{$\mathbf{2 0 2 0}$} \\
\hline Precio & Cantidad & PxQ \\
\hline $1,164.00$ & 2 & $2,328.00$ \\
$1,910.00$ & 1 & $1,910.00$ \\
$1,422.50$ & 2 & $2,845.00$ \\
$1,287.66$ & 3 & $3,862.98$ \\
$1,328.00$ & 1 & $1,328.00$ \\
$1,024.00$ & 2 & $2,048.00$ \\
$1,544.33$ & 2 & $3,088.66$ \\
$1,524.00$ & 2 & $3,048.00$ \\
$1,727.00$ & 2 & $3,454.00$ \\
$1,234.00$ & 2 & $2,468.00$ \\
$1,652.33$ & 2 & $3,304.66$ \\
$1,577.00$ & 1 & $1,577.00$ \\
$1,265.50$ & 1 & $1,265.50$ \\
$1,181.00$ & 2 & $2,362.00$ \\
$2,068.50$ & 1 & $2,068.50$ \\
$2,444.50$ & 2 & $4,889.00$ \\
$1,485.33$ & 2 & $2,970.66$ \\
$1,286.66$ & 1 & $1,286.66$ \\
$2,218.00$ & 1 & $2,218.00$ \\
$1,291.00$ & 4 & $5,164.00$ \\
$1,025.00$ & 1 & $1,025.00$ \\
$1,332.50$ & 1 & $1,332.50$ \\
\hline & & $55,844.12$
\end{tabular}

\begin{tabular}{ccc}
\hline \multicolumn{3}{c}{$\mathbf{2 0 2 1}$} \\
\hline Precio & Cantidad & PxQ \\
\hline $1,164.00$ & 1 & $1,164.00$ \\
$1,910.00$ & 1 & $1,910.00$ \\
$1,422.50$ & 2 & $2,845.00$ \\
$1,287.66$ & 2 & $2,575.32$ \\
$1,328.00$ & 1 & $1,328.00$ \\
$1,024.00$ & 2 & $2,048.00$ \\
$1,544.33$ & 2 & $3,088.66$ \\
$1,524.00$ & 2 & $3,048.00$ \\
$1,727.00$ & 2 & $3,454.00$ \\
$1,234.00$ & 2 & $2,468.00$ \\
$1,652.33$ & 2 & $3,304.66$ \\
$1,577.00$ & 1 & $1,577.00$ \\
$1,376.50$ & 1 & $1,376.50$ \\
$1,181.00$ & 2 & $2,362.00$ \\
$2,068.50$ & 1 & $2,068.50$ \\
$2,444.50$ & 2 & $4,889.00$ \\
$1,485.33$ & 1 & $1,485.33$ \\
$1,286.66$ & 1 & $1,286.66$ \\
$2,218.00$ & 1 & $2,218.00$ \\
$1,291.00$ & 2 & $2,582.00$ \\
$1,025.00$ & 1 & $1,025.00$ \\
$1,332.50$ & 1 & $1,332.50$ \\
\hline & & $49,436.13$
\end{tabular}




\section{Muebles Comerciales}

\begin{tabular}{lrrr} 
& \multicolumn{3}{c}{$\mathbf{2 0 1 8}$} \\
\cline { 2 - 4 } & \multicolumn{1}{c}{ Precio } & Cantidad & \multicolumn{1}{c}{ PxQ } \\
\cline { 2 - 4 } Enero & 732.00 & 1 & 732.00 \\
Enero & $1,042.00$ & 2 & $2,084.00$ \\
Enero & $1,666.33$ & 3 & $4,998.99$ \\
Febrero & $1,208.00$ & 1 & $1,208.00$ \\
Febrero & $1,461.00$ & 2 & $2,922.00$ \\
Febrero & $2,347.50$ & 2 & $4,695.00$ \\
Marzo & 980.00 & 1 & 980.00 \\
Marzo & $1,016.33$ & 3 & $3,048.99$ \\
Marzo & $1,554.33$ & 3 & $4,662.99$ \\
Abril & $1,115.50$ & 2 & $2,231.00$ \\
Abril & $1,309.66$ & 3 & $3,928.98$ \\
Mayo & $1,412.00$ & 1 & $1,412.00$ \\
Mayo & $1,148.00$ & 3 & $3,444.00$ \\
Junio & $1,120.50$ & 2 & $2,241.00$ \\
Junio & $1,316.33$ & 3 & $3,948.99$ \\
Julio & $1,445.00$ & 1 & $1,445.00$ \\
Julio & $1,023.00$ & 2 & $2,046.00$ \\
Agosto & $1,414.00$ & 1 & $1,414.00$ \\
Agosto & $2,081.00$ & 2 & $4,162.00$ \\
Setiembre & $1,448.00$ & 1 & $1,448.00$ \\
Setiembre & $1,347.66$ & 3 & $4,042.98$ \\
Octubre & $1,903.00$ & 1 & $1,903.00$ \\
Octubre & $1,248.00$ & 3 & $3,744.00$ \\
Noviembre & $1,060.00$ & 3 & $3,180.00$ \\
Noviembre & $1,107.66$ & 3 & $3,322.98$ \\
Diciembre & $1,003.00$ & 2 & $2,006.00$ \\
Diciembre & $1,147.66$ & 3 & $3,442.98$ \\
\cline { 2 - 4 } & & & $74,694.88$
\end{tabular}

\begin{tabular}{rcr}
\hline \multicolumn{1}{c}{$\mathbf{2 0 1 9}$} & \\
\hline \multicolumn{1}{c}{ Precio } & Cantidad & \multicolumn{1}{c}{ PxQ } \\
\hline 732.00 & 1 & 732.00 \\
$1,042.00$ & 2 & $2,084.00$ \\
$1,666.33$ & 2 & $3,332.66$ \\
$1,208.00$ & 1 & $1,208.00$ \\
$1,461.00$ & 2 & $2,922.00$ \\
$2,347.50$ & 2 & $4,695.00$ \\
980.00 & 1 & 980.00 \\
$1,016.33$ & 3 & $3,048.99$ \\
$1,554.33$ & 3 & $4,662.99$ \\
$1,115.50$ & 2 & $2,231.00$ \\
$1,309.66$ & 3 & $3,928.98$ \\
$1,412.00$ & 1 & $1,412.00$ \\
$1,148.00$ & 3 & $3,444.00$ \\
$1,120.50$ & 2 & $2,241.00$ \\
$1,316.33$ & 2 & $2,632.66$ \\
$1,356.00$ & 1 & $1,356.00$ \\
$1,023.00$ & 2 & $2,046.00$ \\
$1,414.00$ & 1 & $1,414.00$ \\
$2,081.00$ & 1 & $2,081.00$ \\
$1,448.00$ & 1 & $1,448.00$ \\
$1,347.66$ & 2 & $2,695.32$ \\
$1,903.00$ & 1 & $1,903.00$ \\
$1,248.00$ & 2 & $2,496.00$ \\
$1,060.00$ & 3 & $3,180.00$ \\
$1,107.66$ & 2 & $2,215.32$ \\
$1,003.00$ & 2 & $2,006.00$ \\
$1,147.66$ & 1 & $1,147.66$ \\
\hline & & $63,543.58$
\end{tabular}

\begin{tabular}{|c|c|c|}
\hline \multicolumn{3}{|c|}{2020} \\
\hline Precio & Cantidad & PxQ \\
\hline 732.00 & 0 & 0.00 \\
\hline $1,042.00$ & 2 & $2,084.00$ \\
\hline $1,666.33$ & 2 & $3,332.66$ \\
\hline $1,204.00$ & 1 & $1,204.00$ \\
\hline $1,461.00$ & 2 & $2,922.00$ \\
\hline $2,347.50$ & 1 & $2,347.50$ \\
\hline 980.00 & 1 & 980.00 \\
\hline $1,016.33$ & 2 & $2,032.66$ \\
\hline $1,554.33$ & 2 & $3,108.66$ \\
\hline $1,115.50$ & 2 & $2,231.00$ \\
\hline $1,309.66$ & 3 & $3,928.98$ \\
\hline $1,412.00$ & 1 & $1,412.00$ \\
\hline $1,148.00$ & 1 & $1,148.00$ \\
\hline $1,120.50$ & 2 & $2,241.00$ \\
\hline $1,316.33$ & 2 & $2,632.66$ \\
\hline $1,356.00$ & 1 & $1,356.00$ \\
\hline $1,023.00$ & 2 & $2,046.00$ \\
\hline $1,414.00$ & 1 & $1,414.00$ \\
\hline $2,081.00$ & 1 & $2,081.00$ \\
\hline $1,448.00$ & 1 & $1,448.00$ \\
\hline $1,347.66$ & 1 & $1,347.66$ \\
\hline $1,903.00$ & 1 & $1,903.00$ \\
\hline $1,248.00$ & 2 & $2,496.00$ \\
\hline $1,060.00$ & 2 & $2,120.00$ \\
\hline $1,107.66$ & 2 & $2,215.32$ \\
\hline $1,003.00$ & 2 & $2,006.00$ \\
\hline $1,147.66$ & 1 & $1,147.66$ \\
\hline
\end{tabular}

\begin{tabular}{rcr}
\hline \multicolumn{1}{c}{$\mathbf{2 0 2 1}$} & \\
\hline \multicolumn{1}{c}{ Precio } & Cantidad & \multicolumn{1}{c}{ PxQ } \\
\hline 732.00 & 0 & 0.00 \\
$1,042.00$ & 2 & $2,084.00$ \\
$1,666.33$ & 1 & $1,666.33$ \\
$1,204.00$ & 1 & $1,204.00$ \\
$1,461.00$ & 2 & $2,922.00$ \\
$2,347.50$ & 1 & $2,347.50$ \\
980.00 & 1 & 980.00 \\
$1,016.33$ & 2 & $2,032.66$ \\
$1,554.33$ & 1 & $1,554.33$ \\
$1,115.50$ & 2 & $2,231.00$ \\
$1,309.66$ & 2 & $2,619.32$ \\
$1,412.00$ & 1 & $1,412.00$ \\
$1,148.00$ & 1 & $1,148.00$ \\
$1,120.50$ & 2 & $2,241.00$ \\
$1,316.33$ & 2 & $2,632.66$ \\
$1,356.00$ & 1 & $1,356.00$ \\
$1,042.00$ & 2 & $2,084.00$ \\
$1,414.00$ & 1 & $1,414.00$ \\
$2,081.00$ & 1 & $2,081.00$ \\
$1,448.00$ & 1 & $1,448.00$ \\
$1,347.66$ & 1 & $1,347.66$ \\
$1,903.00$ & 1 & $1,903.00$ \\
$1,248.00$ & 1 & $1,248.00$ \\
$1,060.00$ & 1 & $1,060.00$ \\
$1,107.66$ & 1 & $1,107.66$ \\
$1,003.00$ & 1 & $1,003.00$ \\
$1,147.66$ & 1 & $1,147.66$ \\
\hline & & $44,274.78$
\end{tabular}


Carpintería en Obra

\begin{tabular}{lrrr} 
& \multicolumn{3}{c}{$\mathbf{2 0 1 8}$} \\
\cline { 2 - 4 } & \multicolumn{1}{c}{ Precio } & Cantidad & \multicolumn{1}{c}{ PxQ } \\
\cline { 2 - 4 } Enero & $2,398.66$ & 3 & $7,195.98$ \\
Enero & $2,744.50$ & 2 & $5,489.00$ \\
Enero & $2,672.50$ & 4 & $10,690.00$ \\
Febrero & $3,042.66$ & 3 & $9,127.98$ \\
Febrero & $2,513.75$ & 4 & $10,055.00$ \\
Febrero & $2,544.50$ & 2 & $5,089.00$ \\
Marzo & $2,581.33$ & 3 & $7,743.99$ \\
Marzo & $2,794.50$ & 2 & $5,589.00$ \\
Abril & $1,832.33$ & 3 & $5,496.99$ \\
Abril & $2,221.50$ & 4 & $8,886.00$ \\
Mayo & $2,852.66$ & 3 & $8,557.98$ \\
Mayo & $3,691.33$ & 3 & $11,073.99$ \\
Mayo & $2,492.50$ & 4 & $9,970.00$ \\
Junio & $2,769.66$ & 3 & $8,308.98$ \\
Junio & $2,200.00$ & 4 & $8,800.00$ \\
Junio & $2,102.33$ & 3 & $6,306.99$ \\
Julio & $1,676.66$ & 3 & $5,029.98$ \\
Julio & $3,030.33$ & 3 & $9,090.99$ \\
Julio & $2,616.25$ & 4 & $10,465.00$ \\
Julio & $2,043.00$ & 3 & $6,129.00$ \\
Agosto & $2,757.25$ & 4 & $11,029.00$ \\
Agosto & $1,963.33$ & 3 & $5,889.99$ \\
Agosto & $2,765.00$ & 4 & $11,060.00$ \\
Agosto & $1,711.00$ & 3 & $5,133.00$ \\
Setiembre & $2,131.66$ & 3 & $6,394.98$ \\
Setiembre & $2,469.50$ & 4 & $9,878.00$ \\
Octubre & $2,264.00$ & 3 & $6,792.00$ \\
Octubre & $3,193.00$ & 3 & $9,579.00$ \\
Noviembre & $2,549.75$ & 4 & $10,199.00$ \\
Noviembre & $2,502.50$ & 4 & $10,010.00$ \\
Noviembre & $3,024.00$ & 3 & $9,072.00$ \\
Diciembre & $3,316.33$ & 3 & $9,948.99$ \\
Diciembre & $2,659.75$ & 4 & $10,639.00$ \\
Diciembre & $2,947.50$ & 4 & $11,790.00$ \\
Diciembre & $2,767.00$ & 3 & $8,301.00$ \\
\cline { 2 - 4 } & & & $294,811.81$ \\
& & &
\end{tabular}

\begin{tabular}{lcr}
\hline & 2019 & \\
\hline Precio & Cantidad & \multicolumn{1}{c}{ PxQ } \\
\hline $2,398.66$ & 3 & $7,195.98$ \\
$2,744.50$ & 2 & $5,489.00$ \\
$2,672.50$ & 4 & $10,690.00$ \\
$3,042.66$ & 3 & $9,127.98$ \\
$2,513.75$ & 4 & $10,055.00$ \\
$2,544.50$ & 3 & $7,633.50$ \\
$2,581.33$ & 3 & $7,743.99$ \\
$2,794.50$ & 3 & $8,383.50$ \\
$1,832.33$ & 3 & $5,496.99$ \\
$2,221.50$ & 4 & $8,886.00$ \\
$2,852.66$ & 3 & $8,557.98$ \\
$3,691.33$ & 3 & $11,073.99$ \\
$2,492.50$ & 4 & $9,970.00$ \\
$2,769.66$ & 3 & $8,308.98$ \\
$2,200.00$ & 4 & $8,800.00$ \\
$2,102.33$ & 3 & $6,306.99$ \\
$1,676.66$ & 3 & $5,029.98$ \\
$3,030.33$ & 3 & $9,090.99$ \\
$2,616.25$ & 4 & $10,465.00$ \\
$2,043.00$ & 4 & $8,172.00$ \\
$2,757.25$ & 4 & $11,029.00$ \\
$2,177.33$ & 3 & $6,531.99$ \\
$2,765.00$ & 4 & $11,060.00$ \\
$1,711.00$ & 3 & $5,133.00$ \\
$2,131.66$ & 3 & $6,394.98$ \\
$2,469.50$ & 4 & $9,878.00$ \\
$2,264.00$ & 3 & $6,792.00$ \\
$3,193.00$ & 3 & $9,579.00$ \\
$2,549.75$ & 4 & $10,199.00$ \\
$2,502.50$ & 4 & $10,010.00$ \\
$3,024.00$ & 3 & $9,072.00$ \\
$3,316.33$ & 3 & $9,948.99$ \\
$2,659.75$ & 4 & $10,639.00$ \\
$2,947.50$ & 4 & $11,790.00$ \\
$2,767.00$ & 3 & $8,301.00$ \\
\hline & & \\
& &
\end{tabular}

\begin{tabular}{lcr}
\hline & 2020 & \\
\hline Precio & Cantidad & \multicolumn{1}{c}{ PxQ } \\
\hline $2,398.66$ & 3 & $7,195.98$ \\
$2,744.50$ & 3 & $8,233.50$ \\
$2,672.50$ & 4 & $10,690.00$ \\
$3,042.66$ & 3 & $9,127.98$ \\
$2,513.75$ & 4 & $10,055.00$ \\
$2,544.50$ & 3 & $7,633.50$ \\
$2,581.33$ & 3 & $7,743.99$ \\
$2,794.50$ & 3 & $8,383.50$ \\
$1,832.33$ & 3 & $5,496.99$ \\
$2,221.50$ & 4 & $8,886.00$ \\
$2,852.66$ & 3 & $8,557.98$ \\
$3,691.33$ & 3 & $11,073.99$ \\
$2,492.50$ & 4 & $9,970.00$ \\
$2,769.66$ & 3 & $8,308.98$ \\
$2,200.00$ & 4 & $8,800.00$ \\
$2,102.33$ & 3 & $6,306.99$ \\
$1,676.66$ & 3 & $5,029.98$ \\
$3,030.33$ & 4 & $12,121.32$ \\
$2,616.25$ & 4 & $10,465.00$ \\
$2,043.00$ & 4 & $8,172.00$ \\
$2,757.25$ & 4 & $11,029.00$ \\
$2,177.33$ & 3 & $6,531.99$ \\
$2,765.00$ & 4 & $11,060.00$ \\
$1,711.00$ & 3 & $5,133.00$ \\
$2,131.66$ & 3 & $6,394.98$ \\
$2,469.30$ & 5 & $12,346.50$ \\
$2,264.00$ & 3 & $6,792.00$ \\
$3,193.00$ & 3 & $9,579.00$ \\
$2,549.75$ & 4 & $10,199.00$ \\
$2,502.50$ & 4 & $10,010.00$ \\
$3,024.00$ & 3 & $9,072.00$ \\
$3,316.33$ & 3 & $9,948.99$ \\
$2,659.75$ & 4 & $10,639.00$ \\
$2,947.50$ & 4 & $11,790.00$ \\
$2,767.00$ & 3 & $8,301.00$ \\
\hline & & 31197.14
\end{tabular}

\begin{tabular}{lcr}
\hline & 2021 & \multicolumn{1}{r}{} \\
\hline Precio & Cantidad & \multicolumn{1}{c}{ PxQ } \\
\hline $2,398.66$ & 3 & $7,195.98$ \\
$2,744.50$ & 3 & $8,233.50$ \\
$2,672.50$ & 4 & $10,690.00$ \\
$3,042.66$ & 3 & $9,127.98$ \\
$2,513.75$ & 4 & $10,055.00$ \\
$2,544.50$ & 3 & $7,633.50$ \\
$2,581.33$ & 3 & $7,743.99$ \\
$2,794.50$ & 3 & $8,383.50$ \\
$1,832.33$ & 3 & $5,496.99$ \\
$2,221.50$ & 5 & $11,107.50$ \\
$2,852.66$ & 3 & $8,557.98$ \\
$3,691.33$ & 4 & $14,765.32$ \\
$2,492.50$ & 4 & $9,970.00$ \\
$2,769.66$ & 3 & $8,308.98$ \\
$2,200.00$ & 4 & $8,800.00$ \\
$2,102.33$ & 3 & $6,306.99$ \\
$1,773.66$ & 3 & $5,320.98$ \\
$3,030.33$ & 4 & $12,121.32$ \\
$2,616.25$ & 4 & $10,465.00$ \\
$2,043.00$ & 4 & $8,172.00$ \\
$2,757.25$ & 4 & $11,029.00$ \\
$2,177.33$ & 3 & $6,531.99$ \\
$2,765.00$ & 4 & $11,060.00$ \\
$1,711.00$ & 3 & $5,133.00$ \\
$2,131.66$ & 3 & $6,394.98$ \\
$2,469.30$ & 5 & $12,346.50$ \\
$2,264.00$ & 4 & $9,056.00$ \\
$3,193.00$ & 3 & $9,579.00$ \\
$2,549.75$ & 4 & $10,199.00$ \\
$2,502.50$ & 4 & $10,010.00$ \\
$3,024.00$ & 3 & $9,072.00$ \\
$3,316.33$ & 3 & $9,948.99$ \\
$2,659.75$ & 4 & $10,639.00$ \\
$2,947.50$ & 4 & $11,790.00$ \\
$2,767.00$ & 3 & $8,301.00$ \\
\hline & & $319,546.97$
\end{tabular}


Servicio de Mantenimiento

\begin{tabular}{llcc} 
& \multicolumn{3}{c}{$\mathbf{2 0 1 8}$} \\
\cline { 2 - 4 } & Precio & Cantidad & PxQ \\
\cline { 2 - 4 } Enero & $29,257.50$ & 1 & $29,257.50$ \\
Enero & $16,612.50$ & 2 & $33,225.00$ \\
Enero & $10,344.00$ & 1 & $10,344.00$ \\
Febrero & $14,628.75$ & 2 & $29,257.50$ \\
Febrero & $16,612.50$ & 2 & $33,225.00$ \\
Febrero & $10,344.00$ & 1 & $10,344.00$ \\
Marzo & $14,628.75$ & 2 & $29,257.50$ \\
Marzo & $16,612.50$ & 2 & $33,225.00$ \\
Marzo & $10,344.00$ & 1 & $10,344.00$ \\
Abril & $14,628.75$ & 2 & $29,257.50$ \\
Abril & $16,612.50$ & 2 & $33,225.00$ \\
Abril & $10,344.00$ & 1 & $10,344.00$ \\
Mayo & $14,628.75$ & 2 & $29,257.50$ \\
Mayo & $16,612.50$ & 2 & $33,225.00$ \\
Mayo & $10,344.00$ & 1 & $10,344.00$ \\
Junio & $14,628.75$ & 2 & $29,257.50$ \\
Junio & $16,612.50$ & 2 & $33,225.00$ \\
Junio & $10,344.00$ & 1 & $10,344.00$ \\
Julio & $14,628.75$ & 2 & $29,257.50$ \\
Julio & $16,612.50$ & 2 & $33,225.00$ \\
Julio & $10,344.00$ & 1 & $10,344.00$ \\
Agosto & $14,628.75$ & 2 & $29,257.50$ \\
Agosto & $16,612.50$ & 2 & $33,225.00$ \\
Agosto & $10,344.00$ & 1 & $10,344.00$ \\
Setiembre & $14,628.75$ & 2 & $29,257.50$ \\
Setiembre & $16,612.50$ & 2 & $33,225.00$ \\
Setiembre & $10,344.00$ & 1 & $10,344.00$ \\
Octubre & $14,628.75$ & 2 & $29,257.50$ \\
Octubre & $16,612.50$ & 2 & $33,225.00$ \\
Octubre & $10,344.00$ & 1 & $10,344.00$ \\
Noviembre & $14,628.75$ & 2 & $29,257.50$ \\
Noviembre & $16,612.50$ & 2 & $33,225.00$ \\
Noviembre & $10,344.00$ & 1 & $10,344.00$ \\
Diciembre & $14,628.75$ & 2 & $29,257.50$ \\
Diciembre & $16,612.50$ & 2 & $33,225.00$ \\
Diciembre & $10,344.00$ & 1 & $10,344.00$ \\
\cline { 2 - 4 } & & & $\mathbf{8 7 3 , 9 1 8 . 0 0}$
\end{tabular}

\begin{tabular}{ccc}
\hline & 2019 & \\
\hline Precio & Cantidad & PxQ \\
\hline $29,257.50$ & 1 & $29,257.50$ \\
$16,612.50$ & 2 & $33,225.00$ \\
$10,344.00$ & 1 & $10,344.00$ \\
$14,628.75$ & 2 & $29,257.50$ \\
$16,612.50$ & 2 & $33,225.00$ \\
$10,344.00$ & 1 & $10,344.00$ \\
$14,628.75$ & 2 & $29,257.50$ \\
$16,612.50$ & 2 & $33,225.00$ \\
$11,294.00$ & 1 & $11,294.00$ \\
$14,628.75$ & 2 & $29,257.50$ \\
$16,612.50$ & 2 & $33,225.00$ \\
$11,206.00$ & 1 & $11,206.00$ \\
$14,628.75$ & 2 & $29,257.50$ \\
$16,612.50$ & 2 & $33,225.00$ \\
$11,404.00$ & 1 & $11,404.00$ \\
$14,628.75$ & 2 & $29,257.50$ \\
$16,612.50$ & 2 & $33,225.00$ \\
$10,344.00$ & 1 & $10,344.00$ \\
$14,628.75$ & 2 & $29,257.50$ \\
$16,612.50$ & 2 & $33,225.00$ \\
$10,344.00$ & 1 & $10,344.00$ \\
$14,628.75$ & 2 & $29,257.50$ \\
$16,612.50$ & 2 & $33,225.00$ \\
$10,344.00$ & 1 & $10,344.00$ \\
$14,628.75$ & 2 & $29,257.50$ \\
$16,612.50$ & 2 & $33,225.00$ \\
$10,344.00$ & 1 & $10,344.00$ \\
$14,628.75$ & 2 & $29,257.50$ \\
$16,612.50$ & 2 & $33,225.00$ \\
$11,044.00$ & 1 & $11,044.00$ \\
$14,628.75$ & 2 & $29,257.50$ \\
$16,612.50$ & 2 & $33,225.00$ \\
$10,344.00$ & 1 & $10,344.00$ \\
$14,628.75$ & 2 & $29,257.50$ \\
$16,612.50$ & 2 & $33,225.00$ \\
$11,324.00$ & 1 & $11,324.00$ \\
\hline & & $878,470.00$
\end{tabular}

\begin{tabular}{lcc}
\hline & $\mathbf{2 0 2 0}$ & \\
\hline Precio & Cantidad & PxQ \\
\hline $29,257.50$ & 1 & $29,257.50$ \\
$16,612.50$ & 2 & $33,225.00$ \\
$11,219.00$ & 1 & $11,219.00$ \\
$14,628.75$ & 2 & $29,257.50$ \\
$16,612.50$ & 2 & $33,225.00$ \\
$11,284.00$ & 1 & $11,284.00$ \\
$14,628.75$ & 2 & $29,257.50$ \\
$16,612.50$ & 2 & $33,225.00$ \\
$11,294.00$ & 1 & $11,294.00$ \\
$14,628.75$ & 2 & $29,257.50$ \\
$16,612.50$ & 2 & $33,225.00$ \\
$11,206.00$ & 1 & $11,206.00$ \\
$14,628.75$ & 2 & $29,257.50$ \\
$16,612.50$ & 2 & $33,225.00$ \\
$11,404.00$ & 1 & $11,404.00$ \\
$14,628.75$ & 2 & $29,257.50$ \\
$16,612.50$ & 2 & $33,225.00$ \\
$11,374.00$ & 1 & $11,374.00$ \\
$14,628.75$ & 2 & $29,257.50$ \\
$16,612.50$ & 2 & $33,225.00$ \\
$11,214.00$ & 1 & $11,214.00$ \\
$14,628.75$ & 2 & $29,257.50$ \\
$16,612.50$ & 2 & $33,225.00$ \\
$10,344.00$ & 1 & $10,344.00$ \\
$14,628.75$ & 2 & $29,257.50$ \\
$16,612.50$ & 2 & $33,225.00$ \\
$10,344.00$ & 1 & $10,344.00$ \\
$14,628.75$ & 2 & $29,257.50$ \\
$16,612.50$ & 2 & $33,225.00$ \\
$11,044.00$ & 1 & $11,044.00$ \\
$14,628.75$ & 2 & $29,257.50$ \\
$16,612.50$ & 2 & $33,225.00$ \\
$11,204.00$ & 1 & $11,204.00$ \\
$14,628.75$ & 2 & $29,257.50$ \\
$16,612.50$ & 2 & $33,225.00$ \\
$11,324.00$ & 1 & $11,324.00$ \\
\hline & & $\mathbf{8 8 3 , 0 4 5 . 0 0}$ \\
& &
\end{tabular}

\begin{tabular}{lcc}
\hline & $\mathbf{2 0 2 1}$ & \\
\hline Precio & Cantidad & PxQ \\
\hline $29,257.50$ & 1 & $29,257.50$ \\
$16,612.50$ & 2 & $33,225.00$ \\
$11,219.00$ & 1 & $11,219.00$ \\
$14,628.75$ & 2 & $29,257.50$ \\
$16,612.50$ & 2 & $33,225.00$ \\
$11,284.00$ & 1 & $11,284.00$ \\
$14,628.75$ & 2 & $29,257.50$ \\
$16,612.50$ & 2 & $33,225.00$ \\
$11,294.00$ & 1 & $11,294.00$ \\
$14,628.75$ & 2 & $29,257.50$ \\
$16,612.50$ & 2 & $33,225.00$ \\
$11,876.00$ & 1 & $11,876.00$ \\
$14,628.75$ & 2 & $29,257.50$ \\
$16,612.50$ & 2 & $33,225.00$ \\
$11,404.00$ & 1 & $11,404.00$ \\
$14,628.75$ & 2 & $29,257.50$ \\
$16,612.50$ & 2 & $33,225.00$ \\
$11,374.00$ & 1 & $11,374.00$ \\
$14,628.75$ & 2 & $29,257.50$ \\
$16,612.50$ & 2 & $33,225.00$ \\
$11,214.00$ & 1 & $11,214.00$ \\
$14,628.75$ & 2 & $29,257.50$ \\
$16,612.50$ & 2 & $33,225.00$ \\
$10,344.00$ & 1 & $10,344.00$ \\
$14,628.75$ & 2 & $29,257.50$ \\
$16,612.50$ & 2 & $33,225.00$ \\
$10,344.00$ & 1 & $10,344.00$ \\
$14,628.75$ & 2 & $29,257.50$ \\
$16,612.50$ & 2 & $33,225.00$ \\
$11,523.00$ & 1 & $11,523.00$ \\
$14,628.75$ & 2 & $29,257.50$ \\
$16,612.50$ & 2 & $33,225.00$ \\
$11,204.00$ & 1 & $11,204.00$ \\
$14,628.75$ & 2 & $29,257.50$ \\
$16,612.50$ & 2 & $33,225.00$ \\
$11,324.00$ & 1 & $11,324.00$ \\
\hline & & $884,194.00$
\end{tabular}


Tienda de Acero Inoxidable

\begin{tabular}{|c|c|c|c|c|c|c|c|c|c|c|c|c|c|c|c|c|c|c|c|c|}
\hline & \multirow{2}{*}{\multicolumn{5}{|c|}{2018}} & & & & & & & & & & & & & & & \\
\hline & & & & & & \multicolumn{5}{|c|}{2019} & \multicolumn{5}{|c|}{2020} & \multicolumn{4}{|c|}{2021} & \\
\hline & \multicolumn{2}{|c|}{ Cantidad V. Vta Unit. \$ V } & \multirow{2}{*}{$\begin{aligned} \text { V. Vta Total \$ } \\
1,080.00\end{aligned}$} & \multicolumn{2}{|c|}{ TC V. Vta Total S/ } & \multirow{2}{*}{$\frac{\text { Cantidad V }}{4}$} & \multicolumn{2}{|c|}{$\begin{array}{l}\text { I. Vta Unit \$ V. Vta Total \$ } \\
270.00 \\
1080.00\end{array}$} & \multirow{2}{*}{$\begin{array}{l}\text { TC V V } \\
3.355 \\
3.355\end{array}$} & \multirow[t]{2}{*}{$\frac{\text { V. Vta Total S/ }}{3,623.40}$} & \multicolumn{2}{|c|}{$\frac{\text { Cantidad V. Vta Unit. S }}{4.27000}$} & $\begin{array}{l}\text { V. Vta Totals } \\
1,080.00\end{array}$ & \multirow{2}{*}{$\begin{array}{l}\text { TC V V } \\
3.403 \\
3.403\end{array}$} & \multirow{2}{*}{$\begin{array}{r}\text { V. Vta Total S/ } \\
3,675.24\end{array}$} & \multicolumn{2}{|c|}{ Cantidad V.Vta Unit. $\$ \mathrm{~V}$} & $\begin{array}{l}\text { S V. Vta Total S } \\
1,080.00\end{array}$ & & \\
\hline $\begin{array}{l}\text { Producto } \\
\text { Caja china mediana (T }\end{array}$ & $\begin{array}{l}4 \\
4\end{array}$ & $\begin{array}{l}278.00 \\
180.00\end{array}$ & & $\begin{array}{l}3.335 \\
3.355\end{array}$ & & & $\begin{array}{l}270.00 \\
180.00\end{array}$ & $\begin{array}{r}1,080.000 \\
72.00\end{array}$ & & & $\begin{array}{l}4 \\
5\end{array}$ & $\begin{array}{l}270.00 \\
180.00\end{array}$ & $\begin{array}{l}1,080.00 \\
900.00\end{array}$ & & & $\begin{array}{l}4 \\
5\end{array}$ & $\begin{array}{l}270.00 \\
180.00\end{array}$ & $\begin{array}{r}1,080.00 \\
900.00\end{array}$ & & \\
\hline & 1 & 1,380 & & 3.355 & & 1 & 1,380 & & 3.355 & & 2 & & & & & & & & & \\
\hline & 1 & $1,130.00$ & 30.00 & 3.355 & & 1 & 1,1 & & 3.355 & & 1 & 1,13 & & & & & & & & \\
\hline & 1 & & & 3.355 & & & & & 3.355 & & & & & & & & & & & \\
\hline & & & & 3.34 & & & & & 3.3 & & & & & & & & & & & \\
\hline \multirow{2}{*}{$\begin{array}{l}\text { Parrillas Std pequeña (Parrilla dual I (ga } \\
\text { Varios } 3 \text { 3 bases fijas) }\end{array}$} & a & & & 3.34 & & & & & 3.3 & & & & & & & & & & & \\
\hline & & 550.00 & 550.00 & 3.345 & & 1 & 550.00 & 550.00 & 3.355 & 1845.2 & & 550.00 & & 3.403 & & & 550.00 & 550.00 & 3.349 & \\
\hline & & & 1400.00 & & 630.28 & & & $10,690.00$ & & $5,864.95$ & & & $12,250.00$ & & $41,686.75$ & & & $13,870.00$ & & \\
\hline
\end{tabular}

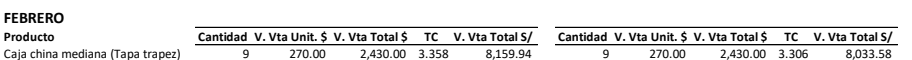

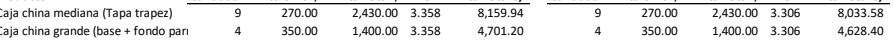

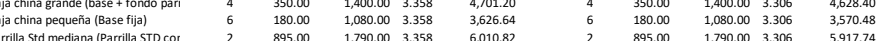

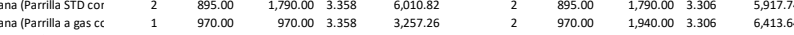

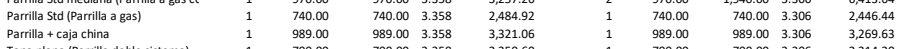
Tapa plana (Parrilla doble sisten

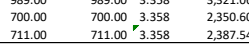

MARZO

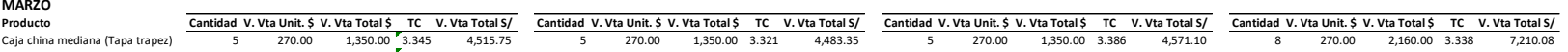

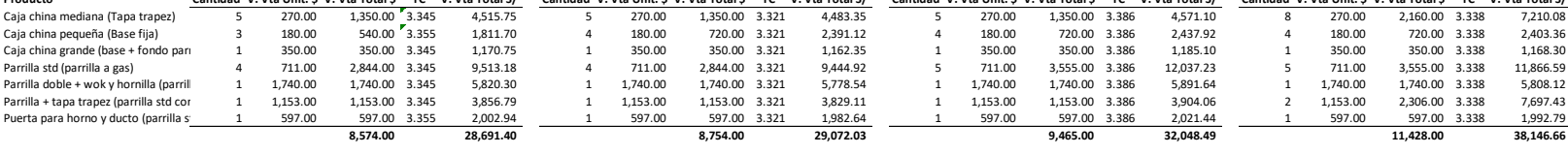

ABRIL

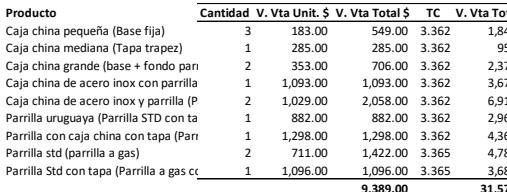

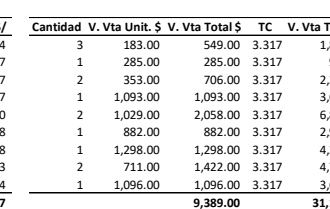

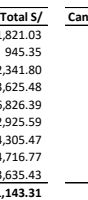

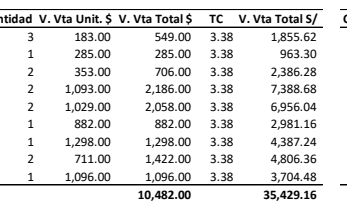

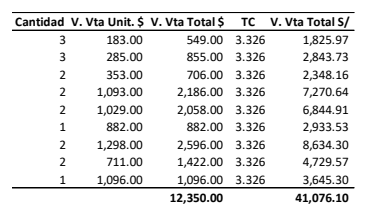

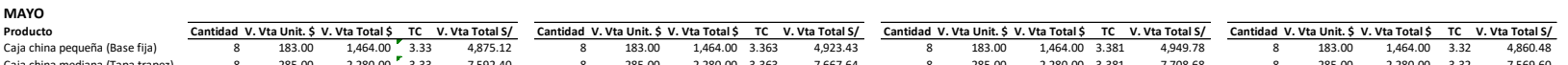

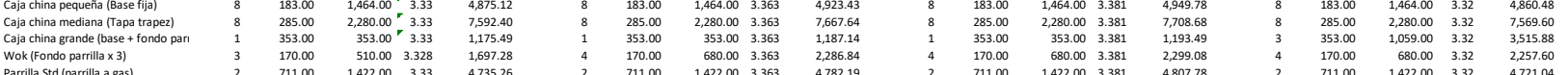

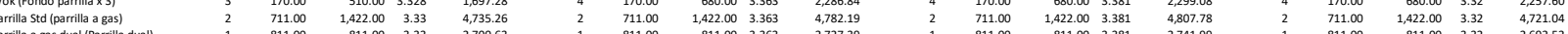

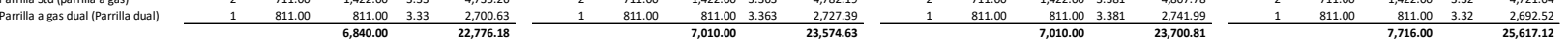

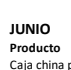

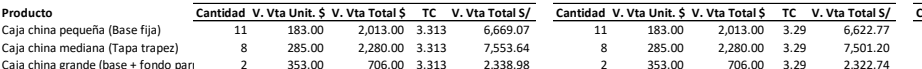
(44) Silla de madera con base de ace

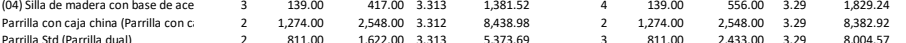
\begin{tabular}{lrrrrr} 
Parrilla Std (Parilla dual) & 2 & 811.00 & $1,622.00$ & 3.313 & $5,373.69$ \\
Parrilla con caja china y tapa trapez: & 1 & $1,421.00$ & $1,421.00$ & 3.313 & $4,707.77$ \\
Parrilla doble sistema con tapa (Parr & 1 & $1,274.00$ & $1,274.00$ & 3.313 & $4,220.76$ \\
\hline
\end{tabular}

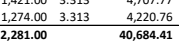
\begin{tabular}{rrrrr}
1 & $1,421.00$ & $1,421.00$ & 3.29 & $4,6075.09$ \\
1 & $1,274.00$ & $1,274.00$ & 3.29 & $4,191.46$ \\
\hline & $13,231.00$ & & $43,529.99$
\end{tabular}

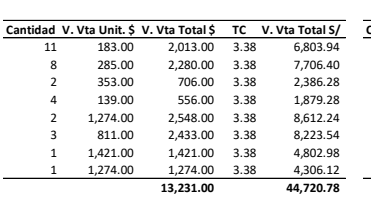

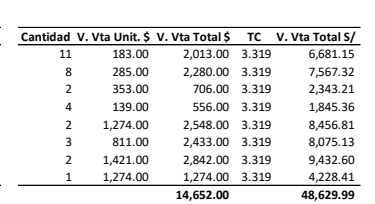

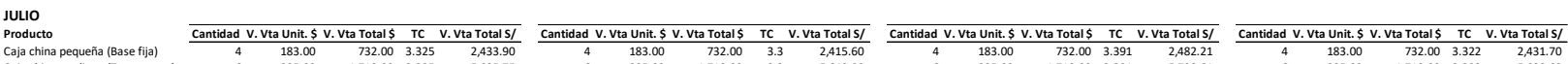

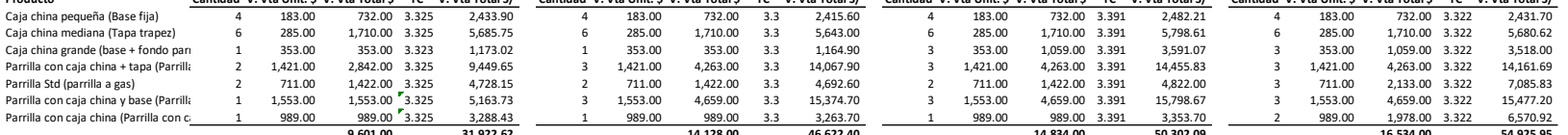

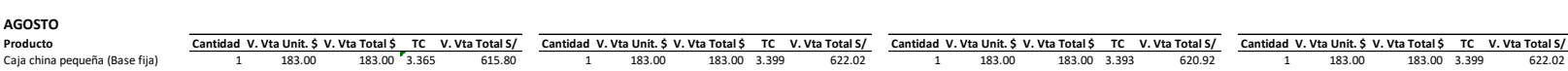

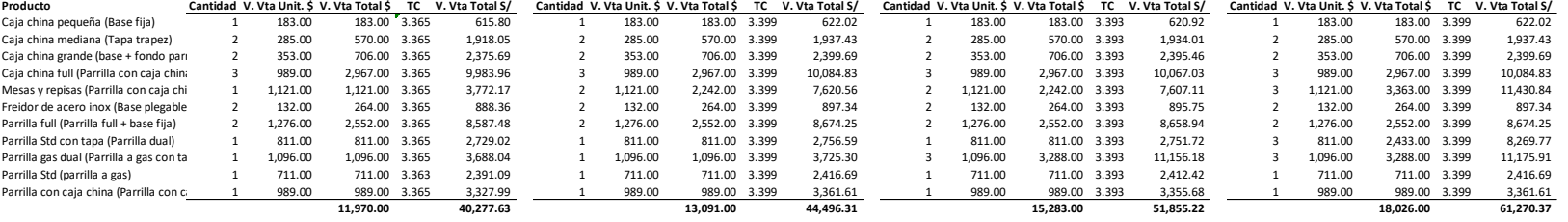

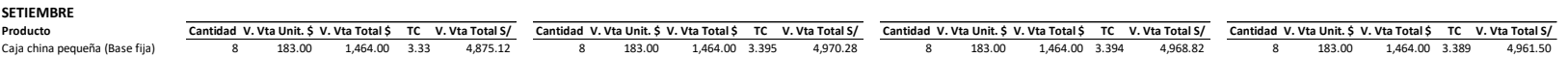

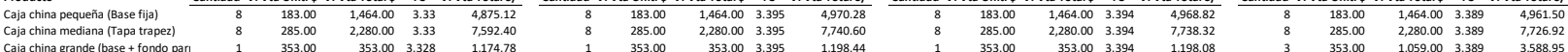

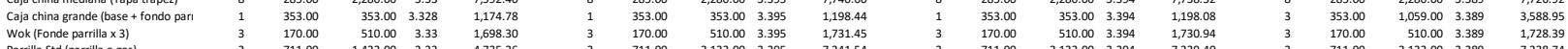

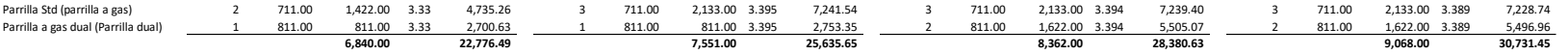

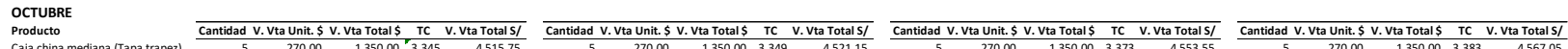

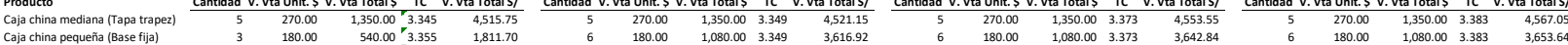

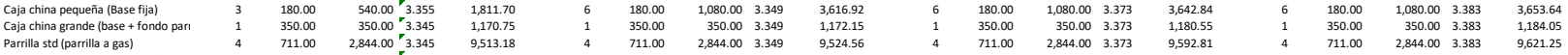

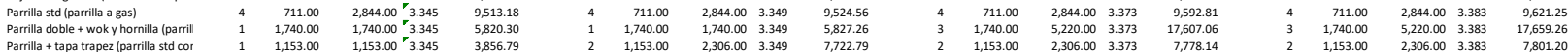

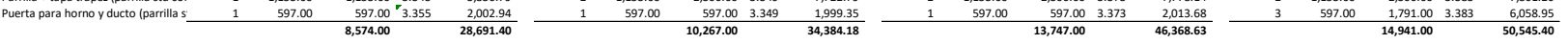

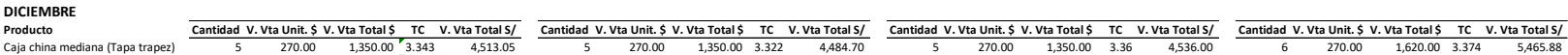

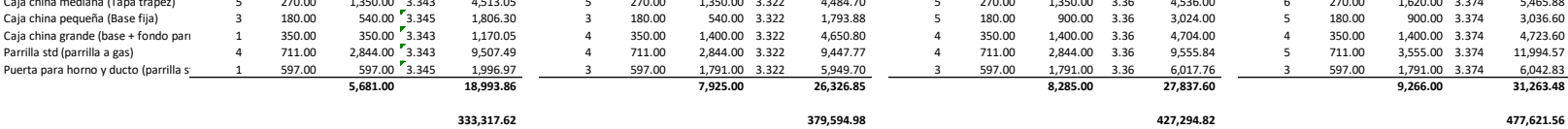

